Göttingen Series in Social and Cultural Anthropology

Paul Christensen

\title{
Geister in Kambodscha
}

Existenz, Macht und rituelle Praxis

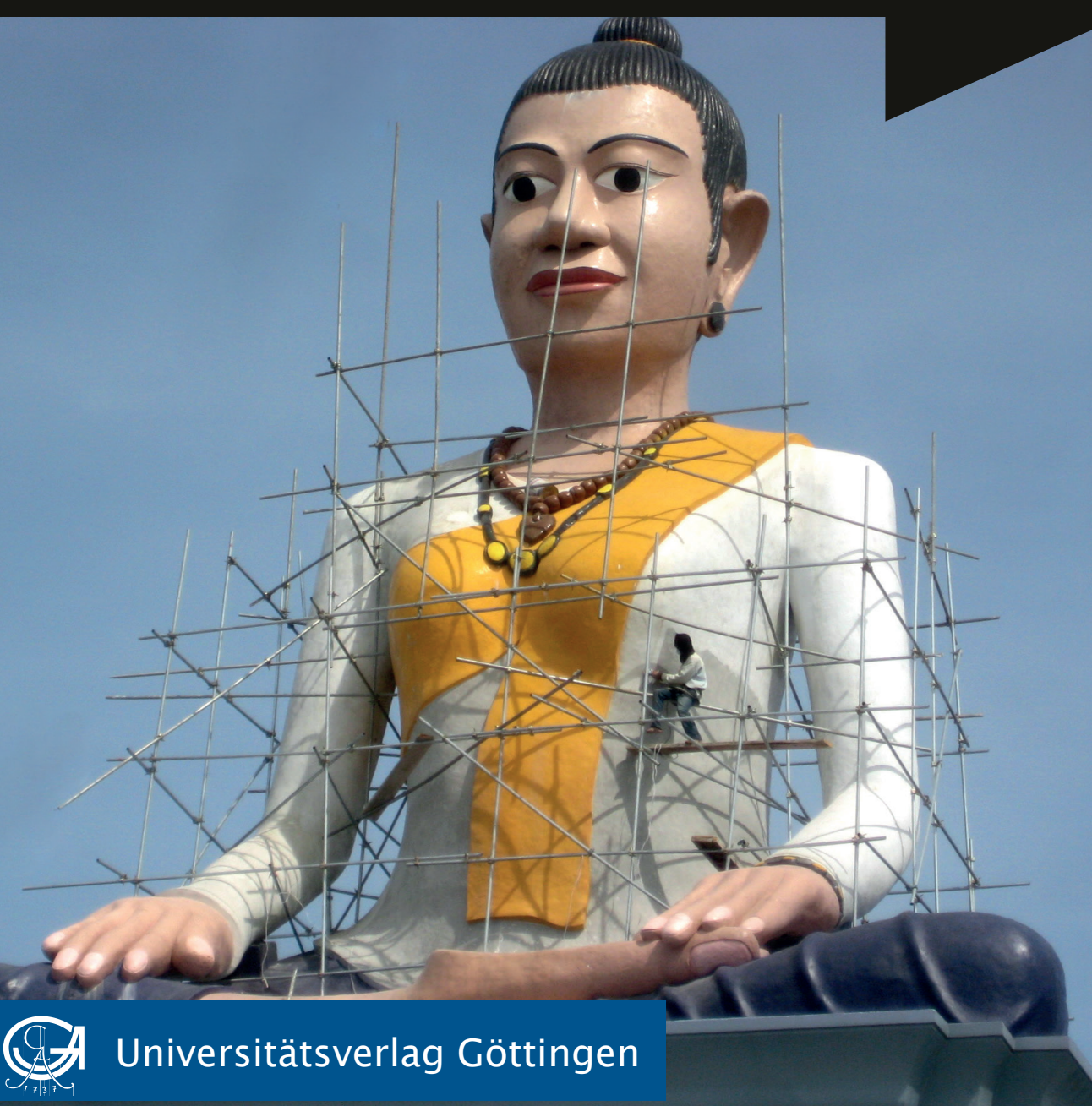



Paul Christensen

Geister in Kambodscha

Dieses Werk ist lizenziert unter einer

Creative Commons

Namensnennung - Weitergabe unter gleichen Bedingungen

4.0 International Lizenz.

(c) $\underset{\mathrm{BY}}{\mathrm{i}}$ () 
erschienen als Band 17 in der Reihe „Göttinger Reihe zur Ethnologie Göttingen Series in Social and Cultural Anthropology“"

im Universitätsverlag Göttingen 2020

Diese Reihe ist eine Fortsetzung der „Göttinger Beiträge zur Ethnologie“ 
Paul Christensen

Geister in Kambodscha

Existenz, Macht und rituelle Praxis

Band 17

Göttinger Reihe zur Ethnologie -

Göttingen Series in Social and

Cultural Anthropology

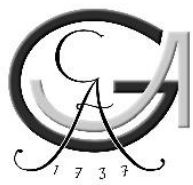

Universitätsverlag Göttingen 2020 


\section{Bibliographische Information der Deutschen Nationalbibliothek}

Die Deutsche Nationalbibliothek verzeichnet diese Publikation in der Deutschen Nationalbibliographie; detaillierte bibliographische Daten sind im Internet über $<$ http://dnb.dnb.de $>$ abrufbar.

"Göttingen Series in Social and Cultural Anthropology" Editors

Prof. Dr. Elfriede Hermann

Prof. Dr. Andrea Lauser

Prof. Dr. Roman Loimeier

Prof. Dr. Nikolaus Schareika

Institute of Social and Cultural Anthropology

Georg-August-Universität Göttingen

Theaterplatz 15

D-37073 Göttingen

Dissertation, Georg-August-Universität Göttingen

Dieses Buch ist auch als freie Onlineversion über die Homepage des Verlags sowie über den Göttinger Universitätskatalog (GUK) bei der Niedersächsischen Staats- und Universitätsbibliothek Göttingen (https://www.sub.uni-goettingen.de) erreichbar. Es gelten die Lizenzbestimmungen der Onlineversion.

Satz und Layout: Paul Christensen

Coverabbildung: Eine neu konstruierte Statue von Yāy Mao auf dem Phnom Bokor, Provinz Kampot, Kambodscha (C) Paul Christensen)

(C) 2020 Universitätsverlag Göttingen https://univerlag.uni-goettingen.de ISBN: 978-3-86395-441-3

DOI: https://doi.org/10.17875/gup2020-1249

eISSN: 2512-6881 


\section{Inhaltsverzeichnis}

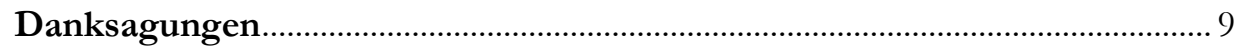

Anmerkung zur Transliteration............................................................................. 11

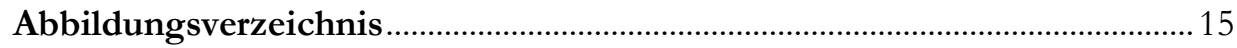

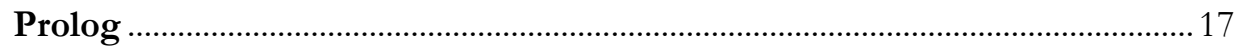

1 Einleitung: Geister und Geistmedien in Kambodscha...................................19

1.1 Die Geisterlandschaft und die Untersuchung der Geister-Existenz ................21

1.2 Die Untersuchung von spirituellen Machtaushandlungen..................................2 23

1.3 Das Forschungsfeld: Geister in Kambodscha ………………………………....2

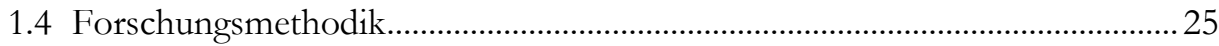

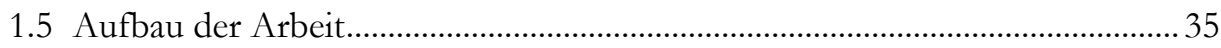

I Thematischer Kontext und Methodik........................................................ 39

2 Kambodscha: Geschichte, Religion und Macht .............................................. 41

2.1 Historische Konfigurationen von weltlicher und spiritueller Macht................ 41

2.2 Der Hybride Religionsbegriff des kambodschanischen Buddhismus............. 49

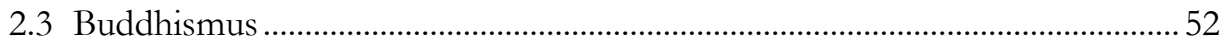

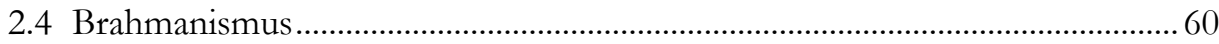

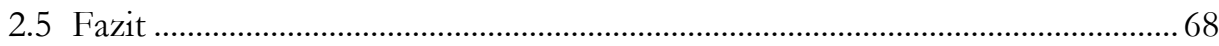


3 Spiritscapes und die Existenzweisen von Geistern....................................... 71

3.1 Spiritscapes - die kambodschanische Geisterlandschaft.................................. 72

3.2 Aktuelle Debatten zur Untersuchung von Geister-Existenz............................76

3.3 Die ANT - Radikaler Realismus und Symmetrische Anthropologie...............77

3.4 Die Konstituierung des Akteurs, Geist' während eines Besuches bei

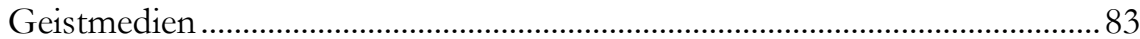

3.5 Zwei Geister in Prozessen des Blackboxing ....................................................... 86

3.6 Fazit: Geister und ihre Existenz in Kambodscha............................................. 97

II Existenzweisen der kambodschanischen Geister ........................ 99

4 Die An- und Abwesenheit von Totengeistern .......................................... 101

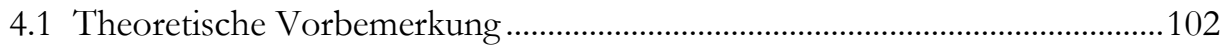

4.2 Historische Phasen des Umgangs mit Khmer-Rouge-Toten .........................103

4.3 Das heutige Verständnis von Totengeistern ...................................................106

4.4 Totengeister in lokalen und nationalen Verarbeitungsprozessen...................115

5 Ortsgeister und ihre Existenzbedingungen............................................117

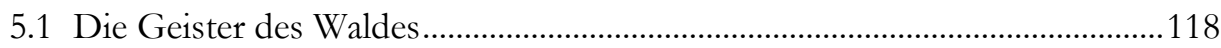

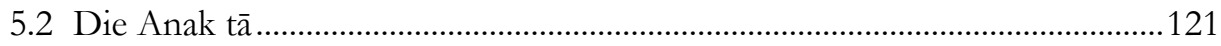

5.3 Abschließende Bemerkung zur Existenzweise kambodschanischer Geister.

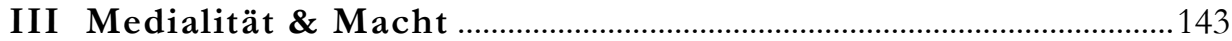

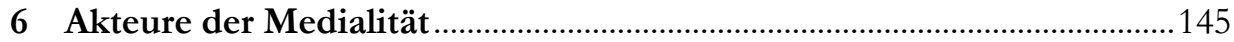

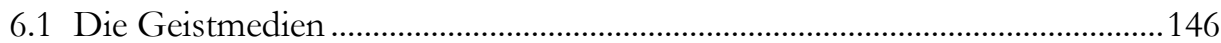

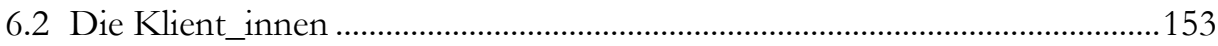

7 Sothys Heilungsanliegen und die Frage nach der Authentizität medialer Rituale...

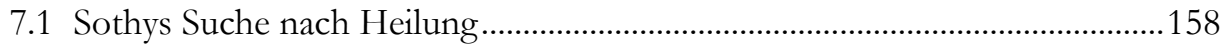

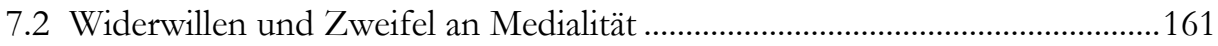

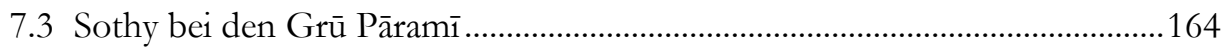

7.4 Die Funktionsweise der brahmanistischen Heilungspraxis ............................ 168

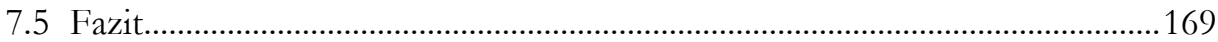


8 Moderne Formen brahmanistischer Segenspraxis ................................. 171

8.1 Geschäftsorientierte Anliegen und rituelle Reaktionen .................................172

8.2 Die Wirkungsweise der brahmanistischen Segenspraxis ................................ 176

8.3 Ein optimiertes Ritual: loeng anak tā.............................................................. 177

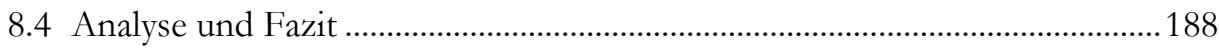

9 Die Inszenierung von Geistern im politischen Feld................................. 191

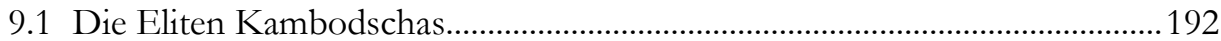

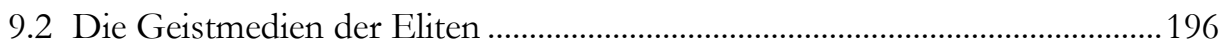

9.3 Nationale Identität und magische Praktiken ..................................................203

9.4 Die Inszenierung von Geistern im Wahlkampf 2013 ...................................215

9.5 Das subversive Potential der Medialität...........................................................220

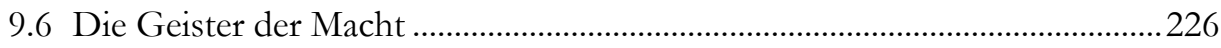

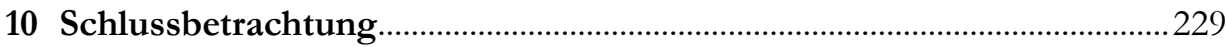

10.1 Geister als ergiebiger Untersuchungsgegenstand ethnologischer

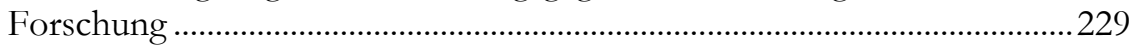

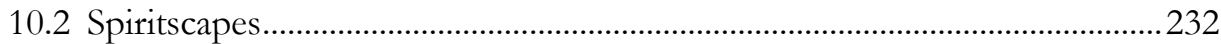

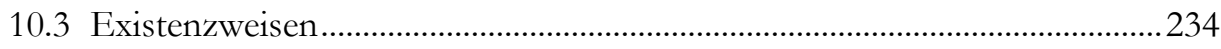

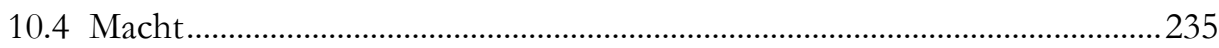

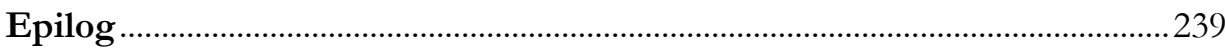

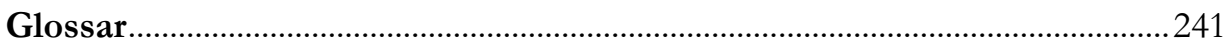

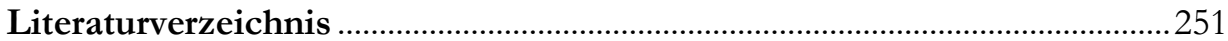

Index der Personen, Orte und Begriffe..........................................................2279 



\section{Danksagungen}

Diese Arbeit über die Geister und Geistmedien in Kambodscha ist das Ergebnis meiner einjährigen Forschung von 2012 bis 2013 und des anschließenden Analyseund Schreibprozesses von 2013 bis 2019. Gefördert wurde ich während dieser Zeit unter anderem von dem großzügigen Promotionsstipendium der Studienstiftung des deutschen Volkes e.V., deren Vertreter_innen und Förder_innen ich zu großem Dank verpflichtet bin.

Darüber hinaus danke ich Frau Prof. Andrea Lauser für die persönliche und leidenschaftliche Betreuung der Arbeit, in deren Rahmen wir einen freundlichen und höchstförderlichen Austausch pflegten, der von einem Monat der gemeinsamen Forschung in Kambodscha gekrönt wurde.

Mit seiner lokalen Expertise war Buth Sereybunnwath von unerlässlichem Wert für die Umsetzung dieses Dissertationsprojekts. Er übersetzte von Beginn an meine Interviews und war nicht nur ein aktiver Mitarbeiter und -denker meiner Forschung, sondern wurde bald $\mathrm{zu}$ einem Freund, dem ich ein herzliches

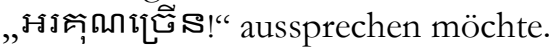

Außerdem danke ich Sok Koemsiek für die Unterstützung der Feldforschung mit ihren Ideen und ihrem Engagement sowie der warmherzigen Familie Suon, insbesondere Suon Bony und Stefanie Suon-Szabo, die für mich wichtige Ansprechpersonen in Kambodscha waren. Während meiner Forschung entwickelten sich zudem Freundschaften mit Alexandra Kent, Caroline Bennett, Tallyn Gray 
und Billy Tai, denen ich hiermit für die fachliche Diskussionen, den bereitwilligen Austausch von Informationen und den freundlichen Kontakt in dieser Zeit danken möchte.

Weiteren fachlichen Austausch pflegte ich zudem mit Brigitte HauserSchäublin, Didier Bertrand, Anne Guillou, Erik W. Davis, John Marston, Elisabeth Guthrie, Astrid Norén-Nilsson, Judith Strasser, Sotheara Chhim, Sreang Heng, Patrice Ladwig, Aditya Eggert, Karen Greene, Peter Gyallay-Pap und Kathryn Poethig, die alle direkt oder indirekt zu dieser Arbeit beigetragen haben, wofür ich ihnen herzlich danken möchte. Es war insbesondere eine Ehre für mich, Ang Chouléan zu treffen und seine umfassende Unterstützung zu erfahren.

Die Beziehungen zu den Mitarbeiter_innen am Institut für Ethnologie in Göttingen waren neben dem fachlichen Austausch von ausgeprägter Kollegialität und Freundschaft. Meine Dankbarkeit für die Zeiten des gemeinsamen Schreibens, Essens und Diskutierens richte ich an Jannik Schritt, Jovan Maud, Julia Vorhölter, Paul Sorrentino, Antonie Fuhse, Carolin Landgraf und vor allem an Bianca Volk, Sascha Kesseler, Kristina Schneider und Jelka Günther, die mir wertvolles Feedback auf meine Texte gegeben haben, was ein Geschenk war, für das ich ihnen hiermit sehr herzlich danken möchte. Für die Hilfe bei der Formatierung der Veröffentlichung danke ich zudem Vera Benter.

Gewidmet ist diese Arbeit meiner Frau Nicola, die mich mit ihrem Zuspruch in jeder Phase meiner Promotionszeit unterstützt hat, und meinen Söhnen Rio und Jesse, die mir ein Vorbild waren mit ihrer Neugier an der Welt und ihrer Begeisterung am Entdecken. 


\section{Anmerkung zur Transliteration}

Es gibt eine Vielzahl von verschiedenen Transliterations- oder Transkriptionssystemen des Khmer. Keines dieser Systeme hat sich bisher auf wissenschaftlicher Ebene durchgesetzt, aus verschiedenen Gründen: die Transliteration (wie beispielsweise nach dem System der US Library of Congress, kurz: ALA-LC) bietet die genaue Übersetzung der Schreibweise der Wörter, wie beispielsweise für die Geister-Kategorie pisāca (บิธีษ). Leser_innen mit Sanskrit-Kenntnissen werden damit schnell an die ursprüngliche Bedeutung und Herkunft des Wortes (पिशाच, piśāca) herangeführt. Das Problem der Transliteration ist der große Unterschied der heutigen Aussprache zu ihrer Schreibweise. Das oben genannte Wort บิธีธ wird beispielsweise nach der Transkription des Systems von Franklin E. Huffman (1983) ,besaach“ geschrieben, was der englischen Transkription des gesprochenen Khmer sehr nahe kommt, jedoch nicht der deutschen. Während meiner Feldforschung habe ich in meinen Aufzeichnungen phonetisch abgeleitete Transkriptionen der Khmer-Wörter benutzt und habe das oben genannte Wort im Deutschen als ,beisadj' transkribiert. Da es im Deutschen jedoch noch keine standardisierte Transkription des Khmer gibt, benutze ich in dieser Arbeit die oben genannte Transliterationen der Khmer-Wörter nach ALA LC von Larry Ashmun ${ }^{1}$, da diese

\footnotetext{
${ }^{1}$ Siehe: http://www.loc.gov/catdir/cpso/romanization/khmer.pdf, letzter Zugriff: 04.02.2020.
} 
international vergleichbar und aufgrund der oben genannten Vorteile von höherem akademischem Wert sind.

Alle Khmer-Wörter in dieser Arbeit habe ich zusätzlich bei Erstnennung in deutscher Phonetik transkribiert. Sie sind im Glossar am Ende der Arbeit aufgelistet. Bei einigen bereits in den allgemeinen Sprachgebrauch übergegangenen Begriffen wie Karma, Dharma, Nirvana oder Buddha habe ich auf eine Umschrift verzichtet. Außerdem wurden zum besseren Verständnis die internationale Umschrift der Namen der Provinzen oder der berühmten Tempel (wie Angkor Wat oder Preah Vihear) übernommen und nicht die transliterierte Form. Bei den Eigennamen der Geister sind mir viele unterschiedliche Schreibweisen begegnet, so dass ich ihre Namen nach deutscher Lautschrift transkribiert habe und keine Transliteration nach ALA-LC vornehmen konnte. 


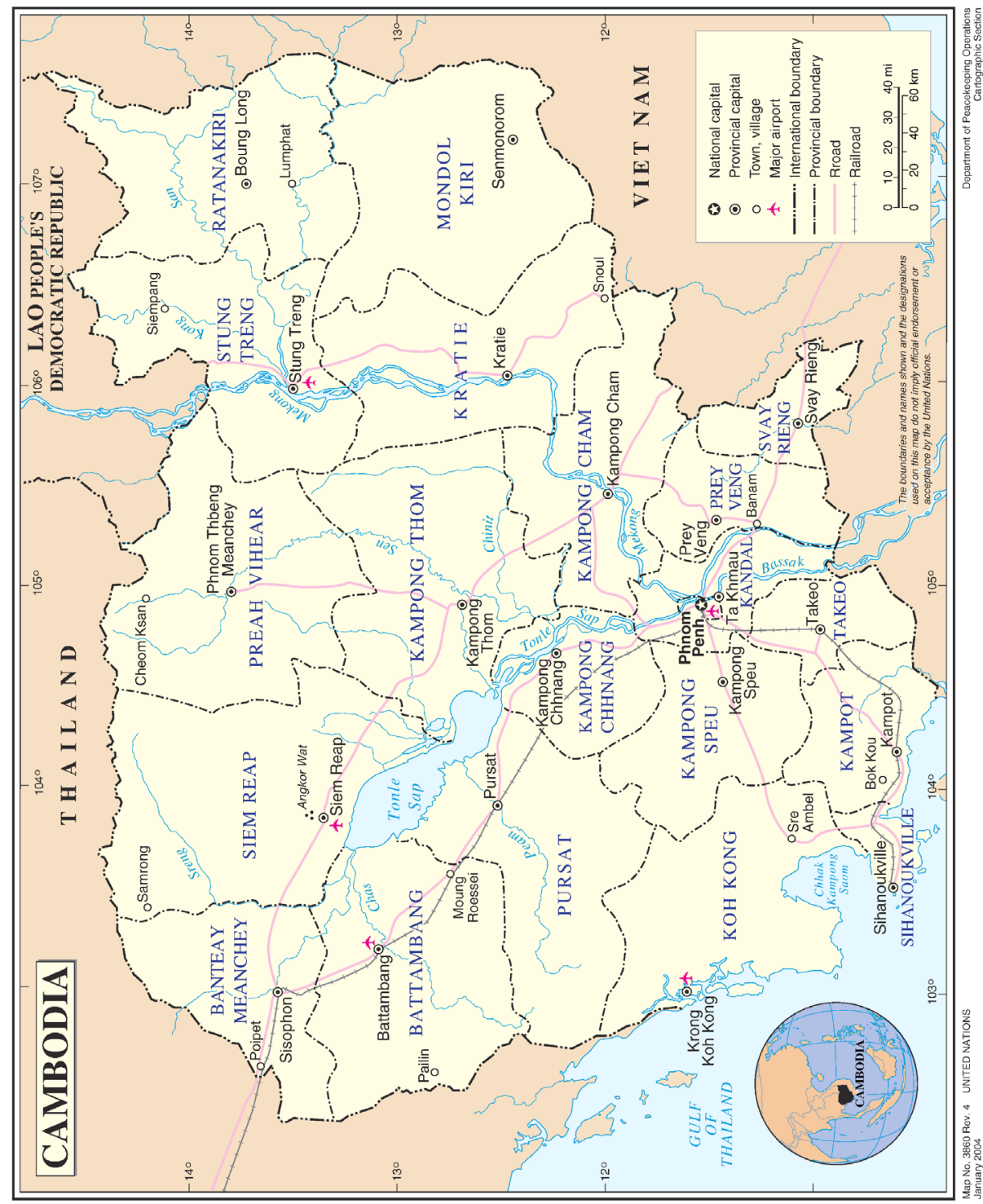

Abb. 1: (C) United Nations. Politische Karte von Kambodscha. Karte Nr. 3860 Rev.4, Januar 2004. 



\section{Abbildungsverzeichnis}

Abb. 1: (C) United Nations. Politische Karte von Kambodscha

Abb. 2: (C) Lauser. Bunnwath und ich während eines Interviews mit

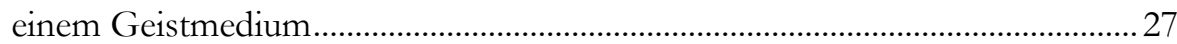

Abb. 3: (C) Autor. Bun Ly vor seinem Schrein in der Provinz Takeo......................... 32

Abb. 4: (C) Autor. Die Karma-Wechselwirkung ...............................................................56

Abb. 5: (C) Autor. Die Spiritscapes und die ANT als Analyserahmen

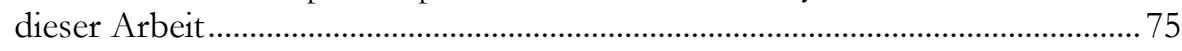

Abb. 6: () openstreetmaps. Landkarte von Choam ........................................................ 90

Abb. 7: (C) Autor. Wandbild des Wat Phnom, Phnom Penh ......................................108

Abb. 8: (C) Autor. ,Buddhisierte' Form eines dörflichen anak tā-Schreins .............124

Abb. 9: (C) Autor. Ein Termitenhaufen als Sitz von anak tā.....................................125

Abb. 10: (C) Autor. Anak tā Schrein eines Geistmediums, Provinz Takeo.............126

Abb. 11: (C) Autor. Buddhistischer pāy sī im Wat Botumwadei

(Nebengebäude), Phnom Penh. 
Abb. 12: (C) Autor. Ein männliches Geistmedium aus der Provinz Siem Reap 131

Abb. 13: (C) Autor. Yāy Mao in der Nähe von Anlung Veng. 138

Abb. 14: (C) Autor. Yāy Mao auf dem Phnom Bokor (Provinz Kampot) 140

Abb. 15: C) Autor. Das sro dyjk-Ritual 174

Abb. 16: (C) Autor. Die etwa 1000 Jahre alte Tempelanlage Sen Nih Mull 179

Abb. 17: (C) Autor. Der pāy sī für Zeremonien wie loeng anak tā 180

Abb. 18: C Bennett. Grū Ly in Geistbesessenheit seines Geistes 184

Abb. 19: (C) Bennett. Eine grū teilt gesegnetes Wasser 185

Abb. 20: C) Autor. Der Hauptsponsor kniet vor dem pāy sī. 187

Abb. 21: (C) Lauser. Grū Lunn in seinem Tempel. 198

Abb. 22: (C) Autor. Nächtliche Besessenheit für den Sponsoren der Zeremonie 208

Abb. 23: (C) Eng. Statue von Sdech Khan in Kep. 217

Abb. 24: () CC BY 4.0. Пресс-служба Президента России. Foto des Premierministers Hun Sen. 


\section{Prolog}

Meine Beschäftigung mit kambodschanischen Geistern begann im Jahr 2011 als Reaktion auf journalistische und akademische Publikationen, in denen Kambodscha vor allem über seine Geschichte - insbesondere die schreckliche Epoche der Roten Khmer von 1975-79 - thematisiert wurde. In diesem Zeitraum hatten Hundertausende Menschen durch Erschöpfung, Hunger und Exekutionen ihr Leben verloren und über 19.000 über das ganze Land verteilte Massengräber waren entstanden. Eine religionsethnologische Beschäftigung mit dieser folgenschweren Zeit bot sich insbesondere mit Blick auf akademische Debatten in Bezug auf die spirituelle Verarbeitung des zweiten Indochina-Kriegs in Vietnam an (Endres und Lauser 2011; Kwon 2008, 2006; Bradley 2001; Tai 2001; Malarney 2001), die mich inspirierten, die ,Aufarbeitung' jener folgenschweren Zeit nicht ausschließlich politischen und juristischen Debatten zu überlassen. Die vielfach beschriebene rituelle Praxis mit vietnamesischen Totengeistern, beziehungsweise den „umherirrenden Geistern“ (Kwon 2006), die aktiv in die Leben der Überlebenden eingriffen und ihnen damit einen unmittelbaren Umgang mit ihrer Geschichte ermöglichten, nutzte ich als Ausgangspunkt für eine Studie über den Umgang von Kambodschaner_innen mit ihrer Geschichte.

In meinem Forschungsexposé stellte ich demnach die These auf, dass Kambodschaner_innen auf ,alternative' Praktiken der Verarbeitung dieser Zeit zurückgriffen. Dazu zählte ich Rituale, die Menschen in die Lage versetzen durch den 
Körper eines menschlichen Mediums ${ }^{2}$ mit den Geistern von Verstorbenen zu kommunizieren. Die mit dieser religiösen Praxis ermöglichte Kommunikation mit den Toten und die Verabschiedung von anonym verstorbenen Verwandten - so meine These - diene noch heute der Versöhnung und Trauma-Verarbeitung. Diese Rituale plante ich im Kontext von Themen wie Erinnerung, Schuld und Gerechtigkeit ethnologisch zu erforschen.

Mit diesem Vorhaben begann ich im Februar 2012, begleitet von meiner Frau und meinem einjährigen Sohn, meine empirische Feldforschung in Kambodscha. Die Suche nach Totengeistern aus der Zeit der Roten Khmer gestaltete sich jedoch schwieriger als angenommen. Sowohl in alltäglichen Gesprächen als auch in ersten Interviews mit Hochschullehrern, Mönchen und menschlichen Medien von Geistern konnte nur wenig von Ritualen mit Totengeistern aus der Zeit der Roten Khmer berichtet werden. Stattdessen führte mich die Suche nach Totengeistern beständig zu anderen Geistern und ihren Geistmedien. Sie pflegten eine spannende, dynamische Ritualpraxis, die - wie sich im folgenden Forschungsjahr herausstellte - außerordentlich hohe Popularität besaß. Daher sah ich mich gezwungen, den Relevanzen meiner Forschungsteilnehmenden zu folgen und das Thema meiner Dissertation dahingehend zu verändern

${ }^{2}$ In der Folge auch ,Geistmedien' oder - nach der lokalen Bezeichnung - grū (gesprochen: ,kru') genannt. 


\section{Einleitung: Geister und Geistmedien in Kambodscha}

„Am Tag des Kambodschanischen Neujabrsabends 3 fubr ich zum Kloster Botumwadei im Zentrum der Stadt [Phnom Penh]. Es waren fast keine Menschen vor Ort, ${ }^{4}$ nur ein Radio beschallte den leeren Platr. Schließlich traf ich auf einen Mönch, der mir half, die schnell sprechende Stimme im Radio zu verstehen. Pünktlich um 19:11 Ubr, zum genauen Zeitpunkt des diesjährigen Jahreswechsels, rief die Stimme aus dem Radio: „Kemera Devi kommt näher zu uns herab. Sie kommt! Noch näher! Sie reitet auf ihrem Büffel, sie hat ihr Schwert dabei und ihre Pen5! Gleich ist sie da! ...... Jeeeeetrt!!!" Zu den Klängen von Musik börte man nun Jubelgeschrei aus dem Radio. Der Mönch erklärte mir, dass Kemera Devi gerade mit dem Kopf ibres Vaters Kapila Moha Brahm vom Berg Meru herabgestiegen sei. Ihre Schwester Kariney Devi, die im letzten Jahr über das Land gewacht hätte, ritte nun auf ihrem Elefanten zum Berg Meru zurück und nähme den Kopf ihres Vaters wieder mit" (Feldnotiz vom 14.04.2012).

${ }^{3}$ Nach buddhistischem Kalender entspricht das dem Jahr 2555 nach Buddhas Tod, beziehungsweise seinem Einzug in das Nirvana. Das Neujahrsfest beginnt stets am 13. oder 14. April und dauert drei bis vier Tage.

${ }^{4}$ An Feiertagen fahren die Stadtbewohner_innen gemeinhin zu ihren Familienangehörigen in ländliche Gebiete.

${ }^{5}$ Kambodschanisches Musikinstrument, das Ähnlichkeiten zu einer Sitar aufweist. 
Nicht nur an jenem Neujahrstag, sondern während meines gesamten forschenden Alltags in Kambodscha wurde ich fortwährend mit verschiedensten Geistern konfrontiert, die mich herausforderten, eine ganze ,Geisterlandschaft' ordnen zu müssen. Statt weiterhin die offensichtlich weniger bedeutsamen Totengeister zu suchen, befasste ich mich wegen ihrer Relevanz im Alltag schon bald mit den Dynamiken einer anderen, aber sehr viel populäreren Geister-Praxis. Ohne meine Fragestellung nach den ,umherirrenden Geistern' ganz aus den Augen zu verlieren (Kap. 4), war mein Blick auf ein wesentlich ergiebigeres Forschungsfeld gelenkt worden, in denen Geister, ihre Medien und deren Klient_innen die wichtigsten Akteursgruppen darstellten.

Von diesem religiösen Feld, das ich im Folgenden als Spiritscapes (Lauser und Endres 2011) bezeichne, handelt die vorliegende Dissertation. Im Folgenden widme ich mich der Frage, welche Bedeutung Geister und Geistmedien im Leben der Kambodschaner_innen einnehmen. Dabei untersuche ich neben den sozialen auch die ökonomischen, politischen und militärischen Kontexte, in denen Geister Präsenz zeigen. Zur Bearbeitung dieses Anliegens stelle ich zwei Themen in den Fokus dieser Arbeit: erstens erarbeite ich mir anhand einiger aus der AkteurNetzwerk-Theorie entliehenen, theoretischen ,Werkzeuge die Grundzüge der kambodschanischen Geister-Existenz. Dabei frage ich:

- Unter welchen Bedingungen existieren Geister in Kambodscha?

- Wann werden sie als mächtig erachtet und inwiefern gilt ihre Macht als überzeugend?

Neben der Beantwortung dieser Fragen, die ein grundsätzliches Verständnis der Geisterpraktiken in Kambodscha ermöglichen, stelle ich ein theoretisches Programm vor, das das Konzept der Spiritscapes und die Ideen der Akteur-NetzwerkTheorie in einen außereuropäischen Kontext überträgt und auf empirische Forschungsergebnisse anwendet (Kap. 3-5).

Mit dieser Methode betrachte ich zweitens die Bedeutung der Geisterpraxis für machtpolitische Zwecke. Durch ihre spezifische Konzeption eröffnen Geister Möglichkeiten zur Machterlangung und -erhaltung und zur Stärkung von individueller Handlungsmacht der involvierten Kambodschaner_innen. Diese Formen der Machtakkumulation stellen einen Gegenentwurf zur Deutungshoheit des buddhistischen Machtverständnisses dar, da sie nicht auf Karma und moralischen Taten, sondern auf individuellen Beziehungen zu Geistern beruhen (Kap. 6-8). Somit frage ich:

- Welches Potential bietet diese alternative Machtkonzeption für soziale und politische Aushandlungen von Macht? 
Ein großer Teil dieser Analysen (Kap. 9) wird sich auf die tiefgreifenden Verflechtungen von kambodschanischer Politik und Geistern konzentrieren. Unter anderem überprüfe ich dabei die These, ob die aufblühenden Geister-Praktiken das Potential des Widerstandes gegen die autoritäre Machtausübung von Premierminister Hun Sen erhöhen könnten oder ob Geister-Rituale zur Stärkung nationaler Identität eingesetzt werden. Mit den untersuchten Teilbereichen von kambodschanischer Geister-Existenz und den Machtaushandlungen zwischen Geistern und Menschen argumentiere ich, dass die Rituale mit Geistern, das Kanalisieren spiritueller ${ }^{6}$ Diskurse und die Legitimation von Macht in Kambodscha weitreichende gesellschaftliche Konsequenzen besitzt, die bisher zu wenig erforscht worden sind.

\subsection{Die Geisterlandschaft und die Untersuchung der Geister-Existenz}

Inspiriert von der Konzeptmetapher der „Spiritscapes“ von Endres und Lauser (2011) und in Anlehnung an Appadurais Konzept (1996: 33) der scapes als fluid gedachte Landschaft in einer global vernetzten Welt verstehe ich Geister als individuelle Akteure ${ }^{7}$ in einem dynamisch konzipierten Raum, der von einem komplexen (und mitunter auch kontroversen) Beziehungsgeflecht geprägt ist. Wie ich in Kapitel 3 ausführen werde, befördern zudem theoretische Ansätze der AkteurNetzwerk-Theorie das Projekt der Erforschung der Geisterlandschaft in Kambodscha. Mit der Kombination dieser beiden Ansätze werden Strukturen in fluid gedachten Landschaften sichtbar gemacht, während zugleich die Diversität der Beziehungen zwischen menschlichen und nicht-menschlichen Akteuren betont wird und transversale Verknüpfungen zwischen der Landschaft als Raum und den einzelnen Akteuren aus verschiedenen Zeiten (Verstorbene, Mächte aus der AngkorZeit, gegenwärtige Klient_innen der Geistmedien) aufgezeigt werden. Diesen Denkbahnen folgend untersuche ich die konstituierenden Bedingungen der kambodschanischen Geister-Existenz, was den wesentlichen Teil der Untersuchung der Geisterlandschaft ausmacht.

Die Frage nach der Existenz von Geistern wurde in ethnologischen Debatten lange Zeit gemieden. Viele Jahrzehnte lang folgten Ethnolog_innen dem Vorbild Evans-Pritchards, der Geister aus der Sicht der lokalen Bevölkerung als existent

\footnotetext{
${ }^{6}$ Ich benutze „spirituell“ im Folgenden in der naheliegenden Bedeutung des Wortes ,geistig“ und „religiös“. Letzteren Begriff verwende ich jedoch vor allem für Beschreibungen institutionalisierter Religiosität, während „spirituell“ für die Beschreibung von Geistern und Medialität passender erscheint.

${ }^{7}$ Das Wort „Akteur“ wird im Folgenden nicht gendergerecht angepasst, da es zum einen aus dem Englischen (actor) übernommen wurde und zum anderen den Bezug zur Akteur-NetzwerkTheorie betonen soll.
} 
beschrieb, ansonsten jedoch Zweifel an ihrer Existenz erkennen ließ. ${ }^{8}$ Eine populäre Ausnahme bildet hierbei Edith Turner, die im Laufe ihrer Forschung von der Existenz von Geistern überzeugt wurde (1993). Ihr Ansatz eines „methodologischen Theismus" (Bielo 2015: 39-41), die Geister per se als existent wahrzunehmen, wurde kürzlich von Vertreter_innen der „Paranthropologie“ wie Fiona Bowie $(2014,2013)$ und gleichgesinnten Wissenschaftler_innen umgesetzt (Hunter 2015; Hunter und Luke 2014; Castro et al. 2014; Luke 2013).

Indem ich den Mittelweg zwischen beiden Denkrichtungen im Sinne eines „methodologischen Agnostizismus“9 bestreite, verfolgt meine Studie dezidiert das theoretische Ziel, die Existenz von Geistern zu analysieren, ohne sie per se als existent oder nicht existent einzustufen. Mit meiner Methodik untersuche ich die Existenz von Geistern und knüpfe damit an ähnliche Herangehensweisen an (Blanes und Espirito Santo 2014; Jensen und Blok 2013; Ochoa 2010). So werden in dieser Arbeit die Bedingungen herausgearbeitet, unter denen die Existenz von kambodschanischen Geistern als mehr oder weniger ,stabil' aufgefasst wird. Diese Methodik erlaubt mir zudem, die differenzierten Zwischenstadien der GeisterExistenz zu beschreiben.

In die Fragestellung nach dem ontologischen Status der Geister ziehe ich in folgerichtiger Vermeidung der dichotomen Trennung von Objektivität und Subjektivität alle relevanten nicht-menschlichen Akteure mit ein. Demnach können Geister - unter bestimmten Bedingungen - für Subjekte objektiv existent sein. Daher ist die Frage nach der Existenz von Geistern nicht ontologisch, sondern nur ,relational' zu beantworten. In konsequenter Umsetzung dieses Ansatzes zeige ich die Beziehungen der untersuchten Akteure auf, denen ich in meiner ethnografischen Forschung stetig gefolgt bin. Die Ergebnisse dieser Studie liefern somit die Gründe, warum die Existenz der Geister für einige mehr und für andere weniger kohärent nachvollziehbar ist. So komme ich der ethnografischen, methodologischen Forderung nach, die emischen Logiken zu verstehen und ernst zu nehmen, denn „conceiving (...) spirits as authentic social and political actors/agents in networks of distributed agency brings us nearer to the point of view of the devotees" (Lauser und Endres 2011: 11-12).

${ }^{8}$ Evans-Pritchard schreibt in seinen „Erinnerungen und Überlegungen zur Feldforschung“ (1976: 240): "I have often been asked whether, when I was among the Azande, I got to accept their ideas about witchcraft. This is a difficult question to answer. I suppose you can say I accepted them; I had no choice. In my own culture, in the climate of thought I was born into and brought up in and have been conditioned by, I rejected, and reject, Zande notions of witchcraft. In their culture, in the set of ideas I then lived in, I accepted them; in a kind of way I believed them."

${ }^{9}$ Bielo (2015: 36-38) definiert den methodologischen Agnostizismus als Denkrichtung der Religionsforschung, nach der die ontologische Wahrheit des Religiösen nicht beantwortet werden kann, aber im Interesse einer „ethnografischen Gelegenheit“ (ebd.: 36) untersucht wird, um damit epistemologisch auf soziale Realitäten ableiten zu können. 


\subsection{Die Untersuchung von spirituellen Machtaushandlungen}

Nicht nur in Kambodscha, sondern auch in anderen regionalen Kontexten Südostasiens zeigen machtanalytische Untersuchungen, wie Geister in gesellschaftlichen Aushandlungsprozessen der ,Moderne' bedeutende Rollen einnehmen (Jackson 2016, 1999b; Århem und Sprenger 2016; Bubandt 2014; Bräunlein 2014; Ladwig 2011; Endres und Lauser 2011; Pattana 2008, 2005a, 2005b; Platenkamp 2007; Willford und George 2005; White 2005; Kendall 2001). Mit Blick auf diese Debatten einer Anthropologie Südostasiens befasse ich mich in dieser Arbeit eingehend mit der Bedeutung der spirituellen Ebene für weltliche Machtzuschreibungen. Dabei stelle ich fest, dass meine kambodschanische Fallstudie im südostasiatischen Vergleich auf eine bemerkenswert enge Verflechtung von Politik und Spiritualität hinweist und Geister einen erheblichen Einfluss auf die Aushandlung von weltlicher (das heißt, politischer und wirtschaftlicher) Macht ausüben. Zudem werden die Existenz von Geistern und ihre Wirkmächtigkeit im Gegensatz zu anderen südostasiatischen Ländern nicht öffentlich angezweifelt. ${ }^{10}$

Beweggründe für das öffentliche Engagement der Mächtigen mit Geistern offenbaren sich mit einem Blick auf die öffentliche Inszenierung von Macht, bei der spirituelle Aspekte von erheblicher Bedeutung sind. Wie Stuart-Fox und Jacobsen (2013) zeigten, wird weltliche Macht (ạnnāca) aus der Summe von spiritueller Macht (pāramī), sozialem Status (punya sak) und Wohlstand (mān) definiert, deren Maß wiederum durch die Summe der schlechten Taten (Karma) der vergangenen Leben limitiert wird. Ich werde das von den Autoren vorgestellte Konzept von spiritueller Macht - pāramī - in Kambodscha um einen bedeutenden Aspekt ergänzen, indem ich es anhand meiner Daten als weitaus flexibler und mehrdeutiger konzipiere. Pāramī wird als ein außerhalb des Menschen verortetes, fluides Konzept von (magischer) Macht definiert, das selbst ,handeln' kann (Guillou 2017c). Zur Steigerung der eigenen Handlungsmacht konsultieren Gläubige die subjektivierte Macht. Demnach bedeutet ,mächtig' zu sein, mit menschlichen und nichtmenschlichen Subjekten (wie Geistern) Beziehungen einzugehen und diese Beziehungen durch Tauschhandlungen aufrechtzuerhalten.

\footnotetext{
${ }^{10}$ In anderen Ländern wie Thailand (Pattana 2012, 2002), Vietnam (Sorrentino 2013; Endres 2011; Phạm 2009) oder Indonesien (Bubandt 2014; Christensen 2014) wurde die rituelle Praxis mit Geistern und besonders die praktizierte Medialität von staatlicher und religiös institutionalisierter Seite sanktioniert oder verboten, allerdings immer wieder auch mit ausgehandelten Ausnahmen (Dror 2016; Lauser 2018, 2008).
} 


\subsection{Das Forschungsfeld: Geister in Kambodscha}

Die hier angesprochene emische Perspektive auf kambodschanische Geister zeichnet sich durch ihre Vorstellung einer allgegenwärtigen Präsenz von Geistern aus. Ihre Anwesenheit ist von beeindruckender Relevanz. Nicht nur in den Gesprächen werden sie als wichtig erachtet; ihre Präsenz- und Verehrungsorte finden sich vor jedem Haushalt, auf Reisfeldern, im Wald, auf dem Gelände buddhistischer Pagoden, an Berghängen, Wegkreuzungen und anderen Orten wie Termitenhaufen, Brücken und Denkmälern. Jedes Haus besitzt drei Schreine zur Verehrung verschiedener Geister, jedes Dorf hat durchschnittlich ebenso viele gemeinschaftlich genutzte Verehrungsstätten und auch in den Städten gibt es zahlreiche, aktiv genutzte Residenzorte von Geistern.

Dennoch gibt es bisher noch nicht viel Literatur zu diesen spirituellen Akteuren. In Berichten aus der Kolonialzeit (Leclère 1899, 1895; Aymonier 1883) wurden bereits Schlaglichter auf kambodschanische Religiosität geworfen, die später von vertiefenden Studien (Porée-Maspéro 1962, 1961a; Porée und Maspéro 1938) ergänzt wurden. Die ersten ausführlichen Studien zu Geistern in Kambodscha veröffentlichten bis heute Ang (1986) und Forest (1992). Forests Studie stellt eine gründliche Analyse von Interviews dar, die in den frühen 1970er Jahren gemacht wurden und dadurch einen Einblick in die religiöse Situation vor der Roten Khmer-Zeit (1975-79) bietet. Dies trifft auch auf das Werk von Ang Chouléan (1986) zu, der für seine Dissertation geflüchtete Kambodschaner_innen in Paris interviewte und anhand dieser Daten einen erkenntnisreichen Überblick der verschiedenen Geister-Kategorien erarbeitete.

Erst nach der Beendigung des Roten Khmer-Konflikts Ende der 1990er Jahre wurden wieder vermehrt Forschungen ,vor Ort ${ }^{6}$ durchgeführt. So erschienen wenig später die ersten Publikationen mit Bedeutung für die kambodschanische Religionsforschung. Hervorzuheben sind die Sammelbände von Guthrie und Marston (2004), Chandler und Kent (2008) und Hansen und Ledgerwood (2008), in denen auf die große Bedeutung des Religiösen und speziell auch von Geistern hingewiesen wird - auch wenn sich die Autor_innen nur selten darauf fokussierten. Dennoch liefern diese neueren Werke im Angesicht meiner aktuellen Daten deutliche Hinweise auf die Entwicklung der von mir untersuchten Geister-Praxis. Auch in zeitgleich erschienenen Monographien zum kambodschanischen Buddhismus wurde auf dessen enge Verknüpfung mit Geisterpraktiken verwiesen und ihre Relevanz über die letzten Jahrhunderte aufgezeigt, was mir zur historischen Einordnung dieser religiösen Phänomene in Kapitel 2 dient (Forest 2012; Harris 2012, 2005).

Für die gegenwärtige, spirituelle Situation sind die Veröffentlichungen von Didier Bertrand (2005, 2004, 2001) und John A. Marston (2008a, 2008b, 2008c, 2006, 2004) hervorzuheben, die sich in ausführlicher qualitativer Forschung mit Geistmedien und ihren Geistern beschäftigten, was ich als Grundlage zur Kategorisierung der Geister heranziehe und die mir zahlreiche Anknüpfungspunkte für 
Themen der spirituellen Legitimation von Macht, der Geistmedien-Praxis und Fragen von Buddhismus und Moral bot. Zentral für meine Beschäftigung mit Buddhismus und Geistern sind auch die Werke von Erik W. Davis (2015a, 2015b, 2009). Davis untersucht in seinen Studien zur buddhistischen Konzeption des Todes und der Wiedergeburt ausführlich die ,Gegenwelt' des Brahmanismus, der als Überbegriff zur religiösen Einordnung von Geisterpraktiken dient. Zudem lässt sich fachkundige Expertise zum Thema Totengeister in den kürzlich erschienenen Publikationen von Caroline Bennett (2018, 2015) und Anne Guillou (2016, 2013, 2012) finden, die neuerdings (als erste nach Ang Chouléan und Alain Forest) auch die Gesamtheit der kambodschanischen Geister untersucht (Guillou 2018, 2017a, 2017c) und damit die Argumentation der vorliegenden Dissertation maßgeblich stützt.

Wie diese jüngeren Studien belegen, beziehen sich Interaktionen mit Geistern nur äußerst selten auf vergangene Zeiten wie etwa die Rote Khmer-Zeit. Die Klient_innen der heutigen Geister-Praxis formulieren vor allem gegenwärtige und zukünftige Anliegen zur ,magischen Bearbeitung' durch die Geister (Kap. 6), die meist auf die Heilung psychischer Krankheiten (Kap. 7), die Erhöhung der finanziellen Möglichkeiten oder die Erlangung von spiritueller Macht zum Ziel haben (Kap. 8). Gefragt ist die spirituelle Praxis in allen Bevölkerungsschichten: von Dorf- und Stadtbewohner_innen, Arbeiter_innen und Politiker_innen bis hin zu Angehörigen des Militärs und der Wirtschaft (Kap. 9).

\subsection{Forschungsmethodik}

Für die Gewinnung empirischer Daten war ich während meiner ethnografischen Feldforschung auf einen engen Kontakt zu kambodschanischen Forschungspartner_innen angewiesen. Wie alle Ethnolog_innen musste ich mich möglichst gut in die Gesellschaft integrieren und am Alltag teilhaben um ein tiefergehendes Verständnis dafür entwickeln.

\subsubsection{Rollenzuschreibungen im Feld}

Die kontinuierliche Reflexion des eigenen gesellschaftlichen Status und der damit verbundenen Rollenzuschreibungen ist wesentlicher Bestandteil des ethnologischen Forschungsprozesses (Breidenstein et al. 2013; Wolcott 2005). Während ich Südostasien zuvor als unverheirateter Student besucht und beforscht hatte (Christensen 2014, 2009), war ich nun verheiratet und - dank meines Dissertationsstipendiums - mit einem vergleichsweise hohen Einkommen ausgestattet. Meine neue Rolle als Ehemann und Vater brachte mich in Einklang mit kambodschanischen Familienvorstellungen, nach denen eine Heirat mit etwa 20 Lebensjahren angestrebt wird. Die zugeschriebene Identität als Familienvater reduzierte meine zugeschriebene Ambiguität und erleichterte mir den Zugang zu ähnlich gestellten 
Kambodschanern. Zu weiblichen oder Transgender-Personen gestaltete sich der Zugang schwieriger, dennoch erleichterte mir der Status als verheirateter Ehemann, ein Verhältnis aufzubauen, das frei von Erwartungen an mögliche Beziehungs- oder Ehekonstellationen war, was während vorherigen Besuchen einige Freundschaften beeinträchtigt hatte.

Mein neuer gesellschaftlicher Status war respektgebietend und daher für mich gewöhnungsbedürftig, auch weil ich diese gesellschaftliche Position nur teilweise ausfüllen wollte und konnte. Die genaue Höhe meines Einkommens war ständiges Gesprächsthema in informellen Gesprächen. Ich entsprach mit meinen finanziellen Ressourcen und technischen Hilfsmitteln (wie Aufnahmegerät und Fotoapparat) in einigen Hinsichten der typischen Konzeption eines pārāng. ${ }^{11}$ Erstaunen löste dagegen mein Fortbewegungsmittel aus, da ich - unangemessen hinsichtlich meines angenommenen Status - ,nur' Moped (und kein Auto) fuhr. Die Ausgestaltung der Mobilität war normalerweise ein wichtiger Bezugspunkt für die Einschätzung des Wohlstands einer Person und damit auch ihres sozialen Status.

Wie das Moped störte auch mein hartnäckiges Interesse an der kambodschanischen Religiosität die Entsprechung eines ,echten' pārāng. Sobald ich in Gesprächen auf Khmer mein Forschungsthema und die Namen zahlreicher Geister vorstellen konnte, hatte ich die Rolle eines seltsamen ,Exoten' inne. Sie gab mir die Freiheit, den üblichen, an pārāng gestellten Erwartungen zu entkommen und schaffte mir zugleich erleichterten Zugang zu den Geistmedien, die ihrerseits ,Exot_innen' zwischen zwei Welten darstellten. Schließlich richtete ich mich in der für Ethnolog_innen angestrebten Rolle des marginal native ein (Hammersley und Atkinson 2007: 89; Freilich 1970).

\subsubsection{Forschungsassistenz}

Um die sprachlichen Hürden der empirischen Datensammlung zu meistern, benötigte ich eine Forschungsassistenz. Meine Suche nach englischsprachigen Studierenden wurde freundlicherweise von Alexandra Kent und Heng Sreang unterstützt, die für mich die Rolle von Sponsoren annahmen (Breidenstein et al. 2013: 52-56; DeWalt und DeWalt 2011: 46-53). Dank ihrer Vermittlung konnte ich bereits nach wenigen Wochen Interviews mithilfe von Alexandras Freundin Chanta und eines Studenten von Heng Sreang namens Buth Sreybunnwath durchführen. Mit Sreybunnwath, im Folgenden nur Bunnwath genannt, verstetigte sich der Kontakt über regelmäßige Forschungsexkursionen.

Wir merkten schnell, dass wir eine förderliche Zusammenarbeit für beide Seiten eingegangen waren. Bunnwath eignete sich Wissen und Erfahrung in ethnologischer Forschungspraxis an und ich profitierte von seiner lokalen Expertise und seinen Sprachkenntnissen. Auch persönlich verstanden wir uns sehr gut und führ-

\footnotetext{
11 Pārāng ist von dem Wort „francais“ abgeleitet. Seit der französischen Kolonialzeit werden alle
} westlich-aussehende Menschen so bezeichnet, ähnlich wie in Thailand das Wort farang. 
ten über zehn Monate fast alle Interviews und teilnehmenden Beobachtungen für diese Forschung gemeinsam durch. Die ausdauernde, gemeinsame Zusammenarbeit stellte einen entscheidenden Vorteil für mein Forschungsvorhaben dar. In mehrtätigen Reisen stimmten wir unsere Arbeitsweise in zunehmendem Maße aufeinander ab. In Interviewsituationen bewährte sich diese Zusammenarbeit, da unsere Interviewführung von abwechselnden Nachfragen, vertraulich geführte Absprachen und von nonverbaler Kommunikation geprägt war. Die große Vertrautheit war nicht nur von Bedeutung für Forschungssituationen, sondern auch eine wichtige Grundlage für andere Aufgaben des Forschungsprozesses, wie beispielsweise der langwierigen, gemeinsamen Transkription von Interviews.

Für Bunnwath war das Forschungsthema anfangs eine besondere Herausforderung, da er mit Geistern und Geistmedien vorsichtig und in manchen Fällen ängstlich interagierte. Neben der durchaus gewöhnungsbedürftigen Situation, mit multivokal sprechenden Medien zu kommunizieren, fürchtete er sich davor, Übersetzungsfehler zu begehen, die die betreffenden Geister hätten ärgerlich machen können. Seine größte Angst war es, damit selbst ein Medium für Geister werden und als solches die Regeln der Geister einhalten zu müssen.

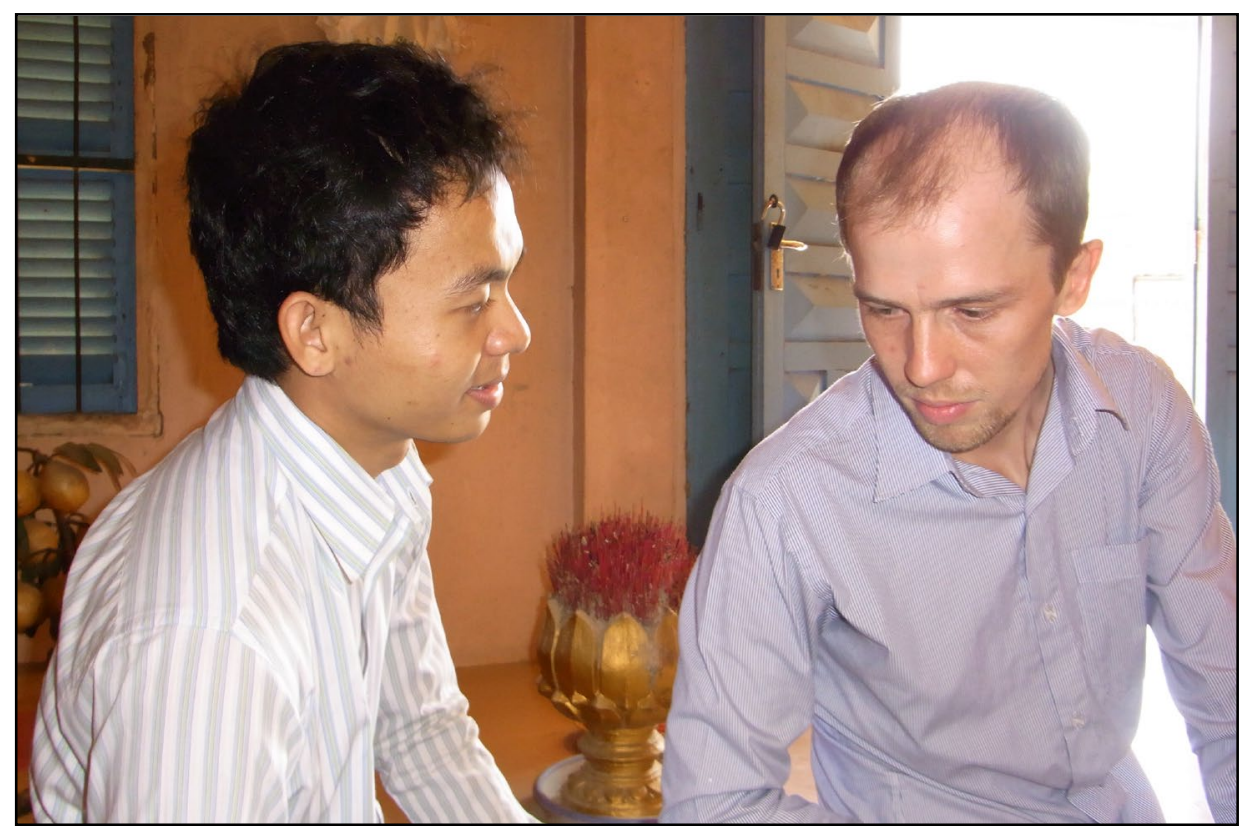

Abb. 2: (C) Lauser. Bunnwath und ich während eines Interviews mit einem Geistmedium in der Region Samraong

Bunnwath war in einfachen, ländlichen Verhältnissen aufgewachsen und lebte seit mehreren Jahren im Wat Botumwadei (Kloster Botumwadei) im Zentrum Phnom 
Penhs als kmeng wat, das heißt als junger Laien-Helfer der Mönche. Als solcher fürchtete er sich anfangs vor der teilweise ,un-buddhistisch' anmutenden Praxis der Geistmedien.

Daher unterstützte er meine Forschung nicht nur durch seine Mitarbeit; er vermittelte mir zudem die Perspektive eines in der Stadt sozialisierten Studenten, der dem reformierten Buddhismus weitaus näher stand als den Geister-Ritualen. Auf der einen Seite kamen ihm die Medien und ihre Praxis veraltet vor und er hatte Mitleid mit ihnen, auf der anderen Seite hatte er gleichzeitig große Ehrfurcht vor den Geistern, mit denen sich die Geistmedien ,verbündet' hatten. Somit nahm er selbst die Rolle eines marginal native in unserem Forschungsfeld ein und musste - wie ich - zunächst einen Zugang finden.

Nach einiger Zeit wurde unser Umgang mit den Geistmedien routinierter und Bunnwath war bald erleichtert, dass sich seine oben genannten Befürchtungen nicht bewahrheitet hatten. In dieser Rolle war Bunnwath, mehr noch als andere in meine Forschung Involvierte, ein mitgestaltender Partner des Dissertationsprojekts und nicht nur ,Informant', ,Übersetzer' oder ,Assistent' (Gottlieb 1995).

\subsubsection{Forschungsprozess}

In der explorativen Phase der Forschung initiierten Bunnwath und ich zunächst ein ,Schneeball-System‘, indem wir uns bei allen besuchten Medien nach weiteren Adressen von möglichen Gesprächspartner_innen erkundigten (Bernard 2011: 146-150). Diese Zeit war geprägt von „kontinuierlichem Werben um Vertrauen, im Gewinnen von Gesprächspartnern“ und „diplomatischem Einflechten neugieriger Fragen“ (Breidenstein et al. 2013: 60). Wir begründeten unser Anliegen stets mit dem Schreiben eines Buches über Geistmedien, was vonseiten der Medien begrüßt und gefördert wurde. Die Geistmedien waren in der Regel kommunikative Gesprächspartner_innen, die vor allem Wert darauf legten, die Wirkmacht ihres Geistes zu betonen.

Da sich Geistmedien weniger in den Städten aufhielten, verlagerte sich unsere Forschung auf die ländlichen Gebiete, die wir in Tagesausflügen oder mehrwöchigen Exkursionen bereisten, was die Forschungsmethodik im wörtlichen Sinne multilokal, beziehungsweise multi-sited (Falzon 2009; Marcus 1995) gestaltete. Dies gab mir die Möglichkeit, die Verbreitung der rituellen Praxis zu ergründen und ihre lokalen Merkmale zu vergleichen.

Bunnwath und ich sprachen in den ersten sechs Monaten mit etwa 60 Geistmedien aus 17 Provinzen (vor allem in West-, Süd- und Nordkambodscha) und führten Interviews durch, die wir stets halbstrukturiert begannen, indem wir offene Fragen über die allgemeine Lebenssituation des Mediums stellten. Danach leiteten wir zu unstrukturierten, biographischen Fragen über (Bernard 2011: 156186). Die Interviews sollten zu jeder Zeit, Gespräche' bleiben, obgleich ich zuweilen als Autoritätsperson wahrgenommen wurde und sich die Unterhaltung zu einer Situation des ,Abfragens' entwickelte. Zur Auflockerung einer solchen Ge- 
sprächssituation brachte ich beispielsweise eine neue Lektion meiner Sprachkenntnisse zur Anwendung, was die hierarchisierende Rollenverteilung wieder aufbrach, da ich nun von allen Seiten belehrt werden musste, was meist eine erheiternde Stimmung erzeugte. Nach den Gesprächen mit den Medien führten wir meistens auch Interviews mit den Geistern durch, die uns allerdings viel weniger ergiebige Angaben zu ihrer Biographie oder ihren Fähigkeiten machten und uns bei Fragen danach oftmals an die Medien zurückverwiesen.

Für die Transkription der Interviews trafen Bunnwath und ich uns regelmäßig in Phnom Penh und übersetzten die Audiodateien entweder wörtlich oder in ausführlichen Interviewprotokollen. Dieses aufwendige Vorgehen hatte den entscheidenden Vorteil, dass wir unbeantwortete oder neu auftauchende Fragen sofort per Telefonanruf oder in späteren Besuchen bei den Medien klären konnten.

Nach sechs Monaten, in denen ich mir einen Überblick über die ,Medialität ${ }^{612}$ in Kambodscha verschafft hatte, verlagerte ich den Mittelpunkt meiner Forschung auf die Region Samraong in der Provinz Takeo, etwa $50 \mathrm{~km}$ südlich von Phnom Penh. Dort leben drei sich stark voneinander unterscheidende Geistmedien in unmittelbarer Nähe des Berges Chisou (Phnom Chisou). Die regelmäßigen Treffen mit ihnen boten mir die Gelegenheit, die sensiblen Prozesse der Geistbesessenheit und der Bearbeitung persönlicher Anliegen ihrer Klient_innen detaillierter $\mathrm{zu}$ untersuchen. Ich konnte durch den engen Kontakt zu ihnen intime Einblicke in ihre Lebensführung, die Aushandlung ihres sozialen Status, ihre Praktiken und ihre weitverzweigten Beziehungen gewinnen und ein alltägliches Verhältnis zu ihnen aufbauen. In zahlreichen Interviews mit diesen drei Medien konnte ich tiefer gehende Fragen stellen, so dass problemzentrierte Interviews allmählich die offenen und biographischen Gesprächsformen ablösten.

\subsubsection{Forschungspartner_innen}

Die drei Medien der Region Samraong, die im Folgenden immer wieder in Beispielen für unterschiedliche Aspekte kambodschanischer Medialität herangezogen werden, stelle ich im Folgenden kurz vor. Ihre biographischen Vignetten vermitteln antizipatorisch Einblicke in die Themen und Probleme ihrer Lebenswelt und ihrer Praxis.

\footnotetext{
12 Ich benutze diesen Begriff im Folgenden in einer engen Definition für mediale Fähigkeiten von Menschen, abgeleitet vom englischen Begriff mediumship. Schüttpelz unterscheidet zwischen technologischen (Massen-) und technischen Medien, die auch über menschliche Fähigkeiten (zum Beispiel als Geistmedien) funktionieren. Wie in dieser Arbeit entwickelt Schüttpelz in seinen Analysen medialer Prozesse Latours methodisches Instrumentarium weiter, siehe Schüttpelz (2013).
} 
Einleitung: Geister und Geistmedien in Kambodscha

\section{Chantrea}

In einem der ersten Besuche in der Region Samraong wurden Bunnwath und ich von einem Helfer einer Pagode zu Chantrea ${ }^{13}$ geführt. Sie war geschmeichelt von unserem Interesse, betonte aber, nichts von ihrem Geist zu wissen, da sie keine Erinnerung an die Besessenheit habe und darüber hinaus keinen Kontakt zu ihrem Geist pflege. Nach und nach erfuhr ich von Chantrea die obligatorischen Bedingungen zur ,Stabilisierung' einer Geister-Existenz, womit sie mein Vorhaben der Untersuchung der Existenzbedingungen von Geistern unterstützte.

Chantrea war bei unserem ersten Treffen im Jahr 201234 Jahre alt. Sie lebte in einem einfachen Holzhaus abseits eines kleinen Dorfes, umgeben von Reisfeldern. Eine schwere Krankheit befiel sie im Jahr 1992, als sie 14 Jahre alt war. Wie viele gru $\bar{u}^{14}$ sträubte sie sich zunächst beharrlich gegen die Initiation als Medium und versuchte, ihr Leben als Bäuerin und bald auch als Mutter weiterzuführen. Ihre Mutter erzählte mir, dass sie zu dieser Zeit geistig abwesend gewesen sei, bisweilen drei Tage lang geschlafen und sehr wenig gegessen hätte. Über einen Zeitraum von acht Jahren scheiterten die kostspieligen Versuche der Heilung in Krankenhäusern und bei Ärzten. Zur Finanzierung dieser Anstrengungen musste die Familie einen Großteil ihrer Ländereien verkaufen, die sie als ehemals hochrangige Rote Khmer für sich beansprucht hatten. Im Jahre 2000, mit 22 Jahren und als Mutter von zwei Kindern, gab sie dem Drängen des Geistes in ihrem Körper nach und wurde sein Medium. Er stellte sich als alt gewordener, nationaler Held namens lok $t \bar{a}^{15}$ Konhaö Deik vor, der im Körper Saruns ,allen guten Menschen helfen' wollte, wie er es formulierte. Die ausdrucksstarke Art von Chantreas Geistbesessenheit war ungewöhnlich im Vergleich zu anderen Geistmedien. Nach meinem ersten Besuch bei ihr beschrieb ich folgende Szene:

„Es war 11:30 Uhr, als wir an ibrem Haus ankamen. Wir wurden sofort hoch ins Holzhaus geschickt, da ,er gerade da' sei (...) Die grü bot wirklich einen außergewöhnlichen Anblick. Ihr Kopf war tief auf die Brust geneigt, ibre sehr langen Haare waren zu einem einzigen, dicken Dreadlock verfilat. Sie sah mit seltsam aufgerissenen Augen zur Seite, den Kopf steif nach vorne gerichtet. (...) Sie sprach mit einer sehr tiefen Stimme und war sogar im Sitzen auf einen großen, aufwendig mit Schlangen verzierten Holzstock gelehnt. Während unseres Gesprächs entfuhr ibr manchmal ein ansteckendes Lachen, das langsam und greisenhaft klang" (Feldnotiz vom 03.06.2012).

${ }_{13}$ Dieser Name wurde zum Schutz der Anonymität des Mediums geändert.

${ }^{14}$ Der Begriff lässt sich vom Sanskritbegriff guru (Lehrer, Meister) ableiten und bildet im heutigen Kambodscha eine höfliche Anrede für Respektpersonen. Im Kontext der Medialität adressierten die Klient_innen die Geistmedien als grū, während die Medien ihre Geister auch grū nannten. Im Folgenden benutze ich es jedoch ausschließlich als Bezeichnung der Geistmedien.

${ }_{15}$ Die Anrede lok tā (,verehrter Großvater) oder lok yāy (,verehrte Großmutter) wird in dieser Arbeit - etwas systematischer als in Kambodscha - für einzelne Geister verwendet, während anak tā die Gesamtheit der Ortsgeister bezeichnet. 
Chantrea lebte zurückgezogen und scheute die Öffentlichkeit aus Angst vor spirituellen Angriffen anderer gru - aus diesem Grund ist es mir auch untersagt, Fotos von ihr veröffentlichen. Sie empfing nur zu bestimmten Zeiten Klient_innen (während der Regenzeit täglich von 14 bis $15 \mathrm{Uhr}$ ) und übernahm in der restlichen Zeit Aufgaben als Mutter und Hausfrau. Bei Besuchen wurden wir schnell in das Familienleben integriert und sahen mit den Kindern TV, aßen frischgeerntete Früchte und wurden Nachbarn und Freunden vorgestellt.

Chantrea sprach nicht gern über ihre Arbeit als Medium; umso emsiger traten dafür ihr Ehemann und ihre Mutter in Erscheinung, wenn es darum ging, die Macht ihres Geistes oder die Geschichte ihrer Initiation in extenso nachzuerzählen. Diese Rollenverteilung der Helfer_innen von Medien war stets dieselbe - was mir zeigte, dass die Deutungshoheit dieser ,nicht-alltäglichen Erfahrung' nach der Initiation des Mediums den Umstehenden oblag, sobald die Betroffenen selbst keine Erinnerung an die Zeit der Besessenheit abrufen konnten. Diese Form der Entase $^{16}$, verbunden mit Zuständen des possession trance ${ }^{17}$ war wesentlich seltener als die alltägliche Kommunikation der Medien mit ihren Geistern, die Bun Ly pflegte.

Bun Ly

Bun Ly war während meiner Forschung etwa 60 Jahre alt, sein genaues Alter wusste er - wie viele ältere Kambodschaner_innen - nicht. Er besaß eine ruhige Art des Sprechens und einen ausgeprägten Tatendrang. Sein Geist offenbarte sich als der Eremit Eysey, der ihn unangekündigt immer wieder spontan besetzte. Dann unterbrach er seine Gespräche mit Sequenzen einer Geister-Sprache, die außer seinem Geist niemand verstehen konnte. Die Anwesenden waren dann zum Warten gezwungen, bis er sich wieder ihnen zuwandte.

\footnotetext{
${ }^{16}$ Entase meint das Eintretens eines Geistes in den Körper, während die Extase das Verlassen eines Geistes (bzw. der ,Seele) aus dem Körper bezeichnet.

${ }^{17}$ Diese Form der Geistbesessenheit in Trance unterscheidet sich von der in Kambodscha üblichen Geistmedien-Praxis, die in der Regel keine tiefen Trance-Zustände induziert, in der dennoch der Geist aus dem Körper des Mediums sprechen kann, was ich in der Folge als Geistbesessenheit (in Anlehnung an spirit possession) bezeichne. Zur aktuellen Debatte der Diskurse zu Trance und spirit possession, siehe Sorrentino (2018).
} 


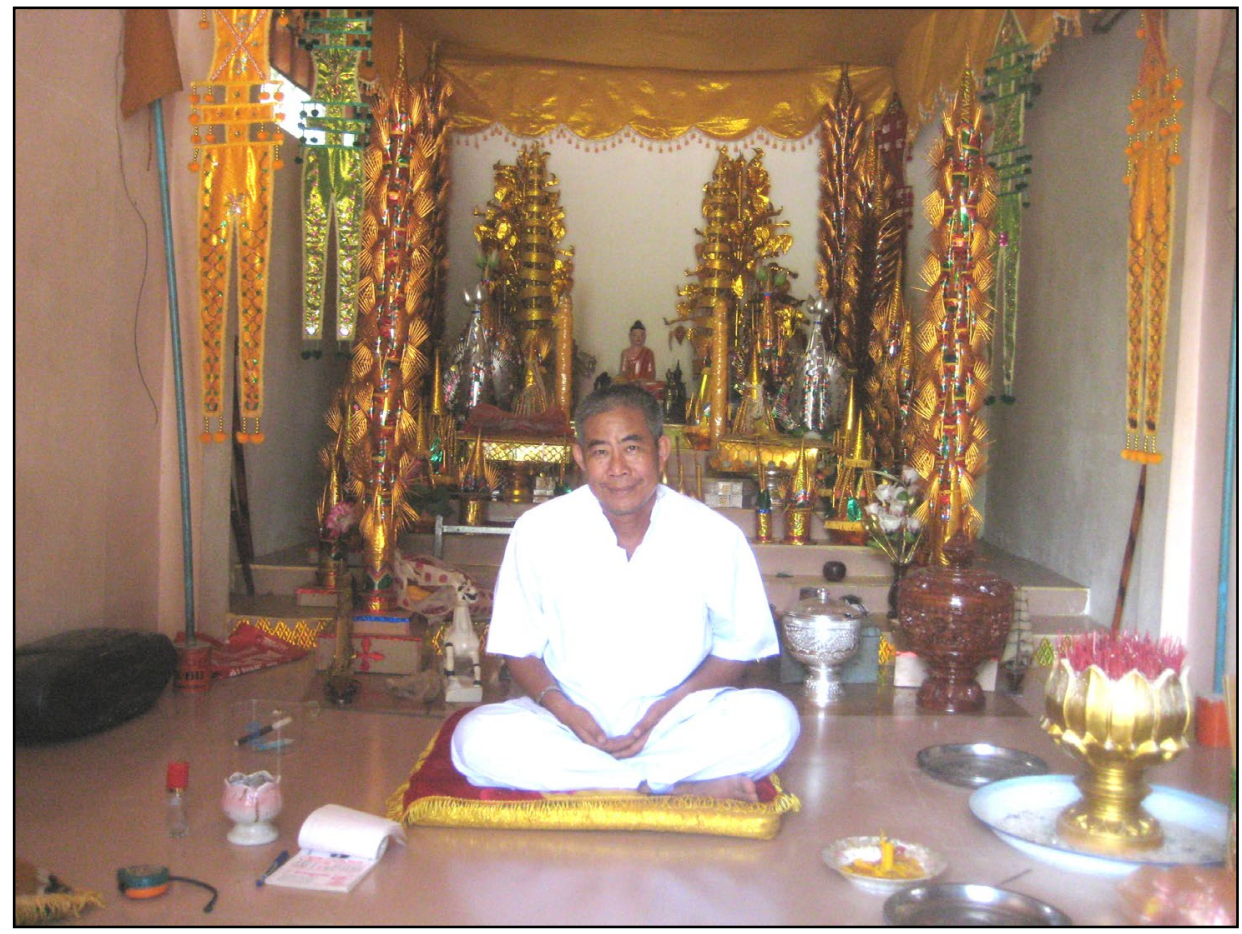

Abb. 3: (C) Autor. Bun Ly vor seinem Schrein in der Provinz Takeo.

Mir begegnete dieser grū, bei dem der Grat zwischen madman and mystic besonders schmal war, sehr zugewandt. Er sah in mir die Reinkarnation eines Generals aus der Angkor-Zeit, der aufgrund dieser Erfahrung aus früheren Leben wieder nach Kambodscha - sozusagen auf der Suche nach seinen Wurzeln - zurückgekehrt sei. Bunnwath wäre damals mein Kommandant gewesen und Bun Lys Geist ein Berater des Königs. Diese ehemaligen Netzwerke wollte Ly reaktivieren: er warb nicht nur um Spenden, sondern forcierte ungefragt das Herbeirufen ,meines ${ }^{6}$ Schutzgeistes, was mich, wie in Kapitel 3.4 deutlich werden wird, in ergiebige Beziehungsnetzwerke mit Menschen und Geistern eintreten ließ.

Bun Ly hatte etwa zur gleichen Zeit wie Chantrea mit der Arbeit als Medium begonnen nachdem er als erfolgreicher Geschäftsmann einen psychischen Zusammenbruch erlitten hatte (Kap. 6). Er lebte in dem kleinen Haus, das den Schrein seines Geistes beherbergte und empfing wesentlich mehr Klient_innen als Chantrea.

Seine ihm vom Geist aufgetragene Hauptaufgabe war die Organisation von großen Besessenheitsritualen mit Musik und Tanz, die Bun Ly regelmäßig etwa alle zwei Monate organisierte. Dafür konnte er über sein weit verzweigtes soziales Netzwerk Dutzende Geistmedien mobilisieren, die bis zu 500km Fahrt auf sich nahmen, um den mehrtägigen Zeremonien beizuwohnen. Vor und während der 
Zeremonien konnte ich die Organisation und seine Interpretation dieser RitualPraxis dokumentieren, die mir später als Beispiel für die ökonomische und machtpolitische Bedeutung der Praxis dienen wird (Kap. 8).

Srun

Auf das dritte Medium in dieser Region stieß ich über eine Kontaktperson in Phnom Penh. Srun ${ }^{18}$ war ein Mann von etwa 50 Jahren, der beste Verbindungen in die einflussreichsten politischen und wirtschaftlichen Kreise der Machthabenden Kambodschas unterhielt und daher in seinem Dorf beneidet und gefürchtet wurde. Seine wohlhabenden Klient_innen hatten die Straße vor seinem Haus asphaltieren lassen und ihm ein großes Haus finanziert. Im Gegensatz zu den beiden erstgenannten Medien war es anfangs schwierig, eine Vertrauensbasis zu ihm aufzubauen. Nach zahlreichen Besuchen bei ihm, in denen wir Zeit mit Smalltalks und gemeinsamen Mahlzeiten verbrachten, wurde der grū ein Freund, von dem ich (unter Voraussetzung der Einhaltung seiner Anonymität) differenzierte Informationen zu Geistern in der Politik Kambodschas erhielt. Sein Geist, lok tā Kong Cha ${ }^{19}$, besetzte ihn zu keiner Zeit. Srun ließ sich stattdessen - unhörbar für andere - von seinem Geist beraten. Er hatte einflussreiche Klient_innen aus der Stadt und eröffnete mir so eine Perspektive auf eine gemäßigtere Form der Medialität, die besonders beliebt war unter Gläubigen der urbanen Mittel- und Oberschicht, was ich im dritten Teil der Dissertation (Kap. 6-9) thematisieren werde.

Bis zum Ende meiner Forschung suchte ich die drei Medien regelmäßig in ihrer Region auf und wandelte mich von einem exotischen Gast zu einem Verbündeten, der nicht nur interessiert war an ihren Leben teilzuhaben - ich trat zudem vereinzelt als Sponsor ihrer Rituale auf, was unsere Beziehung um eine ökonomische Komponente erweiterte, deren methodologische Implikationen an mehreren Stellen dieser Arbeit reflektiert werden.

\subsubsection{Schreib- und Analyseprozess}

Nach der Feldforschung und der Rückkehr nach Deutschland musste ich die mühsam erarbeitete Rolle des Verbündeten und Freundes der Geistmedien langsam abstreifen. Mein Blick auf die Feldforschungsberichte, Interviewtranskriptionen, Videos und Fotos wurde notwendigerweise analytischer. Auch ich sah mich wie so viele Ethnograf_innen vor mir - mit einer Vielfalt an ethnografischen Daten konfrontiert - sowohl zu allgemeinen Themen als auch individuellen Interpre-

\footnotetext{
18 Dieser Name wurde zum Schutz der Anonymität des Mediums geändert.

${ }^{19}$ Kong heißt „rund“ und cha „Scheibe“, was eines der Attribute in der Darstellung von Vishnu darstellt. Zahlreiche hinduistische Götter wurden mit dem wachsenden Einfluss des Buddhismus ab dem 12. Jahrhundert als Ortsgeister uminterpretiert, so auch Vishnu, der als brah Noray bekannt ist (Kap. 5).
} 
tationen - und stand nun vor der fachspezifischen Aufgabe, diese Daten in eine kohärente Form zu bringen.

Die Komposition und Präsentation von ethnologisch gesammelten Daten zur Beschreibung komplexer Lebenswelten im Rahmen einer Ethnografie stellt eine der grundlegendsten Herausforderungen der Ethnologie dar: „Die Untersuchung von Kultur ist in ihrem Wesen nach unvollständig. Und mehr noch, je tiefer sie geht, desto unvollständiger wird sie“ (Geertz 1983: 41). Damit spricht Geertz die Problematik an, kulturelle Wirklichkeit, die sich durch Vielschichtigkeit, Mehrdeutigkeit und Widersprüchlichkeit auszeichnet, in einem einzigen Text widerspiegeln zu wollen, dessen Struktur eher von Linearität und Chronologie geprägt ist. Aufgrund dieser Probleme zeichnen sich Ethnografien durch eine große Bandbreite von textlichen Darstellungsformen aus. Dabei haben sie immer das Ziel, Annäherungen an das Wirklichkeitserleben und die alltäglichen Handlungspraxen anderer Menschen zu ermöglichen. Es gilt, die gemachten Erfahrungen in sachlicher Überlegung auf ihre wissenschaftliche Bedeutung hin zu befragen, zu selektieren und zu interpretieren.

Die vorliegende Arbeit ist Ergebnis dieses Selektions- und Interpretationsprozesses, der von dem ständigen ,Pendeln zwischen empathischen Eintauchen und analytischer Distanz, zwischen engagierter Teilnahme im Feld und isoliertem Schreiben am Arbeitsplatz, zwischen dem Einlassen auf die Themen und Kategorien der Gesprächspartnerinnen und dem Heranziehen forschungsrelevanter Konzepte und Theorien“ (Günther 2018: 47) geprägt war.

Eine weitere ethnologisch-relevante Frage stellte sich mir schließlich während des Lektorats: die Verwendung des ,ethnografischen Präsens', mit dem ich in dieser Arbeit einen Großteil meiner Forschungseindrücke wiedergebe, wurde in ausführlichster Form von Fabian (1983) kritisiert und als a-historisierend herausgestellt: implizit läge in der ethnografischen Benutzung der Präsensform die Vorstellung zugrunde, dass sich die beschriebenen Inhalte weder lokal differenzieren noch im Wandel der Zeit verändern könnten (Fabian 1983: 80-88). Die berechtigte Kritik Fabians an der damals verbreiteten essentialistischen (Re-)Präsentation von Gesellschaften durch Ethnograf_innen verleitet heute jedoch einige Forschende dazu, ihre Ethnografien grundsätzlich in der Vergangenheit zu schreiben, um den prozesshaften Charakter des untersuchten - möglicherweise schon veränderten - Forschungsfelds kenntlich zu machen.

Hastrup (1990) hingegen verweist, ähnlich wie Pina-Cabral (2000) oder Sanjek (1991), auf den längst vollzogenen Wandel des ethnologischen Diskurses, nach dem Gesellschaften in heutigen Ethnografien durchgängig lokal historisiert und als wandelbar repräsentiert würden. Realität würde nicht mehr zeitlos zugeschrieben - stattdessen spricht die Annahme vom dynamischen Kreieren der Gegenwart für die Darstellung der „impliziten Wahrheiten“ (Hastrup 1990: 57) aus dem Feld im ethnografischen Präsens. In Anlehnung an Hastrup vertrete ich die Meinung, dass die unmittelbare Forschungserfahrung eine spezifische Gegenwart 
schafft, die dank mannigfaltiger Dokumentationstechniken der Forschenden erhalten bleibt - und die es im Rahmen der Ethnografie auch auf sprachlicher Ebene (gegenwärtig!) abzubilden gilt.

Ich verstehe meine Arbeit somit als ein Schlaglicht auf kambodschanische Religiosität, der Ergebnisse aus einer vom Wandel geprägten Zeit zugrunde liegen. Heute kann die von mir beschriebene Situation in Kambodscha schlicht nicht mehr dieselbe sein wie zu Zeiten meiner Forschung. Mit der Beschreibung im ethnografischen Präsens teile ich meine damals erlebte Gegenwart mit den Leser_innen unmittelbar, nicht ohne an dieser Stelle ausdrücklich darauf hinzuweisen, dass die hier beschriebene Gegenwart in derselben Form nicht weiter bestehen kann.

\subsection{Aufbau der Arbeit}

Die vorliegende Arbeit besteht aus drei Teilen und insgesamt 10 Kapiteln. Der erste Teil (I.) beschreibt mit einer Übersicht der Thematiken und der theoretischen Überlegungen den Kontext der Arbeit (Kap. 2-3). Im zweiten Teil (II.) lege ich besonderes Interesse auf Geister in ihren Stadien der Existenz und NichtExistenz, sowie der An- und Abwesenheit (Kap. 4-5). Der dritte Teil (III.) konzentriert sich auf die Lebenswelten der Geistmedien und ihren rituellen Praktiken (Kap. 6-9), bevor im Fazit Antworten auf die beiden zentralen Fragen der Existenz und der Macht von kambodschanischen Geistern gegeben werden.

Für das gegenwärtige Verständnis der religiösen und politischen Situation Kambodschas nehme ich in Kapitel 2 eine religionshistorische Kontextualisierung vor. Die von Bunnwath empfundene Ambivalenz zwischen Buddhismus und Geisterglaube spiegelt aus individueller Perspektive eine viel grundsätzlichere Dynamik von Politik und Religion in der Geschichte Kambodschas wider. Über Jahrhunderte des hinduistischen Einflusses kam es ab dem 13. Jahrhundert zu einem Prozess der Buddhisierung, in dem erst das Königshaus und dann die Bevölkerung dem Buddhismus folgten. Indem ich diese historisch gewachsene Beziehung in Kapitel 2 skizziere, stelle ich neben dem Buddhismus auch den sogenannten Brahmanismus vor, der auf die vor-buddhistische Ära verweist und auf den sich die Geistmedien als Herkunft ihrer magischen Macht beziehen. Die spezifische ,hybride‘ Ausformung eines kambodschanischen Buddhismus äußert sich auch in einer Reihe von lokalen Konzeptionen und führte nicht zuletzt wegen der schwach ausgebildeten Existenzgrundlage von Totengeistern zu einer Modifikation meiner Forschungsfragen. Mit der Ausführung der spirituellen Konzeptionen von Karma, Verdienst und Wiedergeburt werden wichtige Bezüge der alltäglichen Aushandlungen von Macht und sozialem Status dargelegt. Diese hier beschriebenen Konzepte dienen dem Verständnis von Macht auf lokaler Ebene und werden für die Analyse von Spiritscapes im folgenden Kapitel grundlegend sein. 
Mit der Denkfigur der Spiritscapes und dem analytischen, Werkzeug' der Akteur-Netzwerk-Theorie führe ich in Kapitel 3 ein geeignetes Vokabular zur Analyse der Existenzweisen von Geistern und ihrer (Macht-)Beziehungen ein. Zur Veranschaulichung meiner Methodik dienen zwei Beispiele von Geistern, die sich während meiner Forschung in Zwischenstadien ihrer Existenz befanden: Pol Pot und $t \bar{a}$ Noël, einem von Bun Ly eigens für mich herbeigerufenen Geist. An ihrem umstrittenen Status stelle ich das Vokabular und die Bedeutung meiner Untersuchung der Existenzbedingungen von kambodschanischen Geistern vor.

Hieran anknüpfend beschäftigt sich der zweite Teil (II) der Dissertation mit der Existenz und Nicht-Existenz verschiedener Geister, insbesondere der Totengeister (Kap. 4) und der populären Ortsgeister anak tā (Kap. 5). In diesem Teil findet gleichsam die Überleitung meiner anfänglichen Fragestellung bezüglich der Totengeister aus der Zeit der Roten Khmer zu meinem späteren Forschungsthema der hochrelevanten Ortsgeister anak tā (gesprochen: ,neak ta ${ }^{\circ}$ ) statt, die sich wesentlich besser zur Untersuchung der kambodschanischen Spiritscapes und ihren inhärenten Machtbeziehungen eigneten.

Zunächst zeige ich im vierten Kapitel, dass ein buddhistisch institutionalisierter Umgang mit dem Tod in einem widersprüchlichen Spannungsverhältnis mit einer vorbuddhistischen Konzeption von Totengeistern steht. Totengeister in Kambodscha haben im Gegensatz zum Nachbarland Vietnam eine schwache Existenzgrundlage'. Begründet ist diese Differenz durch eine Deutungshoheit des kambodschanischen Theravada-Buddhismus zum Thema Tod. Am Fallbeispiel eines Geistmediums, das Totengeister kontaktieren konnte, zeige ich den dynamischen Aushandlungsprozess verschiedener Geister-Konzeptionen in aufwendigen Ritualen der Besessenheit. Somit finde ich Antworten auf meine Ausgangsfragestellung zur Relevanz der Totengeist-Verehrung für gesellschaftliche Prozesse der Verarbeitung und Versöhnung.

Im Kontrast dazu bezieht sich das fünfte Kapitel auf die Gegenwart und die populären Ortsgeister, die im Gegensatz zu Totengeistern besonders ,stabile Existenzen besitzen. Hier zeige ich, wie die Existenz und die Macht dieser Geister mit einer Vielzahl von menschlichen und nicht-menschlichen Akteuren konstituiert werden und erarbeite anhand dessen die Existenzbedingungen dieser GeisterKategorie aus. Diese Analyse schafft einen Überblick über die emische Konzeption der anak tā, die im Wechselspiel mit ihren, relationalen' Akteuren aktiv Einfluss auf Personen, Ereignisse und Prozesse ausüben. Am Beispiel der vielschichtigen Biographie des weiblichen Geistes yāy Mao veranschauliche ich anschließend das Zusammenspiel von Menschen, Erzählungen, Dingen, Räumen und Macht. Auf diese Weise mache ich nicht nur die kollektive Bedeutung, sondern auch den individuellen Handlungsspielraum der Geister deutlich, womit ich zum dritten Teil der Arbeit (III) überleite, der sich den spannungsreichen Kontexten der Medialität und der Inszenierung der Geister in der kambodschanischen Gesellschaft widmet. 
Dazu führe ich im sechsten Kapitel in das Thema der kambodschanischen Medialität ein. Die Hauptakteure der Geistbesessenheit sind (neben den im zweiten Teil beschriebenen Geistern) die menschlichen Medien. Mit der Analyse ihrer Biographien, insbesondere ihrer Initiation als Medium werden sie in ihrem lokalen Kontext verortet, wodurch die alltägliche Geister-Praxis in den Mittelpunkt gerückt wird. Dabei wird deutlich, dass das spannungsreiche Verhältnis zwischen Geist und Medium von beidseitigen Aushandlungen über die Privilegien und Pflichten der gemeinsamen Arbeit geprägt ist. Anschließend wird eine weitere wichtige Akteursgruppe zur Inszenierung der Geister-Wirkmacht eingeführt: die Klient_innen der Geistmedien. Ihre Anliegen stellen die Triebfeder der kambodschanischen Medialität dar, die nicht nur individuelle Probleme, sondern Themen gesellschaftlicher Tragweite wiederspiegeln.

Anknüpfend daran ziehe ich im siebten Kapitel das Fallbeispiel einer jungen, städtischen Kambodschanerin heran, die sich nach einigen erfolglosen Heilungsversuchen zunächst widerwillig den Ritualen der Geistmedien zuwendet. Fragen nach der Authentizität der Praxis werden damit aus der Perspektive einer reformistisch geprägten Studentin gestellt, die unterschiedlich spirituell ausgerichtete Geistmedien prüft und damit einen emischen Blick auf die feinen Unterschiede der medialen Praxis lenkt. Als skeptische Klientin verdeutlicht sie nicht nur die bestehenden Zweifel an dieser Praxis aus Klient_innensicht, sondern - im späteren Verlauf ihrer Suche nach Heilung - auch die Überzeugungskraft der Geisterexistenz und die Wirkungsweise der angenommenen Geister-Macht.

Neben der Heilungspraxis untersuche ich im achten Kapitel weitere zentrale Erwartungen an mediale Rituale, die in Zusammenhang mit Profit und beruflichem Erfolg der Anfragenden stehen. Diese Anliegen stellen die am häufigsten vorgetragenen Gesuche der Klient_innen dar. Dabei drängt sich der Vergleich mit ähnlichen Geisterpraktiken aus Thailand auf, die von Jackson (1999a) als prosperity religion bezeichnet wurden. Unter Berücksichtigung der großen Verbreitung und Akzeptanz dieser Praxis, die den Segen als machtübertragenden Schlüsselmoment der Rituale konstruiert, konzentriere ich mich auf deren Weiterentwicklung (beziehungsweise Optimierung) durch Geistmedien. Anhand einer (von Bun Ly organisierten) Zeremonie wird die Opportunität des Machtgewinns exemplifiziert, wodurch die Legitimationsstrategien des Brahmanismus im Kontrast zum Buddhismus offengelegt werden.

Mit dem Interesse, die Wirkungsweisen des Machtgewinns durch GeisterRituale differenziert und auf Mehrschichtigkeit achtend darzustellen, fokussiert das letzte Kapitel die Beziehungen zwischen Geistern, Geistmedien und Akteuren der Politik, des Militärs und der Wirtschaft. An den Beispielen Wahlkampf, Protest und Rituale zur Stärkung der nationalen Identität zeige ich, wie kambodschanische Geister einflussreiche Menschen unterstützen, indem die Geister von ihnen in gesellschaftlich relevanten Kontexten inszeniert werden. Die deutlichen Referenzen dieser prestigeträchtigen Personen zu Geistern und zum Brahmanismus 
animieren meine wissenschaftliche Analyse der religiösen und spirituellen Situation Kambodschas, in der Mechanismen und Strukturen politischer Macht und gesellschaftlichen Statusaushandlungen offengelegt werden.

Allgemein bietet diese Dissertation einen Überblick über die religiöse Situation Kambodschas, und beschreibt im speziellen die alläglichen Aushandlungen zwischen Menschen und Geistern mithilfe ihrer Medien. Die gelebten Beziehungen zu Geistern zeigen, wie ihnen Existenz verliehen wird und welche machtvollen Rollen den Geistern in sozialen, politischen und individuellen Prozessen zuteilwerden. 


\section{THEMATISCHER KONTEXT UND METHODIK}





\section{Kambodscha: Geschichte, Religion und Macht}

Dieses Kapitel stellt den historischen und machtpolitischen Kontext vor und ist von einem Fokus auf unterschiedliche, religiöse Machtkonzeptionen geprägt. Anhand einer religionshistorischen Vorstellung dieser Konzepte ebne ich damit den Weg durch die kambodschanische Geisterlandschaft.

\subsection{Historische Konfigurationen von weltlicher und spiritueller Macht}

\subsubsection{Die Angkor-Zeit und das Mittlere Zeitalter}

Während der Angkor-Periode (8.-14. Jh.) regierten hinduistische Könige, die sich in Gestalt eines devarāja ${ }^{20}$, also eines Gott-Königs, krönen ließen. Konzeptuell basierte die devarāja Verehrung auf einer angenommenen Verbindung zwischen dem König und dem Gott Shiva. Laut Kulke (1974) ließ sich in Kambodschas Geschichte die deutlichste Ausprägung dieser Verehrung finden. Die enge Verbindung von religiöser und weltlicher Macht, die bis heute Relevanz besitzt, ende-

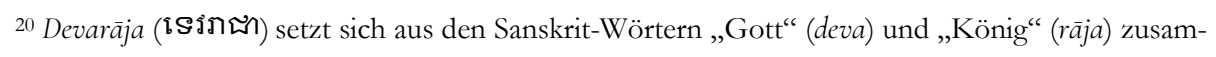
men. 
te auch nicht nach der prominenten Konversion von Jayavarman VII. (11251218) zum Buddhismus. Der Buddhismus wurde allmählich nicht nur die Religion der Könige, die sich in Fortführung des devarāja-Kults als buddharāja krönen lieBen, sondern auch die der Bevölkerung. Die Regeln der buddhistischen Praxis ließen es zu, dass animistische, brahmanistische und buddhistische Aspekte des religiösen Lebens gleichermaßen gepflegt werden konnten, was auch ein Grund für dessen erfolgreiche Adaption durch die Bevölkerung darstellte (Pou 19871988: 340). Aus lokaler Perspektive gilt das Angkor-Zeitalter als harmonische Epoche, in der Könige mithilfe brahmanistischer Macht und buddhistischer Moral das Khmer Reich auf weite Teile des südostasiatischen Festlands ausweiten konnten; ein Narrativ, das insbesondere von Geistmedien reproduziert wurde.

Im folgenden, sogenannten ,mittleren Zeitalter' (15. bis 19. Jh.) konvertierten zunehmend Menschen zum in Siam ${ }^{21}$ und Burma bereits etablierten TheravadaBuddhismus, während die hinduistischen Gottheiten nicht verschwanden, sondern in der buddhistischen Kosmologie als hochrangige Diener des Buddha anerkannt blieben (Edwards 2007: 98; Pou 1987-1988: 341; Ang 1993).

Das einst mächtige Khmer-Reich verlor durch den über Jahrhunderte andauernden Konflikt mit seinen Nachbarländern Vietnam und Siam (heute Thailand) an Einfluss, bis es Ende des 19. Jahrhunderts unter beiden Mächten aufgeteilt und vollständig okkupiert werden sollte (Chandler 2008: 141-171, 1972). Zum Schutz seiner Integrität schloss sich Kambodscha im Jahr 1867 dem französischen Protektorat an. Durch den Einfluss der kolonialen Macht bildeten sich vor allem in städtischen Gebieten Reformationsbestrebungen des damals praktizierten Buddhismus. Es bildeten sich vor allem zwei Orden des Buddhismus: Während sich der vom siamesischen König Mongkut (1804-1868) gegründete DhammayutOrden vor allem in Kreisen des Königshauses erfolgreich etablierte, blieb der Großteil der Bevölkerung dem weniger orthodoxen Mahānikāy-Orden zugehörig (Harris 2005: 207-230).22 Die ersten Berichte der religionsinteressierten Besucher dieser Zeit betonen die enge Verschränkung zwischen Geister- und buddhistischer Praxis (Leclère 1899, 1898, 1895, 1894; Aymonier 1883).

Das erklärte Ziel der Reformationsbestrebungen war die Modernisierung des Buddhismus durch eine Rückbesinnung auf die ,ursprünglichen' Lehren und Praktiken zur Abstimmung einer ,modernen ' Definition von Buddhismus als ,rationale Religion (Hansen 2008; Edwards 2007). Die Anführer dieser Bewegung, die sich selbst als modern (samăya) bezeichneten, waren die Mönche und Patriarchen Chuon Nath (1883-1969) und Huot Tath (1891-1975). Diese Reformisten und ihre Anhänger_innen waren bemüht, ihren ,modernen` Buddhismus von älteren, nicht-buddhistischen Praktiken (wie beispielsweise der Geisterverehrung) zu ,reinigen' (Hansen 2004b: 58). Dabei betonten sie nicht nur die Differenzierung zwi-

\footnotetext{
${ }^{21}$ Siam wurde bis 1939 das Land genannt, das zu großen Teilen dem heutigen Thailand entspricht.

22 Dies geschah parallel zu anderen damaligen Reformationsbewegungen, wie zum Beispiel in Thailand (Keyes 1989; Tambiah 1976: 401-433).
} 
schen modern (samăya, gesprochen: ,samai') und altertümlich (purāna, gesprochen: ,boran), sondern bezeichneten alles nicht-buddhistische als Brahmanismus (brahmanya-sāsanā) in Opposition zum Buddhismus (buddha-sāsanā). ${ }^{23}$ Das Konzept von sāsanā in seiner Bedeutung als 'Lehre, Doktrin, Gewohnheit' wurde zum kambodschanischen Äquivalent des westlichen Religionsbegriffes herangezogen, und fortan als buddha-sāsanā bezeichnet (Hansen 2004b). Guillou (2017a: 75) bezeichnet diese Differenzierung als „religionisation“, in dem der Buddhismus nach den Vorstellungen der französischen Besatzer als rationalste aller ,Weltreligionen“ inszeniert wurde (vgl. Masuzawa 2005: 121-145).

Die reformistische Bewegung entsprang vor allem dem urbanen Umfeld, wo ihre streng nationalistische Ausrichtung nach dem ersten Weltkrieg in die Unabhängigkeitsbewegung mündete. Durch sie wurde der Begriff des, kambodschanischen Buddhismus' prominent vertreten, um ihn als ,moderne' (samăya) und ,nationale Khmer-Religion` zu etablieren. Die Anhänger_innen der ,traditionellen` purāna-Ausrichtung hingegen verteilten sich über die ländlichen Gebiete und waren somit deutlich in der Mehrheit. Sie grenzten sich von der neuen Bewegung ab, indem sie purāna ihrerseits als authentisch-kambodschanisch darstellten, da es die einzigartigen Praktiken der verschiedenen Epochen des Landes berücksichtigen würde.

Die religiösen Unterschiede in dieser Zeit waren Teil der gegenseitigen Abspaltung zwischen der Stadt- und Landbevölkerung, in dessen Verlauf sich die Landbevölkerung wegen der schnell fortschreitenden Modernisierungsbemühungen der städtischen Mittel- und Oberschicht benachteiligt wahrnahm. Somit förderte der schnell wachsende Widerstand gegen die urbane ,Entfremdung' nicht nur theologische Auseinandersetzungen zwischen den beiden Schulen des Buddhismus (Marston 2008b), sondern auch die anhaltenden gesellschaftlichen Auseinandersetzungen zwischen Stadt- und Landbevölkerung.

Die Stärkung der nationalen Identität, unter anderem begünstigt durch die fortschreitende konzeptionelle Ausgestaltung des, kambodschanischen Buddhismus' führte zur Vereinigung zahlreicher politischer Gruppen mit dem Ziel der Unabhängigkeit. König Norodom Sihanouk erklärte 1953 einseitig die Unabhängigkeit von Frankreich - mit Erfolg. Nach den Wahlen von 1955, die Sihanouk als gefeierter Held der Unabhängigkeit für sich entschied, regierte er in einer von vielen Kambodschaner_innen als ,goldenen Ära' betitelten Amtszeit bis 1970. Durch den Krieg zwischen den USA und Vietnam geriet Sihanouk politisch unter Druck und einige der stark angewachsenen Oppositionsbewegungen, wie der Khmer Issarak und anderen kommunistischen Gruppen, riefen zum bewaffneten Widerstand gegen den König auf. Ihre Mitglieder wurden schnell als die „Khmer

${ }^{23}$ Śāsana in Sanskrit, sāsana in Pāli; das Wort sāsanā lässt eine Vielzahl von Übersetzungen zu, wie ,Lehre', ,Doktrin', oder als Bezeichnung für das jeweils 5000 Jahre andauernde Zeitalter der verschiedenen Buddhas. 
Teil I: Thematischer Kontext und Methodik

Rouge“ bekannt. ${ }^{24} 1970$ wurde Sihanouk von dem Südvietnam unterstützenden, ehemaligen Polizeichef Lon Nol gewaltsam gestürzt und lief selbst zum kommunistisch geprägten Widerstand der Landbevölkerung über. Diese Bewegung bekam stetig Zulauf von durch amerikanische Luftangriffe Vertriebenen. ${ }^{25}$

Das kambodschanische Militärbündnis der kommunistischen Gruppen bezeichnete sich in dieser Zeit schlicht als „Organisation“ (angkär, gesprochen: ,angkaar'). Sie eroberten zwischen 1970-1975 weite Teile des Landes und marschierten am 17. April 1975 in Phnom Penh ein. Offiziell gilt dieser Tag als Machtübernahme der Roten Khmer, doch dabei wird häufig nicht berücksichtigt, dass sich andere Teile des Landes zu diesem Zeitpunkt schon jahrelang unter ihrer Herrschaft befunden hatten, wie beispielsweise in meiner Forschungsregion Takeo, wo es nach Angaben der Bewohner_innen schon seit 1973 Internierungslager gegeben haben soll.

\subsubsection{Die Eliminierung des Buddhismus in der Zeit der Roten Khmer} (1975-1979)

Direkt nach der Machtübernahme Phnom Penhs im Jahre 1975 vertrieben die Roten Khmer, die sich größtenteils aus junger Landbevölkerung zusammensetzten, die Stadtbewohner_innen über das ganze Land. Sie galten als von modernen Entwicklungen entfremdetes, ,neues Volk' und als Menschen zweiter Klasse im Vergleich zum ,alten Volk' der agrarwirtschaftlich orientierten Roten Khmer. Mit ihrer Machtübernahme implementierten sie radikale gesellschaftliche Veränderungen, die alle Bereiche des alltäglichen Lebens betrafen. Die Zeitrechnung begann im Jahre Null; Geld und Besitztümer galten als wertlos, grundlegende gesellschaftliche Werte und die vom Buddhismus geprägten Moralvorstellungen wurden auBer Kraft gesetzt. Das Ideal der Roten Khmer, beziehungsweise der allgegenwärtigen und personifizierten angkār, war das Formen der Jugend nach ihrer agrarkommunistischen Maxime. Die ältere Generation, vor allem die Angehörigen des ,neuen Volks' sollten ,umerzogen` werden. Aber nicht um jeden Preis: „Dich zu verschonen kein Gewinn, dich zu töten kein Verlust“", war ein verbreiteter Slogan dieser Zeit (Locard und Chandler 2004). Das Land wurde in Zonen und Kooperativen eingeteilt, alle Menschen mussten die für die Landbevölkerung typische schwarze Kleidung tragen. Trotz einer mangelnden Versorgungslage wurden die Arbeiter_innen täglich zu 12-14 Stunden Landarbeit gezwungen. Viele von ihnen fielen den Folgen von Überarbeitung und Unterernährung zum Opfer, andere

\footnotetext{
${ }^{24} \mathrm{Da}$ sich die kommunistischen Parteien und Gruppierungen oftmals neu gründeten und umbenannten, fasste Sihanouk sie mit dem französischen Begriff ,Khmer Rouge' zusammen.

25 Zwischen 1965 und 1973 wurden 2,7 Mio Tonnen Sprengmaterial über Kambodscha abgeworfen und damit etwa so viel wie von den Alliierten im Zweiten Weltkrieg über ganz Europa (Kiernan und Owen 2006; Kiernan 1989).
} 
wurden wegen mutmaßlicher Vergehen gegen angkār ${ }^{26}$ als Feinde oder Spione bezeichnet. Als solche galten per se Intellektuelle, Angehörige der Elite und vor allem Mönche (Gyallay-Pap 2002). Kam es zu einem Verhör, wurde den Beschuldigten unter Folter ein Geständnis abgepresst, um sie anschließend in den sogenannten killing fields (den auf dem Land ausgehobenen Massengräbern) oder anderen Plätzen zu töten. Wer den Anweisungen von angkār (personifiziert durch die Vorgesetzen) nicht folgte, konnte selbst Opfer des Regimes werden (Hinton 2005).

Unter dieser Herrschaft wurde die buddhistische Gemeinschaft beinahe vollständig ausgelöscht. Einige ehemalige Stadtbewohner_innen berichteten mir, wie sie sich als einfache Bauern ausgaben, um als Mitglied des ,altes Volks ${ }^{6}$ zu gelten. Die kahlrasierten Mönche seien jedoch leicht als solche erkannt und deportiert worden. Die Pāli-Schriften wurden vielerorts mutwillig zerstört, während die Pagoden wegen ihrer stabilen Bauweise als Gefängnisse und Internierungslager benutzt wurden.

Die brahmanistische Praxis der Geister und Geistmedien stand jedoch weniger im Fokus der Vernichtung, und einige Medien überlebten diese Zeit trotz oder sogar wegen ihrer spirituellen Fähigkeiten. Eine Gesprächspartnerin aus Battambang galt wegen ihrer angenommenen Beziehung zu einem Geist beispielsweise als unverwundbar und stieg zu einer regionalen Führungskraft der Roten Khmer auf. Von den meisten Geistern wurde jedoch angenommen, dass sie sich im Wald versteckt hielten und den Menschen dort nicht mehr helfen konnten.

\subsubsection{Die langsame Revitalisierung des Religiösen unter der Vietnamesischen Okkupation (1979-1989)}

Die aus dem zweiten Indochina-Krieg siegreich hervorgegangene vietnamesische Armee marschierte 1979 in Kambodscha ein und vertrieb die Führungskader der Roten Khmer und einige Tausend Anhänger_innen in den Nordwesten des Landes. ${ }^{27}$

Während der anschließenden vietnamesischen Besatzung wurde die Ordinationslinie des populärsten Mönchsordens Mahānikāy durch Mönche aus Thailand und Vietnam re-etabliert, die Zahl der Ordinationen blieb jedoch stark eingeschränkt (Keyes 1994; Löschmann 1989). Nach Marston (2008b: 105) entsprach die samăya-Ausrichtung innerhalb des neugegründeten Mahānikāy-Ordens am ehesten der vietnamesischen Vorstellung von Religiosität, weshalb sie der purānaAusrichtung vorgezogen wurde.

\footnotetext{
${ }^{26}$ Die Organisation wurde in ihrer personifizierten Übernatürlichkeit und ihrem moralischem Auftreten in auffälliger Ähnlichkeit zu Geistern konzipiert (LeVine 2010).

27 Als Vorhut für den Einmarsch der Vietnamesen wurden ehemalige Deserteure der Roten Khmer eingesetzt. Unter diesen ,Rückkehrern' befanden sich auch Hun Sen, der nach dem Sieg Vietnams über die Roten Khmer das Land regierte, und der seitdem als Verbündeter Vietnams gilt.
} 
Die brahmanistische Revitalisierung verlief unauffällig und wurde keinen Restriktionen unterworfen. Wegen des Mangels an Mönchen wurde zur Bearbeitung religiöser Anliegen vielerorts die rituelle Praxis der Geistmedien in Anspruch genommen, von denen einige kurz nach Ende der Roten Khmer-Zeit ihre Arbeit wieder aufnahmen. Die anak tā und die spirituelle Macht pāramī waren zu dieser Zeit der Umstellung und des Überlebens eine Quelle der moralischen Führung (Bennett 2015; O'Lemmon 2014), da sie die einzigen moralischen Akteure dieser Zeit darstellten. Auch zur sozialen Wiedereingliederung waren die Geister von Bedeutung, da beispielsweise psychisch erkrankte Menschen, die als unheilbar krank galten, mit der Identifizierung eines Geistes in ihrem Körper zu einer anerkannten, wenn damals auch noch marginalisierten Form der Arbeit als Geistmedium nachgehen konnten.

Bis 1989 befand sich das Land in einer Phase der Neu-Orientierung und des Wiederaufbaus. Die vietnamesischen Besatzer inszenierten einen Schauprozess gegen die Führungskräfte der Roten Khmer, denen unter dem Namen „Pol Pot/Ieng Sary-Clique“ die alleinige Verantwortung für die Tragödie angelastet wurde - alle niedriger gestellten Kader wurden damit vor einer juristischen Verurteilung bewahrt (Gray 2014). Eine weitere Legitimierungsstrategie schloss den Bau von Gedenk- und Mahnstätten ein, um an die Verbrechen der Roten Khmer zu erinnern, was jedoch viele Kambodschaner_innen eher als Zurschaustellung ihrer Verbrechen interpretierten (Bennett 2015; Kidron 2014). Bis heute ist der wissenschaftliche Diskurs zu grundlegenden Fragen der Khmer Rouge Herrschaft - wie beispielsweise die Anzahl der Todesopfer und der möglichen Implementierung von ,Gerechtigkeit ${ }^{\star}$ - in hohem Maße umstritten. Die Schätzungen der Todesopfer reichen dementsprechend von 740.800 bis zu drei Millionen Toten und werden noch immer vehement diskutiert (Tabeau 2010; Sharp 2008; Kiernan 2003). ${ }^{28}$

\subsubsection{Religiöse Revitalisierung und Aufbruchsstimmung der Gesellschaft}

Nach dem Zerfall der UdSSR zog Vietnam seine Truppen zwischen 1989-1990 allmählich ab. Obwohl von einigen westlichen Staaten geplant worden war, den Roten Khmer nach dem Abzug der vietnamesischen Truppen wieder an die Macht zu verhelfen (James 1990), konnte Hun Sen seine Stellung behaupten. Sihanouk wurde wieder König, doch die Staatsform wurde zu einer konstitutionellen Monarchie umgewandelt und Sihanouk somit machtpolitisch degradiert. ${ }^{29}$

\footnotetext{
${ }^{28}$ Aufgrund der andauernden Diskussion und der darin geäußerten Zweifel an der Genauigkeit dieser Zahlen lege ich mich in dieser Arbeit auf keine Zahl fest. Entscheidend ist, dass die hohe Anzahl von Todesopfern verheerende, noch heute spürbare Auswirkungen auf die kambodschanische Gesellschaft hatte.

${ }^{29}$ Kambodscha wurde ab 1993 wieder das „Königreich Kambodscha“, namensgleich zur ,goldenen Ära' der Regierungszeit von Sihanouk (1953-1970). Astrid Norén-Nilsson (2016) erkennt darin Hun Sens Absicht, seine nicht-royale Herrschaft mit den Methoden der Könige vor ihm zu legitimieren, worauf ich in Kapitel 9.4 nochmals ausführlich eingehe.
} 
Nach dem Abzug der vietnamesischen Truppen wuchs die buddhistische Gemeinschaft der Mönche (sangha) schnell auf ihre alte Größe heran. Der Dhammayut-Orden wurde wieder gegründet, auch wenn er bis heute nur wenige Anhänger_innen zählt. Die Mehrheit der Laien und Mönche nahmen ihre vormals etablierte purāna Praxis wieder auf, die von einer breiten Akzeptanz von brahmanistischen Elementen geprägt war. ${ }^{30}$ Im Jahr 1991 gab es etwa 20000, im Jahr 2005 schon knapp 60000 ordinierte Mönche in Kambodscha (Ledgerwood 2008a: 149; Khy 2008: 259; Gyallay-Pap 2002). Über 4000 buddhistische Klöster (in Kambodscha ,Pagoden' genannt) wurden wieder- oder neuerrichtet. ${ }^{31}$ Dabei wurden den anak tā oftmals ein eigener Raum auf dem Gelände der Pagoden eingeplant, die zum Teil besser besucht wurden als die buddhistischen Schreine (O'Lemmon 2014), was einen Beleg für die wachsende Popularität der Geisterpraxis darstellt.

Mithilfe der Vereinten Nationen wurden 1993 Wahlen abgehalten. Die Partei Sihanouks, die FUNCINPEC ${ }^{32}$, wurde stärkste Partei und Sihanouks Sohn Norodom Ranariddh besetzte mit Hun Sen eine Doppelspitze zweier Premierminister. Bis dahin hatten sich immer noch einige Tausend Rote Khmer-Kämpfer in der nordöstlichen Grenzregion zu Thailand verschanzt. Ihr ehemaliger Führer Pol Pot wurde 1998 nach internen Machtkämpfen von anderen Rote Khmer-Kadern zu lebenslanger Haft verurteilt und starb kurze Zeit später unter nicht geklärten Umständen. Im selben Jahr noch wurde der Konflikt mit den Roten Khmer anhand einer win-win-Strategie beigelegt, die den zu tausenden desertierten Rote Khmer Kämpfer_innen Straffreiheit und Arbeitsplätze im Militär und im Regierungsapparat zusicherte. Wenig später ergaben sich die letzten kommunistischen Kader der Regionen Anlung Veng und Pailin, die bis zu diesem Zeitpunkt (23 Jahre nach ihrer Machtübernahme) von den Roten Khmer hermetisch abgeriegelt und kontrolliert worden waren (Wood 2009). ${ }^{33}$

Politisch verschärfte sich der Konflikt zwischen den beiden Lagern um den royalistischen Premierminister Norodom Ranariddh auf der einen und um Premierminister Hun Sen auf der anderen Seite. Auch innerhalb der Militäreinheiten bildeten sich zwei Lager, die sich im Juli 1997 einen blutigen Machtkampf auf Phnom Penhs Straßen lieferten, aus dem Hun Sen als Sieger hervorging. Nach dieser vollständigen Machtübernahme Hun Sens und der Kapitulation der Roten Khmer öffnete sich das Land wirtschaftlich: der Export von Agrarprodukten wie

\footnotetext{
${ }^{30}$ Dies geschah nicht immer konfliktfrei. Marston (2008b: 105) berichtet von Begebenheiten, in denen die Gläubigen den Mönchen die täglichen Essensspenden verweigerten, bis diese ihre reformierte samăya-Orientierung aufgaben und die purāna-Praxis wieder aufnahmen.

${ }^{31}$ Das Geld für den Bau einer Pagode stammte dabei nicht nur von den umliegenden Haushalten, sondern auch aus hohen politischen Kreisen und aus dem Ausland - insbesondere vonseiten der geflüchteten Kambodschaner_innen aus den USA und Frankreich (Kent 2003: 8).

32 FUNCINPEC ist das Akronym von ,Front Uni National pour un Cambodge Indépendant, Neutre, Pacifique, et Coopératif (,Nationale Einheitsfront für ein unabhängiges, neutrales, friedliches und kooperatives Kambodscha).

${ }^{33}$ Mehr zum Geist von Pol Pot in Kapitel 3.4.
} 
Teil I: Thematischer Kontext und Methodik

Reis und Tabak an Nachbarländer war nicht mehr der gewinnreichste Wirtschaftssektor; stattdessen wurden die verarbeitende Textilindustrie für global agierende Konzerne und der Tourismussektor zu den wichtigsten Wirtschaftszweigen. Inund ausländische Investitionen steigerten die Wirtschaftskraft, während vermehrt ökonomische Konzessionen über die Nutzung natürlicher Ressourcen vergeben wurden, was weitere Investoren (vor allem aus China und Vietnam) anzog. Bis 2013 sind über zwei Millionen Hektar Land als ökonomische Landkonzessionen ${ }^{34}$ verpachtet worden, und Tausende wurden in diesem Zusammenhang von ihrem Land vertrieben. Noch leben mehr als 80\% der Bevölkerung auf dem Land, doch die Urbanisierungsrate ${ }^{35}$ ist hoch, da es die junge Bevölkerung Kambodschas (über 50\% sind unter 25 Jahre alt) in die Städte Siem Reap, Battambang und besonders Phnom Penh zieht.

Nach den Wahlen 2013, aus denen Hun Sen knapp als Sieger hervorging, verschärften sich die Proteste gegen die Missstände seiner autoritären Herrschaft. Die Proteste wurden brutal niedergeschlagen. Seitdem wurden alle kritischen Zeitungsverlage zur Schließung gezwungen, Medienberichte (inklusive Beiträge bei facebook) wurden zensiert und juristisch verfolgt. Zahlreiche politische Aktivist_innen wurden verhaftet oder ermordet. Die Oppositionspartei wurde im Angesicht der Parlamentswahlen 2018 aufgelöst und ihre Spitzenkandidaten unter Hausarrest gestellt oder mit Strafandrohungen ins Exil getrieben. In zunehmend diktatorischen Stil des Einparteisytems ist Hun Sen seit über 30 Jahren Premierminister des Landes. Er hat ein autokratisches System der Selbstbereicherung aufgebaut, in dem seine Familie und deren Verbündete monopolisierten Zugang zu wirtschaftlichen Ressourcen und große Privilegien wie Straffreiheit genießen (Strangio 2014; Karbaum 2008). Die gesamte Entwicklung des Landes unter der Herrschaft Hun Sens gestaltet sich ebenso unvorhersehbar wie ambivalent: Obwohl noch knapp 20\% der Menschen unterhalb der Armutsgrenze von 1,25 USDollar (5000 Riel) am Tag leben, verzeichnete Kambodscha eine Rekordrate in der Reduktion von Armut (ADB 2014). Den fatalen sozialen Folgen der Landvertreibung, politischen Verfolgung, mangelnden Presse- und Meinungsfreiheit, juristischen Willkür und Korruption stehen die zahlreichen Neugründungen von Kleingewerbe und die stetige Verbesserung der ökonomischen Lebensbedingungen gegenüber. Nachdem die Marktwirtschaft erst in den 1990er Jahren für ausländische Investor_innen geöffnet wurde, erlebt das Land jährlich eine Steigerung des Bruttoinlandsprodukts von etwa $7 \%$, vorangetrieben von der ständig wachsenden Textilindustrie.

\footnotetext{
${ }^{34}$ Der internationale Begriff für die Form der Verpachtung ist Economic Land Concessions oder nur ELC. Dabei werden oft sehr große Teile von Land für mindestens 99 Jahre an private Inverstoren verpachtet, die damit das Recht zur Ressourcenausschöpfung (z.B. Holz oder Bodenschätze) in diesen Gebieten erworben haben.

35 Die Urbanisierungsquote beträgt laut CIA (2018) 3,25\%.
} 
Meine Interpretation dieser ambivalenten Entwicklung der Gesellschaft lässt sich, abgeleitet von den Aussagen meiner Gesprächspartner_innen, am treffendsten mit der Metapher eines „Aufbruchs“ beschreiben. Allgemein war die Perspektive meiner Gesprächsteilnehmer_innen von Plänen und Gedanken zur Zukunft oder Gegenwart geprägt. Kein Verharren in vergangenen Zeiten war spürbar, sondern eine optimistische Ausrichtung auf eine friedliche Zukunft, die vor allem die Älteren herbeisehnten. Mein Eindruck dieser ,Aufbruchsstimmung' wird untermauert von einem Aufbegehren der Bevölkerung gegen offensichtliche Missstände im politischen System (insbesondere der nach den Parlamentswahlen 2013), ihrer wachsenden Mobilität (zum Beispiel in Form von Urbanisierung) und speziell von ihrer privatwirtschaftlichen Orientierung, die von einem ausgeprägten Streben nach Wohlstand charakterisiert ist. Diese Haltung leite ich nicht nur von zahlreichen alltäglichen Gesprächen, sondern auch von den Anfragen der Klient_innen bei Geistmedien ab (Kap. 6.2).

Die Suchbewegung der Kambodschaner_innen nach einem Leben in Wohlstand führt zu einem Bedeutungszuwachs des Brahmanismus. Dessen ,magische Wirkungsweise wird zu diesen Zwecken der buddhistischen Praxis vorgezogen, obgleich beide Religionen als hybride Teile einer Religion, dem ,kambodschanischen Buddhismus', gelten, was ich im nächsten Abschnitt erkläre (Kap. 2.2). Nachdem ich anschließend die verschiedenen Machtkonzeptionen der beiden Religionen näher erläutere (Kap. 2.3, 2.4), mache ich anhand von Beispielen aus der religiösen Praxis Aneignungs- und Aushandlungsformen dieser unterschiedlichen Mächte deutlich (Kap. 2.5).

\subsection{Der Hybride Religionsbegriff des kambodschanischen Buddhismus}

Der kambodschanische Buddhismus ist von einer dynamischen Aushandlung verschiedener religiöser Systeme geprägt. In offiziellen und öffentlichen Diskursen wird der Begriff im Sinne der purāna-Auslegung als Ausdruck der spezifischen Ausformung der verschiedenen, historisch gewachsenen religiösen Traditionen des Animismus, Brahmanismus und Buddhismus benutzt (Ang 1986: 9-20). ${ }^{36}$ Bei meinen Fragen nach den Beziehungen zwischen den Religionen wurde stets betont, wie eng der Buddhismus mit den früheren Religionen verbunden sei. Nur in Ritualen, in die ich durch meinen religionsethnologischen Forschungsschwerpunkt häufig geriet, wurde zwischen den verschiedenen religiösen Traditionen unter-

\footnotetext{
${ }^{36} \mathrm{Im}$ wissenschaftlichen Diskurs wurde die hybride Religionspraxis lange als Anlass genutzt, den kambodschanischen Buddhismus als ,degeneriert' darzustellen und seine ,synkretistische' Ausformung als zentrales Merkmal zu definieren: "Khmer Buddhism has been understood as a degenerate or even heretical form of Buddhism, interesting mostly for its deviations from South Asian orthodoxy“" (Davis 2009: 10).
} 
Teil I: Thematischer Kontext und Methodik

schieden. Hier sehe ich in Übereinstimmung mit Guillou (2017a: 75) das wichtigste Moment der Differenzierung, das insbesondere in brahmanistischen Ritualen häufig auftaucht, wenn ,Buddhistisches ${ }^{6}$ von ,Brahmanistischem unterschieden wird.

Auch Bunnwath unterschied als Schüler von reformistischen Mönchen immer wieder zwischen samăya und purāna oder Buddhismus und Brahmanismus. Bei manchen Ritualen teilte er mir resigniert mit, dass dies eben „typisch für den kambodschanischen Buddhismus" sei. Seine Einstellung entsprach damit der Beschreibung von Davis: „reformists see ,Brahmanist' influences in Buddhism as a fault; if they cannot reform it now, they tolerate such practices out of compassion for the practitioners" (2015a: 219). Bunnwath und ich teilten somit das Interesse für die Herkunft der verschiedenen Bestandteile des kambodschanischen Buddhismus - wir unterschieden uns jedoch darin, dass er die Vermischung von Brahmanismus und Buddhismus sorgenvoll und ich interessiert begutachtete. Weitere Personen in meinem Umfeld, die beständig zwischen den beiden Religionen trennten, waren die Geistmedien. Je vertrauter ich zu den Medien sprechen konnte, desto deutlicher trat ihre jeweilige Ausrichtung zwischen Buddhismus und Brahmanismus zutage.

Trotzdem ist das integrative Verständnis des kambodschanischen Buddhismus auch im südostasiatischen Vergleich bemerkenswert. Ein Grund für die öffentliche Inklusion des brahmanistischen Erbes war das Handeln hochrangiger Politiker_innen und anderer öffentlichen Personen, die sich in brahmanistischen Ritualen engagieren und daher kein Interesse an der Reformation, Differenzierung oder Abgrenzung verschiedener Praxen zeigen. ${ }^{37}$ Auch die Medienanstalten werden von diesen Eliten kontrolliert, so dass über diesen Weg keine kritischen Stimmen, wie beispielsweise bei Pattana (2002) aus Thailand beschrieben, an die Öffentlichkeit gelangen. Auch der einflussreiche Patriarch des größten Mönchsordens Mahānikāy, Tep Vong, betont die gemeinsamen Aspekte der Religionen. Durch jahrzehntelange Zusammenarbeit mit der Regierung ist er zu einem engen Verbündeten von Premierminister Hun Sen geworden, der keine Kritik an der Regierung duldet (Strangio 2014: 201). Alle derzeit leitenden Mönche von Pagoden wurden von politischer Ebene in dieses Amt gehoben (Kent 2011), wodurch Kritik an der Regierung durch hochrangige Mönche größtenteils unterbunden wird. Den Mönchen wurde seit den ersten Wahlen 1993 die Teilnahme an politischen Wahlen untersagt und politisch engagierte Mönche wurden sanktioniert oder ver-

\footnotetext{
${ }^{37}$ Neusten Veröffentlichung zufolge scheint sich jedoch in mehreren Ländern Südostasiens eine ähnlich offene Positionierung von Eliten zu Geisterritualen zu etablieren, wie beispielsweise in Thailand (Jackson 2016, 2009), Burma (Brac de la Perrière 2017; Foxeus 2017) oder Laos (Platenkamp 2010; Evans 2002). Der Unterschied zu Kambodscha besteht jedoch immer noch darin, dass hier kaum öffentliche Zweifel zum Beispiel in Form eines,Quacksalber'-Diskurses (siehe Kitiarsa 2002) zu erkennen sind.
} 
haftet (ebd.). Die Kontrolle der politischen Kräfte über den sangha ${ }^{38}$ und der Presse fördert die von der Regierung vertretende Definition des kambodschanischen Buddhismus, mit der sich alle Kambodschaner_innen in brahmanistischen Ritualen engagieren und dies moralisch als kambodschanisch-buddhistisch legitimieren können. Die routinierte Differenzierung der Religionen zeigt die folgende Beschreibung des Rituals bhjum pinda (gesprochen: ,pchum ben').

\subsubsection{Fallbeispiel: Das hybride Ritual Bhjum Pinda}

Das Ritual bidhi39 bhjum pinda wird an 14 aufeinanderfolgenden Tagen zur Ehrung der Totengeister gefeiert, die an diesen Tagen aus der buddhistischen Unterwelt kommen und in der Welt der Menschen (thān manuss) verweilen dürfen (vgl. Kap. 4). Das Ritual wird seit Mitte des 19. Jahrhunderts durchgeführt (Holt 2012: 55) und obwohl es nicht im Pāli-Kanon beschrieben steht (ebd.: 11), wird es zusammen mit dem Neujahrsfest als das wichtigste Fest im kambodschanischen Jahreszyklus erachtet. ${ }^{40}$ Die meisten Teile der Zeremonie werden in der Pagode abgehalten, womit es bei den meisten Praktizierenden als eindeutig buddhistische Praxis gedeutet wird. Denn wie in anderen buddhistischen Ritualen üblich, fokussieren auch an bhjum pinda die meisten Handlungen das Generieren von buddhistisch konzipiertem Verdienst (siehe unten).

Eine bedeutende Ausnahme zur buddhistischen Prägung bildet das nächtliche Ritual am letzten Tag der Feierlichkeiten. Dabei handelt es sich um poh pāy pinda, das ,Werfen der Reisbälle‘: Die Opfergaben für die hungrigen Totengeister werden in Form von Reisbällen und anderen Nahrungsmitteln von den Teilnehmer_innen während einer dreimaligen Prozession in die Umgebung der Pagode geworfen. Auch in klassischen purāna-Klöstern wurde dafür nicht die Hauptgebetshalle (sala) des Klosters benutzt, sondern ein Nebengebäude. Auffällig ist, dass es das einzige Teilritual von bhjum pinda ist, bei dem die Mönche sich kurz vor dem Ritual verabschieden, während sie die letzten 14 Tage als Hauptakteure der Geschehnisse aufgetreten waren.

Die Anwesenden warten, bis alle Mönche außer Sichtweite sind; dann übernehmen die $\bar{a}$ cary $\bar{a}^{41}$ (gesprochen: ,adjaa') die Leitung der Prozession. Die Gläubigen umkreisen die Pagode und werfen ihre Opfergaben wahllos in die nähere Umgebung des Pagodenkomplexes. Dabei geht es aufgrund der Absenz der Mön-

\footnotetext{
38 Sangha: buddhistische Gemeinschaft; der Begriff wird im Deutschen oft weiblich verwendet, in Anlehnung an Gemeinde oder Gemeinschaft. Ich verwende die männliche Form nach dem korrekten Genus des Pāli-Wortes.

${ }^{39}$ Bidh (gesprochen: ,pithi') bedeutet ,Ritual' oder ,Zeremonie'.

40 Wie andere Zeremonien zu Ehren der Toten in Südostasien weist bhjum pinda einige Ähnlichkeiten zum indischen śräddha-Ritual und der chinesischen Zeremonie der ,hungrigen Geister' auf (Holt 2012: 62-68; Davis 2009: 160-162; Michaels 2004: 148).

${ }^{41}$ Nicht-ordinierte Ritualexperten meist höheren Alters, die Kenntnisse in der Rezitation buddhistischer Pāli-Verse besitzen und in Ritualen Verantwortung übernehmen.
} 
che viel ausgelassener zu als bei allen vorhergegangenen Ritualen. Es wird sogar zunehmend (insbesondere von Jugendlichen) als eine Gelegenheit für nächtliche Treffen mit Freunden und Freundinnen verstanden, in dessen Verlauf gescherzt, geneckt, gelacht und geflirtet wird. Die Bedeutung des Opferns für Tote kommt bei der Prozession von bhjum pinda wenig zur Geltung.

Für moderne Vertreter der samăya-Schule gilt das poh pāy pinda aufgrund des brahmanistischen Ursprungs und der freizügigen Gestaltung der Prozession als ein problematisches und moralisch fragwürdiges Ritual. ${ }^{42}$ Die Aufteilung der Ritualleitung verdeutlicht hierbei, wie sich die buddhistischen und brahmanistischen Akteure bei moralischer Ambiguität von Ritualen beständig aus dem Weg gehen (vgl. Kap. 8.3). Obwohl die brahmanistischen Aspekte von bhjum pinda von den Mönchen als moralisch deviant wahrgenommen werden, ermöglicht das routinierte Ausweichen (auch in anderen rituellen Kontexten) die Vermeidung von Konflikten und damit die Aufrechterhaltung der integrativen Definition des kambodschanischen Buddhismus.

Im Folgenden greife ich die während der Rituale von sämtlichen religiösen Akteuren vollzogene Differenzierung der ,Religionen' (sāsanā) auf und begreife diese im Zuge meiner religionsethnologischen Analyse als eigenständige Religionssysteme, da mit ihnen verschieden ausgeprägte, supplementäre Machtkonzepte assoziiert werden. Diese sind eng mit dem Phänomen der Medialität in Kambodscha verbunden und stellen somit eine wichtige Grundlage zum Verständnis medialer Rituale dar. Dabei sollten die Leser_innen stets die in formalen Kontexten synchron gedachte Normierung der ,offiziellen Religion' unter dem Begriff ,kambodschanischen Buddhismus` berücksichtigen.

\subsection{Buddhismus}

Der Theravada-Buddhismus in Kambodscha wird in erster Linie durch die Gemeinschaft der Mönche (sangha) repräsentiert, der sich in die bereits genannten Orden (Mahānikāy oder Dhammayut) aufteilt, in denen sich die Mönche an den Strömungen samăya oder purāna orientieren. Die Differenzierung zwischen Buddhismus und Brahmanismus wird an ihren verschiedenen Definitionen von spiritueller und weltlicher Macht vorgenommen. Das betrifft insbesondere den Prozess der Legitimation von weltlicher mittels spiritueller Macht, dessen Funktionsweise ich nun darlege. In diesem Teilabschnitt über die buddhistische Konzeption von Macht wird deutlich, wie die religiöse Deutungshoheit des sangha über Fragen der Moral und des Todes eine konservative Wahrnehmung von säkularer Macht in Kambodscha begünstigt. Dabei stelle ich wichtige Charakteristika des kambodschanischen Buddhismus, wie den sangha oder die Wechselwirkung zwischen Ver-

\footnotetext{
${ }^{42}$ Das betrifft den Umgang der Reformist_innen mit Totengeistern ganz allgemein, siehe Kap. 4.
} 
dienst, Karma und Wiedergeburt vor, um danach zu einer alternativen Machtkonzeption des Brahmanismus überzuleiten.

In meinem Vorhaben, die soziale Realität von Menschen und ihrer Religiosität zu beschreiben, fokussiere ich mich hier auf die prozesshafte Umsetzung und Aushandlung von religiös legitimierter Macht aus einer praxisorientierten Perspektive. Da die Schriften den meisten Menschen in Kambodscha nur bruchstückhaft oder gar nicht bekannt sind, ${ }^{43}$ werden höchst selten Referenzen zu einschlägigen Quellen wie dem Pāli-Kanon gemacht, womit eine textbasierte Hermeneutik dieser Schriften für mein Vorhaben abwegig erscheint.

\subsubsection{Der sangha - die buddhistische Gemeinschaft der Mönche}

Das Verhältnis von sangha und Laien ist von einer versorgenden Spendenpraxis geprägt und weist klare Geschlechterverhältnisse auf, da die Laien, die täglich Opfergaben zu den Mönche in die Pagode bringen, zu einem deutlich überwiegenden Anteil Frauen sind. Männliche Gläubige partizipieren nur an großen Feiertagen an den Zeremonien in Pagoden. Somit gehörte zur allgemein wahrgenommenen Aufgaben von Frauen (neben der Haushaltsführung und dem Verwalten des Geldes) das Verdienst-Erzeugen für die eigene Familie. Sie sind damit von existenzieller Bedeutung für die (ausschließlich männlichen) Mönche des sangha, ohne selbst Möglichkeiten einer ähnlich hohen religiösen Stellung zu haben (Guthrie 2004b). ${ }^{44}$

Entgegen des klassischen Bilds des Mönches als weltabgewandtem Gelehrten, der sich in religiöser Askese übt, um damit Erleuchtung zu erlangen, weckt die Ordination für junge Männer in Kambodscha heutzutage in der Regel andere Hoffnungen. Dazu gehört nicht nur das Abwägen der Vorteile des Klosterlebens wie das Einsparen von finanziellen Mitteln, während man die unentgeltliche Versorgung durch Essen und Unterkunft in den Klöstern in Anspruch nimmt. Auch die Ehrung der Familie oder die Inanspruchnahme von Bildungsangeboten (wie beispielsweise Englisch- und Computerunterricht) für Mönche spielen wichtige Rollen und einige hegen zudem machtstrategischen Aspirationen - ein Umstand, der historisch erklärt werden kann.

Wie oben beschrieben, wurden in der Zeit der vietnamesischen Besatzung nur ausgewählte (linientreue') Mönche zur Ordination zugelassen, die nicht durch buddhistische Kenntnisse sondern vor allem durch Parteitreue auffielen. Daraus erwuchsen enge Verbindungen zwischen politischen und buddhistischen Verantwortlichen im Land. Auch nach der Liberalisierung der religiösen Praxis nach

${ }^{43}$ Dieser Umstand bekommt nach Berücksichtigung der kambodschanischen Geschichte eine spezielle Bedeutung, denn durch die Vernichtung des sangha in der Zeit der Roten Khmer wurden zahlreiche Intellektuelle getötet und die buddhistischen Schriften zerstört.

${ }^{44}$ Frauen dürfen in Kambodscha nicht ordiniert werden, obwohl es zahlreiche, vor allem ältere Frauen gibt, die ebenso viele Regeln beachten- sie werden țūnjī (gesprochen: donchi) genannt. Sie sind in weiß gekleidet und helfen meist im klösterlichen Umfeld aus. 
1989 entschied nicht theologisches Wissen über die Auswahl der Leitung von Pagoden, sondern die Anpassung der Religionsausübung an die Ansichten der Regierungspartei KVP (Kent 2008). Diese Entwicklung fördert bis heute einen spezifischen Vorbildcharakter: unter jungen Männern ist es üblich, sich aus machtstrategischen Gründen ordinieren zu lassen; sie treten bewusst in das klösterliche, soziale Netzwerk von streng hierarchischen Machtbeziehungen ein, um nach ,oben` Dienste erweisen und nach ,unten' einfordern zu können. Ein Aufstieg innerhalb dieser Netzwerke wird auch bei Mönchen durchaus weltlich belohnt; einige Mönche besitzen Geländewagen und andere Luxusartikel wie Handys, Laptops und Schmuck; finanziert von privilegierten Gönnern. Auch der (eigentlich untersagte) Umgang mit Geld ist unter Mönchen - außerhalb der rituellen Praxis üblich. So ist es möglich, innerhalb der sangha-Strukturen aufzusteigen und Besitztümer anzuhäufen, ähnlich zu Arbeitnehmern in privatwirtschaftlich geführten Unternehmern.

Theologisch interessierte Mönche sind diesem System gegenüber kritisch eingestellt und hegen eine gewisse Nostalgie für die (Kolonial-)Zeit der orthodoxen Reformisten mit ihrer Rückbesinnung auf orthodox-buddhistische Werte. Kritik an der offensichtlichen Korruption der Patriarchen und dem Aufweichen der klösterlichen Ordnung (Harris 2001: 91) wird jedoch aus Angst vor Sanktionierungen unterlassen. ${ }^{45}$ Kontroverse theologische Debatten könnten schnell als Affront gegen Autoritäten des sangha und damit der Regierung interpretiert werden, was in der Regel repressive Maßnahmen nach sich zieht. ${ }^{46}$

\section{Die moralische Autorität des sangha}

Dennoch ist es bemerkenswert, dass die Kambodschaner_innen dem sangha noch immer mehr als allen staatlichen Institutionen vertrauen, insbesondere in Fragen von Gerechtigkeit und Moral (Nissen 2008). Andere Institutionen genießen nicht nur (noch) weniger Vertrauen in der Bevölkerung, sie werden aufgrund ihrer Willkür und der vorherrschenden Korruption sogar gefürchtet:

"For the majority of Cambodians, the hope of securing survival for themselves and their world is vested not in secular institutions such as the police force, the judiciary or politics. On the contrary, people may seek protection from such institutions, which often perpe-

${ }^{45}$ Der prominente Mönch Sam Bunthoeun wurde beispielsweise wegen seiner Kritik an magischen Praktiken von Mönchen für Politiker_innen und an der Einschränkungen des Wahlrechts für Mönche im Jahr 2003 innerhalb seines Klostergeländes in Phnom Penh erschossen (Kent 2008). Die Suche nach den Mördern des Mönches wurde offensichtlich von staatlicher Seite behindert (Saing und Kihara 2003).

46 Im Moment ist Luon Sovath der bekannteste kritische Mönch des politischen Systems in Kambodscha. Ihm wurde schon oft Gewalt und ein Entzug seines Mönchsstatus angedroht und zwei Familienmitglieder wurden 2009 bei einer Landvertreibung erschossen, doch bisher gewährt ihm seine internationale Prominenz als socially engaged monk und Preisträger des Martin-EnnalsMenschenrechtspreis (2012) eine gewisse Immunität. 
trate violence against the people, rather than in them. It is more strikingly into the realm of religion that many people pour their efforts and hopes" (Kent 2008: 79, Hervorbeb. $i$. O.).

Im Alltag wird die hohe Autorität des sangha über Fragen der Moral beispielsweise daran deutlich, dass zu allen religiösen und säkularen Ritualen wie Hochzeiten, Erntedankfeste oder auch Treffen von Geistmedien buddhistische Mönche eingeladen werden, um die Veranstaltungen durch ihre Präsenz moralisch aufzuwerten oder - wie in Fällen von nicht-buddhistischen Zeremonien - moralisch zu legitimieren. Doch woran liegt es, dass der sangha bei moralischen Fragen als vertrauenswürdiger Ansprechpartner gilt, obwohl er gleichzeitig eng verknüpft mit staatlichen Akteuren auftritt? Zum einen werden Regelverstöße von Mönchen innerhalb des sangha strenger geahndet als auf staatlicher Ebene. Zum anderen macht die Unterscheidung zwischen (moralisch) guten und schlechten Taten einen wichtigen Teil der buddhistischen Lehre aus, was dem sangha weitreichende Autorität in moralischen Fragen verleiht. Davis (2015a) leitet diese Autorität des sangha vom monopolisierten Umgang der buddhistischen Akteure mit dem Tod ab: Nach dem Tod eines Menschen entscheidet die Summe von guten Taten (Verdienst) und schlechten Taten (Karma) über den sozialen Status des nächsten Lebens, was Keyes $(1983,1973)$ als kammic theory bezeichnet. Diese Lehre, die ich im Folgenden aufgrund ihrer praktischen Kausalität besser mit „Karma-Wechselwirkung“ umschrieben sehe, ist von grundlegender Bedeutung für das buddhistisch geprägte Verständnis von Macht und sozialer Hierarchie in Kambodscha.

\subsubsection{Karma-Wechselwirkung}

Wie Jacobsen und Stuart-Fox in ihrem Artikel zu verschiedenen Machtkonzeptionen in Kambodscha (2013) feststellen, verdient der kausale Zusammenhang zwischen Karma, Verdienst (punya) und Wiedergeburt besondere Aufmerksamkeit für das Verständnis von buddhistisch konzipierter Macht. ${ }^{47}$ Die Befreiung aus diesem Kreislauf der Wiedergeburten (samsara) kann nur durch die Erleuchtung, das heißt, die vollständige Tilgung des eigenen Karmas erlangt werden. Karma steht für alle als ,schlecht' erachteten Taten, die nach dem Lebensende nicht durch ,gute Taten' (Verdienst) ausgeglichen werden konnten. Die Menge des eigenen Karmas ist jedoch unbekannt, da es aus vorherigen Leben mitgenommen wird, an die man sich in der Regel nicht erinnern kann. Erleuchtung zu erlangen und damit das Nirvana zu erreichen, ist jedoch kein realistisches Ziel für normale Gläubige (diese Chance wird lediglich Menschen in höchstem spirituellem Rang eingeräumt) - für sie gilt daher die Vermeidung von Karma und die Anhäufung von Verdienst zur Verbesserung ihrer Situation nach der nächsten Wiedergeburt.

47 Die hier beschriebene Wechselwirkung deckt sich in vielen Punkten mit Beschreibungen aus anderen Theravada-buddhistischen Kontexten, wie beispielsweise Thailand (Keyes 1973). 


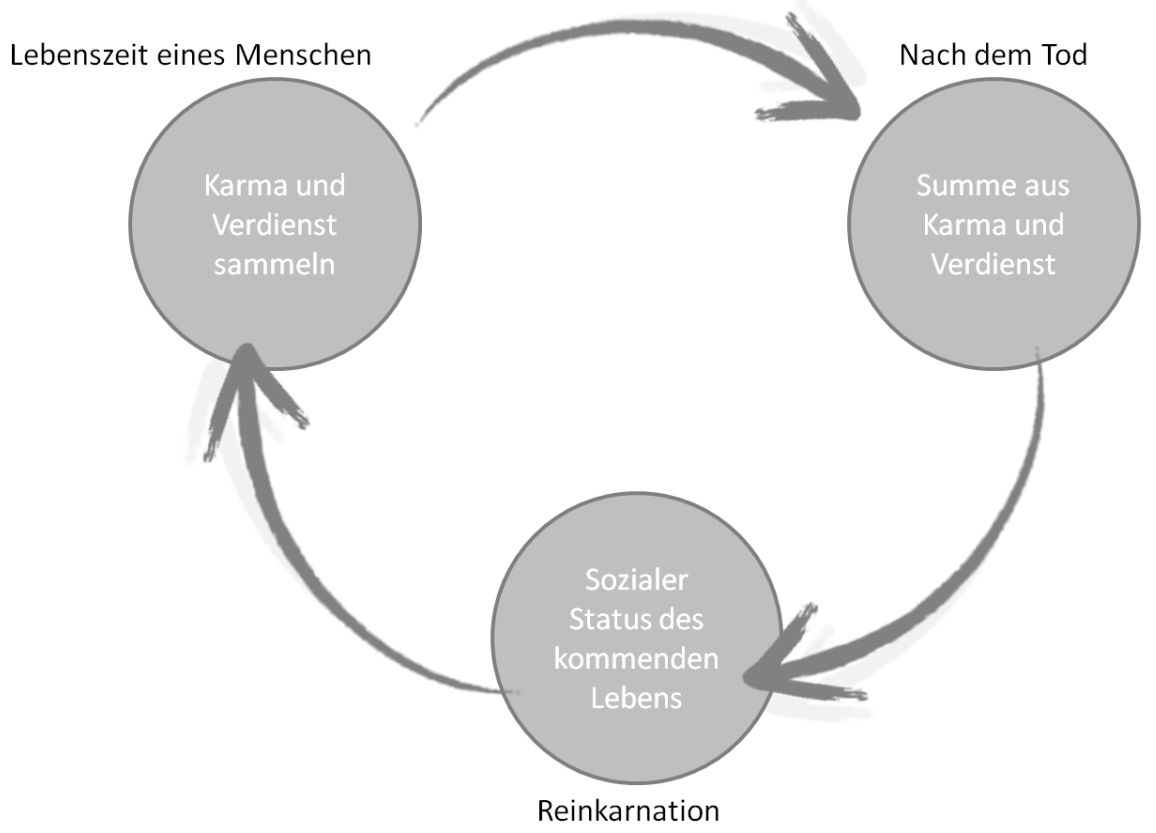

Abb. 4: (C) Autor. Die Karma-Wechselwirkung. Nach dem Tod eines Menschen legt die Summe aus den schlechten Taten (Karma) und den guten Taten (Verdienst) den sozialen Status des kommenden Lebens fest. Karma kann auch über mehrere Lebenszylklen bestehen bleiben. In der Grafik nicht berücksichtigt ist eine Statusänderung während einer Lebenszeit, die mit plötzlich eintretendem Karma erklärt wird (siehe unten).

Die Summe aus Karma und Verdienst der vergangenen Leben bildet die ,Ermessensgrundlage' für den sozialen Status des gegenwärtigen Lebens. Das bedeutet, dass Armut und Krankheiten auf Fehlverhalten in früheren Leben zurückgeführt werden, genauso wie reichen und erfolgreichen Menschen eine besonders tugendhafte Führung ehemaliger Lebenszyklen nachgesagt wird. Die einzige Möglichkeit, das Karma des derzeitigen und der früheren Leben abzubauen und damit das eigene Schicksal (dieses und der kommenden Leben) zu verbessern, ist es, Verdienst zu sammeln. ${ }^{48}$ Doch Karma wirkt nicht nur vor der Geburt - es kann auch im Laufe eines Lebens unerwartet eintreten - so werden beispielsweise Todesfälle von Kindern oder andere unerwartete Schicksalsschläge erklärt (Keyes 1973).

\footnotetext{
48 Der Spruch „tue Gutes, bekomme Gutes; tue Schlechtes, bekomme Schlechtes“ begegnete mir häufig während meiner Forschung als geflügeltes Wort der buddhistischen Lehre. Dabei war die Bedeutung von ,bekommen' auf die Zeit nach dem Tod bezogen.
} 


\section{Verdienst als grundlegendes Motiv der buddhistischen Praxis}

Verdienst lässt sich auf Khmer als punya (gesprochen: ,bonn') oder sīla (gesprochen: ,sil $\left.{ }^{\circ}\right)$ übersetzen. Sìla bezeichnet eine besonders tugendhafte Einstellung oder Geisteshaltung, die durch Praktiken wie Meditation oder die Einhaltung der gleichnamigen buddhistischen Regeln erlangt werden kann. Der beste Weg für die Generierung von sīla ist es, Mönch (oder tūujjù) zu werden.

Die letztere Form von Verdienst (punya) ist jedoch als bedeutsamer im heutigen Kambodscha einzustufen. Die Akkumulation von punya beruht größtenteils auf der Spendenpraxis (Swearer 2010: 19), die sowohl in täglichen als auch in jährlich stattfindenden Ritualen gepflegt wird. Nach der buddhistischen Lehre sollte Verdienst nicht an der Höhe der Spende, sondern an der Einstellung (sìla) der gebenden Personen gemessen werden. So könne punya in vielen alltäglichen Kontexten in Form von ,guten Handlungen' (dhvoe 1', gesprochen: ,twö la.o'), aber auch mit der Ehrung Älterer, insbesondere den eigenen Eltern, generiert werden.

Nach populärer Meinung der Gläubigen ist es jedoch vor allem die Höhe der Spende, die über das Ausmaß von punya entscheidet. Demnach kann man beispielsweise besonders viel punya mit der Unterstützung von gemeinnützigen Projekten oder der Finanzierung von buddhistischen Bauwerken sammeln (Marston 2008a: 183). Das alltägliche, allen zugängliche Verdienst-Sammeln geschieht durch Rituale wie (sangha-)dāna (gesprochen: ,dian') oder namasakāra (gesprochen: ,neakmassaka'), in deren Rahmen Laien den Mönchen Essens- und andere materielle Spenden darbieten (dazu mehr im nächsten Abschnitt).

Ein wichtiger Aspekt hierbei ist die Offenlegung dieser Spenden. Die wohltätigen Spenden und der durch Rituale generierte Verdienst stellen nicht nur den sozialen Status der gebenden Person zur Schau, sondern beweisen auch die tugendhafte Führung früherer Leben. Die Absenz von Hunger, schwerer Arbeit oder Krankheit wird als kausale Folge ihrer verdienstreichen Leben im und vor dem derzeitigen Lebenszyklus gesehen, womit die öffentliche Inszenierung des Verdienstmachens zur Legitimation von weltlicher Macht genutzt wird.

Der soziale Status (punya sak) eines Menschen wird demnach als ,Konsequenz der früheren Taten und des gesammelten Verdienstes verstanden, und gilt somit als zu einem hohen Grad determiniert. Besonders viel punya können somit Menschen generieren, die genügend Wohlstand $(m \bar{a} n)$ besitzen, um diesen für Rituale des Verdienstmachens zu nutzen. Wie bereits beschrieben, galt mān jedoch auch eine Konsequenz des punya aus vergangenen Leben - womit sich der Kreis der hier beschriebenen Wechselwirkung schließt.

Grundlegend für die Wahrnehmung von Macht war somit die karmische Wechselwirkung zwischen den Taten früherer Leben und der Spendenbereitschaft des gegenwärtigen Lebens. Die Tilgung des eigenen Karmas und die Verbesserung im Kreislauf der Wiedergeburten war also leichter für Menschen mit Zugang zu Wohlstand $(m \bar{a} n)$ und mit einem hohen sozialen Status (punya sak). 
Teil I: Thematischer Kontext und Methodik

\section{Rituale von Verdienst und Macht}

Das dāna ${ }^{49}$ (\$าS) Ritual sieht den alltäglichen und grundlegendsten Austausch von Spenden gegen den Segen der Mönche vor. Damit wird vor allem die notwendige Versorgung der Mönche sichergestellt, die aufgrund des Verbotes, mit Geld umzugehen, nur gespendete Nahrungsmittel konsumieren dürfen. Der schematische Ablauf des Rituals verläuft folgendermaßen: Allmorgendlich versammeln sich Gläubige (größtenteils Frauen) aus der Nachbarschaft der Pagode und reichen den Mönchen ihre Spenden in Form von gekochtem Reis, anderen zubereiteten oder gekauften Speisen und sonstigen Bedarfsgegenständen. Die Mönche rezitieren buddhistische Mantras und leiten dabei den gemachten Verdienst an die verstorbenen ,Ahnen' weiter, die ihrerseits günstigen Einfluss auf den Lebenszyklus der Spender_innen nehmen können. Die meisten Besucher_innen verlassen danach die Pagode; nur einige freiwillige Helfer_innen verteilen die Speisen auf die Teller der Mönche, die diese einzige Mahlzeit des Tages vor $12 \mathrm{Uhr}$ mittags eingenommen haben müssen.

Die Bedeutung des dāna ist natürlich nicht auf die Nahrungsaufnahme der Mönche beschränkt. Das Ritual zeigt die einfachste Form des Tausches von materiellen Waren gegen Verdienst. Einvernehmlich wurde mir erklärt, dass die Spenden als moralische Handlung Verdienst erzeugten. In der Vorstellung der Beteiligten konnte dieser Verdienst an lebende Menschen oder an Verstorbene transferiert werden, auch wenn diese Vorstellung nach Keyes (1983) nicht der formalen Lehre entsprach. Die meisten Spender_innen gaben jedoch an, den Verdienst mit ihren Familienangehörigen zu teilen. ${ }^{50}$

Neben der alltäglichen dāna-Praxis bieten auch jährlich stattfindende Rituale einen möglichen Rahmen für hohe Spenden an den sangha. Das verdienstträchtigste dieser Rituale heißt kathen. An ihm lässt sich die Karma-Wechselwirkung in seiner auffälligsten Form beobachten. Kathen findet am Ende der Regenzeit im elften Monat des lunaren Kalenders statt. Die ursprüngliche Bedeutung dieser Zeremonie war die Erneuerung der Mönchsroben, die ihnen nach einer besonders intensiven Zeit der Einkehr (genannt: cul vassa) gespendet wurden. Bis heute sind Mönche während der Regenzeit strengeren Regeln unterworfen. ${ }^{51}$ Kathen wird somit zu einem Zeitpunkt gefeiert, an dem die Mönche drei Monate in tugendhaften Handlungen geübt haben und selbst punya sammelten, beziehungsweise ein besondere silla (tugendhafte Geisteshaltung) annehmen konnten. Dieser Umstand macht die Spendenpraxis in den Augen der Gläubigen auch für sie besonders

\footnotetext{
${ }^{49}$ Skr. ,Gabe' oder, Spende‘.

${ }^{50}$ So verhielt es sich beispielweise auch mit dem Verdienst, der mit einer Ordination eines männlichen Familienangehörigen erzeugt wurde. Diesen als sehr hoch erachteten Verdienst widmeten junge Männer oftmals ihren Eltern.

${ }^{51}$ Beispielsweise dürfen Mönche in den drei Monaten von cul vassa ihre Pagode nicht über Nacht verlassen. Sie können also auch keine Verwandten auf dem Land besuchen, was sonst durchaus üblich ist.
} 
effektiv, da die Mönche durch ihre strenge Einhaltung buddhistischer Regeln in der Lage sind, in ihrer Rolle als Vermittler mehr Verdienst als üblich weiterzugeben.

In Phnom Penh ist kathen eine gut organisierte Veranstaltung. Die größten Pagoden der Innenstadt legen die Termine für die Ausrichtung des Festes selbst fest, laut Vorschrift müssen sie nur innerhalb des elften Monats stattfinden. Damit möglichst viele Spender_innen erscheinen können, stimmen sich die Pagoden für die Terminfindung ab. Die Spitzenpolitiker_innen und Geschäftsleute haben die Tempel unter sich ,aufgeteilt', Hun Sen und seine Frau Bun Rany treten beispielsweise jedes Jahr als Mäzen des zentral gelegenen Klosters Botumwadei auf. Im Verlauf der Zeremonie werden zu den Klängen von ,altertümlicher Musik' (bleng purāna) das oben beschriebene dāna-Ritual in leicht abgewandelter Form durchgeführt. Der Unterschied liegt vor allem im Ausmaß der Spenden: es werden wenig Speisen, sondern aufwendig gestaltete Geschenkkörbe, hohe Geldsummen und natürlich Roben gespendet. Die Tempelhelfer, manchmal auch die ācaryā, nehmen die Spenden an, quittieren und verkündigen die genaue Summe über die Lautsprecher.

Im Jahr 2012 waren in der kathen-Zeremonie des Wat Botumwadei über 400.000 US-Dollar Spendengelder für das Kloster zusammengekommen. Die breite Berichterstattung darüber in Zeitungen und Fernsehen betonte vor allem den wohltätigen Zweck der Veranstaltung. Dies ist die öffentlichkeitswirksame Erklärung für die hohen Spenden. Unter Berücksichtigung der patron-client geprägten Beziehungen in Kambodscha schaffen die Spenden zudem Verbindlichkeiten, woraufhin Mönche und Leiter des oben genannten Klosters angehalten sind, ihre Zustimmung zur Politik der regierenden KVP von Hun Sen öffentlich $\mathrm{zu}$ formulieren. Aus diesem Grund bezeichneten Ang Chouléan und Chea Vannath ${ }^{52}$ die Zeremonie als politisches Machtinstrument, das auch durch das Mäzentum ,eigener ${ }^{6}$ Pagoden der Mächtigen aufrechterhalten wird (Kaing und Colin 2012). So dient die buddhistische Praxis zur Stärkung von patronage-Beziehungen und als religiöses Werkzeug der Legitimation von weltlicher Macht.

Das Verständnis des sozialen Status einer Person ist damit hochgradig von spirituellen Einflüssen abhängig und wird religiös ausgehandelt. Ausführliche Beispiele dafür finden sich in mehreren Teilen dieser Arbeit wieder: so generierten beispielsweise manche Politiker_innen dermaßen viel Verdienst, dass sie als unangreifbar und spirituell mächtig angesehen wurden (Kap. 8). Andererseits wurde ,niedrigen“ Totengeistern viel weniger Macht zugesprochen als anderen Geistern. Die Medien der Totengeister mussten mit großem Aufwand ihren sozialen Status in der Dorfgemeinschaft wiederherstellen (Kap. 4). Und wie ich im nächsten Ka-

\footnotetext{
${ }^{52}$ Chea Vannath ist politische Aktivistin und arbeitet unter anderem für das Centre for Peace and Conflict Studies (CDS) in Siem Reap. Sie wurde 2005 für den Friedensnobelpreis nominiert. Ihre Aktivitäten in den Bereichen Menschenrechte und Korruptionsbekämpfung bringen sie bis heute in die Schusslinie der regimetreuen Kritik.
} 
Teil I: Thematischer Kontext und Methodik

pitel zeigen werde, wird Pol Pot auch nach dem Tod noch so viel Macht zugesprochen, dass er von Anwohner_innen als Ortsgeist verehrt wird, was nach einer Darstellung der brahmanistischen Machtkonzeption nachvollziehbar wird.

\subsection{Brahmanismus}

Wie Guillou (2017c) anmerkt, wird der Brahmanismus situativ in Sprechakten vom Buddhismus abgegrenzt, um etwas als 'nicht-buddhistisch' zu deklarieren. Ergänzend dazu argumentiere ich, dass der Brahmanismus insbesondere in der ,Funktionsweise ${ }^{6}$ der Rituale und der andersartigen Machtkonzeption vom Buddhismus unterschieden wird. Mit dem Blick auf diese Differenzierung beschreibe ich im Folgenden den Brahmanismus als ,moderne' religiöse Strömung, deren pragmatisch-wirkmächtige Handlungen von Geistern und Geistmedien einen viel größeren Bezug zur Gegenwart aufweisen als es buddhistische Rituale tun.

Indem ich im Folgenden (Kap. 2.4.1) die verschiedenen Definitionen aus akademischen, alltäglichen und offiziellen Diskursen zusammentrage, werden Dynamiken zwischen Vereinheitlichung und Differenzierung der beiden Religionen Buddhismus und Brahmanismus deutlich. Mit dem Fokus auf ihre Unterscheidung ziehe ich anschließend das Beispiel der performativ wandelbaren religiösen Selbstidentifikationen der Geistmedien heran, das die verschiedenen Funktionsweisen der buddhistischen und der brahmanistischen Praxis veranschaulicht (Kap. 2.4.2). Das zentrale Merkmal der Unterscheidung stellt das Machtkonzept pāramī dar, das ich anschließend vorstelle, bevor ich die ökonomisch geprägte Anwendung dieses Machtkonzepts in Anlehnung an das Konzept der prosperity religion untersuche (Kap. 2.4.3).

\subsubsection{Definitionen des Brahmanismus}

Aus akademischer Sicht leitet sich der Begriff Brahmanismus von der Ausbreitung sogenannter ,brahmanistischer ${ }^{6}$ Lehren durch die indische Kaste der Brahmanen vom 8. bis zum 3. Jahrhundert v. Chr. in Südostasien ab. Unter Religionshistorikern gilt er eher als Gesellschaftsordnung (und weniger als Religion), in der Brahmanen einen besonderen Einfluss auf Königshäuser besaßen (Bronkhorst 2011: 57-58; Gombrich 2006: 22-31). Südostasien war bis zum ersten Jahrtausend n. Chr. von einem sogenannten Prozess der ,Indianisierung' geprägt, der nach heutigem Forschungsstand eher aus einer bereitwilligen lokalen Adaption zahlreicher Aspekte des indischen Lebens wie Kunst, Philosophie oder Religion bestand als aus einer politisch oder militärisch motivierten Ausweitung des Einflusses Indiens (Hansen 2004a: 105). In dieser vor-buddhistischen Zeit wurde die religiöse Praxis von der Verehrung indischer Götter und Geister bestimmt, worauf sich die heutige Benutzung des Begriffs Brahmanismus in Kambodscha noch bezieht. 
In gegenwärtigen Alltagsdiskursen wird der Brahmanismus als Sammelbegriff für alle Formen der nicht-buddhistischen Religiosität benutzt (Davis 2009: 11). Trotz dieser Abgrenzung wird er - wie oben beschrieben - zwar nicht als Teil der offiziellen Lehre, aber als Bestandteil des ,kambodschanischen Buddhismus' anerkannt. Angesprochen auf den Brahmanismus, wurde in informellen Gesprächen mit Kambodschaner_innen häufig auf die Angkor-Periode verwiesen, die nicht nur als glorreiches Zeitalter, sondern auch als ,Blütezeit' der brahmanistischen Praxis gilt. Das Königshaus, wo bis heute noch angestellte pāragū (Brahmanen) brahmanistische Rituale pflegen, wird als zentraler Bezugspunkt des Brahmanismus angesehen. Gleichzeitig entsteht mit diesem Rückbezug eine idealisierte Wahrnehmung der Angkor-Zeit: Demnach lebten die Könige damals in einer harmonischen Gesellschaft, der Kontakt zwischen Göttern, Geistern und Königen sei ungestört gewesen, so dass den Herrschern Zugang zu göttlicher Macht gewährt worden sei. Dabei wird oftmals auf die Tempel der Angkor-Periode verwiesen, die ohne die Hilfe von mächtigen grū niemals hätten erbaut werden können. Auch Kriege (gegen Königreiche im heutigen Thailand und Vietnam) seien damals mit Hilfe von Geistern gewonnen worden.

Somit wird ,Brahmanismus' heute noch synonym zu vetamon benutzt, das wörtlich als ,vedische Formel' oder Mantra übersetzt wird (Pou und Ang 19871990: 125) und in Kambodscha die Bedeutung von ,Magie‘ annimmt. Wie in anderen Kontexten Südostasiens bildet das ,Magische“ damit eine Art supplementären Gegenpol zum Buddhismus, indem es für Anliegen von moralischer Ambiguität genutzt wird, was die spirituelle Beeinflussung von gegenwärtigen Phänomenen einschließt (White 2016).

Neben der Dokumentation des Alltagsdiskurses befragte ich zudem Mönche und Mitarbeiter des Ministeriums für Kult und Religion als Vertreter des offiziellen religiösen Diskurses. Grundsätzlich waren die Aussagen der Mönche von einer „wohlwollenden Gleichgültigkeit“ bestimmt, wie White (2005: 71) es ausdrückt. Sie unterschieden vor allem die Erwartungen der Laien an die buddhistischen Praktiken: Wenn Personen Verdienst sammeln wollten, müssten sie buddhistische Handlungen vollziehen. Der Brahmanismus und die mit dem Begriff verbundenen Geister-Rituale entsprachen nicht immer der buddhistischen Lehre, und man sollte sie nur für harmlose Zwecke nutzen. Allgemein sei der Brahmanismus lediglich ein Teil des religiösen Erbes Kambodschas - einige Mönche betonten, dass dieses Erbe gepflegt werden müsste, während andere dies für unnötig hielten. Die Vertreter des Ministeriums für Kult und Religion definierten Brahmanismus als „zweite Religion“ Kambodschas, die nach der sāsanā chi (der chinesischen Religion) nach Kambodscha gekommen sei. ${ }^{53}$ Die sāsanā chi sei die erste Religion Kambodschas gewesen und hätte den Kambodschaner_innen den Respekt vor Hierarchien, vor Ahnen und den älteren Familienangehörigen gelehrt, was heute in

${ }^{53}$ Interview mit San Samphors, Way Vibol und Chek Chuon (09.01.2013). 
Kambodscha noch immer sehr ausgeprägt sei. ${ }^{54}$ Danach hätte der Brahmanismus Kambodscha aus Indien erreicht und die Menschen verehrten seitdem indische Götter, ohne die Lehren von sāsanā chi vergessen zu haben. Der Assistent des Ministers Chek Chuon sagte dazu: „Den Brahmanismus zu respektieren, bedeutet vetamon zu praktizieren, so wie es bei den Soldaten der alten Könige üblich war und heute noch ist. Wenn wir Opfer geben, um damit unsere persönliche Zukunft zu beeinflussen, das ist Brahmanismus". So war auch bei der Verbreitung der dritten Religion, des Buddhismus, keine der vorhergegangen Religionen ganz vergessen worden und der Brahmanismus sei somit noch heute Teil des kambodschanischen Buddhismus. Obgleich man gegenwärtig nur vom Buddhismus als Staatsreligion sprechen würde, würden die Kambodschaner_innen darunter immer alle drei Religionen verstehen.

Anhand der verschiedenen Perspektiven wird deutlich, dass trotz der bemühten Vereinheitlichung des kambodschanischen Buddhismus Unterschiede zwischen den ,Religionen' gemacht wurden. Die Vertreter des offiziellen religiösen Diskurses legten die Unterschiede zwischen Buddhismus und Brahmanismus vor allem in der Wirkung der rituellen Praxis und der Intention der involvierten Akteure fest. Auch von den interviewten Geistmedien und ihren Klient_innen wurden die brahmanistischen Rituale mit Geistern als gegenwartsbezogen und flexibel bezeichnet: Klient_innen suchten magische Unterstützung in einer großen Bandbreite von Angelegenheiten, wie beispielsweise um eine Prüfung zu bestehen, einen Partner/eine Partnerin zu finden, um Konflikte zu schlichten oder um bestimmte Objekte segnen zu lassen. Die Bandbreite dieser Objekte umfasste beispielsweise das eigene Auto, in der Absicht Unfälle zu verhindern oder das eigene Handy, um erfolgsverheißende Anrufe zu erhalten. Die beiden populärsten Anliegen betrafen jedoch Heilung oder ökonomischen Erfolg, was ich in den Kapiteln 7 und 8 ausführlich analysiere.

Zentrales Merkmal der brahmanistischen Praxis war aus Sicht der Involvierten somit die große Flexibilität, die auf den Mangel an textlichen Quellen (einer ,brahmanistischen Lehre) zurückgeführt werden kann. Die grü betonten, dass sie beinahe alle Anliegen bearbeiten könnten, und dass die Wirkung ihrer Rituale innerhalb weniger Tage einsetzen müsste, während eine Verbesserung durch buddhistisches Verdienstmachen normalerweise erst nach dem Tod erreicht werden könne. Diese Differenzierung von diesseitiger und jenseitiger Ausrichtung der religiösen Praxen wurde von sämtlichen Kambodschaner_innen geteilt. Die Klient_innen der Geistmedien bezeichneten den Bezug auf die Gegenwart ausdrücklich als Vorzug gegenüber der buddhistischen Praxis, was dazu führte, dass sich

\footnotetext{
54 Allerdings war das Ministerium der einzige Ort in Kambodscha, an dem ich von sāsanā chi gehört hatte. Möglicherweise wurde diese religiöse Tradition von den Mitarbeitern des Ministeriums vertreten, weil die Regierung nach ihren, chinesischen Wurzeln' und damit nach Gemeinsamkeiten mit ihrem einflussreichsten Handelspartner sucht.
} 
die Medien mehr oder weniger explizit als Anhänger_innen des Brahmanismus positionierten und, je nach Anliegen, performativ in ihrer Selbstdarstellung als wirksam-brahmanistisch oder moralisch-buddhistisch wechselten.

\subsubsection{Die Performative Aushandlung der Religionen in Geister-Ritualen}

Geistmedien verorten sich religiös sehr unterschiedlich zwischen Buddhismus und Brahmanismus. Eine gewisse Grundorientierung wird während der Initiation der Medien mit ihren Geistern ausgehandelt. Darüber hinaus verstehen sich einige grū darin, ihre religiöse Orientierung performativ mittels verschiedener Techniken ,buddhistischer oder ,brahmanistischer" zu gestalten.

,Buddhistisch' ausgerichtete grü betonen die Kompatibilität ihrer Rituale mit buddhistischen Regeln. Das beinhaltet beispielsweise die Beachtung des buddhistischen Grundsatzes, nach dem keine Statue auf ihrem treppenförmigen Schrein gleichhoch oder höher als das Abbild des Buddhas stehen darf. ${ }^{55}$ Zudem verweisen sie auf ihre Spendenbereitschaft gegenüber der örtlichen Pagode. Sie arbeiten nicht an buddhistischen Feiertagen, da auch ihre Geister strenge Buddhisten seien, die in einem Bottisattwa-ähnlichen Dasein die buddhistische Lehre verbreiten wollten. Die Geister seien zu den Menschen gekommen, um ihnen zu helfen in Einklang mit der buddhistischen Lehre (Dharma) zu leben. Zudem hob die Mehrheit dieser Medien den Aspekt des Verdienst-Machens (dhvoe punya) in und außerhalb ihrer rituellen Praxis hervor und wies ausdrücklich darauf hin, dass ihre Geister keine schädigenden Praktiken (amboe, gesprochen: ,ampöw ${ }^{56}$ vollziehen könnten. Angesprochen auf den magischen Aspekt ihrer Arbeit reproduzierten sie die offizielle Konzeption des kambodschanischen Buddhismus und unterstrichen die religiöse Vormachtstellung der Mönche.

,Brahmanistisch ausgerichtete ${ }^{6}$ gru bezeichnen sich nur selten als Brahmanisten, sie werden in der Regel von ihren Klient_innen als solche charakterisiert. Begründet wird diese Zuordnung erstens durch das Fehlen äußerlicher Marker wie buddhistische Abbildungen oder Statuen im Arbeitsraum der Medien, zweitens durch die mangelnden Orientierung ihrer rituellen Praxis an den etablierten, buddhistischen Ritualen und drittens durch die Aussagen der grū zur Bedeutung der Karma-Wechselwirkung und allgemein zur buddhistischen Lehre. Selten weisen Medien eine explizit-brahmanistische Haltung in allen drei Aspekten auf; der Großteil der Geistmedien positioniert sich je nach Anliegen der Klient_innen

\footnotetext{
55 Mit den Buddha-Statuen auf der höchsten Eben des Schreins stellen die grū ihren Respekt vor dem Buddhismus zur Schau und beruhigen damit manche zögerliche Klient_innen (wie beispielsweise Bunnwath). Ohne Buddha-Abbild auf dem pāy sī fiel es meinem in der Pagode wohnenden Freund sichtlich schwer, dem pāy sī seine Ehrerbietung in Form dreimaliger Verbeugung zu zeigen.

${ }^{56}$ Schwarze Magie heißt übersetzt amboe, was wörtlich auch ,Tat' oder ,Mord' heißen kann. Im alltäglichen Kontext wurde amboe auf die schädlichen Praktiken der Geistmedien angewandt, die sie nach dieser Definition mithilfe von Geistern durchführten (siehe Kap. 9.5).
} 
Teil I: Thematischer Kontext und Methodik

,buddhistischer ${ }^{\varsigma}$ oder ,brahmanistischer', denn für die Klient_innen gibt es für unterschiedliche Anliegen bestimmte Vorstellungen, wie buddhistisch oder brahmanistisch ein Medium sein solle.

Aus diesem Grund machen es zahlreiche grū vom rituellen Anlass und von ihrer Einschätzung der Klient_innen abhängig, wann sie sich magischbrahmanistisch oder moralisch-buddhistisch inszenieren. Besonders bei unerfahrenen Klient_innen betonen die grū den Wert der buddhistischen Moral, indem sie klarstellen, dass die Geister nur praktizierenden Buddhisten helfen würden, weil die Geister selbst strenge Gläubige seien. Generell versuchen grū sich ausreichend buddhistisch zu positionieren, um nicht als, verrückt ${ }^{67} \mathrm{zu}$ gelten und gleichzeitig so brahmanistisch, um sich als Gelehrte der, alten und magischen Macht ${ }^{6}$ darzustellen, die den Klient_innen mit diesen Kräften helfen können.

Bei einer eifersüchtigen Klientin beispielweise, die nach einem Ritual fragte, das ihr ihren untreuen Ehemann zurückbringen sollte, sprach der angesprochene grū auffällig oft in der Sprache der Geister (bhāsā khmoc) ${ }^{58}$ und rezitierte während der Rituale weniger Pāli als üblich. Er kommunizierte öfter mit seinem Geist und positionierte sich anhand dieser Praktiken brahmanistischer als bei anderen Gelegenheiten. Somit konnte er sich als jemand darstellen, der dank seiner brahmanistischen Macht (pāramī) unmittelbare Wirkung auf den Ehemann erzielen könnte. Der Bezug zum Buddhismus war von dem Medium in Falle dieser Klientin vernachlässigt worden, da ihr Anliegen als moralisch fragwürdig gelten kann und sie sich durch buddhistische Bezüge möglicherweise hätte verunsichern lassen.

Die brahmanistische Macht pāramī ist fundamental zum Verständnis von Geistern und der Macht der Geistmedien in Kambodscha. Der folgende Abschnitt wird ihre Konzeption sowie ihre Erscheinungsformen näher ausleuchten.

\section{Das brabmanistische Machtkonzept pärami}

Der Begriff pāramī (gesprochen: ,boramey) wird im Khmer als zentrale Referenz zu spirituell konzipierter Macht verwendet (Guillou 2017c; Work 2014; Bertrand 2005, 2001; Bizot 1994; Forest 1992). ${ }^{59}$ Der Begriff bedeutet ,Perfektion` oder ,Vollendung ${ }^{6}$ und bezieht sich nach klassisch-buddhistischer Interpretation auf die zehn Vollendungen des historischen Buddhas auf dem Weg zur Erleuchtung.

${ }^{57}$ Das Label ,verrückt‘ (chkuat) war durch einen Mangel an moralischem Verhalten gekennzeichnet. Somit konnte man schon als verrückt gelten, wenn man seinen Eltern nicht ausreichend viel Respekt entgegenbrachte (siehe Kap. 9.2).

${ }^{58}$ Die bhāsā khmoc (gesprochen: ,piasa khmaodj) wurde mir von den Geistmedien als Ur-Sprache beschrieben, die Menschen und Götter in längst vergessenen Zeiten miteinander geteilt hätten. Die Medien lernten die Sprache von ihren Geistern und unterhielten sich mit dieser Sprache untereinander. Für Außenstehende war sie unverständlich.

${ }^{59}$ Es wird aber nicht nur in spirituellen Kontexten verwendet. Als allgemeiner Bezeichnung für ,Macht‘ wird er auch synonym zu anderen Begriffen verwendet, wie kanlaen (Stärke/Macht,

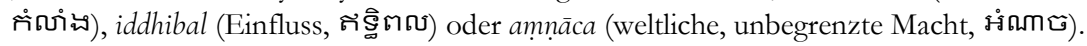


Etymologisch erscheinen zwei Interpretationen des Pāli-Begriffs sinnvoll: erstens kann es vom Wort parama abgeleitet werden, das als ,Höchstes' übersetzt werden kann. Damit wurden in Pāli Schriften auch Hochgestellte wie z.B. Bodhisattwa angeredet, die alle zehn Vollendungen (pāramitā) der buddhistischen Lehre gemeistert hatten. Eine zweite Ableitung kann aus den Pāli Worten pāra und (m)ita hergeleitet werden. Pāra wird mit ,Jenseits' übersetzt, während mita ,angekommen ‘ oder ita ,weiter gehend' bedeutet und damit als, über das Jenseits hinausgehend beziehungsweise ,transzendent ${ }^{\star}$ übersetzt werden kann (Lopez 1988: 21). Wie diese Pāli-Bezeichnungen im kambodschanischen Sprachgebrauch benutzt werden, offenbaren die Definitionen von pāramī nach Ang und Pou (1987-1990: 111):

- Perfection suprême réalisée par le Buddha (Höchste Vollendung des Buddha)

- Le Buddha lui-méme ou sa représentation plastique (Buddha selbst oder seine materielle Repräsentation)

- Forme réduite de brāy pāramì ou brāy brah pallank (Verkürzte Form von brāy pāramī oder brāy brah pallank ${ }^{60}$ )

Die erste Bedeutung spiegelt den oben beschriebenen Ursprung des in Pāli und Sanskrit vorkommenden Konzeptes wider. Die zweite Bedeutung b) ist bereits nah an der Benutzung im heutigen, alltäglichen Sprachgebrauch, da es vor allem als Bezeichnung für eine ,wohlwollende, spirituelle Macht' benutzt wurde, in diesem Fall von Buddha. Dass diese Benutzung sich jedoch nicht nur auf die Macht von Buddha bezog, sondern auch als Macht von Geistern verstanden wurde, zeigte während meiner Forschung vor allem die dritte Definition c). Bertrand (2001: 32) nimmt an, dass es zu einer Umdeutung von a) zu b) und schließlich zu c) kam, indem von Menschen oder anderen Wesen angenommen wurde, dass diese die gleichen Vollendungen des Buddha gemeistert hatten und, verkürzt dafür stehend, nur noch pāramī genannt wurden. ${ }^{61}$

Bis heute kann der Begriff zwei differenzierte Konzeptionen von spiritueller Macht umfassen. Erstens gilt pāramī als Eigenschaft, die jemand oder etwas innewohnen oder ausstatten kann oder bestimmte Orte oder Gebiete charakterisiert. Tempel, Ruinen, Statuen oder Bäume können von pāramı̄ geprägt sein - aber auch Menschen wie Sihanouk, Pol Pot oder Hun Sen wird pāramī zugesprochen, da sie als charismatische Redner gelten, die mit ihren Worten eine magische Wirkung erzielen könnten (Jacobsen und Stuart-Fox 2013: 10). In diesem Kontext wird die Macht als ein Attribut verstanden.

\footnotetext{
${ }^{60}$ Brāy stellen bestimmte Geister dar, die der Wildheit und des Waldes zugeordnet werden, siehe Kapitel 5.1. Der Begriff brah (gesprochen: ,preah) bezeichnet eine Gottheit bzw. die respektvolle Anrede eines Geistes.

61 "In a popular reappropriation of the word in Cambodia, pāramī are believed to constitute a benevolent form of power" (Bertrand 2004: 151).
} 
Auf einer zweiten Bedeutungsebene können pāramı̄ auch individualisierte Subjekte, also Geister, bezeichnen. Dabei werden sie beispielsweise als Synonym zur wichtigen Geister-Kategorie der anak tā benutzt. Einige grū sprachen von ihren Geistern nur als pāramī. ${ }^{62}$ An der heutigen, synonymen Benutzung zu anak tā erkannten Bertrand (2004: 159), Forest (1992: 74-83) and Ang (1986: 218-222) eine Form der 'Buddhisierung' der animistisch geltenden Ortsgeister brāy und anak tā (Kap. 5), auch wenn ich kritisch anmerken muss, dass die Benutzung der Begriffe keine Rückschlüsse auf die religiöse Ausrichtung der Medien geben kann, da auch ,brahmanistisch ausgerichtete ' grü ihre Geister als pāramī bezeichneten.

Wie das Beispiel eines von mir besuchten Klosters verdeutlicht, kann pāramī folgende Bedeutungsebenen aufweisen: das Kloster gilt als Sitz von pāramī, was an Orten der Geister-Verehrung, wie Statuen und einem geschmückten Baum auf des Klostergelände deutlich wird. Auf Nachfragen bei Anwohner_innen betonen diese den fluiden Charakter dieser am ganzen Ort präsenten Wirkmacht, ohne auf spezifische Eigenschaften der Macht einzugehen. Ein Geistmedium in der Nähe des Klosters bereicherte mein Verständnis dieser Wirkmacht anschließend, indem es von der Kloster-pāramī besessen wurde und somit eine subjektivierte Repräsentation verkörperte, mit der direkte Kommunikation möglich war.

Auf den dividuellen Charakter der spirituellen Machtkonzepte und nichtmenschlichen Wesen verweist auch Sprenger unter Berücksichtigung zahlreicher südostasiatischer Geisterkonzeptionen:

"dependent on context, they [nicht-menschliche Wesen] variously appear as vaguely defined classes without discernible individuals, or as impersonal life-forces or potencies, while in others they emerge as communicative, well-defined, albeit graded persons" (Sprenger 2017: 110).

In der vorliegenden Arbeit verstehe ich pāramī als wohlwollende Macht, die sich in der kambodschanischen Geisterlandschaft sowohl als fluides Machtkonzept, als auch als individuelles Subjekt in Gestalt von Geistern präsentiert.

In der fluiden Form und angenommenen Wirkung unterscheidet pāramī sich grundlegend von der deterministisch geprägten Karma-Konzeption des Buddhismus. Diese Differenzierung soll im nächsten Abschnitt abschließend thematisiert werden, indem ich veranschauliche, dass sich die brahmanistische Praxis als prosperity religion an der Nachfrage von wirtschaftlichem Wachstum orientiert und durch diese Verbindung derzeit einen Aufschwung erlebt. Die Berücksichtigung der oben skizzierten ,Aufbruchsstimmung ${ }^{6}$ in der kambodschanischen Gesellschaft (Kap. 2.1.3) verhilft dabei zu einer kontextualisierten Sichtweise auf die Aktualität der brahmanistischen Wirkungsweise.

${ }^{62}$ Nach Guillou (2017c) wurde die Schreibweise für die individualisierte Macht eines einzelnen

Geistes in paramī geändert. Von ihrer Aussprache abgeleitet, benutzten und akzeptierten meine

Gesprächspartner_innen beide Formen, ohne auf spezifische Unterschiede hinzuweisen. 


\subsection{3 „Wenn wir nur dem Buddhismus folgen, werden wir nie reich werden“}

Historische Unterschiede in der Betonung der einzelnen Elemente des kambodschanischen Buddhismus sind kein neues Phänomen. Der Brahmanismus stellte früher schon einen Referenzpunkt dar, der im Lauf der Geschichte, je nach Konfiguration der kambodschanischen Verhältnisse, mehr oder weniger betont wurde:

"Buddha and ghosts, prayers at the temple and invocations of spirits, monks and mediums are all part of the same religious culture and simply different aspects of which are called into play at different, appropriate times" (Ebihara 1968: 364; qitiert in: Davis 2015a: 223; Holt 2012: 16).

Den letzten Aspekt in Ebiharas Aussage aufgreifend, stelle ich die These auf, dass die Liberalisierung der Marktwirtschaft und die damit verbundene ,Aufbruchsstimmung' (Kap. 2.1) in der kambodschanischen Gesellschaft seit den frühen 1990er Jahren die Betonung der brahmanistischen Anteile des kambodschanischen Buddhismus begünstigt haben. Der Grund für diesen Anstieg sind die verschiedenen Bezugnahmen der religiösen Traditionen zur seit 20 Jahren wachsenden, liberal ausgerichteten Marktwirtschaft. Sie diktiert neue Arbeitsbedingungen, die weniger auf kommunale Landwirtschaft als auf individuelle Einkommensgenerierung ausgerichtet ist, was einerseits Aufstiegschancen und individuellen Ehrgeiz im kambodschanischen patronage-System fördert, aber auch Konkurrenzdenken und die Möglichkeiten von sozialem Abstieg begünstigt. Der Wunsch des sozialen Aufstiegs ist zwar dank des wirtschaftlichen Aufschwungs greifbarer, aber auch existentieller geworden.

Nach buddhistischer Lehre der Karma-Wechselwirkung ist eine gravierende Statusänderung erst nach dem Tod möglich; die Geistmedien und ihre brahmanistischen Praktiken dagegen bieten die Möglichkeit, das Schicksal von Einzelnen sofort (günstig) zu beeinflussen. Sie allein haben Zugang zu pāramī, abgesehen von einigen sogenannten magic monks, die dieselben Praktiken vollziehen. Den Zugang zu dieser Macht erlaube es den Klient_innen, so die grū, unmöglich scheinende Dinge wahr werden zu lassen, wie beispielsweise in absehbarer Zeit (das heißt, im derzeitigen Leben) reich zu werden - was die buddhistische KarmaKonzeption kaum in Aussicht zu stellen vermag.

Wie Jackson (2016, 2009, 1999a, 1999b) und andere (Pattana 2012, 2008; Klima 2004) zeigen, waren die brahmanistischen Praktiken der spirituellen Machterlangung auch Teil der Geistmedien-Praxis in Thailand, die insbesondere durch die gesellschaftliche Implementierung der kapitalistischen Marktwirtschaft an Bedeutung gewann. Auch in Vietnam werden analog dazu religiöse Bewegungen sichtbar, wie beispielsweise die Rituale der Muttergottheitsverehrung lên dông (Lauser 2018; Phạm 2009; Fjelstad und Nguyễn 2006). Parallel zur kambodschanischen Medialität suchen Klient_innen dabei vor allem in Geschäftsfragen Rat und Unterstützung (Salemink 2008: 155-159). Die spirituelle Unterstützung schafft Hoffnung auf materiellen Wohlstand und stellt, so wie in Kambodscha, die Hauptmo- 
tivation der Geisterverehrung dar, was die wachsende Popularität dieser Bewegung erklärt (Ngo 2009: 89; Salemink 2008: 153; Lauser 2008; Kwon 2007).

In Anlehnung an Webers Säkularisierungsthese einer fortschreitenden Rationalisierung der neuzeitlichen Gesellschaften spricht Jackson heute von einer südostasiatischen Moderne, die sich „verzauberter denn je“ 63 gestalte (vgl. Jackson und Brac de la Perrière i.E.). Die gesellschaftliche Bedeutung der Geister-Praxis wird auch von anderen Wissenschafter_innen der südostasiatischen Religionsforschung auf wirtschaftliche und politische Anliegen zurückgeführt (Endres und Lauser 2011; Willford und George 2005).

Ich argumentiere in dieser Arbeit, dass der kambodschanische Brahmanismus, der zeitgleich mit der Liberalisierung der Marktwirtschaft an Bedeutung gewann, die Form einer prosperity religion angenommen hat. Die enge Beziehung zwischen Ökonomie und Spiritualität wird daran deutlich, dass die Mehrheit der Klient_innen geschäfts- und karrierefördernden Anliegen vorbrachte (Kap. 6). Nachdem vor etwa 20 Jahren von einem Mangel an Geistmedien in ländlichen Gebieten berichtet wurde (Bertrand 2004: 158-159), erzählten mir sämtliche meiner Gesprächspartner_innen, dass es noch nie so viele grū gegeben hätte wie in der gegenwärtigen Zeit. Die überwältigende Mehrheit der von mir interviewten Medien (56 von 60) hatten ihre Arbeit erst in den letzten zehn Jahren aufgenommen. Fragte ich in ländlichen Gegenden nach einem grū in der Nähe, wussten die Angesprochenen in der Regel mehrere Adressen aus dem näheren Umfeld, was auf eine gravierende Präsenz von Geistmedien unter der Landbevölkerung (die etwa 80\% der Gesamtpopulation ausmacht) schließen lässt. Ich schlussfolgere daraus, dass die praxisbezogene Diesseitigkeit den Brahmanismus in oben dargelegter Form zu einer ,modernen' Erscheinung kambodschanischer Religiosität werden ließ und die derzeitige Epoche die Betonung der brahmanistischen Elemente des kambodschanischen Buddhismus begünstigt.

\subsection{Fazit}

In diesem Kapitel wurde deutlich, welche Ausprägungen der hybride kambodschanische Buddhismus in Verlauf der letzten Jahrzehnte angenommen hat. Zum Brahmanismus werden seit der Kolonialzeit Geisterpraktiken und die spirituelle Macht pāramı̄ gezählt. Die Wirkungsweise dieser Machtkonzeption lässt die Nachfrage nach magischer Hilfe in beruflicher und finanzieller Hinsicht in Korrelation mit dem wirtschaftlichen Aufschwung steigen. Der Buddhismus stellt das konzeptionelle und rituelle Rahmung für den Umgang mit dem Tod bereit und kann somit Antworten auf grundlegende Fragen vom eigenen Schicksal, einer möglichen Zukunft und einer nach moralischen Maßstäben ,richtiger' Lebensführung

63 "A World Ever More Enchanted: Modernity Makes Magic in 21st Century Southeast Asia", Vortrag von Peter A. Jackson, ICAS 10, Chiang Mai 2017. 
geben. Zentral dafür ist die oben beschriebene Karma-Wechselwirkung, die nicht nur Erklärungsmuster für die oben genannten Fragen liefert, sondern auch die Grundlage für soziale Hierarchien bildet.

Auffallend an den definitorischen Unterschieden zwischen den Religionen sind vor allem die gegensätzlichen Auffassungen der angenommenen Wirkung und ihrer moralischen Dimension. Wie in diesem Kapitelabschnitt beschrieben, wird die Wirkung brahmanistischer Rituale stärker auf die Gegenwart bezogen, während buddhistische Rituale zum Erzeugen von Verdienst durchgeführt werden, das in der Regel erst in späteren Leben eine Wirkung entfalten kann. Verdienst kann jedoch nur durch moralische Handlungen erzeugt werden, während die moralische Dimension der Praktiken mit pāramī direkt mit den Geistern ausgehandelt wird und gesellschaftlich weniger anerkannt wird. Diese Aufteilung wurde 2015 von der Landvertriebenen Tep Vanny auf den Punkt gebracht, die brahmanistische schädigende Rituale gegen Pächter ihres Lands durchführte und dazu kommentierte:

'When we do Buddhist rituals, we don't curse, we only sit still and do meditation, we wish in peaceful way. (...) But when we follow the Brahmanist way, we curse them and do different kinds of activity" (Jackson und Mao 2015).

Abhängig vom Geschick in der Aushandlung mit den Geistern bietet die brahmanistische Praxis jedoch nicht nur Hilfe bei derart moralisch fragwürdigen Anliegen (Kap. 9.5). Da sie öffentlich kaum kritisiert wird und die Medien es normalerweise verstehen, sich ausreichend buddhistisch und damit moralisch einwandfrei zu positionieren, wächst die Akzeptanz der brahmanistischen Praxis in der kambodschanischen Gesellschaft. Die Anfragen der Klient_innen basieren auf dem Verständnis, die Macht der Geister zum Ausbau des eigenen Einflussbereichs zu nutzen, um selbst handlungsfähiger und mächtiger zu werden. Somit stellen die Aneignungs- und Aushandlungsprozesse von Macht einen großen Teil der religiösen Praxis von Kambodschaner_innen dar.

In antizipatorischer Anwendung meines theoretischen Netzwerk-Ansatzes verstehe ich diese verschiedenen Machtkonzeptionen als Hauptreferenzpunkte der kambodschanischen Geisterlandschaft, die Beziehungen zwischen menschlichen und nicht-menschlichen Akteuren bündeln. Die prägenden Akteure in diesem Netzwerk sind die Geistmedien mit der Bereitstellung ihrer Körper, die ihren Geistern zu ihrer ,Existenz' (und Gestalt) verhelfen und ihnen damit helfen eine Beziehung zu Menschen herzustellen, über die nach lokaler Wahrnehmung Macht vermittelt wird. Diesen Verbindungen komme ich in den folgenden Kapiteln nach. Zur Vorbereitung auf die Untersuchung von Existenz und Nicht-Existenz von kambodschanischen Geistern (Kap. 4-5) stelle ich nun meine AkteurNetzwerk-inspirierte Sicht auf Geister, Geistmedien und Macht in Kambodscha vor. 



\section{Spiritscapes und die Existenzweisen von Geistern}

Zur Untersuchung der kambodschanischen Geister halte ich zwei theoretische Ansätze für zweckmäßig. Zum einen greife ich die Konzept-Metapher der Spiritscapes auf und stelle ihn als Bezugsrahmen meiner theoretischen Überlegungen vor. Zum anderen verknüpfe ich diesen Bezugsrahmen mit theoretischen Konzepten der Akteur-Netzwerk-Theorie (ANT).

Entsprechend dazu stelle ich im Folgenden zunächst meine theoretischen Überlegungen zu den Spiritscapes vor, wobei ich mich auf die Themen Migration, materieller Austausch und Zeitlichkeiten fokussiere (Kap. 3.1). Daran schließt sich die Entwicklung einiger Aspekte zur Untersuchung von Geister-Existenz an, mit der ich die beiden theoretischen Fragestellungen nach der Existenz und NichtExistenz von Geistern und nach der spirituell geprägten Konzeption und Aushandlung von Macht in Kambodscha bearbeite. Zunächst gehe ich auf die Debatten über die ANT und der, ontologischen Wende' ein (Kap. 3.2), um darauf aufbauend meinen Ansatz zwischen radikalem Realismus und symmetrischer Anthropologie zu verorten (Kap. 3.3). Meine Methodik veranschauliche ich anhand der Inszenierung von Geister-Existenz während eines Besuchs bei kambodschanischen Geistmedien. Daran zeigt sich bereits, dass es unterschiedlich ,stabil' ${ }^{\complement}$ erhaltene Existenzformen von Geistern gibt, die ich im nachfolgenden Abschnitt (Kap. 3.4) in den Mittelpunkt meiner Analysen stelle. Hier veranschauliche ich 
Teil I: Thematischer Kontext und Methodik

anhand von zwei Beispielen, Pol Pot und dem neu entstandenen Geist tā Noël, das ,Erscheinen', beziehungsweise ,Verschwinden“ von Geistern aufgrund unterschiedlich stabiler Existenzbedingungen.

\subsection{Spiritscapes - die kambodschanische Geisterlandschaft}

Zur Untersuchung von globalen Modernisierungsprozessen führt Arjun Appadurai fünf -scapes ein, in Anlehnung an die vielfältigen Perspektiven und Orte einer ,Landschaft' (landscape): ethnoscapes, mediascapes, technoscapes, financescapes, und ideoscapes (1996). Als Leitmotiv der -scapes formuliert Appadurai das Vorhaben, den Austausch und die Überschneidungen der fünf -scapes zu untersuchen (1996: 33). Damit schafft er neue Denkmodelle für die Erforschung globaler Prozesse, da alte Aufteilungen zwischen Zentrum und Peripherie oder Nation und Verwandtschaft ihm in der heutigen Zeit wachsender Mobilität nicht mehr angemessen erscheinen. In Erweiterung von Andersons imagined communities (1991) spricht Appadurai von imagined worlds, die nicht nur Teil einer anderen, offiziellen Institution sind (wie z.B. eines Staates) sondern darüber hinaus so wirksam agieren, dass sie mächtige Bezugsrahmen bilden, die kollektiv in dynamischem und globalem Austausch verhandelt und, gestaltet' werden. Weltweiter kultureller und materieller Austausch sowie Migration beförderten diese Konstruktion, in der die imaginierten Welten als Orientierung der realen Leben von Menschen dienen.

In Anlehnung an dieses gedankliche Modell, erweitern Lauser und Endres Appadurais Konzeption um die Metapher der Spiritscapes (2011). In diesem Sinne betont Spiritscapes die Dynamik der Geisterwelt und hilft dabei, die vielfältigen verschiedenen Orte, an denen ,Geisterlandschaften' sichtbar und erfahrbar werden, als vitalen Raum wahrzunehmen, der kulturelle, politische, öknomische und historische Komponenten aufweist und in dem Geister in Beziehung zu menschlichen oder nicht-menschlichen Akteuren treten. Die kambodschanischen Spiritscapes manifestieren sich in zwei lokal verankerten, imaginierten Welten'. Damit ist sowohl die ,obere Welt' (thān suok) als auch die ,untere Welt' (thān norok) gemeint, in denen kambodschanische Geister im Gegensatz zur Menschenwelt (thān manuss) ausschließlich ,unter sich' agieren. Diese imaginierten Welten sind jedoch von einem regen Austausch zu Menschen geprägt, wo „competing and even contradictory emplacements and temporalities” (Brambilla 2014: 22) interagieren. Diese performativen Aushandlungen mit Geistern bilden den konzeptionellen Analyserahmen dieser Arbeit. Drei Kennzeichen dieser Interaktion werde ich dabei besondere Aufmerksamkeit beimessen: Ähnlich wie die wachsende Mobilität der Menschen und damit verbundenen Migrationsbewegungen zu einer Deterritorialisierung (Appadurai 1996: 37-39) führen, ,migrieren' Geister beständig zwischen verschiedenen Welten. Die Mobilität der Geister kann einen Wandel ihres ontolo- 
gischen Status beinhalten, was an verbreiteten Narrationen deutlich wird, in denen beispielsweise als Lichtkugel konzipierte Geister in menschliche Körper schlüpfen und mit/in diesen agieren. Es findet zudem eine beständige Verwandlung von Menschen zu Geistern und wieder zu Menschen statt, die durch Tod und Wiedergeburt bestimmt werden, wenn beispielsweise Totengeister aus der ,unteren Welt ${ }^{6}$ als Menschen wiedergeboren werden. Diese dynamischen Migrationsprozesse zwischen verschiedenen imaginierten Welten und ihrem ontologischem Status führen zu einer ,relativen Deterritorialisierung' (Deleuze und Guattari 2004: 911). ${ }^{64}$

Die Deterritorialisierung der Geister führt gleichzeitig zu einer Reterritorialisierung der Menschen. Die bedeutendsten kambodschanischen Geister sind Ortsgeister, die aus der oberen Welt migrierten, um ein bestimmtes Gebiet in der menschlichen Welt (thān manuss) zu beschützen. Die (in einigen Situationen als obligatorisch angenommene) Verehrung der Ortsgeister stellt einen Bezug zu jener Region und ihren spirituellen Orten dar. Der Landschaftsmetapher wird dabei eine wörtliche Bedeutung beigemessen, denn einige Geister werden als Teil der physischen Landschaft verstanden; so zeigen Beispiele wie der Erdgeist Krung Bali oder die Göttin des Meeres (Kap. 5.2), wie auch diese Landschaften im Sinne der scapes ständig neu ,erschaffen' werden.

"The landscape is 'the land 'scaped', 'shaped' or created as place and polity by people through their practices of dwelling - their 'doing', 'undoing', and 'redoing' of landscape" (Brambilla 2014: 23).

Zweitens legt meine Interpretation der Spiritscapes einen Fokus auf die tragende Bedeutung des (materiellen) Austausches zwischen der Geister- und der Menschenwelt. Den Transfer von Waren und Geld innerhalb und zwischen den scapes bezeichnet Appadurai als global flows. In der spirituellen Praxis Kambodschas wird zwar auch global getauscht, wichtiger ist jedoch die Frage nach der Art von Gaben und ihren erhofften Erwiderungen. Geisterverehrung ist von einem Tausch von spiritueller Macht gegen Opfergaben geprägt. Zur Erforschung dieser Interaktion setze ich die Methode der symmetrischen Anthropologie (Latour 1993) ein, die auch nicht-menschliche ,Objekte' des Tausches wie Geistern, Waren und spiritueller Macht einen Akteursstatus zuspricht, wenn diese als eine „Quelle von Aktion“ (Latour 2005: 137) interpretiert werden können. Somit können, unter Berücksichtigung nicht-menschlicher und nicht-materieller Gaben, die vielfältigen Tauschbeziehungen adäquat erfasst werden.

Ein weiteres Merkmal der kambodschanischen Spiritscapes ist ihre Eigenschaft, verschiedene Zeitlichkeiten an einem Ort zu vereinen. Damit sind zeitliche Referenzen gemeint, die spezifische Bedeutungen transportieren, wie beispielsweise der ,Brahmanismus'. Er wird einer vor-buddhistische Ära zugeschrieben, in der

${ }^{64}$ Hier muss jedoch klargestellt werden, dass Macht für Deleuze und Guattari, im Gegensatz zu meiner Benutzung davon, stets immanent (und niemals transzendent) verstanden wird. 
mächtige Herrscher in Verbindung mit Geistern gestanden haben sollen. Laut Geistmedien diene ihre rituelle Praxis als verbindendes Element zur brahmanistischen Zeit der Geisterverehrung, da sie den damaligen Geistern zur Rückkehr auf die Erde behilflich seien und nun die spirituelle Macht der spirituellen Würdenträger des damaligen Khmer-Großreichs vermittelten.

Wesentlich kürzer zurückliegende Zeiten wurden mit der rituellen Praxis mit Totengeistern re-inszeniert. Ihre Rückkehr zur Menschenwelt kann eine Begegnung mit der eigenen Vergangenheit oder der der Elterngeneration bedeuten auch wenn ich zeigen werde, dass die buddhistische Prägung des Austausches mit den Toten wenig Raum für die Rückholung der Vergangenheit lässt (was zudem bedeutsam für die Rolle der gesellschaftlichen Verarbeitung der humanitären Krise Kambodschas ist, siehe Kap. 4). Somit werden spezifische Zeitlichkeiten durch die Migration zwischen den imaginierten Welten vereint, womit ich in der von mir untersuchten Fallstudie an Diskurse von Zeitlichkeit (bzw. temporalities) anknüpfe, die von der Vorstellung verschiedener Zeitebenen charakterisiert werden. Eisenlohr vertritt am Beispiel von Pilgerreisen die Auffassung zweier Zeitlichkeiten (2004); einerseits der linearen, leeren' in Anlehnung an Anderson (1991) und andererseits der ancestral time, die er von Benjamins Konzept der „messianischen Zeit" (2017) ableitet, und die, so wie in kambodschanischen Besessenheitsritualen, vergangene Zeiten, vergegenwärtigt'. Diese Ebenen werden nach Eisenlohr durch linguistische und semantische Praktiken verbunden, worauf ich in Kapitel 5.2 nochmals eingehen werde. Allgemein ist ein wesentliches Merkmal der kambodschanischen Spiritscapes die mediale Praxis, die als ein Vergegenwärtigungsmoment einer „Zeit zwischen den Zeiten“ (Bräunlein 2010: 458) in Analogie zu Turners Zustand des in-betwixt-Seins verstanden werden kann (1967: 93-111).

Diese drei Merkmale der Spiritscapes mit ihren ,Migrationsbewegungen', ihrem Austausch von Gaben und Erwiderungen und ihrer räumlichen Inszenierung verschiedener Zeitlichkeiten, unterstützen die Analyse der Aushandlung und Aneignung von Macht, indem sie meine Analyse der Geisterlandschaft während der Forschung und Analyse bereicherte und meinen Blick für wesentliche Merkmale der Geister-Praxis schärfte. In den folgenden Kapiteln werden Orte der Geisterlandschaft vorgestellt, in denen diese Prozesse anhand ihrer verschiedenen Ausprägungen demonstriert werden. Mit Blick auf die individuellen Aneignungs- und Aushandlungsprozesse bediene ich mich dabei einiger Elemente der AkteurNetzwerk-Theorie (ANT). Mein Motiv dieser Adaption ist von der Frage nach den Existenzbedingungen der kambodschanischen Geister bestimmt. Mit ihrer Beschreibung werden individuelle Aspekte schematisiert und die Interaktionen zwischen Akteuren der Spiritscapes und Menschen en détail analysiert. 


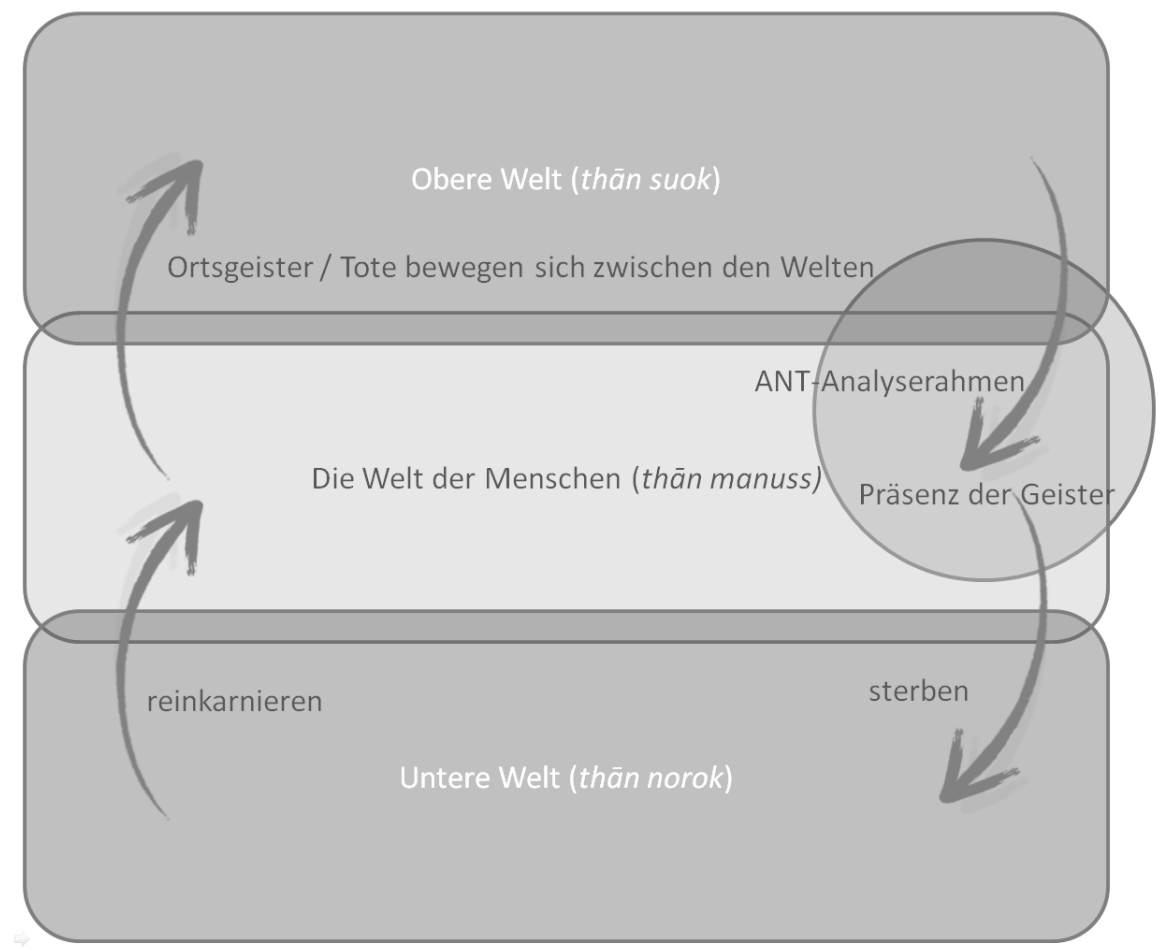

Abb. 5: (C) Autor. Die Spiritscapes (grau) als großer und die ANT (Kreis) als kleiner Analyserabmen dieser Arbeit.

Wie auf Abb. 5 zu erkennen ist, bilden die Spiritscapes den übergeordneten Bezugsrahmen dieser Arbeit, der sich aus oberer Welt und unterer Welt zusammensetzt und mannigfaltige Formen der Interaktion mit der Welt der Menschen aufweist (zum Beispiel in Ritualen der Geistbesessenheit). Um diese spezifische Assoziation zwischen Mensch und Geist und ihren Aushandlungen von Macht und Materie gerecht zu werden, benutze ich die ANT als ,Brennglas' auf verschiedene Konstellationen aus transzendenten und immanenten Akteuren und Aktanten, die performativ in ihren einzigartigen Formen existieren. Sie offenbaren dabei ein Muster von Existenzbedingungen, das weitere Analysen von Geistererscheinungen erkenntnisreich auszuwerten erlaubt. 


\subsection{Aktuelle Debatten zur Untersuchung von Geister- Existenz}

Meine theoretischen Überlegungen zur Untersuchung von Existenzbedingungen sind von Debatten inspiriert, die nicht nur auf Bruno Latour zurückzuführen sind. Latour definierte - wie andere Vertreter_innen der Wissenschaftsforschung (Science and Technology Studies oder STS) - am Ende der 1980er Jahre die Trennung zwischen Natur und Kultur als ureigenes Merkmal seines Untersuchungsgegenstands ,(westliche) Wissenschaft‘ (Latour 1990, 1987). Während der Wissensproduktion in Laboren der Universitäten wurde die allgegenwärtige Trennung zwischen Natur und Kultur und zwischen Objekten und Subjekten besonders deutlich, die seit der Aufklärung in Europa als ,wissenschaftlich' gilt, da sich ein ,Fakt ${ }^{`}$ dadurch auszeichnet, dass er frei von Subjektivität ist und allem, was allgemeinhin der ,Kultur ${ }^{6}$ zugesprochen wird. Damit die Ergebnisse der Wissenschaft diese Merkmale aufweisen, müssten sie nach Latour in den Laboren von jener Subjektivität ,gereinigt' werden (purification). Dieses ,Reinigen“ von Daten und Sachverhalten bezeichnet Latour als grundlegendes Prinzip der westlichen Moderne (1993) und als inadäquate Praxis heutiger Forschung, da auch die Prozesse der akademischen Wissensproduktion und ihre Ergebnisse sozial konstruiert seien und - nach seiner Interpretation - in verschieden ,stabil ${ }^{`}$ ausgeprägten Netzwerken von Akteuren beruhten.

Heute wird in vielen Wissenschaftsbereichen die Frage nach gängigen Trennungen zwischen Ontologie/Epistemologie, Subjekt/Objekt, Natur/Kultur, Körper/Seele und nicht-menschlichen/menschlichen Akteuren neu diskutiert. Es wird diesbezüglich auch von einem ontological turn gesprochen (Pedersen 2012). ${ }^{65}$ Inspiriert von der einflussreichen Beschreibung der „Ontologie der Ojibwa“ von Hallowell (1960) und der wissenschaftstheoretischen Analysen Latours werden kontextgebundene Ontologien beschrieben, die Geister als Teil der Realität (und nicht als Repräsentation, Symbol oder auf Glauben beruhend) einschlossen (Descola 1996; Viveiros de Castro 1992).

Dies war ein provokanter Schritt in der Fachgeschichte der Ethnologie, die ihren letzten großen turn (die interpretative Wende) mit der Beschreibung verschiedener Interpretationen einer Realität vorgenommen hatte. Viveiros de Castro definierte in Anlehnung an den ,Multi-Kulturalismus' den Begriff des ,MultiNaturalismus' (Viveiros de Castro 1998). Seine Gesprächspartner_innen im Amazonasgebiet konzipieren ihr Leben mit einer Kultur (eines allen Lebewesen innewohnenden Geistes) in vielen Naturen (verschiedenen Welten und Körpern); wodurch er schlussfolgerte, dass es nach ihrer Weltanschauung eine Epistemologie und viele Ontologien geben musste. De Castro berief sich auf philosophische Ansätze des Perspektivismus, der einen Perspektivenwechsel außerhalb einer ein-

65 Obgleich dieser Begriff mitsamt seines Anspruchs, eine neue Denkrichtung der Ethnologie zu prägen, umstritten ist (vgl. Münzel 2017; Carrithers et al. 2010). 
zigen, westlichen Ontologie und den oben genannten Trennungen umsetzt (Viveiros de Castro 2015). Demnach haben alle menschlichen und nichtmenschlichen Akteure eine eigene, determinierende Perspektive auf die Welt (Schmidt und Huskinson 2010: 12-13). Geister könnten somit nicht zum Bereich der Kultur gezählt werden, da ihnen damit implizit die ontologische Existenz abgesprochen würde (Viveiros de Castro 2015). Im Zuge dieser ontological turnDebatte wurden zahlreiche neue wissenschaftliche Konzepte vorgestellt, wie das der relational epistemology (Bird-David und Naveh 2008; Bird-David 1999) oder der relational ontology (Benjamin 2015; Aspers 2010).

Latour beobachtete diese Debatten mit Interesse (Latour 2009), auch wenn seine ANT viele Erkenntnisse der neuernannten ,Perspektivist_innen“ bereits beinhaltete, wie beispielsweise seinen Fokus auf Netzwerke von Beziehungen (relations) die die klassischen Dichotomien von Kultur/Natur oder von Körper/Geist aufweichten; die er jedoch im Gegensatz zu den ontologischen Debatten von Beginn an weniger starr (nicht als Ontologie) kategorisiert (Lezaun 2014). ${ }^{66}$ Latours Fokus auf performativ geschaffene und nicht beständige Beziehungen halten mehr Freiräume von Zwischenstadien der Existenz offen. Die Offenheit seines Ansatzes bringt er folgendermaßen auf den Punkt: „ANT is simply the social theory that has made the decision to follow the natives, no matter which metaphysical imbroglios they lead us into" (2005: 62). Gemäß dieser Einstellung definierte er später Existenzbedingungen (Latour 2014), die der Konzeption der, Ontologien` zwar ähneln, aber unvollständiger, verwobener und unbeständiger gedacht werden.

\subsection{Die ANT - Radikaler Realismus und Symmetrische Anthropologie}

Ohne einem dieser Ansätze bedingungslos Folge zu leisten, habe ich mich von diesen Debatten insofern inspirieren lassen, dass auch ich die Beziehungen (,Relationen') zwischen Subjekten in den Fokus der Betrachtung stelle und die oben genannten Trennungen von Ontologie/Epistemologie, Subjekt/Objekt, Natur/Kultur und nicht-menschlichen/menschlichen Akteuren durch diese Methodik überbrücke (Bond und Bessire 2014).

Einige Ideen dieser ontologischen Wende kombiniere ich mit Konzepten der frühen Arbeiten Latours, wonach ich beispielsweise Beziehungen als ,Referenzen“ und Subjekte als ,Akteure' verstehe. Nach der von ihm vertretenden AkteurNetzwerk-Theorie, die seiner Richtigstellung nach eigentlich eine Methodik darstellt (Latour 1999a), finden sich in allen Objekten oder sogenannten, objektiven Fakten' das Subjektive und Soziale wieder. Daher fordert er, während der For-

66 " $[T]$ hese classifications [by Descola] tend to bring back the very rigidity and closure of analysis that the first approach [by Latour, Ingold] aims to break away from" (Sprenger 2017: 109). 
Teil I: Thematischer Kontext und Methodik

schungspraxis menschlichen oder nicht-menschlichen Akteuren gleichgroße Aufmerksamkeit zu schenken, was er ,symmetrische Anthropologie nennt (Latour 1993). Die Symmetrie besteht demnach darin, alle relevanten ,Akteure' eines Forschungsfeldes gleichberechtigt zu untersuchen und im Zuge eines, radikalen Realismus' nicht von subjektiven Einflüssen zu ,reinigen'. Für meinen Ansatz zur Untersuchung der Existenzbedingungen der kambodschanischen Geister greife ich auf folgende Konzepte der Akteur-Netzwerk Theorie zurück:

\subsubsection{Akteur, Aktant}

Latour sieht auch in nicht-menschlichen Akteuren das Potenzial ,in Aktion zu treten' und spricht ihnen damit die passive Natur des Objektstatus ab. Diskurse, Ideen, Ereignisse, Institutionen, Mikroben, Dinge (und, wie ich zeigen werde, auch Geister) haben nach Latours Akteur-Konzept die gleiche ontologische Basis; das heißt, alle Akteure teilen das gleiche Potential zu existieren. Im Zusammenspiel mit anderen Akteuren können Menschen und Nicht-Menschen ,agieren', sobald sie eine „Quelle von Aktion“ (Latour 2005: 137) darstellen. Es sei ein Akt der oben beschriebenen ,Reinigung,, ihnen diesen Handlungsspielraum abzustreiten und nur Menschen zuzusprechen. Ein einzelner Akteur hat nach Latours Theorie noch keine Existenz, denn ihnen wird erst durch ihre Beziehungen (,Referenzen', siehe unten) zu anderen Akteuren zu einer Existenzform (mode of existence) verholfen. Konstellationen von Akteuren, die im Zusammenspiel gegenseiter Verbindungen stehen, nennt Latour „Aktanten“. Geistmedien stellen beispielsweise Aktanten dar, die aus den Akteuren des menschlichen Mediums und des nichtmenschlichen Geistes bestehen. Dieser Aktant ist mit zahlreichen weiteren Akteuren und Aktanten verbunden, wie beispielsweise den Opfergaben, den Klient_innen, einigen Erzählungen über den Geist, dem Schrein, und vielen mehr.

\subsubsection{Das Netzwerk}

Ein Netzwerk ist eine Ansammlung von Akteuren in gegenseitigen Beziehungen. Um einen Geist-Akteur zu verorten, um seine Existenzweise (beziehungsweise -bedingungen) zu untersuchen, gehe ich (den relevanten) Verbindungen im Netzwerk des Geistes nach und betrachte diese analytisch. Im Netzwerk können alle oben definierten Akteure vorkommen. Es überbrückt damit gängige wissenschaftliche Dichotomien von Subjekt/Objekt oder der Mikro-/Makro-Perspektive, denn je nach Untersuchungsgegenstand kann es weitreichende oder kleine Netzwerke geben.

Wichtig hierfür sind zwei Aspekte: es werden in Beschreibungen der AkteurNetzwerk-Methodik alle relevanten Akteure eines Netzwerkes beschrieben. Natürlich haben die Akteure darin unendlich viele Beziehungen zu anderen Akteuren, doch für eine Beschreibung werden nur die berücksichtigt, die an der für die Fragestellung des Forschungsprojekts wichtigen Konstellation beteiligt sind. Zudem 
muss Latours performative Sicht auf die Entstehung von Netzwerken beachtet werden: Netzwerke sind von sich aus unbeständig (der Begriff des Netzwerks ist auch für Latour irreführend statisch, siehe Latour 1999a), sie werden erst durch konstituierende Referenzen erhalten (Elder-Vass 2014: 104-110; Harman 2009: 161; Belliger und Krieger 2006: 38-45).

\subsubsection{Referenz}

Den von Latour geprägten Begriff der „zirkulierenden Referenz“ (1999b) vereinfache ich im Sinne der vorliegenden Arbeit etwas. Grundlegend für das Verständnis der Referenzen in dieser Arbeit ist die Annahme, dass miteinander verbundene Akteure Eigenschaften oder generelle Existenz nur durch ihre Referenzen erhalten (Law 2007: 2). Bedeutung wird situativ anhand dieser Beziehung zugeschrieben; nichts hat ,objektiv' Bedeutung. Referenzen sind demnach maßgeblich für die Existenz eines Akteurs verantwortlich. Je mehr Referenzen ein Aktant eingeht, desto stabiler und ,realer' wird er für andere Akteure.

Dies stellt ein wichtiges Fundament für die Beschreibung von Geistern in den folgenden Abschnitten dar: Solange der Akteur durch seine Referenzen zu anderen Akteuren in seiner Existenz bestätigt wird, gilt seine Existenz als stabil. Latour wird wegen dieses Fokus auf die Verbindungen zwischen Akteuren zu Recht als „Relationist“ bezeichnet (Harman 2009: 75), was durchaus im wörtlichen Sinne gemeint ist. Aber im Gegensatz zum Relativismus, in dessen Nähe Latour oftmals gebracht wird (Sokal 1997), gibt es für Latour eine Realität; jedoch nicht außerhalb von Referenzen. Stabile Akteure haben einzigartige Referenzen, die sie eindeutig als solche identifizierbar machen, solange sie immer wieder neu erschaffen werden. Somit sind die Referenzen die wichtigsten Elemente, die eine Antwort auf die Frage der Existenz von Geistern geben können. Ich gehe in den folgenden Abschnitten der Frage nach, welche Referenzen den kambodschanischen Geistern zu ihrer Existenz verhelfen.

In einem Beispiel veranschauliche ich nun den Prozess des Referierens. Dabei wird deutlich, dass die Stabilität, beziehungsweise Fragilität der Referenzen zwischen den Akteuren entscheidend für die Existenz der Akteure ist.

Latour hat den Prozess der Entstehung von wissenschaftlichen Fakten mehrfach en détail dargelegt, am anschaulichsten in einer wissenschaftsethnologischen Studie im Amazonasgebiet (Latour 1999b: 24-79). Mit Hilfe qualitativer Forschungsmethoden vollzog er die einzelnen Arbeits- und Denkschritte von Bodenkundler_innen nach: die Entnahme von Bodenproben, der Zuordnung der Proben zu Farbcodes anhand von Farbskalen, die Erstellung von Diagrammen, die Diskussion der Ergebnisse und die gemeinsame Publikation. Der wissenschaftliche Artikel der Bodenkundler_innen stellte schlussendlich einen sprachlichen Verweis auf die Welt dar, der trotz zahlreicher Transformationen noch auf den Boden des erforschten Amazonas-Gebietes, referiert'. Erst duruch die Rückverfolgbarkeit der Referenzen wird die Kette der Referenzen stabil und existent. Ge- 
Teil I: Thematischer Kontext und Methodik

nauso schnell kann die Existenz dieser hier geschaffenen, wissenschaftlichen Fakten jedoch geschwächt werden, beispielsweise durch neue wissenschaftliche Ergebnisse, die eine andere Erklärung für die gleichen Phänomene liefern. Alle nachfolgenden Publikationen, die den veröffentlichten Artikel der Bodenkundler_innen zitieren, verweisen damit also auf ein darin kondensiertes Netzwerk von Akteuren von Menschen, Technologien, Bodenproben, Regenwürmern und vielen mehr, die diesem Artikel zur seiner Existenz verholfen haben.

Für meine Frage nach der Existenz von Geistern bedeutet dies, dass nicht nur die Anzahl der Referenzen, sondern auch die Stabilität der Referenzen zwischen allen assoziierten Akteuren ihres Netzwerks darüber entscheidet, wie widerspruchsfrei die Existenz der Geister eingeschätzt wird - und sie somit ein wichtiges Kriterium für meine Untersuchung bildet.

\subsubsection{Existenz}

,Real' oder ,existent' sind Akteure nicht per se, und auch andere Akteure haben streng genommen keinen Anteil daran. Es sind die Verbindungen (oder Referenzen) zwischen Akteuren, die etwas Neues, Reales erschaffen (Latour 1991). Latour vertritt somit die Annahme der in einzelnen sozialen Situationen geborenen Realität (Latour 2013a; Tresch 2013, 2013: 303).

In seinem Werk „The Modes of Existence“ (2013a) hat Latour die oben vorgestellte ,Referenz' als einen Existenzmodus neben dreizehn anderen konzipiert, die in seinem Buch von einer fiktiven Forscherin in der westlichen Gesellschaft der ,Modernen“ (Menschen) entdeckt werden. Es gibt in „Modes of Existence“, was in anderen Werken Latours schon angedeutet wurde (Latour 2010, 2013b), einen religiösen Existenzmodus, den er mit [REL] ${ }^{67}$ abkürzt. Ich zeige in dieser Arbeit, dass dieser Modus auch Geister mit einschließen kann. Latour spricht hierbei von ,religiösen Wesen' und bezieht sich in seiner mitunter stark eurozentrischen Sicht und als bekennender Katholik dabei offensichtlich auf Engel.

\section{„Bei den religiösen Wesen wie bei den psychischen Wesen oder denen der Fiktion besteht die Gefahr, den Faden der Gründe zu verlieren, indem man zu schnell ak.zeptiert, sie für ,irrational" zu halten" (Latour 2013a: 424).}

Diesem Ansatz folgend, betrachtet Latour „religiöse Wesen“ als nichtmenschliche Akteure. Sie bilden eine eigene Existenzweise, die von einer eigenen Rationalität getragen wird. [REL] definiert sich durch die Abhängigkeit von

\footnotetext{
${ }^{67}$ „Der Existenzmodus [REL] bezieht sich nicht auf die institutionalisierte Religion und auch nicht auf Religion als übergeordnete Bezeichnung eines Netzwerkes von Akteuren, sondern auf den speziellen Modus der Übersetzung von allen Akteuren, die mit dem Adverb, religiös ‘ verbunden werden. Diese Betrachtung erlaubt es, einige Bedeutungen zu verstehen, die von der institutionalisierten Religion vertreten werden." (Übersetzung des Autors der Definition von [REL], zu finden auf Latours Internet-Projekt modesofexistence.org unter http://modesofexistence.org/crossings//\#/en/rel, letzter Zugriff: 24.04.2019).
} 
menschlichen Erfahrungen: „Und wir wissen (...), dass es in dieser Haltung keinerlei ontologische Laxheit gibt, sondern den einfachen Respekt vor der Pluralität der Erfahrung“ (ebd. 426).

Es macht somit keinen Unterschied, ob wissenschaftliche Messinstrumente oder Menschen die Existenz von Geistern bestätigen. Interessant ist vielmehr, wie sie es tun und an welche Bedingungen diese Existenz geknüpft ist. Sobald in einem sozialen Kontext Akteure die Existenz von Geistern für real halten, können Geister existieren. Sind Zweifel darüber im Umlauf, existieren sie weniger stabil und befinden sich in Aushandlungsprozessen. Gibt es wenige oder keine Akteure, die auf Geister referieren, ist die Existenz schwach oder nichtig. Für mein Forschungsvorhaben gilt es daher, die Aushandlung zwischen Existenz und NichtExistenz von Geistern, und damit die Bedingungen ihrer Existenz zu untersuchen.

Ein Beispiel dafür bietet Latour, in dem er die Zweifler_innen an der Existenz der religiösen Wesen zu Wort kommen lässt, die das scheinbar sporadische Auftauchen und Verschwinden der religiösen Wesen in der menschlichen Erfahrung als Beweis ihrer Nichtexistenz anführen. Latour sieht darin keinen Beweis der Nicht-Existenz, sondern lediglich ein definitorisches Merkmal des Existenzmodus [REL].

„Im übrigen hat man sich auf dieses zeitweilige Aussetzen gestützt, um sich über sie zu
mokieren und darin den Beweis ihres Mangels an Sein zu sehen, ihres phantombaften
und illusorischen Charakters - diese Gelegenheit ließ der kritische Geist sich nicht entge-
hen. Doch der ganze Vorteil einer Untersuchung über Existenzmodi besteht im Gegen-
teil darin, dieses Merkmal ins Anforderungsprofil einschließen zu können: Eines ihrer
Charakteristika ist, daß man ihr Erscheinen und ihr Verschwinden nicht beherrschen
kann"(ebd. 426-7, Hervorhebung im Original).

An diesen Zitaten wird Latours Vorstellung des von ihm proklamierten ,Realismus' (Latour 1999b) deutlich: er untersucht die Dinge, Erfahrungen, Diskurse genauso, wie sie auftreten; ohne auf dieser Grundlage über die Existenz dieser Akteure zu urteilen.

Doch es ist nicht der Existenzmodus [REL], den ich in dieser Arbeit untersuchen oder ,anwenden' möchte; dafür ist der Modus zu eng mit der Deutungshoheit der institutionalisierten Religion der von Latour untersuchten ,westlichen Moderne' assoziiert. Ich werde die individuellen Existenzmodi der kambodschanischen Geister beschreiben, die keine übergeordnete Institution aufweisen. Zudem ist das Besondere an vielen Geistmedien, dass sie das Erscheinen und Verschwinden ${ }^{68}$ der Geister sehr wohl steuern können. Mithilfe dieser Steuerung innerhalb der Rituale kann ich die ,religiösen Wesen' in Kambodscha wesentlich genauer in

\footnotetext{
${ }^{68}$ In den folgenden Kapiteln werde ich neben Erscheinen und Verschwinden auch Präsenz/Anwesenheit beziehungsweise Absenz/Abwesenheit benutzen, was immer eine epistemologische Zustands- oder Situationsbeschreibung darstellt und nicht synonym zu der ontologischen Unterscheidung von Existenz/Nicht-Existenz verstanden werden sollte.
} 
Teil I: Thematischer Kontext und Methodik

den Blick nehmen. Schließlich gilt ihre Existenz als viel weniger umstritten als die der Engel in Latours Beschreibung. In den meisten Fällen wurden Geister in Kambodscha als blackbox wahrgenommen; ein Konzept, das ich im Folgenden erläutere.

\subsubsection{Blackbox}

Während seiner Forschung zur akademischen Wissensproduktion (Latour 1999b; 1987; Latour und Woolgar 1986) fand Latour heraus, dass die meiste Zeit der Arbeit der Forscher_innen damit verbracht wird, ihre neu erschaffenen Daten oder Technologien in eine blackbox zu verwandeln, das heißt in einen besonders stabilen Aktanten, bei dem man die ihn konstituierenden Akteure und die mögliche Fragilität ihrer Referenzen vergisst und ihn als sogenannten ,Fakt' akzeptiert.

"These strategies help to create convergence by locking actors into the network. The more fixed or stable it appears, the more 'real' and durable it becomes, and the less controversy and ambiguity are evident. (...) The aim, then, is to put relations between actors into 'black boxes' where they become a matter of indifference - scientific 'facts', technical artifacts, modes of thought, habits, forces, objects" (Hardy et al. 2001: 538).

Die aus analytischer Perspektive als blackbox zu bezeichnenden Phänomene werden von einer Mehrheit von Menschen als selbstverständlich wahrgenommen. Mit der wissenschaftlichen Beschreibung ihrer Referenzen (der Öffnung der blackbox) sollen die konstituierenden Akteure sichtbar gemacht werden. Durch das Öffnen bestehender blackboxes werden die Prozesse und Anstrengungen sichtbar gemacht, die unternommen werden, um die Existenz von Geistern zu stabilisieren, was ich im Folgenden als blackboxing bezeichne. Wie sich in dieser Arbeit zeigen wird, sind Geister für fast alle Kambodschaner_innen blackboxes und alle Geistmedien betreiben blackboxing.

Meine Sichtweise auf Geister orientiert sich demnach an den theoretischen Ansätzen einer symmetrischen Anthropologie (Latour 1993), und eines radikalen Realismus. Das heißt, ich werde alle Akteure von Bedeutung einer beschriebenen Situation oder eines Prozesses beschreiben, ohne dabei die Symmetrie zwischen menschlichen und nicht-menschlichen Akteuren zu vernachlässigen. Ich stelle damit eine Form der Analyse vor, die wesentlich näher an das lokale Verständnis der Geister heranreicht als es streng funktionalistische, interpretative oder strukturalistische Herangehensweisen tun würden. Mit der detaillierten Beschreibung der lokalen Existenz von Geistern nehme ich zudem einen Perspektivenwechsel in Angriff und kehre damit zum ,orthodoxen Motiv' der Ethnologie zurück, wie Malinowski es auf den Punkt brachte: ,to grasp the native's point of view, his relation to life, to realize his vision of his world." (Malinowski 1922: 25; vgl.: Willerslev 2013: 42). Umsetzen werde ich dieses Vorhaben, indem ich Geister als das beschreibe, was sie in Kambodscha waren: aktive und soziale Wesen. Ich werde 
nicht nur hervorheben, dass sie für viele Kambodschaner_innen existent waren, sondern zeigen warum sie es waren und wie sie es wurden. Damit fälle ich kein Urteil, ob Geister existent oder nicht-existent sind, sondern zeige unter welchen Umständen sie in Kambodscha als existent wahrgenommen werden. Weiterhin wird in meinen folgenden Analysen deutlich, dass ich nicht nur horizontale Beziehungsgeflechte unter egalitären Akteuren untersuche, wie es Latour oftmals zum Vorwurf gemacht wird. Ich zeige dagegen deutlich, dass eine stabile Existenz unausweichlich zu einer hohen Wirkmacht und einem hohen wahrgenommenen Status des betreffenden Aktanten führt.

Anhand eines mit der oben vorgestellten Methodik untersuchten Beispiels eines durchschnittlichen Besuchs bei Geistmedien werde ich nun einige der existenz- und machtkonstituierenden Referenzen auf Geister in Kambodscha veranschaulichen.

\subsection{Die Konstituierung des Akteurs ,Geist' während eines Besuches bei Geistmedien}

Genau genommen stellt ein Schrein von Geistmedien ( $p \bar{a} y$ sī, gesprochen: ,beysey') die erste Referenz auf den Geist dar und ist damit ein konstituierender Akteur. Die Referenz ist von ihrer Zuweisung als Aufenthaltsort für Geister geprägt, was an den dort platzierten nicht-menschlichen Akteuren deutlich wird: Er bildet die materielle Erscheinungsform des Geistes. Dort werden die Geister verortet, während sie nicht in den Körpern der Medien weilen. Auf dem pāy sī stehen oftmals Artefakte wie Statuen, Steine, Packungen mit Räucherstäbchen und aus Palmenblättern gefertigte Schmuckelemente, die vor allem in einem (feierlichen) buddhistischen Kontext benutzt werden.

Ihr Akteurstatus zeigt sich beispielsweise an der üblichen Reaktion auf ihre Präsenz, die aus drei ehrerbietenden Verbeugungen auf den Knien besteht, die alle Besucher_innen vor dem pāy sì vollziehen. Dabei offenbaren sich an dieser Stelle wechselseitige Beziehungen zwischen den Akteuren Klient, Geist, und pāy sì. Ohne pāy sī wären keine Verbeugungen nötig, die der Klient über diesen Weg an den Geist richtet. Die Verbeugungen sind somit eine weitere existenzfördernde Referenz auf den Geist.

Die anwesenden Familienmitglieder, andere Klient_innen des Mediums oder das Medium selbst erhöhen in aller Regel vor dem Gespräch mit den neuen Klient_innen die Anzahl der Referenzen auf die anwesenden Geister, indem sie mit Erzählungen über die Macht der Geister Bezüge zu ihnen herstellen. Dies können beispielsweise Narrationen über prominente Klient_innen sein, die das Medium in der Vergangenheit schon besuchte - oder andere Geschichten über erfolgreiche Heilungen, Prognosen oder Segen werden erzählt. Weitere mögliche Nacherzählungen, die vor Beginn jedes Rituals reproduziert werden, sind das (gute) Verhält- 
nis des Mediums zu buddhistischen Akteuren, die (ausgeprägte) Moral des Geistes, die asketische, moralische Lebensweise des Mediums, die Einhaltung der sīla (Vorschriften des buddhistischen Mönchstums) durch das Medium, die hohe Stellung des Geistes in der Hierarchie zu anderen Geistern und die Anzahl der Geister, die das Medium zu kontaktieren fähig ist.

Mit diesen verbal geschaffenen Referenzen wird kontinuierlich ein Netz von Referenzen gesponnen, das auf die Präsenz und das Wirken des Geistes verweist noch bevor dieser in Erscheinung tritt. Zahlreiche grū praktizieren sogar gar keine Geistbesessenheit und können anhand dieser Referenzen trotzdem erfolgreich ihrer Arbeit nachgehen, da die Narrationen die Klient_innen bereits von der Präsenz der Geister von ihrem mächtigen Akteursstatus überzeugen.

Die Geistbesessenheit ist jedoch bei weitem die stärkste Referenz auf den Geist. Die Klient_innen sind damit von Beginn des Rituals an in der Lage, direkt mit Geistern zu reden und sich von ihrer Existenz zu überzeugen. Das Herbeirufen des Geistes wird mithilfe von Mantras ${ }^{69}$ eingeleitet, die, wie oben beschrieben, abhängig von der benutzten Sprache (Pāli oder, Geistersprache') Referenzen zum Buddhismus oder Brahmanismus herstellen, um religiöse Ambiguität abzuschwächen oder zweckmäßig zuzuspitzen.

Sobald ein Geist oder mehrere Geister in den Körper eines Mediums eingetreten sind, haben die Klient_innen Gelegenheit sich vorzustellen und ihr Anliegen vorzutragen. Die Geister treffen in dieser frühen Phase der Unterhaltung häufig Aussagen über die Lebensumstände der Klient_innen, die das menschliche Medium nicht wissen kann. Es handelt sich also um Wissen, aus dem die Klient_innen keine Verbindung zwischen Medium und beschriebenen Sachverhalt herstellen, sondern nur als eine verifizierte Verbindung zwischen dem (allwissendem) Geist und ihrem persönlichen Sachverhalt verstanden werden kann. Somit wird eine überzeugende Referenz auf die Macht (und damit die Existenz) des Geistes erzeugt. Anschließend folgt die verbale oder rituelle Reaktion der Geister auf die Anliegen der Klient_innen, wobei große Individualität in der Gestaltung und Ausübung der Rituale und der Schaffung von Authentizität herrscht (siehe Teil III, insbesondere Kap. 7).

Nach der Unterredung verlassen die Geister die Körper der Medien wieder, was meist durch eine kurze Meditation des Mediums angezeigt wird. Danach haben es die Klient_innen wieder nur mit der medial befähigten Person zu tun, der nicht mehr Respekt entgegengebracht wird als anderen Menschen. Besonders Klient_innen, die deutlich höher in der sozialen Hierarchie der kambodschani-

\footnotetext{
${ }^{69}$ Mantras werden in dieser Arbeit alle Sprechakte genannt, die in Pāli oder Khmer gesprochen und eindeutig dem buddhistischen Singen in der Pagode nachempfunden sind. Einige sind eindeutig als buddhistische Mantras erkennbar, wie das bei Medien und Mönchen verbreitete namasakāra, das zu Beginn jeder buddhistischen Zeremonie gesungen wird. Andere von manchen Geistmedien gesungene Mantras werden aus Pāli-Bruchstücken und anderen Sprachen oder Lauten improvisiert.
} 
schen Gesellschaft stehen als die Medien, sehen geringschätzig auf die grū herunter, was sich just im Moment der Geistbesessenheit ändert. ${ }^{70}$

Diese Diskrepanz zwischen niedrigem gesellschaftlichen Ansehen im Alltag und großer Autorität in der Situation der Geistbesessenheit prägt die Reputation der Geistmedien-Beschäftigung: Die Arbeit als Geistmedium wird nicht hoch angesehen; sie gilt eher als Bürde denn als Privileg und keinesfalls als eine Arbeit, die jemand freiwillig tun wollte (Kap. 6). Dieser geringe soziale Status der meisten gru ist wiederum eine starke Referenz auf den Handlungsspielraum des Geistes. Ein grū sagte zu mir: „Wenn die Geister sich nicht meinen Körper ausgesucht hätte, könnte ich ein normales Leben führen, mehr Geld verdienen und tanzen gehen“. Daher ist die Abneigung davor, ein Medium der Geister werden zu müssen, ein oft referiertes Motiv in den Initiations-Erzählungen der Geistmedien. Die Medien geben an, alles versucht zu haben, um ihrem Schicksal zu entkommen bis sie wegen gesundheitlicher Probleme (ausgelöst von Geistern) kurz vor dem Tod gestanden hätten. Dann erst erkannten sie die Existenz der Geister in ihrem Körper an und bauten ihre typische materielle Manifestation in Form eines Schreins $(p \bar{a} y, s \bar{l})$. Dieser Werdegang wurde von den Medien in sehr ähnlichem Ablauf erzählt. Somit erfahren die Klient_innen nicht nur, dass es (lebens-) gefährliche Konsequenzen haben konnte, Zweifel an der Existenz der Geister zu hegen. Sie haben es zudem mit einem Medium zu tun, das früher zweifelte und nun aus Erfahrung bestätigen konnte, dass die Existenz von Geistern ein gesicherter ,Fakt' sei.

Hieran wird deutlich, dass die Existenz der Geister auf vielen verschiedenen grundlegenden Referenzen zwischen Räumen, Dingen, Erzählungen, menschlichen Körpern und auch sozialen Zwängen beruht, die in ihrer Gesamtheit die Realität eines Geistes stärken. Die Existenz der Geister gilt in alltäglichen und öffentlichen Diskursen als stabil, weil zahlreiche menschliche und nichtmenschliche Akteure mit großer Überzeugungskraft auf die Geister referieren. So vernahm ich in meinen Gesprächen mit Kambodschaner_innen zwar Zweifel an einer hohen Wirkmacht einzelner Geister, aber nicht an ihrer Existenz.

Noch deutlicher zeigen sich die Existenzbedingungen jedoch an Beispielen von Geistern, deren Existenz fragil konzipiert ist. Diese Geister befinden sich in einem Prozess der Aushandlung; das bedeutet, ihr Netzwerk von Akteuren ist relativ klein, wenige Referenzen bestätigen ihr Dasein - ihre blackbox ist nicht ,geschlossen'. Im folgenden Abschnitt beschreibe ich die Aushandlung zweier Ortsgeister (anak tā), die sich während meiner Forschung im Prozess der Entstehung befanden.

\footnotetext{
${ }^{70}$ Zur Beziehung zwischen hochrangigen Klient_innen und Geistmedien, siehe Kap. 9.
} 


\subsection{Zwei Geister in Prozessen des Blackboxing}

\subsubsection{Ist Pol Pot ein Anak tā?}

Anak tā sind Geister von Personen, die nach Angaben der Geistmedien ( $g r \bar{u})$ vor etwa 200 und 1500 Jahren gelebt haben sollen (vgl. Kap. 5). Der weit zurückliegende Tod der, vergeistigten 'Persönlichkeiten wurde schon in frühen Veröffentlichungen als Merkmal von anak tā genannt (Porée-Maspéro 1962; Leclère 1899). Umso überraschender war es, auch Medien von anak tā kennenzulernen, die sich nicht auf eine lang vergangene Zeit des Heldentums bezogen. So traf ich die anak $t \bar{a}$ von Chuon Nath (dem 1969 gestorbenen und von den Reformbuddhist_innen gefeierten Patriarchen des Mohanikka-Ordens) und von Pol Pot, dem 1998 verstorbenen Machthaber zur Zeit des Demokratischen Kampuchea-Regimes. ${ }^{71}$ Als ich dann hörte, dass Pol Pot als Ortsgeist an seinem Grab in der Nähe von Anlung Veng in Nordwest-Kambodscha verehrt wird, bekam ich die Gelegenheit, einen anak tā im Prozess seines, Entstehens' zu dokumentieren. Kann es sein, dass ein im Jahr 1998 Gestorbener, jetzt schon' als anak tā verehrt wird? Wieso ausgerechnet der als Massenmörder bekannte ,Bruder Nummer Eins' der Roten Khmer?

Auf den Spuren von Pol Pot als anak tā, fuhren Bunnwath und ich mehrmals nach Anlung Veng. Von dort waren es nur wenige Kilometer zu Pol Pots Grab nördlich der Stadt im Dorf Choam ${ }^{72}$. Erste Gesprächspartner_innen reagierten gereizt auf meine Fragen nach Pol Pot und verweigerten jegliche Aussagen. Dies ist nicht weiter verwunderlich in Anbetracht der Tatsache, dass seit einigen Jahren westliche Tourist_innen und Journalist_innen das Gebiet um Anlung Veng aufsuchen, um zu beobachten, wie Kambodschaner_innen Opfergaben vor das Grab des ehemaligen Machthabers legen. Wenn die Zeitung „The Scotsman“ am 14.04.2008 titelte: „During Pol Pot's reign of terror $1.7 \mathrm{~m}$ died. Now locals pray at his grave“ (Stewart 2008), verweist sie auf die scheinbar paradoxe Kausalität einer (illegitimen) Verehrung eines Massenmörders, was jedoch die lokale Konzeption von Ortsgeistern ignoriert. Diese Kluft zwischen den beiden Vorstellungen von Pol Pot vor und nach seinem Tod lässt sich von verschiedenen religiösen Nachtodkonzeptionen ableiten. Die abwertenden Reaktionen der Journalist_innen und Besucher_innen des Grabs sind der christlich geprägten Vorstellung von dichotomen spirituellen Mächten geschuldet. Demnach könnte ,gute` Macht nur von ,guten Geistern` (also von Engeln oder Heiligen) ausgehen und eine ,böse ${ }^{\varsigma}$ Macht

\footnotetext{
${ }^{71} \mathrm{Zu}$ biographischen Informationen zu Pol Pot, siehe Chandler (1992).

72 Der Ort liegt in der Region Trapang Brai, im Distrikt Anlung Veng, Provinz Oddar Meanchey. Als weiteren Namen für den relativ neu gegründeten Ort direkt an der Grenze wurde auch der Name Phum Cherng Phnom benutzt.
} 
auch nur ,Böses ${ }^{6}$ hervorbringen (zum Bespiel vom Teufel). ${ }^{73}$ Verehrungswürdig wäre demnach ausschließlich die erstgenannte Macht.

Das kambodschanische Machtkonzept pāramī wird jedoch nicht nach moralischen Kriterien klassifiziert. Eine pāramī wird dort verortet, wo mächtige Persönlichkeiten mit großer Handlungsmacht und Entscheidungsgewalt starben. Pol Pot - als charismatische Person und ehemals mächtigster Mann Kambodschas - bildet demnach eine besonders mächtige pāramī, da er mit seiner Politik imstande gewesen war, in knapp vier Jahren hunderttausende Menschen töten zu lassen.

"In his lifetime, Pol Pot was a powerful man, who could order the murder of anyone he wanted. This power remains after his death and it is also associated with the place where he lived at the end of his life, and where he died. (...) Pol Pot remains powerful, although this power can be used in a positive or a negative way, just like that of the neak tā [anak tā]. He is believed to be able to help the living who come and pay tribute to him, but I assume that, on the contrary, he can harm those who are not respectful towards the place where his ashes have rested since his cremation" (Guillou 2012: 224).

Pāramī besteht somit ungeachtet von Verstößen gegen moralische Grundsätze, Menschenrechte oder kambodschanisches Recht. Pol Pots Biographie weist deutliche Parallelen zu anderen, länger etablierten anak tā auf - wie der von lok tā Kleang Moeung ${ }^{74}$, der schon zu Lebzeiten ein mächtiger Kommandant war und sich durch seinen (nach buddhistischer Ansicht allerdings strikt verbotenen) Selbstmord unsterblich machte (Kap. 5.2). Heute gilt seine pāramī als wirksamste Kambodschas. Die Höhe der spirituelle Macht wird kongruent zur ehemals weltlichen Macht gemessen (Work 2012: 122), die dabei jedoch weder schlecht oder schädlich bewertet wird. Pol Pot wird an seinem Grab nicht für seine Taten als Mensch verehrt - vielmehr werden die lokalen Spenden an seine heute dort ansässige pāram̄̄ adressiert. Diese weist kaum noch Bezüge zur tatsächlichen Biographie der verstorbenen Person Pol Pot auf, sondern agiert typisch für eine pāramī, wie beispielsweise mit der Nennung der richtigen Lottozahlen oder der Bestrafung moralischer Vergehen (Guillou 2012: 224).

Doch nicht alle Bewohner_innen von Choam gingen bei meinen Befragungen gleich stark von der Wirkmacht von Pol Pots Geist aus. Es wurde beispielsweise darauf verwiesen, dass es andere (,echte) anak tā in der direkten Umgebung gäbe, die weitaus mächtiger seien. Dazu gehörte unter anderem das zweckentfremdete Rote Khmer-Denkmal von yāy Mao (Kap. 5.2), das nur 1,5 km entfernt liegt. Desweiteren finden sich in der Umgebung eine Statue von lok tā Kar Krahom,

\footnotetext{
${ }^{73}$ In der Geschichte des Christentums wurden häufig ehemals ambivalent zu bewertende Charaktere zu eindeutig dem Christentum entgegenstehende Mächte uminterpretiert. Ein Beispiel stellt der Satan dar, der im Alten Testament der Bibel als Helfer Gottes und im Neuen Testament als Herausforderer und als Karikatur eines Engels dargestellt wurde (Maurer 2007).

${ }^{74}$ Der Name ist nach Guillou (2012: 219) thailändischer Herkunft und bedeutet ,zentrale Säule des Gebietes'.
} 
von lok tā Visnuka, einem weiteren lokalen anak tā und einem achtgesichtigen anak $t \bar{a}$ vor dem ehemaligen Wohnhaus des Roten Khmer Führers tā Mok. ${ }^{75}$ Es scheint wenig Anreiz für die meisten Anwohner_innen zu geben, einen Geist im Entstehungsprozess einem etablierten anak tā vorzuziehen, zumal Pol Pots Grab für viele nicht den Kriterien einer Verehrungsstätte von Ortsgeistern entspricht. Zudem scheut die Mehrheit der Anwohner_innen die Grabstelle aus Angst davor, von anderen Besucher_innen des Grabs angesprochen oder fotografiert zu werden. Somit gibt es noch nicht viele Akteure, die die pāramı̄ von Pol Pot als gesicherte und machtvolle Existenz unterstützen.

Es gab bei meinen Recherchen zu dem Thema jedoch auch Personen, die das blackboxing von Pol Pots Macht aktiv vorantrieben. Sie schufen ständig neue Referenzen zu seiner Macht und versuchten, andere davon zu überzeugen. Eine dieser Personen war Kim Suon, sie pflegte das Grab von Pol Pot mit ihrem Ehemann Ngia Chrein. Für die Instandhaltung der touristisch relevanten Gedenkstätte wurde sie von der Regierung mit 500000 Riel (125 US-Dollar) im Monat bezahlt. AuBerdem durfte sie als Pflegerin des Grabes die Opfergaben von den Gläubigen in Form von gekochten Hühnern, Obst und Alkohol nach einer gewissen Zeit selbst konsumieren. In mehreren längeren Interviews mit ihr und ihrem Ehemann erzählten beide von den Anfängen und den Gründen der Verehrung von Pol Pot. Diese Geschichte ist in mannigfaltiger Form mit der politischen Entwicklung des Landes verzahnt, wie ich nun zeigen werde.

Die Region Anlung Veng, die an Thailand angrenzt, war von Mitte der 1980er Jahre bis 1998 ein abgeriegeltes Rote Khmer-Rückzugsgebiet (Wood 2009). Die Versorgung der Einheiten von Pol Pot und $t \bar{a}$ Mok wurden unter anderem durch den Verkauf von kostbarem Tropenholz an Thailand finanziert. Nach Pol Pots Tod und dem darauffolgenden Zerfall der Roten Khmer-Strukturen im Jahr 1998 nahm die Mehrheit der Rote Khmer Kämpfer das Immunitätsabkommen der Regierung von Hun Sen an und durften so unbestraft in ihre Heimatregionen zurückkehren.

Nach Ansicht der Anwohner_innen von Anlung Veng nutzten die thailändischen Truppen die politischen Unruhen dieser Monate aus und verschoben die Grenze um etwa $10 \mathrm{~km}$ auf das kambodschanische Territorium. Die Regierung in Phnom Penh soll dies nicht bemerkt haben, da das Gebiet vorher so abgeriegelt gewesen war. Direkt vor dem Grab von Pol Pot in dem Ort Choam endete jedoch die Grenzverschiebung. Schließlich hätten die thailändischen Verantwortlichen nicht rechtfertigen können, warum das Grab plötzlich auf ihrem Territorium lag. Der Ehemann von Pol Pots Grabpflegerin, Ngia Chrein, interpretierte dies als

\footnotetext{
${ }^{75}$ Es ist nach meiner hier vertretenden Argumentation nicht weiter verwunderlich, dass die anak tā in Choam so zahlreich in Erscheinung traten. Als letzte Bastion der Roten Khmer waren Anlung Veng und Choam die Heimatorte der - mittlerweile größtenteils verstorbenen - Führungspersönlichkeiten der Roten Khmer: Ihre (weltliche) Macht war Ausgangspunkt für die neu erschienenen anak tā in der Nähe ihrer ehemaligen Wohn- und Arbeitshäuser.
} 
Handlung von Pol Pots pāramī, die ,ihr Territorium‘verteidigt hätte. Da Pol Pot in diesem Ort gelebt hatte und dort gestorben war, galt er als ehemaliger mächtiger Herrscher noch immer als wirkmächtig.

Die Grabstelle Pol Pots wurde nach der Kremation seines Leichnams von einigen Anwohner_innen auf der Suche nach Knochen und Zähnen durchsucht (Gray 2014: 203). Danach verwaiste die Grabstelle über mehrere Jahre. Als am Anfang der 2000er Jahre eine neue Straße und ein neuer Grenzübergang in direkter Nähe dazu gebaut wurden, lockte die Regierung zahlreiche Grenzsoldaten aus Kampong Cham (eine der ärmsten Provinzen des Landes) in die Region. Vor dem Umzug in die neue Region baten sie üblicherweise die anak tā der Gegend um ihren Segen, was auch Pol Pots Geist betraf. Kim Suon lebte schon zu Zeiten der Roten Khmer hier und hatte sich seit 1998 jahrelang mit dem illegalen Handel von Waren nach Thailand finanziert. Da ihr einfaches Haus schon damals direkt neben dem Grab lag, pflegte sie das Grab zunächst unentgeltlich. Mit der Übersiedlung der Grenzsoldaten und ihrer Familien einige Jahre später bekam Kim von Regierungsbeamten den Auftrag, sich um das Grab zu kümmern. Zur gleichen Zeit hätte sie geträumt, wie Pol Pots Geist sie darum bat, auf ,seinen' Platz aufzupassen und sich um dessen Instandhaltung zu kümmern. Im Traum hätte er zu ihr gesagt: „Ich habe jetzt nichts mehr. Das ist das einzige Stück Land, das ich noch mein eigen nennen darf; bitte gib darauf acht und pass auf, dass es mir niemand wegnimmt". Somit habe sie in direkter Kommunikation mit dem Geist den Auftrag zur Pflege des Ortes bekommen.

Das Interesse an dem Grab sei jedoch bis zum Jahr 2010 noch sehr gering ausgefallen. Wie Kim berichtete, kämen jedoch seit ein paar Jahren immer mehr ranghöhere Kambodschaner_innen aus anderen Gebieten Kambodschas, die Pol Pot als anak tā verehrten. Darunter seien auch Minister des Kabinetts von Hun Sen gewesen. Inspiriert von den Spenden der prominenten Besucher_innen stieg nun auch die Zahl der Opfergaben seitens anwohnender Dorfbewohner_innen, insbesondere an spirituell, günstigen' Tagen (thngai sīla).

Neben den Plänen der Regierung, Anlung Veng zu einem weiteren Touristenziel auszubauen, stieg die Attraktivität von Choam durch die Nähe zur thailändischen Grenze und der Eröffnung eines großen Kasinos, das 2012 in etwa 100 Meter Abstand zu Pol Pots Grab erbaut worden war. ${ }^{76}$ Kurz vor der Eröffnung des Kasinos träumte Kim Suon erneut von Pol Pot. Der Geist hätte sie diesmal vor dem Kasino gewarnt, da der Besitzer mehrere anak tā und einen brāy (einen ,wild‘ konzipierten Geist, siehe Kap. 5.1) beauftragt habe, den Spieler_innen „nichts als Pech“ zu bringen, um seinen eigenen Reichtum zu vermehren.

\footnotetext{
76 Allerdings war es für Kambodschaner_innen verboten, Glücksspiel zu betreiben. Entlang der Grenze zu Thailand wurden dennoch vermehrt Kasinos gebaut, um Kundschaft aus Thailand anzulocken, wo Glücksspiel ebenfalls verboten war.
} 


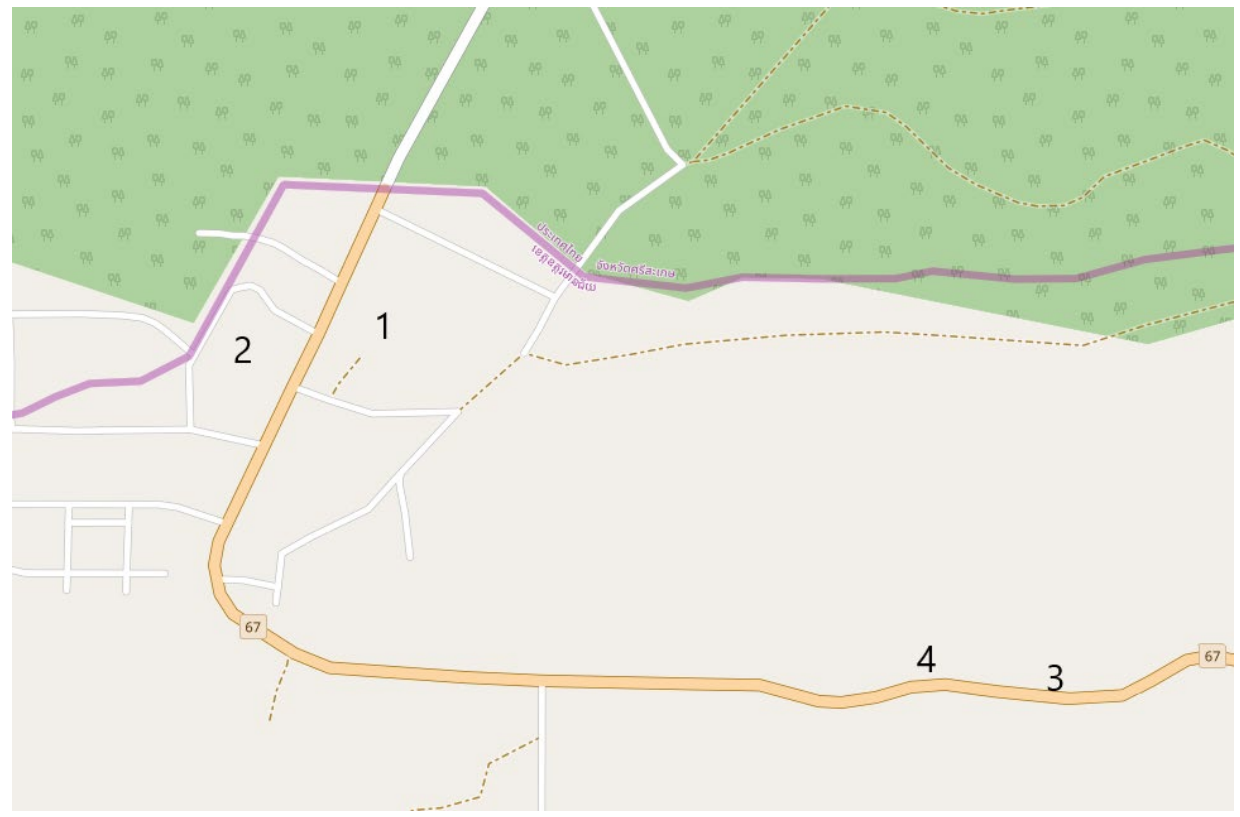

Abb. 6: (C) openstreetmaps. Landkarte von Choam. Der Ort liegt an der thailändischen Grenze (violett) mit dem Grab Pol Pots (1) und dem Kasino (2). Andere anak tā wie yāy Mao (3) und lok tā Krahom Kar (4) befinden sich auf Straße nach Choam (siehe Kap. 5.3).

Der Besitzer des Kasinos, der erfolgreiche kambodschanische Geschäftsmann Lim Heng ${ }^{77}$ hat bereits zu Beginn der Bauarbeiten für das Kasino 2010 eine Zeremonie abhalten lassen, in deren Verlauf umfangreiche Opfergaben für Pol Pots Geist dargereicht wurden. Nach dem Traum von Kim, den sie auch Lim Hengs Mitarbeiter_innen erzählt hätte, beteiligte sich Lim Heng nach ihren Aussagen noch stärker an der Verehrung Pol Pots. Zwar hatte er vor dem Kasino typische anak tā-Statuen aufstellen lassen, aber diese scheinen dort lediglich als Schmuck zu dienen - somit war Pol Pot, wenn man ihn als solchen begreift, der nächstgelegene anak tā zum Kasino. ${ }^{78}$

${ }^{77}$ Lim Heng ist Vizepräsident der kambodschanischen Handelskammer (Cambodian Chamber of Commerce), und Teilhaber der An Mady Group, die für ihre Förderung von Kohle und Mineralien und den Handel mit Holz umstrittene Konzessionen in Kambodscha erhalten hat, für die in verschiedenen Teilen des Landes Menschen von ihrem Land vertrieben wurden (United Nations High Commissioner for Human Rights (OHCHR) 2007). Mit dem Kasino verschaffte er sich Zugang zu einem weiteren, lukrativen Wirtschaftszweig.

${ }^{78}$ Dazu sollte erwähnt werden, dass selbst der ehemalige König Sihanouk auf die spirituelle Macht von Pol Pots Geist hinwies, der Sihanouk zum Erfolg im Glücksspiel verholfen haben soll (Guillou 2012: 224). Gray (2014: 203) sieht eine Korrelation zwischen diesem Narrativ und dem Neubau des Kasinos in unmittelbare Nähe von Pol Pots Grab. 
Lim Heng behandelte Pol Pot demnach seit 2010 als anak tā, was er durch regelmäßige Opfergaben, die er an jedem ,günstigen“ Tag (thngai sīla) von seinen Mitarbeiter_innen bringen lässt, bekräftigt. Die Opfergaben beinhalten jedes Mal ein gekochtes Huhn, Obst, Spirituosen, Räucherstäbchen und, was im Gegensatz zu den genannten Dingen eher ungewöhnlich für anak tā-Spenden ist, ,Totengeld aus Papier. ${ }^{79}$ Das Geld wird dabei vor dem Grab verbrannt und anschließend mit Alkohol übergossen, was offensichtlich auf eine Anfrage nach finanziellem Erfolg zurückzuführen ist.

Die Mitarbeiter_innen, die dies durchführten als ich anwesend war, hatten vermutlich die Anweisung bekommen, dabei mit niemandem zu sprechen. Nachdem eine Mitarbeiterin des Kasinos Fotos von mir gemacht hatte, versuchte ich die Gruppe mit üblichen Begrüßungsformeln auf Khmer anzusprechen. Obwohl ich den Eindruck hatte, dass die Mitarbeiter_innen gern darauf eingegangen wären, stiegen sie nach den hastig durchgeführten Opfergaben in einen Minivan des Kasinos und fuhren die 100 Meter zurück zu ihrem Arbeitsplatz. Ihr Schweigen zur rituellen Praxis mit dem Geist hing meiner Einschätzung nach damit zusammen, dass besonders bei Ritualen im Zusammenhang mit kürzlich Gestorbenen die buddhistische Kritik daran am deutlichsten vorgebracht wurde. Mönche unterschieden in Gesprächen mit mir zwischen Geistern, die man verehren könnte (zum Beispiel anak $t \bar{a}$ ) und Totengeistern, mit denen nur buddhistische Gelehrte rituellen Umgang pflegten sollten (vgl. Gray 2014: 204). Pol Pot, da waren sich die meisten Mönche einig, würde in den nächsten Jahrzehnten nicht wiedergeboren werden und müsste noch lange im Status eines Totengeistes verharren. In Reaktion auf diese buddhistische Kritik, mit der ich Kim konfrontierte, erzählte sie, dass Lim Heng einen buddhistischen Stupa über das Grab bauen, und den Platz vor dem Grab betonieren und generell ,modernisieren ${ }^{6}$ wollte. ${ }^{80}$ Er benötigte dafür lediglich eine Genehmigung des Ministeriums für Tourismus in Phnom Penh, die er - Kim zufolge - bald erhalten würde.

Aus meiner Akteur-Netzwerk-inspirierten Sicht auf Geister spielten mehrere Akteure an Pol Pots Grab eine tragende Rolle in der Aushandlung seiner fragilen Existenz als Ortsgeist. Dazu gehörten Kim und ihr Ehemann, das Kasino, Lim Heng, die Anwohner_innen, die Opfergaben, die Träume von Kim und Pol Pots pāramī. Kim kommt in diesem Vorhaben die Bedeutung eines wichtigen Aktanten zu, der mit der Vermehrung weiterer Akteure im Netzwerk von Pol Pots Geist aktive Rollen im blackboxing des neu entstandenen Geistes einnimmt. Kims Träu-

\footnotetext{
${ }^{79}$ Die imitierten Geldscheine werden in der chinesischen Praxis der Totenverehrung benutzt und auf lokalen Märkten verkauft. Da Menschen aus China in Kambodscha als ranghoch und ,modern angesehen werden, gewinnt diese Praxis (vor allem während des Totenfestes bhjum pinda) zunehmend an Popularität, auch unter Khmer-Kambodschaner_innen nicht-chinesischer Abstammung.

${ }^{80}$ Stupas in Kambodscha konnten als Monument der Erinnerung, aber auch zur Aufbewahrung von Relikten (des Buddha oder anderen spirituellen Vorbildern) gebaut werden.
} 
me von Pol Pot stellten dabei eine starke Referenz auf die Existenz des Geistes dar. Geister in Träumen werden in Kambodscha als Begegnungen beurteilt, denen viel mehr Realität zugeschrieben wird, als es nach der schulmedizinischen Ausrichtung der westlichen Psychologie (im Sinne eines ,Symbols') üblich wäre.

Somit hat sich die Zahl der Referenzen im Netzwerk von Pol Pots Geist während meiner Forschung erhöht, da es vermehrt Menschen gab, die sich einen Vorteil aus dem Tauschgeschäft von Pol Pots Macht gegen Opfergaben erhofften. Unter ihnen war Lim Heng selbst, einer der einflussreichsten Geschäftsmänner Kambodschas. Sein Verhalten, dem Geist mit aufwendigen und regelmäßigen Opfergaben Respekt entgegenzubringen und seine Präsenz mit einem repräsentativen Stupa zu ehren, machte ihn zu einem wichtigen Akteur, der noch viele Referenzen zu einflussreichen Akteuren für Pol Pots Geist schaffen und somit eine stabilere Existenz des Geistes als anak tā vorantreiben könnte. Der Stupa, falls er gebaut wird, wäre zudem ein buddhistischer und offizieller Ort, der einen Geist aus kambodschanischer Sicht verehrungswürdig macht. Somit waren die wichtigsten Faktoren dieser ,Anak tā-isierung ${ }^{61}$ Pol Pots die Referenzen der Anwohner_innen und der nationalen Eliten, die Erscheinungen des Geistes in Träumen sowie die materielle Ausgestaltung seiner Grabstelle.

Dennoch gilt er damit selbstverständlich noch nicht als existent für alle, die von der Geschichte hören. Einige der lokalen Anwohner_innen zweifelten offenbar daran, dass Kim die Wahrheit sagte, da sie das Bedürfnis nach Anerkennung für den Geist und den damit zusammenhängenden eigenen Vorteil (die Opfergaben behalten zu dürfen) deutlich erkennen ließ. Bei anderen Ortsgeistern, wie der nahegelegenen yāy Mao (Kap. 5.2) gibt es einen Konsens in der Gesellschaft, dass sie eine mächtige anak tā sei. Bei Pol Pot dagegen gab es zahlreiche Personen, die seine pāramī nicht getrennt von seinen als Mensch begangenen Taten sehen wollten und die ihn somit nicht als anak tā verehrten. Das blackboxing von Pol Pots Geist ist daher ein Prozess mit offenem Ausgang.

\subsection{2 ,Tā Noël ${ }^{`}$ - ein westlicher Geist in Kambodscha}

Zum Ende meiner Forschungszeit wurde ich zu mehreren von grū Bun Ly organisierten Zeremonien eingeladen, die loeng anak tā (gesprochen: ,larn neak ta) heißen, was ,Hochpreisen der anak tā' bedeutet. Hierbei gewährten bis zu 20 Geistmedien ihren Geistern gleichzeitig Präsenz in ihren Körpern, so dass die Zeremonien als Versammlung von anak tā gelten können. Die Geister tanzten miteinander, segneten die Anwesenden, sprachen oder stritten untereinander. Als Gast eingeladen, spendete ich zwischen 20-50 US-Dollar pro Zeremonie, da ich mich ,standesgemäß` nach der Höhe meines Einkommens in die Reihe der Spender_innen für die (unterschiedlich großen) Zeremonien einordnen wollte.

\footnotetext{
${ }^{81}$ Im englischsprachigen Austausch mit Kolleg_innen nannte ich diesen Prozess neakta-fication, siehe Gray (i.E.).
} 
Schon in den ersten Interviews betonte grū Bun Ly die engen Beziehungen zwischen Menschen und Geistern in früherer Zeit. Seiner Meinung nach stammten alle Menschen aus einer einzigen Urfamilie; sie wären somit trotz unterschiedlicher Religionszugehörigkeit miteinander verwandt. Danach führte er stets in einer langen Liste von verschiedenen Geistern „aus aller Welt“ auch den Namen „tā Noël“ an. Weder Bunnwath noch ich ahnten, was sich hinter diesem Namen verbarg - doch da es häufiger vorkam, dass wir von uns unbekannten Geistern hörten, beachteten wir dies zunächst nicht weiter.

Schließlich eröffnete uns grū Bun Ly am Ende meiner Forschung voller Vorfreude, dass bei der nächsten loeng anak tā-Zeremonie auch ein Medium von tā Noël anwesend sein würde. Er sagte: „Du wirst Dich freuen, denn er kommt aus Deiner Heimat Europa. “ An dieser Stelle ließen wir uns den Namen buchstabieren, den ich vorher immer als „tā Nöw El“ notiert hatte, und wir ließen uns die Geschichte von $t \bar{a}$ Noël erzählen: Als lebender Mensch sei $t \bar{a}$ Noël ein Millionär gewesen, der auf einem „fliegenden Pferd“" „Wohltätigkeit praktiziert“ (am naoy) und den Menschen Geschenke gebracht habe. Er habe in Europa gelebt, sei dort gestorben und nun als Geist für Europa zuständig. Da verstand ich erst, dass der Name „Nöw El“ eigentlich das französische Wort für Weihnachten (Noël) bezeichnete. ${ }^{82}$ Grü Ly betonte, wie fremd sich dieser Geist hier fühlte und eigentlich einen europäischen Körper (rüpa) bevorzugen würde, was ich als (wiederholten) Versuch von Ly deutete, mich selbst zum Geistmedium und zu seinem ,Schüler zu initiieren. Ohne darauf einzugehen, nutzte ich die Gelegenheit, einen Geist treffen zu können, der als Ortsgeist, meiner Heimat' galt.

In Poipet, an der Westgrenze zu Thailand, sprachen wir mit $t \bar{a}$ Noël und seinem Medium. Von dem jungen grü erfuhren wir, dass er 28 Jahre alt war, und in Thailand als Verkäufer in einem Geschäft für Kleidung arbeitete. Einige Wochen vor unserem Treffen hätten ihn gesundheitliche Probleme (Magen-, Kopf- und Gliederschmerzen) geplagt, und auch Medikamente hätten nicht geholfen. Da beinahe die ganze Familie seines Onkels in Poipet als Geistmedien tätig sei, rechnete er mit dem gleichen Schicksal. Sein Onkel, der ein hochrangiger Mitarbeiter der kambodschanischen Grenzpolizei war und dessen Geist nach schwerer

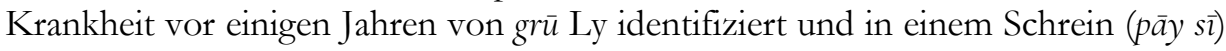
manifestiert worden war, hatte Bun Ly erneut kommen lassen, um den Geist seines Neffen zu kontaktieren. Nach den Angaben des jungen grū hätte Ly den Geist als $t \bar{a}$ Noël identifiziert, der von weit her gekommen sei und leider kein Khmer spreche. Er habe daraufhin jede Nacht vor dem riesigen pāy sī seines Onkels ge-

\footnotetext{
${ }^{82}$ Dazu muss gesagt werden, dass ich die Bezeichnung des Geistes damals noch mit „Weihnachtsmann" übersetzte, aber kurz darauf von Karen Greene korrekterweise darauf hingewiesen wurde, dass ,tā Noël' ein eigenes, kambodschanisches Konzept darstellte, das nicht leichtfertig mit dem Konzept des, Weihnachtsmanns' gleichgesetzt werden kann. Tatsächlich lassen sich viele Unterschiede zwischen den beiden Figuren feststellen - von der Beschreibung des Akteurs bis hin zu seiner lokalen Manifestation (vgl. Hauschild 2012).
} 
Teil I: Thematischer Kontext und Methodik

schlafen und durch die Nähe zum Schrein nachts durch Träume versucht, Kontakt zu seinem Geist aufzunehmen. Kurz darauf sei sein Körper während einiger kleinerer Rituale von tā Noël in Besitz genommen worden, doch der Geist im Körper des neuen Mediums hätte jedes Mal angefangen zu weinen, weil er sich deplatziert und fremd gefühlt hätte. In Besessenheit könnte er nur ein Kauderwelsch sprechen, das keiner verstehe. Da diese Ereignisse erst so kurze Zeit zurücklagen, war die Zeremonie, zu deren Anlass ich den jungen grū sprechen konnte, die erste für das Medium von tā Noël.

Was sich dann in der Nacht vor dem loeng anak tā ereignete, erzählt mein Feldforschungsbericht vom 01.10.2012:

„Der grū tā Nö̈l wurde plötzlich besessen. Er fing sofort bitterlich an zu weinen. (...)

Nachdem er außerbalb der Sichtweite der hochrangigen Gäste gebracht wurde, saß er zwischen einer Gruppe von grü im hinteren Teil des Raumes vor dem pāy sì und weinte.

Die grū konnten ihn auch nach mehr als zehn Minuten nicht berubigen.

Grū Bun Ly hatte schließlich die Idee: der ,pārāng' (also ich) sollte mit ibm reden, denn schließlich würde ich diesen Geist am besten von allen hier kennen. Also ging ich mit einer Mischung von Unsicherheit, Belustigung und Nengier zu ibm und setzte mich vor den weinenden grū. Ich verbeugte mich (wie gegenüber allen besessenen Geistmedien üblich) dreimal tief vor ihm. Ich versuchte auch danach mit non-verbalen Mitteln der Gestik tiefe Verehrung für ihn auszudrücken, auch weil ich das Gefühl hatte, dass dies von den versammelten grū neben mir erwartet wurde. Schließlich hatte grū Bun Ly hatte mir ja ständig versichert, dass dies ,mein' Geist sei. Der grū von tā Nö̈l redete unverständlich; die umstehenden grū mutmaßten, dass es Indonesisch oder Deutsch sei. Ich begriff, dass nun erwartet wurde, dass ich den grü verstehen würde. Erst börte ich nur zu, bis ich von grū Bun Ly (töwen! - antworte!) aufgefordert wurde, mit dem grū zu sprechen. Also redete ich auf Deutsch mit ihm (...)

Das Weinen des grū wurde etwas schwächer, als ich sprach. Er antwortete erst zögernd und dann sicher und bestimmt in seiner Sprache. Die anderen [circa 10] grü und andere Schaulustige nun um uns herum waren sich nun sicher, dass wir uns auf Deutsch unterbielten. Das Gesicht des weinenden Mannes bellte sich nach und nach auf und plötrlich lachte er-die umstehenden grü und auch die anderen im Raum jubelten.

Ich hatte den Erwartungen der Umstehenden entsprochen und den grū von tā Noël aufgeheitert. Wir lachten uns noch etwas an, dann wurde schnell eine Parfümflasche organisiert, da tā Noël mich segnen wollte. Er sprühte mir die halbe Flasche auf meinen gesenkten Kopf und die gefalteten Hände, während er sein Kauderwelsch in vielfachem Tempo aufsagte. Manche Silben platrten laut und explosionsartig aus ihm heraus und sein Körper zuckte dabei (diese Art des Segnens hatte ich auch schon bei seinem Onkel beobachtet; er scheint sowas wie sein Lehrer zu sein). Danach sollte auch Bunnwath noch 
gesegnet werden, der auf Englisch mit dem grū sprach. Tā Nö̈l wirkte nun fröhlich und gutgelaunt. Wir verabschiedeten uns in gegenseitigem Woblwollen und setzten uns wieder."

Die Situation schildert eine entscheidende Episode des Akteurs tā Noël in seinem fragilen Prozess des blackboxing. Er wurde zwar als anak tā von allen anwesenden grū anerkannt, doch das Verhältnis zwischen grū und Geist war von Missverständnissen geprägt. Außerdem hatte der Geist noch keinen pāy sī, wenige Anhänger_innen und keine Referenzen auf große Wirkmacht nachzuweisen. Auch seine Biographie war den meisten Anwesenden aufgrund seiner Fremdheit unbekannt. Es hatte sich nur herumgesprochen, dass ein pārāng-Geist bei dieser Zeremonie anwesend sein würde. Einige Besucher_innen hielten mich (aufgrund meines Aussehens) für den grū dieses Geistes und sprachen mich während der Zeremonie diesbezüglich an. Ich musste sie dann mehrfach darauf hinweisen, dass der Geist von $t \bar{a}$ Noël sich ein kambodschanisches Medium gesucht hatte und nicht mich.

Nach der Analyse der zahlreichen Interviews mit den involvierten Medien dieser Zeremonie gewann ich zunehmend die Erkenntnis, dass grü Bun Ly mich als Geistmedium für tā Noël gewinnen wollte, und wegen meines Widerwillens den ,Umweg' über den jungen grū genommen habe. Schon in früheren Interviews hatte Ly mehrfach erwähnt, dass ich ein Geistmedium werden würde - so hätte er es von seinem Geist erfahren. Dies sei somit mein ,vorherbestimmtes' Schicksal und die Erklärung dafür, warum sich ein pārāng wie ich für Geister in Kambodscha interessieren würde. In vorherigen Leben hätte ich als General im vorbuddhistischen Kambodscha gekämpft, und Bunnwath wäre ein Soldat meiner Einheit gewesen. Somit verstand er unsere Zusammenkunft und unser freundschaftliches Verhältnis während der Forschungszeit nicht als Folge einer zufälligen Begegnung, sondern als ein spätes, Wiedersehen' alter Khmer-Soldaten, die ihre damalige pāramī mithilfe von Geistern wieder abrufen könnten.

Bun Ly versuchte mich mit verschiedenen Mitteln dazu zu bringen, das Medium von tā Noël zu werden: Bei einer späteren Zeremonie in Poipet hatte Bun Ly erneut das Gerücht im Ort gestreut (er war für die Vorbereitungen schon früher dorthin gereist), dass ich als ,grū pārāng" teilnehmen würde. Nach meiner Anreise kamen daraufhin wieder Anwohnerinnen zu mir, die mich bei ihren persönlichen Anliegen um Hilfe baten, was ich erneut zurückweisen musste. Zudem litt ich bei dieser Zeremonie an starken Kopfschmerzen als Folge von massiver Hitze und Dehydration. Diese profane Erklärung wies grū Ly entschieden zurück: es sei tā Noëls Versuch gewesen, in meinen Körper zu kommen. Da es dem Geist im Körper des jungen grū nicht gut ginge, hätte ich es nur ,zulassen' müssen, um einen Wechsel der Medien für ,meinen' Geist möglich zu machen.

Grū Ly und ich hatten ein sehr gutes Verhältnis zueinander und so konnte ich ihn einige Monate später nochmals zu tā Noël befragen. Er erzählte, wie er sich mit dem Onkel des jungen grū über finanzielle Angelegenheiten gestritten und schließlich den Kontakt zu der Familie in Poipet eingestellt habe. ,Mein` ehren- 
werter tā Noël, so grū Ly, habe den jungen grū danach verlassen, da dieser (wie der Rest der Familie) unehrlich zu grū Ly gewesen sei. Nun sei tā Noël wieder in der oberen Welt (thān suok). Er habe keinen Körper und sei auf der Suche nach einem Medium. Wahrscheinlich werde er sich einen grü in Phnom Penh suchen, aber das konnte grü Ly nicht sicher sagen. Auf die Frage, warum er den Geist für mich gerufen hatte, machte er deutlich, dass es ihm während unseres engen Kontakts meiner Forschungszeit unhöflich erschienen sei, Spendengelder von mir anzunehmen für Zeremonien, bei denen nur kambodschanische (Orts-)Geister anwesend gewesen seien. Da ich aus einer anderen Region der Welt gekommen sei, hätte er mir für meine vergleichsweise hohen Spendengelder einen Segen von einem meiner (Orts-) Geister bieten wollen.

Somit war gru Ly einer der maßgeblichsten Akteure des blackboxing-Prozesses von $t \bar{a}$ Noël. Er hat das Projekt seiner verstetigen Akteurschaft (beziehungsweise Existenz) initiiert und vorangetrieben. In seinem Erfindungsreichtum verfolgte Bun Ly zwei Anliegen, um mich zu entschädigen: Er wollte mich zum einen in sein Netzwerk von Geistmedien integrieren und mir damit Zugang zu magischen Praktiken und einem (aufgrund meiner Exotik möglicherweise großen) Klient_innenstamm verhelfen. Damit hätte er sein soziales Netzwerk zudem durch einen weiteren finanzkräftigen Akteur bereichert. Zum anderen sollte die Präsenz und der Segen von $t \bar{a}$ Noël dazu dienen, die fehlende Gegengabe für meine Spendengelder im Rahmen des üblichen Tausches von Geld gegen Segen wieder auszugleichen, denn so konnte er mir einen individuell auf mich zugeschnittenen Segen bieten. Dies war die übliche Dienstleistung für einen als ,Sponsoren` klassifizierten Teilnehmer der Zeremonien wie mich.

Mit dem Herbeirufen von $t \bar{a}$ Noël fand Ly eine Methode, beide Anliegen miteinander zu verknüpfen. Die zeitweise Erscheinung im Körper des jungen grü blieb die einzige ,materielle ${ }^{‘}$ Erscheinungsform von $t \bar{a}$ Noël. Vor allem das Fehlen eines pāy sī ist nach ANT-Sicht entscheidend, da nicht-menschliche Akteure allgemeinhin stärkere und längerfristige Referenzen aufbauen als menschliche Akteure (Latour 2006). Dies war im Fall der Schreine von Geistmedien klar ersichtlich. Der pāy sī ist der materielle Ort des Geistes von Geistmedien. Ohne diesen Ort ist ein Geist nicht bei seinem grū manifestiert. Desweiteren konnte grū tā Noël wenig über die ruhmreiche Vergangenheit seines Geistes berichten, konnte nicht mit ihm kommunizieren und keine Narrationen über die pāramī seines Geistes verbreiten. Für den jungen grū war die einzige Kontaktmöglichkeit zu seinem Geist gru Bun Ly, der den Geist in der oben beschriebenen zweifachen Hinsicht für mich bestimmt hatte. Als ich aus Kambodscha abreiste und der Kontakt dem Grenzpolizisten und Bun Ly durch einen Streit gestört wurde, wurden die stärksten Referenzen des exotischen Geistes (zu dem jungen grū, zu mir und zu grü Ly) schwächer. Schließlich wurde tā Noël kein anak tā und wartet bis heute auf neue, existenzfördernde Referenzen. 


\subsection{Fazit: Geister und ihre Existenz in Kambodscha}

Meine ANT-inspirierte Methode, die Existenzweisen von Geistern mittels Konzepten von Netzwerk, Akteur, blackbox und Referenz zu untersuchen, bietet mir die Gelegenheit, die lokalen Aushandlungen der angenommenen Präsenz und Wirkmacht von Geistern deutlich zu erfassen. Ihre Existenz ist offensichtlich verhandelbar - für viele Kambodschaner_innen stellt sich jedoch nicht die Frage ob es Geister gibt, sondern wann und wie es sie gibt. Dennoch sind sie nicht per se existent; ihnen wird über Referenzen von Akteuren und Praktiken (wie beispielweise die Verehrung durch Opfergaben) zu ihrer Existenz verholfen, während andere Geister aufgrund mangelnder Referenzen zu anderen Akteuren vergessen werden. Dazwischen gibt es, und dies stellt einen entscheidenden Vorteil der Betrachtung der Existenzbedingungen von Geistern dar, „sehr viel feinere Differenzierungen“ (Latour 2002: 380) dieser Existenzweisen, die über dem „Alles-odernichts“ (edb.), beziehungsweise der „pauschalen Abgrenzung von Existenz und Nichtexistenz" (edb.) hinausgehen, wie ich in diesem Kapitel anhand der Beispiele von tā Noël und Pol Pot gezeigt habe.

Die ontologische Frage, ob es Geister ,wirklich` gibt, ist somit nicht entscheidend. Stattdessen möchte ich mit meiner hier vorgestellten Methode erreichen, die Existenz von Geistern nicht mehr als eine, Glaubensfrage ${ }^{6}$ zu begreifen (Bell 2002), sondern die Geister als mögliche Akteure in einem vielfältigen und sich ständig wandelnden Netzwerk zu verstehen. Somit ist die Antwort auf die Frage nach der Existenz der Geister nicht so erkenntnisreich wie die Beziehungen, die sie mit anderen Akteuren eingehen.

Geister verwischen die von der ,modernen' Wissenschaft hergestellten Trennungen zwischen Ontologie/Epistemologie, Subjekt/Objekt, Natur/Kultur und nicht-menschlichen/menschlichen Akteuren. Anak tā werden als Ortsgeister und als ein Teil ihrer Umwelt verstanden und sind für viele Kambodschaner_innen natürliche und reale Akteure der sprichwörtlichen Geister-Landschaft - in unterschiedlichen ,grades of personhood“ (Sprenger 2016): als fluid konzipierte Macht, örtliches Potential oder als Subjekt, zum Beispiel im Körper eines Mediums. Ihnen wohnt ein ständiges Potential inne, zu Subjekten zu werden - als bloße ,Objekte‘ oder ,Glaubensinhalte' können sie dagegen nicht gelten. Ihre Existenz wirft somit keine ontologischen Fragen nach ihrem ,eigentlichen Wesen' auf, sondern hängt vielmehr von Akteuren wie grū Ly, tā Noël, dem Kasino oder Kim Suon ab, die selbst entscheiden, inwieweit sie Teil des Netzwerks von Geistern werden möchten, in dem sie auf ihre Existenz verweisen oder sie als nicht-existent ignorieren.

Diese hier vorgestellte Methodik wird die Grundlage bilden für den nächsten Teil, in die die Existenzweisen von anak tā und Totengeistern untersucht, die von einer rituellen Kontrolle ihrer An- und Abwesenheit geprägt sind. Dabei zeigt sich im vierten Kapitel, dass die Beschäftigung mit Totengeistern grundlegende Erkenntnisse zum kambodschanischen Umgang mit Vergangenheit und der Erinne- 
rung daran zulässt. Zugleich formt sich unter dem gegenwärtigen buddhistischen Einfluss die spirituelle Form des Gedenkens und des Erinnerns neu und wird im Folgenden als hybride, im Prozess der Aushandlung befindliche Praxis beschrieben. Im darauffolgenden Kapitel werden komplementär dazu die spirituell geprägten Aspirationen der individuellen und kollektiven Zukunft anhand der populären anak tā-Praxis zusammengetragen. Die Analyse dieser Ortsgeister hilft dabei, die gängigen Existenzbedingungen der kambodschanischen Geister abschließend zu bestimmen, bevor ich im dritten Teil der Arbeit auf die Rolle der Geistmedien und ihre gesellschaftlichen Implikationen eingehe. 


\section{EXISTENZWEISEN DER}

KAMBODSCHANISCHEN GEISTER 



\section{Die An- und Abwesenheit von Totengeistern}

Dieses Kapitel behandelt die religiöse Auseinandersetzung der Kambodschaner_innen mit ihrer Vergangenheit, insbesondere ihren lokalen Umgang mit den (Toten-) Geistern des Krieges. Ich knüpfe damit an ethnologische Forschungen zu dem Thema an, die gezeigt haben, dass zur Beantwortung der Frage nach Erinnerung und Vergangenheitsbewältigung religiöse Aspekte, wie die Vorstellung von Totengeistern oder dem Nachtod ${ }^{83}$, eine entscheidende Rolle spielen (Bennett 2015; Guillou 2012; Ledgerwood 2012, 2008a; Hinton 2005). Das Ziel dieses Kapitels ist es, den - von medizinischen und humanitären Disziplinen dominierten Diskurs der (mutmaßlich mangelnden) Verarbeitung der Rote-Khmer Zeit (vgl. Ciorciari 2006; Linton 2004; Etcheson 2004) zu bereichern, indem gezeigt wird, wie die An- und auch die Abwesenheit ${ }^{84}$ der Toten zu einer alternativen, lokalen Verarbeitung beigetragen hat. Zur Differenzierung der An- und Abwesenheit der Totengeister aus der Zeit des Demokratischen Kampuchea (1975-79) ziehe neben meiner Akteur-Netzwerk inspirierten Methodologie zwei Kategorien des Spukens

${ }^{83}$ Den Begriff des Nachtods (englisch: afterlife) entlehne ich Axel Michaels Konzeption (1998: 148175).

${ }^{84}$ Einleitend zur nachfolgenden Untersuchung der Totengeister möchte ich terminologisch trennen zwischen den dichotomen Begriffspaaren von Existenz/Nicht-Existenz und An- oder Abwesenheit, wobei im ersten Fall eine ontologische Abgrenzung gemacht wird, während die letztgenannte Unterscheidung epistemologisch auf eine Präsenz beziehungsweise Absenz von (existenten) Akteuren hinweist. 
(haunting) von Lincoln und Lincoln (2015) heran (Kap. 4.1). Einleiten werde ich die Untersuchung mit einer historischen Darstellung des Umgangs mit Totengeistern seit 1979 (Kap. 4.2). Die Analyse zweier unterschiedlicher Konzeptionen des kambodschanischen Nachtods zeigen, wie die Vorstellung einer aktiven Interaktion mit den Geistern des Krieges allmählich von Auffassungen ihrer Abwesenheit abgelöst wurde. Die vorgenommene Differenzierung der Nachtodkonzeptionen dient dem Verständnis der grundverschiedenen (und teilweise widersprüchlichen) Existenzmodi von kambodschanischen Totengeistern. Das folgende Beispiel des hov braling Rituals (gesprochen: ,hau prolin) erinnert jedoch daran, dass die Totengeister während der lokalen Ritualpraxis nicht eindeutig der einen oder anderen Konzeption zugeordnet werden und von einem hohen Grad an Hybridität gekennzeichnet sind. Im letzten Abschnitt (Kap. 4.3) fasse ich die verschiedenen Existenzweisen der Toten(-geister) der Roten Khmer-Zeit zusammen, die wesentlich zu einer lokalen (und wenig beachteten) Form der Verarbeitung beigetragen haben.

\subsection{Theoretische Vorbemerkung}

Neben meiner oben vorgestellten Methodik, die mich Geister als aktive Wesen in Beziehungsnetzwerken begreifen lässt, bediene ich mich im folgenden Kapitel der beiden Konzeptionen des ,Spukens' (haunting) nach Lincoln und Lincoln (2015). Obwohl die von den Autoren für Vietnam beschriebene Situation nicht dieselbe ist wie in Kambodscha, ist die Unterscheidung von primary haunting zu secondary haunting ein geeigneter Ausgangspunkt für die Beschreibung kambodschanischer Totengeister, da sie verschiedene Ebenen des Diskurses von Toten(-geistern) in Kambodscha auf konstruktive Weise trennt.

Lincoln und Lincoln zufolge ist primary haunting von der Annahme einer ,realen` Existenz der Totengeister charakterisiert. Prägende Merkmale dieser Spukform sind das spezifische Wirken und Handeln (auch als angreifende, schädliche Akteure) der Geister und ihrem Bedürfnis nach ritueller Pflege. Diese Art der Geisterpräsenz basiert auf lokalen Begegnungen mit Menschen, zum Beispiel im Kontext von Geistbesessenheit. Dabei können Geister eine Gabe oder eine Handlung einfordern und erinnern die Hinterbliebenen damit an ihren eigenen, ,schlechten'Tod.

Wie in Vietnam oder anderen Kontexten werden ,schlecht ${ }^{6}$ Verstorbene aus kriegerischen Auseinandersetzungen und speziell in Fällen von Exekutionen oftmals als störende Totengeister im Sinne der primary hauntings verstanden (Kwon 2008; Malarney 2001; Ong 1987; Comaroff 1985; Fox 1973). In Kambodscha existiert das Konzept des ,schlechten' Todes auch, das mit den Begriffen khmoc chkae (,toter Hund'), khmoc chao (,rohe Tote') oder khmoc täy hon (, unbeholfene Tote) beschrieben wird und Ähnlichkeiten zum vietnamesischen Konzept vom ,Tod auf der Straße' (chet duong) aufweist (Bennett 2015: 105; Kwon 2008: 20; Pou 
und Ang 1987-1990: 100). ${ }^{85}$ Im Gegensatz zu Kambodscha gelten diese Toten in Vietnam als mächtig und rastlos; sie stören die Hinterbliebenen und müssen in Ritualen beschenkt und ,befriedet' werden.

Das secondary haunting beschreiben die Lincolns ${ }^{86}$ als metaphorisches Spuken: in öffentlichen Debatten wird es als Ausdruck im Kontext des Erinnerns, des andauernden Schmerzes und von Schuldzuweisungen verwendet. Wissenschaftliche Abhandlungen dieser Form der Geistererscheinungen liegen beispielsweise von Gordon (2008), Carsten (2007) oder Davis (2007) vor, die diese Geister zwar als existent einstufen, doch nicht als Subjekte, sondern als Repräsentanten eines kollektiven, moralischen Gewissens. Sie werden demnach nicht individuell, sondern anonym und kollektiv verstanden, wie am Beispiel der ,Geister des Holocausts' (vgl. Feuchtwang 2011: 139) deutlich wird.

"Here, as in secondary haunting generally, the ghost becomes an exceptional moral agent who serves as a constant goad to the living, while permanently deferring their redemption" (Lincoln und Lincoln 2015: 202).

Die Geister handeln demnach nicht selbst, sie werden von Menschen in Texten oder Sprechakten in Erinnerung gerufen. Dabei können sie nicht befriedet oder erlöst werden, sondern sollen die Erinnerung an ein Verbrechen aus der Vergangenheit aufrechterhalten. Die Lincolns zitieren beispielhaft aus ihrer Forschung den Ethnologen Nguyễn-võ Thu-hương, dem zufolge Länder wie die USA und Vietnam „für immer“ (ebd.) von den Geistern ihrer kriegerischen Vergangenheit heimgesucht werden würden.

Die Unterscheidung dieser beiden Arten von Geistererscheinungen ist einerseits von Nutzen, um wissenschaftliche Veröffentlichungen zum Thema ,Geister zu kategorisieren; andererseits zeigt das Beispiel von Kambodscha im Gegensatz zu Vietnam, dass die beiden Kategorien von Totengeistern auffallend unterschiedliche Präsenz im kambodschanischen Alltag haben.

\subsection{Historische Phasen des Umgangs mit Khmer-Rouge- Toten}

Während der Zeit der Roten Khmer waren Verstorbene allgegenwärtig. Von einigen gut dokumentierten Orten wie dem Foltergefängnis Tuol Sleng in Phnom Penh ist bekannt, dass die Gefangenen in Trucks nach Choeung Ek gefahren, dort umgebracht und in Massengräbern verscharrt wurden.

\footnotetext{
${ }^{85}$ Begrifflich wird dabei der gewaltsame Tod mit khmoc tāy hoì bezeichnet, während die anderen Begriffe vor allem das Fehlen von Bestattungsritualen implizieren.

${ }^{86} \mathrm{Da}$ es sich bei Martha Lincoln um die Tochter von Bruce Lincoln handelt, erlaube ich mir diese Schreibweise.
} 
Oftmals wird jedoch mit dem Fokus auf diese bekannten Gedenkstätten übersehen, dass dieser Ort schon bei seiner Errichtung eine Ausnahme darstellte, da hier viele ehemalige Kader des Regimes ermordet wurden und es insgesamt stringenter organisiert wurde (Bennett 2015: 54). Normalerweise wurden die Toten in beliebigen Waldstücken exekutiert und dort liegen gelassen - oder sie mussten dort liegen gelassen werden, wo sie an Erschöpfung, Hunger oder aus anderen Gründen gestorben waren. Von der Insel Koh Sop berichtet ein Anwohner:

"[The bodies were left] like rubbish, where they died; they were left where they were put. Sometimes they dug some dirt to cover them. Many of them were killed and they left the bodies here and there. The clothes, the blood, the hair were still fresh. They killed people all over the land" (Bennett 2015: 69).

Das Begräbnis Toter oder das Trauern um Verstorbene stellte für die Roten Khmer Formen von Sentimentalität und Religiosität dar, die mit dem Tod bestraft werden konnten. Mit der ständigen Präsenz der Toten sollte zudem ein Exempel statuiert werden, welches vor ungehorsamen Verhalten warnen sollte (Arensen 2017: 75).

Nach dem Sturz der Roten Khmer durchliefen Totengeister verschiedene Stadien, die auf verschiedene Nachtodkonzeptionen verweisen und somit zu scheinbar widersprüchlichen Existenzweisen der Geister führte. Zum Verständnis dieser komplexen Alternation der Geister orientiere ich mich im Folgenden an Bennetts Vorschlag, die historische Entwicklung der Totengeister seit 1979 in vier Phasen einzuteilen:

"In each area the dead had undergone similar changes: from frightened and frightening entities that haunted [1], to benevolent dead helping the living [2], to powerless spirits waiting to be reborn [3], to reincarnated beings now inhabiting Cambodia [4]" (Bennett 2015: 137, Nummerierung durch Autor).

Die erste Phase, direkt nach dem Sturz der Roten Khmer, beinhaltete demnach primary hauntings der Totengeister, die in dieser Konzeption als khmoc ${ }^{87}$ bezeichnet werden. Diese wurden unterschiedlich ,aufdringlich ${ }^{6}$ wahrgenommen. Einige meiner Gesprächpartner_innen sahen leuchtende Erscheinungen oder Schatten über den Gräbern schweben, andere wurden von ihnen in Menschengestalt im Traum heimgesucht. Bedrohlich wirkten die Beschreibungen nur selten - und die von ihnen hervorgerufenen (meist gesundheitlichen) Probleme konnten stets mit kleinen Opfergaben im privaten Kontext gelöst werden. Darum war auch an den Massengräbern und in den Dörfern, in denen zahlreiche Menschen gestorben waren, die Angst vor khmoc nicht besonders groß. Die meisten Menschen kämpf-

\footnotetext{
${ }^{87}$ Der Terminus khmoc (gesprochen: ,khmaodj) ist vom Verb khüc (,verderben, sterben') abgeleitet (Pou und Ang 1987-1990: 100) und weist keine Pāli-Herkunft auf. Die Bedeutung dieses Terms ,includes a strong element of continued animation, intentionality and potential danger" (Davis 2009: 110).
} 
ten nach 1979 selbst noch um ihr Überleben. Sie pflanzten Reis oder Obstbäume auf die Massengräber, oder verlegten Märkte in die Nähe der Gräber, um die Geister dort durch den Betrieb der Menschen zu vertreiben (Guillou 2012: 216).

Die khmoc wurden, ähnlich wie die Menschen zu damaliger Zeit, als verängstigt, orientierungslos und hungrig beschrieben. So wie viele Menschen nach der Vertreibung der Roten Khmer verhungerten, starben nach Aussagen einiger Kambodschaner_innen zahlreiche Totengeister aufgrund mangelnder Opfergaben. Die Bereitschaft, Nahrung mit den hungernden Geistern zu teilen, war aufgrund der Notsituation beschränkt. Begründet wurde dies auch damit, dass die khmoc aufgrund der massiven Dislokation der Bevölkerung in den Jahren davor nur in den seltensten Fällen der eigenen Familie angehören würden und die Pflege der Toten normalerweise in der Verantwortung der Familienangehörigen läge (Arensen 2017: 75).

Auch einige Monate später, in der zweiten Phase, war die Angst vor den Totengeistern nicht besonders ausgeprägt, was sich einerseits durch den alltäglichen Umgang mit dem Tod in den Jahren davor und andererseits mit der akuten Notlage erklären lässt. ${ }^{88}$ Leichenfledderei war in dieser Zeit der Not weit verbreitet. In den Erzählungen über diese Zeit wird das Finden von Wertsachen als aktives Wirken der Totengeister verstanden. Nach Meinung der Überlebenden ,schenkten' die Totengeister ihnen beispielsweise das gefundene Zahngold und halfen ihnen damit zu überleben. Andere Form der ,Hilfestellungen` sollen die Totengeistern in der Nahrungsbeschaffung geleistet haben. Die Reisernte soll auf den Massengräbern reicher ausgefallen sein; die Krabben und Fische, die jahrelang mit den Toten der Roten Khmer gefüttert worden waren, sollen enorme Ausmaße angenommen haben. In manchen landwirtschaftlich genutzten Feldern manifestierten sich die Toten laut Aussagen der Anwohner_innen in Pflaumen, die, voll mit Blut ${ }^{6}$ waren und in Mangos, die ihrer Meinung nach menschliches Fett beinhalteten (Bennett 2015: 140-141). Obwohl diese Nahrungsmittel aufgrund des khmocEinflusses als unrein galten, waren sie in der Zeit des Hungerns von existentieller Bedeutung für die Überlebenden.

Innerhalb weniger Jahre verebbten sowohl die anfragenden Erscheinungen als auch die Hilfe der Geister. ${ }^{89}$ In der dritten Phase warteten die Toten nun, abhängig von ihrem individuell angesammelten Karma, auf ihre Wiedergeburt. Zu dieser Zeit werden die meisten widersprüchlichen Aussagen zu Totengeistern gemacht. Den Grund hierfür bilden zwei konkurrierende Nachtodkonzeptionen, die ich als

\footnotetext{
${ }^{88}$ Guillou berichtet beispielsweise, dass die Kinder der Überlebenden mit den Schädeln der Toten gespielt hätten (Guillou 2012: 216).

89 Andere Geister, wie anak tā, traten in Erscheinung. Sie wurden im Gegensatz zu den Totengeistern als mächtig wahrgenommen und verehrt (siehe nächstes Kapitel).
} 
brahmanistisch (im emischen Sinne von vor-buddhistisch ${ }^{90}$ ) und buddhistisch interpretiere.

Nach mehreren Ausführungen von Überlebenden, die ich auf eine brahmanistische Konzeption zurückführe, warteten die Totengeister in der Welt der Menschen auf ihre Wiedergeburt und behielten das Potential einer plötzlichen Erscheinung bei. ${ }^{91}$ Sie entsprachen der Konzeption der primary hauntings, in dem ihnen aufgrund ihres, schlechten Tods' bis zu ihrer Wiedergeburt Handlungsfähigkeit als khmoc zugeschrieben wurde. Zudem wurde ihre Situation, wie oben angedeutet, in der Welt der Menschen in deutlicher Korrelation mit den Lebensumständen der Menschen gesehen: diese Geister konnten sogar zu nützlichen Verbündeten rekrutiert werden, und entsprachen der Perzeption von ,unsichtbaren Mitmenschen'.

Die vierte Phase war von der Revitalisierung des buddhistischen sangha geprägt, die nach 1989 zu einem verstärkten Wiederaufgriff der buddhistischen Nachtodkonzeption führte. Für den rituellen Umgang mit Verstorbenen aus der Rote Khmer-Zeit wurde die buddhistische Praxis jedoch kaum in Anspruch genommen, da die Toten (aufgrund ihres geringen Karmas eines schuldlosen Todes) damals schon als wiedergeboren verstanden wurden.

"However, even once Buddhist rituals were re-established, few occurred for the dead, either individually or collectively. They did not need to be, because the dead would be reborn" (Bennett 2015: 170).

Stattdessen wurde die hohe Zahl der Geburten in den 1980er und 1990er Jahren mit den Wiedergeburten der Toten erklärt, die nun erneut Kambodscha bevölkerten. Wie Davis (2015b, 2008a), Thompson (2008: 103-105) und Bennett (2015) beschreiben, gibt es heute zahlreiche Menschen, die ihre verstorbenen Verwandten in ihrer Wiedergeburt in einem anderen Körper erkannt haben und ihre Beziehungen, teils über weite Entfernungen, pflegen. Die Vorstellung, die Toten nun wieder als neue Menschen (nur selten als Tiere) unter den Lebenden zu wissen, sorgte für Erleichterung bei den Hinterbliebenen.

\subsection{Das heutige Verständnis von Totengeistern}

Bis heute dominiert diese buddhistische Konzeption von Totengeistern das Verständnis von kambodschanischen Totengeistern. Davis (2009: 119) kommt zu dem Ergebnis, dass die moralische Autorität, die buddhistischen Akteuren heute zugesprochen wird, aus ihrem rituellen Umgang mit dem Tod abgeleitet werden muss. Davis' Analyse von kambodschanischen Bestattungsritualen zeigt, dass die

\footnotetext{
${ }^{90}$,Vorbuddhistisch' meint im Folgenden jene Zeit vor dem 13. Jahrhundert, worunter ich sowohl die ,animistischen' als auch die indisch-brahmanistischen Kulturausprägungen verstehe.

${ }^{91} \mathrm{Vgl}$ übereinstimmend dazu die Berichte in Bennett (2018, 2015) und Arensen (2017: 72).
} 
Rituale der buddhistischen Kremation eine performativ veranschaulichte Dominanz über die vor-buddhistischen Konzepte braling92 und khmoc darstellt (Davis 2015a, 2009). Nach dem Tod wird den für den Buddhismus grundlegenden Konzepten von Karma, Verdienst und Wiedergeburt in ihrer oben beschriebenen Wechselwirkung eine hohe Bedeutung zugeschrieben - womit die brahmanistische Nachtodkonzeption überlagert wird, was auch an der veränderten Bezeichnung der Totengeister als preta (gesprochen: ,pret') - statt khmoc - deutlich wird.

Nach der Kremation, die sieben Tage nach dem Tod stattfinden sollte, kommen die Totengeister nach buddhistischer Vorstellung zu Yum Riek, dem Herrscher über die ,untere Welt' (thān norok). ${ }^{93}$ Yum Riek ist die kambodschanische Bezeichnung des Gottes Yama, der sowohl im Rgveda als auch im Pāli-Kanon als Richter über die Toten beschrieben wird. Er wird weder verehrt ${ }^{94}$ noch besonders gefürchtet; er gilt stattdessen als unbarmherziger Richter über die preta. Das Karma, das Menschen in ihren vorherigen Lebenszyklen anhäuften, wird demnach von Yum Riek mit dem gesammelten Verdienst (punya) des Lebens aufgewogen und in eine Zeitspanne umgerechnet, die die Toten in der Hölle verbringen müssen. Je nach Menge des gesammelten Karmas variiert der Zeitraum zwischen zwei Wochen bis zu drei Jahren, bis Yum Riek eine Wiedergeburt erlaubt. Nur Mörder von Mönchen oder ähnlich schlimme, moralische Vergehen können mit einem Verbleib in der Unterwelt von bis zu 20 Jahren bestraft werden. Während des Zeitraums im Reich Yum Rieks werden preta Folter, Hunger und anderen Qualen ausgesetzt, was ein beliebtes Motiv von Wandbildern in Pagoden darstellt und vor moralischen Vergehen abschrecken soll.

92 Braling stellt eine Kategorie von (neunzehn verschiedenen) Lebenskräften dar, die die Konzeption des menschlichen Körpers (rüpa) um eine geistliche Ebene erweitern (ähnlich zum christlich geprägtem Konzept der ,Seele'), siehe nächster Abschnitt.

${ }^{93}$ In abweichenden Interpretationen gab es für Tote, die in ihrem Leben wenig oder keine moralischen Regelverstöße begangen hatten, eine kurze Zwischenphase, in der sie sich für wenige Tage oder Wochen frei zwischen Unterwelt (thān norok), Welt der Menschen (thān manuss) und dem Himmel (thān suok) bewegen konnten.

${ }^{94}$ Holt gibt an, dass eine Statue von Yama vor dem Wat Oudon in Phnom Penh steht (2012: 50-51). Die Ikonographie der Statue, sowie die Übersetzung eines der vierzehn Namen Yamas als ,Stabträger ' bringt ihn historisch mit dem sogenannten ,Lepra-König‘ und dem Geist lok tā Dambang Deik in Verbindung, was den Umstand erklärt, dass die gleiche Statue bereits als Repräsentation des Lepra-Königs beschrieben wurde (Hang 2004). 


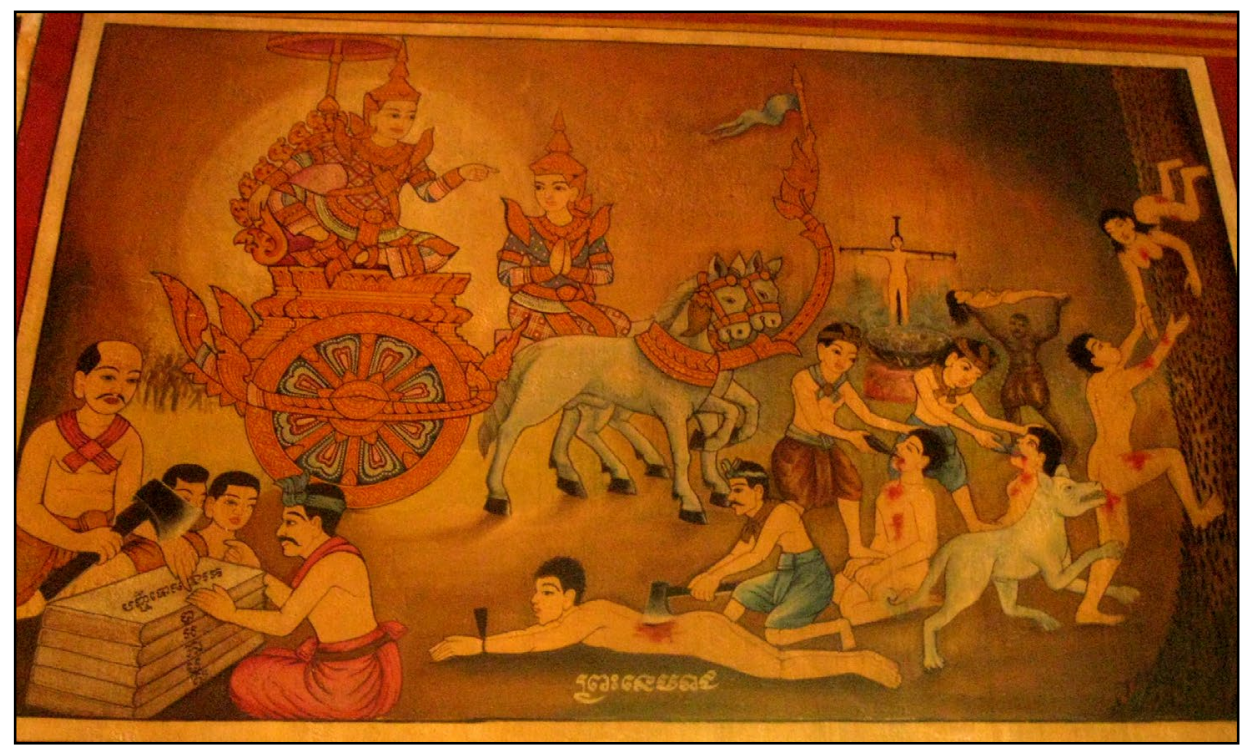

Abb. 7: (C) Autor. Wandbild des Wat Phnom, Phnom Penh. Am linken Bildrand ist Yum Riek qu sehen, der einem neu angekommenem khmoc sein Urteil verliest.

Auffällig an dieser Gegenüberstellung der brahmanistischen und der buddhistischen Nachtodkonzeption ist der Unterschied im örtlichen Verbleib der Toten bis zu ihrer Wiedergeburt. In der heute dominanten Vorstellung werden die Totengeister nicht mehr unter den Lebenden verstanden, sondern nach sieben Tagen von ihnen sondiert und in das Reich der Toten verbannt. Sie verschwinden in der anonymen Masse der preta und können nur indirekt kontaktiert werden, indem buddhistischer Verdienst für sie gesammelt wird.

Hier sind beispielsweise die Rituale von bhjum pinda zu nennen: nach kambodschanischer Vorstellung werden in jenem fünfzehntägigen Rahmen die preta von Yum Riek auf die Erde gelassen, doch ihre individuelle Präsenz wird oftmals aufgrund ihrer Orientierungslosigkeit und ihrer Handlungsunfähigkeit auf Erden angezweifelt. Ihre Anwesenheit ist auch nicht notwendig, da der Verdienst der Opfergaben auch an bhjụ pinda, wie in buddhistischen Ritualen üblich, unabhängig von ihrer Präsenz an eine anonyme Masse der preta gerichtet wird. Selbst hier, in der kurzweiligen Präsenz der preta auf Erden, wird nach buddhistischer Kon- 
zeption eine Existenzweise der Totengeister offenbar, die von Anonymität, Kollektivität und einem Mangel an Handlungsmacht ${ }^{95}$ geprägt ist.

Auffällig an der buddhistischen Konzeption der preta sind die Analogien zu der metaphorischen Erscheinungsform von Toten als secondary hauntings nach Lincoln und Lincoln (2015). In Übereinstimmung mit dieser Kategorie des Spukens werden preta als Repräsentanten eines kollektiven, moralischen Gewissens verstanden, deren armselige Existenz (bis zu ihrer Wiedergeburt) als Warnung vor Verstößen gegen buddhistische Grundsätze in Erinnerung gerufen wird.

Die Unterscheidung dieser beiden Nachtodkonzeptionen in ihren Ausprägungen buddhistisch/brahmanistisch und primary/secondary haunting veranschaulicht nicht nur verschiedene Existenzformen der Totengeister zwischen unsichtbaren ,Mitmenschen' oder schuldig wahrgenommenen Gefangenen; es bringt erste Erkenntnisse über die alltägliche Perzeption von Totengeistern, die von hybriden Vorstellungen beider Konzeptionen geprägt ist. In der heutigen Wahrnehmung werden die Geister der Toten (nach der Kremation des Leichnams) als abwesend verstanden, während ihnen jederzeit das Potential eingeräumt wird, in Träumen, Visionen oder Erscheinungen zu erscheinen. Dies wirkt zunächst widersprüchlich; doch wie ich zeigen konnte, verdeutlicht dieses Verständnis lediglich die parallele Anwendung zweier Existenzweisen, in denen die Totengeister entweder buddhistisch als preta oder brahmanistisch als khmoc auftreten können.

In der Praxis gibt es keine bewusste Differenzierung zwischen diesen Nachtodkonzeptionen, die ich hier zum besseren Verständnis voneinander abgrenze. Rituale der Geistbesessenheit bieten Räume der kreativen Komposition verschiedenster Vorstellungen und Konzeptionen unter der Leitung der Medien - auch in der Praxis mit Totengeistern. Obwohl diese Rituale die einzige Möglichkeit schaffen, Totengeister bewusst zu kontaktieren, stellten sie nach 1975 keine populäre Form der lokalen Verarbeitung von Verlust- und Trauergefühlen dar. Dies lag zum einen daran, dass es direkt nach der Vertreibung der Roten Khmer kaum Geistmedien gab. Zum anderen war der Zeitraum vor der Reinkarnation, in dem der Kontakt hätte stattfinden müssen, auf wenige Jahre beschränkt. In dieser Zeit konnten die Menschen nur wenig spenden, weil sie sich um die Wiederherstellung ihrer Lebensbedingungen kümmerten.

Heute bieten einige Medien Rituale an, in denen kürzlich Verstorbene zurückgerufen werden. Diese als brahmanistisch geltende Praxis ist keineswegs unangefochten. Nach der Kremation, so die Mönche, sei der Buddhismus die einzig legitime Anlaufstelle zur (indirekten) Kontaktaufnahme mit den Toten. Daher spre-

${ }^{95}$ Die preta gelten als machtlos - von ihnen kann keine Gefahr ausgehen. Sie können auch keinen Segen spenden oder den Menschen behilflich sein. Beispielhaft für ihren niedrigen Status lässt sich während des Rituals poh pāy pinda beobachten, wie Opfergaben auf den Boden geworfen werden, was laut Davis (2009: 181) eine respektlose Handlung gegenüber den preta darstellt, der jedoch als gerechtfertigt angesehen wird, da die Toten diesen Zustand nur erleiden müssten, weil sie schlechte Taten begangen hätten. 
chen die Klient_innen nicht gern über ihren Besuch bei solchen Medien. Thre Motivation besteht darin, eine der selten angebotenen Möglichkeiten wahrzunehmen, kürzlich verstorbene Verwandte oder Freunde noch ein letztes Mal sprechen zu können. Obgleich den Totengeistern wenig oder gar keine Macht zur magischen Einflussnahme in die Schicksale von Menschen zugeschrieben wird, nutzen die Klient_innen die Rituale zur Überwindung ihrer Verlustschmerzen.

Im Folgenden stelle ich anhand eines Beispiels vor, wie sich die verschiedenen Nachtodkonzeptionen in einer hybriden Ritualpraxis manifestieren. Der Besuch bei gru Yumm zeigt ihre rituell herbeigeführte Transformation von preta in khmoc - unter mühsamen Anstrengungen die buddhistische preta-Konzeption nicht in Frage zu stellen. Die streng regulierte Form von Präsenz der Totengeister setzt eine Ausnahmereglung von Yum Riek voraus, die erst nach langen Verhandlungen erreicht werden kann. Das Ritual repräsentiert zwar eine geächtete brahmanistische Praxis mit Toten, doch es wird deutlich, dass die buddhistische Nachtodkonzeption letztlich bekräftigt wird.

\subsubsection{Grū Yumm und die Rituale zum Zurückrufen der Toten}

Grū Yumm war bei meinem ersten Besuch (im Oktober 2012) 67 Jahre alt und bewohnte ein einfaches Holzhaus auf hohen Pfeilern in der Provinz Kampong Cham, Region Preak Pou, in der unmittelbaren Nähe des Mekong. Obwohl sie als Geistmedium einen recht hohen Bekanntheitsgrad erreicht hatte und täglich Klient_innen empfing, lebte sie in sehr einfachen Verhältnissen. Die drei Häuser, in denen sie mit den Familien ihrer beiden Töchter lebte, waren aus Holz; die fünf Erwachsenen teilten sich lediglich zwei ältere Mopeds. Im Vergleich zu Medien von anderen Geistern wurde ihr sozialer Status aufgrund ihrer Mittellosigkeit und ihrer Praxis mit Toten als gering wahrgenommen.

Dies wurde auch im Gespräch mit Bunnwath deutlich, der grū Yumm als besonders un-buddhistisch einstufte. Es hatte für Bunnwath ,überhaupt nichts mit Buddhismus zu tun", wenn man Tote in ihrem Status zwischen Tod und Wiedergeburt in die Welt der Menschen holte, um sie dort noch einmal sprechen zu können. Wie ich später bemerkte, teilte sogar die Mehrheit von Yumms Klient_innen diese Ansicht. Die grū war sich dieser Vorwürfe durchaus bewusst. Im ersten Interview gab sie an, den größten Teil ihrer Einnahmen an die örtliche Pagode, beziehungsweise für buddhistische Zeremonien zu spenden. Bunnwath betonte danach, dass sie sich durch ihre Rituale mit den Totengeistern eben mehr als andere Menschen engagieren müsste, um als praktizierende Buddhistin wahrgenommen zu werden.

Zudem wird, wie oben dargestellt, Totengeistern keine pāramī zugeschrieben. Dies hatte bedeutende Auswirkungen für grü Yumm und ihre Geister-Praxis. Sie konnte den üblicherweise an grü herangetragenen Anfragen nach besseren Geschäften, Zukunftsprognosen oder einer Einflussnahme auf die Zukunft der Klient_innen nicht nachkommen. Ihrer Arbeit haftete also nicht nur etwas Un- 
buddhistisches, sondern auch der Ruf eines geringen Handlungsspielraums an. Das ließ sie während der Rituale noch mehr zu einer passiven Vermittlerin für ihre Geister werden als es andere gru mit spirituell konzipierter Handlungsmacht (pāramī) taten. Somit wurde die grü, ähnlich wie die Totengeister, bestenfalls bemitleidet, keinesfalls jedoch hochgeachtet. Das machte sich beispielsweise in der Höhe der Spenden bemerkbar. Für ein einstündiges Ritual wurden ihr selten mehr als vier US-Dollar gespendet - so viel wie andere gru (von anak tā) für einen kurzen Segen bekommen konnten.

Die rituelle Praxis mit Totengeistern von grū Yumm wurde hov braling (,das Rufen der braling) genannt. Dabei müssen zwei Auslegungen dieses Rituals unterschieden werden. Nach orthodoxer Interpretation, die Ang (2004) und Thompson (2005) beschreiben, stellt braling eine Lebenskraft dar, von der jedes Individuum neunzehn verschiedene besitzt. Diese könnten durch plötzlich auftretende, negative Ereignisse, verloren' gehen, wodurch dieses so entstandene Ungleichgewicht im Körper Krankheiten begünstigen würde. ${ }^{96} \mathrm{Um}$ die verlorenen braling wieder in den Körper ,zurückzurufen' (hov), müsste hov braling durchgeführt werden. In Abgrenzung zur Konzeption des formalen Ritualablaufs nach Thompson (ebd.) muss betont werden, dass yāy Yumm ein gleichnamiges, jedoch grundverschiedenes und eigen konzipiertes Ritual durchführte. Nach ihrer Auslegung steht braling synonym für khmoc als ,tote Person' oder ,Totengeist'. Das Zurückrufen der braling beinhaltet für Yumm demnach die direkte Kontaktaufnahme zu khmoc und keine gesundheitliche Maßnahme zum Sammeln der körperlichen Lebenskräfte. ${ }^{97}$

Im Folgenden stelle ich anhand meiner Feldforschungsnotizen ${ }^{98}$ grū Yumms hov braling-Ritual vor, das zeigt, wie sie trotz der dominanten preta-Konzeption Totengeister zu aktiven khmoc transformiert und wie sie diese Praxis religiös legitimiert. An dem Beispiel wird deutlich, wie die grū deutliche Referenzen auf die buddhistische Nachtodkonzeption herstellt und somit die Vorstellung von Totengeister nach vorbuddhistischer Sicht entkräftet.

„Nach dem kurzen Gespräch mit der Tochter von grü Yumm stiegen wir die Stufen ibres Hauses binauf. Hier gab es nur zwei sehr kleine Holzverschläge zum Schlafen und Umziehen, ansonsten war der Wobnraum gan₹ ibrer Arbeit als Geistmedium gewidmet. Die rechte $W$ and war fast vollständig von ibrem Geister-Schrein pāy sī ausgefuillt. Daneben war Platz für einen Kassettenrekorder, den der circa 40 jäbrige Sohn der grü bediente. Alle Sitzungen wurden mit einem Mikrofon, das direkt vor Yumm stand, aufgezeichnet und anschließend den Klienten für 5 US-Dollar zum Kauf angeboten. Wir sa-

\footnotetext{
${ }^{96}$ Sie werden dabei im Wald (brai) verortet. In Kambodscha gibt es eine weit verbreitete Dichotomie zwischen, (unkultiviertem) Wald‘ (brai) und ,(kultiviertem) Feld‘ (srok), siehe Zucker (2013), Forest (2012) und Chandler (1982), sowie in dieser Arbeit Kap. 5.

97 Ähnlich wie das christlich geprägte Konzept der Seele gilt braling bei Lebenden als inneres Ich, welches den Körper nach dem Tod verlässt und weiter besteht.

98 Alle in diesem Abschnitt zitierten Passagen stammen aus meinem Feldforschungsbericht vom 12.11.2012.
} 
hen die grū auf dem Boden sitzen. Sie war eine ,Großmutter' [yāy], glatzköpfig, mit schwarz gefärbten Zähnen. Ihre Stimme war laut und eindringlich."

In dem hier analysierten Fall bekam Yumm eine Anfrage einer neunköpfigen Familie, die ihren kürzlich verstorbenen Familienvater sprechen wollte. Dafür mussten sie die für jedes kambodschanische Ritual üblichen Opfergaben bereitstellen: Räucherstäbchen, Kerzen, Zigaretten und eine Geldspende. Das Medium stellte danach den Klient_innen einige Fragen über die gesuchte Person: Geschlecht, Familienstand, Alter, Herkunft. Anhand dieser Angaben rief sie, nach einiger kurzen Meditation und einem Gebet, bestimmte Autoritäten herbei, die sie nicht wie üblich dem Schrein zugewandt, sondern in Richtung Raummitte anspricht.

„Die grū bielt bei jeder Antwort der Klient_innen Zwischensprache mit devatāa9 und Yum Riek. Sie fragte damit sozusagen im Himmel [thān suok] und in der Hölle [thān norok] nach, wo der Tote zu finden sei. Während sie die Antworten der Familie jedes Mal für die verantwortlichen Geister wiederholte, beschwerte sie sich bei den Geistern über die generelle Nicht-Einhaltung von buddhistischen Ritualen, die sie als „KhmerRituale" bezeichnete. Ab und zu stellte sie auch konkrete Fragen, die sie von den Geistern weitergab - zum Beispiel, ob es jener Tem Srun ${ }^{100}$ sei, der auch vietnamesisch sprechen konnte. Die Familie bejabte die Frage, überrascht über das Vorwissen und wirkte verunsichert. Die grū erklärte, dass es deswegen schwer gewesen sei, ihn zu finden, weil er nach seinem Tod von Yum Riek nach Vietnam geschickt worden war, dann aber aufgrund seiner Herkunft zurück nach Kambodscha musste. (...)

Nach der Klärung der Identität des Toten erzählte die grū, dass der Gesuchte sich in der Hölle aufhielt, aber noch nicht gefunden worden war. Sie hatte jedoch bereits weitere Informationen über die spirituellen Umstände des Todes von Yum Riek erfahren: Eigentlich sollte die (anwesende) Frau des verstorbenen Familienvaters sterben. Doch aufopferungsvoll wäre Tem Srun einen Tausch mit Yum Riek eingegangen, der ibn daraufhin ins Totenreich bolte und seine Frau verschonte. Wäre er diesen Tausch nicht eingegangen, bätte er laut Yum Riek noch 11 Jabre gelebt und wäre dann erst mit 74 Jabren gestorben. Ob der Mann kurz vor seinem Tod etwas von einem solchen Traum (in dem er mit Yum Riek geredet hatte) erzählt hätte, wollte grū Yumm wissen - plötzlich unterbrach sie die unsicher vorgetragene Antwort streng und fragte stattdessen, ob der Tote regelmäßig zur Pagode gegangen oder sogar Mönch oder ācaryā gewesen wäre. Die Familie erwiderte, er wäre einmal Mönch gewesen - was die grū sofort als Lüge bezichtigte und sich dafür bei den Geistern entschuldigte. „Sie sind dumm und lügen, wollen aber ibren $V$ ater nur in gutem Licht erstrablen lassen, entschuldigt sie", bat die grū mit kräftiger Stimme und untermalte diese Bitte mit ausholenden Handbewegungen in verschiedene

${ }^{99}$ Die devatā (gesprochen: ,tevda ${ }^{9}$ ) sind weibliche ,Gottheiten` der oberen Welt; die lokal als ,Engel ${ }^{6}$ übersetzt werden.

${ }^{100} \mathrm{Im}$ Respekt vor den lebenden und verstorbenen Beteiligten verwende ich an dieser Stelle ein Pseudonym. 
Richtungen. Danach fragte sie die verlegen wirkende Familie nachdrücklich, ob alle erforderlichen Zeremonien am ersten und siebten Tag erfolgt seien und wann die Leiche das erste Mal bewegt worden sei. Die Ehefrau des Toten wusste es nicht mehr, beteuerte aber, dass sie alle Khmer seien und die Bestattung nach der Khmer-Tradition erfolgt wäre."

Deutlich reproduziert Yumm hier die buddhistische Nachtodkonzeption, nach der die Toten im buddhistischen Totenreich eingesperrt waren und von Yum Riek bewacht wurden. Ihre Fragen nach der Einhaltung der Bestattungsriten machte deutlich, welch hohe Bedeutung dieser buddhistischen Praxis ihrer Ansicht nach zukam. Ihr Ritual ließ Einblicke in das Totenreich zu, welches allen buddhistischen Kambodschaner_innen von Wandbemalungen aus Pagoden oder ähnlichen Abbildungen bekannt war und welches nach ihrer Auslegung erstaunlich bürokratisch organisiert war:

„Wieder bat sie bei den nur für sie sichtbaren Autoritäten um Gnade für die unachtsame Familie des Verstorbenen und bemühte Yum Riek und die devatā, in ibren Listen nach dem Namen Tem Srun zu suchen. Den Namen, den sie immer wieder laut und verständlich für die Geister wiederholte, folgte jedes Mal die etwas saloppe Beschreibung „,nur Shorts, dick, 63 Jahre alt“. (...)

Die Gespräche unter Geistern, Klient_innen und grü dauerten nun schon 30 Minuten. Der grū wurden drei Mal (für uns unsichtbare) Formulare von den Geistern vorgelegt, die sie mit weit ausschweifenden Bewegungen in der Luft unterschrieb. Dies waren, ihren Angaben zufolge, unterschiedliche Dokumente und Verträge, die die AusnabmeRegelung eines außerordentlichen Besuchs unter Menschen bescheinigten.

Schließlich sagte die grū der Familie, dass sie den gesuchten Verstorbenen nun gefunden hatte; nach genau 45 Minuten des Aushandelns mit den zuständigen Geistern. Sie sagte: ,Er steht nun direkt vor mir. Shorts, dick und graue Haare: Die Familie sah sich erschrocken um, auch die Zweifler_innen unter ibnen schienen das erste Mal wirklich beunrubigt zu sein. Die grū kündigte an, ihren Körper in wenigen Augenblicken zu verlassen, damit der Geist ihren Körper benutzen konnte. (...) Wenig später fiel die grū regungslos nach binten um und wurde von den Anwesenden aufgefangen."

Dies stellte eindeutig den emotionalen Höhepunkt des Rituals dar, da die Klient_innen nun davon ausgingen, mit dem Totengeist ihres verstorbenen Familienmitglieds zu sprechen. Die meisten Familienmitglieder begannen zu weinen, den Körper der grū zu drücken und zu küssen, während sie sich ihrer Zuneigung für den Verstorbenen versicherten und letzte Absprachen trafen:

„Der Geist des V aters im Körper des Mediums fing dann mit tiefer Stimme an, bedächtig zu seiner Familie zu sprechen. Die Mutter und einige der Kinder weinten. Der Tote sagte, dass er seine beiden Ehefrauen (von denen nur die zweite anwesend war) geliebt habe und alle Kinder gleich liebte. Alte Streits sollten nun vergessen werden. Er erzählte vom Moment des Todes, als er sie alle sprechen und weinen bören, aber nicht mehr ant- 
worten konnte. Der Sohn betonte unter Tränen, wie sehr er seinen Vater vermissen würde. Dieser tröstete ihn mit der Information, dass seine Qualen in vier Wochen ein Ende bätten, da er dann wiedergeboren werden würde.

Im Verlauf des Gesprächs wurden auch praktische Dinge angesprochen, wie zum Beispiel, dass die Ehefrau das Moped des Verstorbenen nicht verkaufen sollte, weil es später noch jemand brauchen würde. Er fragte auch, ob die Familie seine Brieftasche gefunden habe, die in einer Jackentasche im Haus gewesen sei. (...)

Nach etwa 15 Minuten wurde die Unterredung zwischen den Toten und ibren Familienangehörigen beendet, und der Totengeist musste in das Totenreich zurückkehren. Der Wechsel der Identitäten im Körper der grū war auch in diesem Fall ein hochemotionaler Moment. Denn gehen konnte der Totengeist im Rabmen dieses Rituals nur, indem er seine letzte Todesursache (wie beispielsweise im oben beschriebenen Fall von Tem Srun einen Herzinfarkt) erneut durchlebte. Der Geist des Familienvaters, erlebte" also einen erneuten Herzinfarkt, was die Familienangebörigen emotional hart traf. Kurze Zeit war das Medium wieder Yumm. Die Ein- und Austrittspraktiken der Besessenheit waren für sie eine anstrengende Aufgabe, und nach jedem Ritual musste sie sich etwas erholen, bevor die nächsten Klient_innen ihr Anliegen vortragen durften."

Das Beispiel zeigt die hybrid verstandene Konzeption des Nachtods in Kambodscha. Gerade Praktiken von Medialität sind Anlässe einer kreativen Auslegung vorhandener Glaubensinhalte. Grü Yumm verhalf kürzlich verstorbenen preta zu einer aktiven Rolle als khmoc, wie sie selbst betonte. Durch die direkten Aushandlungen mit Yum Riek und der Unterzeichnung seiner unsichtbaren ,Dokumente machte sie überzeugend deutlich, wie streng bewacht die untere Welt sei - und nicht zuletzt, dass es sie tatsächlich gibt.

Die Dominanz der buddhistischen Nachtodkonzeption machte sich an der Vehemenz bemerkbar, mit der sie auf die Einhaltung der Bestattungsriten pochte und Regelbrüche bei den zuständigen Geistern anzeigte. In den Interviews mit mir betonte sie die Bedeutung der Karma-Wechselwirkung und schenkte den Umständen des Todes (ob es beispielsweise ein ,guter oder ,schlechter ' Tod sei) wenig Beachtung. Sie hob hervor, dass Tote, die länger als fünf Jahre tot seien, nicht mehr gerufen werden könnten, weil sie dann bereits wiedergeboren seien - sie müssten auf der anderen Seite aber schon mindestens acht Wochen tot sein, weil dann erst alle Formalitäten in thān norok erledigt seien. Mit ihrer Positionierung als gläubige Buddhistin vermied sie konzeptionelle Konflikte mit der buddhistischen Vorstellung des Nachtods; obwohl sie nicht anerkannte Begegnungen zwischen khmoc (nicht preta) und Lebenden ermöglichte.

Diese Hybridität zwischen buddhistischer und vor-buddhistischer Konzeption des Todes erklärt zudem die Attraktivität ihrer Geistbesessenheit. Denn für lang anhaltende Trauer, die Kambodschaner_innen auch nach den buddhistischen Bestattungszeremonien noch empfinden, gibt es nach buddhistischer Vorstellung lediglich die Möglichkeit, Verdienst zu sammeln, doch diese Rituale stellten keine 
direkte Kontaktaufnahme mit individuellen Toten dar. Für diese Klient_innen schafft grū Yumm mit ihrem hov braling Ritual einen ,buddhisierten' Rahmen der brahmanistischen Geistmedien-Praxis.

\subsection{Totengeister in lokalen und nationalen Verarbeitungsprozessen}

Meine These, dass Totengeister in Besessenheitsritualen als Akteure der direkten Artikulation von Erinnerungen an die Zeit der Roten Khmer auftreten können, hatte sich demnach nur bedingt bewahrheitet. Erinnerung und Schuld in Kambodscha werden zwar größtenteils religiös konzipiert, doch anders als in Vietnam gelten sämtliche Geister des Krieges ${ }^{101}$ heute als wiedergeboren.

Während die erste Phase nach der humanitären Katastrophe durch die ständige Wiederkehr der khmoc in Form eines primary haunting gekennzeichnet war, setzte sich anschließend die oben beschriebene buddhistischen Konzeption der preta durch, die die Form von secondary hauntings annehmen. Heute ist die Praxis mit Totengeistern im Speziellen, und anderen Geistern im Allgemeinen von groBer Flexibilität und Kreativität gekennzeichnet, was sich in hybriden Spielarten der oben beschriebenen Ritualpraxis zeigt. So können Schlecht-Verstorbene, die nach den Bestattungsriten als buddhistische Totengeister gelten, dennoch in Formen freiwilliger (hov braling Ritual) oder unfreiwilliger Besessenheit (zumeist naher Verwandter der Verstorbenen) in Erscheinung treten. Dem Einfluss der Theravada-buddhistischen Nachtodkonzeption ist es dabei zuzuschreiben, dass diese khmoc-Erscheinungen zunehmend als harmlos beschrieben werden und die preta größtenteils als abwesend gelten.

Ihre einzige andauernde Präsenz haben Totengeister in Form eines secondary haunting auf politischer Ebene - allerdings werden diese Diskurse in der Bevölkerung nur ungern reproduziert. Nach 1979 bemühte sich die vietnamesischen Besatzungsmacht um die Legitimation ihrer Okkupation, indem sie beispielsweise an strategisch günstig gelegenen Pagoden (das heißt in der Nähe von Massengräbern und staatlichen Institutionen) Knochen und Schädel für Gedenk-Stupas (phdah khmoc) einsammeln ließen (Bennett 2015: 209f; Guillou 2012). Das Foltergefängnis Tuol Sleng wurde direkt nach der Machtübernahme als Museum umgebaut und zum Besuchsort für Staatsgäste umfunktioniert (Chandler 1999). Dort fanden mehrmals im Jahr politische Empfänge oder Zeremonien statt, bei denen die Toten geehrt und als Beleg für die schrecklichen Taten der Khmer Rouge benutzt wurden, womit die Besatzung Kambodschas öffentlichkeitswirksam begründet

${ }^{101}$ Damit sind alle Toten der humanitären Krise zwischen 1970-1998 gemeint, das heißt Opfern der amerikanischen Bombardements (1971-1974), des Genozids der Roten Khmer (1975-79) und der Gefechte zwischen den verbliebenen Roten Khmer Anhängern und den Regierungstruppen (1979-1998). 
werden sollte - was diese Orte für Kambodschaner_innen zu verhassten Exempeln ihrer schmachvollen Niederlage gegen die vietnamesischen Truppen werden ließ (Kidron 2014; Guillou 2012; Hughes 2006).

Mit dem Abzug der vietnamesischen Truppen im Jahre 1989 waren diese Bemühungen nicht mehr nötig: Der Feiertag wurde nicht mehr weitergeführt und die Gedenkstätten nicht mehr gepflegt, bis die Einrichtung des ECCC ${ }^{102}$ eine erneute Legitimation und damit eine erneute Inszenierung dieser Toten erforderte (Bennett 2015:203), in denen diesmal ausländische Institutionen wie NGOs die rituelle Praxis der Totengeist-Inszenierung wieder aufnahmen (vgl. Agger et al. 2012). So werden die Geister der Toten in dieser Form zu Akteuren in einem bis heute vehement geführten Diskurs um Schuld, Gerechtigkeit und Versöhnung.

Die methodischen Denkmuster der Lincolns (2015) und die Untersuchung der historischen Transformation der Totengeister lassen mich zwischen zwei Formen ihrer Existenz differenzieren, die spezifische Ausprägungen der kambodschanischen Spiritscapes offenbaren. Die Interaktion zwischen Menschen und Geistern ist einerseits von einer fehlenden Reziprozität im Gabentausch der rituellen Praxis geprägt, während die Totengeister andererseits von ihrer eingeschränkten Mobilität und ihrer deterritorialisierten Situation charakterisiert werden. Ihre Reise zwischen den Welten darf die 14 Tage von bhjum pinda nicht überschreiten, auch wenn dies die quasi-physische Verkörperung einer erinnerten Vergangenheit darstellt, die während der Rituale von bhjum pinda kollektiv und gegenwärtig wird. Der kurzweilige, spendenbasierte Austausch mit den Toten im Kreis der Familie schafft eine wohl dosierte Konfrontation mit dem Tod und den Toten, die man schon nach wenigen Jahren als wiedergeboren wähnt. Die Reinkarnation stellt hierbei die Reterritorialisierung der Toten dar, die mit einer erneuten Transformation ihres ontologischen Status einhergeht.

Diese lokalen Blickwinkel auf die Geschichte und die Gegenwart der Totengeister eröffnet eine bisher wenig beachtete Perspektive auf den Diskurs von Schuld, Gerechtigkeit und Versöhnung. Ich argumentiere, dass die Existenzweise der kambodschanischen Totengeister von einer hybriden Konzeption charakterisiert ist. So habe ich oben gezeigt, wie ihre angenommene An- und Abwesenheit in Menschenwelt und thān norok zu einer lokalen Verarbeitung des Konfliktes beigetragen haben.

Die hier beschriebene Dynamik der Spiritscapes wird noch sichtbarer bei den Geistern, die weniger stark buddhisiert wurden. Im folgenden Kapitel stelle ich die Existenzbedingungen jener Geister vor, die starke Referenzen auf den Brahmanismus aufweisen und dabei stabile Existenzweisen vorweisen.

\footnotetext{
102 Die „Außerordentlichen Kammern an den Gerichten von Kambodscha“ oder „Extraordinary Chambers in the Courts of Cambodia" (ECCC) sind ein kambodschanisches Sondergericht, das 2006 mit Unterstützung der Vereinten Nationen zur Verurteilung der hochrangigen Rote Khmer-Kader eingerichtet wurde.
} 


\section{Ortsgeister und ihre Existenzbedingungen}

Nach der Verortung der Totengeister als dynamische Akteure zwischen verschiedenen Stadien der Existenz und der An- und Abwesenheit richtet sich der Fokus dieses Kapitels nun auf die ,stabilen' und ständig präsenten Ortsgeister der kambodschanischen Spiritscapes. In diesem Zusammenhang gebe ich Antwort auf die Fragen, welche Geister als existent gelten und wie sich ihre Existenzweisen gestalten. Die Untersuchung der Existenzweisen bewegt sich im konzeptionellen Spannungsverhältnis von Buddhismus und Brahmanismus und der emischen, dichotomen Gegenüberstellung der Ortsgeister zwischen ,Wald“ und ,Dorf‘. Der Konzeption des ,Waldes' ordnet sich dem Khmer-Sprachgebrauch nach alles Wilde, Chaotische und Ungezähmte zu. Im Gegensatz dazu steht sruk nicht nur für den ,zivilisierten' Lebensbereich der Menschen, sondern auch das gleichnamige, landwirtschaftlich genutzte Feld. Die lokalen Ausprägungen und gesellschaftliche Relevanz dieser Konzeption wurden in der wissenschaftlicher Literatur ausgiebig beschrieben (Davis 2015a: 82-86; Zucker 2013; Arensen 2012; Edwards 2008a; Ang 1993; Pou und Ang 1987-1990; Ang 1988, 1986: 116-124; Chandler 1982). Im Folgenden werden in Anlehnung an Ang (1986: 115), Geister des Waldes (khmoc brai) und ,Geister des Dorfes' (khmoc sruk) unterschieden, deren konzeptionelle Grenzen - wie deutlich werden wird - jedoch fließender gedacht werden als in Angs Arbeit (ebd.). Bedeutenden Anteil an der abnehmenden Trennschärfe des Begriffspaars hat, wie am Beispiel der Totengeister bereits deutlich wurde, der 
zunehmende Einfluss des Buddhismus auf die ehemals brahmanistisch dominierte Konzeption der Geisterlandschaft. Allgemein werden die verbliebenen Geister des Waldes heutzutage immer menschlicher, milder und buddhistischer konzipiert als etwa vor 50 Jahren (Forest 1992; Ang 1986). ${ }^{103}$ Diese Prozesse der ,Buddhisierung $^{6}$ können auch bei den Dorfgeistern anak tā beobachtet werden. Als populärste Klasse der Geister stellen sie gleichzeitig die zu höchstem Grad buddhisierten Geister dar und weisen bei Weitem die höchste Relevanz für die kambodschanische Gesellschaft auf. Das wird beispielsweise daran deutlich, dass Geistmedien fast ausschließlich von anak tā besessen werden und auch Rituale im privaten Rahmen vor allem diesen Geistern gewidmet sind. Die wild konzipierten Waldgeister dagegen zeigen weniger Präsenz im kambodschanischen Alltag.

Demnach gehe ich in zwei Schritten vor: Im ersten Teil werden die ,präsenten“ Geister des Waldes ermittelt (Kap. 5.1), um Prozesse der Buddisierung und die Frage der heutigen Permanenz der brai-sruk-Gegenüberstellung zu diskutieren. Anschließend werden die Geister des Dorfes vorgestellt (Kap. 5.2). Am Beispiel des weiblichen Geistes yāy Mao mache ich schließlich die Existenzbedingungen von anak tā sichtbar.

\subsection{Die Geister des Waldes}

Die khmoc brai sind wahrscheinlich die älteste Kategorie von Geistern in Kambodscha. Sie stehen in engem Zusammenhang mit Ritualen der Landwirtschaft und deren Anliegen von Regen oder hohem Ertrag - aber auch mit den Gefahren, denen Menschen in bewaldetem Gebiet ausgesetzt sind wie beispielsweise Angriffe von Tieren, Naturkatastrophen wie Blitzschlag oder Desorientierung in der Wildnis. Heute nimmt die Bedeutung der khmoc brai ab, nicht zuletzt weil große Teile des Waldbestandes durch Abholzung reduziert wurden. ${ }^{104}$ Zahlreiche Geister sollen den Wald daraufhin verlassen haben (Beban und Work 2014; Work 2014; Arensen 2012).

\subsubsection{Brāy}

Die brāy (gesprochen: ,brai') ${ }^{105}$ bilden eine Klasse schädigender Geister von ,schlecht' gestorbenen Frauen vor dem ersten Geschlechtsakt oder von Müttern, die bei der Geburt ihres Kindes gestorben sind. Als Totengeister bilden brāy somit eine ausschließlich weibliche Variante von khmoc, die mir im Gegensatz dazu nicht

\footnotetext{
${ }^{103} \mathrm{Im}$ indischen Kontext, wo heute ehemals wilde, weibliche Göttinnen als sanft und gutmütig (saumya) konzipiert werden, wird dieser Prozess als ,Saumyaisierung' bezeichnet (Zeiler 2008). 1042012 betrug die Quote der jährlichen Abholzung 27\%, was vor allem auf die staatliche Vergabe von ökonomischen Landkonzessionen an private Firmen und den illegalen Einschlag von Tropenholz zurückzuführen ist (Davis et al. 2015).

105 In der englischsprachigen Literatur werden sie preay transkribiert.
} 
anthropomorph, sondern als schwebender, leuchtender Ball beschrieben wurde. Sie gelten als Verursacherinnen von mentalen Krankheiten. In diesen Fällen müssen geschulte Mönche oder Geistmedien die Körper der Betroffenen von den brāy befreien. Ihre Erscheinung wird zudem für chaotische Zwischenfälle verantwortlich gemacht: es kursieren Geschichten, in denen Kambodschaner_innen ihre Kühe auf Bäumen oder ihr Schweine auf Häusern wiederfanden, nachdem sie brāy verärgert haben sollen.

Die in dieser Form noch ,wilden' Geister werden heute zunehmend buddhisiert. Da sie unter der Kontrolle der buddhistischen Institution als ungefährlich gelten, werden sie in Hauptgebetshallen (vihear) von Klöstern eingeladen, um sie so zu zähmen. Dann zeigen die brāy nur noch bei Missachtung der buddhistischen Regeln oder einem Mangel an Respekt mitunter noch ihr gefährdendes Potential gegenüber Menschen (Ang 1988: 38).

\subsection{2 $\overline{\mathrm{Ap}}$}

$\bar{A} p$ (รภ円 $)^{106}$ werden als junge Frauen zwischen zwei Welten beschrieben: Tagsüber verhielten sie sich normal, nachts flöge nur ihr Kopf samt Eingeweiden als blutrünstiger und gefährlicher Geist umher, auf der Suche nach fleischlichen Überresten (beispielsweise Schlachtabfällen oder einer Plazenta nach einer Geburt). Frauen könnten auf zwei Arten zu āp werden: entweder hätten sie eine erblich bedingte Veranlagung oder sie würden von einem Fluch der schwarzen Magie (amboe) zu einem Leben als āp gezwungen.

In ganz Südostasien sind ähnliche Vorstellungen von fliegenden, blutrünstigen, weibliche Geistern verbreitet, deren Kopf selbstständig fliegen kann. ${ }^{107}$ Während der Forschung traf ich allerdings kaum Menschen, die selbst āp gesehen hatten oder eine Frau im Dorf dafür hielten. In Alltagsdiskursen sind sie dennoch sehr präsent, was vor allem auf zahlreiche Kinofilme zurückzuführen ist, die das Thema der ambivalenten, jungen Frau immer wieder aufgreifen (Bräunlein und Lauser 2016; Lauser 2015; Baumann 2013; Baumgärtel 2011). In populären Medien ist das Thema der āp schon seit einigen Jahrzehnten populär: Einer der ersten Filme, der nach der Zeit der Roten Khmer 1980 in Kambodscha veröffentlicht wurde,

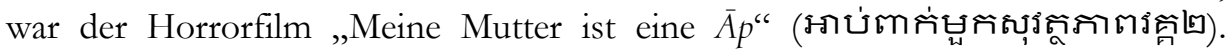
Auch gegenwärtig thematisieren zahlreiche Filme āp und andere ,wilde' Geister. ${ }^{108}$

\footnotetext{
106 Es gibt verschiedene Schreibweisen für āp. In Filmtiteln war früher die Schreibweise ร̊บ่ (āb)

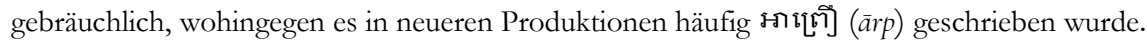

${ }_{107}$ Ähnliche Geister heißen krasue in Thailand, krasu in Laos, hantu penanggal in Malaysia und auf den Philippinen, leyak auf Bali und in Sri Lanka und mai lai in Vietnam (Milladino 2014).

108 Diese Filme weisen komödiantische Züge auf, die mit Schreckens- und Horrorszenen kombiniert

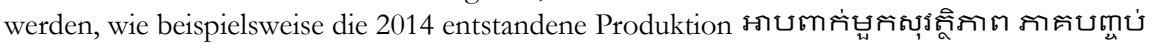
(„Die âp trägt einen Helm“).
} 


\subsubsection{Pisāca}

Auf pisāca (gesprochen: ,beisadj) trifft am ehesten die Übersetzung von ,bösartigen Dämonen` zu, die als solche als nicht ,buddhisierbar' gelten. Sie werden vor allem als Auslöser von mysteriösen Krankheiten identifiziert, somit steht ihre schädliche Wirkung im Fokus vieler Beschreibungen. Pisāca gelten eher als Macht denn als Entität, da ihr Aussehen oder ihre Erscheinungsform ungewiss ist. Der Name pisāca leitet sich vom Sanskrit Wort पिशाच (piśāca) ab und kann als ,unbefriedigter Totengeist' übersetzt werden (Buß 2006). Ihre spontan auftretende Kontrolle über Menschen stellt jedoch einen bedeutenden Unterschied zu den bereits beschrieben Totengeistern dar. Praktizierende der schwarzen Magie (grū dhmáp) werden auch grū pisāca genannt (Kap. 9.5).

\subsection{4 Ārakkh}

Ārakkh (gesprochen: ,arak') hingegen stellt eine Unterkategorie der brāy dar, die ambivalent konzipiert ist (Ang 1986: 115-124). Auf der einen Seite werden sie im Wald verortet und können Menschen krank machen oder unfreiwillig besetzen. Auf der anderen Seite wachen sie über ihre ehemaligen Familien und weisen dabei Ähnlichkeiten zu anak tā als Schutzgeister (einer Dorfgemeinschaft) auf (Pou und Ang 1987-1990: 78). Sie gelten somit als ein Teil der diffusen Kategorie der Ahnengeister. Der populärste Bezugspunkt zu ārakkh beschränkt sich auf Heilungsrituale, in denen die Familien-ārakkh zur Unterstützung eines Heilungsprozesses gerufen werden können. Eine weitere positive Referenz bildet zudem die „ărakkh Musik“ (bhleng ārakkh), die an Zeremonien zur Ehrung von Geistern gespielt wird. Ang (1986: 117) vergleicht diese Geister mit indischen yaksa (यक्ष), die nach der indischen Mythologie ebenfalls sowohl beschützende als auch gefährdende Eigenschaften besitzen.

Weitere ,wild‘ konzipierte Geister (wie die Ahnengeister mepā beispielsweise, siehe Ang (1986: 233-245)) waren trotz intensiver Forschung kaum aufzufinden. Somit scheint es eine Reduktion präsenter khmoc brai seit der Unabhängigkeit gegeben zu haben, da in früheren Schriften wesentlich mehr Klassifikationen getroffen werden (Ang 1986). Entgegen ihrer früheren Konzeptionierung als gefährliche Entitäten wird ihre wahrgenommene Wirkmacht heute größtenteils von moralisierenden Einflüssen des Buddhismus eingeschränkt. Das heißt, sie reagieren eher auf moralische Verstöße und strahlen nur noch selten unmittelbare oder unbegründete Gefahr aus. Auch die weniger buddhisierten Geister zeigen nur noch selten Präsenz, vor allem weil der ihnen per definitionem zugeschriebene Residenzraum des Waldes durch Abholzung massiv reduziert wird.

Die im Folgenden beschriebenen anak tā können als sruk-Geister gelten, da sie grundsätzlich weniger, wild' konzipiert werden. Durch ihre fluide Konzeption und den räumlichen Bezug zur geographischen Landschaft bietet die Metapher der ,Geisterlandschaft ${ }^{`}$ eine adäquate Herangehensweise am Dorfgeister. Die anak tā 
reisen zwischen Welten, durch ihre Präsenz als ,altertümliche` Geister vereinen sie verschiedene Zeitlichkeiten und bestehen (mehr noch als andere Geister) auf eine aufwendige Tauschbeziehung zu Menschen.

\subsection{Die Anak tā}

Die anak tā (oder lok tā) ${ }^{109}$ sind die Geister mit der stabilsten Existenzweise und von großer Bedeutung für die kambodschanische Gesellschaft: „,son importance frappe dès le premier abord tous ceux qui s'intéressent au monde rural khmer" (Ang 1986: 201). Die wissenschaftliche Beschäftigung mit anak tā hat eine lange Tradition, wie an grundlegenden Publikationen von von Porée-Maspéro (1969), Tranet (1981), Ang (1986), Forest (1992), Work (2014) und Guillou (2017c, 2012) deutlich wird.

Die Erscheinungsformen der Ortsgeister anak tā sind vielfältig. Dazu zählen beispielsweise lok tā Dambang Deik, der mit einem Stab (dambang) bewaffnet die Rolle eines strengen Richters einnimmt; Dong Kauk, die Macht des berühmten Geister-Schrein direkt vor dem Königspalast, der einen Kardinalpunkt magischer Macht darstellt oder lok yāy Mao, die ,schwarze Alte', die an die indische Göttin Kali erinnert.

Anak tā werden als ,Verwalter' eines Ortes oder einer Region angesehen (Work 2018; Holt 2009: 16; Harris 2005: 49). Ihr angenommener Zuständigkeitsbereich variiert dabei stark: einige anak tā werden nur innerhalb einer Familie verehrt, anderen wird die Verantwortung für mehrere Dörfer oder Provinzen zugesprochen. Wieder andere Ortsgeister haben sogar nationale oder transnationale Bedeutung (Kap. 9). ${ }^{110}$

\subsubsection{Bezeichnungen und Titel}

Die anak tā werden als Personen (anak oder lok) in Kombination mit der wertschätzenden Verwandtschaftsbezeichnungen $t \bar{a}$ (,Großvater') oder yōy (,Großmutter') angeredet. Die Übersetzung von anak tā oder lok tā lautet demnach ,ehrwürdiger Großvater' und von lok yāy ,ehrwürdige Großmutter' (Ang 1986: 201). Die darauffolgenden Eigennamen der anak tā entstammen entweder den zugeschriebenen physischen Eigenschaften (Bsp. lok tā Krahom Kar - ,Großvater roter Hals', lok yāy Mao, ,schwarze Großmutter') oder seiner materiellen Besitztümer (lok tā Dambang Deik, ,Großvater Eisenschläger). Manche anak tā besitzen auch abstraktere Namen, die auf poetische Weise Wertschätzung für sie ausdrücken, wie lok tā Pih Meas (,Großvater goldener Diamant').

\footnotetext{
${ }^{109}$ Ich verwende lok tā und lok yāy als Titel für spezifische Geister, während anak tā eine übergeordnete Kategorie für alle Ortsgeister bildet.

${ }^{110}$ Einige von diesen populären anak tā wurden zudem von kambodschanischen Migrant_innen in anderen Ländern verehrt (Yamada 2004; Marston 2008c).
} 
Synonym zu anak tā, lok tā oder lok yāy werden diese Geister auch als pāramī bezeichnet, was eine buddhistische Konnotation beinhaltet (Kap. 2.3) und Ang zu der Annahme leitet, dass dies ein Kennzeichen der Buddhisierung der Ortseistern sei (1986: 132-134). Ähnlich wie bei den brāy komme den Ortsgeister heute vermehrt die Rolle der Beschützer der buddhistischen Moral zu (1986: 221).

\subsubsection{Herkunft}

Anak tā werden als verdienstreiche, erleuchtete oder göttliche Wesen beschrieben, die, ähnlich den Bodhisattwas des Mahayana-Buddhismus, zur Erde zurückgekehrt seien, um der Menschheit zu helfen. Viele von ihnen kämen aus der vorbuddhistischen Zeit des Brahmanismus, die gleichzeitig die magische Stärke und die soziale Harmonie dieser Epoche verkörperten. Den Geistmedien gegenüber begründeten die anak tā ihre Präsenz auf Erden oftmals damit, dass sie die ,magische und harmonische Gesellschaft ${ }^{6}$ der Angkor-Zeit wieder herstellen wollten. Dabei lagen exakte Angaben zur Biographie der Geister nicht im Interesse der grū oder ihrer Klient_innen, so dass die Medien meist keine Informationen zur Herkunft der Geister geben konnten.

In Anlehnung an Ang (1986) und Bertrand (2001) lassen sich die Geister ihrer Herkunft nach in fünf Unterkategorien einordnen: Gründer, Götter, Tiere, mythische Helden und Naturerscheinungen. Die (überwiegend männlichen) Gründer eines Dorfes werden als diejenigen erinnert, die den Wald (brai) zum kultivierten Land (sruk) der Menschen transformierten. In einigen Dörfern werden lokale Gründerpersönlichkeiten als Ortsgeister verehrt, die für die (oft landwirtschaftlich geprägten) Anliegen der Dorfbewohner_innen als Hauptansprechpartner gelten.

Andere anak tā können anhand ihrer Bezeichnungen, materiellen Attribute oder Charaktereigenschaften auf hinduistische Götter (brah) zurückgeführt werden, wie beispielsweise lok tā Krahom Kar und lok tā Eysey (Shiva), lok tā Kong Cha und brah Noray (Vishnu) oder brah En (Indra) (Porée-Maspéro 1962: 9). Mit der Ausbreitung des Buddhismus seit dem 13. Jahrhundert sind diese Götter zu einem Teil des Geister-Pantheons geworden und stellen heute lokale Manifestationen der Ortsgeister dar (Chandler 2008: 53; Mus 2011 [1933]). Ihre indische Herkunft ist für die kambodschanischen Gläubigen nicht relevant. Sie werden als kambodschanische Ortsgeister oftmals in Form von Statuen verehrt, die als hoch angesehene anak tā sowohl auf buddhistischen als auch brahmanistischen Schreinen stehen können.

Eine eher niedrig gestellte Subkategorie der anak tā sind die Tiergeister, wie beispielweise Nāga (Siก̃, gesprochen: ,neak'), die bekannte mythische Schlange oder Hanumān, in Affengestalt, der heute nicht mehr als indischer Gott, sondern als Tiergeist bezeichnet wird. Forest (1992) legt nahe, dass sich viele der anak tā ursprünglich von Tiergeistern ableiteten. Nāga soll bereits eine durch indischen Einfluss abgewandelte Form eines mythologischen Krokodils sein, das heute noch 
in einigen spirituellen Kontexten (wie Bestattungen) symbolisch als Fahne in Krokodilsform repräsentiert wird (Davis 2015a: 56; Porée-Maspéro 1962).

Große Bedeutung besitzen zudem die anak tā, die als mythische Helden gelten, obwohl ihre Lebzeiten nicht mehr datiert werden können (Leclère 1899; PoréeMaspéro 1962: 1-16). Vor ihrem Tod hätten diese Helden eine hochrangige Position innegehabt und seien einen gewaltsamen Tod gestorben, wodurch sie sich, ähnlich wie die anderen Totengeister (siehe oben), durch eine andauernd wirkende Präsenz auszeichneten. Das wichtigste Beispiel für eine solche Biographie liefert der populärste aller anak tāa, lok tā Kleang Moeung, ${ }^{111}$ der im Krieg gegen Truppen aus Siam durch seinen Freitod eine ganze Armee von Soldaten-Geistern beschwört haben soll. Auch Pol Pot lieferte in Kapitel 3 eine weitere (wenn auch zeitgenössische) Biographie einer solchen Person, dessen Macht noch lange mit dem Ort seines Todes verbunden bleibt (Guillou 2018).

Schließlich tauchen immer wieder anak tā auf, deren Herkunft aus einer $\mathrm{Na}$ turerscheinung resultiert. Ang bezeichnet diese Geister als „sekundär“, da ihre Präsenz kurzweilig sei und sie von Menschen „erzeugt“ (1986: 208) worden seien. Damit sind anak tā gemeint, die in Pilzen, Palmen, Quellen, Schlangen, Häusern oder Termitenhügeln anhand mystisch anmutender Merkmale ,entdeckt werden, und damit für kurze Zeit eine große Attraktivität für hilfesuchende Menschen erzeugen. Anlässe der Verehrung konnten beispielsweise Python mit magischen Kräften oder ein Baum mit einer Blattzeichnung in Gesichtsform sein, die Menschen zur Heilung oder zu Lotteriegewinnen verholfen haben sollen (Sen 2014; Mom Kunthear 2013, 2012). Anschließend kommen oft Hunderte von Menschen zu diesen Orten, um ähnliche Erfahrungen zu machen. Bleiben sie aus, verwaisen die Orte schnell wieder. Diese anak tā stehen trotz, oder gerade wegen ihrer kurzweiligen Erscheinung im Ruf, eine besonders mächtige pāram̄̄ zu besitzen.

\subsubsection{Materialisation/Orte}

Die anak tā sind die einzigen Geister in Kambodscha, die in materialisierter Form dargestellt werden (Ang 1986: 203). Zuweilen treten sie physisch in menschlichen Körpern in Erscheinung, die meiste Zeit jedoch residieren sie in Objekten. Dabei sind gravierende Veränderungen der letztgenannten Materialisationsformen festzustellen: vor 50 Jahren dominierten noch chthonische Repräsentationen ihr Erscheinungsbild. Sie wurden in Steinen, Termitenhaufen, Bergen, Bäumen oder in antiken Statuen verortet und verehrt. Die Darstellung von anak tā als aufrecht stehender Stein stellt ein Erbe der Verehrung von shiva lingam aus vorbuddhistischer Zeit dar (Tranet 1981; Mus 2011 [1933]; Leclère 1907). Sie verliert wegen wachsender ökonomischer Möglichkeiten und gestiegenen Erwartungen an Geis-

111 ,Kleang' (glāmnn) bedeutet 'Bewacher' und ,Moeung' (mīoeñ) kommt aus dem Thailändischen und bedeutet ,Region, Gebiet'. Er wird auch von kambodschanischen Migrant_innen in anderen Ländern verehrt (Yamada 2004; Marston 2008c). 
ter-Repräsentationen an Popularität, denn seit dem wirtschaftlichen Aufschwung der 1990er Jahre treten anak tā zunehmend in Form von anthropomorphen Statuen in kleinen Häusern aus Beton auf (Work 2018). Diese neuförmige Materialisation von anak tā lässt auf den buddhistischen Einfluss schließen, da die menschlich aussehenden Statuen zunehmend nach buddhistischer Vorbild des im Lotussitz meditierenden Buddha gestaltet werden, was mit den seit einiger Zeit gemachten Zuschreibungen auf ihre Rolle als ,Beschützer des Buddhismus zusammenpasst. Für die Spender_innen stellt die kostspielige Erneuerung von Schreinen und Statuen eine Opfergabe an Geister dar, die ihre Erwartungen auf einträgliche Gegenleistungen steigert.

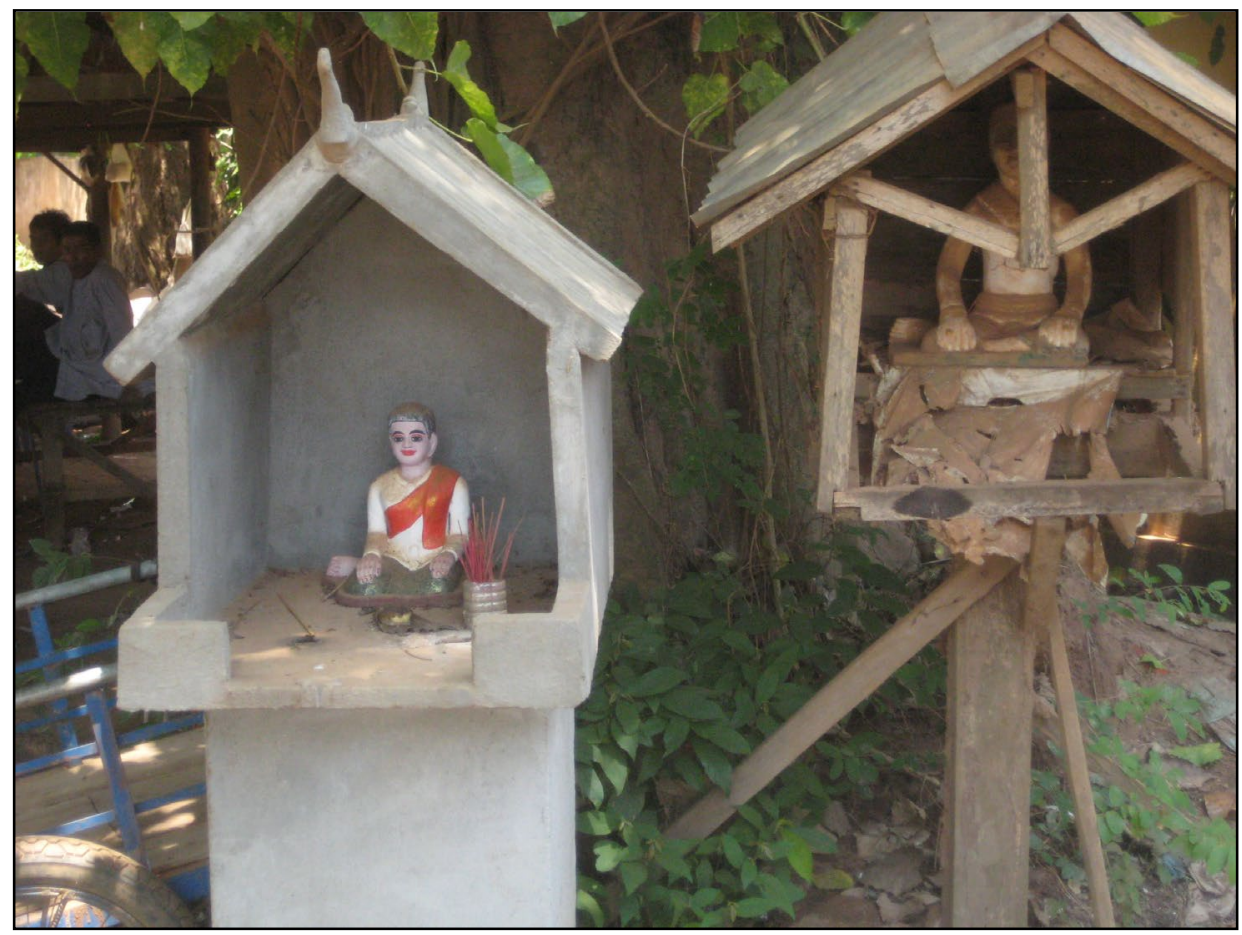

Abb. 8: (C) Autor. ,Buddhisierte' Form eines dörflichen anak tä-Schreins vor einem alten Baum. 


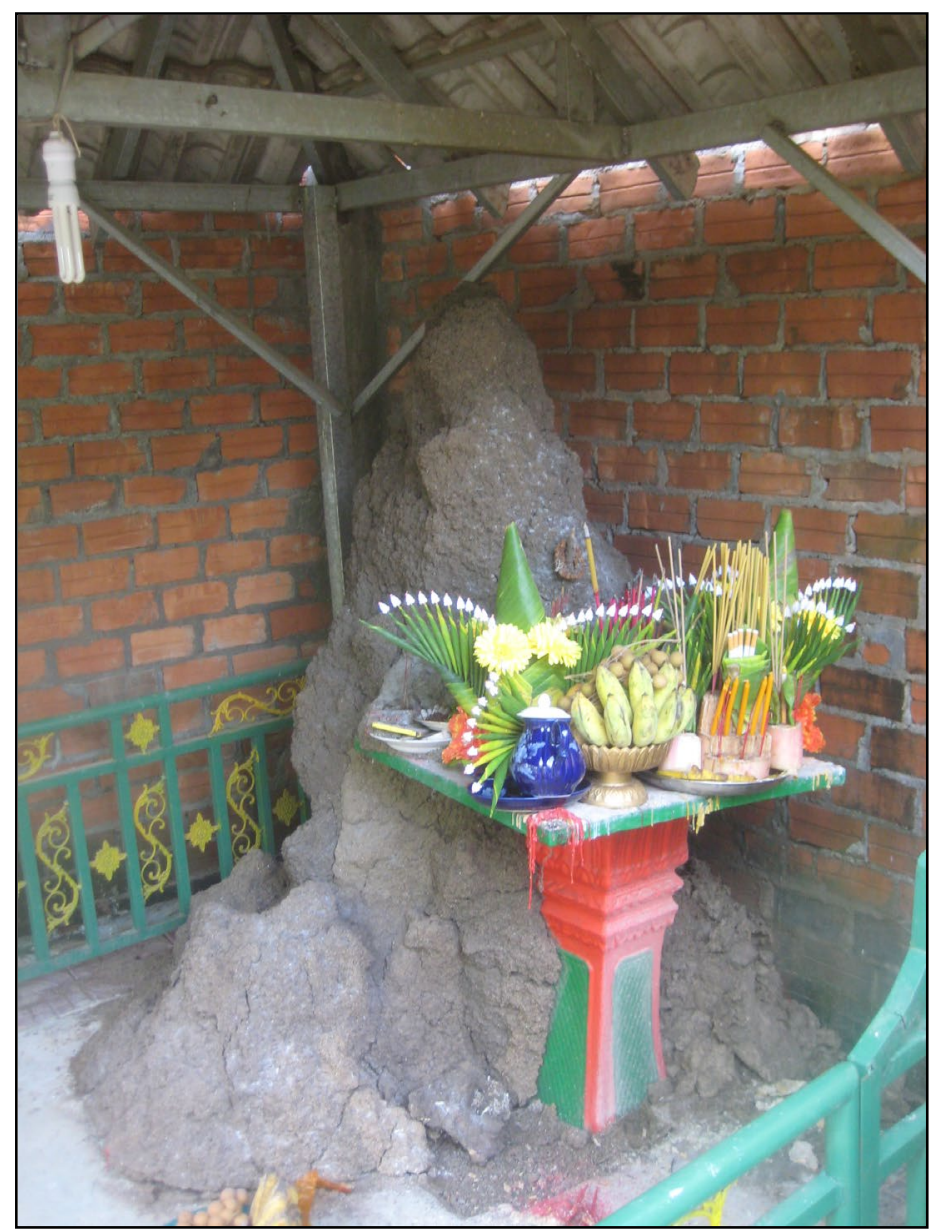

Abb. 9: (C) Autor. Ein Termitenhaufen als Sitž von anak tā, mit Opfergaben.

Eine weitere, bedeutsame Form der Materialisation stellt die Präsenz der Geister in Körpern von Geistmedien dar. Auch bei dieser performativen Verkörperung von Geistern sind fast ausschließlich anak tā involviert. Für die Klient_innen waren die Besessenheitsrituale eine Möglichkeit, direkte Kommunikation mit diesen mächtigen und vielfältigen Geistern zu suchen. Für sie waren die anak tā dabei ebenso präsent wie in den gegenständlichen Erscheinungsformen.

Einigkeit besteht im Alltag darüber, dass alle anak tā mindestens einen eigenen Ort der Verehrung benötigen würden - dies sei essentieller Bestandteil der Konzeption dieser Geister. Erkennen lässt sich diese Tatsache daran, dass Geistmedien ihre Arbeit erst aufnehmen können, sobald sie ihrem Geist einen eigenen Schrein $(p \bar{a} y s \bar{\imath}$ ) gebaut haben. Jedes Dorf hat in seiner Umgebung, vor allem an seinen Grenzen zum ,Wald', mehrere anak tā-Schreine. Sie liegen meist an güns- 
tig konzipierten Orten wie alten Bäumen, Wegkreuzungen, Steinen, von Menschen verlassenen Häusern, Bergen oder Flüssen. Dabei korrelieren Identität und Erscheinungsform eines Geistes nicht zwangsläufig. Die pāramı̄ eines Dorfgründers könnte somit ebenso wahrscheinlich in einem Termitenhügel residieren wie in einer buddhisierten Statue.

Die Geister-Schreine ( $p \bar{a} y$ s $\grave{\imath}$ ) der Medien sind in der Regel aufwendiger gestaltet als der Dorf-anak tā. Die grū statten sie mit einer Vielzahl von Statuen, (Halbedel-)Steinen, Räucherstäbchen und sonstigen dekorativen Artefakten aus, die für religiöse Anlässe auf Märkten gekauft werden können. Dazu gehören mit Palmenblättern verzierte Kerzen und Kokosnüsse, Schmuckelemente aus farbiger Alufolie, Metall- oder Keramikstatuen und Opfergaben in Form von Wasserflaschen und Obst. Auffällig an den Schreinen der anak tā ist die Ähnlichkeit zu buddhistischen pāy sī, die dem Dharma, gewidmet ${ }^{{ }^{1112}}$ waren.

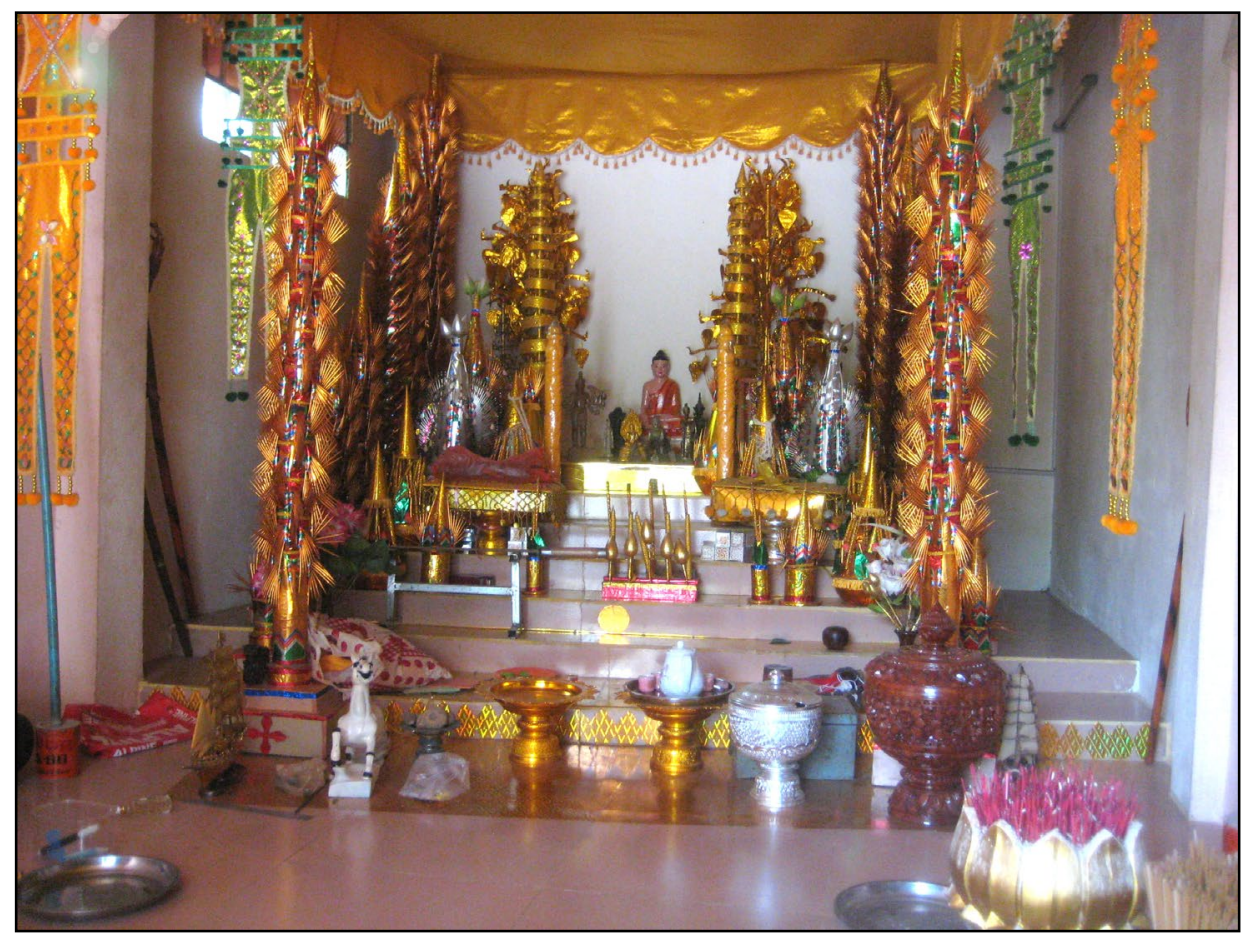

Abb. 10: (C) Autor. Anak tā Schrein eines Geistmediums, Provinz Takeo.

$112 \mathrm{Da}$ Buddha nicht als Gottheit verstanden wird, werden die Schreine nach offizieller Lehre als Erinnerung an die buddhistische Lehre (Dharma) und nicht als Verehrungsstätte verstanden. 


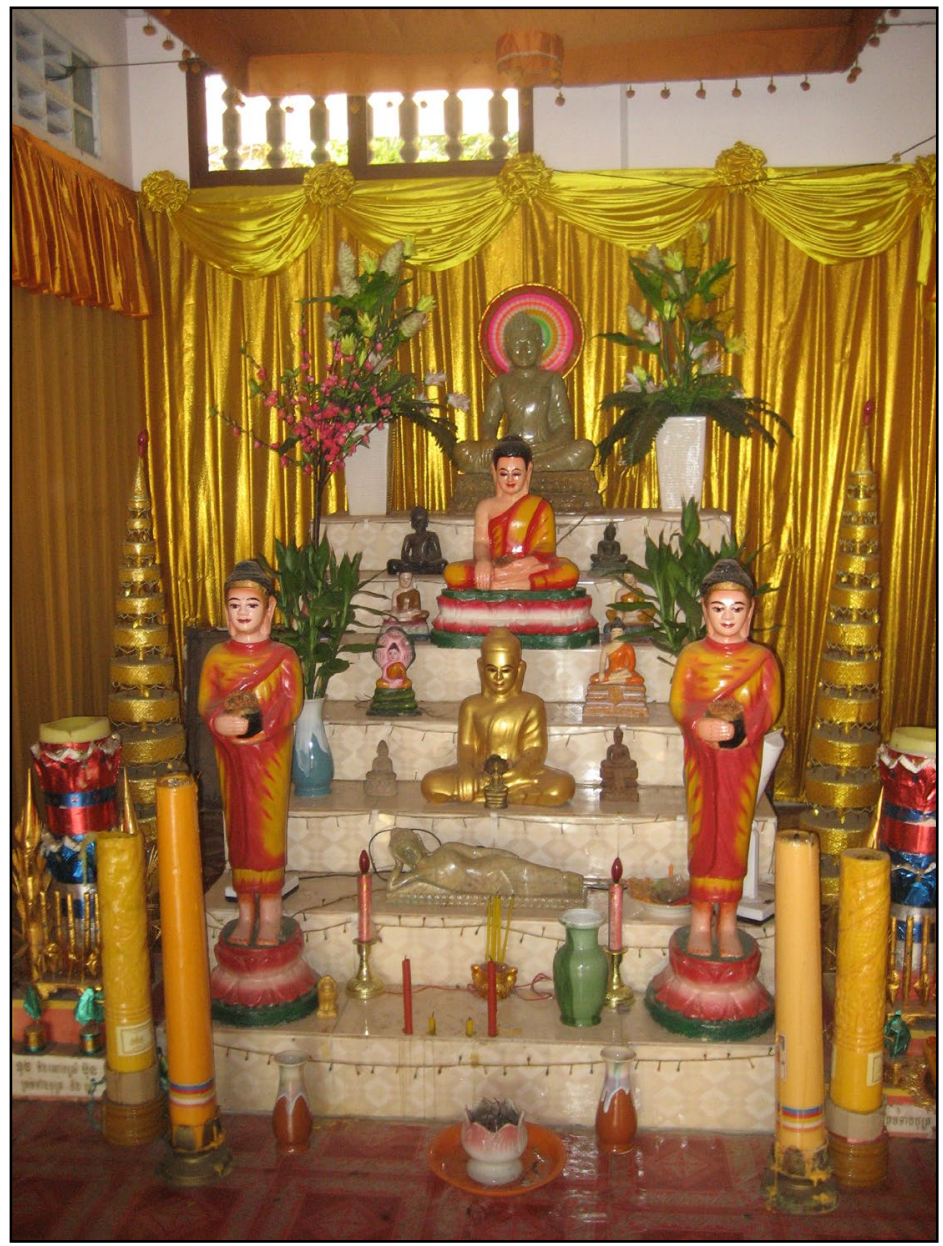

Abb. 11: (C) Autor. Buddhistischer pāy sī im Wat Botumwadei (Nebengebäude), Phnom Penh.

An den Abbildungen der verschiedenen Schreine ist auffällig, dass alle Stufen des buddhistischen Schreins von Buddha-Statuen geschmückt wurden, während der Schrein des grū auf der obersten Stufe nicht nur den Buddha, sondern weitere Statuen von Geistern aufweist. Für Reform-Buddhisten stellt diese buchstäbliche ,Gleichstellung' einen Affront dar. ${ }^{113}$

113 Laien müssen nach den buddhistischen Verhaltensregeln (sīla) niedriger als Mönche sitzen, während Mönche sich niedriger als Repräsentationen des Buddhas platzieren müssen. Medien, für die anak tā als Beschützer und Anhänger des Buddhismus gelten, setzen diese Statuen auf eine niedrigere Stufe. Der in Abb. 10 gezeigte Schrein gehört demnach einem brahmanistisch ausgerichtetem grū. 


\subsubsection{Anak tā Praxis}

Der Kontakt von Kambodschaner_innen zu anak tā gestaltet sich mannigfaltig. Drei Formen der Kontaktaufnahme zwischen Menschen und Ortsgeistern sind von besonderer Relevanz: die alltägliche, die offizielle und die rituelle Form.

Da die Ortsgeister gelten nicht nur als mächtige Eigentümer des Landes, sondern auch als deren Verwalter charakterisiert werden, suchen Kambodschaner_innen aus vielfältigen Gründen den Kontakt mit den anak tā aus ihrer Nachbarschaft. Sie werden beispielsweise um geschäftliche Hilfe, um das Bestehen von Prüfungen, die Heilung von Krankheiten, den Schutz vor Verkehrsunfällen, das Wiederauffinden von Gegenständen oder um die Erfüllung eines Kinderwunsches gebeten. Der Bandbreite der Anliegen ist keine Grenze gesetzt: anak tā bzw. pāramī können zu allen denkbaren Schwierigkeiten um Hilfe gebeten werden. Oftmals steht die Erwartung an eine zeitnahe Erledigung des Problems im Vordergrund - was einen entscheidenden Unterschied zur buddhistischen Praxis darstellt, die vor allem auf das Sammeln von Verdienst zur Verbesserung der Wiedergeburt fokussiert ist.

In weiteren alltäglichen Gegebenheiten treten anak tā als Verwalter ,ihres ' Territoriums auf. Die Verknüpfung ihrer Macht mit ihrer Region ist so stark, dass auch Menschen, die normalerweise den Kontakt zu Geistern scheuen, sich verpflichtet fühlen im Falle eines Umzugs in das Territorium neuer anak tā bei ihnen vorstellig werden - ebenso wie man die anak tā um Erlaubnis und, ihren Segen bittet, wenn man in ihrem Gebiet ein Geschäft eröffnen oder ein neues Haus errichten möchte.

Auch in offiziellen Anlässen können Ortsgeister eine bedeutende Autorität darstellen. So beispielsweise vor Gericht: Zeugen müssen vor den gerichtseigenen anak tā-Schreinen ihren Eid ${ }^{114}$ ableisten (Edwards 2008b; Porée-Maspéro 1962: 12). Da Lügen und damit ein Bruch des Eids im Buddhismus lediglich in weiteres Karma resultieren würde, das erst nach dem Tod zum Tragen käme, entschied man sich während der Kolonialzeit dafür, den Schwur vor einer anak tā-Statue durchführen zu lassen - dabei wurde jedoch anscheinend nicht beachtet, dass Geister generell zu Aushandlungen bereit sind und im Tausch gegen Opfergaben angedrohte Strafen auch widerrufen könnten.

Während sich der Kontakt durch das Darbieten von Opfergaben zu alltäglichen und offiziellen Anlässen auf eine indirekte Art beschränkt, kann unmittelbarer Kontakt zu Ortsgeistern nur über Geistbesessenheit erreicht werden. Dabei werden die anak tā zunehmend als moralische Akteure und als Beschützer der

${ }^{114}$ Das Ablegen des Eids beginnt wie ein Geistverehrungsritual mit dem Entzünden einer Kerze und einigen Räucherstäbchen. Passagen aus dem Schwurtext lauten wie folgt: [Wer nicht die Wahrheit spricht] „,soll mit einem schlechten Tod aus der Folge von Schüssen, Elektrizität, Blitzeinschlag, Schlangenbissen, oder Tigerangriffen bedacht und mit von den Familien getrennten Wiedergeburten und in Armut lebend über 500 Reinkarnationen bestraft werden“ [eigene Übersetzung aus der Neuen Strafprozessordnung]. 
buddhistischen Lehre inszeniert. Sie selbst werden als strenge Buddhisten beschrieben, womit sich die Geistmedien vor ihren Klient_innen als Vertreter_innen buddhistischer Moral positionieren und auf deren Umsetzung pochen können (wie in Kap. 4 gezeigt). Die Geister betonen dabei den Wert der buddhistisch geprägten Moral. Sie belohnen Menschen mit buddhistischer Lebensführung und bestraften die Regelbrüche Anderer. Dennoch unterscheidet sich die Praxis der beiden Religionen in bedeutenden Aspekten, denn Menschen gehen zu den anak $t \bar{a}$, weil ihnen die buddhistische Praxis für ihre Anliegen unpassend erscheint und sie die Hilfe brahmanistischer pāramī in Anspruch nehmen möchten. Dies wird im folgenden Beispiel deutlich:

Eine Mutter kam mit ihrem jugendlichen Sohn zu grū Ly, der vom Geist lok tā Eysey besessen wird. Nach der Begrüßung und der Darreichung der Opfergaben klagte sie in dessen Anwesenheit über den Ungehorsam ihres Sohnes, der nicht für die Schule lernen wollte, den Eltern nicht gehorchte und schon mit Drogen in Kontakt gekommen sei. Sie sei mit ihrem Sohn schon bei Mönchen gewesen, die ihm die Bedeutung des Respekts gegenüber den eigenen Eltern erklärt hätten, doch dies hätte nicht zur Verbesserung seines Verhaltens beigetragen. Das Medium ließ sich von seinem Geist zunächst über den Hintergrund der vorliegenden Situation informieren und teilte dieses Wissen mit der Mutter: der schädliche Einfluss auf den (sonst so tugendhaften) Jungen ginge von seinem Freundeskreis aus. Kurz darauf wurde das Medium von seinem Geist besessen, der sich direkt an den Schüler wandte und eine vehemente und langatmige Ermahnung zu richtigem Verhalten vorbrachte. Der Geist gab dem Jungen zu verstehen, dass er ihn bestrafen würde, wenn er ihm nicht gehorche. Ihm oder einem seiner Freunde könnte schon bald etwas Schlimmes wiederfahren, wenn sie nicht sofort einen anderen Weg einschlagen würden. Der Schüler wirkte anschließend eingeschüchtert, was die Mutter zufriedenzustellen schien.

An diesem Fall wird einer der grundlegendste Unterschied zwischen der buddhistischen und der brahmanistischen Praxis veranschaulicht: brahmanistische Geister wie anak tā sind von ambivalenter Natur und können nicht nur belehrend, sondern auch strafend agieren - und zwar unmittelbar nach einer Anfrage. Ihr ,magisches' Wirken wird von den Medien stets in Einklang mit buddhistischer Moral gesetzt, womit sie als die mächtigsten Geister der kambodschanischen Geisterlandschaft positioniert werden. In zahlreichen Anliegen stellen die Geister zudem Akteure der Aushandlung von Gerechtigkeit und moralischer Ambiguität dar - im oben genannten Fall hätte der Sohn beispielsweise (solche Anfragen waren nicht unüblich) zu einem anderen Medium gehen können und darum bitten können, die Mutter von seinem Privatsphäre fernzuhalten oder sie sogar über sein Fehlverhalten hinwegzutäuschen, um das Ansehen der Familie zu wahren. Einige Medien hätten dies sicher als legitime Begründung für ein magisches Eingreifen zugunsten des Sohnes interpretiert (Kap. 8.1). 
Um die Existenzbedingungen der anak tā in der kambodschanischen Spiritscapes zu beschreiben, widme ich mich nun den grundlegendsten Referenzen, die anak tā nicht nur zur Stabilisierung ihrer angenommenen Existenz, sondern auch zu ihrer ausgesprochen hohen Wirkmacht verhelfen. Das Netzwerk von menschlichen und nicht-menschlichen Akteuren konstituieren die Ortsgeister somit emisch in überzeugender Weise. Die blackbox der anak tā scheint so selbstverständlich, dass sie nicht hinterfragt werden. Zwar gibt es Unterschiede in dem Ausmaß der angenommenen Wirkmacht der Geister, das heißt, in der Zuschreibung ihrer tatsächlichen Macht (beispielsweise im Vergleich zu anderen Geistern), doch dies führt nicht zu einem Anzweifeln ihrer Existenz.

\subsubsection{Existenzbedingungen der Anak tāa}

In Zusammenführung der oben genannten Eigenschaften der anak tā sind fünf Bedingungen für die Konstituierung ihrer Existenz und ihrer Wirkmacht bedeutsam: eine materielle Manifestation, ein definierter Zuständigkeitsbereich, die Zuschreibung spiritueller Macht, eine ,Biographie der Macht' und die Ansammlung möglichst vieler Referenzen auf die Existenz und Wirkmacht eines Geistes. Nach einer Bestimmung dieser Bedingungen veranschauliche ich im Folgenden die konstituierenden Merkmale der anak tā am Beispiel von yāy Mao.

\section{Materielle Manifestation}

Wie oben bereits deutlich wurde, ist eine materielle Manifestation der Geister (zum Beispiel ein Schrein, eine Statue, ein Tempel oder ein Baum o.ä.) an einem oder mehreren Orten von herausragender Bedeutung. Für Personen bildet dieser Ort den zentralen, geographischen Bezugspunkt einer spezifischen Geister-Macht.

\section{Zuständigkeitsbereich der Macht}

Zudem bedarf es eines lokal definierten ,Verantwortlichkeitsbereiches‘ der Geister, in dem die Geister ihren Handlungsspielraum geltend machen (Guillou 2017c). Dieser geographische Raum befindet sich nach allgemeiner Auffassung in der unmittelbaren Umgebung der materiellen Manifestation eines Geistes. Die Grenzen dieser Bereiche sind flexibel und werden von den umliegend wohnenden Menschen zum Teil unterschiedlich verstanden. Das Territorium von als besonders mächtig erachteten anak tā kann sich über Dorfgranzen hinaus auf mehrere Provinzen erstrecken oder sogar nationale Ausmaße erreichen (Kap. 9.3).

Auch die physische Manifestation im Körper von Geistmedien stellt einen besonders dichten und klar definierten Verantwortlichkeitsbereich von anak tā dar. Obwohl ein menschlicher Körper keine obligatorische Bedingung zur Existenz eines Geistes darstellt, stabilisiert diese Form der Manifestation ihre Existenz in hohem 
Maße, da anak tā, die in Medien erscheinen, im wörtlichen Sinn präsent sind und als mächtig genug gelten, um einen Menschen dazu zu bringen, als ihr Medium zu fungieren.

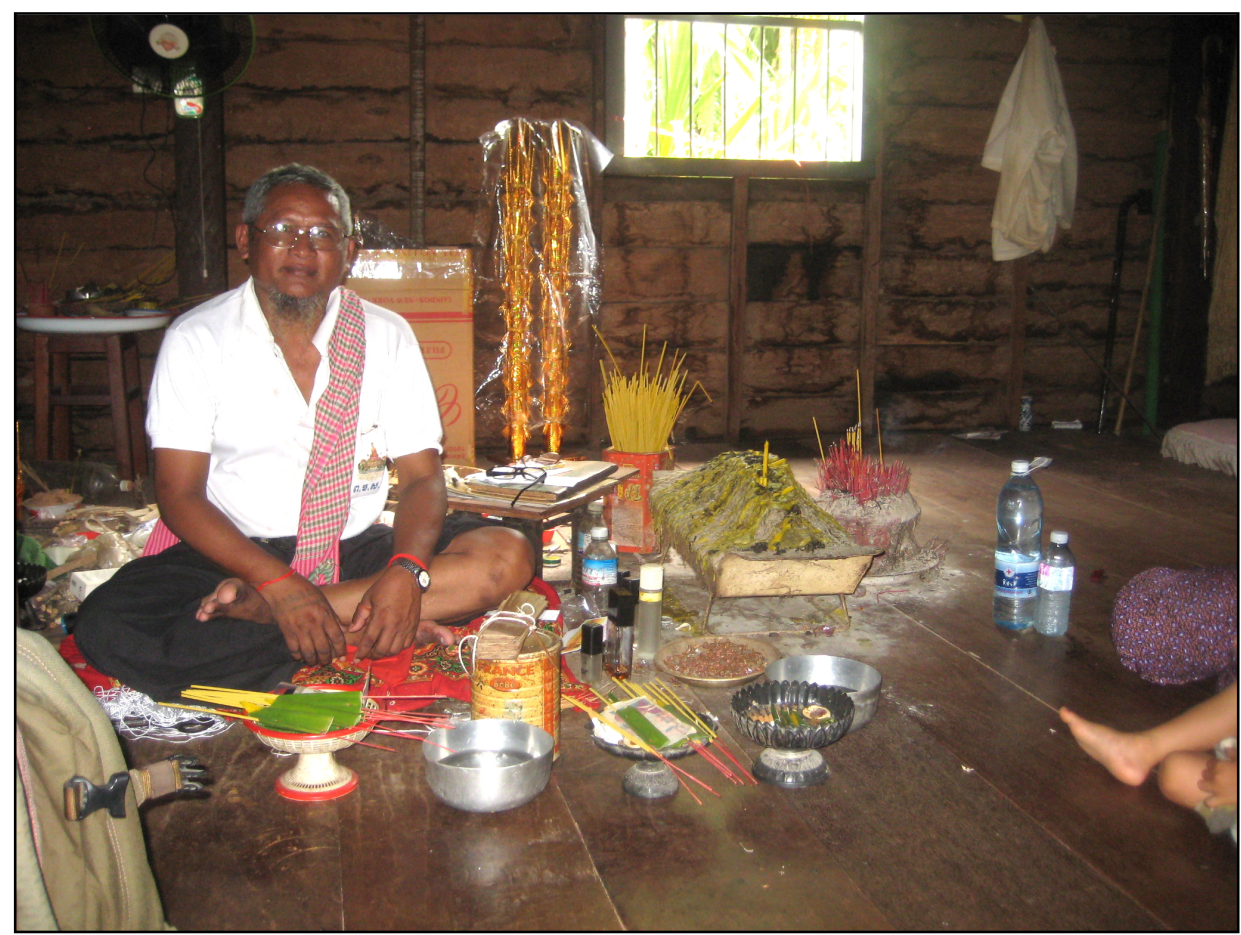

Abb. 12: (C) Autor. Ein männliches Geistmedium aus der Provinz Siem Reap, das von lok tā Kampuul Pech (,Ehrenwerter Großvater Diamant der Spitze") besessen wird, dessen Hauptsitz, im Tempel Angkor Thom liegt.

\section{Das Narrativ spiritueller Macht}

Drittens ist der lokale Diskurs um die Höhe und Ausprägung der spezifischen Wirkmacht (pāramī) eine bedeutende Existenzbedingung von anak tā. Dieses Narrativ wird von Gesprächen, Erzählungen oder von ,Gossip‘ geformt. Schauplätze der informell wiedergegebenen Erzählungen sind Privatgespräche unter Freunden und Familienmitgliedern, unter Nachbarn oder Besucher_innen von Schreinen und Geistmedien, aber auch Zeitungsartikel und Berichte in TV-Sendungen, die beispielsweise die Menschenaufläufe nach anak tā-Erscheinungen (siehe oben) oder die Rituale ,schwarzer Magie، als Protestform (Kap 9.5) thematisierten. Dieses Narrativ der Geister-Macht kommt wegen ihrer starken Betonung vonseiten der lokalen Akteure und ihrer überregionalen Reichweite (auch über das Internet) eine herausragende Bedeutung zu, ähnlich wie Eisenlohr es am Beispiel von Hindus aus Mauritius und Muslimen aus Mumbai verdeutlicht (2015). In den Narrati- 
onen oszillieren die erzählenden Personen zudem deutlich zwischen verschiedenen Zeitebenen der Geister-Vergangenheit und der Gegenwart, die von alten Mächten überlagert würde.

Wenn ich beispielsweise neuen kambodschanischen Bekanntschaften mein Forschungsthema unterbreitete, wurde ich schnell in unterschiedliche Geschichten über Geister eingeweiht - welche anak tā besonders mächtig seien, was Personen in Kontakt mit Geistern bereits widerfahren sei und welche Geister für bestimmte Anliegen besonders hilfreich seien. Ein häufig wiederkehrendes Motiv der Narrationen stellte ein besonderer ,Erweckungsmoment ${ }^{`}$ dar, in dem die erzählenden Personen zunächst an der Wirkmacht von anak tā gezweifelt hatten und dann durch ein bestimmtes Ereignis davon überzeugt wurden, wie das Beispiel des jungen Geschäftsmannes Polin zeigt:

Polin war als Organisator eines Bewerbungsworkshops für junge Studierende in ein Hotel in einen Nationalpark gefahren, in dem es spuken sollte. Da er den Spukgeschichten keinen Glauben schenkte, beachtete er auch die zahlreichen Geisterschreine auf dem Weg zum Hotel nicht. Dies empfand der junge Geschäftsmann später als Fehler, denn während des Wochenendes erschienen den Studierenden so viele Wald-Geister, dass er Mönche einladen musste, um die Teilnehmenden zu beruhigen und die Geister abzuwehren. Er machte deutlich, dass es für ihn nach rationalen Berechnungen in Zukunft eine kleinere Investition bedeuten würde, an den anak tā-Schreinen auf dem Weg anzuhalten und Opfergaben zu hinterlassen, um Vorfälle dieser Art zu vermeiden, als noch einmal so viel Zeit zu verlieren und verängstigte Workshop-Teilnehmende beruhigen zu müssen.

\section{Eine Biographie der Macht}

Ein weitere Existenzbedingung der anak tā ist eine ,Biographie der Macht', die durch große weltliche Macht zu Lebzeiten oder einen ,schlechten Tod bestätigt werden muss. Dies machte ich bereits am Beispiel von Pol Pot deutlich (Kap. 3.3). Guillou, die diesen Aspekt in Anlehnung an Forest (1992) betont, verweist auf die historische Herkunft der anak tā als nicht wiedergeborene Totengeister (2018, 2012), die aufgrund ihrer Taten als Mensch nicht als ,schlecht' Gestorbene, sondern als mächtige Ortsgeister verstanden werden. Diese halten sich - ähnlich zu den Bottisattwa im Mahayana-Buddhismus - freiwillig bei den Menschen auf, um ihnen helfend, schützend und überwachend zur Seite zu stehen. Auch lok tā Kleang Moeung, dessen Biographie nun kurz vorgestellt wird, verkörpert die Bedeutung dieser Existenzbedingung beispielhaft:

Kleang Moeung soll im 15. oder 16. Jahrhundert der Gouverneur und Leiter der Streitkräfte in Pursat gewesen. In dieser Zeit befand sich das Land in ständigen Kämpfen mit ausländischen Invasoren (Chandler 2008). In einem besonders schweren Kampf, bei dem siamesische Soldaten bis kurz vor Pursat vorgerückt waren, soll Kleang Moeung sein Leben geopfert haben, indem er sich in eine tödliche Fallgrube stürzte. In manchen Versionen dieser Nacherzählung begleitete ihn 
auch seine Frau lok yāy Chumteav Kan Keav in den Märtyrertod (Yamada 2004: 216). Mit seinem Tod soll der mächtige Gouverneur eine Armee von Geistern beschworen haben, die den kambodschanischen Truppen zum Sieg verhalf. Der gängigsten Variante nach sollen die Kämpfer aus Siam plötzlich unter Diarrhoe gelitten haben und entkräftet geflohen sein (Guillou 2012; Yamada 2004; PoréeMaspéro 1962: 7, 1961b: 394-398). Einer anderen Deutung nach sollen die gegnerischen Soldaten von den Tieren des Waldes, vor allem Bienen und Schlangen, angegriffen worden sein.

Es ist anzunehmen, dass sich der Narrativ um den Märtyrertod Kleang Moeungs in den darauffolgenden Jahrhunderten großer Beliebtheit erfreute, denn die kambodschanischer Bevölkerung litt noch bis zum 19. Jahrhundert unter den Angriffen aus Siam und Vietnam (Chandler 1982). Bis heute belasten zahlreiche polarisierende Themen die thailändisch-kambodschanischen Beziehungen. ${ }^{115}$ Beim Thema Thailand wird ein ausgeprägter Nationalismus in der kambodschanischen Gesellschaft sichtbar. Die Geschichte von lok tā Kleang Moeung projiziert diese Ressentiments auf ein beliebtes Narrativ, dessen Protagonist bis heute als Vorbild und Schutzpatron der Soldaten und als Verteidiger des Landes gegen externe Feinde anerkannt wird (Guillou 2017c). Mit seinem (heute noch angenommenen) Einfluss auf den derzeitigen Konflikt wird begründet, warum Thailand Kambodscha noch nicht militärisch schlagen konnte. Die thailändischen Soldaten sollen beispielsweise bei Grenzüberschreitungen unter Schlangenbissen und Insektenstichen gelitten haben und wegen dieser ,magischen Gegenwehr demoralisiert geflohen sein. Je heftiger der Konflikt mit Thailand geführt wird, desto wichtiger ist die Rolle von lok tā Kleang Moeung (Kap. 9.3). Die starke Referenz zwischen ihm und den Kambodschaner_innen ist ein Grund dafür, dass er zu einer Identifikationsfigur der kambodschanischen Migrant_innen, ihrer Kinder und Enkel geworden ist, wie die Errichtung eines lok tā Kleang Moeung-Schreins in ,Cambodia Town' im amerikanischen Long Beach, Kalifornien zeigt (Yamada 2004; Needham und Quintiliani 2008: 43).

Die Existenzbedingung einer machtvollen Biographie ihrer Geister wird von den Geistmedien als obligatorisch bezeichnet, auch wenn vielen grü die genauen Biographien ihrer anak tā nicht bekannt sind. Für die Authentizität der Praxis ist dieses Wissen weniger bedeutsam als die Handlungen, die später auf die spirituelle Macht zurückgeführt werden - es wird schlicht zur Existenz eines mächtigen Geistes vorausgesetzt. Auch zu überregional bekannten Ortsgeister lok tā Eysey oder lok tā Dambang Deik konnten nur wenige Medien biographische Informationen liefern. Bei Nachfragen bei grū wurde dann oftmals spekuliert, dass sie aufgrund ihrer derzeitigen Macht zu Lebzeiten eine machtvolle Position innegehabt

\footnotetext{
115 Darunter fallen derzeit der gewaltsame Streit um den Preah Vihear Tempel, die schlechte Bezahlung der kambodschanischen Arbeitsmigrant_innen in Thailand und das gewaltsame Vorgehen der thailändischen Grenzpolizei gegen illegalen Warenhandel.
} 
haben mussten; meist wurde dabei vage auf einen hohen militärischen Rang (wie im Fall von lok tā Dambang Deik) oder die Zugehörigkeit zum Beraterstab eines Königs (lok tā Eysey) verwiesen.

\section{Spannweite des Netrwerks}

Analytisch betrachtet ergibt sich eine weitere Bedingung, die schon an den Beispielen von Pol Pot und tā Noël (Kap. 3.3) deutlich wurde: eine Existenz ist umso stabiler, je mehr menschliche und nicht-menschliche Akteure auf sie referieren. Die Anzahl der Referenzen wirkt sich außerdem auf die Wahrnehmung von Wirkmacht der Geister aus. Darunter fallen Erzählungen, die auf die Geister verweisen, und auch die Opfergaben und die Gläubigen zählen dazu: Letztere achten vermehrt auf Zeichen einer Wirkmacht, die wiederum nur durch Opfergaben möglich gemacht werden können. Ballungszentren der Referenzen bilden zudem die Geistmedien, die den Geistern eine Stimme verleihen, ihnen einen Körper zur Verfügung stellen, um selbst zu handeln und damit einen besonders überzeugenden Aktanten zu bilden.

Somit kann die Frage nach der Existenz der anak tā als ,a matter of indifference“ (Hardy et al. 2001: 538; Restivo 2011) bezeichnet werden; das heißt, die ontologische Frage nach der Existenz der Geister ist unwesentlich, da sie durch stabile Beziehungen zu anderen Akteuren (wie beispielweise Gläubigen, Statuen, Narrationen, Opfergaben oder Medien) im Sinne des blackboxing beständig affirmiert wird.

Das bedeutet nicht, dass die Anwesenheit von anak tā keine Unbeständigkeiten in der Aufrechterhaltung dieser Referenzen aufweist: einige Ortsgeister waren von einer recht begrenzten Lebensdauer gekennzeichnet, was an zahlreichen verlassenen Schreinen in ländlichen Gebieten abzulesen ist. Dennoch wohnt diesen Schreinen das beständige Potenzial einer reanimierbaren Präsenz inne, die mithilfe von einigen Akteuren (wie beispielsweise Träumen, finanziellen Mitteln, Narrationen oder Menschen) wieder , animiert` werden könnte. Die Popularität der anak tā hängt somit maßgeblich von dem Zusammenwirken dieser Akteure ab. Je größer das Netzwerk von Akteuren gespannt wird, und je mehr Referenzen auf die Macht eines Geistes verweisen, desto höher wird allgemeinhin seine Macht eingeschätzt.

Die Beschreibung dieser grundlegenden Mechanismen des blackboxing der anak $t \bar{a}$ soll jedoch keinesfalls den Blick auf die einmalige Performanz einer, GeisterExistenzwerdung' verstellen. Im Folgenden werde ich mich der in der Wissenschafts- und Technikforschung bekannten Methodik bedienen, die Geschichte eines Akteurs im Netzwerks seiner konstituierenden Akteure nachzuzeichnen (Latour 1996; Bijker et al. 1987). Mit dieser methodischen, blackbox-Öffnung' wird die Fragilität der als selbstverständlich angenommenen Referenzen offengelegt und die Gründe für besonders stabile Referenzen werden verständlich. Dabei wird diese detaillierte Methodik auch Erkenntnisse zu grundlegenden Themen der 
kambodschanischen Religiosität liefern, wie beispielsweise zur Buddhisierung von Geistern, der Relevanz der Geister-Verehrung und zur Beziehung der brahmanistischen anak tā zum kambodschanischen Buddhismus.

\subsubsection{Die blackbox der Großmutter Mao}

Der Name lok yāy Mao setzt sich aus, verehrte Großmutter' (lok yāy) und dem Wort ,schwarz' (khmao, kurz: mao) zusammen. Der Name und die Darstellung von yāy Mao verweisen auf die indische Göttin Kālī (wörtl.: „Die Schwarze“) (Forest 1992: 29; Jacobsen 2008; Porée-Maspéro 1962: 9) - auch wenn yāy Mao schon lange nicht mehr mit Kālī assoziiert wird, was daran erkennbar ist, dass der Tempel Prasat Neang Khmao schon im 10. Jahrhundert ihren kambodschanischen Namen trug und trotz brahmanistischer Führung niemals ausdrücklich Kālī gewidmet war (Porée-Maspéro 1962: 9).

Im religionsethnologischen Diskurs erregte die Dynamik ihrer Verehrungspraxis neuerdings Aufmerksamkeit (Zucker 2017; Guillou 2017b; Ang 2016). Ang unterschied dabei ,moderne und ,indigene $e^{6}$ Formen der Darstellung von yāy Mao, während Guillou und Zucker beispielhaft für die Flexibilität ihrer Verehrung ein Denkmal der Roten Khmer im oben beschriebenen Dorf Choam beschreiben, das nach einer Zeit der nachlässigen Behandlung nun als Residenzort von yāy Mao gilt (siehe unten).

\section{Historische Referenzen}

Es gibt eine Vielzahl von Legenden um yāy Mao. Eine Version wird vom Ministerium für Kult und Religion verbreitet, das diese Version als die ,offizielle Version“ der Legende bezeichnet. Demnach wanderte Mao während der Herrschaft von König Ang Duong (1848-1860) mit ihrem Mann, der später als lok tā Krahom Kar (roter Hals) 116 verehrt werden sollte, in einem bewaldeten Abschnitt am Phnom Pech Nil, als eine Horde Elefanten die beiden überraschte. Auf der Flucht vor ihnen rannten Mao und ihr Mann in unterschiedliche Richtungen. Maos Weg führte sie direkt zu einem Tiger, der sie tötete. Obwohl sie nach Hilfe schrie, hörte sie niemand; auch ihr Ehemann kam nicht mehr rechtzeitig. Die Dorfbewohner_innen sollen damals schon am Ort ihres Todes und ihrer gegenwärtigen Hauptverehrungsstätte einen Schrein errichtet haben, der sich noch immer am Phnom Pech Nil, direkt an Transitstraße 4 zwischen Phnom Penh und Sihanoukville, befindet.

Eine andere Version ihrer Geschichte kursiert im ländlichen Kontext des südwestlichen Küstenabschnitts von Kambodscha. Die Legende besagt, dass Mao vor circa 500 Jahren eine ranghohe Angehörige des Militärs gewesen sei. In dieser Zeit

\footnotetext{
116 Die Herleitung seines Namens vom indischen Gott Shiva scheint schlüssig (Porée-Maspéro 1962: 9), da Shiva in alten Schriften des Rigveda als Rudra (der ,Rote) erwähnt wird und dort eine Beziehung zu Kālī pflegt (Michaels 1998: 147).
} 
hätte sich Kambodscha gegen das Königreich Siam verteidigen müssen. Trotz ihrer engen Beziehung zu ihrem Vorgesetzen Kommander Kry habe sie keusch gelebt. Nach seinem Tod soll Mao ihre Truppen bei Pech Nil versammelt und die vorrückenden Truppen dank ihrer magischen Kräfte geschlagen haben. Auch folgende siamesische Angriffe habe sie so abwehren können. In diesem Zusammenhang wird die legendäre Erzählung einer Seeschlacht gepflegt, in der Schiffe aus Siam nach einem einfachen Fingerzeig von Mao gesunken seien. Danach seien die Übergriffe aus Siam abgeebbt und Mao soll souverän über das Grenzgebiet regiert haben. Kurz bevor sie an einer Krankheit verstorben sei, habe sie versprochen, auch nach ihrem Tod als Geist die südwestliche Zone des Landes zu bewachen und dieses Land mittels ihrer magischen Mächte zu verteidigen. Auf ihrer Trauerfeier sollen sich sämtliche ihrer Soldaten ihre Penisse abgeschnitten haben, um sie der bis zum Lebensende keuschen yāy Mao zu opfern.

In den Variationen dieses Entstehungsmythos von yāy Mao verlagert sich der Ort ihrer siegreichen Schlachten auf die verschiedenen Orte ihrer mittlerweile zahlreichen Verehrungsstätten entlang der Küste, so dass dort ihre siegreichen Seeschlachten hervorgehoben werden, während im Landesinneren vor allem auf die Siege ihrer Streitheere (Ang 2016) referiert wird. Gemeinsamkeiten bestehen in der Betonung ihrer strategischen Kriegskunst, ihrer magischen Fähigkeiten und ihrer Keuschheit.

\section{Materialisation und Buddhisierung}

Wie Ang herausstellt (2016), gründen sich aus den oben nacherzählten Biographien zwei grundverschiedene Konzeptionen von yāy Mao, die besonders deutlich an ihrer materiellen Erscheinungsform veranschaulicht werden. Die Verehrungspraxis der Dorfbewohner_innen der Küstenregion im Südwesten des Landes folgt der letztgenannten Erzählung, indem sie yāy Mao in Schreinen ohne spezifische Materialisation Phalli aus geschnitztem Holz oder bearbeiteten Stein opfern. Nach Ang gibt es dort keine materiellen Darstellungen von yāy Mao, da sie als die personifizierte Repräsentation des Ozeans gilt. Wie das Meer könne yāy Mao einerseits ihre gütige Seite zeigen, indem sie den Fischern reichen Fang bescherte und sie andererseits strafen, indem sie sie mit Unwettern überraschte. Als eine solche Verschmelzung mit der Naturgewalt Wasser ähnelt yāy Mao der Erdgöttin brah Bhūmi (auch: brah Dharanī), die als personifizierte Erde verehrt wird (Ang 2016: 259-261).

Heute dominiert jedoch eine andere Konzeption von yāy Mao, die sich auf die Biographie aus der ersten Erzählung bezieht und in dem Kontext der fortschreitenden Buddhisierung der anak tā dafür gesorgt hat, dass der Geist im ganzen Land in materialisierter Form verbreitet ist. Außerdem wird sie zunehmend mit dem Thema der Verkehrssicherheit in Verbindung gebracht, was einer neuen Entwicklung entspricht, die unten nachgezeichnet wird. Für eine eigenwillige Performanz ihrer Existenzweise spricht, dass sie trotz militärischer Siege gegen Besat- 
zungsmächte nicht (wie Kleang Moeung) primär mit der Verteidigung des kambodschanischen Territoriums assoziiert wird. Mein Blick auf die Entstehung ihrer populären Geisterkonzeption zeigt stattdessen die Entstehung einer Assoziation mit Verkehrssicherheit und zeichnet dabei ein detailliertes Bild ihrer gesellschaftlichen Funktion und Relevanz nach.

Zentraler Akteur der erfolgreichen Konstitution des Geistes ist Khiev Rith, ehemaliger stellvertretender Major der Royal Cambodian Armed Forces (RCAF), der zwischen 1979 und 1998 direkt am Phnom Pech Nil stationiert war. Das von ihm herausgegebene Buch „yāy Mao’s Mysterious Life“ (Khiev 2005) beschreibt, wie er kurz nach seiner Ankunft in Pech Nil, einem strategisch wichtigem Pass zwischen zwei Waldgebieten, einen verlassenen Schrein vorfand. Die französischen Besatzer sollen 1944 in den Schrein geschossen haben, so dass er laut Anwohner_innen einen erheblichen Teil seiner pāramī verloren hätte. Khiev ließ den Schrein wieder reparieren, und kurz darauf fing der Geist von yay $\mathrm{Mao}$ an, seine Ehefrau Sao besetzen. Der Geist war zunächst ärgerlich, doch Khiev konnte ihn durch Opfergaben besänftigen. Er vertritt die Meinung, dass er aufgrund seines intensiven Kontakts zu yāy Mao während zahlreicher Gefechte mit den in den Bergen verschanzten Roten Khmer unverletzt geblieben ist. Aus Dankbarkeit dafür investierte er während der 1990er Jahre große Summen in die Renovierung des alten Schreins, der die Statue einer dunkelhäutigen Frau zeigt.

Neben der regelmäßigen Anwesenheit des Geistes im Körper seiner Frau träumte Khiev auch einige Male von yāy Mao und erhielt dort Anweisungen von ihr. Ende der 1990er Jahre bat yāy Mao darum, keine Phallusse mehr zu ihren Ehren opfern zu lassen, da sie nun eine buddhistische Nonne geworden sei. Daraufhin ließ Khiev eine weitere Statue von yāy Mao bauen, die sie als Nonne mit weißem Gewand, kahlgeschorenem Kopf und heller Haut zeigte. Außerdem wies er die Besucher_innen des Schreins mit Schildern auf den Wunsch des Geistes hin.

Kurz darauf wurde die Schnellstraße 4 zwischen Phnom Penh, Sihanoukville und Thailand saniert, die nun direkt am Schrein vorbeiführt. Damit wuchs die Bedeutung des Schreins. Die Erzählungen über die Wirksamkeit des Geistes häuften sich: so soll yāy Mao einem chinesischen Geschäftsmann die richtigen Lottozahlen genannt haben, der daraufhin einen weiteren, großen Schrein für sie am Pech Nil bauen ließ. Die Wirkmächtigkeit des Ortes wurde im ganzen Land bekannt, das heißt, die Referenzen auf yāy Mao nahmen zu. Bald darauf wurden die zahlreichen Verkehrsunfälle auf der Straße 4 (sie gilt als die unfallreichste Schnellstraße) auf eine mangelnde Verehrung ihrer Wirkungsstätte zurückgeführt, so dass die Mehrheit der vorbeifahrenden Verkehrsteilnehmenden sich heutzutage gezwungen fühlt, kurz anzuhalten, um Schutz für die Weiterfahrt zu erbitten.

Heute wächst die Zahl der Verehrungsstätten in Pech Nil - zurzeit finden sich dort neben der schwarz- und der weißhäutigen Statue und noch eine blauhäutige (neben mehreren anderen Geister-Schreinen). Die verschiedenen Statuen werden 
teilweise für unterschiedliche Anliegen adressiert: die erste Darstellung ist bekannt dafür, auch bei moralisch mehrdeutigen Anliegen zu helfen, wie sexuellen Anliegen, Liebesanliegen oder Anfragen nach schulischem oder beruflichem Erfolg. Die anderen Statuen werden vor allem um eine sichere Weiterreise gebeten.

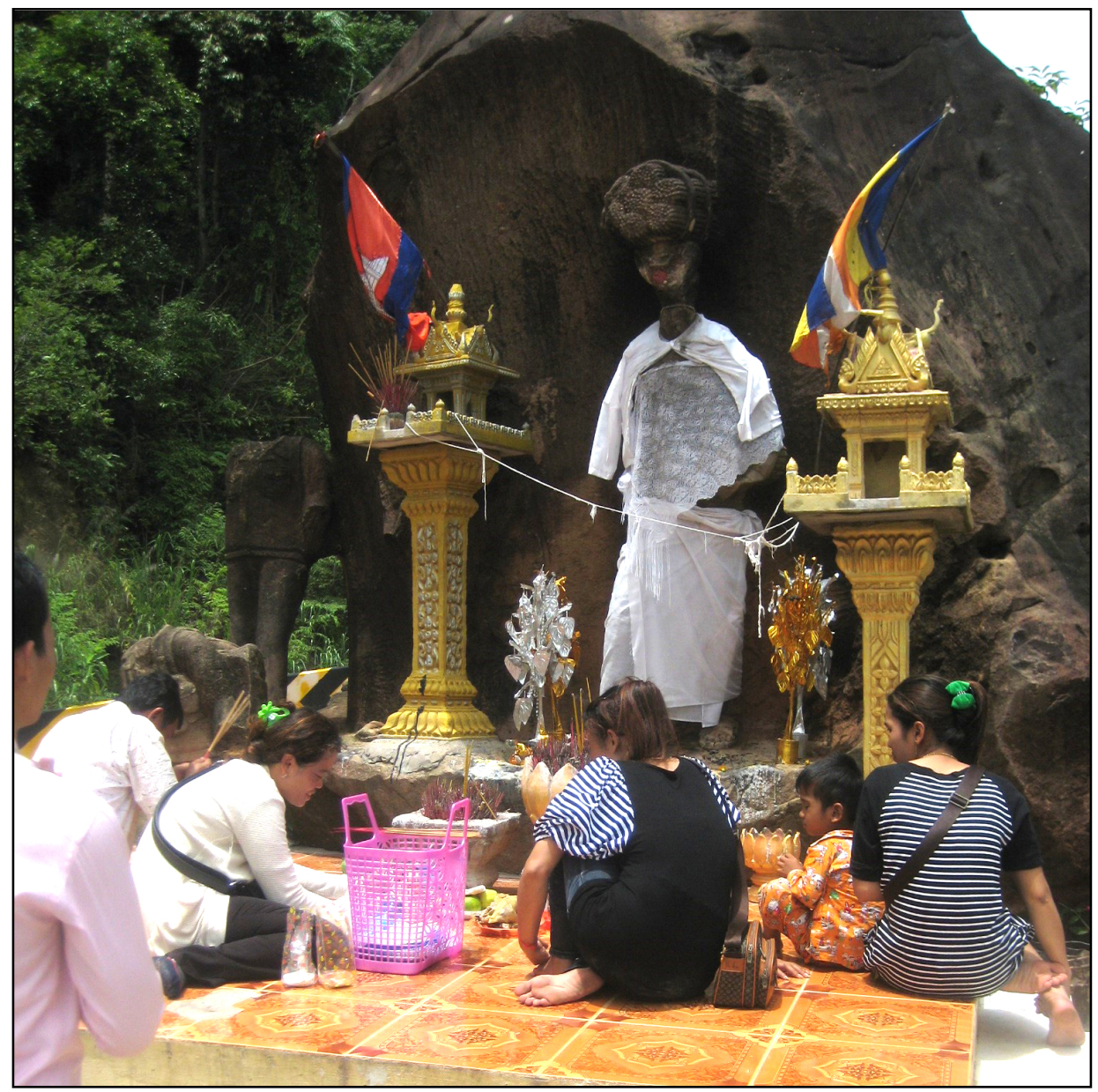

Abb. 13: (C) Autor. Yäy Mao in der Nähe von Anlung Veng. In ihrer Erscheinung einer alten Khmer Rouge Kämpferin werden yāy Mao Opfergaben dargereicht. Mittlerweile trägt sie (mönchsgleiche) orangefarbige Tücher und um den kopflosen Soldaten neben ibr bängt, vermutlich in Anlehnung an lok tā Krahom Kar, ein roter Schal.

Damit hat yōy Mao bereits mehrere wichtige Existenzbedingungen erfüllt: sie versammelt Akteure wie Statuen, zahlreiche Narrationen, Träume und Personen in Pech Nil um sich. Das Netzwerk des Geistes wurde über die Zeit von einer wachsenden Anzahl von Akteuren bereichert, und speziell die Renovierung der 
Straße mit ihrer logistischen Bedeutung führte zu einem massiven Bedeutungszuwachs des Schreins.

Heute wird yāy Mao auch in anderen Gegenden als Verursacherin von unerwarteten Verkehrsunfällen gesehen, wie beispielsweise im Dorf Choam, wo eine Statue von yāy Mao nördlich von Anlung Veng auf einer Verkehrsinsel vor dem Grenzübergang zu Thailand steht (Kap. 3.5). Bis in die 1990er Jahre war dieser Ort ein Khmer-Rouge Checkpoint und die in den Stein gehauenen Statuen stellten eine Gruppe Bauern nach kommunistischem Ideal dar. Die einzige Frau in ihren Reihen trug ein Bündel von Bambusspitzen an die militärische Frontlinie, die in vergifteter Form von den Khmer Rouge als ,heilige Waffen'verstanden wurden (Dy und Dearing 2014: 63-65). Nach dem Ende der Khmer Rouge Herrschaft in Anlung Veng im Jahre 1998 wurde das Denkmal teilweise zerstört, bis yāy Mao nach zahlreichen Verkehrsunfällen in einer der Statue identifiziert wurde. Zucker (2017) argumentiert, dass die spirituelle Besetzung der Statue symbolisch als ein Sieg der Geisterwelt über die antireligiöse Khmer Rouge-Vergangenheit betrachtet werden kann, zu denen die vormals unterdrückte Bevölkerung nun wieder vermehrt Kontakt aufnimmt.

Heute ist yāy Mao eine der populärsten Geister in Kambodscha. Viele Orte, die ihr geweiht sind, liegen an Hauptverkehrstrassen und werden mit Verkehrssicherheit assoziiert, was wegen immer höheren Verkehrsaufkommens und steigenden Zahlen von Verkehrstoten ein wichtiges Thema in der kambodschanischen Gesellschaft darstellt. Andere Manifestationen orientieren sich am Narrativ der ,Nonne Mao', die damit als buddhisierter anak tā eine vorzeigbare Wirkung für offizielle Anlässe erzielt. Prominentes Beispiel dieser Repräsentation ist die etwa 20 Meter hohe Statue von yāy Mao auf dem Berg Bokor, die der wohlhabende Eigentümer des Gebiets, Sok Kong, zum Start seines Städtebauprojekt 2012 errichten ließ. Dass die Geisterstatue vor allen anderen Gebäuden erbaut wurde, folgt der Vorstellung, dass anak tā als Zuständige des Landes über Erfolg und Misserfolg eines neuen (Geschäfts-)Projektes entscheiden. 


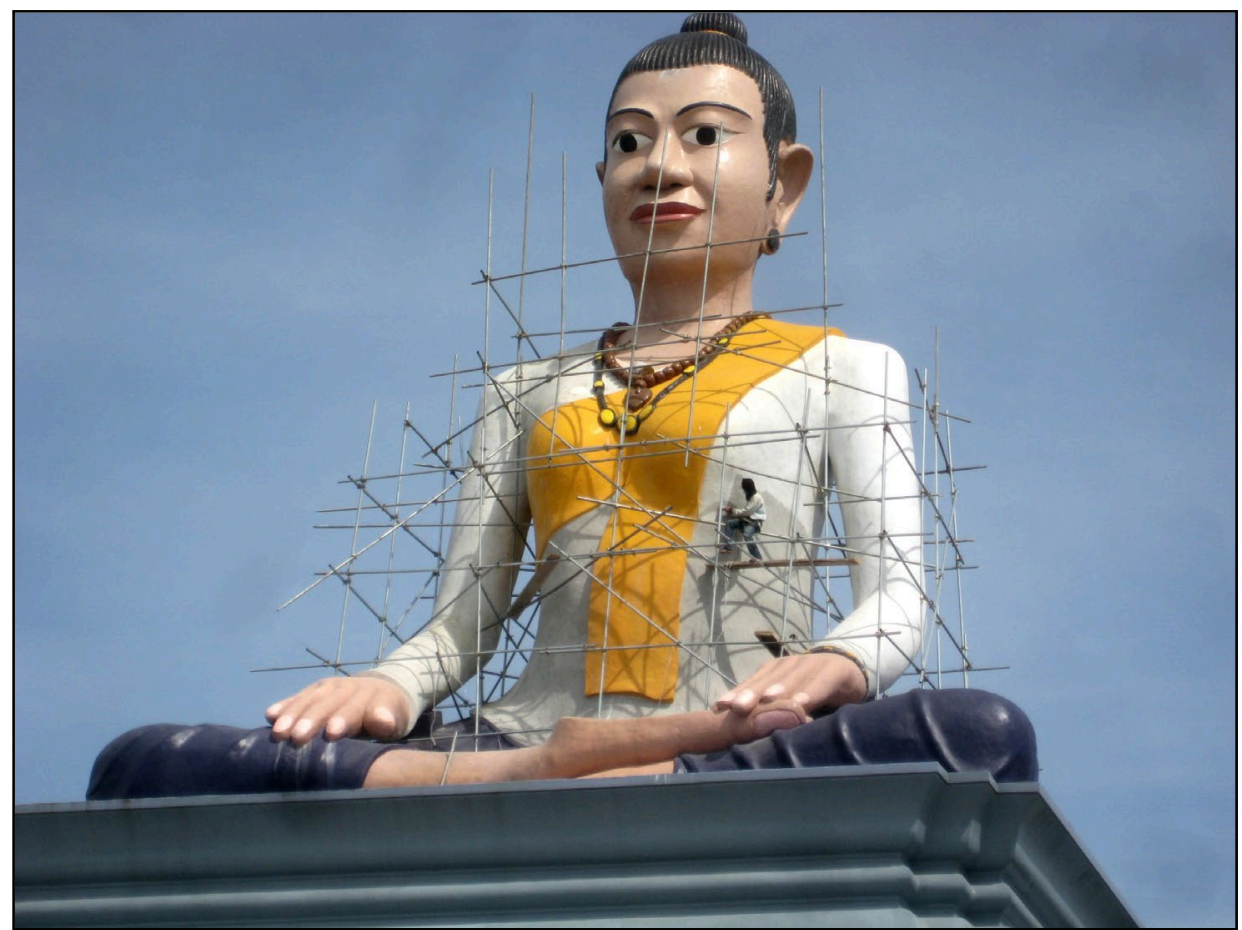

Abb. 14: (C) Autor. Yāy Mao auf dem Phnom Bokor (Provinz Kampot) im Jahr 2012. Diese nicht vollständig fertig gebaute, riesige Statue von yāy Mao zeigt sie in ibrer modernen Darstellung mit weißer Hautfarbe und jungem Aussehen. Unterhalb der Statue befindet sich zudem ein Schrein für lok tä Krahom Kar.

\subsection{Abschließende Bemerkung zur Existenzweise kambodschanischer Geister}

Anak tā bereichern die kambodschanische Geisterlandschaft mit einer auffällig flexiblen Konzeption: ihre imaginierte Form kann sowohl fluid als auch subjektiviert verstanden werden; ihre Materialisation variiert stark oder sie fehlt ganz; ihre Präsenz wird in Objekten oder menschlichen Körpern verortet und ihre Praxis ist derart breit gefächert, dass ihre Wirkungsweise bei so gut wie jedem Anliegen, sei es buddhistisch oder brahmanistisch geprägt, funktionieren kann.

Als entscheidend für das Verständnis der anak tā erweist sich die Untersuchung ihrer Existenzbedingungen. Sie ermöglichen eine breite und rekursive Kontextualisierung unter Berücksichtigung des emischen Kontextes. Wie ich am Beispiel von yāy Mao gezeigt habe, weisen anak tā individuelle Biographien auf, die gesellschaftliche Relevanz erhalten, sobald sie materielle Repräsentationen, definierte Handlungsspielräume, biographische Referenzen auf weltliche Macht sowie 
magische Wirkmacht vorweisen können, was zu einer Akkumulation von Referenzen und damit zu einer stabilen Existenz führt. Einige dieser Existenzen bleiben fragil und andere derart stabil, dass die in offiziellen Diskursen tragende Rollen einnehmen. Als Verwalter und Beschützer des Landes werden daher einige anak tā wie yāy Mao oder lok tā Kleang Moeung als identitätsstiftende Akteure der kambodschanischen Nation inszeniert (Kap. 9).

Abschließend für die Untersuchung der Geister-Existenzweisen lässt sich zusammenfassen, dass Totengeister wie khmoc oder preta, wilde Geister wie brāy oder pisāca oder die anak tā in ihrer brahmanistischen oder buddhistischen Ausprägung, eine dynamische Geisterlandschaft formen. Darin werden verschiedene Zeitlichkeiten, Identitäten, Wirkungsweisen, Erfahrungen und Religionen in vermeintlich widersprüchlicher Form verbunden. Die Geisterlandschaft bildet durch die Integration dieser Bestandteil ein sinn- und wertstiftendes Feld der Aushandlung von gesellschaftlich geprägten Problematiken sowie individuellen Aspirationen.

Die Praxis der Medialität ist Gegenstand des dritten Teils der Arbeit. Im Zustand der Geistbesessenheit verdichtet sich ein Netzwerk der relevantesten Akteure für die Geister-Existenz (Geister, Menschen, Opfergaben, Schreine und viele mehr). Durch Praktiken der Medialität sind die involvierten Akteure in der Lage, Raum und Zeit zu transzendieren: Geister aus anderen Welten und Zeiten werden in der Jetztzeit verkörpert und treten mit Menschen und ihren zeitgenössischen Anliegen in Kontakt. Durch diese transversale Verbindung wird ein ,übernatürliches ${ }^{6}$ Potential konstruiert, das nur in diesen medialen Ritualen ausgeschöpft werden kann. Wie in diesem Teil der Dissertation deutlich werden wird, artikulieren Rituale der Geistbesessenheit Grenzen der menschlichen Vorstellungs- und Handlungsmacht und helfen den involvierten Akteuren dabei, diese Grenzen des Individuums, der Gesellschaft und der Politik neu auszuhandeln. 



\section{MEDIALITÄT \& MACHT}





\section{Akteure der Medialität}

Neben Geistern, Schreinen und Opfergaben, die im Netzwerk der kambodschanischen Spiritscapes wesentliche Rollen einnehmen, ist dieses Kapitel den menschlichen Akteuren - den grū und ihren Klient_innen - gewidmet. Damit komplettiere ich die Beschreibung des Geister-Netzwerks um die medialen Akteure, die sich als grundlegend für die im Folgenden beschriebenen Rituale des Segens, der Heilung und der spirituellen Machtakkumulation herausstellen werden. Das Vorgehen in diesem Kapitel konzentriert sich zunächst auf den typischen Werdegang von grū: von den ersten Anzeichen ihrer ,Berufung' bis zur Ausübung ihrer Ritualpraxis (Kap. 6.1). Ich beantworte die Frage, wie Personen Geistmedien werden und inwiefern dieser vielschichtige Transformationsprozess ihren sozialen Status ändert. Als weitere Akteure der Medialität beziehe ich mich danach auf die Klient_innen der grü (Kap. 6.2), die mit ihren Anfragen und ihren Besuchen existentielle Bedeutung für die Medien besitzen. Mit der Darstellung dieser Beziehung und der damit verbundenen ,Inkorporation' von Geistern in die Gesellschaft schafft dieses Kapitel Grundlagen zum Verständnis von Wirksamkeit und Attraktivität der brahmanistischen Rituale (Kap. 7-9). 


\subsection{Die Geistmedien}

Geistmedien stellen die im ganzen Land präsenten Hauptakteure der Medialität dar. Sie werden als rūpa (Körper), snān (Diener) oder grū (Lehrer, Meister) bezeichnet, wobei der letztgenannte den gängigsten Begriff darstellt.

\subsubsection{Verschiedene Grū}

Grundlegend werden drei unterschiedliche Gruppen von grū unterschieden: die grū pāramī, die grū khmer und die grū dāy. Die grū cūl rūpa (wörtlich: ,Lehrer eintreten Körper), auf die ich mich wegen ihrer besonderen Beziehung zu Geistern und ihrer Praxis der Geistbesessenheit fokussiert habe, gehören zu der Gruppe der grū pāramī, da sie mit der gleichnamigen spirituellen Macht arbeiten. Bevor ich näher auf diese Geistmedien eingehe, stelle ich kurz die die beiden anderen Gruppen von spirituellen,Lehrer_innen'vor.

Grū khmer (gesprochen: ,kru khmaä) sind meist männlich und auf Heilungen mit Hilfe sogenannter, traditioneller ${ }^{6}$ Medizin aus pflanzlichen Produkten spezialisiert. Der Beiname „khmer“ bezieht sich auf die Anwendung von lokalem, medizinischem Wissen in Abgrenzung zur, importierten' Schulmedizin (Ovesen und Trankell 2010: 134). Während der Zeit der Roten Khmer (1975-79) waren lediglich Behandlungen von grū khmer zugelassen. Westliche Medizin galt als imperialistisch, und spirituelle Behandlungen wurden als religiös abgelehnt und verfolgt. Dieser Umstand hat bis heute zur Folge, dass grü khmer sich stets als Fachkundige, Gelehrte oder Mediziner bezeichnen und keine spirituelle Deutung ihrer Arbeit akzeptieren (vgl. Ovesen und Trankell 2010: 139). Obwohl manchen von ihnen der Umgang mit pāramī nachgesagt wird, nennen sie sich nicht grū pāramī, sondern bestehen auf dem Namen grū khmer, da sie ihre Arbeit damit in Anlehnung an die frühere Bezeichnung als medizinisch und weniger spirituell interpretieren als die grū pāramì.

Die grū dāy (gesprochen: ,kru tiey') arbeiten astrologisch und sind somit auf Zukunftsvoraussagen und Horoskope spezialisiert. Ihre Bezeichnung lässt sich wörtlich mit ,Lehrer Voraussage ${ }^{6}$ übersetzen. Die Zahl der praktizierenden Männer und Frauen ist ausgeglichen und sie sind nicht nur in ländlichen, sondern auch vermehrt in urbanen Kontexten anzutreffen. Damit bilden sie die einzige Gruppe von grū, die in Städten (auf Märkten, ihren Privathäusern oder in kleinen Läden) tätig sind. Sie pflegen keinen direkten Kontakt zu Geistern; ein Großteil ihrer Arbeit besteht in der astrologischen Berechnung von Prophezeiungen (Poonnatree i.E.). Diese Prognosen beruhen beispielsweise auf der Angabe des genauen Geburtstages und des Tierkreiszeichens der Klient_innen. Grū dāy interpretieren auch die Bedeutung von Handlinien oder zufällig gezogenen Spielkarten. Dabei stellen sie ihre Praktiken als rational und empirisch dar und streiten eine mögliche magische Wirkung ihrer Handlungen ab. Die Besuche bei den grū dāy sind flüchtiger Art - während des Einkaufs auf dem Markt - und charakterisiert von kurzen 
Anfragen nach einem Horoskop oder einem Ratschlag für zukünftige Entscheidungen.

Bei den grū pāramī können Klient_innen auch größere Anliegen vorbringen. Nicht alle von diesen Geistmedien praktizieren Besessenheitsrituale. Bestehen sie darauf, grū pāramī aber nicht grū cūl rūpa (gesprochen: ,kru djol rub') genannt zu werden, so gehörten sie zur großen Gruppe der grū, deren Kontakt mit Geistern ,indirekt ${ }^{\star}$ stattfindet. Das heißt, die Klient_innen können nicht mit dem Geist sprechen, sondern mit dem Medium, der von einem oder mehreren Geistern ,beraten' wird. Grū cūl rūpa dagegen sind grū pāramī, die von anak tā oder pāramī besessen werden können. Ich interessierte mich besonders für diese Kategorie der grū, da bei ihnen die Existenz der Geister am ,greifbarsten' war und sich hier ihre Existenzbedingungen offenbarten und die Perspektive der Geister deutlich wurde.

\subsubsection{Die Initiation zum Grū cūl rūpa}

Bis zu ihrer Initiation durchleben und -leiden alle grü ähnliche Stadien. Analog zu liminalen Ritualstrukturen (Turner 1969; van Gennep 1909) lässt sich die Entwicklung zum Medium in drei Phasen einteilen: Krankheit, Heilung/Initiation, Rehabilitation.

Die erste Phase beginnt stets mit körperlichen oder geistigen Symptomen der gesellschaftlichen Nonkonformität und/oder Krankheit. Derart ,nonkonforme Verhaltensweisen schließen Selbstgespräche, plötzliche Kontrollverluste, mangelndes Schamgefühl und weitere als ,verrückt ${ }^{6}$ (chkuat) geltende Handlungen ein. Daneben treten allgemeine Krankheitssymptome auf wie Schmerzen, Niedergeschlagenheit, Inkontinenz oder langanhaltende Bewusstlosigkeit (phlāk $k^{117}$ ). Diese erste Phase wird von den Betroffenen und ihren Angehörigen, die oftmals viel Geld in gescheiterte Heilungsversuche investieren, rückblickend als chaotischer, bisweilen auch als lebensbedrohlicher Zustand beschrieben.

„Nach dem Tod meines Vaters, mit 15 Jahren, sab ich den Geist zum ersten Mal und wurde daraufhin für einige Monate sehr krank. Dann verlor ich für 10 Monate sogar ganz den Verstand und wurde verrückt (chkuat). Niemand konnte mir belfen, ich lief obne Bewusstsein herum. Da ich verrückt, allein und Jungfrau war, versuchten einige Männer mich zu vergewaltigen, aber obne Erfolg, da der Geist und mein Onkel sich um mich kümmerten. Der Geist brachte mich zum Erbrechen, wenn ich normale Nahrung essen wollte und ließ mich in dieser Zeit nur Blumen und Regenwasser konsumieren" (Grū Bah, Interview am 15.05.2012).

Häufig wird die Krankheit von spirituellen Visionen begleitet. Nach einigen gescheiterten Heilungsversuchen durch Ärzte werden sie von Mönchen oder ande-

\footnotetext{
117 „Etat d'une personne plongée dans un coma prolongé (trois jours et au delà). Ses 'âmes' voyagent pendant ce temps dans l'au-delà et sont témoins de divers événements" (Pou und Ang 19871990: 80).
} 
ren grū auf die Präsenz eines Geistes in ihrem Körper hingewiesen. Dies stellt einen Moment der Enttäuschung und Verzweiflung dar. Denn alle grü betonten mir gegenüber nachdrücklich, dass sie niemals Geistmedien werden wollten. ${ }^{118}$ Eine große Zahl von ihnen wehrte sich sogar gegen das bevorstehende Schicksal, in dem sie dem Geist den Kontakt verweigerten und ihm beispielsweise keinen Schrein bauten, was generell ein erster Wunsch eines Geistes ist. Je größer der Widerstand gegenüber dem Geist jedoch ausfällt, desto eher verschlimmert sich der gesundheitliche Zustand der Betroffenen, wie hier am Beispiel von grū Ly deutlich wird:

„....ich war unfähig geworden, selbst einfachste Dinge zu verrichten. So batte ich meine Arbeit aufgeben müssen (...) und verbrachte die meiste Zeit untätig ₹u Haus. In den ₹u dieser Zeit häufig wiederkebrenden Träumen von lok tā Eysey hatte ich anfangen, über meine Zukunft zu verbandeln. Der Geist würde mich aber erst wieder gesund machen, wenn ich ibm gehorchte. Ich sagte zu ihm: , Aber wenn ich grū werde, musst du, lok tā Eysey, meinen Kindern helfen und ibnen ein eigenes profitables Geschäft ermöglichen sie sollen reich werden, sonst werde ich kein grü' Nach mehreren Träumen dieser Art bandelte ich einen 20 prozentigen Anteil der Einnahmen aus dem GeistmediumGeschäft aus, die ich nicht wobltätig spenden musste. (...) Sobald wir uns einig wurden und ich den Schrein gebaut hatte, wurde ich wieder gesund"119 (Interview grü Ly vom 06.12.2012).

Erst mit der Kontaktaufnahme zu dem Geist und seiner weltlichen Manifestation des Geisterschreins (pay si) endet die liminale Phase der Medien und ihre gesundheitliche Situation verbessert sich. ${ }^{20}$ Die anak tā aus der Angkor-Zeit bringen somit eine ordnende Struktur in die chaotisch erlebten Lebensumstände der Medien. Dieses entscheidende Moment beinhaltet alle Aspekte der oben vorgestellten Spiritscapes: in einer Migrationsbewegung der Geister zwischen thān suok und Menschenwelt werden verschiedene Zeitlichkeiten in Form von uralten Mächten der brahmanistischen Epoche verkörpert und fordern den Aufbau einer Tauschbeziehung ein.

\footnotetext{
118 Aus älteren Berichten geht hervor, das die Profession des Mediums von Schüler_innen erlernt (Eisenbruch 1992) oder vererbt (Forest 1992: 53) werden konnte. Dies ist heute nur noch selten der Fall.

119 Es war üblich, dass Geistmedien einen Teil ihrer Einnahmen der Pagode oder wohltätigen Zwecken spenden mussten. Die Höhe des eigenen Anteils war bei allen unterschiedlich und variierte zwischen 10\%-50\%.

120 Vergleiche das Beispiel der gescheiterten Manifestation von $t a \bar{a}$ Noël in Kap. 3.4.
} 
Nach der erfolgreichen Etablierung dieser Beziehung müssen sich die Novizen einer Belehrung durch ihren Geist unterziehen. In einigen Fällen passiert dies mit einer ,geistigen Reise ${ }^{121}$ in die obere Welt (thān suok), wie im Fall von grū Srun:

„Jeden Monat hatte grū Srun drei Tage und vier Nächte seinen Körper verlassen, um sich im Himmel bei den devatā und seinem Geist lok tā Kong Cha spirituell unterveisen zu lassen. Dabei war ein weißes Tuch über ibn gelegt worden (wie bei einem Toten) und ein Mönch war jeden Tag gekommen, um ihn in diesem Zustand der Bewusstlosigkeit (phlāk') zu segnen"(Forschungsbericht vom 10.07.2012).

Andere Medien erhalten in Träumen Anweisungen und Lehren vonseiten ihrer Geister, wieder andere stehen mit den geistigen Wesen im ständigen Dialog und werden permanent ,unterwiesen'. Die Belehrungen, die in vielfältiger Form und Intensität vorkommen, charakterisieren den Abschluss des Initiationsprozesses der Geistmedien. Da es keine institutionalisierte oder anderweitig standardisierte Ausbildung für diese Aufgabe gibt, kommt es zu einer großen Individualität der brahmanistischen Praxis. Die grū stehen von diesem Zeitpunkt an vor der Aufgabe, ihrem neuen $g^{122} \mathrm{zu}$ dienen.

\subsubsection{Die Pflichten und Privilegien der Medialität}

Allen Geistern ist gemeinsam, dass sie ein enthaltsames, mönchsgleiches Leben ihrer Medien fordern. Somit führen die Heilung und die Initiation als Geistmedium zu grundlegenden Einschränkungen des Lebensstils der Betroffenen.

„Dann fragte ich (...) ob sie [Ming Bah] gern grū sei. Sie erzäblte erst, dass sie ,wie ein Mönch' leben müsse: sie darf nicht tanzen, sich nicht schminken, keinen Schmuck tragen. Sie muss viel beten und immer auf eine angemessene Sprache und gute Umgangsformen achten. Ob ich wirklich glaubte, dass sie diese Einschränkungen genießen würde, fragte sie mich spöttisch zurück" (Feldforschungsbericht vom 15.05.2012).

Viele grū betonten, dass sie sich mit der Manifestierung der Geister in ihren Körpern einem Leben nach purāna (,altertümlicher', in diesem Fall: asketischer) Art verschreiben mussten, da ihre Geister keinen samăya (,modernen') Lebensstil dul-

${ }^{121}$ Damit folgt sie dem Ablauf der sogenannten Schamanenkrankheit (shamanistic initiatory crisis). Bei genauer Betrachtung sind jedoch keine weiteren Übereinstimmungen mit gängigen Schmananismus-Konzepten aus Mittelasien oder Korea zu kambodschanischer Medialität erkennbar (Forest 1992: 51-52).

122 Der Geist eines Mediums wurde von ihnen ebenso als grü bezeichnet, wie die Medien von den Klient_innen. 
den würden. ${ }^{123}$ Bei Verstößen gegen die von den Geistern auferlegten Regeln mussten die Medien fürchten, wieder krank zu werden. Sie blieben aber nicht nur in der passiven Rolle der Erduldung von Vorschriften, sondern handelten ihre Privilegien und Verpflichtungen (wie grü Ly oben) aktiv mit ihren Geistern aus. Dabei geht es um persönliche Anteile von Spendengeldern, die Einhaltung von moralischen Pflichten und auch um die zeitliche Dauer ihrer körperlichen Präsenz in den menschlichen Körpern - einige waren ständig von einem oder mehreren Geistern besessen, andere wehrten sich dagegen und arrangierten ihre Beziehung so, dass die Geister bei Bedarf gerufen oder aus der Ferne befragt werden konnten.

Ähnlich wie in einem Arbeitsverhältnis werden die Medien mit mehr Erfahrung oftmals besser, entlohnt'. Anfangs müssen sich die Medien in strengerer Askese üben und haben noch viel von ihren Geistern zu lernen. Bei Medien mit langjähriger Erfahrung kommt es nach einigen Jahren oftmals zu einer Phase der Emanzipation, in der Pflichten und Privilegien der Medialität der Arbeit neu und zu ihrem Vorteil ausgehandelt werden.

Dennoch bedeutet das von den Geistern gewünschte asketische Leben für die grū zunächst eine Herabsetzung ihrer bekannten Lebensumstände. Ganz gleich, wie aktiv manche Novizen ihre Privilegien gegenüber ihren Geistern verteidigten - sie schlossen sich alle dem weitverbreiteten Narrativ an, wonach sie in unerfreulich ärmlichen Verhältnissen lebten. Von ihren Geistern würde ihnen auferlegt, viel zu hohe Anteile von ihren eher geringen Einnahmen zu wohltätigen Zwecken abgeben zu müssen, was ihre wirtschaftliche Handlungsmacht stark beeinträchtigen würde. Somit stellten sie sich als Menschen dar, die gern moderner, reicher und sozialer gewesen wären, es aber wegen ihrer Besessenheit von uralten Mächten (pāramī purāna), mit denen sie sich gezwungenermaßen arrangieren mussten, nicht oder nur sehr bedingt sein konnten.

Diese Selbstwahrnehmung korreliert mit der Sicht der Klient_innen auf die soziale Stellung der grū. Die Klient_innen, insbesondere die der wachsenden urbanen Mittelschicht, galten für die Geistmedien auf dem Land als typische Vertreter_innen des ,modernen' Lebens. Die Medien wurden von ihnen für ihre asketische Lebensführung bedauert, und dafür, dass sie sich mit den als unberechenbar geltenden Geistern abgeben mussten. Mit dieser verbalen Abgrenzung positionierten sich die Besucher_innen der grū selbst als ,moderner' Gegenpol zu den Medien, die damit - auch durch ihr eigenes Klagen - zu ,vormodernen' Vertreter_innen degradiert wurden.

123 Als Personen mit „exemplarischer Moral“ (Bertrand 2004: 160) knüpfen sie an eine lange Tradition von spirituellen Experten in Kambodscha an, deren Wirken bereits durch Steininschriften und Berichte aus dem 13. Jahrhundert (Zhou 1992 [1296]: 35) überliefert wurde; auch wenn die Geistmedien heute nicht als kulturelle Kontinuität dieser Eremiten zu verstehen sind, sondern als eine Belebung oder Neu-Interpretation dieser Praxis (Thompson 2008: 118; Mus 2011 [1933]). 
Gleichzeitig driften hier meiner Ansicht der Narrativ der Initiation und die gelebte Praxis auseinander, denn eine andere Seite ihrer Arbeit verschwiegen die Geistmedien gänzlich: Sie hatten durch ihren neuen Status ebenfalls Privilegien gewonnen, und befanden sich in einer sozialen Sonderstellung, die es ihnen erlaubte, sich über gesellschaftliche Normen hinwegzusetzen und sich individueller zu entfalten als es normalerweise üblich war. Es ist beispielsweise homosexuellen (Trans-)Personen ${ }^{124}$ gestattet, in einer Atmosphäre der Nonkonformität außerhalb von gängigen heteronormativen Vorstellungen von Partnerschaft zu leben. Ich traf männliche grū, die relativ offen homosexuelle Beziehungen pflegten, unverheiratet blieben oder effeminiertes Verhalten zeigten, ohne dass sie negative Reaktionen darauf von ihrem sozialen Umfeld befürchten mussten.

Auch weibliche Geistmedien gehen häufig gestärkt aus ihrer Initiation als Geistmedium hervor. Einige von ihnen verließen , auf Geheiß der Geister ${ }^{6}$ ihren Ehemann; sie rauchten und tranken Alkohol, wenn sie besessen waren (was normalerweise gesellschaftlich geächtet wird). Denn die Verbote sind nur den menschlichen Medien auferlegt: in Besessenheit können grū ausgelassen miteinander zu lauter Musik tanzen, rauchen und trinken. Nicht zuletzt bekommen Menschen mit psychischen und/oder sozialen Problemen durch die Initiation ein geregeltes Einkommen in Form von Spenden, dargereicht von ihnen respektvoll gegenübertretenden Menschen.

Die Konsequenzen der Initiation sind jedoch nicht Teil des von den grū vertretenen Narrativs zur Initiation. Stattdessen schaffen sie es mit ihrer Betonung auf die Pflichten der Medialität, ihre Frömmigkeit zu betonen und ihre Referenzen auf die ,alte, mächtige Zeit‘ zu stärken.

\subsubsection{Das soziale Umfeld der Geistmedien}

Diese besonderen Lebensumstände der Medien prägen auch ihre Rollen in ihrer örtlichen Dorfgemeinschaft. In den Anfängen ihrer Reintegration in das gesellschaftliche Leben als grū können Nachbarn, Freunde und selbst Familienmitglieder misstrauisch und verständnislos ob der neuen Berufung der ehemals gut in die Gemeinschaft integrierten Personen reagieren, was am Beispiel von Bun Ly deutlich wird.

„,Nach der Initiation bielt er] im Alltag unvermittelt und in regelmäßigen Abständen Zwiesprache mit ibnen [seinen Geistern], was seine Frau schockierte. Als er grū wurde, stellte sie den Kontakt zu ibrem Ehemann weitestgehend ein (...) Nur zum Essen und $W$ aschen durfte er in das große Haus der Familie (...) er schlief im kleinen Haus mit seinen Schreinen, da er nicht im Haus bei seiner Frau und den Kindern schlafen durfte" (Feldforschungsbericht vom 06.12.2012).

${ }^{124}$ Ich beziehe mich hierbei vor allem auf männliche Homosexuelle und Transfrauen (khdoey). Offener Umgang mit weiblicher Homosexualität ist auch bei Geistmedien stark tabuiert. 
Von ihrem sozialen Umfeld werden die grū nach ihrer Initiation als semi-religiöse Akteure verstanden, die die gesellschaftlichen Normen der Menschen den geforderten Handlungen der Geister unterordnen und die sich zudem in unterschiedlichem Maß deviant zum Buddhismus verhalten (Kap. 2). Um diesen Vorwurf zu entkräften, positionieren sich die Medien als Personen ,exemplarischer Moral ${ }^{6}$ (Bertrand 2004: 160), indem sie beispielweise fünf, acht, oder zehn der tugendhaften sīla-Vorschriften aus dem Pāli-Kanon folgen. ${ }^{125}$ Sie betonen, dass sie diesen Regeln folgen müssten, um von ihrem Geist belohnt zu werden, beziehungsweise um Bestrafungen zu entgehen. Je wohlhabender die Medien sind, desto eher gelten sie als moralisch ,rein', da ihr Reichtum als Belohnung für ihre Tugend verstanden wird (Bertrand 2004). Somit sind erfolgreiche gru meist besser angesehen in sozialen Gemeinschaften, als die weniger erfolgreichen Geistmedien. Das folgende Beispiel von grū pāramī Kon tā Ma zeigt diese Kausalität am Beispiel ihres Ehemanns auf:
„Mein Mann trennte sich in dieser Zeit von mir, da er nicht an Geister glaubte und mich für verrückt bielt. Der Geist befahl mir, ein kleines Haus in der Nähe von Phnom Penh zu suchen und dort Menschen zu beilen. Ich tat es (...) und war erfolgreich. Mein Mann kam daraufhin zurück und glaubt heute auch an die Macht der Geister, (...) da ich nun ein bohes Einkommen babe" (Interview grü Kon tā Ma vom 22.04.2012).

Die einzige Einkommensquelle der grū bilden die Spenden der Klient_innen. Die Opfergaben müssen immer Zigaretten, Kerzen, Räucherstäbchen und eine wählbare Summe Geld beinhalten, sind jedoch nicht darauf beschränkt. Ihre Bedeutung ist einerseits substantiell, denn die grū dürfen die Spenden nach der Darbietung an ihren Geist behalten, weiterverkaufen oder selbst konsumieren. Die materiellen Güter sind andererseits auch für den sozialen Stand der Medien in ihrer jeweiligen Dorfgemeinschaft von großem Wert. Denn die Summe und das Aus$\mathrm{maß}$ an Spenden an grū sind wichtiger Bestandteil der informellen Gespräche der Dorfbewohner_innen und damit ausschlaggebend für den Erfolg der Medien. Zudem bilden die Klient_innen so etwas wie das, unfreiwillige Aushängeschild“ der Geistmedien. Da die Weiterempfehlungen anderer Klient_innen die einzige Werbung für die gru darstellt, ist ihre Reputation von großer Bedeutung für den Erfolg der grū.

Andere Geistmedien, insbesondere die grū cūl rūpa mit ihren Besessenheitsritualen, haben mehr Probleme in ihren örtlichen Gemeinschaften als andere Medien und müssen aktiv um Anerkennung werben. Für ihrer Kritiker_innen stellen sie Repräsentanten einer ,zu brahmanistischen' Religiosität dar, die Misstrauen erzeugt. Diese Antipathien können auch explizit werden: Es gab Vorwürfe gegen

125 Während die fünf silla Töten, Stehlen, Lügen, sexuelles Fehlverhalten oder Drogenrausch verbieten, untersagen die acht sīla das Essen nach $12 \mathrm{Uhr}$, das Besuchen von Unterhaltungsveranstaltungen, die Benutzung von Schmuck oder Kosmetika und das nicht-erhöhte Sitzen und Schlafen. Die zehn sīla ergänzen die Reihe um sexuelle Abstinenz (Edwards 2008b). 
grū, die angeblich ihre Spendeneinnahmen veruntreuten oder ihre Macht zu Missbrauch nutzen würden. Die grū haben somit existentielle Angst vor dem Vorwurf der Veruntreuung oder, noch gravierender, der schwarzen Magie (amboe). Wird ein solcher Vorwurf gegen grū von einem Großteil der Dorfgemeinschaft geteilt, sind körperliche Angriffe von Gruppen in Selbstjustiz bis zum Tod der sogenannten ,Hexer' oder ,Hexen“ (dhmáp) keine Seltenheit (Hruby 2014; Davis 2009: 223). ${ }^{126}$

Der Großteil der gru hat jedoch nicht unter derartigen Vorwürfen zu leiden und lebt gut integriert in ihrer Dorfgemeinschaft. In vielen Fällen unterstützen die Geistmedien beispielsweise wohltätige Zwecke auf lokaler Ebene, indem sie Geld für Stupas sammeln, in der die Asche von Toten aufbewahrt werden kann, deren Angehörige sich keinen Bau eines eigenen Stupas leisten können. Dies fördert die Beziehungen zur Dorfgemeinschaft, in der die Medien leben und aus der viele ihrer Klient_innen stammen. Somit bauen die Medien sich oftmals einen festen Kundenstamm auf, der ihnen soziale Interaktion und adäquate Grundlagen der Subsistenz ermöglicht.

\subsection{Die Klient_innen}

\subsubsection{Ihre Anliegen}

Nach Auswertung von über 40 beobachteten Konsultationen von Klient_innen bei Geistmedien unterscheide ich vier Arten von Anliegen: die meisten der Besucher_inner der grū wollten einen Segen des Geistes für ihr berufliches Leben oder zur allgemeinen Verbesserung ihrer Lebensumstände. Eine große Anzahl war außerdem zwecks Heilung von zum Teil körperlichen, vor allem aber von geistigen oder psychischen Krankheiten zu den grū gekommen. Andere Klient_innen hatten Probleme in der Beziehung zu ihren Partner_innen, zu ihren Eltern, Kindern oder Freund_innen. Die letzte, diffuse Kategorie von Anliegen betrifft alle anderen Gesuche, die sich wegen ihrer Individualität keinem Bereich zuordnen ließen. Hier reichte die Bandbreite von der Nennung der Lottozahlen, der Erfüllung eines Kinderwunsches, der Übernahme von Erziehungsaufgaben, dem magischen Verhindern von Verkehrsunfällen bis zu dem Segnen von Gegenständen wie Autos oder Handys. Ein großer Teil der Klient_innen stand vor konkreten, wichtigen Entscheidungen in einem der oben genannten Bereiche und suchte nach Empfehlungen.

\footnotetext{
${ }^{126}$ Im Jahr 2014 wurden mindestens vier Menschen wegen des Vorwurfs der schwarzen Magie von aufgebrachten Menschenmengen umgebracht - von solchen Fällen berichtet schon Leclère aus dem 19. Jahrhundert (1895: 132).
} 


\subsubsection{Ihre Beweggründe}

In den Gesprächen mit den Klient_innen vor oder nach ihren Konsultationen wurden meist positive Zuschreibungen auf die brahmanistische Praxis der grū gemacht. Nur selten wurden Ängsten und Zweifel angesprochen (siehe nächstes Kapitel). Vielmehr kann ich aus den Gesprächen mit Klient_innen fünf Eigenschaften der Medialität ableiten, die häufig als Vorteile der Praxis herausgestellt und betont wurden. Demnach wird die Geistmedien-Praxis als preisgünstig, magisch, machtvoll, flexibel und persönlich wahrgenommen.

Erstens wurde das Preis-Leistungsverhältnis betont. Formulierungen wie „auch wenn es nicht nützt, wird es jedenfalls nicht schaden“ fielen in fast allen Gesprächen mit den ratsuchenden Personen. Somit wurde die eher geringe Spende von einem bis drei US-Dollar als sinnvolle Investition im Tausch gegen die Möglichkeit spiritueller Hilfe wahrgenommen. Zweitens war die magische Komponente von großer Bedeutung. Mit ihrer angenommenen magischen Wirkung (vetamun) sind die Geistmedien in der Lage, sofortigen Einfluss auf Ereignisse, Personen und Objekte auszuüben. Dies unterscheidet sie maßgeblich von den buddhistischen Mönchen, die lediglich das Sammeln von Verdienst (punya) für das kommende Leben oder den Toten möglich machen. Drittens spielt der Zugang zu pāramī eine entscheidende Rolle. Die Macht der Geister gilt als den menschlichen Kräften weit überlegen. Ihre pāramī ist theoretisch imstande, alles Vorstellbare umzusetzen. Darüber hinaus betonten die Klient_innen die Flexibilität der Praxis. Ohne schriftlich festgehaltene Vorgaben reagieren grū sehr individuell auf die unterschiedlichsten Anliegen der Klient_innen. Dies gilt auch für die moralische Bewertung der Anliegen, die sich nur nach der Argumentation der Klient_innen richten konnte. Fünftens, und diesen Punkt füge ich hinzu, weil ich ihn für grundlegend halte, obwohl die Klient_innen ihn nur selten betonten - schätzen die Klient_innen den persönlichen Kontakt zu den grū, die sich viel Zeit nehmen. Im Rahmen ihrer Konsultation wird ein Forum des Austausches geboten, in dem das eigene Anliegen mit dem Geistmedium, den Geistern und oft auch mit anderen, wartenden Klient_innen besprochen (und zuweilen auch ,ausdiskutiert') wird.

Diese Zusammenstellung zeigt (vgl. auch das Beispiel des Geschäftsmannes in Kapitel 5.2.), dass die Klient_innen den Besuch bei grū als vorteilshaft und legitim zur Lösungssuche für Probleme empfinden und die Spenden an Geister als rationale Investition bewerten.

Nach der Vorstellung der menschlichen Akteure der kambodschanischen Spiritscapes lenke ich den Fokus nun auf die medialen Praktiken, in denen die Beziehungen zwischen Klient_innen, Geistmedien, Geistern und zahlreichen materiellen ,Akteuren' wie Schrein und Opfergaben zum Tragen kommen. Die alltägliche Akteur-Netzwerkbildung von Geistern und Geistmedien nimmt bei den Klient_innen ihren Anfang. Sie wenden sich mit ihren Anliegen an die Medien, die in der kambodschanischen Gesellschaft höchst ambivalente Rollen einnehmen: sie gelten als bemitleidenswerte Untergebene ihrer Geister, die unfreiwillig in diese 
Rolle gedrängt werden. Durch die Internalisierung der Geister-Macht sind die grū jedoch geachtet und mitunter auch gefürchtet. Im Spannungsfeld dazu positionieren sie sich und ihre Geister als moralische Akteure, die in Einklang mit buddhistischen Lehren agieren.

Wie ich im folgenden Kapitel zeigen werde, sind es jedoch vor allem die Aushandlungen der moralischen und magischen Aspekte, die die brahmanistische Praxis für Kambodschaner_innen so attraktiv werden lässt. Das folgende Kapitel der Heilungsgeschichte von Sothy ${ }^{127}$ führt aus, wie und warum auch Personen mit Zweifeln und Ängsten vor Geistern auf Praktiken der Medialität zurückgreifen.

${ }^{127} \mathrm{Da}$ im Folgenden (unter expliziter Erlaubnis der betroffenen Person) sensible Prozesse einer Heilungsgeschichte nacherzählt werden, habe ich zum Schutz ihrer Privatsphäre ein Pseudonym gewählt. 



\section{Sothys Heilungsanliegen und die Frage nach der Authentizität medialer Rituale}

Die meisten Kambodschaner_innen kommen im Laufe ihres Lebens mit der Arbeit von grü in Berührung. Sie lassen sich von ihnen beraten, segnen, heilen und magisch aushelfen. Doch nach welchen Bewertungskriterien entscheiden sich Klient_innen für das mediale Angebot und worin bestehen möglicherweise Zweifel? Beispielhaft für das Abwägen der Vor- und Nachteile der Medialität zeige ich in diesem Kapitel den Auswahlprozess verschiedener medizinischer Instanzen durch die junge Mutter Sothy. Ihre Suche (Kap. 7.1) und ihr Widerwille den medialen Akteuren gegenüber (Kap. 7.2) ergänzen die bereits vorgestellten Diskurse der geringen öffentlichen Kritik (Kap. 2) und der ,faktisch ${ }^{6}$ angenommen Existenz der Geister (Kap. 3) um eine weitere Binnen-Perspektive auf Medialität. Mit der Vorstellung verschieden ausgerichteter Medien und der Darstellung von GeisterHeilungsritualen (Kap. 7.3) stelle ich die Funktionsweise des brahmanistischen Heilungsangebots (Kap. 7.4) sowie die emische Konstruktion medialer Authentizität in den Fokus (Kap. 7.5). 


\subsection{Sothys Suche nach Heilung}

Sothy war, als ich sie 2012 kennenlernte, 26 Jahre alt. Sie ist verheiratet und hat eine Tochter. Ihre Mutter ist in der Lokalpolitik der Regierungspartei engagiert, der Vater arbeitet in einem staatlichen Ministerium. Damals studierte sie und hatte selbst nicht viel Geld, war aber durch ihre Verwandten sozial abgesichert. Sothy repräsentiert damit eine durchschnittliche Vertreterin der wachsenden Mittelschicht Phnom Penhs. Wir lernten uns über die Universität kennen, als ich dort nach einer Forschungsassistenz suchte.

Während unserer nachfolgenden, freundschaftlichen Treffen in Phnom Penh begann sie mit einem Mal von mysteriösen, körperlichen Leiden zu erzählen, die bei jedem Treffen drastischer zu werden schienen. Es begann mit Armschmerzen, die nur nachts auftraten. Gleich von Beginn an habe sie an den Einfluss von Geistern gedacht und deswegen einige Räucherstäbchen angezündet, um sich für unbewusst begangene Fehler zu entschuldigen. Die Armschmerzen seien dadurch jedoch nur kurzfristig besser geworden. In den darauffolgenden Wochen plagten Sothy immer häufiger Beschwerden, die sie wechselnden Körperregionen zuordnete: dem Kopf, den Armen und Beinen, den Gelenken und den Muskeln, der Leber, dem Blut, den Knochen und dem Gehirn. In diesen Bereichen schmerzte, pochte, zog oder drückte es ihren Ausführungen nach. Außerdem war sie überzeugt davon, dass ihre ,Knochen schwach' und ihr ,Blut süß oder ,dick' sein musste, wie sie es ausdrückte. ${ }^{128}$ Ich erwartete, dass sie ein Bedürfnis verspüren müsse, die Ursachen dieser Beschwerden ausfindig zu machen, doch Sothy wollte sich zunächst nicht eingehender damit beschäftigen. So stufte sie die Schmerzen zunächst als ,mysteriös' ein, ohne darauf genauer eingehen zu wollen und wartete zunächst auf ein natürliches Ende ihrer Leiden.

Entgegen ihrer Hoffnungen wurden Sothys Schmerzen stärker und beeinträchtigten sie zunehmend. Wochenlang konnte sie wegen stechender Schmerzen unter den Fußsohlen nur humpelnd laufen. Danach fiel ihr wegen ihrer Armschmerzen das Motorradfahren schwer. Die Beschreibungen ihrer Leiden nahmen immer größeren Raum unserer regelmäßigen Treffen ein. Schließlich entschied sie sich dafür einen Arzt zu besuchen und obgleich sie selbst eine spirituelle Ursache in Betracht zog, ängstigte sich Sothy vor den Mächten der alternativen Heiler_innen.

Für ihre Angst nannte sie zwei Gründe: einerseits fürchtete sie, dass ihr die gru absichtlich (in Form von schwarzer Magie) oder unabsichtlich (durch Fehler im Umgang mit Geistern) schaden könnten. So könnte sie ,verrückt“ (chkuat) werden. Damit verbunden war stets die Furcht vor der Diagnose ,Geistbesessenheit', die ihr den Zwang auferlegen würde, selbst grū werden zu müssen - und das wollte sie auf keinen Fall. Sie bevorzugte eine schulmedizinische Behandlung und wir besuchten ein Krankenhaus in der Innenstadt Phnom Penhs.

128 Zu lokalen Konzeptionen von Krankheitsursachen, siehe Hinton et al. (2014; 2010; 2005; 2003), Langford (2013) und Eisenbruch (1990). 


\subsubsection{Das Krankenhaus}

Der Arzt dort untersuchte Sothys Mund, Ohren und Nase und fühlte ihren Puls. Nach weiteren Fragen kam er zu dem Schluss, dass Sothys Körper keine Fehlfunktionen aufwies und die Schmerzen wahrscheinlich durch Stress ausgelöst würden. Sothy war enttäuscht über dieses lapidar klingende Ergebnis. Die Diagnostik hatte ihrer Meinung nach einen zu engen Ausschnitt ihrer vermeintlichen Gesundheit umfasst. Denn Sothy spürte nach wie vor die körperlichen Symptome ihrer Krankheit. Nachdem wir die Behandlung bezahlt hatten, zog Sothy kurzzeitig eine psychiatrische Behandlung in Erwägung. Es gab wenige derartige Einrichtungen und diese waren weit über ihre Kapazitäten ausgelastet (vgl. Pichayada 2016). Zudem wurden dort vor allem schwere Fälle behandelt und Sothy vermutete, dort mit ihren Beschwerden abgewiesen zu werden. Ohne Nachweise ihrer körperlichen Beschwerden kam sie zu dem Schluss, ihre spirituelle Verfassung untersuchen zu lassen.

Dabei fiel ihre erste Wahl auf einen magic monk. Bei den Mönchen war sie sicher, im Gegensatz zu den grü, dass diese aufgrund ihrer hohen moralischen Autorität nur wohlwollende Mächte zur Heilung benutzten und ihr daher nicht schaden könnten. Von ihren Nachbarn bekam sie die Adresse von einem magic monk in der Umgebung Phnom Penhs, zu dem wir einige Tage später fuhren.

\subsubsection{Der magic monk}

Für die Position als Vorsitzender seiner Pagode war der magic monk mit etwa 35 Jahren relativ jung. Er strahlte großes Selbstbewusstsein aus und rauchte zunächst ein paar Zigaretten mit Freunden, bevor er sich Sothys Problem widmete. ${ }^{129} \mathrm{Er}$ wies uns an, vor dem riesigen pāy sī Platz zu nehmen. Sothy legte 20.000 Riel (5 US-Dollar) auf eine Schale mit den üblichen Opfergaben (Zigaretten, Räucherstäbchen, Kerzen) und übergab sie ihm. Ohne auf die Spende oder die ausführlich vorgetragenen Leiden Sothys einzugehen, fragte er nach ihrem Geburtsdatum und ihrem Familienstand und sprach dann leise mit seinem Geist in Richtung pāy sī.

Kurze Zeit später kam er zu dem Schluss, dass Sothy ein Problem mit einer verstorbenen „Großmutter“130 von ihr habe. Der Mönch listete bestimmte Opfergaben auf, die Sothy in einer Pagode ihrer Wahl spenden sollte; darunter waren neben üblichen Dingen wie Nahrungsmittel und Räucherstäbchen auch speziell arrangierte Beigaben, die Sothy selbst nur dem Namen nach kannte. ${ }^{131}$ Er ver-

\footnotetext{
129 Auch wenn es nicht unüblich in Kambodscha war, dass Mönche rauchten, überging der Mönch damit eine Vorschrift, nach der Ordinierte keine Suchtmittel zu sich nehmen durften.

${ }^{130}$ Der gebräuchliche Name für Ahnen in Kambodscha ist tūn tā; also ,Großmutter und Großvater. Sie werden in den Hausschreinen der Haushalte verehrt und spielen für mediale Rituale keine Rolle.

${ }^{131}$ Darunter war beispielsweise slá dharm, eine junge Kokosnuss, die mit Blättern der Arekapalme und Räucherstäbchen bestickt wurde, siehe Ang (1986: 88).
} 
sprach ihr mit großer Bestimmtheit, dass ihre Probleme nach diesem speziellen Verdienstgewinn gelöst sein würden.

Nachdem wir uns von dem Mönch und dem pāy sī mit dreimaligen Verbeugungen auf den Knien verabschiedet hatten, fragte ich Sothy nach ihrer Wahrnehmung des Mönchs und seiner Aussagen. Sothy wog zögerlich ab: ein Problem mit ihren Ahnen hatte sie schon früher als Erklärung für ihre Krankheit in Betracht gezogen und so klang die Diagnose des Mönches für sie überzeugend. Sie wollte den Anweisungen des Mönches auch Folge leisten; allerdings sei sie nicht zufrieden mit der schnellen und unaufmerksam durchgeführten Diagnostik. Zwar hätte der Mönch ihr Problem richtig erkannt, doch seine Umgangsweise sei ihr zu überheblich gewesen, was sie an der spirituellen Macht des Mönches und damit an dessen Fähigkeit zum Heilen zweifeln ließ. Trotzdem kaufte Sothy einige Tage später auf den Märkten der Stadt die richtigen, vom Mönch aufgelisteten Opfergaben und spendete sie den Mönchen in der nächstgelegenen Pagode in Phnom Penh.

Die Tage danach fühlte sie jedoch keine spürbare Besserung. Die Verdienstgenerierung der spezifischen Opfergaben habe ,wahrscheinlich eins meiner Probleme gelöst“, aber „nicht das wichtigste“, wie sie sich ausdrückte. Durch den mangelnden Effekt der Opfergaben war sie sich nun wieder unsicher, ob ihre Beschwerden spirituell oder doch eher körperlicher Art waren. Bevor sie zu einer weiteren spirituellen Behandlung und damit eventuell zu einem grū gehen würde, unterzog sie sich spontan einem ausführlichen Medizincheck nach, westlicher Art'.

\subsubsection{Die ,Diagnose-Maschine}

Sothy fand eher zufällig ein neueröffnetes Krankenhaus, das eine kostenfreie Diagnose mithilfe einer Maschine der „,neusten deutschen Bauart“ (wie der Werbezettel versprach) anbot. Sie sei vor Ort professionell von einer Krankenschwester empfangen worden. Diese habe Sothy an ein Blutmessgerät angeschlossen, woraufhin die Maschine für ein paar Minuten Sothys Puls gemessen habe. Auf Grundlage dieser Blutdruckwerte erstellte die Maschine eine zehnseitige englischsprachige Analyse, die Toleranzwerte für circa 150 Gesundheitskriterien auflistete und die am Puls, gemessenen' Werte damit verglich. In der Analyse waren Ergebnisse für sämtliche inneren Organe, die Anzahl der roten und weißen Blutkörperchen und sogar die Einschätzung einer „mental power“ aufgeführt. Dem Diagnoseschreiben nach war Sothys Gesundheitszustand in etwa einem Dutzend Kriterien von der gesunden Norm abweichend. Ein Arzt besprach die Ergebnisse anschließend mit ihr und riet ihr dringend zur Einnahme von Medikamenten im Wert von 200 US-Dollar, die sie vor Ort kaufen sollte.

Obwohl ich wegen des Verdachts auf Betrug versuchte, Sothy vom Kauf der Medikamente abzubringen, konnte ich sie nicht vollständig überzeugen. Sie hatte während ihrer Krankheit immer wieder den Wunsch nach einer ,objektiv'erstellten Diagnose geäußert, auf die sie nun - wie zu Anfang ihrer Beschwerden 
erhofft - mit Medikamenten reagieren konnte. Für Sothy war die Maschine so überzeugend, weil die Diagnostik nicht von menschlichen Akteuren (mit subjektivem Empfinden) durchgeführt wurde. Stattdessen beruhten sämtliche Krankheitswerte auf der Untersuchung des nicht-menschlichen Akteurs der Maschine. Während bei den anderen Stationen immer die menschlichen Akteure im Fokus von Sothys Kritik gestanden hatten (der Arzt hätte sie nicht richtig untersucht; der Mönch sei moralisch nicht einwandfrei), schien das Diagnosegerät frei von Subjektivität und Moral zu sein. Mit der seriösen Aufmachung als technisch gut ausgestattetes Krankenhaus, das nach allgemeiner Ansicht für eine objektivwissenschaftliche Ausrichtung der medizinischen Versorgung steht, ist sie davon überzeugt worden, die Maschine liefere ,Fakten'. Im Gegensatz zum ersten Besuch im Krankenhaus, wo der Arzt Sothys körperliche Unversehrtheit festgestellt hatte, ließ sie sich von den schockierenden Statistiken und der therapeutischen Empfehlung der Maschine von der Einnahme von Pharmazeutika zumindest teilweise überzeugen. Arzneien sind in Kambodscha preiswert und ihre bedenkenlose Einnahme weit verbreitet. Bei vergangenen Beschwerden hatte Sothy bereits gute Erfahrungen mit Schmerzmitteln gemacht und stellte sich nun den Heilungsverlauf ähnlich unkompliziert vor.

Daher kaufte sie sich einen Teil der von dem ,Arzt ${ }^{\varsigma}$ vorgeschriebenen Medikamente wesentlich günstiger in einer anderen Apotheke und nahm sie fortan. Anschließend war sie der Meinung, dass die Arzneien einige ihrer Beschwerden linderten; ihre Gelenk- und Gliederschmerzen sowie die Kopfschmerzen wurden jedoch schlimmer. Nach weiteren Wochen der körperlichen Beeinträchtigung kam sie in ihren Überlegungen zurück zu der Diagnose des spirituellen Problems mit ihren Ahnen. Schließlich erzählte sie mir etwas resigniert, dass sie inzwischen bereit sei für eine Konsultation bei grū. Bevor wir einige Adressen meiner bekannten Geistmedien aufsuchten, sprachen Sothy und ich über ihren Widerwillen und ihre Zweifel an medialen Ritualen.

\subsection{Widerwillen und Zweifel an Medialität}

Zwei Motive, die ich im Folgenden beschreibe, waren nicht nur bei Sothy, sondern auch bei anderen Kambodschaner_innen für die Abneigung der medialen Praxis ausschlaggebend: die Angst vor den Geistern und die schlechte Beurteilung der Geistmedien-Arbeit, weil sie sie als irrational und unmodern ansahen.

Auffällig an Sothys Beispiel ist ihre zögerliche Haltung grū gegenüber. Kritische Stimmen zur Medialität vernahm ich nicht nur unter den jungen Angehörigen der städtischen Mittel- und Oberschicht Kambodschas, sondern auch von Menschen in ländlichen Gebieten. Dieser Widerwille interessierte mich, da ich zunächst annahm, dass die Existenz der Geister (Kap. 3) angezweifelt wurde. Die Zweifel waren jedoch nicht von ontologischen Fragen geprägt, sondern bezogen sich vor allem auf die Gefahren der Praxis, die von Geistern und gru ausgehen 
konnte. Da alle Geister ambivalente Züge aufwiesen (sowohl wohlwollend als auch strafend), formulierten Zweifelnde Befürchtungen, wonach sich ihre Situation nach einem möglicherweise fehlerhaften Umgang mit Geistern oder grū noch verschlechtern könnte. Besonders Personen mit wenig Erfahrung hatten Bedenken, einen folgenschweren Fehler in Anwesenheit der Geister zu begehen. Andere Kambodschaner_innen fürchteten sich vor der mangelnden Moral der grū und assoziierten mit ihnen Praktiken schwarzer Magie (amboe).

Damit basieren die kritischen Bemerkungen nicht nur auf der angenommenen Macht der Geister, sondern betonen diese sogar, indem sie Narrationen über kuriose Bestrafungen, erschreckende Begegnungen mit Geistern oder Spukerscheinungen verbreiten. In diesen Erzählungen werden Geister als Relikte längst vergangener Zeiten dargestellt, womit die Menschen, die diese Geister verehren, als Anhänger_innen einer veralteten und irrationalen Praxis dargestellt werden. Daher gelten die kambodschanischen Geister selbst für ihre Kritiker_innen als mächtig, der Kontakt zu ihnen wird jedoch als etwas Unmodernes und potentiell Gefährliches wahrgenommen.

\subsubsection{Zwei Perspektiven auf mediale Authentizität}

Trotz dieser Bedenken fragte Sothy bei Familienmitgliedern und in ihrem Freundes- und Bekanntenkreis nach Informationen über zuverlässige und vertrauenswürdige grū pāramī. Natürlich ließ sie sich auch von mir beraten, da ich im Rahmen meiner Forschung bereits einige Dutzend Geistmedien besucht hatte. Ich konnte ihr mit einigen Adressen aus meiner Forschung weiterhelfen, doch in einem vorbereitendem Gespräch zeigte sich, dass wir verschiedene Vorstellungen von Authentizität der grū hatten, die zwei verbreitete Perspektiven auf Medialität widerspiegeln.

Sothys Kriterien, nach denen sie einigen Geistern und ihren Medien mehr vertraute als anderen, beruhten erstens auf dem sozialen Status der grü, zweitens auf ihrer Beziehung zum Buddhismus und drittens auf der nachgewiesenen Wirkung des Geistes. Der Status eines Mediums sollte ihrer Ansicht nach möglichst hoch sein, da dies nach der Logik der Karma-Wechselwirkung auf eine ,moralisch-reine Biographie dieser Personen in diesem oder in vorherigen Leben schließen lässt. Mit dieser Voraussetzung hätten die Medien auch eher Zugang zu pāramī. Zur Instandhaltung der moralischen Reinheit sollten die Medien zudem eine gute Beziehung zum Buddhismus pflegen, und, in ihren Worten gesprochen, „die Lehre Buddhas höher bewerten als die Macht der Geister". Aus Furcht vor schädlicher, schwarzer Magie (amboe) vertraute sie nur diesen ,buddhistischen gr $\bar{u}^{6}$. Außerdem musste der Geist seine Wirkmacht laut Sothy schon durch richtige Prognosen, Heilungen und schutzspendenden Segen unter Beweis gestellt haben.

Damit entsprach Sothy der großen Mehrheit des Geistmedium-Klientels, die diese Authentizitätsmerkmale werthielten. Das wurde schon daran ersichtlich, wie grū neue Klient_innen begrüßten: unaufgefordert betonten sie, wie mächtig ihr 
Geist sei, wann und wie er dies unter Beweis gestellt hätte und wie eng ihre Beziehung zum Buddhismus im Allgemeinen sei. Zudem empfingen wohlhabende Medien eine wesentlich größere Besucherzahl als ihre weniger begüterten Kolleg_innen.

Der offensichtliche Wohlstand einiger Geistmedien ist - mehr noch als bei Mönchen - kein Widerspruch zu dem ,asketischen' Lebensstil, den Geister gemeinhin einfordern, denn "the desire for material success (...) is believed to be complementary to the Buddhist path" (Bertrand 2004: 168). Somit wird, gemäß der Karma-Wechselwirkung, weltlicher Reichtum und den damit verbundenen Verschonung vor buddhistisch-konzipierten Leiden wie Hunger und Krankheiten als verdiente Belohnung einer verdienstreichen Biographie angesehen. Reiche und erfolgreiche Medien können somit ,authentischer' wirken als die in ärmeren Verhältnissen lebenden grū.

Ich hingegen gehörte zu einer kleineren Gruppe von Klient_innen, die andere Prioritäten für die Inszenierung authentischer Geister-Macht formulierte. Voraussetzung für eine authentische Besessenheitsperformanz war für mich die deutliche Differenzierung verschiedener Subjekte; das heißt, wenn sich das Erscheinungsbild, die Stimme und die Gestik der verschiedenen Geister wesentlich von denen der menschlichen Medien unterschieden; sobald ich also klar unterscheiden konnte, dass andere Entitäten die Kontrolle des Körpers übernommen hatten. Dies unter Beweis zu stellen, war jedoch weder für die Klient_innen noch für die grū von besonderer Bedeutung. Für die Mehrheit der Besucher_innen waren die Geister unsichtbare, aber ständig gegenwärtige Akteure, die ihren Subjektstatus nicht ,nachweisen' mussten. Das Verhalten der Medien mit oder ohne Besessenheit änderte sich kaum, und einige gru wechselten ihre Rollen so oft hintereinander, dass ich dies anfangs als ,missglückte Performanz' bewertete. Meine Erwartung, zwei voneinander deutlich abgegrenzte Identitäten in einem Körper unterscheiden zu können, wurde in den meisten Fällen nicht erfüllt.

Geister von ranghohen Medien, die Sothy aufgrund der oben beschriebenen Karma-Wechselwirkung für besonders wirkmächtig hielt, hatten für mich zuweilen sogar weniger Überzeugungskraft. Ich empfand rangniedrige, in armen Verhältnissen lebende grū als ,authentischer', was ich nun selbstkritisch als selbst vorgenommene Differenzierung zwischen ,modern' und ,traditionell' begreife. ,Moderne' gru mit materiellem Wohlstand wie einem eigenen Geländewagen und einem Smartphone, die als Marker einer hohen Position in der sozialen Hierarchie gelten, bildeten demnach einen Widerspruch zu den ,uralten Mächten' ihrer Geister. Außerdem hielt ich die enge Verbindung zum institutionalisierten Buddhismus für eine weniger starke Referenz zu einem Geist, während mir ein klarer Bezug zum Brahmanismus nachvollziehbarer schien. Meine ,traditionell' geprägte Auffassung von Authentizität (im Gegensatz zu Sothys buddhistisch legitimierter) war für Kambodschaner_innen zwar nicht abwegig, jedoch weniger verbreitet. 
Des Öfteren hatten Sothy und ich uns bis dahin über unsere unterschiedlichen Einschätzungen der Geistmedien-Authentizität ausgetauscht. In Abwägung dieser Differenzen entschied sie, dass sie zuerst zu einer grū pāramī fahren wollte, die sie von Freunden empfohlen bekommen hatte, da sie meinen Vorschlägen nicht traute.

\subsection{Sothy bei den Grū Pāramī}

\subsubsection{Bei grū Djang Ly}

Auf dem Weg zur ersten grū namens Djang Ly hielten wir vorher kurz an einem Markt, um die üblichen Opfergaben für die Geister zu kaufen: Früchte, Zigaretten und Kerzen. Die gru lebte in einem einfachen Stelzenhaus am Rand eines Dorfes. Das Haus war klein und in die Jahre gekommen, auf dem Hof stand ein altes Moped. Die etwa 40-jährige Frau bat uns in ihr Haus und wir folgten ihr die steile Holztreppe hinauf. Sie verschwand in einer kleinen Kammer in einer hinteren Ecke des Raumes. Neben einigen persönlichen Habseligkeiten in einem Regal wurde fast das gesamte Zimmer von einem gewaltigen pāy sī eingenommen.

Über dem treppenförmigen Schrein, vor dem Sothy und ich nun in dem verdunkelten Raum knieten, hing ein Bild des Buddha und eine kleine Statue von ihm stand auf der obersten Stufe des Schreins. In den Stufen darunter standen einige Statuen von anak tā, unter anderem lok tā Eysey. Links und rechts am Rand der Stufen standen kleinere Türme aus geschmücktem Bambus und kleine Bäumchen aus Plastik mit Blättern aus grüner Alufolie. Wir knieten vor dem pāy sī nieder und verbeugten uns (wie es auch vor buddhistischen Schreinen üblich ist) drei Mal. Die grū kam nun einheitlich weiß gekleidet aus ihrer Kammer und kniete sich neben uns vor den pāy sì. Dabei wirkte sie konzentriert und sprach kein Wort zu uns. Ihr Ehemann kam in den Raum, nahm unsere mitgebrachten Früchte und legte sie auf eine Schale vor dem pāy sī. Danach reichte er uns eine weitere Schale, auf die wir 10.000 Riel, Zigaretten, Räucherstäbchen und Kerzen legten. Sie wurde auch vor den pāy sì gestellt. Die grū zündete einige Kerzen und drei abgezählte Räucherstäbchen an, die sie in eine igelartig aussehende Schale mit Hunderten Stielen von abgebrannten Räucherstäbchen steckte. Sothy machte mit ihrem Telefon einige Fotos. Schließlich wandte sich die grū uns zu und sprach uns an. „Wie kann ich Euch helfen?". Sothy fing sogleich an, von ihren Problemen zu erzählen. Die grū nickte dabei und machte nach einiger Zeit mit Handbewegungen deutlich, dass sie ihren Geist um Rat fragen werde und sie bereits genug gehört habe.

Dafür versank die grū für kurze Zeit in ein leise geflüstertes Gebet, das sie mit geschlossenen Augen und vor der Nase gefalteten Händen an den payy sì richtete. Nach etwa einer Minute ließ sie ihre Hände sinken und wandte sich mit starrem Blick an Sothy. 
Wir begrüßten den Geist mit erneuten Verbeugungen und Sothy wurde von ihm aufgefordert, (nochmals) ihr Anliegen vorzutragen. Nachdem sie dies getan hatte, stellte er sich als lok tā Djam Rannah (wörtlich: „,verehrter Lehrer verbessern") vor und lieferte eine Erklärung für Sothys Beschwerden. Ihre Probleme seien auf einen Fehler zurückzuführen, den Sothy in einem früheren Leben gemacht hatte: als sie sich vor einigen hundert Jahren zwischen zwei Lebenszyklen im Himmel (thān suok) aufgehalten hatte, hätte sie dort unachtsam etwas Wertvolles fallen lassen und damit einige Geister erzürnt. Nun müsse sie bestimmte Opfergaben an mehreren aufeinander folgenden, günstigen Tagen (thngai sīla) erbringen, um dieses Karma auszugleichen. Danach bedankten und verabschiedeten wir uns von dem Geist und die gru kam nach einer kurzen Meditation wieder in ihrem Körper zu Bewusstsein. Wir verabschiedeten uns nun auch von ihr und ihrem Ehemann und fuhren nach Phnom Penh zurück. Auf dem Weg fragte ich Sothy nach ihrer Einschätzung der Konsultation.

Für Sothy schien die Erklärung der grū schlüssig. Sie passte zu der Diagnose des magic monk, wonach sie ein ,Ahnenproblem' hätte. Überzeugend war zudem, dass die grü ihr die gleichen Opfergaben wie der magic monk zur Generierung ihres Verdienstes genannt hatte. Somit war sie zwar zufrieden mit der Arbeit des Mediums, hatte aber das Gefühl, den Heilungsweg des Verdienst-Generierens schon einmal gegangen zu sein und empfand es daher als sinnlos, ihn nochmals anzutreten. Stattdessen wollte sie ein weiteres Medium besuchen, das auch heilen konnte. Schließlich willigte sie ein, Bun Ly zu besuchen, den ich ihr als meinen vertrautesten grū nahegelegt hatte.

\subsubsection{Bei grū Ly}

Bei unserer Ankunft in seinem Haus begrüßte uns der grü freundlich, wir übergaben ihm die vorher erstandenen Früchte und gingen in das kleine Haus, in dem die beiden pāy sī untergebracht waren.

Grü Ly redete sogleich auf uns ein und fasste uns, nachdem wir uns vor seinen Schrein gesetzt hatten, sogleich seine Auffassung von der Geschichte Kambodschas zusammen, was ich vorher schon öfter von Bunnwath übersetzt bekommen hatte. Dabei bemerkte ich, dass Sothy während des Erzählens eingeschüchtert wirkte. Nachdem der gru sie nach ihrem Anliegen befragt hatte, spielte sie ihre Beschwerden untypischerweise herunter und erwähnte nur noch ihre Kopfschmerzen.

Der gru fragte daraufhin seinen Geist lok tā Eysey um Rat. Dieser gab ihm (für uns unhörbar) zu verstehen, dass Sothy an Stress leide, der durch das Lernen für die Universität entstehe. Der Geist lobte Sothy indes dafür, dass sie eine fleißige Studentin sei. Sie sollte sich vor „Versuchungen hüten und weiter ihren Weg gehen“, indem sie „auf ihr Herz hören“ sollte. Ihr Stress sei zudem die Folge der hohen Erwartungen ihrer Eltern, zitierte Bun Ly seinen Geist weiter, die gern wieder einmal von ihr besucht werden wollten. Sobald ihre Eltern (durch ihre 
Besuche) glücklicher geworden seien, würden ihre Erwartungen weniger stark auf Sothy lasten und es würde nicht nur ihr, sondern allen Beteiligten besser gehen. Der grū bot ihr an, sie vor dem Besuch ihrer Eltern einem sneh ${ }^{\circ}$-Ritual ${ }^{132}$ (zur Erhöhung der Ausstrahlung, Kap. 8.1) unterziehen zu können, falls Sothy Angst vor der Begegnung mit ihnen habe. Sothy hatte jedoch ein gutes Verhältnis zu ihren Eltern und lehnte das Angebot höflich ab. Auch einem Segensritual (sro dijk, siehe Kap. 8) wollte sie wegen eines angeblichen Termins in Phnom Penh nicht zustimmen. So verabschiedeten wir uns nach wenigen Minuten wieder von dem grū.

Während unserer Fahrt zurück nach Phnom Penh zeigte ich mich verwundert über Sothys Zurückgezogenheit während unseres Besuchs bei grū Ly. Sie schien mich nicht in die Gründe dafür einweihen zu wollen und bemerkte nur, dass sie beeindruckt sei über das Wissen des grū (zum Beispiel, dass sie eine fleißige Studentin sei und ihr Stress von den Erwartungen der Eltern herrührte).

Es dauerte ein paar Tage, bis ich Sothy nochmals fragen konnte, was sie während unseres Besuches bei grū Ly so eingeschüchtert hatte. Statt einer Antwort fragte sie mich vorwurfsvoll zurück, warum ich sie zu einem so brahmanistischen Medium gebracht hätte. Ihrer Meinung nach habe er sich gleich am Anfang respektlos dem Buddhismus gegenüber geäußert, da er in den geäußerten Vorstellungen zur Geschichte Kambodschas das Ende der glorreichen Angkor-Periode in direkten Zusammenhang mit der Konversion der alten Khmer-Könige zum Buddhismus gebracht hatte. Wie Bunnwath auch, fand Sothy, dass der grū ein ,richtiger Brahmanist` sei. Das hatte sie zum Beispiel daran gesehen, dass der grū die Statuen auf seinem pāy sī alle auf die höchste Stufe gestellt hatte und keine darunter. Der Buddha darauf sei klein und umringt von vielen brahmanistischen Statuen gewesen. Sothy sah das als untrügliches Zeichen dafür, dass der grū dem Buddhismus zu wenig Respekt entgegenbrachte. Zugleich befürchtete sie, dass Ly seine Rituale ohne die Beachtung moralischer Pflichten gestalten würde und er ihren Eltern mit dem angebotenen sneh $^{\circ}$-Ritual möglicherweise Schaden hätte zufügen können. Sothy war sich sicher, dass sie nicht noch einmal zu diesem Medium gehen wollte, und bestand auf einen Besuch bei einem ,buddhistischen ${ }^{6} \mathrm{Me}-$ dium.

\subsubsection{Bei grū Srun}

Also fuhren wir wenige Tage später zum Haus des mir bekannten Mediums Srun, der uns freundlich in Empfang nahm. Seine Frau erzählte uns gleich von den einflussreichen Klient_innen, die der grū schon empfangen hatte. Aufgrund dieser Kontakte zu anak dham (gesprochen:, neak thom) lebte das Ehepaar in überdurchschnittlich guten Verhältnissen.

132 Das Wort โญฺุบ์ wird nach der ALA-LC Transliteration tatsächlich mit einem kleinen Kreis am Ende geschrieben, um den brachialen Laut der letzten Silbe zu kennzeichnen. 
$\mathrm{Zu}$ Beginn saßen wir etwa 30 Minuten vor Sruns Haus und besprachen alltägliche Dinge mit ihm. Ohne dass wir uns dazu vor den pāy sī gesetzt hatten, erzählte Sothy ausführlich von ihren Problemen. Der grü hörte ihr bei der Beschreibung ihres Heilungsanliegens etwas ungeduldig zu und unterbrach sie bald mit der Begründung, dies alles schon von seinem Geist lok tā Kong Cha erfahren zu haben: sie habe ein Problem mit einer ,Großmutter'. Er wies Sothy an, zum nächsten Vollmondtag wiederzukommen. Sie sollte mit einer (lebendigen) Schildkröte, einem Bund Lotusblumen und einem großen, weißen Leinentuch zurückkehren damit würde er Sothys Ahnen-Problem lösen können.

Sothy schien sich gut mit dem grū zu verstehen und vertraute ihm. Dabei verwies sie als Begründung auf die enge Relation zum Buddhismus, die Srun durch seine Bemerkungen und seinem Umgang mit dem Geist unter Beweis gestellt hatte. Er hatte die gleiche Diagnose gestellt wie der magic monk und sei „nicht so sehr Brahmanist“" wie andere Medien. Seine pāramı̄ sei zudem „sehr mächtig“, was man daran sehen könne, dass hochrangige Personen zu ihm kommen würden.

\subsubsection{Das Heilungsritual von grū Srun}

Zwei Wochen später, am Tag des Vollmonds, hatte Sothy zunächst Probleme, in Phnom Penh eine Schildkröte zu finden. Erst auf dem dritten Markt erstand sie eine, da der Handel mit lebendigen Schildkröten nicht legal ist. Wie vom grū vorgeschrieben, kauften wir neben der Schildkröte ein riesiges Bund Lotusblumen, Obst und ein vier Meter langes, weißes Leinentuch.

Nach der Ankunft an seinem Haus erfuhren wir, dass der grū anderweitig beschäftigt sei. Als Srun abends nach Sonnenuntergang eintraf, hatten wir zusammen mit anderen Klient_innen viele Stunden vor seinem Haus gewartet. Sothy wurde als erste von acht Klient_innen behandelt, da sie den längsten Anreiseweg hatte. Srun war schon etwas müde und nicht sehr gesprächig. Nach der Identität der störenden Ahnin gefragt, gab er lediglich zurück, dass eine gestorbene Verwandte aus der Familie von Sothys Mutter ihre Probleme verursachen würde.

Sothy wurde zunächst rituell mit Wasser ,gereinigt', indem Srun ihr mehrere Behälter mit Wasser über Kopf und Körper goss (sro dykk-Ritual, Kap. 8.1). Srun rezitierte währenddessen, wie in buddhistischen Pagoden üblich, Pāli-Mantras. Danach sollte Sothy ihre Schildkröte in beide Hände nehmen und sich durchnässt auf den Steinboden vor dem Haus des grü legen. Das von uns mitgebrachte weiße Tuch wurde vollständig über ihren reglosen Körper gelegt, was eindeutige Assoziationen mit dem kambodschanischen Totenritual (Davis 2015a, 2009) schuf. Das Medium sprach wieder Mantras und schwenkte Räucherstäbchen über Sothys bedeckten Körper. Mit einem Mal riss der grü das weiße Tuch weg und schleuderte es zur Seite - die anderen Klient_innen wichen aus, da es offensichtlich, wie ein Leichentuch, als unrein angesehen wurde. Danach sollte Sothy aufstehen und die Schildkröte so kräftig wie möglich in den Teich von Sruns großzügigem Garten werfen. Von Srun wurde mehrfach betont, dass sie das Tier möglichst wuchtig 
werfen sollte. Seinen Angaben nach hatte das Ritual das schlechte Karma von Sothys Ahnen nun auf die Schildkröte übertragen. Sie sollte sich nun mit all ihrer Macht des materialisierten Problems entledigen. Dennoch galt die Schildkröte danach nicht als unrein, ${ }^{133}$ ihre Funktion beschrieb Srun später als „Filter“. Nachdem Sothy die Schildkröte in Sruns Teich geworfen hatte, war das Ritual beendet und Sothy zog sich wieder um. Abschließend legte sie ihre finanzielle Spende und das mitgebrachte Obst in eine Schale vor dem pāy sī im Haus und verabschiedete sich mit drei Verbeugungen bei Srun, beziehungsweise seiner pāramī.

Sothy fühlte sich nach diesem Ritual wesentlich besser. Sie empfand sich als beinahe vollständig geheilt und klagte in der Folge nicht mehr über Schmerzen. Mit diesem Beispiel konnte die Geistmedien-Praxis einerseits in ihrem Kontext zwischen anderen Angeboten der Heilung zu beschreiben; andererseits wird deutlich, wie auch zweifelnde, ,moderne' Kambodschaner_innen das mediale Angebot der Medialität prüfen und welche Rolle die religiöse Positionierung der Medien dabei spielt.

\subsection{Die Funktionsweise der brahmanistischen Heilungspraxis}

Für Sothy waren die Geistmedien bewusst die allerletzte Instanz, die sie hatte besuchen wollen. Aus der Sicht der Dorfbewohner_innen, die auf weniger finanzielle Mittel und schlechtere medizinische Infrastruktur zurückgreifen können, stellen ihre Auswahlmöglichkeiten einen modernen Luxus dar. Die Menschen in ländlichen Gebieten gingen bei allen (auch nicht-medizinischen) Problemen zu grū. Für alle Klient_innen der Medien war der soziale Status der Medien bedeutsam, doch die Nähe zum Heimatdorf spielte eine noch größere Rolle als für Sothy, die sich erlauben konnte, viel Zeit für den Weg aus Phnom Penhs Innenstadt in die ländlichen Regionen auf sich zu nehmen. Für die Mehrheit der Kambodschaner_innen stellt Medialität eine attraktive Heilungspraxis dar, deren Funktionsweise maßgeblich von drei Aspekten abhängt, die nun ausgeführt werden: einer erfolgsabhängigen Spendenpraxis, der Externalisierung und Subjektivierung und der hohen Autorität der Diagnostik.

Die relativ hohe Vorauszahlung im Krankenhaus und die fehlende Krankheitsdiagnose hatte Sothy abgeschreckt. In diesem Punkt entsprachen die Heiler_innen (wie grū khmer, grū cūl rūpa, oder grū pāramī) eher den Erwartungen der Kambodschaner_innen als die Akteure der westlichen Medizin: die Bezahlung vor der vollendeten Heilung führte nach Ovesen und Trankell schon in den ersten französischen Krankenhäusern Kambodschas zu Missverständnissen und Frustra-

\footnotetext{
${ }^{133}$ Schildkröten gelten als Glückssymbole, z.B. wurde es als gutes Omen gesehen, wenn sie unbeachtet in ein Haus kamen. Das Freilassen von eingesperrten Tieren ist zudem eine verdienstgenerierende Praxis in buddhistischen Tempeln, was Srun in diesem Fall leicht modifizierte.
} 
tion bei Kambodschaner_innen (2010: 11). Bis heute ist es bei den Heiler_innen üblich, keine Bezahlung zu verlangen. Stattdessen nehmen die grü Spenden in beliebiger (oder von grū empfohlener) Höhe an. Während ein kleinerer Geldbetrag am Anfang jedes Geisterkontakts als obligatorisches Opfer für die Geister erbracht werden muss, geben die Klient_innen bei größeren Anliegen (wie dem Heilungsritual mit der Schildkröte) ihre eigentliche Spende erst nach der Heilung, während sie den Schrein oder das Medium nochmals aufsuchen.

Die Logiken der oben vorgestellten Diagnoseverfahren sind grundverschieden: Der Arzt und die Maschine unter dem Siegel der westlichen Diagnostik versuchten, Sothys Krankheit als nachweisbaren Fakt zu verifizieren und sie damit zu objektivieren. Im Gegensatz dazu war die Problemfindung bei den indigenen Heiler_innen wie magic monk und grü durch die Externalisierung und Subjektivierung der Ursachen der Krankheit bestimmt. Demnach wurde das Problem nicht nach allgemeinen Kategorien innerhalb des Körpers gesehen, sondern wurde von den grū mit einem Maximum an Intentionalität ausgestattet und außerhalb des Körpers verortet (Viveiros de Castro 2004: 469). Die Diagnose der störenden Ahnin, die von grū und Mönch übereinstimmend außerhalb des Körpers identifiziert wurde, hatte es Sothy schließlich ermöglicht, die Ursache ihrer Krankheit zu akzeptieren. Zudem befähigte sie dieser Befund, eigenständig mit ihrem Problem umzugehen. Wie deutlich wurde, wird der Heilungsprozess mentaler und/oder uneindeutiger Krankheiten in Kambodscha eher als ein mangelndes Gleichgewicht zwischen sozialen, moralischen und spirituellen Einflüssen der betroffenen Person wahrgenommen denn als rein physisches Problem (Ovesen und Trankell 2010: 219; Bertrand 2005).

Eine Diagnose ohne pathologischen Befund, wie sie Sothy im Krankenhaus bekommen hatte, stellen die Geistmedien nur äußerst selten. Gerade bei rätselhaften Beschwerden werden spezifische Befunde (wie eine gestörte Beziehung zu Ahnen oder Familienmitgliedern, Spiel- oder Drogensucht) von ihnen mit großer Bestimmtheit diagnostiziert und die therapeutischen Maßnahmen klar definiert. Dies vermittelt den Klient_innen ein hohes $\mathrm{Ma} \beta$ an Sicherheit und Vertrauen, denn die hohe spirituelle Autorität der Geister und ihre Authentizität werden nur selten angezweifelt.

\subsection{Fazit}

Die Nacherzählung von Sothys Suche nach einer adäquaten Heilungsinstanz eröffnet die Perspektive einer städtischen Klientin, die Zweifel und Ängste vor der brahmanistischen Praxis hegt. Mit der Beschreibung dieser Bedenken offenbarte sich eine weit verbreitete Einstellung den Geistmedien gegenüber. Die Zweifel betrafen nicht die Existenz der Geister, denn Geister werden in kambodschanischen Besessenheitsritualen für eine Mehrheit ihrer Anhänger_innen überzeugend inszeniert. Die Authentizität der Geister-Präsenz beruht - wie in bereits Kapi- 
tel 3.4. beschrieben - auf stabilen Referenzen zu Räumen, Dingen, Narrationen, Menschen und sozialen Normen, die sich während der Performanz der Besessenheit verdichten. Die von Sothy formulierten Risiken der Praxis betrafen die moralische Ausrichtung der Geistmedien. Erst nach einer passenden Konstellation des Geist-Medium-Netzwerks (ohne Besessenheit, mit zahlreichen buddhistischen Bezügen und Referenzen zu anderen, hochrangigen Klient_innen) war für Sothy ein passender ritueller Rahmen entstanden, um ihr ,Ahnen-Problem ' zu behandeln. Andere Klient_innen entscheiden sich - je nach eigener religiöser Einstellung und nach Anliegen - auch für brahmanistisch ausgerichtete Medien. Die große Flexibilität der kambodschanischen Medialität schafft eine Auswahl von verschiedenen Kontexten der Geistbesessenheit, die es selbst zweifelnden Klient_innen ermöglicht, mediale Ritualen in Anspruch zu nehmen. Weiterhin hat das Kapitel gezeigt, dass die Geistmedien-Praxis eine alternative Ressource von Heilung darstellt, da die Krankhäuser überlastet und auf die Heilung mentaler Störungen nicht ausgelegt sind (vgl. Ovesen und Trankell 2010).

Von allen Anliegen der Besucher_innen der Geistmedien dominieren jedoch die Praktiken um einen brahmanistischen Segen ${ }^{134}$ in zahlenmäßiger und umsatzkräftiger Hinsicht. Diese unorthodoxe, flexible und attraktive Segenspraxis ist prägend für die kambodschanische Geisterlandschaft und Thema des folgenden Kapitels.

${ }^{134}$ Auch wenn in allen spirituellen Ritualen gesegnet wird, bezeichnet die ,Segenspraxis‘ im Folgenden solche Konsultationen bei grū, die lediglich ausgeführt werden, um den Anfragenden einen Anteil der spirituellen Macht der Geister zu gewährleisten. 


\section{Moderne Formen brahmanistischer Segenspraxis}

Während meiner Besuche bei grū fielen die Besucher_innen, die nur einen Segen ausgesprochen bekommen wollten, zunächst kaum in mein forschendes Interesse. Als sich jedoch zeigte, dass diese Anfragen die Mehrheit aller GeisterKonsultationen bestimmten, erkannte ich, dass der brahmanistisch erteilte Segen eine moderne Ritualpraxis offenbart, die als ein Hauptdistinktionsmerkmal zur buddhistischen Praxis gelten muss.

Im Folgenden zeige ich, inwiefern sich die brahmanistische Segenspraxis als ,modernste Ausprägung der kambodschanischen Religiosität der gegenwärtigen ,Aufbruchsstimmung' angepasst hat. Die Analyse einer, Optimierung' von Ritualen nach marktwirtschaftlicher Logik ist Fokus dieses Kapitels. Dafür ziehe ich zunächst verschiedene geschäftsorientierte Anliegen von Klient_innen heran, um damit einen Eindruck der alltäglichen Geistmedien-Praxis zu vermitteln (Kap. 8.1). Dabei wird deutlich, dass zahlreiche Segenspraktiken zu geschäftlicherfolgsversprechenden Ritualen modifiziert werden. In der anschließenden Analyse ihrer magischen Funktionsweise (Kap. 8.2) ziehe ich Parallelen zur Konzeption der prosperity religion nach Jackson (1999a). Hier manifestiert sich deutlich ein grundlegendes Unterscheidungsmerkmal zur buddhistischen Lehre und Praxis. Als Beispiel der optimierten Ritualpraxis beschreibe ich im letzten Abschnitt das Rituals loeng anak $t \bar{a}$, das zur Bereitstellung von Macht im Tausch gegen Spenden so 
umgestaltet wurde, dass es öfter und ,effektiver ' durchgeführt werden kann (Kap. 8.3). Dabei wird antizipatorisch zum neunten Kapitel die Mitwirkung einflussreicher Personen an brahmanistischen Praktiken demonstriert.

\subsection{Geschäftsorientierte Anliegen und rituelle Reaktionen}

Alle grü bearbeiteten Anliegen zur Verbesserung der beruflichen und finanziellen Situation mit bestimmten Formen des Segnens. Während einige grū pāramī ausschließlich darauf spezialisiert waren, konnten auch heilende Medien oder grū dāy Hilfe für berufliche Anliegen anbieten. Meine Analyse der Klient_innengruppen weist darauf hin, dass dieses Streben charakteristisch für Mitglieder der Mittel- und Oberschicht ist. Geringverdienende wie landwirtschaftlich Beschäftigte kommen seltener wegen umsatzsteigernden Anliegen zu grü, auch weil sie direkte Anfragen an öffentlichen Schreinen der Ortsgeister des Dorfes bevorzugen.

Die mittelständischen Klient_innen mit beruflichen oder finanziellen Anliegen bitten die Geister beispielsweise um eine Neuanstellung, eine Beförderung oder höheren Profit des eigenen Geschäfts. Als Reaktion auf diese Anfragen spezialisieren sich einige grū auf solche Anliegen. Sie ,verkaufen' gesegnete Räucherstäbchen-Packungen und Parfüm-Fläschchen gegen festgelegte Spendensummen. Innerhalb der kurzen Besuche werden die Klient_innen lediglich aufgefordert, ihr Anliegen zu spezifizieren. Die grū integrieren die gegebenen Antworten in ihre kurzen Mantras zur Segnung der magischen Objekte und lassen die Spendengelder von Helfer_innen einsammeln. Auch solche Medien, die eigentlich ein anderes ,Spezialgebiet' haben, können gesegnete Räucherstäbchen zu Festpreisen anbieten. Vor der Abholung ist nur noch ein einfacher Segen notwendig.

Für anspruchsvollere Anliegen, wie den Erfolg in einem Bewerbungsverfahren oder das Beeinflussen Anderer zum eigenen Vorteil, werden wesentlich aufwendigere Rituale angeboten. Diese Praktiken haben einen ausgeprägten kompetitiven Charakter, da die grü im Allgemeinen davon berichten können, dass auch andere Personen durch Beauftragung, ihrer' Geistmedien einen magischen Vorteil in beruflichen Belangen erwirkten. Damit wächst die Bereitschaft der Klient_innen zur Investition von Geld und Zeit in weitere Rituale, durch deren Vollzug der bereits angenommene Vorteil ihrer Mitstreiter_innen kompensiert werden soll.

Einige dieser Rituale umfassen beispielsweise die Segnung von Dingen wie Parfüm oder khsae ${ }^{135}$ (gesegnete Armbänder), die die Klient_innen am Körper tragen sollen. Außerdem werden zu diesem Anlass reinigende sro dijk- oder ausstrahlungssteigernde sneh $^{\circ}$-Rituale offeriert.

\footnotetext{
${ }^{135}$ Das Wort für ,Faden` kann ebenso die Bedeutung von ,Verbindung' annehmen und bezeichnet damit sowohl die rituell benutzten Baumwollfäden, als auch die Zugehörigkeit/Loyalität eines Menschen zu anderen Personen (Kap. 8-9).
} 


\subsubsection{Das sro dy்k-Ritual}

Die umfangreichste Segnung, die so gut wie alle grū anbieten, ist die rituelle Reinigung des ganzen Körpers durch das Ritual sro djk (wörtlich: werfen Wasser). Den Klient_innen, die nur in Waschkleidung (dem sarung) bekleidet sind, wird dabei in sitzender oder hockender Haltung gesegnetes (und oft mit Blumenblüten oder Parfüm aromatisiertes) Wasser über den Kopf geschüttet. Dabei sprechen die grū Mantras, die zum Teil in Pāli aufgesagt werden. Die Rezitation nimmt Bezug auf die Durchführung des gleichen Rituals von Mönchen in Pagoden, die dies ebenfalls zur rituellen Reinigung und zur Segnung vornehmen. ${ }^{136}$ In den schnell vorgetragenen Reden der Medien wechseln sich Pāli-Bruchstücke mit Geistersprache und den in Khmer angerufenen Geisternamen ab; zudem werden die Anliegen und die Namen der Klient_innen in den Sprechgesang eingebaut und ständig wiederholt. Die Segnung wird nur durch andere Segenspraktiken unterbrochen, wie beispielsweise das sanfte Schlagen der Klient_innen mit brennenden Räucherstäbchen oder das Besprühen mit Parfüm. Nach fünf bis fünfzehn Minuten und einem abschließenden Segen per Handauflegen ist das sro djk der grü beendet und die Klient_innen ziehen sich wieder um.

Allgemein gilt das sro dyk als geistige Reinigung von schlechten Einflüssen, die Bedeutung wird jedoch selten genauer spezifiziert. Dies erleichtert individuelle Interpretationen des Rituals durch die grū. Die Besonderheit der sro djkk-Rituale bei Geistmedien ist die spezielle Macht des Segens, die von den anwesenden Geistern der Medien ausgeht. Von ihrem Segen konnte nach Meinung der grū eine unmittelbare, magische Macht ausgehen, die von der gleichen Segenspraktik in anderen Kontexten (wie der Pagode oder den Eltern) nicht erwartet werden könne. Auch wenn es keinerlei Restriktionen gab, war es nach Angaben älterer grū vor 1975 nicht üblich für Geistmedien, in alltäglichen Ritualen sro djk zu praktizieren - was einen Indikator für einen Wandel der Segenspraxis darstellt. Die Mehrzahl der gegenwärtig aktiven Medien bietet diese Segnung an, wobei die Gebete und Mantras auf die jeweiligen Anliegen der Gäste zugeschnitten sind und dadurch als effektiver wahrgenommen werden.

136 Die Anwendung des Rituals ist jedoch nicht auf Pagoden oder grū beschränkt, denn auch Eltern konnten beispielsweise ihre Kinder auf diese Art rituell segnen. 


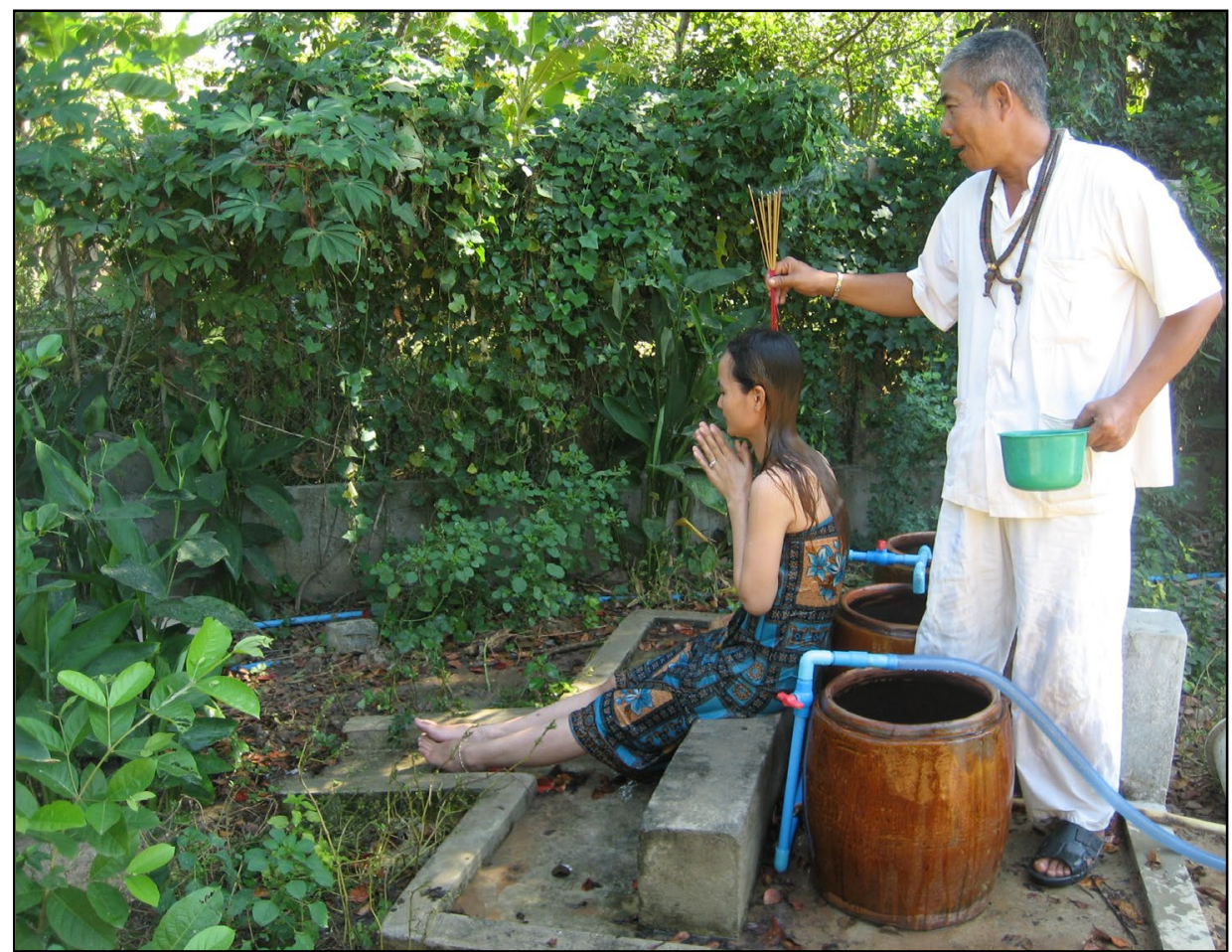

Abb. 15: (C) Autor. Das sro djk-Ritual. Der grū gießt das gesegnete Wasser der Klientin einige Minuten lang über den Kopf. Zwischendurch bält er - wie auf dem Foto zu sehen ist - inne, um schnell vorgetragene Mantras zu rezitieren.

\subsubsection{Sneh ${ }^{\circ}$-Rituale}

Auch andere Rituale, die seit jeher von grū durchgeführt wurden, werden für gröBere Effektivität in geschäftlichen Belangen modifiziert. Eines davon ist bidh $\bar{\imath}$ sneh $^{o}$ (Ritual der Zuneigung) ${ }^{137}$, an dem der historische Wandel von einem als ,unmoralisch` klassifiziertem Ritual zu einer allgemein anerkannten, erfolgversprechenden Praxis nachvollziehbar wird.

Sneh ${ }^{\circ}$-Rituale sind Handlungen, die die, Wirkung' von Menschen auf Andere verbessern soll. Ang (1986: 66) definiert sneh (gesprochen: ,snäh) als „charme d'amour“ (Liebeszauber), der der Steigerung der „attirance magique“ (magischen Anziehungskraft oder Zuneigung) dient. Während diese Rituale bis vor einigen Jahren noch als amoralisch galten, weil sie darauf ausgelegt sind, in die Leben Anderer einzugreifen, konnte ich eine höhere Akzeptanz ihnen gegenüber feststellen. Deutlich wird dies schon an der Tatsache, dass sneh ${ }^{\circ}$-Rituale nicht mehr dem

${ }^{137}$ Auch bezeichnet als bidhī srálan (Ritual der Liebe). 
ehemaligen Klischee entsprechend von armen, mittellosen grū angeboten werden, zu denen bürgerliche Stadtbewohner_innen wegen dieses Hierarchie-Gefälles nicht gehen würden; stattdessen offerierten auch die bei städtischen MittelschichtKlient_innen etablierten grū diese Art von ,Liebeszauber'.

Die Anlässe für sneh ${ }^{\circ}$-Rituale sind jedoch vielzählig und keineswegs nur auf Liebesbeziehungen beschränkt. Sie kommen allgemein für alle Situationen in Frage, in denen Klient_innen ihre Beziehung zu anderen Menschen mithilfe von spiritueller Macht verbessern wollen. Oftmals handelte es sich bei diesen Menschen um Vorgesetzte, Kreditgeber_innen, Geschäftspartner_innen, Schwiegereltern, Freund_innen des Partners oder Lehrer (vgl. Ovesen und Trankell 2010: 144-147). Im beruflichen Wettstreit geht es oftmals um eine Steigerung des Ansehens zum Zweck einer besseren Bezahlung oder einer Beförderung, während Familienmitglieder meist dazu gebracht werden sollen, neu eingeheiratete Ehepartner_innen ${ }^{138} \mathrm{zu}$ akzeptieren oder einer Hochzeit zweier Liebenden zuzustimmen.

Um diese Absichten durchzusetzen, gibt es vielseitige Möglichkeiten, sneh ${ }^{\circ}$ zu benutzen ${ }^{139}$ : entweder erhöhen die gru die Ausstrahlung der Klient_innen oder andere Personen werden magisch beeinflusst, um diesen Klient_innen in spezifischer Weise wohlgesonnen zu sein. Unterschiede basieren vor allem auf dem Maß des magischen ,Übergriffes‘. Die Absicht, massiv in Leben anderer, nicht anwesender Menschen einzugreifen, gilt zumindest als moralisch zweifelhaft. Viel üblicher ist die Steigerung der eigenen Ausstrahlung zur positiven Beeinflussung von Gesprächspartner_innen.

Beispielhaft dafür ist das von mir beobachtete Ritual zu nennen, in dessen Verlauf eine gru einem jungen Klienten das Gesicht mit Vaseline eincremte und es dann sorgsam mit Blattgold bedeckte. Nach einigen Gebeten wurde das Gold in die Gesichtshaut ,einmassiert'. Mit diesem sneh ${ }^{\circ}$ wollte der Student einen amerikanischen (nicht anwesenden) Freund dazu bringen, ihn mit hohen Summen von Geld zu unterstützen. Das Medium beteuerte, dass sich dieses sneh ${ }^{\circ}$ in Anwesenheit des Freundes entfalten würde und ihn während der nächsten drei Treffen dazu bringen würde, mindestens 1000 US-Dollar in das Studium des jungen Mannes zu investieren.

Somit erhoffte sich der Klient, wie die Mehrheit aller Besucher_innen bei Geistmedien, einen privatwirtschaftlichen Gewinn der medialen Praxis. Er spendete für dieses Ritual 10000 Riel (2,5 \$) und kommentierte dies später mit den Worten: „wenn es nicht nützt, hat es nicht viel gekostet - doch wenn es nützen

\footnotetext{
138 In Kambodscha gibt es eine anhaltende Präferenz zur uxorilokalen Residenzregel (vgl. Ebihara 1968: 104), wobei der (angehende) Ehemann oftmals schon vor der Hochzeit probeweise zur Familie der Ehefrau zieht.

${ }^{139}$ Das Wort sneh $^{\circ}$ wird sprachlich auch als eigenständiges Subjekt benutzt; das heißt, man kann sneh $^{\circ}$ ,haben' oder ,bekommen', es auf andere ,werfen' oder sneh ${ }^{\circ}$ kann sich - wie im hier angesprochenen Fall - ,entfalten'.
} 
sollte, hat sich die Spende wirklich gelohnt“. Diese Kosten-Nutzen-Überlegung zeigt den überlegten Gebrauch der magischen Praktiken, die nicht etwa auf einen Mangel an Information oder Rationalität zurückzuführen ist. Insbesondere die Segenspraxis steht für eine besonders, rationale' Ausprägung der kambodschanischen Religiosität, auf die ich nun näher eingehe.

\subsection{Die Wirkungsweise der brahmanistischen Segenspraxis}

Wie in Kapitel 2.4. bereits angedeutet, bewerte ich den rituellen Fokus auf geschäftlichen Erfolg als religiöse Ausprägung einer, verzauberten Moderne', die den Glauben an eine universelle Säkularisierung und die ,Entzauberung der Welt' in vielfältigen Kontexten in- und außerhalb Südostasiens in Frage stellt (Jackson und Brac de la Perrière i.E.; Gottowik 2014; Endres und Lauser 2011; Pattana 2008). Dabei wurde die klassische Rationalisierungsthese von Max Weber (1973) zu Recht als ethnozentristisch kritisiert (Kaviraj 2005; Chakrabarty 2000). Interessanter als der Vergleich zu Europa ist nach Bräunlein (2014) die komparatistische Betrachtung des südostasiatischen Raums. Wie Jackson und Brac de la Perrière (i.E.) feststellen, lässt sich in muslimischen und christlichen Ländern eine Erstarkung der religiösen Orthodoxie beobachten, während in buddhistisch geprägten Gesellschaften Ausprägungen religiöser Vielfalt, insbesondere mit Geistern, betont wird. Die Gründe für das Aufblühen der Geisterpraxis in Burma, Thailand, Laos, Kambodscha, Vietnam und China müssen demnach eng verzahnt mit der fortschreitenden Liberalisierung der Marktwirtschaften betrachtet werden.

In Thailand datiert Jackson die Gründung von „boom-time religions of prosperity" auf eine Periode des wirtschaftlichen Aufschwungs (1999a), deren Ausmaß nach der ökonomischen Krise des Landes in 1997 jedoch weiter anstieg. Denn auch ohne wirtschaftlichen Boom kam es anschließend zu einer erhöhten Nachfrage der Praxis von Geistmedien. Dies ist auch in der kambodschanischen Gesellschaft der Fall, in der es wegen immer deutlicher zu Tage tretenden Ungerechtigkeiten (zum Beispiel von Landvertreibungen, geringem Lohn und Korruption) zu einem weit verbreiteten Gefühl der Unsicherheit kommt. Die spirituellen Helfer aus der oberen Welt verhelfen den selbstsicher auftretenden Geistmedien zu einer übermenschlich-legitimierten Autorität, was ein Grund für die steigende Nachfrage nach Medialität darstellt. Die Popularität der Geistmedien-Praxis kann jedoch nicht ausschließlich mit dem Mangel an politischer Sicherheit, medizinischer Versorgung oder psychologischer Beratung erklärt werden. Ein bedeutender Faktor der Attraktivität der Medialität sind die vielseitigen Möglichkeiten, die Gegenwart magisch beeinflussen zu können.

Im Vergleich zu buddhistischen Ritualen sind die kambodschanischen GeisterRituale herausragende Beispiele religiösen Wandels und synkretistischer Kreativi- 
tät. Die brahmanistischen Rituale (insbesondere die Segenspraxis) mit ihrer involvierten pāramī gelten als Abkürzung zu einem besseren Leben - und zwar nicht in einem nächsten Leben, sondern in der Gegenwart. Dieser angenommenen Wirkung folgend, werden alte Rituale modifiziert und neue konstruiert, was ich als einen Optimierungsprozess des rituellen Tausches von spiritueller Macht (pāramī) gegen Spenden verstehe. Besondere Rollen spielen dabei die materiellen ,Akteure der Medialität. Es verhält sich ebenso wie in Thailand von Pattana (2008: 120 121) als prosperity cult beschrieben:

"in the prosperity cults, bun [punya] and barami [pāramī] [are] symbolically and materially reduced to moral capital or religious-sounding idiom to encourage people to achieve wealth and power by means of religious commodities".

Ich verstehe die „religiösen Verbrauchsgüter“ wie Bänder, Kleidungsstücke, Glücksbringer oder Gesichtsbehandlungen als Akteure, sofern diese ihre oben beschriebene Wirkung aus Sicht der Klient_innen erzielt haben. Die Dinge erweitern ihre körperlichen Grenzen um einen möglichen Zugang zur spirituellen Hilfe aus der oberen Welt, womit sie als aktive Vermittler der kambodschanischen Spiritscapes eingesetzt werden.

Nachdem ich die geschäftlich motivierte Modifikation der brahmanistischen Rituale in obigen Beispielen nur skizziert habe, um die Logik dieser Optimierungsprozesse aufzuzeigen, komme ich nun im abschließenden Teil des Kapitels zur ausführlichen Beschreibung und Analyse einer besonders prägnanten Abwandlung dieser Art. Die Finanzierung von und das Engagement in der brahmanistischen Zeremonien loeng anak tā gehört zur effektivsten Akkumulationsmöglichkeit von magischer Macht (pāramī). ${ }^{140}$ Mit der Beschreibung einer dieser Zeremonien, die erst kürzlich zu diesem Zweck modifiziert worden ist, entwerfe ich ein Bild von den Strategien, den Möglichkeiten und dem Nutzen der pāram̄̄Generierung

\subsection{Ein optimiertes Ritual: loeng anak tā}

Die Übersetzung von loeng anak tā bedeutet das, Preisen der anak tā und sieht in der Regel ein Fest im Freien vor, bei dem Ortsgeister geehrt werden sollen. Ich unterscheide zwei Typen von loeng anak tā: erstens die üblichste Form, die von den ācaryā und Dorfbewohner_innen zum Ende der Reis-Ernte gefeiert wird. Die Funktionen dieses Festes werden von den Beteiligten sowohl spirituell als auch sozial erklärt. Demnach bringen die Dorfbewohner_innen während der Zeremonie Opfergaben für die Geister, um sich damit für die eingefahrene sowie die kommende Ernte zu bedanken und die Harmonie innerhalb der Gemeinschaft zu

140 Äquivalent dazu gilt der Klosterbau als die größtmögliche Generierung von buddhistischem Verdienst (punya) (Marston 2008a: 183). 
stärken. Nach Ang (1986: 77-78), Work (2014: 119) und Forest (1992: 23) festigten die Dorfbewohner_innen durch dieses Fest vor allem den reziproken Charakter der Mensch-Geist-Beziehung. Die weltliche Erklärung für das Fest, die mir vor allem junge Menschen lieferten, unterstrich den sozialen Charakter der Veranstaltung, da die Beteiligten nach einer langen Zeit der tagesfüllenden landwirtschaftlichen Arbeit sich nun Zeit nehmen konnten, um ein gemeinsam organisiertes Fest zu feiern. Diese Zeremonie findet demnach höchstens jährlich statt und die Organisation obliegt meist den ācaryā oder den Ältesten des Dorfes.

Die zweite Ausprägung von loeng anak tā ist jüngeren Ursprungs und stellt eine ,optimierte Version der erstgenannten Festlichkeit dar. Es wird nicht von den $\bar{a}$ caryā oder Dorfbewohner_innen, sondern ausschließlich von Geistmedien organisiert. Die Zeremonien werden kaum in den umliegenden Dörfern angekündigt, weshalb nur wenige Anwohner_innen partizipieren. Sogar private loeng anak tā können so organisiert werden und können dann auch in Privathäusern stattfinden, was einen gravierenden Unterschied zum öffentlichen Charakter der erstgenannten Zeremonieform offenbart. Obwohl sich der Ablauf identisch mit dem erstbeschriebenen Typus gestaltet, liegt der Fokus der Veranstaltung weniger auf einer Stärkung eines Gemeinschaftsgefühls. Hier spielen finanzkräftige Sponsoren eine tragende Rolle, die während der Zeremonie im Zentrum der Beachtung aller Medien stehen, da sie die Gelegenheit eines persönlichen Segens vieler, anwesender Geister nutzen, um damit eine magische Konsequenz für ein persönliches Anliegen zu erwirken.

\subsubsection{Organisation der Zeremonien}

Grū Ly war bekannt dafür, diese Art von Zeremonie zu veranstalten. Seine Motivation dafür bestand darin, dem ausdrücklichen Wunsch seines Geistes zu entsprechen, „den Menschen zu helfen“. ${ }^{141}$ Durch seine vormalige Laufbahn als Firmenchef einer Baufirma stellte sich Ly als hochqualifiziert für die verbundenen Aufgaben der Zeremonie-Organisation heraus. Seine weitverzweigten Beziehungsgeflechte (khsae) zu anderen grū und zu einigen hochrangigen Geschäftsleuten ermöglichte es ihm, mehrere Zeremonien pro Jahr an verschiedenen Orten zu veranstalten.

Vor Beginn jedes loeng anak tā war zunächst die Akquise von mindestens 500 US-Dollar erforderlich. Das Geld wurde entweder gleich von den Sponsor_innen bereitgestellt oder die beteiligten grū stockten das Budget mit eigenen Zuschüssen auf. Sobald der Betrag akquiriert war (bei dem grū dauerte dies dank seiner einflussreichen Klient_innen etwa acht Wochen) wählte er in Absprache mit seinen Geistern die Lokalität und plante den Ablauf des geplanten loeng anak tā. Die Orte

\footnotetext{
${ }^{141}$ Nebenbei konnte er sich damit auch auf dem wachsenden ,Markt' der gesponserten loeng anak tā behaupten und mehr Geschäftsbeziehungen in diesem Bereich knüpfen, was während meiner Forschung zunehmend von Erfolg gekrönt war.
} 
waren immer machtvoll konzipierte pāramī-Orte; es konnten alte Tempelanlagen sein, Wälder, Berge oder als besonders machtvoll erachtete Schreine für die Geister (vgl. Guillou 2017c). Anschließend musste er mit den verschiedenen Akteursgruppen der Veranstaltung (Mönchen, Musikern, Sponsoren und verschiedenen Verleihern der Lautsprecheranlage, von Zelten, Tischen und Stühlen) einen gemeinsamen Termin vereinbaren und für die Errichtung des temporären pāy sī sowie die Bereitstellung der Opfergaben für Geister und Mönche Sorge tragen.

Die Einladung an andere Geistmedien wurde laut Ly über „,mentale Kommunikation" verschickt. Dafür bat er seinen Geist lok tā Eysey, die anderen Geister in der thān suok nach ,guten' grū zu fragen und diese dann einzuladen - auch wenn er viel telefonierte und die Beteiligten somit auch informierte, bedeutete diese Art von Einladung, dass alle anwesenden grū, die er zum großen Teil auch privat kannte und schätzte, ,gute ${ }^{6}$ Medien sein mussten, da sie von ,höchster Ebene als solche identifiziert worden waren.

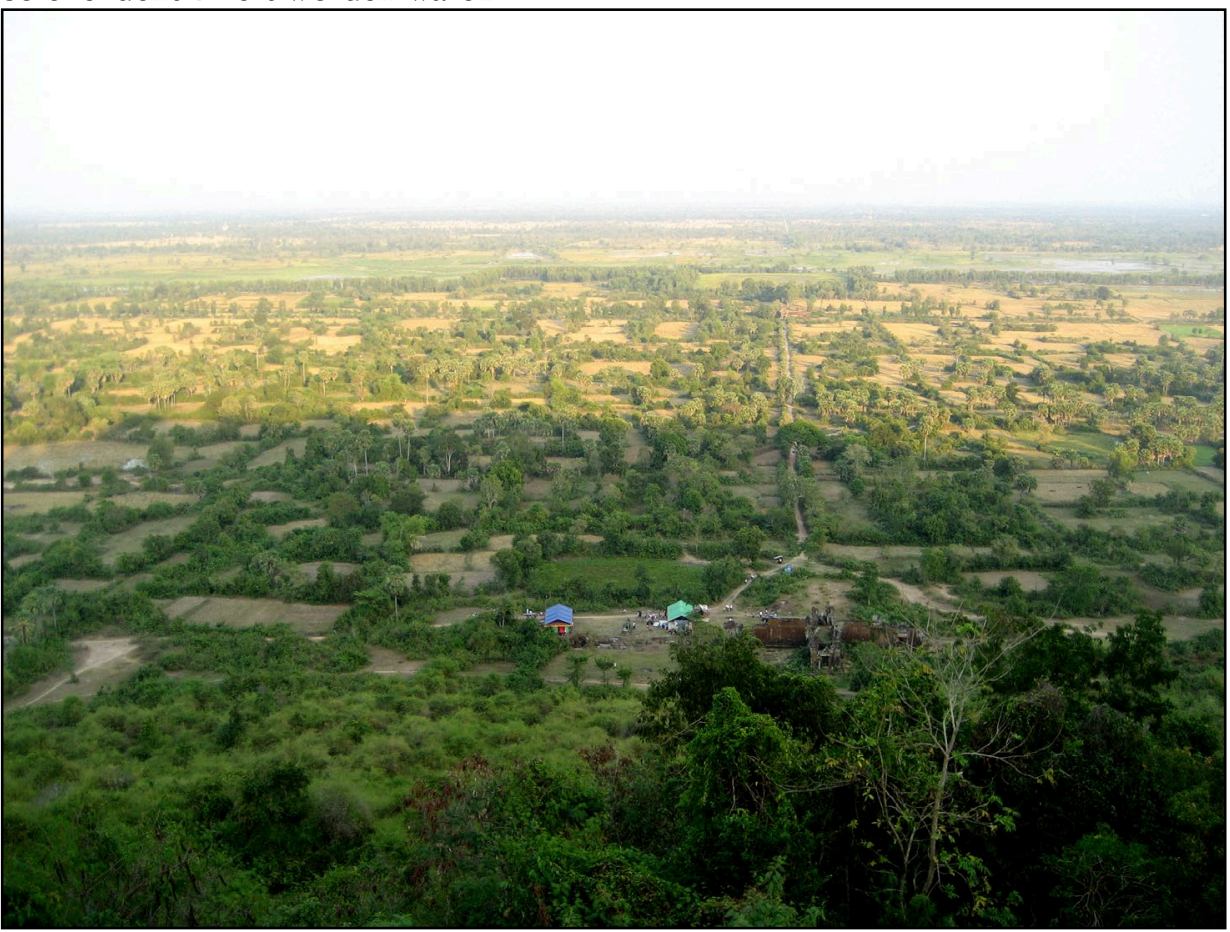

Abb. 16: (C) Autor. Die etwa 1000 Jabre alte Tempelanlage Sen Nib Mull aus der Perspektive des Phnom Chisou. Links daneben sind die Zelte der loeng anak tā-Zeremonie zu erkennen. 


\subsubsection{Fallbeispiel: Ein loeng anak tāa am Phnom Chisou}

Dieses loeng anak tā war die erste von fünf Zeremonien dieser Art, die ich von grū Ly dokumentieren konnte. Sie fand zu Beginn der Regensaison in der Region Takeo statt, unweit des Wohnortes von grü Ly.

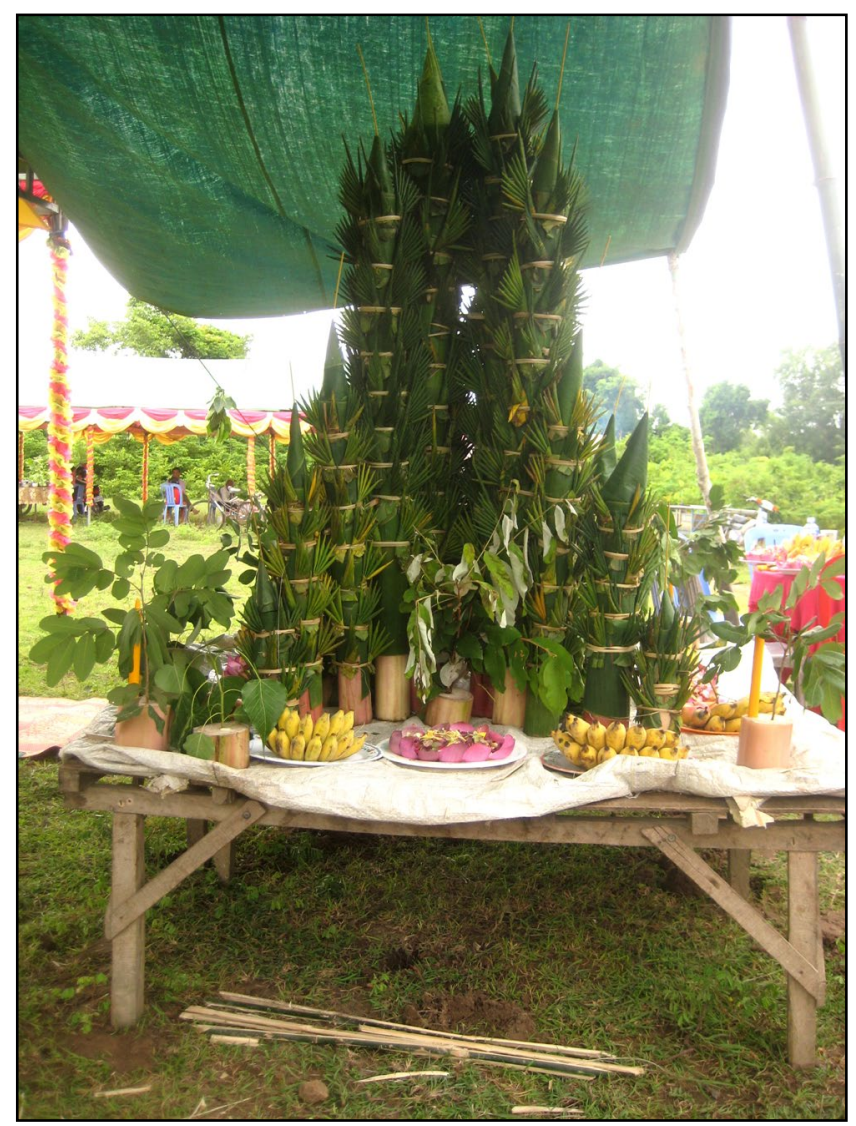

Abb. 17: (C) Autor. Der pāy sī für Zeremonien wie loeng anake tā. Er besteht aus Türmen von Bambusstämmen mit gefalteten Palmenblättern und stellt damit eine temporärere Form des pāy sì dar, da er anschließend entsorgt wird.

Schon kurz nach Sonnenuntergang begannen die Vorbereitungen an den Tempelanlagen von Sen Nih Mull142 (unterhalb des Bergs Chisou). Dort bewirteten einige grū zusammen mit zahlreichen Dorfbewohner_innen alle 60 Mönche der benach-

${ }^{142}$ Neben dieser lokalen Bezeichnung wird die Anlage auch Sen Thmol genannt (Zieger 2006: 162164). 
barten Pagode im Rahmen des täglichen dāna-Rituals (Kap. 2.3). Nach dem verdienstreichen Ritual, an dem zwischen 150 bis 200 Laien teilnahmen, wurden die Mönche zur Pagode gefahren und auch die Dorfbewohner_innen machten sich auf den Heimweg. Am Tempel verblieben nur noch die Geistmedien, ihre Helfer_innen und Familien, die sich auf den brahmanistischen Teil der Veranstaltung am Nachmittag vorbereiteten.

Im Zuge der Vorbereitungen trafen beständig weitere grū aus der Umgebung ein. Besondere Beachtung aller Anwesenden bekam der pāy sī, der zu diesem Anlass zehn ,Stufen' ${ }^{143}$ hatte, was als ein Indikator für die hohe Macht des Schreins gesehen wurde.

Die Opfergaben wurden, ähnlich einem Gedeck für eine Hochzeitsfeier, auf zwei Tische verteilt. Jeder Platz bekam ein Schälchen Reis, eine Dose Limonade, eine Dose Bier und eine Flasche Wasser; dazu ein Glas und Besteck. In der Mitte eines Tisches lag ein gegrillter Kopf eines Schweins ${ }^{144}$ und eine Schale mit Bananen. Ein Tisch war für die Soldaten des alten Angkor-Reiches ${ }^{145}$ bestimmt, die hier vor langer Zeit einen ehrenhaften Tod gestorben seien. Ly betonte, dass die Menschen heutzutage die Soldaten nicht vergessen dürften, weil er ihre Präsenz an diesem Ort immer noch ,spüren' konnte. Ein anderer Tisch war in hierarchischer Trennung für die Offiziere der Soldaten bestimmt. ${ }^{146}$ Beide Tische blieben während der gesamten Zeremonie (von Menschen) unberührt.

\section{Multireligiöse Vorbereitungsriten}

Mittags waren bereits 15 grū eingetroffen, darunter auch grū Chantrea (Kap. 1.4), die einen besonderen Stellenwert im Ablauf einnehmen sollte. Aus früheren Treffen mit der etwa 40jährigen grū wusste ich, dass sie von einem besonders alten Geist namens lok tā Konhaö Deik besetzt wurde. Das Medium erzählte mir, dass sie bald selbst ein eigenes loeng anak tā veranstalten würde (wie sich einige Wo-

143 Bei den fest installierten, oft aus Beton gemauerten Schreinen in Pagoden oder Häusern waren es tatsächlich Stufen eines treppenähnlichen Aufbaus. Bei der temporären Version aus Bambusblättern hatte der pāy sī das Aussehen einer Pyramide, bei der die verschieden hohen Türme (die auch pāy sī genannt wurden) diese ,Stufen' darstellten (siehe Abb.19).

144 Eine typische Opfergabe für ,Ahnen', die auf keinem loeng anak tā fehlte. Mit dieser Opfergabe werden auch Hochzeiten in der oberen Welt angekündigt (Ang 1986: 237-238).

145 Der Begriff für diese Soldaten war กัฒธัต, gesprochen ,kong toab‘, was übersetzt ,Armee' bedeutet.

146 Es ist Teil der brahmanistischen Praxis, die rezente Geschichte weniger stark zu betonen als die vor-buddhistische Zeit. Wie ich später erfuhr, wurde der Tempel erst in den 1970er Jahren von amerikanischen Bomben zerstört. Durch die verstärkten Bombenangriffe ab 1973 seien auch in der Nähe dieses Ortes Menschen getötet worden, ebenso wie zur Zeit der Roten Khmer danach. Die Zeremonie fand aber zum einen zu Ehren der Soldaten des Angkor-Reiches statt, denen pāramī zugeschrieben wird. Zum anderen ist dieser Verweis weniger politisch und polarisierend, da in diesem Gebiet (wie in anderem Orten auch) ehemals verfeindete Angehörige von Regierungstruppen, Rote Khmer oder Helfer_innen der vietnamesischen Besatzern in einer Dorfgemeinschaft lebten. 
chen später herausstellte, war es auch für den Segen eines Geschäftsmanns ausgerichtet). Während des Gesprächs mit dem Medium und ihrem Ehemann wurde ein Mönch zum Ort der Zeremonie gefahren. Er wurde nur von den Laien beachtet, die ihm vereinzelt private Opfergaben überreichten (darunter ein Radio) und die im Gegenzug gesegnet wurden. Die Medien nahmen keinen Kontakt zum Mönch auf und zeigten auch im weiteren Verlauf der Veranstaltung kein Interesse an seiner Präsenz. Der ācarya des Dorfes nahm die vermittelnde Instanz zwischen den brahmanistischen und buddhistischen Akteuren vor Ort ein. Am Mikrofon begann er mit dem üblichen Eröffnungsritus krung palī (gesprochen: ,krong bali'), das einen festen Platz im kambodschanischen Ritualkanon innehält und mit dem auch bei Hochzeiten oder buddhistischen Totenfeiern sämtliche Geister ${ }^{147}$ begrüßt und willkommen geheißen werden. Erste Opfergaben für die eingeladenen Geister wurden gemacht und der ācaryā bat die spirituellen Mächte mehrfach um ein harmonisches Fest.

Anschließend zogen sich die Medien ihre einfarbige (meist weiße) Kleidung an. Noch während sie sich bereit machten, bat der ācaryā die Geister, den seit dem frühen Morgen andauernden Nieselregen ,von jetzt bis zwölf Uhr mittags am nächsten Tag“ zu stoppen. Als direkt danach der Regen aufhörte, interpretierten die Besucher_innen dies als Einfluss spiritueller Mächte und reagierten mit dem üblichen Ausruf nach Erhalt eines Segens (,ssadhu, sādhu, sādhu"), während die grū ohne sichtbare Reaktion blieben. Die Musiker spielten einige Lieder, danach folgte das buddhistische Gebet namasakāra, das vor jeder festlichen Aktivität in Kambodscha gesprochen wird. Der ācaryā, der das namasakāra über das Mikrofon vorsprach, machte (wie im Kloster auch üblich) immer wieder Pausen in dem rhythmisch vorgetragenen Gesang, so dass die grü und anderen Laien den Text in diesen Abschnitten allein weitersprachen. Statt den üblichen 30 bis 40 Minuten, die das Gebet in der Pagode in Anspruch nahm, dauerte es in dieser für das loeng anak tā zugeschnittenen Version nur etwa 5 Minuten. Während in der Pagode anschließend das Bekenntnis zum achtfachen Pfad folgte, war bei diesem loeng anak tā der ,buddhistische Teil' der Veranstaltung beendet, was man auch daran erkennen konnte, dass der Mönch nun wieder mit einem Moped in die Pagode gefahren wurde. Mein Begleiter Bunnwath wirkte eingeschüchtert ob der schwachen Referenz zum Buddhismus und war sich sicher, dass dieses loeng anak tā nun „wirklich nichts mit mehr Buddhismus" zu tun hatte. Ein grü bekam das Mikrofon und lud in schnell vorgetragener Aufzählung mehrere Geister ein. Neben einiger gängigen Geisternamen (wie zum Beispiel Krung Bali als Beschützer der Erde) kamen zahlreiche individuelle Namen der anwesenden Geister vor. Der sprechende grū warf währenddessen rohe Reiskörner und Nüsse auf den pāy sì. Es folgte ein patriotisches Musikstück, zu dem alle Anwesenden aufstanden und andächtig

${ }^{147}$ Mit ,sämtlich' meine ich, dass es je nach Gründlichkeit bis zu 15 Minuten dauern kann, bis alle bekannten Geister, darunter auch devatā und buddhistische Gelehrte, namentlich eingeladen wurden. 
schwiegen. Damit gingen die rituellen Vorbereitungen der Zeremonie nach einer Stunde zu Ende.

\section{Brahmanistisches Vorspiel}

Nun fingen die grū an, von ihren Geistern besessen zu werden. Sie nahmen sich dafür eine ungerade ${ }^{148}$ Anzahl von Räucherstäbchen und beteten vor dem pāy sī. Nachdem sie die Räucherstäbchen zwischen den Palmenblättern des pāy sī befestigt hatten, eröffneten sie den Tanz - die Besessenheit hatte damit begonnen. Die Tanzstile entsprachen den Persönlichkeiten der Geister: Eine ältere grū war von einem jungen Geist besessen und tanzte leichtfüßig um den pāy s̄̄, ein männlicher grū, von der mythischen Schlange Nāga besessen, robbte auf dem Boden. Ein Medium stand mit weit ausschweifenden Armbewegungen neben einer jungen weiblichen grū, die unaufhörlich von einem Bein aufs andere hüpfte und dabei schwer verständliche Anekdoten aus der thān suok erzählte. Zwischendurch segneten die besessenen Medien die unter dem Zelt sitzenden Besucher_innen mit Wasser oder gaben ihnen etwas von dem Obst vom pāy sī, das von den Zuschauer_innen ehrfürchtig entgegengenommen wurde.

Grū Ly verstand seine Aufgabe zunächst darin, den Geistmedien bei ihrem Eintritt in die Besessenheit zu helfen. Dafür forderte er die Medien zu gemeinsamen Tanzbewegungen auf und segnete sie mit Sprühstößen aus seiner Parfümflasche. Dies brachte die Medien in Besessenheit, und sie tanzten auf ihre individuelle Weise allein weiter. Als einige den Zustand der Geistbesessenheit schon wieder beendet hatten, lud auch grū Ly seinen Geist lok tā Eysey ein und mischte sich unter die anderen tanzenden grū am pāy sì.

148 Die Zahlen drei und neun gelten in vielen buddhistischen Ländern als erfolgs- und glücksversprechend. 


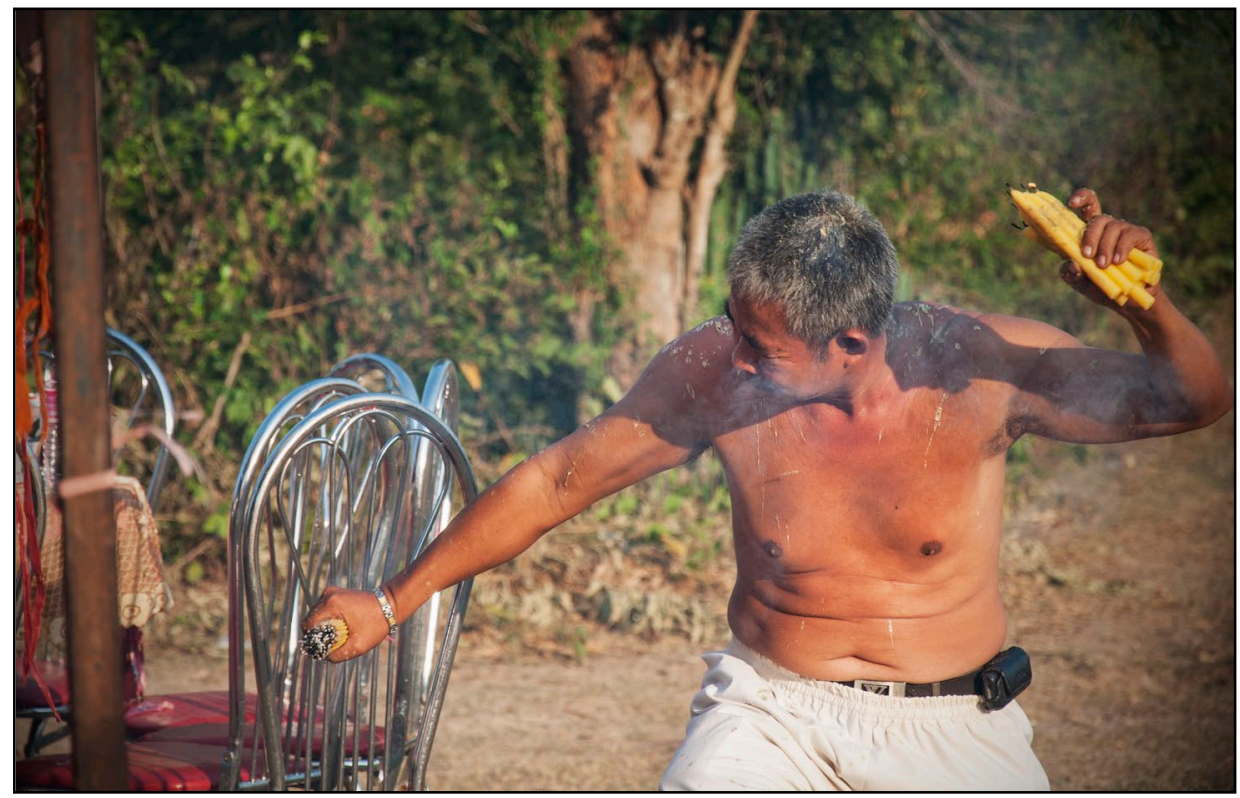

Abb. 18: (C) Bennett. Grū Ly in Geistbesessenheit seines Geistes lok tā Eysey. In den Händen trägt er ein Bündel Räucherstäbchen und mehrere Kerzen, die er synchron zu seinem langsamen Schritttempo wechselnd über Kopf oder im nach vorn gestrecktem Arm bält.

Die Musik wurde zweimal abrupt für kleinere Anliegen der Geister unterbrochen. Ein Geist versuchte in pathetischer Manie, alle Anwesenden zum Tanzen aufzufordern. Der Ehemann von grū Chantrea erklärte uns daraufhin, dass einige Geister bereits betrunken auf die Erde kämen. Das Anliegen des Geistes wurde demnach nicht besonders ernst genommen. Einige schmunzelten ob des vergeblichen Versuchs des betrunkenen Geistes und die Musik spielte kurz darauf wieder, ohne dass jemand der Aufforderung des Geistes nachgekommen war.

Die zweite Unterbrechung bestand darin, dass eine ältere, elegant angezogene grū eine anschauliche und komödiantische Rede hielt und davon berichtete, wie beschwerlich es wäre, vom Himmel auf die Erde zu kommen, wenn dazwischen Gewitterwolken lägen. Den Zweck dieser Reise beschrieb sie mit der Absicht, einen Bräutigam für ihre Nichte zu finden. Da sie besessen war, meinte sie damit ihre Geister-Nichte, für die sie einen Geister-Bräutigam suchte. Es meldete sich aber keiner der anwesenden Geister und die Zuhörer_innen kicherten belustigt über die Suche des Geistes. 


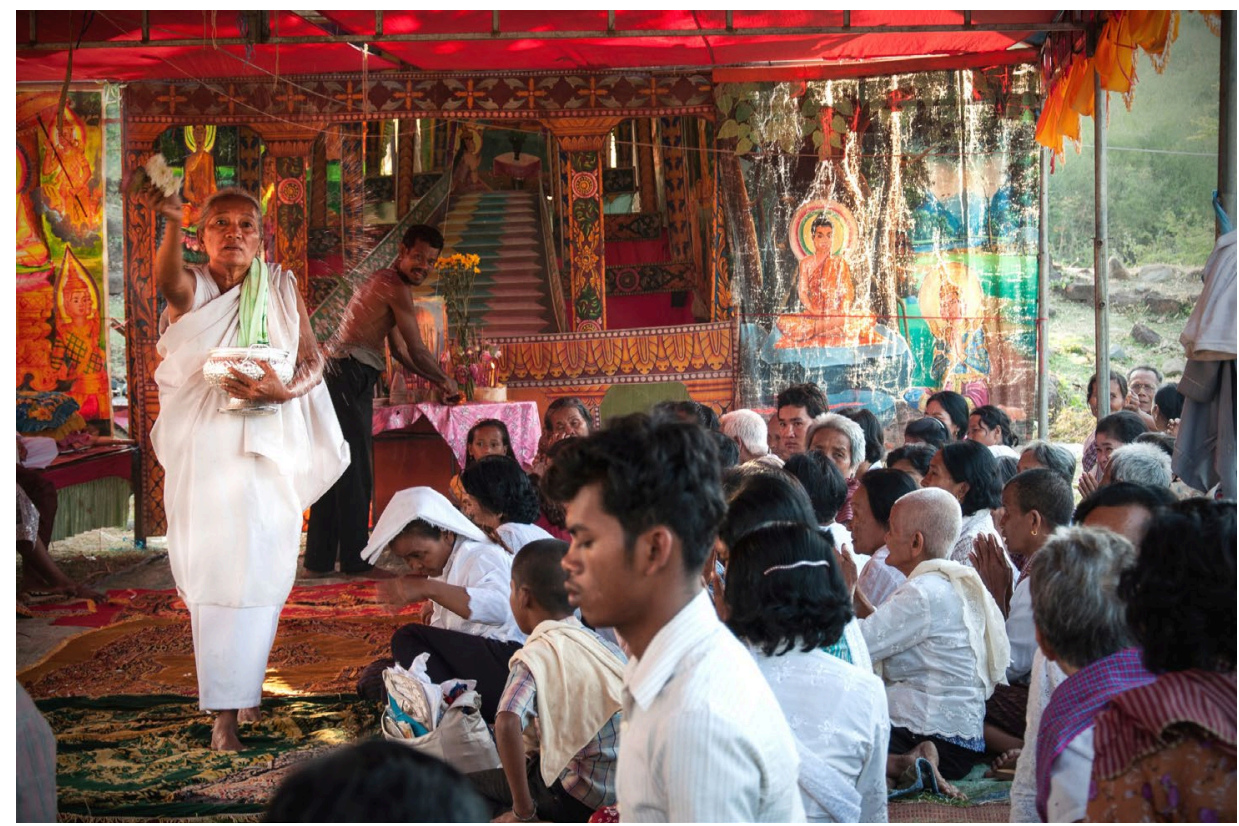

Abb. 19: (C) Bennett. Eine grū teilt gesegnetes Wasser mit den Anwesenden.

Demnach wurden die beiden Beiträge, obwohl sie mit der Autorität der anak tā vorgetragen wurden, als unterhaltsames Zwischenspiel interpretiert. Wie bei anderen rituellen Anlässen auch, verschwammen in der Performanz der Geisterpraktiken die Ebenen von Ironie und Autorität, von Effektivität und Unterhaltung (Schechner 1977: 75). Ähnlich wie bei Willerslevs Studie in Siberien, nehmen die Beteiligten der kambodschanischen Rituale die anwesenden Geister „seriously, but not too seriously“ (2013), indem sie mit ihnen scherzen und in ironischen Kontakt treten.

\section{Hauptteil: Segnung des Sponsors}

Als gerade eine Stunde getanzt worden war, erhielt grū Ly einen Anruf. Aufgrund seiner ehrfürchtigen Art des Sprechens am Telefon musste es sich um einen einflussreichen Klienten handeln. Nach dem Telefonat sprach der grū mit der jungen gru Chantrea, woraufhin sie sich vor dem pāy sì setzte und zum ersten Mal ihren Geist herbeirief. Da jetzt schon nicht mehr viele Geistmedien tanzten und grü Ly seine volle Aufmerksamkeit der jungen grū schenkte, bildete sich eine Menschenmenge um die beiden. Es wurde durch diese Sonderbehandlung deutlich, dass es sich bei dieser Besessenheit um einen besonders mächtigen Geist handeln musste. Die Musik stoppte und die junge grū wurde nach ihrem Gebet und einigen Stößen aus der Parfümflasche von Ly auf ihre spezifische, spektakulärere Art besessen (Kap. 1.4). Ihr ganzer Körper zuckte und schüttelte sich, so dass es verwunderlich 
schien, wie sie im Sitzen die Balance halten konnte. Plötzlich hielt sie inne und beugte ihren Kopf weit nach unten. Sie war nun von General Konghaö Deik besessen und begann mit einer kehligen Stimme zu sprechen. Der hauptverantwortliche gru Ly begrüßte den Alten und ermunterte ihn zu sprechen. Die Umstehenden scherzten über die offensichtliche Verwirrtheit des Geistes, dem es als alter Mann bei einer solchen Veranstaltung eigentlich nicht besonders gefiel, wie er gestand. Auch zur wieder einsetzenden Musik wollte er nicht tanzen und schüttelte schmunzelnd den Kopf. Erst nach einigen Versuchen von grü Ly ließ sich der Geist davon überzeugen, mithilfe seines Gehstockes aufzustehen. Tanzen wollte er aufgrund der , modernen' Musik jedoch weiterhin nicht.

Während die Musiker ein Lied nach dem anderen anstimmten und damit abgelehnt wurden, fuhr ein teurer Geländewagen auf das Gelände. Grū Ly eilte zum Auto und begrüßte den elegant angezogenen älteren Mann ehrfürchtig - obwohl dieser deutlich zu spät gekommen war, entschuldigte sich der grü für den ,frühzeitigen Beginn" der Zeremonie. Es wurde deutlich, dass der Mann der Hauptsponsor der Zeremonie war, der Lys Angaben nach über 500 US-Dollar für die Festlichkeit gespendet hatte. Wie ich später erfahren sollte, war der Sponsor ein erfolgreicher Geschäftsmann, der an einer schweren Krankheit litt. Er war regelmäßig als Klient bei gru Ly gewesen, von dem er vor einiger Zeit erfahren hatte, dass er selbst von einem mächtigen Geist beschützt wurde. Dieser hatte ihm bisher zu Wohlstand verholfen, doch die Ursache seiner Krankheit sei laut Ly auf ein Problem zwischen dem Geist und dem Geschäftsmann zurückzuführen. Der grū riet dem Geschäftsmann daraufhin, seinen Geist jährlich in Form solcher loeng anak tā zu ehren, was den Geist zur Heilung des Sponsors animieren sollte.

Sogleich setzte er sich vor den pāy sī und da lok tā Konghaö Deik nun ein passendes Lied gefunden hatte, umkreiste grū Chantrea den Geschäftsmann im Tanz. Zusätzlich zu dieser individuellen Form des Segens sammelten sich nun auch die anderen Medien um ihn und knieten vor ihm nieder. Daraufhin wurde der Geschäftsmann selbst von seinem Geist besessen, womit sich die Richtung des Segens überraschend umkehrte und der wohlhabende Besucher anfing, das vor ihm stehende Wasser auf die Köpfe der umstehenden Personen und grū zu verteilen und sie damit zu segnen. Während er mehrmals um den pāy sī schritt, verbrauchte er mehrere Eimer Wasser mit der Segnung des drängelnden Publikums. Am Ende verteilte er unter ihnen einige Flaschen des von ihm gesegneten Wassers zum Mitnehmen. 


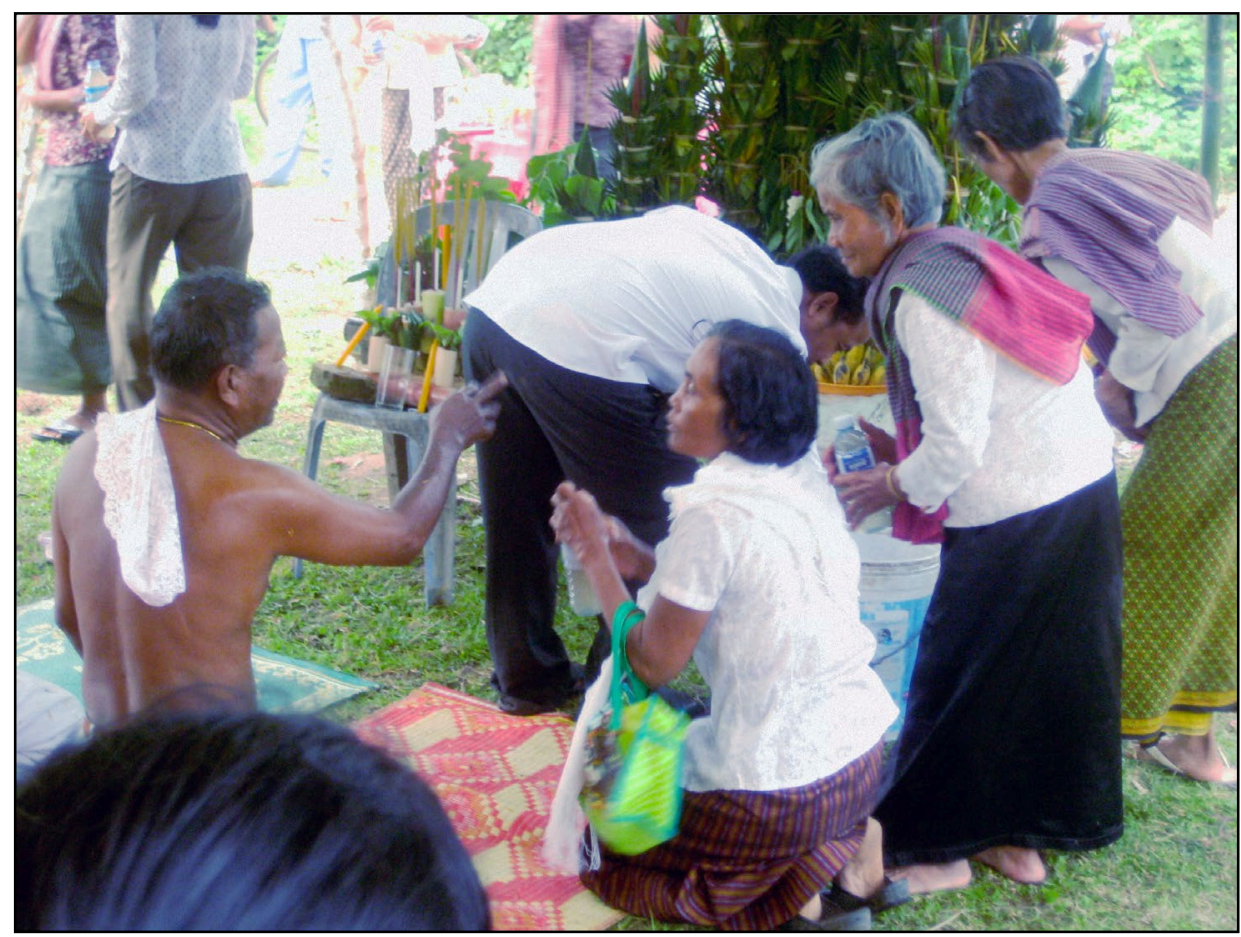

Abb. 20: (C) Autor. Der Hauptsponsor kniet vor dem pāy sī. Er ist in Besessenheit und sein Geist spricht mit einigen Franen, die sich das von ihm gesegnete $W$ asser aus dem Eimer in Flaschen abfüllen.

Aufgrund seiner Doppelrolle als Sponsor und Geistmedium nutzte der Geschäftsmann sämtliche Vorteile der reziproken Tauschbeziehung von Spenden gegen Segen. Er wurde erst von der brahmanistischen pāram̄̄ der anderen Geister gesegnet und durfte sich danach ,zurück-segnend' dankbar erweisen. Bei genauerer Betrachtung spiegelt der gesamte Ablauf inhärente Machtstrukturen der Zeremonie wider: Ly stand in seiner Rolle des Ritualleiters bereits über den meisten Medien, da er ihren Geistern den Eintritt in die Körper ihrer Medien erleichtern konnte. Dem alten Geist Konghaö Deik gegenüber zeigte er wiederum großen Respekt. Dieser wurde jedoch nur eingeladen, um den ranghöchsten Menschen zu segnen, der schließlich auch den ranghöchsten Geist beherbergte.

Nach der Segnung des Sponsors wurde das loeng anak tā mit einer kurzen Dankesrede von grū Ly beendet. An einem kleinen Tisch saßen zwei Helfer und nahmen Spenden aller Beteiligten entgegen, deren Höhe in ein Heft eingetragen wurde. Die meisten Beteiligten verabschiedeten sich schnell und fuhren auf Fahrrädern oder Mopeds davon. Grū Ly und einige seiner befreundeten Medien erholten sich danach an den Tischen, aßen Reis und unterhielten sich, während die Abbauarbeiten liefen. Nachdem die Spendensumme feststand, beglich der grü vor Ort die Rechnungen der Ausstatter_innen und Musiker_innen. Einen Teil des 
Geldes gab er an andere Geistmedien weiter, die bestimmte Aufgaben oder lange Anreisen auf sich genommen hatten, und den Rest ,durfte' er nach Erlaubnis seines Geistes für sich behalten.

\subsection{Analyse und Fazit}

Die Beschreibung des loeng anak tā zeigt die Modifikation der Zeremonie und deren Fokus auf die Bereitstellung von Macht im Tausch gegen Spenden. Das loeng anak tā in seiner ursprünglichen Form bietet den grū dank seiner unorthodoxen Ausrichtung ein rituelles,Grundgerüst' für eine modernisierte Neuakzentuierung. Die flexibel gehandhabte Praxis stellt den Austausch von Spenden gegen Segen zwischen Menschen und Geistern in den Mittelpunkt und ist dabei weniger an buddhistische Moralvorstellungen und Lehren (wie das Sammeln von Karma für die kommenden Lebenszyklen) gebunden. Für Geistmedien wie grū Ly bietet es somit einen geeigneten rituellen Rahmen, um in diesen Austausch das Sponsoring dominierend in den Mittelpunkt zu stellen. Er bildete damit keine Ausnahme. Die junge Chantrea fing kurz darauf an, eigene Zeremonien dieser Art in ihrem Wohnhaus zu veranstalten und immer wieder traf ich grü, die ihre Rituale für Sponsoren veränderten, um ein Maximum an magischer Wirkung für ihre hochrangigen Klient_innen zu erzielen. Ich sehe grū Ly somit als Teil einer florierenden Medialitätsbewegung, die mit einer Modifizierung bestehender Zeremonien ,neue Traditionen' erschafft, die öfter und effektiver als üblich durchgeführt werden können. Dabei erneuern diese Medien Referenzen zum ,brahmanistischen Erbe Kambodschas' und betonen die Bedeutung der Geister, die ihrer Ansicht nach kontinuierlich das Schicksal des Landes bestimmt hätten.

Grundlegende Eckpunkte des Ablaufs werden in der neuen Form eingehalten, wie beispielsweise das buddhistische dāna-Ritual vor der Zeremonie oder die Einladung des Mönches zur Eröffnung der Veranstaltung. Die Einbindung der buddhistischen Akteure in die Zeremonien hatte die Funktion, sie als moralisch und religiös einwandfrei zu legitimieren. Bei jeder Gelegenheit war es für die öffentliche Wahrnehmung von religiösen Veranstaltungen nötig, Zeremonien durch die Präsenz von buddhistischen Mönchen oder ācaryā moralisch ,legitimieren' zu lassen. Sogar in diesem Fall des brahmanistischen loeng anak tā befürchtete grū Ly, dass man ihn für „,verrückt“ (chkuat) halten würde, wenn er keine Mönche eingeladen hätte. Trotzdem hielt er nicht besonders viel von den buddhistischen Mönchen und dem sangha, die er als korrumpierende Institution wahrnahm. Das auBerordentlich kurze namasakāra und die zahlreichen Referenzen auf die vorbuddhistische Angkor-Periode waren Indikatoren dieser Antipathie, die buddhistisch sozialisierte Personen wie Bunnwath beunruhigte. Für ihn waren die loeng anak tā-Zeremonien aus diesen Gründen ,zu brahmanistisch“, womit er eine Nähe zu schwarzer Magie (amboe) andeutete. Als Schüler der samăya-orientierten Mönche des Wat Botumwadei und als eher unfreiwilliger Besucher solcher Veran- 
staltungen interpretierte er die fehlenden Buddhismus-Bezüge besonders drastisch. Für die anwesenden (purāna-sozialisierten) Teilnehmer_innen waren die Bezüge zum Buddhismus offensichtlich ausreichend und frei von moralischer Ambiguität. Organisatoren wie grū Ly zeigten großes Geschick in der anlassspezifischen Kombination buddhistischer und brahmanistischer Aspekte, um einerseits eine legitime Form des Rituals zu entwickeln und dabei andererseits durch brahmanistische Bezüge den Eindruck möglichst großer magischer Wirkmacht für die beteiligten Personen zu erwecken. Somit sind die hier beschriebenen Aushandlungen und der Wandel der brahmanistischen Rituale auch bedeutsam für die Teilnahme von einflussreichen Personen an den medialen Ritualen, was bereits zum nächsten Kapitel der politisch relevanten Beziehung zwischen Geistern und Eliten überleitet. 



\section{Die Inszenierung von Geistern im politischen Feld}

"The political field, understood both as a field of forces and as a field of struggles aimed at transforming the relation of forces which confers on this field its structure at any given moment" (Bourdieu 1991: 171).

Das politische Feld Kambodschas gestaltet sich durchaus als durchdrungen von verschiedenen Kräften, mit denen private und öffentliche Machtkämpfe ausgetragen werden. Ich werde mich in diesem Kapitel vor allem den spirituellen Mächten widmen, derer sich elitäre Personen bedienen. Dank meiner ethnografischen Herangehensweise beschränke ich mich dabei nicht nur auf die für die Politik charakteristischen, öffentlichen Ausdrucksformen politischen Handelns, sondern ergänze die Darstellung mit Daten aus semi-öffentlichen und privaten Kontexten. Die emische Perspektive erlaubt es mir zudem, die lokale Relevanz spiritueller Diskurse und Narrative im politischen Feld Kambodschas zu erfassen. Die Ergänzung spiritueller Aspekte zur politikwissenschaftlichen Analyse ist notwendig in einem Land, in dem Machtverhältnisse explizit religiös definiert und ausgehandelt werden.

Teil der in diesem Kapitel beschriebenen Aushandlungen sind beispielsweise die Reproduktion von spirituellen Diskursen und Narrativen, die öffentliche Durchführung von magischen Praktiken, die spirituelle Legitimierung von weltli- 
cher Macht, das Stiften von nationaler Identität durch brahmanistische Rituale oder die Infragestellung dominanter Machtdiskurse. Dazu werden vielfältige Akteure mobilisiert: die Geister, die Geistmedien, die elitären Vertreter_innen von Militär, Politik und Wirtschaft, ihre Angestellten, die (journalistischen) Medien oder Menschenrechtsorganisationen. Sie bilden ein politisches Feld, ein Netzwerk von Akteuren mit zahlreichen Bezügen zur kambodschanischen Geisterlandschaft, an dem sich gesellschaftliche, wirtschaftliche, nationale und strategische Kräfte untersuchen lassen. Dieses Kapitel fragt, wie und zu welchem Zweck Geister im politischen Feld Kambodschas inszeniert werden.

Zur Beschreibung des politischen Engagements spiritueller Akteure gliedert sich das Kapitel in fünf Teile, die verschiedene brahmanistische ,Schauplätze` ihrer politischen Einflussnahme repräsentieren. Im ersten Teil beschreibe ich die gesellschaftliche Wahrnehmung von ranghohen Personen (Kap. 9.1). In der Folge lassen sich an zwei Biographien besonders erfolgreicher gru die Interaktionen der anak dham und der grü ablesen (Kap. 9.2). Anschließend wende ich mich der Aushandlung von nationaler Identität zu und analysiere diesbezüglich zwei Rituale von hochrangigen politischen Akteuren (Kap. 9.3). Nach dem dort dargestellten außenpolitischen Machtkampf komme ich auf spirituelle Diskurse im innenpolitischen Wahlkampf zu sprechen, in denen Themen wie Religiosität und Wiedergeburt seit 20 Jahren eine (in politikwissenschaftlichen Analysen häufig unterschätzte) Rolle spielen (Kap. 9.4). Im letzten Abschnitt (Kap. 9.5) gehe ich auf das subversive Potential der Geistmedien-Praxis im politischen Feld Kambodschas ein, das von Betroffenen der Landvertreibung abgerufen wird, die mit Praktiken schwarzer Magie politische Prozesse zu stören und somit die eigene politische Handlungsmacht zu stärken versuchen.

\subsection{Die Eliten Kambodschas}

Anak dham heißt wörtlich übersetzt ,Großer Mensch' und unterscheidet sich in der alltäglichen Benutzung nur geringfügig von anak mān punya (Mensch mit Verdienst) (Jacobsen und Stuart-Fox 2013; Norén-Nilsson 2013). Während der erstgenannte Begriff lediglich den hohen Status von Menschen bezeichnet, verweist der letztgenannte auf die Bedeutung der Karma-Wechselwirkung, die die Machtstrukturen in Kambodscha legitimieren (Kap. 2).

\subsubsection{Die spirituelle Legitimation von Macht und das patronage-System}

So gut wie jedes hierarchisch-soziale Gefüge in Kambodscha ist durch eine Patron-Klient-Beziehung (patron-client-relationship) gekennzeichnet: von der Ebene der herrschenden Elite bis zur Bevölkerungsschicht der subsistenzwirtschaftlich arbeitenden Bauern oder der Textilarbeiter_innen. Bei genauer Untersuchung wird sichtbar, dass das Prinzip nicht nur durch die Reziprozität von Taten und Waren 
charakterisiert ist, sondern dass die karmische Vergangenheit hierbei die Ausgangslage bildet. Zum besseren Verständnis lohnt ein Blick in die kambodschanische Geschichte: Bis 1970 wurde das Land ausschließlich von Monarchen regiert. Die devarāja-Verehrung der Könige von Angkor wurde nach dem Einzug des Mahayana und des Theravada Buddhismus ab dem 13. Jahrhundert von den ähnlichen Konzepten des ,gerechten Herrschers' (cakravartin) ${ }^{149}$ beziehungsweise des ,zukünftigen` oder ,kommenden` Buddha (Buddha Maitreya) 150 abgelöst (Thompson 2004b; Keyes 1990; Kulke 1974). Thompson (ebd.) beschreibt, dass Herrscher während der Mittleren Periode (14. bis 19. Jahrhundert) ihre politische Macht stets mit dem Konzept des cakravartin oder des Buddha Maitreya (und damit religiös) rechtfertigten. Die Könige in dieser Zeitspanne untermauerten ihre spirituelle Macht insbesondere durch die Unterstützung des buddhistischen sangha (Karbaum 2014a: 10) und durch die öffentlichen Gaben an Götter und Geister (Harris 2005: 51). Mit diesen öffentlichen Spenden, zum Beispiel im Rahmen von mehrtätigen larn neak tāa, wollten die Könige und ihre Familien schon vor der französischen Kolonisation den Schutz des Landes gewährleisten und gleichzeitig ihren privilegierten Kontakt zu den Geistern unter Beweis stellen (Chandler 1974). Damit legitimierten sie ihre weltliche Macht (amnnāca, gesprochen: omnaidj) und positionierten sich bewusst als Erben der großen devaräja wie Jayavarman II oder Jayavarman VII (Forest 2008). ${ }^{151}$ In Übereinstimmung mit Harris (2005: 49) stellt Kent fest, dass selbst die Könige zu dieser Zeit annahmen, dass nicht sie, sondern die anak tā die rechtmäßigen Herrscher für das Land darstellten (2007: 338). Die royalen Herrscher seien lediglich durch ihr Geburtsrecht und ihre Spenden begünstigt worden, das Land zu verwalten.

Mit einer zunehmenden Buddhisierung begann die Bedeutung von Karma und Verdienst im Zuschreibungsprozess von Machtstellungen zu wachsen. Mächtige Herrscher gelten seitdem als anak mān punya ${ }^{152}$, „Personen mit Verdienst“, die ähnlich wie Bottisattwas im Mahayana-Buddhismus so viel Verdienst angesammelt haben, dass sie nicht mehr wiedergeboren werden müssten. Lange galten lediglich

${ }^{149}$ Cakravartin bezeichnet den, idealen` buddhistischen Monarchen, der das Rad (cakra) des Dharma dreht (vartin); eine Formulierung, die der Pāli-Erzählung von Buddhas erster Missionstätigkeit entlehnt ist, bei der er das ,Rad des Dharma in Schwung setzte' (Bareau 1962: 232). In Kambodscha wird es synonym zu preah bat thommik benutzt. Das Konzept des preah bat thommik (Dharmischer Herrscher oder Gerechter Herrscher) wurde maßgeblich von der sehr populären und bekannten buddhistischen Prophezeiung Putth Tumneay geprägt, indem dieser moralisch ,reine' Herrscher das Land aus einer Zeit des Schreckens und der Tyrannei befreit.

${ }^{150}$ Maitreya Buddha nimmt im kambodschanischen Buddhismus eine prominente Rolle ein. Er repräsentiert den ,noch kommenden' Buddha, der nach einer folgenschweren Krise in die Welt der Menschen (thān manuss) herabsteigen und den Buddhismus rekonstituieren wird.

${ }^{151}$ Eine der letzten großen Machtdemonstrationen eines kambodschanischen Königs anhand von öffentlichkeitswirksamen Spenden an Geister fand vor 140 Jahren statt, als 1877 König Norodom dem Ortsgeist Meh Sar in Ba Phnom zwei Menschen opfern ließ (Chandler 1974).

152 Gesprochen: ,neak mian bonn'; bezeichnet Personen, denen viel Verdienst aus vergangenen Leben nachgesagt wird. 
Könige als Menschen mit derart hohem Verdienst, doch die buddhistische Konzeption des anak mān punya wurde im Zuge politischer Patronisierung uminterpretiert und bezeichnet heute im alläglichen Verständnis einen ,hochrangigen Menschen' (Khing 2008; Keyes 1977: 288). Keyes hat für Thailand herausgestellt, wie grundlegend diese religiösen Konzepte für das Verständnis der anak mān punya sind:

"Those who are recognized as phī mī bun [anak mān punya] are believed to have an exceptional legacy of 'merit' from previous existences, the beneficial consequence of which can be shared with those who become their followers" (1973: 99)

Die Übertragung des Verdienstes, beziehungsweise der damit legitimierten Macht auf andere Personen bildet eine wichtige Grundlage für das Verständnis von kambodschanischen patronage-Beziehungen. Den Verdienst mit anderen teilen zu können, bedeutet einerseits die Chance der Empfänger_innen auf eigenen Reichtum zu erhöhen. Andererseits wird auch die Arbeit für derart verdienstvolle Menschen als verdiensterzeugende Handlung verstanden. Wohlhabenden Menschen wird demnach die Fähigkeit nachgesagt, anderen nicht nur wirtschaftlich, sondern auch spirituell aus ihrer Bedürftigkeit helfen zu können. Konkret bedeutet dies, dass Macht in der kambodschanischen Gesellschaft in vertikal verlaufenden Netzwerken zugeschrieben und weitergereicht wird - den anak mān punya oder anak dham an dessen Spitzenpositionen ordnen sich bewusst und intentional Menschen unter, die nicht nur aus Hoffnung auf eine direkte Gegenleistung, sondern auch auf eine indirekte Auswirkung ihres Handelns in Form von punya hoffen. Somit gilt es als Privileg, Teil eines Netzwerks hochrangiger anak dham zu werden (Nissen 2008: 285).

Diese Netzwerke werden khsae genannt, das mit ,Faden' oder ,Verbindung' (auch im Sinne von ,Beziehung) übersetzt wird. Innerhalb eines khsae müssen sich Untergebende loyal gegenüber Höhergestellten zeigen, während diese zur Aufrechterhaltung der Verbindung Schutz und Sicherheit gewähren (Norén-Nilsson 2016; Ledgerwood 2008b). Scopis (2011) analysierte die Umverteilung von Ressourcen in khsae-Netzwerken und beschreibt beispielhaft dafür folgende Praxis: 
'Prominent businessmen, in fact, have been systematically invited by Senior Ministers to 'sponsor' projects of 'national development'; and, in turn, they have been granted major business facilitations and honorary titles, [such as] Oknha." "153

Die von Scopsis untersuchten Spenden der wohlhabenden Personen für Regierungsprojekte haben noch eine andere Bedeutung, ebenso wie das Geld an Pagoden nicht nur als Generierung von Verdienst zu verstehen ist: Öffentliche Geld- und Sachspenden dienen auch der performativen Zurschaustellung des eigenen Status und Verdienstes:

"the man who devotes significant portions of his wealth to the construction of religious artifices not only accumulates merit that will improve his future karmic status, but also demonstrates that his wealth was gained as the result of past merit" (Keyes 1977: 287).

Dabei bildet eine Offenlegung des eigenen Wohlstandes eine bedeutsame Voraussetzung der Anerkennung als anak dhạ̣ oder anak mān punya.

"This ability of phū mì bun [to share merit] can be realized only if they are recognized as such; thus, claimants to be one who 'has merit' must display certain characteristics which mark them as set apart from ordinary men" (Keyes 1973: 99).

Zur Aufrechterhaltung des elitären Status müssen die anak mān punya demnach ständig zwei Merkmale vorweisen können: sie müssen ihren Reichtum unter Beweis stellen und sich in moralischen Belangen öffentlichkeitswirksam präsentieren. Ersteres wird durch die Zurschaustellung von materiellem Wohlstand erreicht (teure Autos, Immobilien, Kleidung, etc.), letzteres kann nur mit Verbindungen zum buddhistischen sangha vorgenommen werden. „Moral legitimacy is achieved by exercising one's power in ways that resonate with Khmer religious notions of righteousness and proper world order“ (Kent 2006: 350-351). So ist das weit verbreitete Phänomen zu erklären, dass anak dham als Patrone buddhistischer Pagoden auftreten. Durch die Patronisierung der religiösen Würdenträger erhalten die anak dhạ̣ einen privilegierten Zugang zu punya, und können auf die Loyalität der Mönche vertrauen, die im Gegenzug hohe Geldspenden und andere materielle Güter erhalten (Kent 2006, 2003).

Diese als obligatorisch angenommenen Bedingungen zur anak dhamPerformanz verweisen jedoch bereits auf ihre Fragilität. Obwohl Karma im Ver-

153 Die Notwendigkeit von Gegenleistungen für die Loyalität und die Unterstützung seiner Gefolgsleute hat Hun Sen bereits dazu veranlasst, ehemals sehr selten erteilte royale Titel wie Okhna reihenweise an wohlhabende Geschäftsmänner zu vergeben. Laut Karbaum (2008: 218) müssen die Unternehmer für den prestigeträchtigen Titel zudem 100000 US-Dollar an die Regierung zahlen. Auch Militärränge werden nach diesem Schema vergeben, so dass Kambodscha mit 2200 Generälen weltweit die meisten in seinen Streitkräften aufweist. Karbaum (2014b) rechnet vor, dass ein General durchschnittlich weniger als 50 Soldaten befehlen würde. Die USStreitkräfte hätten beispielsweise 1500 Generäle weniger als Kambodscha. Dies zeigt, dass der Rang lediglich eine Auszeichnung darstellt und nur selten Verantwortlichkeiten miteinschließt. 
gleich zu pāramī eher deterministische Machtzuschreibungen zulässt, besteht auch in der buddhistischen Machtkonzeption Potential für Veränderungen. Ein wirtschaftlicher Abstieg eines anak dham hätte somit auch einen sozialen Abstieg zur Folge und würde religiös als ,spät einsetzendes Karma ${ }^{c}$ aus früheren Leben interpretiert werden.

Das patronage-System wird jedoch auch zur Generierung von pāramī und magischem Potential benutzt. Zum Schutz vor Unglücksfällen, spirituellen Angriffen oder generell zur Stärkung der weltlichen Macht wird - etwas weniger öffentlich, aber nicht versteckt - der Kontakt zu Geistmedien und ihren Geistern gesucht (Marston 2008c: 104). Es gilt zudem als unstrittig, dass anak dham nicht nur sehr viel punya generiert hätten, sondern dass sie außerdem auch selbst pāramī besäßen. Für diese pāramī müssten sie nach oben vorgestellter Logik eigene pāy sī mit mächtigen, magischen Gegenständen in ihren Häusern errichten, die dank ihres Wohlstands von ihren ,persönlichen' Geistmedien gepflegt würden. Diese grū seien nicht für die Pflege der pāy sī zuständig, sondern würden sich auch mittels anderer Praktiken um den spirituellen Schutz der anak dham kümmern, da ihnen wegen ihrer hohen Stellung ein besonderes Bedürfnis nach Sicherheit zugeschrieben wurde. ${ }^{154} \mathrm{Da}$ ich diese Aussagen aus dem Alltagsdiskurs zum Teil verifizieren konnte, mache ich in diesem Kapitel das Argument stark, dass in wohlhabenden Familien ebenso wie in Familien aus einfacheren Lebensbedingungen Männer und Frauen gleichermaßen Geister-Praktiken durchführten. Diese Nutzung trägt zur gesellschaftlichen Akzeptanz der brahmanistischen Praxis bei. Damit reiht sich das politische Feld Kambodschas in ähnliche Kontexte der spirited politics (Jackson und Brac de la Perrière i.E.; Endres und Lauser 2011; Willford und George 2005) ein.

\subsection{Die Geistmedien der Eliten}

Mein geplantes studying up der wirtschaftlichen und politischen Eliten und ihrer Nachfrage nach magischen Praktiken barg Schwierigkeiten. Dies hatte mit der ambivalenten Reputation der Medialität zu tun, die den Austausch mit brahmanistisch praktizierenden anak dham hemmten - auch weil unter den samăya-geprägten Führungskräften die Vorstellung vorherrschte, dass man vor allem in Situationen der Verzweiflung und Schwäche auf mediale Rituale zugreifen würde. Mehrere Geistmedien, die ich traf, pflegten Kontakte zu anak dham und waren Teil ihrer khsae. Auf ,modernisierten` loeng anak tā Zeremonien, zu Segnungen der Polizei-

\footnotetext{
${ }^{154}$ Bei Nachfragen meinerseits wurde betont, dass dies die Reaktion der anak dham auf die anhaltenden politischen Unsicherheiten und die willkürliche Herrschaft im patronage-System Hun Sens war. Demnach wollten die Nutznießer_innen der kambodschanischen Politik so lange wie möglich Macht ausüben und Wohlstand akkumulieren, wie es ihnen während ihrer (wegen willkürlichen Entscheidungen möglicherweise sehr kurzen) Amtszeit möglich sei.
} 
und Militäreinheiten oder zu anderen Anlässen wie Einweihungen von offiziellen Gebäuden oder Hochzeiten trafen sich die verschiedenen Medien der Eliten und bekamen so Zugang zu elitären Kreisen.

Zur Veranschaulichung dieser Beziehungen stelle ich nun zwei prominente Geistmedien vor. Dank meines nach mehreren Besuchen größer gewordenen Vertrauensverhältnisses zu ihnen konnte ich Einblicke über ihre Beziehungen zu anak dham gewinnen.

\subsubsection{Grū Lunn}

Grū Lunn wurde 1952 geboren. Er bemerkte seine medialen Fähigkeiten schon frühzeitig: mit neun Jahren baute er nach eigenen Angaben eine tiefe spirituelle Beziehung zu einem Königspython auf, der ihm jedoch zum Anfang des Bürgerkriegs in den 1970er Jahren abhandenkam. Während eines Kriegsdienstes unter Lon Nol (1970-1975) und der Zwangsarbeit unter den Roten Khmer (1975-1979) pflegte er wenig Kontakt zu seinen Geistern, da sie sich seinen Angaben nach in dieser Zeit von ihrer Heimat Kambodscha abgewendet hätten. Ab 1980, in Zeiten des politischen Umbruchs und des Hungers, seien dann die Geister und auch die Schlange zu ihm zurückgekehrt.

Damit begann für ihn die schwierige Zeit der grū-Initiation. Sein Hauptgeist wurde schnell als Sdech Kamlong identifiziert, den Geist des sagenumwobenen „Lepra-Königs“, der in Inschriften des Bayon Tempel verewigt wurde (Thompson 2004a; Hang 2004). Lunn wanderte zu religiösen Pilgerorten und lernte dort in geistiger Einkehr die Vielzahl der Geister kennen, die in der Folge von seinem Körper Besitz nehmen konnten. ${ }^{155}$ Anfangs habe er sich geschämt, als grū aufzutreten, doch von seinen Klient_innen sei er schnell akzeptiert worden und hätte als einer der ersten grü nach den Roten Khmer den Ruf eines geachteten Geistmediums erlangen können. Seine Klient_innen seien schon damals „aus allen Gesellschaftsschichten“ gekommen, was bedeutete, dass er damals auch schon anak dham-Klient_innen empfing.

Da er „seinen Pflichten als Ehemann“ nicht mehr nachgekommen sei, arrangierte er 1994 eine zweite Hochzeit für seine Ehefrau, mit der er sechs gemeinsame Kinder weiterhin versorgte, denn er blieb anschließend mit ihr und ihrem neuen Ehemann in einem bescheidenen Haus wohnen, obwohl er damals schon wertvolle Gaben von seinen Klient_innen erhalten hatte und zu Wohlstand gekommen war. Der Zulauf von einflussreichen Klient_innen riss nicht ab, was sicherlich auch an der unmittelbaren Nähe eines anderen sehr erfolgreichen Mediums lag, das mittlerweile nicht mehr als solches arbeitet (vgl. Marston 2004).

\footnotetext{
155 Es ist bis heute gängige Praxis in seinem Tempel, dass er pro Abend bis zu zwölf (meist weibliche) Geister verkörpert, wofür er sich jedes Mal umzieht, da alle Geister ihre eigenen Vorlieben von Kleidung und Schmuck haben.
} 
In den 1990er Jahren hatte Lunn zudem damit begonnen, größere Zeremonien mit anderen gru zu organisieren, und hatte dabei Beziehungen zu einigen anak dhaṃ aus dem Militär und dem Königshaus knüpfen können.

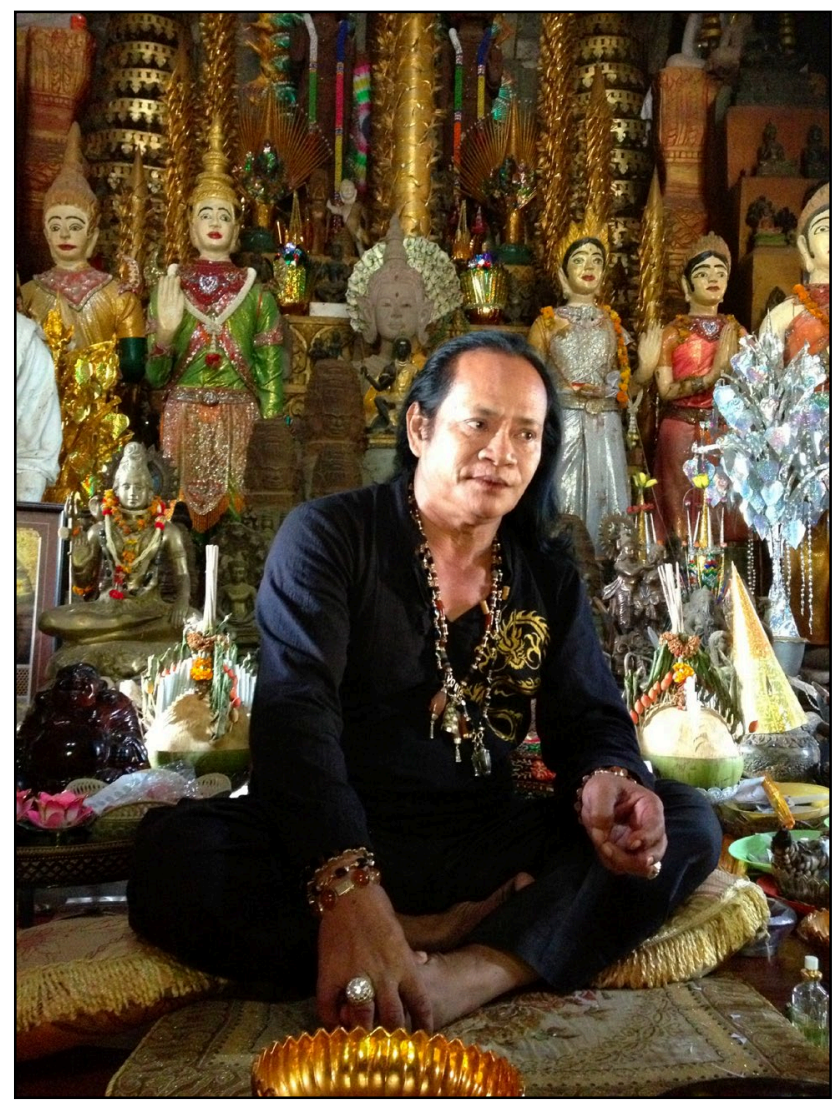

Abb. 21: (C) Lauser. Grü Lunn in seinem Tempel.

Ende der 1990er Jahre ließ er sich von den angesammelten Spendengeldern in der Nähe seines Heimatdorfes südlich von Phnom Penh einen riesigen Tempel bauen, dessen Baustil an die Tempelanlagen der Angkor-Periode erinnert. Der Tempel ist, inspiriert von seiner spirituellen Beziehung zu seinem Python, mit zahlreichen Abbildungen von Nāga (der mythischen Schlange) dekoriert und wird umgangssprachlich als „Nāga-Tempel“ bezeichnet. ${ }^{156}$ Seit der Eröffnung des Tempels im

156 Zur Zeit des Tempelbaus hatte der Psychologe Didier Bertrand schon einige Jahre in Kambodscha geforscht und hatte beeindruckende Daten auch zu grū Lunn sammeln können, die Basis einiger religionsethnologischer Abhandlungen wurden (Bertrand 2004; 2001). Auch der Film „L'esprit du roi lepreux“ (2001) von Didier Fasso, an dem Didier Bertrand mitarbeitete, entstand zu dieser Zeit und liefert ein persönliches Portrait von grū Lunn und seiner Arbeit. 
Jahre 2000 sind zahlreiche Anhänger_innen (vor allem hilfesuchende Kranke) zum Tempel gezogen, wodurch ein kleines Dorf um den neuen Tempelkomplex entstanden ist. Lunn berichtete, dass die anak dham neuerdings dazu übergegangen seien, ihn mit Fahrern zu sich bringen zu lassen, was er mit zahlreichen eingerahmten Fotos aus seinem Tempel belegen konnte. Darunter waren auch Fotos mit dem derzeitigen König Sihamoni ${ }^{157}$ aus dem Königspalast und hochrangigen Angehörigen des Militärs an der thailändischen Grenze.

Heute ist Lunn sicherlich eines der meistbeschäftigten und wohlhabendsten Geistmedien Kambodschas. Sein materieller Wohlstand ließe sich mit dem von anak dham vergleichen, auch wenn er als gru einen Lebensstil pflegte, der zu ungewöhnlich und zu asketisch für eine Identifikation als anak dhaṃ wäre.

Die Gründe für Lunns große Popularität bei anak dham und seinen wirtschaftlichen Erfolg lassen sich leicht an einigen Unterschieden zu anderen grü ablesen, mit denen er sich von ihnen abhebt. Er ist beispielsweise einer von wenigen grü, dessen Besessenheit einen ausgeprägten Unterhaltungscharakter hat, da seine Performanz ungewöhnlicherweise von zahlreichen Kostümen, stark variierenden Stimmlagen und einer großen Anzahl von verschiedenen Geistern geprägt ist. Seine Art des Redens ist ironisch und dennoch empathisch. Zudem stellt er auffällig viele Bezüge zu indischen Gottheiten und ihren Verehrungsformen her. ${ }^{158}$ Dies ist als klare Referenz zu den Ursprüngen des Brahmanismus zu verstehen, obwohl Lunn es wie alle erfolgreichen Medien versteht, sich in einem ausgeglichenen Maß buddhistisch und brahmanistisch darzustellen. Einerseits beschreibt er seine Arbeit stets mit den Worten, dem „Buddha zu dienen“. Jeden Tag lud er Mönche von der benachbarten Pagode ein, damit sie an seinem Tempel Essensspenden empfangen und verzehren konnten. Andererseits umfasst sein breites magisches Angebot, wie der grū nicht ohne Stolz betonte, beispielsweise die Verteilung von gesegneten Polyester-Westen an Soldaten, mit denen sie vor thailändischen Kugeln geschützt seien. Dafür würde er regelmäßig von Soldaten zur thailändischen Grenze gefahren. Außerdem sei er für Heilungsanliegen von wohlhabenden Klient_innen regelmäßig in Singapur, Indien und Burma. Einige anak dham versorgten ihn mit monatlichen Spenden, sowie mit großen Opfergaben zum Erreichen bestimmter Ziele: der Beförderung innerhalb ihres Unternehmens, dem erfolgreichen Ausgang eines Geschäftsjahres, der Vergrößerung ihres Wohlstandes und dem Schutz ihrer Familie vor Widersachern. Bemerkenswert waren außerdem Lunns vielfältige Verbindungen (khsae) zu konkurrierenden politischen Lagern (wie dem König, den Vertretern des Militärs und Angehörigen der Regierungspartei KVP).

\footnotetext{
157 Vor seiner Krönung zum König 2004 soll Sihamoni noch selbst mit dem Fahrrad zu grū Lunn gefahren sein, wie mir Anwohner_innen des Tempels berichteten.

158 Grū Lunn stellte in dem oben genannten Film von Didier Fasso beispielsweise ein tableau vivant dar, ein lebendiges Bild oder jhanki (Luchesi 2015) von Shiva. Derartige Praktiken hatte ich in Kambodscha zu keiner anderen Gelegenheit beobachtet.
} 


\subsubsection{Grū Srun}

Grū Srun ${ }^{159}$ wurde als Kind von wohlhabenden Eltern in Phnom Penh geboren und verbrachte dort einen großen Teil seiner Kindheit. Nach der Machtübernahme der Roten Khmer 1975 arbeitete er als junger Viehhirte für tā Mok, den berüchtigten Leiter der Südwest-Zone der Roten Khmer. ${ }^{160}$ Als die Vietnamesen 1979 anrückten, floh $t \bar{a}$ Mok mit anderen Roten Khmer-Kadern in den Norden grū Srun lief jedoch zu den Vietnamesen über. ${ }^{161}$ Im Anschluss daran kämpfte er sechs Jahre für die vietnamesischen Truppen gegen die im Norden verschanzten Roten Khmer.

Während dieser Zeit bekam er plötzliche Eingebungen, die ihm und seinen Gefährt_innen des Öfteren das Leben rettete. Als er während eines Kampfes auf eine Landmine trat, ohne dass sie explodierte, glaubten die Soldaten in seiner Einheit bereits an die spirituelle Kraft von Srun, während er sie noch anzweifelte. Kurz darauf träumte er das erste Mal von seinem Geist lok tā Kong Cha. Der Kontakt zu dem Geist befähigte ihn Menschen zu heilen und Personen erfolgreich vor zukünftigen, gefährlichen Ereignissen zu warnen. 1985 wurde er für zwei Jahre von der Gefechtsfront im Norden Kambodschas nach Süd-Vietnam versetzt. Als ausgezeichneter Soldat erhielt er nach seiner Rückkehr einen Platz in der Leibgarde Hun Sens, die aus besonders loyalen Kämpfern des Militärs und anderen Eliteeinheiten zum persönlichen Schutz des Premierministers gegründet worden war.

Das Arbeiten fiel ihm jedoch schwer, denn sein Geist besetzte ihn immer häufiger. Nach dem Putsch Hun Sens 1997 zwang ihn Kong Cha dazu, „nicht mehr gegen Khmer zu kämpfen und sie zu töten“. Stattdessen verließ Srun jeden Monat drei Tage und vier Nächte seinen Körper, um in der thān suok von seinem und anderen Geistern spirituell unterrichtet zu werden. Seine Initiation geschah gegen seinen Willen, da ihm der Kontakt zu Geistern nach wie vor „zu brahmanistisch“ vorgekommen sei. Daraufhin hätte sein Geist ihn jedoch auf die pāramī buddha verwiesen, der er (lok tā Kong Cha) selbst folgen würde, was Sruns Zweifel schließlich abschwächte und die späte Initiation des Mediums möglich machte.

159 Grū Srun war ein Medium, das ich in einem frühen Zeitpunkt meiner Forschung traf und zu dem ich über ein Jahr hinweg beständigen Kontakt durch zahlreiche Besuche und Telefonate hielt. Ohne unsere lang erarbeitete Vertrauensbasis hätte ich die nun folgenden Informationen nicht sammeln können. Der Veröffentlichung dieser Daten stimmte er nur unter der Bedingung der Anonymisierung zu.

160 Seine kompromisslosen, internen ,Säuberungen‘ 1977 brachten ihm den Beinamen „der Schlächter" ein.

161 Dies war nicht allzu ungewöhnlich zu dieser Zeit, da in den Invasionstruppen, die in zwei Wochen zwischen dem 25.12.1978 und dem 07.01.1979 bis nach Phnom Penh vorrückten, rund 20000 Exilkambodschaner_innen an der Seite der späteren Regierungsmitglieder Hun Sen, Chea Sim und Heng Samrin mitkämpften (Chandler 2008: 273). 
Kurz darauf im Jahre 2003 lernte er den zukünftigen Leiter des ECCC und Siv $^{162}$ (einen von neun Vize-Premierministern des damaligen Ministerrats) kennen. Von Siv erhielt er eine sogleich einen Auftrag: seine kranke Tochter sei ,verrückt (chkuat) geworden. ${ }^{163}$ Nach zahlreichen Heilungsversuchen bei Ärzten im In- und Ausland sei dies laut Siv die „letzte Chance“ seiner Tochter. Grū Srun nahm sie für mehrere Tage auf und während sein Haus von privaten Leibwächtern ihrer Familie beschützt wurde, konnte er die Tochter mit sro dyk und anderen Ritualen heilen, indem er erfolgreich mehrere pisāca (schädigende Geister, siehe Kap. 5) aus ihrem Körper vertrieb. Außerdem hätte er sie einem „Training zur Abhärtung“ unterzogen, indem sie auch bei schlechtem Wetter draußen auf einer einfachen Pritsche schlafen und das (für anak dham vergleichsweise) einfache Essen der Landbevölkerung essen ließ, was der grū später als grundlegendste Maßnahme für die Heilung der wohlhabenden, jungen Frau ansah.

Nach der Heilung von Sivs Tochter organisierte der grū sogleich ihre Hochzeit mit einem Sohn eines anderen hohen Regierungsvertreters. Sie gehe seitdem einem nach öffentlicher Wahrnehmung, normalen' Leben nach, wie er betonte, und sein Auftraggeber sei hochzufrieden mit der Arbeit des Mediums gewesen. Er ließ gru Srun nicht nur ein neues Haus bauen, sondern auch den gesamten Straßenabschnitt vor seinem Haus asphaltieren.

Danach erhielt grū Srun mehrere Aufträge von anderen anak dham über astrologische Berechnungen (einen Ort für einen pāy sī bestimmen; ein Datum für eine Hochzeit festlegen, o.ä.) und auch Heilungen (er sagte einmal, dass Kinder von reichen Menschen sehr leicht verrückt werden würden). Im Rahmen einer staatlichen Kampagne organisierte der zudem die Errichtung und Inauguration einer öffentlichen anak tā-Statue, die er in Rücksprache mit seinem Geist gestaltete und mit der Macht eines anderen Geistes weihte.

Sein Hauptklient und Patron war jedoch weiterhin Siv. Der grū war des Öfteren in Phnom Penh im Haus von Sivs Familie und kümmerte sich dort um den pāy sī des Politikers. Er betonte, dass er als ,Neffe‘ seines ,Onkels‘ in ,allen Belangen des Haushalts" behilflich sei - was eine typische soziale Positionierung eines engen Geförderten innerhalb eines khsae von anak dham darstellt. Die Beziehung zu Siv verschaffte Srun Privilegien, die an einigen äußeren Kennzeichen deutlich wurden: in seinem Auto befand sich ein aktuelles VIP-Schild (dieses musste jährlich erneuert werden), das ihm sämtliche Sonderrechte im Straßenverkehr einräumte. Außerdem hatte er mit Abstand das beste Haus in seinem Dorf - mit einem großen Garten und eigenem Teich. Die etwa 200 Meter lange, asphaltierte Straße vor seinem Haus mündete an beiden Enden in sandigen Pisten und stellte als beste Straße der Region den Wohnort einer wichtigen Person deutlich zur Schau.

162 Auch die hochrangigen Offiziellen in diesem Beispiel wurden von mir pseudonomisiert.

163 Das einzige Detail dieser, Verrücktheit ${ }^{`}$ habe ich von grū Vanns Frau erfahren, der zufolge die

Tochter „,wild geschrien und ihren Vater beschimpft“ haben soll. 
Trotz unseres guten Kontakts gestaltete es sich jedoch schwierig, über Vanns religiöse Praktiken für Siv zu sprechen. Als ich gegen Ende meiner Forschung einen verbalen Vorstoß diesbezüglich wagte, gab sich Srun verschlossener denn je. Auch in darauffolgenden Besuchen wurde er diesbezüglich sehr vorsichtig. Srun hatte gegenüber Siv darauf bestanden, weiterhin ,normale' Klient_innen zu empfangen und nicht nur für ihn als, Onkel' zu arbeiten, der dafür offenbar von der Verschwiegenheit seines ,Neffen' ausging. Mit meinen konkreten Fragen hatte ich eine Grenze überschritten, die öffentlich gemachte Aussagen zu politischen Themen regulierte. Diesbezüglich tauschten sich Kambodschaner_innen lediglich unter engsten Vertrauten und - auch in diesem Rahmen - ausschließlich im Flüsterton aus.

Dieser Umstand konnte bei der Generation von grū Srun leicht durch die während der Zeit der Roten Khmer erlebte, lebensgefährliche Bedrohung im Falle einer Denunziation erklärt werden. Der Vorwurf, sich kritisch zur politischen Lage geäußert zu haben, war für die Roten Khmer bereits ein legitimer Grund für eine Hinrichtung gewesen. Auch die jüngere Generation hatte durch diverse Methoden der Einschüchterung im gegenwärtigen politischen Kontext gelernt, diese Themen nicht direkt anzusprechen. ${ }^{164}$

Die Ehefrau von grū Vanns war jedoch weniger vorsichtig in Bezug auf das Thema der anak dham. Sie vertraute uns mit gedämpfter Stimme an, dass der Politiker Siv großes Vertrauen in die pāramī ihres Mannes hatte: er würde ,günstige Tage für bestimmte Anlässe ausrechnen, wöchentliche Rituale am pāy sī von Siv zu dessen Schutz durchführen und ihn in wichtigen politischen Entscheidungen beraten. So hätte der grū seinen Patron auch schon darüber informiert, in welcher Form der Politiker nach dem Tod reinkarniert werde, damit dieser dafür bereits Vorbereitungen treffen konnte. Als Beispiel, welch hohen Stellenwert grū Srun in der Familie von Siv einnähme, berichtete sie von einem geplanten Besuch bei dem Haus der Sivs in Phnom Penh. Durch eine Reifenpanne ihres Autos hätten sich der gru und seine Frau um beinahe sechs Stunden verspätet - doch Sivs Familie hätte so lange mit dem Essen gewartet, bis sie alle gemeinsam essen konnten. Da der soziale Status des grü im Gegensatz zu einem anak dham wie Siv normalerweise kein derart langes Warten erfordern würde, sah die Ehefrau dies als Beweis für Sivs Wertschätzung des grū. Zudem würde Siv auf einen Umzug von Srun in dessen Privathaus drängen und habe mehrfach den Wunsch geäußert, als sein einziger Klient behandelt zu werden.

Die Aussagen der Ehefrau zu der Beziehung zwischen den anak dham und dem grū musste ich natürlich kritisch hinterfragen. Wie in Kapitel 6 bereits betont, wurde den Angehörigen und Freunden der Medien stets die Rolle zuteil, die Geistmedien und ihre pāramī bei den Ankömmlingen zu loben und die hohe

\footnotetext{
164 Beispielhaft dafür seien hier die strafrechtlichen Verurteilungen von Kritiker_innen Hun Sen genannt, die wegen Beleidigungen bei facebook Gefängnisstrafen antreten mussten (vgl. Aun 2016).
} 
Wertschätzung der grū durch andere (nicht selten prominente) Klient_innen hervorzuheben. Allerdings prahlte sie in diesem Fall nicht mit der Beziehung zu Siv, sondern vertraute uns diese Information an, nachdem wir das zweite Mal mehrere Stunden auf ihren Mann warten mussten und sie sich damit in unserer Schuld wähnte. Wir hatten sie vorher schon einmal nach der Beziehung ihres Mannes zu Siv gefragt, daher wusste sie von unserem Anliegen und schien unter diesen Umständen bereit zu sein, uns mit den Informationen auszuhelfen. Srun selbst schien dem Druck seines Mäzens, möglicherweise auch als Reaktion auf mein beharrliches Interesse, allmählich nachzugeben: Er kündigte bei meinem letzten Besuch an, nur noch „enge Freunde“ empfangen zu wollen und vermehrt nach Phnom Penh zu Siv zu fahren.

Wie die Fallbeispiele der Geistmedien zeigen, werden erfolgreiche grū mit umfangreichen Spenden von anak dham unterstützt - die stets mit Erwartungen von zu erbringenden Gegenleistungen verbunden sind. Die hier beschriebenen Praktiken auf persönlicher Ebene sollen im nächsten Abschnitt von brahmanistischen Zeremonien nationaler Tragweite ergänzt werden. Beide dort vorgestellte Beispiele illustrieren die enge Verflechtung zwischen Medialität und exekutiver Macht in Kambodscha und verdeutlichen die Handlungsmacht brahmanistischer Akteure.

\subsection{Nationale Identität und magische Praktiken}

Die Befürchtung der anak dham als irrationale Führungskräfte zu gelten, steht in einem Spannungsverhältnis zu der breiten Akzeptanz der Geistmedien-Praxis, die aufgrund der mit dem Land verbundenen Geister als ,genuin kambodschanisch“ gilt. Diesen Zwiespalt formulierte der samăya-geschulte Bunnwath folgendermaBen:

"If I say I believe [in spirits], people think I am not a rational person. But if I say I don't believe, people think ... I am ... not ... a real Khmer!" (Gespräch vom 26.10.2012).

Das Spannungsverhältnis zwischen Rationalität, einer als magisch wahrgenommenen Khmer-Identität (khmerness) ${ }^{165}$ und der brahmanistischen Praxis ist Thema dieses Abschnitts. Dafür beschreibe ich zwei Inszenierungen von Geistern mit Bezug auf die umstrittene Tempelanlage Preah Vihear. Die allgegenwärtige spirituelle Interpretation des militärischen Konflikts um die Tempel aus der AngkorZeit beinhaltet die Vorstellung, dass Kambodschas Streitkräfte in militärischer Hinsicht zwar unterlegen seien, doch dank ihres spirituellen Erbes und des lange bewahrten, magischen Wissens insgesamt eine Vorteilssituation im Kampf um die

165 Khmerness wird umgangssprachlich als „wir Khmer“ (khmer yoen) bezeichnet. Nicht nur in Kambodscha, auch in Thailand, wird der ,magische" Aspekt dieser Zugehörigkeit von einer in Burinam ansässigen Khmer-Minderheit betont, siehe Baumann (2015). 
Tempelanlage innehätten. Dabei wurde statt eines Mangels an modernem Kriegsgerät die Bewahrung von magischer Stärke betont, die mit der gewissenhaften Tradierung von altertümlichen Praktiken und der rituellen Pflege der jahrtausendalten Tempel begründet wurde. Dieser weitverbreiteten Interpretation der, echten khmerness' (khmer daem) nach beanspruchten die Einwohner_innen Kambodschas durch die anhaltende Verehrung der Geister seit der Angkor-Zeit einen privilegierten Zugang zu magischer Macht.

Diesbezüglich werden in alltäglichen Gesprächen oftmals einzelne Narrationen wiedergegeben, in denen die Überlegenheit der Khmer auf religiöser und magischer Ebene bekräftigt wird, wie zum Beispiel die Legende des in einem aussichtlosen wirkenden Kampf als Sieger hervorgegangenen lok tā Kleang Moeung (Kap. 5.2). Andere Erzählungen stammen aus den Zeiten der Roten Khmer und späteren Konflikten und dienten als Belege für die magische Souveränität Kambodschas, wie beispielsweise die Erzählung, nach der die zahlenmäßig unterlegenen Khmer-Kämpfer in den 1980er Jahren das Land nur hätten verteidigen können, weil ihnen die Tiere des Dschungels geholfen hätten, indem sie thailändische Soldaten attackiert hätten. Auch die Roten Khmer hätten (im Gegensatz zu den Thais) als strenge Nationalisten in der Gunst kambodschanischer Geister gestanden. Selbst in Ablehnung jeglicher Religiosität hätten die Roten Khmer demnach auf pāramī zurückgreifen können, während die Thais diese Verbindung auf Kosten ihrer ,modernen' Ausrichtung bereits verloren hätten.

Diese Diskurse von magischer Überlegenheit wurden auch von anak dham reproduziert, was ich im folgenden Abschnitt an zwei Beispielen veranschauliche. Dafür ziehe ich nach einer kurzen Einführung des Konflikts um die Tempelanlage Preah Vihear das Beispiel einer loeng anak tā-Zeremonie heran, die von hochrangigen anak dham zum Schutz des Landes initiiert wurde. Im zweiten Beispiel beschreibe ich ein krung pali-Ritual von Bun Rany, der Ehefrau von Premierminister Hun Sen, das ich mithilfe von Zeitungs- und Zeugenberichten analysiere.

\subsubsection{Der Konflikt um den Tempel Preah Vihear}

Preah Vihear ${ }^{166}$ ist der Haupttempel von einem Komplex über 1000 Jahre alter, religiöser Bauwerke direkt an der thailändisch-kambodschanischen Grenze in der gleichnamigen Provinz Preah Vihear. Nach einer missverständlichen und bis heute kontrovers diskutierten Grenzziehung der französischen Kolonialbeamten im Jahre 1907 brach in den 1930er Jahren ein internationaler Streit um die Anlage aus (Grabowski 2011). Nach dem Urteil des Internationalen Gerichtshofes von Den Haag im Jahre 1962 gehört der Tempel rechtmäßig zu Kambodscha. Die thailän-

166 Eigentlich bedeutet preah vihear wörtlich übersetzt, heiliger Schrein', was die Bezeichnung der Haupthalle jedes Klosters in Kambodscha darstellt. Um Missverständnisse zu vermeiden, sagt man zur Benennung dieses bestimmten Tempels in Khmer prasāda preah vihear (Tempel heiliger Schrein, โติธีรโุะริบัป). 
dische Regierung versäumte die Frist zur Einreichung einer Revision, und bis heute sorgt das Thema Preah Vihear in der Beziehung der beiden Nationen immer wieder für Konflikte. Nach auflodernden Kämpfen 2008 und 2011 plant die Regierung heute die Gegend nördlich vom Flughafen Siem Reap touristisch zu erschließen und die Tempelanlagen als weitere touristische Attraktion in diesen Plan zu integrieren. ${ }^{167}$

\subsubsection{Ein loeng anak tā in Poipet}

In der westlichen Grenzstadt Poipet wurden 2012 innerhalb von sechs Monaten in einem Haushalt nördlich der Stadt drei loeng anak tā der ,modernisierten' Art (Kap. 8.3) veranstaltet. Der Gastgeber war zugleich als wichtiger Grenzpolizist in hohem Rang und als grū cūl rūpa für elitäre Klient_innen tätig. Auch seine Ehefrau, seine Tochter und seine beiden Nichten konnten von Geistern besessen werden, wobei nur die 16jährige Tochter als praktizierendes Medium arbeitete, und dabei von einem mächtigen chinesischen Geist besessen wurde, den ausgewählte Klient_innen des Grenzpolizisten auch sprechen durften.

Alle Geister der Familie waren von gru Ly identifiziert und in einem riesigen $p \bar{a} y s \bar{\imath}$ des Hauses manifestiert worden. Für die Errichtung dieses Familienschreins wurde 2011 ein zusätzliches Stockwerk auf das Wohnhaus der Eheleute gebaut, was zusammen mit dem aufwendig gestalteten Schrein über 40000 US-Dollar gekostet haben soll. Seitdem war der Grenzpolizist zu einem der erfolgreichsten Geistmedien in der Region aufgestiegen und hatte durch seine beruflichen Kontakte mehrere hochrangige Klienten aus dem Militär und der Polizei. Grū Ly war seit der von ihm angeleiteten Initiation der Eheleute und der Tochter als gru in engem Kontakt zu der Familie geblieben. Er hatte den Geist des Grenzpolizisten als lok tā Kong Cha (der gleiche Geist wie von grū Srun oben) identifiziert und schätzte dessen pāramī sogar mächtiger ein als die seines Geistes lok tā Eysey. Den mächtigsten Geist hätte jedoch die Tochter, die deshalb in allen Ritualen eine zentrale Rolle einnahm.

Grū Ly, dessen Heimatregion Takeo etwa 500 Kilometer entfernt lag, nahm als Organisator eine leitende Funktion während jedes loeng anak tā ein. Der erfahrene grū führte die Familienmitglieder und die anderen anwesenden Geistmedien durch die Zeremonie, leitete die Helfer_innen an und stimmte den Ablauf der Handlungen mit den Anliegen der hochrangigen Klient_innen ab. Dafür teilte der gastgebende grū die Einnahmen aus den Spenden später mit Ly.

\footnotetext{
${ }^{167}$ Neben Preah Vihear soll auch Anlung Veng (Kap. 3.3) touristisch erschlossen werden (HauserSchäublin 2011: 54-55), doch bis heute wurde lediglich ein kleiner Teil der geplanten touristischen Infrastruktur errichtet.
} 
Das Anliegen des Hauptsponsors

Am Tag vor einer der Zeremonien im September 2012 trafen sich etwa 15 Geistmedien, die aus verschiedenen Teilen des Landes angereist waren, im Haus des grū-Ehepaars. Welche Medien eingeladen wurden, erklärte mir der grū lok tā Eysey erneut damit, dass er seinen Geist gebeten hatte, alle „mächtigen und wahren gr $\bar{u}^{\text {“ }}$ einzuladen - somit wurde schon vor Beginn die Integrität der anreisenden grū gestärkt. Nach jedem Eintreffen der eingeladenen grū wurde das Eingangstor erneut verriegelt, wodurch im Unterschied zu der ursprünglichen Form von loeng anak tā deutlich wurde, dass andere Besucher_innen nicht erwünscht waren. Es waren fast ausschließlich grū anwesend. Bunnwath und ich waren durch unsere Bekanntschaft mit grū Ly Gäste des Hauses und bekamen abends - wie die anderen grū - Schlafplätze auf dem Boden vor dem riesigen pāy sī zugewiesen. Meinem Feldtagebucheintrag dieses Abends nach gestaltet sich der anschließende Ablauf folgendermaßen:

„Um etwa $21 \mathrm{Uhr}$ hatten sich bereits einige grū schlafen gelegt, als ein neuwertiger Geländewagen (mit VIP-Schild) vor dem Haus park.te. Ein edel gekleideter Mann stieg aus und betrat das Obergeschoss. Die grü begrüßten ihn ehrfürchtig; er war offensichtlich einer der Sponsoren dieses loeng anak tā. Der anak dham, den ich im Folgenden Seng168 nenne, setzte sich neben den mit ihm offensichtlich befreundeten Gastgeber vor den pāy sī, wo schon einige andere Medien Platz genommen hatten. Daraufbin wurde eine grū, die auf mich einen sehr zurückgezogenen Eindruck machte, von einer Sitzposition in einem binteren Teil des Raumes zum pāy sī gebeten. Sie war ein Medium von lok tā Kleang Moeung und kam aus der Nähe seiner Hauptverehrungsstätte in der Provinz. Pursat. Grü Ly erinnerte Seng an die obligatorische Spende, die er in Form eines 100 US-Dollar-Geldscheins in eine Schale vor dem Schrein ablegte. (...)

Die Einladung des Geistes gestaltete sich jedoch schwierig und brauchte länger als erwartet. Die schüchterne grū schien nach einigen Fehlversuchen nervös zu werden und wurde zudem von den anderen Geistmedien immer wieder mit einer Mischung aus Ironie und Ehrerbietung in ihrer Konzentration gestört, indem sie mehrmals pro Minute ,anak tā?" oder ,lok tā?' riefen, um festzustellen, ob der gefragte Geist nun anwesend sei. Dabei zupften sie an der weißen Kleidung des weiblichen Mediums, was ich wiederum als Zeichen ihrer Nervosität ansah. Auch Seng war nun nah an das Medium gerückt und redete leise und beharrlich auf sie ein.

Nach 20 Minuten wurde Seng ungeduldig und sprach laut und streng mit ihr, während sie noch immer versuchte, von ihrem Geist besessen zu werden. Er stand auf und lief nervös im Raum auf und ab, während die anderen Medien noch darüber diskutierten, wa-

168 Der Name ist durch ein Pseudonym ersetzt, weil ich keine Gelegenheit hatte, den anak dham nach seinem Einverständnis zur Veröffentlichung zu fragen. 
rum der Geist nicht kommen wollte. Die grū schien es immer noch zu versuchen und saß in meditativer Haltung vor dem Schrein.

Nach circa 30 Minuten konnte grū lok tā Eysey zur allgemeinen Erleichterung mitteilen, dass das Medium nun besessen sei. Der Geist wurde nun von allen mit drei Verbeugungen begrïßt. Das Verhalten der anwesenden grū und insbesondere des anak dham veränderte sich mit der Ankunft des Geistes. Einige grū sprachen nun mit der für Uneingeweibte unverständlichen Sprache der Geister mit dem Geist, andere boten dem anwesenden Geist nun Opfergaben wie Bier, Bananen und Zigaretten an. Weiterbin sprachen sie mit einer Mischung aus Ironie und Ehrerbietung mit dem Geist und bemühten sich damit, die hohen Erwartungen (ausgedrückt in der hohen Spende) des ungeduldigen Klienten zu erfüllen.

Der Geist weigerte sich jedoch mit einem bestimmten Kopfschütteln, die Opfergaben anzunehmen oder mit Seng zu sprechen. Dieser redete daraufhin immer eindringlicher und bittender auf den Geist ein: ,Anak tā, bitte bilf mir! Erkennst du mich denn nicht, ich habe dir vor deiner Statue in Pursat schon so viel geopfert!"“"

Er nannte erneut seinen Namen und stellte sich dem Geist vor. Dabei erfubren wir, dass er einer der ranghöchsten Politiker einer der zu Thailand angrenzenden Provinzen in Kambodscha war. Er war erst vor kurzem auf diese verantwortungsvolle Position berufen worden und fubr verzweifelt fort:

„,Anak tā, bitte, ich bin neu hier in der nördlichen Region, und ich weiß, du bist für den Norden Kambodschas zuständig - ich bin ein wahrer Khmer [khmer daem] und komme aus Phnom Penh, bitte hilf mir!' Das Medium saß weiterhin schweigend und mit gesenketem Kopf vor dem pāy sī und nabm keinerlei Kontaket zu dem Klienten auf. Seng kam nun auf sein Anliegen zu sprechen, das er laut und verzweifelt ausrief: ,Die Thais bereiten den nächsten Angriff vor; im Dezember; anak tā, sie baben bessere $W$ affen als wir, anak tā, was soll ich tun? Bitte beschütze Kambodscha!' Er wirkete verzweifelt und hatte sichtlich mit seiner Selbstbeherrschung zu kämpfen, da er vor dem Geist keinesfalls ausfällig werden durfte obne Strafen befürchten zu müssen. Immer wieder versuchte er, zu dem Geist durchzudringen: erst auf charmante Weise, dann unterstrich er die Bedeutung seines Anliegens nachdrücklich und am Ende schien er verzweifelt. Um etwa ein Uhr nachts, circa drei Stunden nach Ankunft des Geistes im Körper der grū, gab er die Kontaktversuche zu dem störrischen Geist auf. Die grü beendete daraufhin ibre Besessenheit, obne ein Wort gesagt zu haben und stand sichtlich erschöpft auf. Als wäre nichts passiert, machte sie sich wie alle anderen grū und Seng fertig zum Schlafen vor dem pāy sī.

Etwa eine Stunde später wachte ich davon auf, dass Seng wieder auf die grū einredete. Anscheinend wollte der verzweifelte Politiker es noch einmal probieren. Bei diesem Versuch saß die grū erneut vor dem pāy sī, diesmal in kleiner Runde: es waren nur Seng, grū Ly und eine andere weibliche grū vor dem pāy sī. Nach wenigen Minuten der Meditation meldete sich ein anderer Geist aus dem Körper des Mediums. Er vermeldete: ,der lok tā möchte nicht kommen, weil ihm die Musik ganz, und gar nicht gefällt. Er hört 
nur altertümliche Musike (bleng purāna)؛ Grū Ly widersprach vorsichtig: , aber lok tā, wir hören doch den ganzen Abend schon altertümliche Musik;, doch der Geist erwiderte: ,das war nicht die richtige Musik. Okhnya ${ }^{169}$ Kleang Moeung wird erst sprechen, wenn er die richtige altertümliche Musik genossen hat'. Der Politiker schien mit dieser Antwort vorerst zufrieden. Er kündigte an, dass die Mitarbeiter_innen seines Ministeriums berausfinden würden, welche Musik das sei und rief mitten in der Nacht die Mitarbeiter_innen seines Ministeriums an, um sie mit dieser Recherche zu beauftragen. Die grū hatte in zwischen die Besessenheit beendet und wollte aufstehen, als Seng ibr einen 100 US-Dollar-Schein gab, für den sie sich ehrfürchtig bei ibm bedankte. Anschließend suchten sie sich jeweils einen Platr. zwischen den schlafenden grü auf dem Boden und legten sich schlafen."

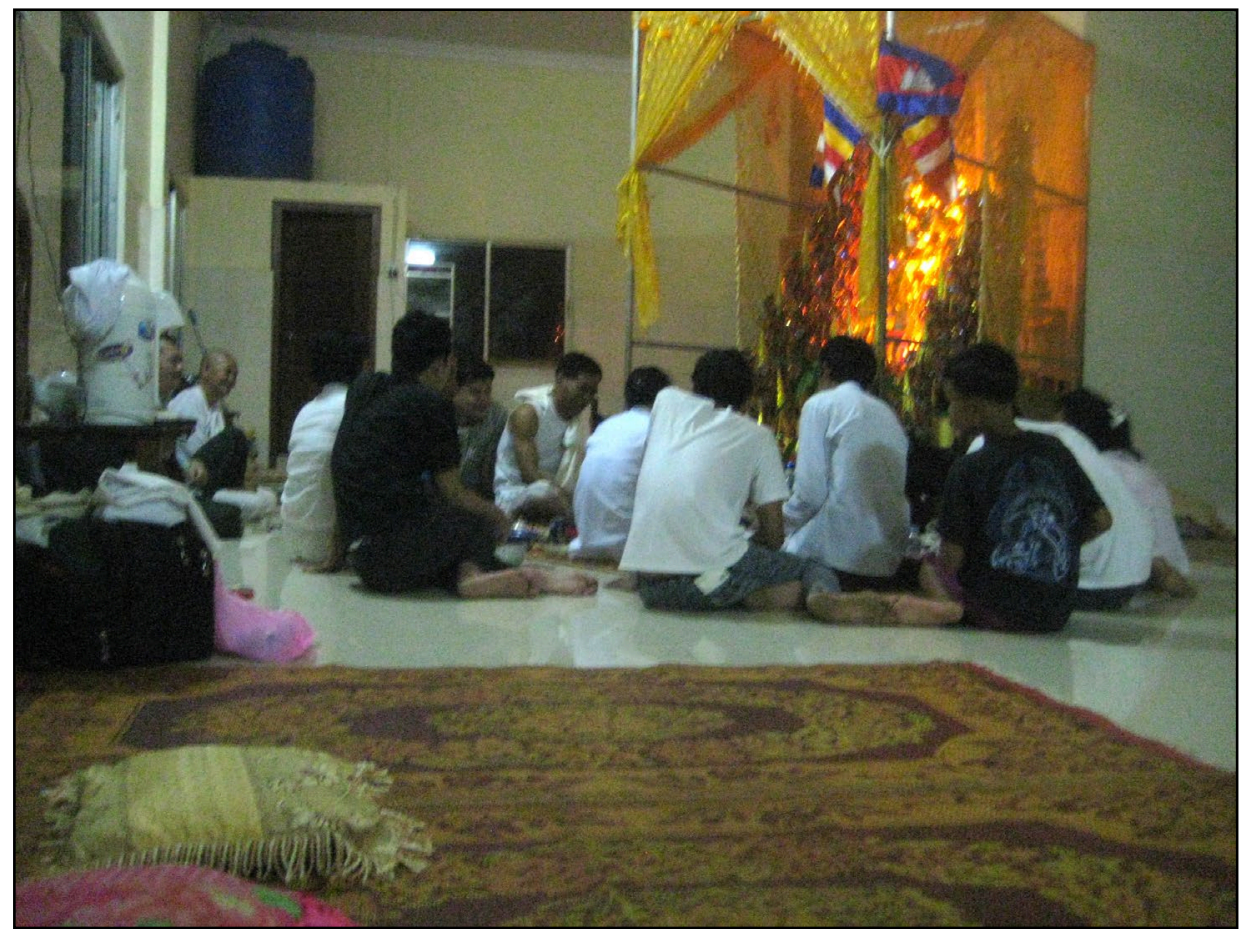

Abb. 22: (C) Autor. Nächtliche Besessenheit für den Sponsoren der Zeremonie.

Der offizielle Teil der Zeremonie begann am nächsten Tag mit einem Fahnenappell vor dem Haus des Gastgebers. An dem dort postierten Fahnenmast spielten Musiker die Nationalhymne und einige Geistmedien wurden dabei von ihren Geistern besessen. Sie schwenkten zu musikalischer Begleitung die kambodscha-

${ }^{169}$ Ein königlicher Titel, siehe 9.1. 
nische Flagge und riefen dabei: „Hoch lebe Kambodscha! Wir werden unsere Feinde schlagen! Hoch lebe Kambodscha! Hoch lebe brah Kong Cha [Geist des Gastgebers]“, und „hoch lebe brah Khan Riet!“. Dieser letztgenannte Geist war der eigene Schutzgeist von Seng, den grū Ly in dessen Körper identifiziert hatte. Damit war deutlich, unter welchen Vorzeichen die kommende Zeremonie stand: der anak dham bat zum einen um seinen persönlichen Schutz, zum anderen um den Schutz der ganzen Nation vor einem thailändischen Angriff.

Während des Fahnenappells kamen die Mönche aus der nächstgelegenen Pagode an, die im Haus des grū-Ehepaars das dāna (Speisung der Mönche) empfangen wollten, das vor jedem loeng anak tā durchgeführt wurde. Mit ihrer Ankunft breitete sich ein Unbehagen unter den Medien aus - weshalb der Fahnenappell mit den tanzenden Medien zwar nicht abgebrochen, aber zu einem baldigen Ende gebracht wurde.

Kurz darauf wurden auch die Dorfbewohner_innen auf das Gelände geführt, die das dāna an diesem Tag nicht wie üblich in die Pagode, sondern in dem Privathaus des Grenzpolizisten durchführen mussten. Während des dāna bekamen die Mönche nicht nur Essen, sondern von den grū und von Seng aufwendig gestaltete Geschenkkörbe überreicht. Die Mönche gaben daraufhin nicht wie üblich den Verdienst der Gabe an die Verstorbenen weiter, sondern segneten auch den $p \bar{a} y s \bar{l}$, was eine bemerkenswerte Anerkennung eines brahmanistischen Schreins vonseiten buddhistischer Akteure darstellt.

Im weiteren Verlauf des loeng anak tā half Seng nicht nur, das besessene und tanzende Gastgeber-Ehepaar auf einer Sänfte um den pāy sī zu tragen, sondern wurde auch von beinahe allen anwesenden grū gesegnet. Nach zwei Stunden Tanz und Segnung der wenigen Besucher_innen des Festes (es waren ja fast nur grū anwesend), wurde das Tor nach draußen geöffnet und mehrere Hundert Menschen, die teilweise stundenlang draußen gewartet hatten, drängelten sich auf das Gelände. Die grū und Seng segneten diese mit Wasser und beschenkten alle Besucher_innen mit je fünf Kilogramm Reis, die Seng mithilfe der Geistmedien austeilte. Der gesamte Ablauf der Zeremonie richtete sich demnach auf die maximale Generierung von Verdienst (punya) und spiritueller Macht (pāramī) für Seng aus.

\section{Die gesegnete Nation}

Einige Tage danach hatte ich die Gelegenheit, die Ereignisse dieses loeng anak tā mit dessen Organisator gru lok tā Eysey in einem langen Interview zu besprechen. Es zeigte sich, dass er Seng zu der Zeremonie eingeladen hatte, da er ihn schon seit einigen Jahren kannte. Der grū hatte im Körper des Politikers die mächtige pāramı̄ brah Khan Riet (göttlicher, königlicher Dolch) identifiziert. Daraufhin hatte der grū dem anak dham einen pāy sì in dessen Haus eingerichtet. Ein Jahr später sei Seng zum Minister befördert worden und besucht den gru (und einige der anderen bei der Zeremonie anwesenden Geistmedien) nun aus Dankbarkeit für die Beförderung regelmäßig. 
Im Gespräch mit dem grū wurde die zweifache Bedeutung der oben beschriebenen Zeremonie für Seng deutlich. Erstens bekam er am Abend vor der Zeremonie Gelegenheit, einen Geist um Hilfe zu bitten, der in ganz Kambodscha als Sieger über siamesische Truppen bekannt war. Dabei wurde sein Wunsch nach Sicherheit deutlich. In seiner verzweifelt vorgetragenen Bitte machte Seng deutlich, dass er Kambodschas Streitkräfte für militärisch unterlegen hielt. Er vertraute stattdessen auf die spirituelle Macht der Geister und versuchte mit ihrer Hilfe, den befürchteten Angriff zu verhindern. Für die Gewährleistung dieses magischen Schutzes investierte er Geld, Zeit und die Arbeitszeit seiner Mitarbeiter_innen. Zu weiteren brahmanistisch-konzeptionierten Taten gehörten neben der Befragung des anak tā am Vorabend die Finanzierung der Zeremonie mit aufwendigen Opfergaben und den dafür erhaltenen Segen der grū zum Zwecke des Schutzes.

Zweitens hatte Seng durch seine Rolle als Sponsor die Gelegenheit, während der Zeremonie Verdienst zu sammeln. Die Opfergaben an die Mönche, die Segnung und die Spende von Reis an die ,Bedürftigen' waren typisch buddhistischkonzeptionierte Verdienst-Handlungen, die auch in anderen religiösen Kontexten durchgeführt wurden. Der gesammelte Verdienst wurde nicht nur (wie in anderen buddhistischen Ritualen üblich) auf Sengs eigenes Karma nach dem Tode bezogen, da das Hauptanliegen der Zeremonie nicht persönlich motiviert war. Es wurde für den nationalen Schutz der gesamten Nation gesammelt, wie mir grū Ly versicherte, denn man könnte punya auch im Namen für jemanden oder etwas anderes sammeln (vgl. Jacobsen und Stuart-Fox 2013: 12). Somit wurde Sengs gesammelter Verdienst während dieses loeng anak tā stark mit seinen Aufgaben als Politiker und Angehöriger des Militärs verbunden. Dies wurde auch an den Sprechakten der zuständigen Geistmedien während der Rituale deutlich, die den Schutz Kambodschas in den Vordergrund stellten.

Wie das oben beschriebene Beispiel gezeigt hat, waren anak dham wichtige Akteure in der Reproduktion des Narratives der magischen Überlegenheit Kambodschas und waren zudem imstande, die brahmanistische Praxis finanziell zu fördern und die Mobilisierung ihrer Akteure zu ermöglichen. Diese Einblicke in die nichtöffentliche, magische Aushandlung von nationaler Identität und Politik werden im folgenden Abschnitt durch die öffentliche Prägung einer magischen, nationalen Identität ergänzt. Dazu analysiere ich das krung pali-Ritual, das die Ehefrau von Premierminister Hun Sen, Bun Rany, am 01. August 2008 an den umkämpften Tempelanlagen von Preah Vihear durchführte. 


\subsubsection{Ein krung palī am Tempel Preah Vihear}

\section{Die Verwalterin der mächtigsten Familie Kambodschas}

Bun Rany wurde 1952 geboren, und heiratete Hun Sen 1976. Wie in Kambodscha üblich, war sie war als Frau für die religiösen und spirituellen Angelegenheiten der Familie Hun zuständig und galt damit auch als deren Verwalterin, Beschützerin und Produzentin von punya und pāramī. In der Öffentlichkeit setzte sie sich erfolgreich als Wohltäterin in Szene und übernahm schon in den 1990er Jahren eines der verdienstreichsten Ämter des Landes, den Vorsitz des Roten Kreuzes. In den von der Regierung kontrollierten Medien wird sie stets als Vorbild für Moral und Gutmütigkeit dargestellt; ein Ruf, den sie während des Wahlkampfes oftmals für die Unterstützung ihres Ehemanns einsetzte. ${ }^{170}$

Als ranghöchste Frau des Landes lagen somit alle spirituellen Belange der machthabenden Familie in Bun Ranys Händen. Im Zuge der KarmaWechselwirkung wurde ihr besonders viel spirituelle Macht zugeschrieben, womit die Rituale von oder mit Bun Rany als besonders verdienstreich und mächtig galten. Dieser Ruf war einer von zahlreichen Gründen, warum das krung pal̄ Ritual am umkämpften Tempel Preah Vihear besonders umstritten war.

\section{Das krung pali Ritual}

Die Bezeichnung krung pal̄ ist laut Guthrie (2004a) und Porée-Maspero (1961a) auf die Erdgottheit Krung Bali zurückzuführen. ${ }^{171}$ Übereinstimmend wurde mir berichtet, dass Krung Bali der zuständige ,Geist der Erde ${ }^{\natural}$ und einer der mächtigsten Geister in Kambodscha sei. So gut wie jede wichtige Zeremonie wird bis heute mit dem sogenannten krung pali-Ritual eingeleitet, dessen Ablauf von der Rezitation von buddhistischen Pāli-Versen und der Einladung von anak tā und anderen Geistern geprägt ist. Den Handbüchern für ācaryā zufolge kann das Ritual in fünf verschiedenen Ausprägungen durchgeführt werden: für Verstorbene, als einleitendes Ritual, als familiäres Ritual, für Könige oder für Götter (Davis 2008b) ${ }^{172}$.

\footnotetext{
${ }^{170}$ Kritiker_innen warfen ihr dabei vor, nicht nur ihren Ruf, sondern auch die finanziellen Ressourcen der wohltätigen Arbeit für den Wahlkampf ihres Ehemanns zu missbrauchen (Hruby 2013; Wency 2003).

171 Diese hatte die Gestalt eines Krokodils oder einer Nāga-Schlange (Gaudes 1993: 349), und kann heute nur noch schwer unterschieden werden von Namen anderer Erdgottheiten wie brah phum oder brah dharan̄i (Guthrie 2004a: 12). Porée-Maspéro (1961a) schlussfolgert nach ihrer Forschung über krung pā $\bar{\imath}$, dass alle drei Namen die gleiche Erdgottheit bezeichnen.

172 Davis übernimmt diese fünf Formen aus einem Handbuch für ācaryā mit dem Titel „Gewohnhei-

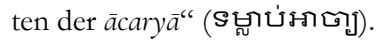


Welche der hier beschriebenen Formen des Rituals Bun Rany am 01. August 2008 am Preah Vihear Tempel durchführte, ließ sie meiner Meinung nach bewusst offen und schaffte somit mehrere Interpretationsmöglichkeiten, die ihr politisch in mehrfacher Hinsicht von Nutzen waren.

\section{Ablauf des magischen Rituals}

Am frühen Morgen des 01. August 2008 besuchte Bun Rany die Tempelanlagen und reichte zuerst im Haupttempel Opfergaben für die dort ansässigen Ortsgeister (unter anderem brah Noray und lok tā Eysey) dar. Anschließend wurde sie zum Veranstaltungsort des Rituals hinter dem Haupttempel begleitet, direkt an der Schlucht, die die Grenze zu Thailand markiert. Dies ist der Ort, an dem die lokalen Bewohner_innen und Soldaten lok tā Dy verehren. ${ }^{173}$ Auf dem dort platzierten pāy sì waren keine Statuen (auch keine Buddha-Statue) zu sehen, was bereits auf eine brahmanistische Akzentuierung des Rituals hindeutet. Bun Rany saß in der ersten Reihe neben zahlreichen Schalen mit Opfergaben direkt vor dem pāy sī. Auf einer Seite rechts hinter ihr saßen und standen Soldaten, auf der anderen Seite saßen Mönche, darunter die ranghöchsten Patriarchen beider Mönchsorden, die eine weitere, erhebliche Aufwertung der spirituellen Macht dieser Zeremonie darstellten. Ein àcaryā leitete den Ablauf der Zeremonie, an der einige Hundert Menschen (darunter viele Soldaten) teilnahmen.

Bun Rany nahm entscheidend am Ablauf des krung pali-Rituals teil: Sie betete schon vor der Rezitation vor dem pāy sī und schmückte ihn mit weiteren Opfergaben (wie Blumenkränzen), die ihr der ācaryā reichte. Er lud anschließend sämtliche Geister dazu ein, an dem Ritual teilzunehmen und bat sie um Schutz und Segen. Dies nahm Bun Rany zum Anlass, die Einladung der Geister und pāramī zu unterstützen, indem sie auch Räucherstäbchen entzündete, die sie danach am pāy $s \bar{\imath}$ platzierte. Besonders häufig adressierte der ācaryā die Macht von pāramī prasāda preah vihear (die spirituelle Macht des Preah Vihear Tempels), die von ihm immer wieder als khmer purāna (altertümlich-kambodschanisch) bezeichnet wurde. Mit diesem sprachlichen Mittel beschrieb er die Macht des Tempels als ,ursprünglich kambodschanisch', was den nationalistisch geprägten Diskurs über die Tempelanlagen unterstrich. In einem Gebet sprach der ācaryā von „Kambodscha als Heimatland der pāramī prasāda preah vihear und anderer Geister", die „das Land schützten“. Er machte ausdrücklich deutlich, dass diese Geister nur in Kambod-

\footnotetext{
${ }^{173}$ Dieser anak tā wurde auf ähnliche Weise wie lok tā Kleang Moeung bekannt, da er sich als Märtyrer in die dahinterliegende Schlucht stürzte, einen schlechten Tod provozierte und eine Geisterarmee beschwor, die einen Angriff siamesischer Truppen erfolgreich abwehren konnten. Die Statue ist in ihrer heutigen Form eine hybride Darstellung des Körpers des anak tā und des Gesichts von Hing Bun Heang, dem Leiter von Hun Sens persönlicher Schutzeinheit (NorénNilsson 2013: 21). Die Verehrungspraxis des lok tā wurde vor allem von dort stationierten Soldaten gepflegt, die in dieser hybriden Form nicht nur dem Geist, sondern auch dem menschlichen Führer der loyalen Streitkräfte Hun Sens Respekt zeigen konnten.
} 
scha residierten. Nach dem Ritual verteilte Bun Rany Opfergaben an die anwesenden Mönche, und spendete Gebrauchsgüter an die Anwohner_innen und Soldaten, was Bun Ranys in der Öffentlichkeit reproduzierte Rolle als Vorbild für Religiosität, Wohltätigkeit und Patriotismus unterstrich.

\section{Fluch oder Segen - Rezeption des Rituals}

Am nächsten Tag wurde in einigen thailändischen Zeitungen das Ritual als spiritueller Angriff auf die thailändische Nation bewertet (Supalak 2008). In der Zeitung ,The Nation' heißt es in einem Artikel:

"Many residents in Si Sa Ket province wore yellow yesterday, ostensibly to help protect Thailand from black-magic spells cast by Khmer 'wizards' who met at Preah Vihear during the solar eclipse yesterday.

Bun Rany, the wife of Cambodian Prime Minister Hun Sen, led Buddhist monks and soldiers to the ancient Hindu temple yesterday morning to call upon their ancestors to protect the temple.

'The first lady called upon ancestral spirits to chase away the enemy,' Min Khin, chairman of Cambodia's festival committee, told reporters after the ceremony. Thai media reports said that the mysterious black-magic spells by Khmer wizards would not only protect the temple but also weaken Thailand. Some astrologers urged locals to wear yellow yesterday to deflect the spells" (ebd).

Die kambodschanische Zeitung Rasmei Kampuchea Newspaper stellte diese Darstellung in Frage und nannte den Zweck für den Besuch Bun Ranys „to visit the troops and civilians there, as well as to perform a religious prayer asking for peace“. ${ }^{174}$ Auch wenn diese Bedeutung von krung pali aus keiner der oben genannten fünf Formen direkt hervorgeht, wurde sie in einem Artikel von Al-Jazeera (2008) vom damaligen kambodschanischen Minister für Tourismus, Thong Khon, bestätigt: "the Cambodian tourism minister said the 1000 or so people had gathered 'to pray to the souls of our ancestors asking for peace"." ${ }^{175}$ Anschließend wird der Minister weiter zitiert mit: "We also pray for success in our defence of our territory", was der ursprünglichen Bedeutung von krung palī entspricht, da Orts- und Erdgeister in Kambodscha als zuständig für die Kontrolle eines Gebiets oder eines Territoriums gelten.

Was an diesem Beispiel deutlich wird, ist die geschickte Wahl Bun Ranys von Ort und Zeit dieses Rituals, um damit die oben skizzierten, multiplen Interpretationsmöglichkeiten zu schaffen. Auf der einen Seite gab es für die wenige Hundert Meter vom umkämpften Tempel entfernten thailändischen Anwohner_innen und

\footnotetext{
174 Auf Khmer erschienen in Rasmei Kampuchea Newspaper (jญ్

175 Mittlerweile wurde der Artikel aus nicht bekannten Gründen um den entsprechenden Absatz gekürzt. Den ungekürzten Artikel findet man unter anderem bei Davis (2008b).
} 
Soldaten genug Anlässe, diese Zeremonie als einen Angriff spiritueller Macht gegen sie zu werten: Bun Rany war mit den höchsten religiösen Führern des Landes zu dem Tempel gereist, hatte seine Macht als altertümlich-kambodschanisch gewürdigt und zahlreiche andere Geister gebeten, Kambodscha und den Tempel zu schützen. Der umkämpfte Ort, an dem jahrzehntelang tödliche Konflikte ausgetragen wurden, ist zu einem Symbol des Nationalismus beider Länder avanciert Bun Rany konnte erwarten, dass ihre Zeremonie an diesem Ort nicht ausschließlich religiös bewertet werden würde.

Auch die gewählte Zeit spielte für die Interpretation als magischen Angriff eine bedeutende Rolle: der 01. August 2008 war der Tag einer partiellen Sonnenfinsternis in Südostasien. Eine Sonnenfinsternis gilt als höchst unheilvoll in der Region. Wichtige Rituale wie Hochzeiten oder Totenfeiern würden an einem solchen Tag unter allen Umständen vermieden werden. Darunter fielen auch krung paliRituale und es erscheint an einem Tag der Sonnenfinsternis unwahrscheinlich, Harmonie und Frieden stiften zu wollen. Dieser Eindruck wird noch verstärkt unter Berücksichtigung der Kambodscha-Wahrnehmung in Thailand. Die spirituelle Praxis in Nachbarländern wie Laos, Burma und besonders Kambodscha wird dort mit schwarzer Magie in Verbindung gebracht (Baumann 2015, 2014; McDaniel 2011: 31; Pasuk und Baker 2008). Somit liegt der Schluss nahe, dass Bun Rany die Interpretation des magischen Angriffs durchaus hatte voraussehen können.

Eine andere Interpretationsmöglichkeit des Rituals lenkt den Blick auf den Ablauf des Rituals und die Tatsache, dass die Durchführung keine Übereinstimmungen mit typischen Ritualen schwarzer Magie besaß (Kap. 9.5). Demnach drückten die Handlungen lediglich die Verehrung für die Geister der Erde, des Ortes und des Tempels aus. Zudem schloss das Ritual hohe buddhistische Mönche als Träger von Moral ein, die nach Ansicht der Allgemeinheit keine schädliche Magie vollziehen konnten, beziehungsweise unterstützen würden. Diese Darstellung hatte zudem Berechtigung, da mir spirituelle Experten versicherten, dass Rituale schwarzer Magie im Geheimen stattfänden und die schädigende Intention sprachlich artikuliert werden müsste, was Bun Rany unterlassen hatte.

Später war die Interpretation der schädigenden Intention des Rituals im alltäglichen Diskurs wirkungsvoller als die des friedenstiftenden Annäherungsversuches zu Thailand. Für Bun Rany (und die Politik ihres Ehemanns) waren die verschiedenen Interpretationsmöglichkeiten strategisch nützlich: der offiziellen Version nach führte sie, ohne ihren Ruf als moralisch-reine Person zu gefährden und unter Anleitung der höchsten buddhistischen Würdenträger, ein ,Ritual für den Frieden` durch. Obwohl die Interpretation des magischen Angriffs von ihrem Sprecher lediglich angedeutet wurde, dominierte sie aus oben genannten Gründen alsbald die öffentliche Wahrnehmung. Dadurch wurde beispielsweise die Moral der dort stationierten Soldaten gestärkt: Wie ein Soldat mir erklärte, seien nach dem Ritual mysteriöse Todesfälle von thailändischen Soldaten bekannt geworden, was vor Ort direkt auf das krung pali von Bun Rany zurückgeführt wurde. 
Schließlich festigte Bun Rany Kambodschas internationalen Ruf als magische Nation und reproduzierte das Narrativ der spirituellen Überlegenheit Kambodschas, das bereits im ersten Beispiel dieses Abschnitts auf lokaler Ebene bedeutsam wurde. Somit konnte ich die Tragweite des brahmanistisch geprägten Narratives der magischen Stärke Kambodschas für Konstruktionsprozesse von nationaler Identität in Kambodscha deutlich machen. Während im zweiten Beispiel des krung pali-Rituals die magische Deutung des Geschehens nicht explizit gemacht wurde, zeigt das erste Beispiel des Politikers in Poipet, wie spirituelle Praktiken in weniger öffentlichen Räumen unmissverständlich magisch durchgeführt wurden. Die inszenierte, magische Dominanz stellt eine diskursive Konstruktion von Macht dar, die auf breite Teile der Bevölkerung , wirkt" und von den hier beschriebenen staatlichen Akteuren „zugleich kontrolliert, selektiert, organisiert und kanalisiert" (Foucault 1998: 7) wird. Die Vorstellung einer magischen Vormachtstellung auf diskursiver und ritualpraktischer Ebene ist bis heute ein wesentlicher Teil der nationalen Identität Kambodschas.

\subsection{Die Inszenierung von Geistern im Wahlkampf 2013}

Das Bekenntnis zu Geistern stellt zudem eine Form der strategischen Selbstpositionierung in der politischen Öffentlichkeit Kambodschas dar. Vielfältige Referenzen wurden in den letzten Jahren von Politiker_innen gemacht, um sich strategisch in der Geisterlandschaft für die Öffentlichkeit zu positionieren. An diesen spirituellen Bezügen der Machthabenden werden konkurrierende Diskurse um die Legitimation von Macht und Herrschaft des Landes sichtbar. Im Folgenden veranschauliche ich die spirituellen Positionierungsprozesse von Premierministers Hun Sen und des damaligen Oppositionsführers Sam Rainsy während des Wahlkampfes $2013 .{ }^{176}$

\subsubsection{Die spirituelle Positionierung von Hun Sen}

Seit der Angkor-Zeit galt die Monarchie als einzige legitime Herrschaftsform in Kambodscha (Kap. 2.1). Nach dem Sturz des Königs 1970 und dem coup d'État gegen die royalistische Regierungspartei 1997 besetzte Hun Sen trotz anfänglicher Ablehnung zahlreiche, ehemals königlich besetzte Ämter und Positionen (Ledgerwood 2008b). Auch sämtliche Funktionen in Ritualen, die ehemals Mitglieder aus der königlichen Familie innehatten, wie zum Beispiel bei der Einweihungszeremonie von spirituellen Gebäuden (sìma), wurden zunehmend von ihm und anderen anak dham übernommen (Kent 2007: 339). Sogar die Rolle des, auserwählten', buddhistischen und gerechten Herrschers cakravartin, die zuletzt König

176 Mittlerweile ist die Oppositionspartei von Sam Rainsy (PRKN) verboten worden und er lebt aufgrund drohender juristischer Sanktionen im französischen Exil. 
Sihanouk für sich proklamierte (Edwards 2008b: 220-227; Thompson 2004a: 109-111), wird heute von Premierminister Hun Sen beansprucht.

Diesen Anspruch untermauert Hun Sen unter anderem damit, sich in der Öffentlichkeit als eine Reinkarnation von Sdech Khan, einem königlichen Herrscher des 16. Jahrhunderts, darzustellen, was Astrid Norén-Nilsson ausführlich analysiert (2013). Eine kurze Zusammenfassung der Biographie Sdech Khans, wie sie der französische Historiker Adhémard Leclère (1911) rekonstruiert, lautet wie folgt:

Sdech Khan arbeitete Anfang des 16. Jahrhunderts als einfacher Helfer in einer Pagode, als seine Schwester eine Konkubine des Königs wurde und ihn mit an den königlichen Hof nahm. Der regierende König Srey Sokonthor Bât wurde jedoch in Träumen und von seinen Wahrsagern darauf hingewiesen, dass er von Sdech Khan gestürzt werden würde. Der König plante daraufhin, Sdech Khan töten zu lassen. Während des Mordversuches im Jahr 1508 konnte Sdech jedoch unverletzt fliehen und kehrte einige Zeit später mit einer Armee zurück, die den König im Jahr 1512 schließlich stürzte und tötete. Sdech Khan brachte das Land danach zu Wohlstand und regierte es als gerechter Herrscher, bis er selbst im Jahre 1525 von seinem Thronfolger Ang Chan I. gestürzt und getötet wurde.

Seit den 1990er Jahren begann sich Hun Sen in seinen öffentlichen Reden auf Sdech Khan zu beziehen. Er beauftragte zu dieser Zeit ein Forscherteam, das mehr Informationen über den ehemaligen Herrscher sammeln sollte (NorénNilsson 2013: 16). Aus der Forschung ging das Buch „Preah Sdach Kân“ von Ros Chantrabos (2007) hervor. Es betonte die Gemeinsamkeiten der beiden Herrscher: Sdech Khan soll wie Hun Sen im Jahr des Drachen geboren worden sein und beide hätten eine Zeit ihrer Jugend als niedrig gestellte Helfer (kmeng wat) in einer buddhistischen Pagode verbracht - vor allem aber seien beide durch gewaltsame Regierungswechsel zu ,gerechten' und ,rechtmäßigen' Herrschern ernannt worden. Auch die Rolle des Thronräubers, die einen (sogar an diesem Beispiel in Schulbüchern geächteten) moralischen Verstoß gegen die Autorität des Königs beinhaltete, interpretierte Hun Sen zu seinen Nutzen um. Denn wie Sdech Khan, habe auch er 1997 einen unberechtigten, königlichen Herrscher des Amtes enthoben.

"The main similarity, alluded to implicity, was the idea of a commoner, rising through bis own revolutionary prowess to govern the polity by toppling an unjust king" (NorénNilsson 2013: 12).

Im Prozess der Re-Interpretation von Sdech Khans Biographie von einem Thronräuber zu einem moralisch legitimierten Herrscher spielte die Arbeit des Forschungsteams eine tragende Rolle. Die Forscher verorteten in ihrer Publikation die ehemalige Hauptstadt und damit das Zentrum der Macht Sdech Khans in der Provinz Kampong Cham, der Heimatprovinz Hun Sens (Norén-Nilsson 2013: 16). In der Einleitung des Buches nennt Hun Sen den Sturz des Königs durch 
Sdech Khan zudem die „erste demokratische Bewegung der Geschichte“ (Ros 2007), die für Freiheitsrechte und Klassenkampf einstanden, lange bevor sie in Europa implementiert worden seien (Theara 2016; Ros 2007).

Eine weitere Maßnahme dieser Art war die Aufstellung von Statuen Sdech Khans in mehreren Provinzen des Landes. Die Künstler, die die Statuen an der Royal University of Fine Arts (RUFA) in Phnom Penh entworfen hatten, waren angewiesen worden, die Gesichter der Statuen nach dem Vorbild von Hun Sens Gesicht zu gestalten (Norén-Nilsson 2013: 18-21). Die Statuen waren jedoch nicht vom Premierminister selbst, sondern von Angehörigen der politischen Elite in Auftrag gegeben worden, die mit der Ehrerbietung gegenüber Sdech Khan indirekt Hun Sen würdigen und damit das Narrativ seiner spirituellen Macht als Wiedergeburt von Sdech Khan unterstützen.

"in recent years the story has been revived by a new official cult extolling Kan's acbievements and linking them with Prime Minister Hun Sen, who, by subtle implication, is presented as the reincarnation of the lost king" (Strangio 2014: 119).

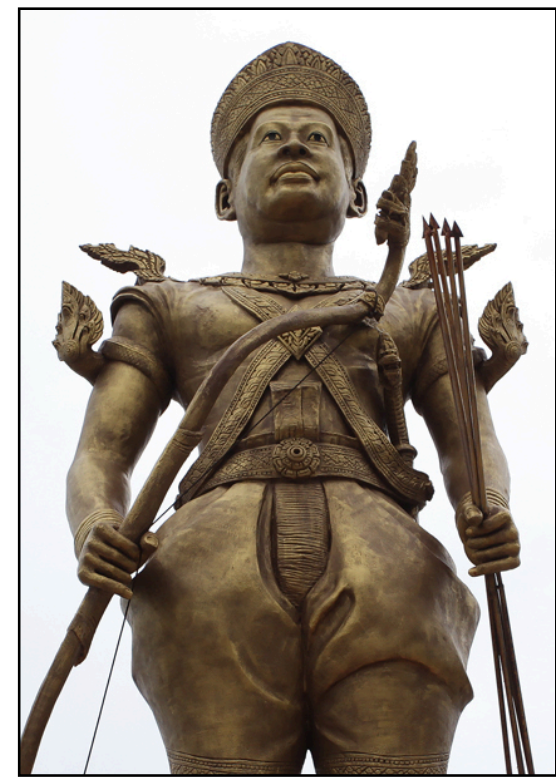

Abb. 23: (C) Eng. Statue von Sdech Khan im Erholungsort Kep, in dem die Königsfamilie früher mehrere Privathäuser besaß.

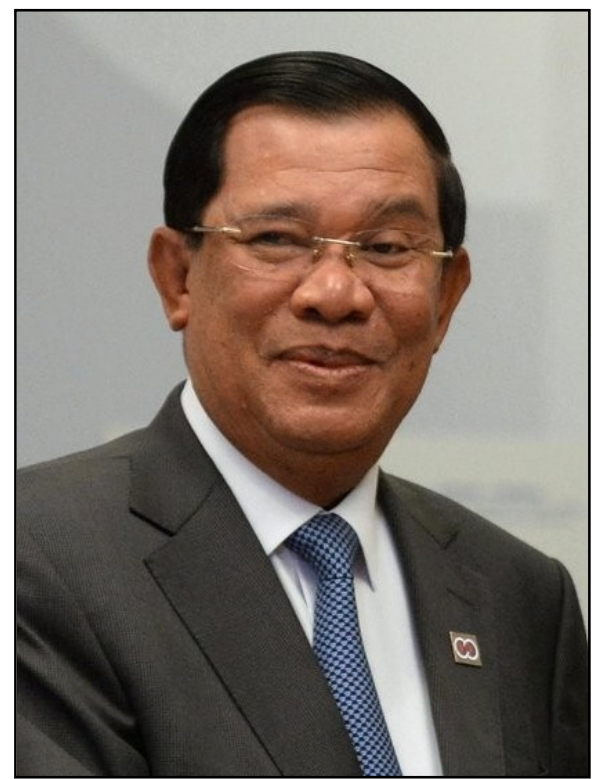

Abb. 24: () CС BY 4.0, Пресс-служба Президента Poсcuи. Foto des Premierministers Hun Sen bei einem Besuch in Hanoi (2016).

Alle anak dham, Hun Sen eingeschlossen, die Sdech Khan in den letzten Jahren ausgiebig für seine Taten preisten und ihm darin große Macht in der Öffentlichkeit zuschrieben, taten dies somit in indirekter Wertschätzung für den Premiermi- 
nister, dem dieses Ansehen als reinkarnierter Khan zugeschrieben wurde. Somit nutzt Hun Sen, der spirituellen Zeichen öffentlich Bedeutung zumisst (vgl. Neou 2013; Kuch und Woods 2012), die Biographie des einzig nicht-royalen Herrschers in Kambodschas Geschichte, um sich selbst als gerechter und mit buddhistischen Idealen kongruenter Führer des Landes zu positionieren. Und die Verehrung Sdech Khans geht weiter: der Großindustrielle Ly Yong Phat produzierte 2016 den bisher teuersten kambodschanischen Film, der Sdech Khans Leben im Stile eines Actionfilms nacherzählt.

\subsubsection{Die spirituelle Positionierung von Sam Rainsy}

Sam Rainsy war während des Wahlkampfes 2013 Oppositionsführer der Partei zur Rettung der kambodschanischen Nation (PRKN). Als Politiker der royalistischen Partei hatte er seit Ende der 1990er Jahre guten Kontakt zum unreformierten Dhammayut-Orden gehalten, dem die Königsfamilie angehört und bei dem er selbst 1996 für drei Wochen als Mönch gelebt hatte (Harris 2005: 219). Schon aus dieser Zeit als Minister der Regierung hatte Sam Rainsy den Hauptschrein von anak tā Kleang Moeung in Pursat besucht (Moeun 1998). Nach seiner Rückkehr in das Land 2013 besuchte er den Geist dort einige Male. In einem privaten Video im Internet bittet Sam Rainsy den anak tā um Unterstützung für seine Partei im Wahlkampf. ${ }^{177}$

Im Allgemeinen vermied Sam Rainsy eine spirituelle Positionierung jedoch. Stattdessen betonte er im Wahlkampf seine hohe Bildung und seine Tätigkeit als Investmentmanager und Gründer einer Buchhaltungsfirma in Frankreich. In seinen Reden trat er für einen ,technischen' und ,rationalen' Umgang mit der Politik ein, womit er sich unmissverständlich von Hun Sens öffentlichen Aussagen über spirituelle Zeichen, Wunder und Geister abgrenzte.

Nach seiner Flucht ins französische Exil im Jahre 2015 war Rainsy als Oppositionsführer größtenteils auf das Internet angewiesen, um den Kontakt zur kambodschanischen Wählerschaft zu erhalten. Kurz nach seiner Exilierung schrieb er auf seinem facebook-Profil über anak tā Kleang Moeung. ${ }^{178}$ In seinem in Khmer geschriebenen Beitrag fasst er die Geschichte des Generals nach der Erzählung in Leclère (1914) zusammen (siehe oben) und bezeichnet ihn als Gefolgsmann von Ang Chan I., dem Nachfolger (und Mörder) Sdech Khans. Sam Rainsy legt im Gegensatz zu Hun Sen großen Wert auf das Ende der Biographie, die mit der Exekution Sdech Khans im Jahre 1525 endet, da Khan das Land angeblich „Siam überlassen wollte“. Unter dem Text der Nacherzählung fügt der Politiker eine englische Notiz an:

\footnotetext{
177 https://youtu.be/iTwYt9963bs, Video vom 22.07.2013, letzter Zugriff: 04.02.2020.

${ }^{178}$ Der Beitrag ist online zu finden unter:

https://www.facebook.com/rainsy.sam.5/posts/1008203205903079, letzter Zugriff: 03.02.2020.
} 
"Oknha Kbleang Moeung is a Khmer national hero who, in the first quarter of the 16th century, sacrificed bis life to belp eliminate a usurper, thus allowing the legitimate beir to accede to the throne under the name of Ang Chan Reachea. The latter subsequently liberated several Cambodian provinces from the Siamese".

Die Parallelen zu Hun Sens Narrativ der Sdech Khan-Wiedergeburt sind offensichtlich: Sam Rainsy bekennt sich zu dem anak tā, der einen „Thronräuber“ stürzte, um damit erneut einen König zum „rechtmäßigen Herrscher“ zu krönen. Anschließend hätte der neue Herrscher verschiedene Provinzen von den Siamesen „befreit“. So stellte Sam Rainsy einen deutlichen Bezug zwischen seiner Person und dem von ihm verehrten Geist lok tā Kleang Moeung her, wie nun deutlich wird.

Ich interpretiere die wiederholte Positionierung Sam Rainsys zu diesem anak tā als eine Handlung mit vielschichtiger, strategischer Bedeutung: Zum einen ist lok $t \bar{a}$ Kleang Moeung einer der populärsten anak tā in Kambodscha. Er stellt für kambodschanische Auswander_innen (die in ihrer Mehrzahl der Opposition nahestehen (Strangio 2014: 95)) und für kambodschanische Einwohner_innen eine Persönlichkeit von nationaler, identitätsstiftender Bedeutung dar (Yamada 2004). Wie oben deutlich wurde, verkörpert er zudem einen Verteidiger des nationalen Territoriums und gilt als ein Schutzpatron der Soldaten, die als regimetreu gelten. Zum anderen gilt er als Widersacher von Sdech Khan, Hun Sen meidet den Bezug auf diesen anak tā und soll den Schrein von Kleang Moeung (im Gegensatz zu vielen anderen Geisterorten) noch nie betreten haben (Guillou 2017c n10).

Außerdem konnte Sam Rainsy mit der Erwähnung der „Befreiung der kambodschanischen Provinzen von den Siamesen" einen der wichtigsten Punkte vom Wahlprogramm der PRKN in diesem Beitrag unterbringen: die Ausweisung ,illegaler ${ }^{6}$ Migrant_innen (vor allem aus Vietnam), denen Hun Sen seinen Anschuldigungen nach auch das Land überlassen wollte, womit Sam Rainsys PRKN während ihres Wahlkampfes offen rassistische Ressentiments schürte.

Durch seine rationale Positionierung und die langen Auslandsaufenthalte lief Sam Rainsy zudem Gefahr, Wähler_innen in bevölkerungsreichen ruralen Gebieten durch mangelnde Bezüge auf wichtige lokale Referenzen (wie anak tā) zu verlieren; seine Partei errang die meisten Wählerstimmen in den Städten (Graham 2013). Mit der Bezugnahme auf anak tā Kleang Moeung stellte er sich als Anhänger des kambodschanischen Buddhismus in seiner hybriden Form dar, in der die Verehrung von Ortsgeistern und von ,nationalen Helden' einen wichtigen Platz einnimmt. Seine Ehrerbietung von anak tā Kleang Moeung sollte ihn trotz geographischer Entfernung und Bildungsklassen-Unterschieden zu den meisten Kambodschaner_innen als einen ,echten' Kambodschaner darstellen.

Somit bediente Sam Rainsy sich durch seinen Bezug auf lok tā Kleang Moeung in ähnlicher Weise spiritueller Narrationen wie Hun Sen es mit dem Sdech KhanNarrativ getan hatte. Im alltäglichen Diskurs waren die Beziehungen zwischen Geistern und anak dham allgemein ein beliebtes Gesprächsthema und auch in 
populären TV-Shows wurden oftmals Streits zwischen anak tā und Machthabenden gezeigt, was ein Indikator für die Bedeutung der spirituellen Legitimation politischer Macht für kambodschanische Herrscher und ihre Wählerschaft ist.

Diesem Argument folgend werde ich im folgenden Abschnitt (Kap. 5.5) den Blick von den Herrschenden auf einige der Leidtragenden der autokratischen Führung unter Hun Sen lenken. Die spirituelle Legimitation der Macht von Mitgliedern der Elite inspirierte auch ihre Kritiker_innen. Ihre Form des Protestes sah die Nutzung von schwarzer Magie zur Schwächung der politischen Hegemonie vor. Anhand verschiedener Perspektiven auf diese Rituale beschreibe ich die Hintergründe und die wahrgenommene Effektivität dieser magischen Praktiken.

\subsection{Das subversive Potential der Medialität}

Nach allgemeiner Auffassung wird ạ̣boe oder schwarze Magie von grū dhmáp (gesprochen: ,thmup) ausgeführt. Diese Rituale waren von einem intimen Charakter und der Verschwiegenheit ihrer Teilnehmenden geprägt und darauf ausgelegt, anderen Personen massiven Schaden zuzufügen (Davis 2015a: 198).

Die typischen Erzählungen in Zusammenhang mit amboe thematisieren Personen, die innerhalb einer Gemeinschaft als dhmáp gelten: wie man sie erkennt, wofür sie angeblich verantwortlich seien und wie man sie loswerden kann. Andere religiöse Akteure legen großen Wert auf eine Distanzierung von derartigen Fremdbeschreibungen, denn vermeintlich, identifizierte' Praktizierende schwarzer Magie werden schnell für Unglücksfalle verantwortlich gemacht, was gefährliche Folgen für die Beschuldigten haben kann: sie werden oftmals gewaltsam verjagt oder sogar getötet (Hruby 2014; Hay Pisey 2014a, 2014b; Ovesen und Trankell 2010: 164).

Doch auch diese amboe-Praxis wandelt sich. Ich traf Geistmedien, die Tötungen Anderer oder schädigende Fremd-Besessenheiten von bösartigen Geistern wie pisāca offen zu ihren Tätigkeiten zählten - immer in sorgsamer Vermeidung der vorbelastenden Begriffe dhmáp oder aṃboe. Die grū rechtfertigten ihre Praxis mit dem strafenden Charakter ihrer Geister, die einem solchen Anliegen nur im Falle tiefgreifender moralischer Schuld Folge leisten würden - somit seien alle wirksamen Angriffe gleichzeitig gerechtfertigt.

Die Form der ,moralisierten' amboe-Praxis wird seit Ende der 2000er Jahre auch in der Öffentlichkeit praktiziert, was einen grundlegenden Wandel der bisher von ihrer Privatheit geprägten Rituale ausmacht. Die Anliegen dieser öffentlichen Rituale hängen meist mit Protesten gegen Landvertreibungen zusammen, die eine wachsende Bedrohung für die kambodschanische Bevölkerung darstellen. 


\subsubsection{Vertriebene Menschen - vertriebene Geister}

Eine Wurzel des Problems der Landvertreibungen liegt in den unklaren Eigentumsverhältnissen seit der Zeit der Roten Khmer. Im Jahr 1975 wurde jeglicher Privatbesitz aufgehoben und eine forcierte Binnenmigration setzte ein: Stadtbewohner_innen wurden auf die ländlichen Kolchosen gebracht, das höhergestellte, ,alte Volk' der landwirtschaftlich Arbeitenden wurde machtstrategisch verteilt.

Nach der vietnamesischen Invasion 1979 wurde das verstaatlichte Ackerland ohne formalen Aufwand verteilt und bewirtschaftet. Im Jahr 1989 widmete Hun Sen sämtliches nicht-wirtschaftlich genutztes Land wiederum in Staatseigentum um und enteignete damit circa 360000 ins Exil geflüchtete Kambodschaner_innen (Levy und Scott-Clark 2008). Nachdem kurz darauf die vietnamesischen Truppen aus Kambodscha abzogen, verkaufte Hun Sen das Land unter seinen nationalen und internationalen Geschäftspartner_innen weiter, um einen Staatsbankrott zu verhindern. Zudem stärkte die Regierung durch die kostengünstige Veräußerung des Landes ihre geschäftlichen Beziehungen zu großen Handelspartnern. Bis 2008 wurden 45\% der staatlichen Landmasse an private Investoren verkauft (Levy und Scott-Clark 2008). Damit waren 12\% (circa $21000 \mathrm{~km}^{2}$ ) der Gesamtfläche Kambodschas als ökonomische Landkonzession an private Unternehmen verpachtet, die im Gegensatz zu Regelungen in Vietnam oder Thailand gänzlich aus dem Ausland kommen dürfen. ${ }^{179}$ Die Landverpachtungen, die über mindestens 99 Jahre angelegt sind, forcieren zuerst den Abbau der natürlichen Ressourcen vor Ort (was in den meisten Fällen eine massive Abholzung beinhaltet) und anschließend den monokulturellen Ackerbau oder den Bau von Bergminen. Die Bewohner_innen dieser Gebiete werden enteignet und gewaltsam (mit Hilfe des nationalen Militärs und der Polizei) vertrieben - zwischen 2003 und 2008 etwa 250000 Menschen (LICADHO 2009). Der zivile Protest dagegen beschränkte sich lange auf ein lokales Niveau und erreichte erst 2011 nationales Ausmaß, als die Weltbank kurzzeitig jegliche Unterstützung für Kambodscha stoppte, um gerechte Lösungen für die von Vertreibung bedrohten Protestierende des Boeung Kak-Geländes in Phnom Penh zu erzwingen. Kurze Zeit später erhöhten die Tötungen des prominenten Umweltaktivisten Chut Wutty und die eines 14jährigen Mädchens in der Provinz Kratie den Druck auf die Regierung (Diepart und Schoenberger 2017: 165).

Die Landvertreibungen betreffen neben den dort lebenden Menschen auch die anak tā, die als Beschützer und Verwalter des Landes gelten (Beban und Work 2014). Mit ihrer Rolle als Verwaltungsinstanz über Territorien nehmen Geister bei Landvertreibungen immer bedeutendere Rollen ein. Während meiner Forschung wurde mir zwar berichtet, dass die Geister die verpachteten Wälder verlassen hät-

\footnotetext{
${ }^{179}$ Eine ständig aktualisierte Karte mit den ökonomischen Landverpachtungen (economic land concessions (ELC)) liefert die Nicht-Regierungsorganisation LICADHO unter: http://www.licadho-cambodia.org/land_concessions/, letzter Abruf am 04.02.2020.
} 
ten, nachdem alle großen Bäume eines Gebietes gerodet waren. In den nun beschriebenen Protestritualen gegen die Landvertreibungen sollten die anak tā jedoch an- und zurückgerufen werden, da sie als ebenso unzufrieden mit ihrer Vertreibung aus den verpachteten Gebieten gelten wie die Menschen. Mit ihren Ritualen versuchen die Protestierenden, die anak tā auf einer moralischen Ebene auf die Ungerechtigkeit der Vertreibung und der massiven Ausbeutung von Rohstoffen in den Gebieten der ehemals landwirtschaftlich genutzten Flächen hinzuweisen und sie zum Handeln zu bringen. ${ }^{180}$

\subsubsection{Rituale schwarzer Magie}

Meinen Befragungen nach unterscheiden sich das Setting und der Ablauf der schädigenden amboe-Rituale sich nicht sonderlich von anderen, wohlwollenden Geistmedien-Praktiken mit anak tā. Vorher werden die üblichen Bedingungen zu Kontaktaufnahme der Geister geschaffen: ein pāy sī wird errichtet, Opfergaben werden davor platziert, ein ācaryā oder Geistmedium leitet die Rituale; die Geister werden per Mantra oder Meditation eingeladen.

Im Unterschied zu Zeremonien wie loeng anak tā sind Rituale schwarzer Magie von der Abwesenheit der Mönche und der kürzeren Dauer der Zeremonie geprägt. Die Orte der Rituale weisen zudem keine eigene pāramī auf; stattdessen stehen sie in Verbindung mit den Zielpersonen des spirituellen Angriffs, wie beispielsweise Gerichtshäuser oder staatliche Institutionen. Teilweise werden die Rituale neben Baggern und Bulldozern abgehalten. Die Anliegen jedoch sind der eklatante Unterschied zu anderen Ritualen mit Geistern: während bei allen anderen Ritualen der Wunsch nach Heilung, Harmonie oder wirtschaftlichem Erfolg im Mittelpunkt stehen, sind die öffentlichen amboe-Rituale von dem ausdrücklichen Wunsch der Schädigung der jeweiligen Zielpersonen geprägt. Dabei wird jede Vorsicht zur Wahrung des ,Gesichts` Anderer in der Öffentlichkeit abgelegt, so dass die Beschimpfungen sehr expliziten Charakter annehmen können. Trotzdem muss, wie schon angedeutet, die Intention der Ritualteilnehmer_innen in moralisch geprägte Diskurse von Gerechtigkeit eingebettet werden. Den anak tā wird der Fall erläutert, und es wird versucht, sie von dem Anliegen zu überzeugen, zum Beispiel dass sich Firmenbesitzer_innen oder Staatsangestellte unrechtmäßig Land zu Eigen gemacht hätten. Im Anschluss an ihre Schilderung der Situation bitten die Protestierenden um eine „gerechte Strafe“, deren Ausgestaltung sie unterschiedlich konkret verbalisieren.

180 Work und Beban (2014) berichten von einem Fall, bei dem durch die Geistbesessenheit einer Anwohnerin und die Mobilisation von Protesten durch einen charismatischen Mönch eine fünf Hektar große Fläche der landesweit größten ökonomischen Landkonzession (von 315000 Hektar Gesamtfläche) an eine Pagode zurückerstattet wurde. Allerdings schließen die Autorinnen daraus, dass die Rekonstitution der Fläche zur lokalen Akzeptanz der Konzession beigetragen hat, da sich die Regierung als Vermittlerin zwischen Bedürfnissen des Pächters und der Anwohner_innen einschalten konnte (2014: 606). 


\section{Ländlicher Protest}

Ein üblicher Ablauf eines ländlichen Enteignungsprozesses und eines Protestes dagegen gestaltet sich wie folgt: Sämtliche Papiere, die das Eigentum von Land bestätigen, werden eines Tages überraschend von lokalen Behörden konfisziert (Mech 2013). Das Land wird anschließend zum Staatseigentum deklariert und an eine Firma verpachtet; die dort lebenden Menschen müssen das Gebiet innerhalb eines angegebenen Zeitraums verlassen. Offizielle Klagen gegen die Vertreibung finden kein Gehör. Daraufhin wenden sich die Vertriebenen an anak tā, die als Wächter über das Land richten. Während des Rituals wird der Geist gebeten, die Vertreter_innen der Firma und der lokalen Behörde „für ihre Taten bezahlen zu lassen“ (ebd.), in dem sie beispielweise Opfer eines Unfalls werden oder ihren Reichtum verlieren. Diese Form des a mboe-Rituals, die vor allem in den ländlichen Gebieten verbreitet ist, beinhaltet deutlich artikulierte Flüche, die im Tausch gegen Opfergaben von anak tā umgesetzt werden sollen. Dabei wird auch in Betracht gezogen, dass die Bestrafung nicht in diesem Leben, sondern in einem der nächsten erfolgen könnte. So werden ausbleibende Reaktionen auf amboe-Rituale erklärt.

Die Effizienz der Rituale soll dabei mit bestimmtern Opfergaben erhöht werden: vergammeltes Fleisch (meist vom Huhn), Chili und Salz werden verwendet, zusätzlich trinken grū bei aṃboe-Ritualen zuweilen Spirituosen. Diese Indikatoren weisen die Rituale als bedrohlich aus, da diese ,heiß ${ }^{`}$ konzipierten Opfergaben den Zorn der Geister erregen und der Alkohol als Indikator für Kontrollverlust auch bei anak tā wirken soll. Die Geister werden also bewusst provoziert. Von einem grū hörte ich zudem eine symbolische Interpretation dieser besonderen Opfergaben: die Zielpersonen der amboe-Rituale sollten einen gewaltsamen Tod im Feuer sterben, der ,heiß` wie die Chili sei. Das Salz würde sich „in Wasser lösen, wie der Mensch im Feuer“ und das vergammelte Fleisch sei demnach ein Symbol für den zerfallenen Körper der verfluchten Personen.

\section{Städtischer Protest}

Hier zeigen sich Unterschiede zu den zahlreichen städtischen ạ̣boe-Ritualen, die während der Proteste von Vertriebenen aus Boeung Kak, Russei Keo oder anderen verpachteten Gebieten im Großraum Phnom Penh gemacht wurden. Während ihrer Demonstrationen durch Phnom Penh, die meist vor dem nationalen Gerichtshof oder dem Justizministerium endeten, wurden beispielweise menschengroße Puppen mit falschen US-Dollar-Geldscheinen beworfen und an Halsschlingen über die Straße gezogen, bevor sie gegen Ende der Demonstration verbrannt wurden. Bei anderen Demonstrationen wurde Reis, Salz, Chili und (altes) Hühnerfleisch in einer kurzen, auf der Straße abgehaltenen aṃboe-Zeremonie für anak tā geopfert, um die Opfergaben dann auf das Gebäude der verantwortlichen Offiziellen zu werfen. Die Rituale im Rahmen städtischen Protests folgten keinerlei ritueller Struktur. Tep Vanny, eine der leitenden Führerinnen der Protestbewe- 
gung von Boeung Kak, sagte dazu: "We have many ways to curse them (...) We're not going to keep doing the same thing. If we do, the public won't pay attention to us" (Jackson und Mao 2015).

Die Schaffung von öffentlichkeitswirksamen Bildern ist jedoch nicht der einzige Zweck der amboe-Praxis. Die folgende Analyse fragt nach dem subversiven Potential dieser Geister-Praxis aus Sicht der Teilnehmenden der Rituale, der breiten Öffentlichkeit Kambodschas und der Zielpersonen der Flüche.

\subsubsection{Perspektiven auf schwarze Magie}

\section{Die Perspektive der Ritualteilnehmer_innen}

Die Ritualteilnehmer_innen wie Tep Vanny sind selbst von der spirituellen Effektivität der Rituale überzeugt:

'When we do Buddhist rituals, we don't curse, we only sit still and do meditation, we wish in peaceful way. (...) But when we follow the Brahmanist way, we curse them and do different kinds of activity (...). We do it when we are angry with them instead of doing physical violence" (Jackson und Mao 2015).

Wie von Tep Vanny bestätigt, sehen die Protestierenden in der religiösen Praxis eine Alternative zu direkter physischer Gewalt. Auffällig ist die vehemente Betonung der rituellen Effektivität. Eine Teilnehmerin einer amboe-Zeremonie in der Provinz Banteay Meanchey erklärte: "One person who stole our land died in a traffic accident last year after we made a similar curse" (Chrann 2009). Laut der Aktivistin Um Sophy sind seit dem ersten amboe-Protest der Boeung KakAktivist_innen bereits drei Offizielle aufgrund ihrer Flüche gestorben (Jackson und Mao 2015). Als Alternative zu direkter Gewalt sind solche Praktiken somit eine rationale Wahl: bei erwünschtem Ausgang des Rituals (zum Beispiel eines tödlichen Verkehrsunfalls eines Verantwortlichen) entgehen die Protestierenden einer juristischen Bestrafung. Zudem gelten die Auswirkungen der Rituale allgemein als gerechtfertigt, da anak tā nicht selbst unmoralisch agieren würden.

Nicht zuletzt ist auch die öffentlichkeitswirksame Durchführung der Rituale ein Faktor der Effektivität, da die Protestierenden mit dem Verbrennen von Puppen, Dollarscheinen, dem Werfen von Reis, Chili und Salz, und dem Opfern von Tieren passende Motive für die Pressefotografen lieferten, die in internationalen und nationalen Massenmedien häufig reproduziert werden. Die dabei öffentlich gezeigten Emotionen der Wut und der Verzweiflung gelten jedoch als gravierender Verstoß gegen die gesellschaftlichen Umgangsformen und erzeugten bei der unbeteiligten Restbevölkerung Scham und Mitleid, wobei diese dennoch spirituell argumentiert. 


\section{Die Perspektive der allgemeinen Öffentlichkeit}

Die Mitglieder der ,allgemeinen Öffentlichkeit', deren Perspektive ich aus zahlreichen informellen Gesprächen mit Kambodschaner_innen ableite, interpretiert die öffentlichen amboe-Rituale als Handlungen, die aus Mangel an Alternativen und aus Gründen der Verzweiflung durchgeführt werden. Zu dieser Interpretation der Praxis gibt es zwei unterschiedliche Vorstellungen von Effektivität:

In der ersten Interpretation wird die Wirkmacht der oben beschriebenen Rituale als sehr limitiert bewertet. Mitleid wird für die Protestierenden ausgedrückt, da sich die Opfer der Landvertreibung nun un-buddhistischen, amoralischen und damit gefährlichen Praktiken hingeben müssten. Zudem seien Angriffe gegen anak dham ohnehin zwecklos: Sie seien durch die spirituellen Angriffe der Protestierenden keiner besonderen Gefahr ausgesetzt, da sie durch die Auswirkungen der Karma-Wechselwirkung durch ihre eigene pāramī (und die pāramī ihrer grū) geschützt würden. Durch ihren Reichtum seien sie zu großen verdienstgenerierenden Opfergaben imstande und könnten ihre Position so anhaltend spirituell legitimieren. Die einzige Einschränkung bilde ein besonders großer moralischer Verstoß (beispielweise ein Mord), bei dem selbst anak dham von Geistern bestraft werden würden. Den oben beschriebenen Versuch der Demonstrant_innen, die Landvertreibung als ein solch gravierendes Vergehen zu definieren, teilten allerdings nur die wenigsten Kambodschaner_innen.

Die zweite Interpretation der Effektivität von amboe wurde von einigen grū formuliert, mit denen ich über die Rituale der Protestierenden sprach. Auch sie interpretierten die rezent durchgeführten Rituale als ,letzten Ausweg ${ }^{c}$ für die Vertriebenen, doch im Gegensatz zu der oben dargestellten Meinung ging diese Interpretation von einer sehr hohen Wirkmacht der Rituale aus. Amboe war demnach die stärkste Waffe des Widerstands, die erst benützt werden dürfte, wenn sämtliche Mittel des zivilen Protests keine Wirkung gezeigt hätten. Es wurde betont, wie gefährlich die Praktiken seien und wie leicht die Strafen auf die Ritualteilnehmer_innen zurückfallen könnten, wenn sie Fehler begingen. Zudem wurde die große Macht der Geistmedien der anak dham betont, die diese Angriffe leicht abwehren könnten. Dies würde man schon am mangelnden Erfolg der Protestierenden erkennen: zum einen besäßen sie keinerlei magisch aufgeladene Gegenstän$\mathrm{de}^{181}$ und würden weniger Opfergaben als wohlhabende Menschen darreichen. Zum anderen würden Geister, langfristiger ${ }^{`}$ denken und nicht nur eine schlechte Tat bestrafen, sondern die Entscheidung gut abwägen, indem sie andere Ahnen befragten und sich auch die früheren Leben der betroffenen Personen anschauten. Demnach wurde auch hier die Karma-Wechselwirkung angesprochen, nach deren Prinzip die höher gestellten anak dham eine ,bessere Ausgangslage‘ haben.

181 Gerüchten zufolge soll Hun Sen Eigentümer des mächtigen Schwerts Preah Khan sein, das schon Jayavarman II gehört haben soll und mit eigener magischer Macht ausgestattet sei. Damit wurde nicht selten Hun Sens lange Regierungszeit begründet. 


\section{Die Perspektive der Zielpersonen}

Die Perspektive der Zielpersonen auf aṃboe-Rituale leite ich aus seltenen, öffentlichen Kommentaren derselben ab. Jackson und Mao (2015) fragten beispielsweise den damaligen Stadtverwalter von Phnom Penh, Long Dimanche, ob er an die (zum Teil an ihn gerichteten) Flüche glauben würde. Er antwortete:

"This question is like a joke (...) They can do whatever they want - it's their rightbut make sure that they're not going to harm anyone physically" (ebd.).

Diese gleichgültig-anmutende Art mit den Flüchen umzugehen, spricht für die oben beschriebene Argumentation der spirituellen Überlegenheit von anak dham gegenüber niedriger gestellten Personen der Gesellschaft. Da die Mehrheit der Protestierenden Frauen sind, die wenig Geld besitzen und einen geringen sozialen Status innehaben, schätzen die anak dham sowie die Mehrheit der kambodschanischen Bevölkerung das magische Potential ihrer amboe-Rituale als gering ein. Die anak dham gelten als Spender_innen und Mäzen_innen für Geistmedien und Pagoden als umfassend geschützt. Die Protestierenden dagegen können die buddhistische Praxis nicht für ihre Zwecke nutzen: Aufgrund der Verstrickungen zwischen den ranghöchsten Mönchen und der Regierungspartei Kambodschas mussten Mönche mit einer Verhaftung und dem Verlust ihres Mönchsstatus rechnen, wenn sie Protestierende unterstützten oder segneten (Khy 2015; May 2014).

Die Unterschiede des sozialen Status haben somit weitreichende Folgen und prägen die Vorstellungen von Moral und Gerechtigkeit zu hohem Grad. Trotz der stetigen Bemühungen, diese Deutungshoheit der determinierten Zukunft durch die Vergangenheit (der früheren Leben) oder magische Praktiken umzudeuten, werden die Rituale der Protestierenden von der überwältigen Mehrheit der anderen Akteursgruppen als wirkungslos interpretiert und finden somit wenig Gehör im politischen Feld Kambodschas.

\subsection{Die Geister der Macht}

Die Inszenierung von Geistern in Kambodschas politischem Feld findet in mannigfaltigen Ausprägungen statt, wie ich in diesem Kapitel an verschiedenen Schauplätzen wie dem Preah Vihear-Konflikt, dem Wahlkampf, dem Landvertreibungsdiskurs und der spirituellen Positionierung der Herrschenden zum Zwecke der nationalen Identitätsbildung, des Protestes oder des kompetitiven Wettstreits veranschaulicht habe. Ich habe in diesem Kapitel die weitreichende Rolle der Mäzene der patronage-Netzwerke hervorgehoben. Sie fördern die Praxis mit materiellen und idealen Ressourcen zur Bearbeitung ihrer eigenen Anliegen und demonstrieren einerseits die Legitimation der Praxis, während sie andererseits zahlreiche Akteure der Spiritscapes mobilisieren und so die Existenz der Geister stärken. Zudem wurde deutlich, dass politisch motivierte Rituale auf die Akkumulation von 
Macht ausgerichtet sind, was sowohl in öffentlichen als auch in privaten Kontexten deutlich wurde. Die involvierten Akteure des politischen Felds prägen die sich ständig im Wandel befindende brahmanistische Praxis somit zu einem wesentlichen Anteil mit und stabilisieren die Existenzweise der kambodschanischen Geister mit großer Wirksamkeit. 



\section{Schlussbetrachtung}

\subsection{Geister als ergiebiger Untersuchungsgegenstand ethnologischer Forschung}

Geister von Verstorbenen oder Ortsgeister, die mal als Subjekt und mal als fluide Macht verstanden werden, sowie Menschen, die von Geistern besessen werden, sind herausfordernde Themen für ein wissenschaftliches Dissertationsprojekt. Grundsätzliche Fragen drängen sich auf: Inwiefern sind Geister relevant genug für eine ethnologische Forschung? Gibt es Geister überhaupt? Meine Studie hat gezeigt: Ja! Für die überwiegende Mehrheit der Menschen in Kambodscha gibt es Geister und sie nehmen machtvolle Rollen in individuellen, sozialen, und politischen Prozessen der kambodschanischen Gesellschaft ein. Neben der Beschreibung dieser Positionen habe ich in dieser Arbeit analysiert, welche Bedingungen an eine überzeugend wirkende Existenz von Geistern gestellt werden und wie ihnen Existenz und Macht zugeschrieben wird. Geister können demnach als Akteure in Erscheinung treten: sie treten in produktive Tauschbeziehungen mit Menschen ein, sie beantworten Fragen, sie heilen Kranke und sprechen Segen aus, die Personen, Objekte oder Orte ermächtigen und Ereignisse auslösen können.

Meine Studie wendet sich einem wenig beachteten Teil kambodschanischer Religiosität zu, der durch die spezielle Geschichte des Landes zusätzliche Relevanz erhält. Nach der beinahe vollständigen Auslöschung des Buddhismus als religiöse 
Institution im Jahre 1979 und den nachfolgenden Jahrzehnten der staatlichen Restriktionen gegenüber der institutionalisierten Religion beschreibe ich das Austarieren eines florierenden religiösen Feldes. Neben der Revitalisierung des Buddhismus als Institution und Alltagspraxis gewinnt der Brahmanismus als Ressource von spiritueller Macht, alternativer Heilung, erfolgversprechendem Segen und als Potential gesellschaftlicher Veränderung an Bedeutung. Hauptakteure dieses brahmanistischen Feldes sind die Geistmedien, ihre Geister und die menschlichen Klient_innen, die in wachsender Anzahl auf die Geistmedien zugehen und der brahmanistischen Religionspraxis Legitimität verleihen. Ich zeige in dieser Arbeit, inwiefern dem Brahmanismus zugeordneten Geistern eine herausragende Rolle in der kambodschanischen Gesellschaft zufällt. Ich habe zwei Gründe für diese Entwicklung bestimmen können.

Erstens ist die spannungsarme Gleichzeitigkeit und Ko-Existenz der brahmanistischen Geisterpraxis neben der Staatsreligion des Buddhismus bemerkenswert. Laut Statistiken folgen 97\% der Kambodschaner_innen dem Buddhismus, bei genauerer Betrachtung offenbart sich allerdings eine große Heterogenität in der Religionsausübung, da buddhistische und brahmanistische Rituale als inhärente Bestandteile des kambodschanischen Buddhismus verstanden werden und somit mit- und nebeneinander praktiziert werden. Unterschieden werden muss hier der samăya-ausgerichtete Buddhismus, der im Sinne einer Orthodoxisierung reformiert werden soll, von der mehrheitlich verfolgten purāna-Ausrichtung, wonach brahmanistische Rituale einen selbstverständlichen Teil religiöser Praxis ausmachen. Diese Mehrheit sieht in der Kontaktaufnahme zu Geistern oder der Benutzung magisch-aufgeladener Objekte keinen Widerspruch zum Buddhismus, sondern ein Potential, ihre Zukunft zu verbessern und Schwierigkeiten zu bewältigen. Dabei lassen sich Personen selten nur ausschließlich einer der beiden Religionsauslegungen zuordnen: stattdessen überlegen sich die Klient_innen der Geistmedien sehr genau, inwiefern sie ihre samăya- oder purāna-Denkweisen mit dem großen Angebot der Medialität in Einklang bringen können (vgl. Beispiel von Sothy, Kap. 7).

Nach ihrer Initiation positionieren sich die Medien als moralische Akteure, die dem Buddhismus nahestehen, während der ausschlaggebende Grund für den Besuch ihrer Klient_innen paradoxer Weise die vom Buddhismus abweichende, brahmanistische Praxis darstellt (Kap. 2.4). Diese Unterschiede in der angenommenen Wirkung der beiden religiösen Systeme lassen die Praktiken mit Geistern wie anak tā für bestimmte Anliegen so geeignet erscheinen (Kap. 5.2). Die ,zähmende Kraft' eines ,orthodoxen' Buddhismus soll dabei eine moralische Ambiguität brahmanistischer Rituale ausgleichen bzw. abschwächen, wie ich am Beispiel der Geister des Waldes zeigen konnte (Kap. 5.1). Ich folge Davis These, der behauptet, der „Buddhismus schaffe den Brahmanismus“ (Davis 2015a: 215-248). In Kapitel 4 konnte ich am Beispiel der khmoc zeigen, wie die unbestrittene Dominanz über die, wilden Mächte` die buddhistischen Akteure dazu verleitet, den 
brahmanistischen ,Gegenpol‘ zu erhöhen, um sich selbst mächtiger darzustellen. Gleichzeitig, und damit ergänze ich Davis These insofern, dass auch der Brahmanismus den Buddhismus fördert, legitimieren sie damit die brahmanistischen Geister und generell den Brahmanismus. Dieser entwickelt sich nun lokal, wie ich am Beispiel von grū Ly gezeigt habe (Kap. 2.4, 7.3, 8.3), zu einer eigenständigen Bewegung, die sich deutlich vom Buddhismus abgrenzt. Der Brahmanismus wird dabei auf mehreren Handlungsebenen in Anspruch genommen, so zum Beispiel auf individueller Ebene, im Bereich der psychischen Gesundheit (Kap. 7) oder in der Aushandlung von sozialen Hierarchien (Kap. 2). Auch auf kollektiver Ebene stellt der Brahmanismus eine religiöse Ressource dar, wie im Umgang mit der konfliktreichen Vergangenheit des Landes (Kap. 4) und auf machtpolitischer Ebene in der Inszenierung von Geistern in Außen- und Innenpolitik, in Protesten oder im Wahlkampf deutlich wurde (Kap. 9).

Eine zweite Quelle der wachsenden Popularität brahmanistischer Praxis stellt die Liberalisierung der Marktwirtschaft dar. Vor allem für die junge Bevölkerung eröffnen sich in der gegenwärtigen Aufbruchsstimmung Perspektiven auf einen gesellschaftlichen Aufstieg durch wirtschaftlichen Erfolg, dem nicht zuletzt mit magischen Mitteln der Geisterpraxis nachgeholfen werden soll. Die Mehrzahl der an die Geistmedien herangetragenen Anliegen war von dem Wunsch nach Erfolg (geschäftlich, edukativ, privat, sozial) geprägt. Wie ich gezeigt habe, passt die schnelle und ökonomische Funktionsweise Wohlstands-orientierender, brahmanistischer Ritual-Praxis zu den Erwartungen der aufstrebenden Mittelschicht Kambodschas, was ich am leistungsoptimierten Ritual loeng anak tā veranschaulichte (Kap. 8). Diese Form der prosperity religion lässt sich treffend mit dem Kommentar von grū Ly beschreiben: „Wenn wir dem Buddhismus folgen, werden wir nie reich werden“" (Kap. 2.4). Sie ist weit verbreitet in der wachsenden Mittelund Oberschicht Kambodschas und weist damit Parallelen zu den südostasiatischen Nachbarn auf (Lauser 2018; Foxeus 2017; Scott 2017; Jackson 2016, 1999a; Sprenger 2014; Salemink 2008).

Ich legte meine Schwerpunkte in dieser Arbeit auf drei Themenbereiche. Die dynamischen Beziehungen zwischen der Menschenwelt und den Geisterwelten wurden mithilfe der Konzeptmetapher der Spiritscapes theoretisch gerahmt und zusammen gedacht. Mit den theoretischen Arbeitsinstrumenten der AkteurNetzwerk Theorie (ANT) wurden die Existenzbedingungen der kambodschanischen Geister bestimmt und mein Blick auf Beziehungen innerhalb der Spiritscapes verdichtet. Auf der Basis dieser Analysen fragte ich drittens nach der ,Authentizität ${ }^{6}$ und ,Effektivität ${ }^{6}$ der spirituellen Macht in Kambodscha und besonders deren Auswirkungen auf weltliche Macht(-aushandlungen). Meine diesbezüglichen Ergebnisse ermöglichen mit ihren neugeschaffenen Perspektiven weitere Forschung. 


\subsection{Spiritscapes}

Drei Faktoren der Konzeptmetapher Spiritscapes von Lauser und Endres (Lauser und Endres 2011) stellten sich für die Untersuchung meines kambodschanischen Falls als sinnvoll heraus: die Inkorporierung verschiedener Zeitlichkeiten, die Mobilität der Geister und der Austausch zwischen ihnen und den Menschen.

\subsubsection{Zeitlichkeiten}

Das Erscheinen oder ,Spuken'von Geistern gilt allgemein als diachronisches Zeichen, denn Geister von Verstorbenen sind Akteure der Vergangenheit. Ihre Präsenz (in der Gegenwart) stellt bereits eine Überlappung verschiedener Zeitebenen dar. Wie Eisenlohr (2015) stellte ich fest, dass sich die Verschränkung dieser Ebenen in Ritualen besonders prägnant zeigt. Für die Untersuchung von Spiritscapes nahm die Analyse der Zeitlichkeiten eine tragende Rolle ein, weil ich so entschlüsseln konnte, welche Bedeutungen die Vergegenwärtigung von Geistern transportiert. Zwei Zeitebenen standen dabei im Vordergrund: das idealisierte Zeitalter des (vorbuddhistischen) Brahmanismus und die totalitäre Zeit der Roten Khmer.

Die vorbuddhistische Zeit des hinduistischen Khmer-Reiches von Angkor gilt in Kambodscha als magische Epoche, die von militärischen Erfolgen und einer Vormachtstellung der Khmer auf dem südostasiatischen Festland geprägt war. Die heute in Geisterritualen herbeigerufenen anak tā stammen größtenteils aus dieser Zeit. Sie werden in der Absicht gerufen, die Macht dieser Zeit zu reaktivieren. Während der Rituale mit anak tā werden Bezüge zum brahmanistischen Zeitalter gemacht, wie am Beispiel der strategischen Referenzen in Ritualen der Politik oder rekonstruierten Reinkarnationslinien deutlich wurde (Kap. 9). Eine weitere Zeitebene wird mit der „Rote Khmer-Zeit“ auf nationaler und internationaler Ebene vergegenwärtigt. Die Referenzen auf die Opfer dieser Zeit sind jedoch aufgrund der religiösen Konzeption und einer fortgeschrittenen Buddhisierung der Totengeister schwach (Kap. 4). Stattdessen konnte ich verdeutlichen, dass die versöhnende Verarbeitung der tragischen Zeit mithilfe brahmanistischer Rituale schon sehr viel weiter vorangeschritten ist, als es die Aushandlungen des Erinnerns und Vergessens auf politischer Ebene suggerieren.

\subsubsection{Mobilität}

Da das Konzept Spiritscapes vom Begriff der Landschaft abgeleitet wurde, verweist es zunächst auf ein räumliches Konstrukt, das jedoch im Sinne Appadurais keinesfalls statisch zu begreifen ist. In Kapitel 3 habe ich gezeigt, dass Spiritscapes (wie andere -scapes) auf die Vielzahl von Akteuren innerhalb einer, Geisterlandschaft ${ }^{\star}$ verweisen, wobei ich vor allem ihre eingegangenen Beziehungen zu anderen Akteuren analysierte. Mit der Betrachtung der Landschaft und ihrer Akteure habe ich zum einen die lokale kosmologische Ordnung abgeleitet, die von ständigen ,Migrationsbewegungen' zwischen lebenden Menschen, Toten und Reinkarnierten 
bestimmt wird. Ehemals mächtige Menschen reinkarnieren als helfende Ortsgeister in der oberen Welt, die zu den Körpern der Geistmedien ,migrieren' können und somit durch die eigene Deterritorialisierung die schwierige Situation der Geistmedien entschlüsseln (Kap. 6). Zum anderen ändern Geister im Zuge ihrer Migration ihre Existenzweise: Menschen werden nach dem Tod zu Geistern, Totengeister werden als Menschen reinkarniert (Kap. 4) und anak tā nehmen in medialen Ritualen Menschengestalt an. Dabei trägt Kommunikation - über und mit Geistern - zum Wechsel des ontologischen Status bei (Sprenger 2017, 2016). Aber auch performative Aspekte während der Geistererscheinungen spielen eine Rolle, was ich anhand mehrerer Beispiele von medialen Ritualen herausstellen konnte.

\subsubsection{Austausch}

Ich erachte die mannigfaltigen Tauschbeziehungen zwischen den Geisterwelten (thān suok und thān norok) und der Lebenswelt der Menschen (thān manuss) als bedeutsam für die Konzeption der Spiritscapes. Die Analyse der Gaben und Gegengaben geben Aufschluss über die angenommene Wirkung und die Sinnhaftigkeit der Geister-Praxis, da materielle Opfergaben oftmals gegen immaterielle Gegengaben, wie spirituelle Macht, Heilung oder eine anziehende Ausstrahlung getauscht werden (Kap. 7-8). Aber auch materielle Güter, wie gesegnete Objekte, spielen für die Beziehung zwischen Geistern und Menschen eine zentrale Rolle, da die Gläubigen durch sie erst auf die aktive Unterstützung und damit auf die Existenz von Geistern zurückschließen. Am Beispiel meines eigenen finanziellen Engagements in Geister-Ritualen verdeutlichte ich die Notwendigkeit einer Gegengabe, die das Erscheinen des als westlich konzipierten Geistes tā Noël (Kap. 3.5) zur Folge hatte. Zudem konnte ich am Beispiel der erfolgreichen Medien (Kap. 9.2) zeigen, dass die Höhe der Gabe konvergent zur erwarteten Gegenleistung steht und großzügige Opfergaben somit - ebenso wie das Ausmaß des gesammelten Verdienstes in der buddhistischen Ritualpraxis - auf eine größere spirituelle ,Ermächtigung' schließen lassen. Analog dazu zeigte die Analyse des subversiven Potentials der Geisterpraxis die geringe Wirkmacht der Protestbewegung der mittellosen Landvertriebenen (Kap. 9.6). Grundlegend für den Tausch mit Geistern ist der durch Opfergaben ausgedrückte Wunsch der Klient_innen, die Macht der Geister zum Ausbau des eigenen Einflussbereichs zu nutzen und somit selbst handlungsfähiger und mächtiger zu werden.

Meine Nutzung des Spiritscapes-Konzeptes und die Ableitung der drei Analysekategorien bieten Anknüpfungspunkte für weitere Untersuchungen. Eine Erweiterung der Austausch-Kategorien um transnationale Netzwerke sowie ein Fokus auf die wirtschaftlichen Implikationen dieser Beziehungen stellen wichtige Forschungsdesiderate dar. Auch das Thema der Mobilität mit dem damit verbundenen Wechsel des ontologischen Status bietet fruchtbare Ansätze für weitere 
Forschung in Südostasien, wo die Beschreibung von Geister-Ontologien im Sinne eines „neuen Animismus“ kürzlich zur Diskussion gestellt wurde (Århem und Sprenger 2016).

\subsection{Existenzweisen}

In einem zweiten Schwerpunkt widmete ich mich der Analyse von GeisterExistenzen. Damit verfolgte ich das Ziel, dem emischen Verständnis ihrer Präsenz näher zu kommen und sie mit einer Analyse ihrer Beziehungen in ihrem Umfeld zu verorten. Mithilfe meiner ANT-inspirierten Methodik entwickelte ich ein Programm für die Umsetzung einer Machtanalyse (Kap. 3); ungeachtet dessen die ANT wegen ihrer Maxime der Symmetrie und Gleichberechtigung aller Akteure dafür zunächst ungeeignet scheinen mag. Mit meinem Vorgehen jedoch konnte ich die ANT fruchtbar auf nicht-westliche Gesellschaften anwenden und einen detaillierten Beitrag zur außereuropäischen Verwendung von Latours Werk leisten (vgl. Jensen und Blok 2013).

Mit Latours Denkansätzen prüfte ich die - auch im südostasiatischen Vergleich - außergewöhnlich stabile Existenzgrundlage kambodschanischer Geister. Zur Bestimmung ihrer konstituierenden Akteure zog ich Nutzen aus der Methode Latours, ohne den als, typisch' für ANT-Studien gewordenen Schwerpunkt auf Objekten Folge zu leisten (Guggenheim und Potthast 2012: 167). Stattdessen ordnete ich die einzelnen Akteure nach ihrer Bedeutung im Stabilisationsprozess des Geister-Netzwerks, womit sich mein späterer Fokus auf die menschlichen Geistmedien (Kap. 6-9) erklärt, denen mit ihrer Verkörperung der Geister ein konstituierender Beitrag zur Existenz und Präsenz der Geister zukommt.

Zur Beantwortung der Frage nach den Existenzbedingungen der kambodschanischen Geister beschrieb ich zunächst einen typischen Besuch bei Geistmedien, um damit die performativen Elemente einer Geistererscheinung zu verdeutlichen (Kap. 3.3), bevor ich die blackbox zweier Geister im Prozess ihres Entstehens öffnete und daran grundlegende Referenzen zur Existenz von Geistern veranschaulichte (Kap. 3.4). Nach diesen methodischen Exkursen, die die Existenz von Geistern in Kambodscha als stabil verifizierte, zwang sich eine weitere Differenzierung ihrer Erscheinungsformen auf. Denn auch wenn Geister unter ontologischen Gesichtspunkten als existent gelten, halten sie sich nicht immer in der Reichweite der Menschen oder Medien auf. In Kapitel 4 führte ich die epistemologische Unterscheidung von Präsenz (oder Anwesenheit) und Absenz (oder Abwesenheit) ein, um damit eine Verortung in der breitgefächerten Geisterlandschaft von ,oberer ${ }^{\varsigma}$ und ,unterer ${ }^{6}$ Welt vorzunehmen. Die hier beschriebenen Totengeister veranschaulichen diese Differenzierung beispielhaft, da buddhistische Nachtodkonzeptionen über das Verständnis früherer Totengeister dominieren, was ich am Beispiel eines äußerst aufwendigen hov braling-Rituals zum „Zurückrufen der Toten“"verdeutlichte. Die Analyse der Existenz- beziehungsweise ,Prä- 
senz-' und ,Absenzbedingungen' von Totengeistern beweist die Dominanz der buddhistischen Deutungsmacht, die auch den nationalen Erinnerungsdiskurs prägt.

Am Beispiel der ständig präsenten und von Medien verkörperten Ortsgeister anak tā leitete ich die grundlegendsten Bedingungen ihrer Geisterexistenz ab und beantwortete so unter Berücksichtigung der drei Bereiche (Zeitlichkeit, Mobilität, Austausch) der Spiritscapes und meiner Überlegungen zu Macht fünf Kriterien zur Stabilisierung von Geister-Netzwerken. Dazu gehören: materielle Repräsentationen (z.B. ein Schrein), definierte Zuständigkeiten (z.B. eine Region), biographische Referenzen in Form von Narrationen (wie lok tā Kleang Moeungs erfolgreiche Geisterbeschwörung gegen thailändische Truppen) und Verweise auf die pāramì eines Geistes (wie z.B. Nacherzählungen erfolgreicher Prognosen, Heilungen, etc.), während hierbei die Anzahl und die Stabilität der Referenzen von entscheidender Bedeutung ist. Als Knotenpunkte und Multiplikator_innen dieser konstituierenden Verweise agieren die menschlichen Geistmedien, die nach ihrer Initiation Kontrolle über An- und Abwesenheit ihrer Geister besitzen, was sie in ihrer gesellschaftlichen Rolle ermächtigt (Kap. 6). Als Medien stabilisieren sie ihre Referenzen zu pāramī und arbeiten aktiv an der Erweiterung dieses Netzwerks mit, zum Beispiel anhand von ständig reproduzierten Narrationen ihrer jeweiligen Wirkmacht.

In methodischer Hinsicht verstehe ich meine Arbeit als Modell für weitere Forschungen zur Existenzweise von nicht-menschlichen Entitäten und Geistern. Mein Vorgehen erwies sich als ein produktives und ergebnisreiches wissenschaftliches Unterfangen, das noch lange nicht an seine Grenzen gestoßen ist. Denkbar für weitere Forschungen wäre sowohl ein tieferes Einsteigen in Latours Programmatik der Untersuchung der Existenzweisen verschiedener Geister in Relation mit den bereits beschriebenen Existenzweisen (2014) ebenso wie ein Weiterdenken seiner methodisch angestrebten Überbrückung der Natur-KulturTrennung durch den Untersuchungsgegenstand der Waldgeister, die vor der Abholzung ihres Lebensraumes mit den Menschen in Verhandlungen treten (Beban und Work 2014). Eine solche Forschung ermöglichte neue Perspektiven auf globale Themen und Forschungsrichtungen wie Ökologie, Klimaforschung und Ressourcenmanagement.

\subsection{Macht}

Diese methodischen und theoretischen Konzepte führten mich während der Analyse meiner Forschungsdaten beständig zu Themen von weltlicher und spiritueller Macht. Anhand der spirituellen Machtkonzeption pāramī, die in der gesamten Arbeit auf ihre Implikationen im politischen, religiösen und sozialen Feld hin analysiert wird, zeige ich die Notwendigkeit einer Ergänzung des politischen Machtbegriffs in Kambodscha. Zudem spielen individuelle ,Ermächtigungen“ 
durch den Kontakt mit spiritueller Macht eine zentrale Rolle bei der GeistmedienInitiation.

Diese Studie liefert Erkenntnisse zu staatlichen, buddhistischen und brahmanistischen Manifestation und Aushandlung von Macht in Kambodscha. Zur Beantwortung meiner Fragestellung nach dem Potential des spirituellen Machtkonzeptes differenzierte ich zunächst weltliche Macht (aṃnāca) von spiritueller Macht (pāramī) (Kap. 2). Ich verwies dabei auf die enge Verknüpfung zwischen dem institutionalisiertem sangha und der KVP-geführten Regierung auf staatlicher Ebene, die bereits zeigten: Verdienst und pāramī stellen zwei Quellen der Machtaneignung dar, mit denen weltliche Macht legitimiert wird. Es wurde deutlich, dass Aneignungs- und Aushandlungsprozesse von Macht einen großen Teil der religiösen Praxis von Kambodschaner_innen ausmachen.

Meine Ergebnisse zeigen die enge Verknüpfung von spiritueller, weltlicher und politischer Macht. Diese Verschränkung begann mit sich wiederholenden Prozessen der spirituellen Legitimation von Macht in der Geschichte Kambodschas, wie an den devarajja- und cakravartin-Verehrungsformen deutlich wird (Kap. 2) und lebt in gegenwärtigen rituellen oder diskursiven Legitimationsbemühungen auf (Kap. 8-9). So veranschaulicht beispielsweise das private Ritual eines Politikers mit einem dringenden außenpolitischen Anliegen (Kap. 9.3) die angenommene Funktionsweise des brahmanistischen Machtkonzepts pāramī: als subjektivierte Kraft soll sie sowohl unmittelbar als auch in Ritualen mit moralischer Ambiguität, dank Spendenbereitschaft und Überzeugungskraft der Menschen, zu machtvollen Handlungen gebracht werden. Auch in Diskursen um die Rechtmäßigkeit von Herrschaft werden Geister wie Sdech Khan oder lok tā Kleang Moeung in Szene gesetzt (Kap. 9.4).

Weiterhin wurden in der Arbeit zwei Legitimationsstrategien von Macht differenziert. Der soziale Status einer Person wird allgemeinhin als Konsequenz der „Karma-Wechselwirkung“ (Kap. 2.3) abgeleitet. Alternativ zu dieser eher statischen Machtkonzeption beschreibe ich die brahmanistische Kraft pāramī als effektive und effiziente Machtressource, die die Möglichkeit des schnellen Machtgewinns und des Aufstiegs in patronage-Netzwerken in Aussicht stellt. Zur Akkumulation von pāramī werden bestehende Rituale verändert, was ich am Beispiel des optimierten loeng anak tā in Kapitel 8 veranschaulichte. Auch in Kambodscha fordert pāramī aufgrund seiner fluiden Beschaffenheit und seiner wechselhaften ontologischen Basis das westliche Verständnis von politischer- und weltlichlegitimierter Macht heraus. Somit kann, wie in Kap. 5 gezeigt, eine Person mit pāramì ausgestattet sein, wenn sie als besonders einflussreich und charismatisch gilt - sie kann jedoch gleichzeitig von pāramī besetzt werden, da pāramī als subjektivierte Macht auch eine eigene Handlungsmacht, eine Biographie und materielle Erscheinungsformen besitzen kann, wie die wichtigste Geister-Kategorie der kambodschanischen Geisterlandschaft, die anak tā, gezeigt haben. Somit stellt 
diese Arbeit einen Beitrag zu einer holistisch inspirierten Kontextualisierung von Macht in der Region dar.

Anknüpfend an Forschungen aus Indonesien (Bubandt 2014), Thailand (Jackson 2016, 2009; Pasuk und Baker 2008), Burma (Schober 2005; Min 2001) oder Laos (Ladwig 2013; Tappe 2013) böten religionsethnologische Forschungen zu südostasiatischen Machtkonzeptionen eine notwendige Bereicherung politikwissenschaftlicher Analysen Südostasiens. Dabei zeigen diese Studien, dass es nicht nur ein Alternativkonzept von weltlicher Macht gibt, sondern die Vielzahl der emischen Machtkonzepte gesammelt werden muss, um einen nuancierten Blick auf Herrschaftslegitimation zu erlangen (vgl. Jacobsen und Stuart-Fox 2013). Die Existenz der Geister ist in Kambodscha also stabil, das heißt, in ihrer derzeitigen Existenzweise gibt es sie tatsächlich. Das wissenschaftliche Interesse des wie oder warum ihrer Existenz gibt Anlass zur weiteren Untersuchung kambodschanischer Geister, da sich ihre Legitimation und Konzeption in beständigem Wandel befinden.

Ich habe in dieser Arbeit gezeigt, dass die wissenschaftliche Beschäftigung mit Geistern mithilfe des Analyserahmens der Spiritscapes und einer ANT-inspirierten Methodik die religiöse Situation Kambodschas erkenntnisreich auszuwerten erlaubt. Darüber hinaus konnte ich mit dieser Zugangsweise kambodschanische Machtstrukturen offenlegen, indem ich mich mit einer religionswissenschaftlichen Perspektive den spirituelle Machtkonzepten, insbesondere Karma und pāramī zuwandte. Dabei machte ich, mit dem Ziel einer Bereicherung politikwissenschaftlicher Analysen, die gesellschaftliche Bedeutung dieser Konzepte deutlich. Nicht zuletzt habe ich die soziale Einbettung medialer Akteure analysiert und ihre ambivalente Rolle als Verbündete der Geister und als potentielle Machtressource für Angehörige der Mittel- und Oberschicht beschrieben. Mein hier vorgestellter Zugang zu Geistern, der von einem Folgen emischer Relevanzen und Referenzen geprägt war, ermöglicht das Verständnis komplexer religiöser, politischer und sozialer Gesellschaftsprozesse. 



\section{Epilog}

Am Neujahrstag des 14.04.2019, zur Ortszeit um 15:11 Uhr, brachte die devatā Tungsa Devi den Kopf ihres Vaters Kapila Moha Brahm vom Berg Meru der thān suok zur Menschenwelt. Ihr letzter Aufenthalt im Jahre 2013-14 wurde, nach den umstrittenen Wahlen im Juli 2013, von politischen Unruhen im ganzen Land begleitet. Sie wird mit ihrer diesjährigen Rückkehr über ein Land wachen, das sich seit ihrem letzten Besuch zu einer Diktatur entwickelt hat. Tungsa Devis religiöse Position bleibt jedoch unverändert, ebenso wie die der zahlreichen Ortsgeister im Land. Sie und die anderen Geister haben sich nahtlos in das System des kambodschanischen Buddhismus integriert und geben den Bewohner_innen moralischen Halt in einer Zeit, in der die Vorbilder dafür schwer zu finden sind. 



\section{Glossar}

\begin{tabular}{|c|c|c|}
\hline $\begin{array}{l}\text { Transliterierter } \\
\text { Begriff } \\
\text { (phonetische Tran- } \\
\text { skription) }\end{array}$ & Khmer-Wort & Wörtliche Übersetzung, Erklärung \\
\hline $\begin{array}{l}\bar{a} \text { caryā } \\
\text { (adjaa) }\end{array}$ & รภตาฏ & $\begin{array}{l}\text { Geachtete, männliche Laien meist höheren } \\
\text { Alters, die Kenntnisse in der Rezitation } \\
\text { buddhistischer Pāli-Verse und ritueller } \\
\text { Praxis besitzen und in Ritualen Verantwor- } \\
\text { tung übernehmen }\end{array}$ \\
\hline Ahnen & & $\begin{array}{l}\text { Diffuse Kategorie von verstorbenen Fami- } \\
\text { lienmitgliedern, die } \Rightarrow t \bar{a} \text { oder } \Rightarrow t \bar{u} n \text { genannt } \\
\text { und als Familiengeister im } \Rightarrow m n \bar{a} \dot{n} \text { pdah } \\
\text { (Hausschrein) verehrt werden }\end{array}$ \\
\hline $\begin{array}{l}\text { amboe } \\
\text { (ampöw) }\end{array}$ & รับ็ณ & $\begin{array}{l}\text { 'Tat' oder ,Mord'; gängige Bezeichnung für } \\
\text { Rituale schwarzer Magie }\end{array}$ \\
\hline
\end{tabular}




\begin{tabular}{|c|c|c|}
\hline $\begin{array}{l}\text { aṃnāca } \\
\text { (omnaidj) }\end{array}$ & รณาஸ & ,Weltliche Macht \\
\hline $\begin{array}{l}\text { anak dham } \\
\text { (neak thom) }\end{array}$ & มูกัตั & $\begin{array}{l}\text {,Große Person‘; Mitglied der Oberschicht, } \\
\text { wohlhabender Mensch }\end{array}$ \\
\hline $\begin{array}{l}\text { anak mān punya } \\
\text { (neak mian bonn) }\end{array}$ & 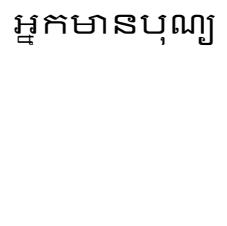 & $\begin{array}{l}\text { 'Menschen mit Verdienst'; Personen mit } \\
\text { wenig angesammelten (schlechten) Taten } \\
\text { aus vergangenen Leben, die dadurch ein } \\
\text { Leben in privilegierten Umständen genie- } \\
\text { Ben }\end{array}$ \\
\hline $\begin{array}{l}\text { anak tā } \\
(\text { neak ta) }\end{array}$ & มูกสก & $\begin{array}{l}\text {,verehrter Großvater'; universelle Bezeich- } \\
\text { nung für Ortsgeister, die als zuständig für } \\
\text { sehr unterschiedlich große Territorien } \\
\text { gesehen werden, oft synonym benutzt zu } \\
\Rightarrow \text { pārami }\end{array}$ \\
\hline $\begin{array}{l}\text { angkār } \\
\text { (angkaar) }\end{array}$ & รง ฟุกการ & $\begin{array}{l}\text {,Organisation'; Bezeichnung der kommu- } \\
\text { nistischen Partei während der Herrschaft } \\
\text { der Roten Khmer, die von ihnen als perso- } \\
\text { nifizierte Kontrollinstanz inszeniert wurde }\end{array}$ \\
\hline $\begin{array}{l}\bar{a} p \\
\text { (Aap) }\end{array}$ & $\begin{array}{l}\text { भภต } \\
\text { (auch: भภบ่, } \\
\text { भภโโตี) }\end{array}$ & $\begin{array}{l}\text { Bösartiger (Wald-)Geist, der in Form eines } \\
\text { Kopfes einer jungen Frau (samt der daran } \\
\text { hängenden Eingeweide) nachts im Wald } \\
\text { umherschwebt; stellt beliebtes Motiv in } \\
\text { Horrorfilmen dar }\end{array}$ \\
\hline $\begin{array}{l}\text { arakkh } \\
\text { (arak) }\end{array}$ & รภรกั & $\begin{array}{l}\text { Schutzgeist der Familie; kann auch als } \\
\text { Ortsgeist über die landwirtschaftlich ge- } \\
\text { nutzten Flächen der eigenen Familie ver- } \\
\text { standen werden }\end{array}$ \\
\hline bhjum piṇda & ^ึํํㄴิณू & $\begin{array}{l}\text {,Ansammlung', (der) ,Reisbälle‘; 14tägige } \\
\text { Feier mit täglichen Ritualen zur Ehrung der } \\
\text {,hungrigen Toten` }(\Rightarrow k h m o c, \Rightarrow \text { preta })\end{array}$ \\
\hline $\begin{array}{l}\text { bidhī } \\
\text { (pithi) }\end{array}$ & ติธีิ & ,Zeremonie' oder ,Ritual‘ \\
\hline
\end{tabular}




\begin{tabular}{|c|c|c|}
\hline blackboxing & & $\begin{array}{l}\text { Nach Latour ein Prozess des „Unsichtbar- } \\
\text { machens von wissenschaftlicher und tech- } \\
\text { nischer Arbeit durch ihren eigenen Erfolg“ } \\
\text { (Latour 2002: 373). In dieser Arbeit wurde } \\
\text { das Konzept auf das Unsichtbar-Machen } \\
\text { der Existenzbedingungen von Geistern } \\
\text { übertragen }\end{array}$ \\
\hline $\begin{array}{l}\text { brah } \\
\text { (preah) }\end{array}$ & โ็ะ & $\begin{array}{l}\text {-Heilig oder ,Gesegnet'; wird als } \\
\text { Anrede für spirituelle Akteure } \\
\text { (Mönche, aber auch Geister) be- } \\
\text { nutzt } \\
\text { - Gott(-heit) }\end{array}$ \\
\hline $\begin{array}{l}\text { brahmanya-sāsanā } \\
\text { (brahman sasna) }\end{array}$ & & $\begin{array}{l}\text {,Brahma-Religion'; der Brahmanismus wird } \\
\text { als Sammelbegriff für nicht-buddhistische } \\
\text { Elemente des kambodschanischen Bud- } \\
\text { dhismus benutzt; Geister werden dem } \\
\text { Brahmanismus zugeordnet }\end{array}$ \\
\hline $\begin{array}{l}\text { braling } \\
\text { (prolin) }\end{array}$ & โ็ญี่ & $\begin{array}{l}\text {,Lebenskraft', ,Seele; Menschen besitzen } \\
\text { nach kambodschanischer Vorstellung } \\
\text { neunzehn braling (Kap. 2.1.) }\end{array}$ \\
\hline $\begin{array}{l}\text { brāy } \\
\text { (brai) }\end{array}$ & [Emes & $\begin{array}{l}\text { Ein weiblicher, bösartiger Geist von } \\
\text { schlecht gestorbenen' Schwangeren oder } \\
\text { jungen Frauen }\end{array}$ \\
\hline cakravartin & & $\begin{array}{l}\text {,Rad‘ (Skr. cakra) (des Universums) ,dre- } \\
\text { hen‘ (Skr. vartin); das Idealkonzept eines } \\
\text { rechtmäßigen Herrschers, das nach der } \\
\text { Ausbreitung des Buddhismus ab dem } 13 . \\
\text { Jahrhundert das Konzept des } \Rightarrow \text { devarāja } \\
\text { ablöste }\end{array}$ \\
\hline chkuat & รูติ & $\begin{array}{l}\text {,verrückt'; gängiger Begriff für nonkon- } \\
\text { formes Verhalten, insbesondere in morali- } \\
\text { schen Belangen }\end{array}$ \\
\hline $\begin{array}{l}\text { dāna } \\
\text { (dian) }\end{array}$ & ราs & $\begin{array}{l}\text {,Gabe oder ,Spende‘ Name des allmor- } \\
\text { gendlichen Almosengebens an Mönche } \\
\text { durch (überwiegend weibliche) Spen- } \\
\text { der_innen }\end{array}$ \\
\hline
\end{tabular}




\begin{tabular}{|c|c|c|}
\hline $\begin{array}{l}\text { Demokratisches } \\
\text { Kampuchea (DK) }\end{array}$ & & $\begin{array}{l}\text { Name des Landes während der Roten } \\
\text { Khmer-Herrschaft (1976-1979) }\end{array}$ \\
\hline devarāja & โรรภานก & $\begin{array}{l}\text { „Gott‘ (deva), ,König' (räja); bezeichnet die } \\
\text { gottgleich verehrten Könige aus der Ang- } \\
\text { kor-Periode }\end{array}$ \\
\hline $\begin{array}{l}\text { devatāa } \\
\text { (tevda) }\end{array}$ & โร์ติ & $\begin{array}{l}\text {,Gottheit‘, lokal als ,Engel` übersetzt; weib- } \\
\text { liche Schutzgöttinnnen }\end{array}$ \\
\hline $\begin{array}{l}\text { Dharma } \\
\text { (thor) }\end{array}$ & นิ์ิ์ & $\begin{array}{l}\text { Gesetz, Lehre; auch: kosmische Ordnung } \\
\text { nach den Lehren Buddhas }\end{array}$ \\
\hline $\begin{array}{l}\text { dhmáp } \\
\text { (thmup) }\end{array}$ & นุติ & $\begin{array}{l}\text { „Hexer_in‘; die schwarze Magie ( } \Rightarrow \text { ampboe) } \\
\text { praktizieren }\end{array}$ \\
\hline $\begin{array}{l}g r \bar{u} \\
(k r u)\end{array}$ & โ等 & $\begin{array}{l}\text {,Lehrer` oder ,Meister'; vom Sanskritbegriff } \\
\text { guru abgeleitet; höfliche Anrede für Res- } \\
\text { pektpersonen. Im Kontext der Medialität } \\
\text { adressierten die Klient_innen die Geist- } \\
\text { medien als grü, während die Medien ihre } \\
\text { Geister auch grü nannten. In der vorliegen- } \\
\text { den Arbeit benutze ich es jedoch aus- } \\
\text { schließlich als Bezeichnung der Geist- } \\
\text { medien }\end{array}$ \\
\hline $\begin{array}{l}\text { grū cūl rūpa } \\
(k r u \text { djol rub) }\end{array}$ & 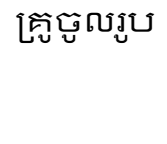 & $\begin{array}{l}\text {,Lehrer }(\Rightarrow g r \bar{u}), \text {,Eintreten` }(c \bar{u} l), \text {,Körper } \\
(\text { rüpa); Bezeichnung für Geistmedien mit } \\
\text { Geistbesessenheitspraktiken }\end{array}$ \\
\hline $\begin{array}{l}\text { grū dāy } \\
\text { (kru tiey) }\end{array}$ & โรูงษ & $\begin{array}{l}\text {,Lehrer }(\Rightarrow g r \bar{u}) \text {, ,vorhersagen }(d \bar{a} y) ; \text { Be- } \\
\text { zeichnung für gru, die sich auf astrologisch } \\
\text { basierte Prophezeiungen spezialisiert haben }\end{array}$ \\
\hline $\begin{array}{l}\text { grü khmer } \\
\text { (kru khmä̈) }\end{array}$ & 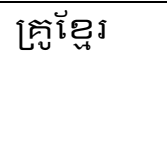 & $\begin{array}{l}\text { „Lehrer }(\Leftrightarrow g r \bar{u}), \text {,Khmer'; Heiler, die sich } \\
\text { auf pflanzliche Arzneien und heilpraktische } \\
\text { Therapieformen spezialisiert haben }\end{array}$ \\
\hline $\begin{array}{l}\text { grū pāramī } \\
\text { (kru boramey) }\end{array}$ & โกูบตริ & $\begin{array}{l}\text {,Lehrer } \quad \Leftrightarrow g r \bar{u}), \quad \text {,spirituelle Macht } \\
(\Rightarrow \text { pāram } \bar{\imath}) \text {; eine übergeordnete Kategorie } \\
\text { von grū, die mit } \Rightarrow \text { anak tā in Kontakt ste- } \\
\text { hen }\end{array}$ \\
\hline
\end{tabular}




\begin{tabular}{|c|c|c|}
\hline $\begin{array}{l}\text { grū sneh }{ }^{\circ} \\
\text { (kru snäh) }\end{array}$ & โูู่โญบ์ & $\begin{array}{l}\text {,Lehrer' }(\Rightarrow g r u \bar{u}) \text {, Zauber ' }\left(\text { sneh }^{9}\right) \text {; Geist- } \\
\text { medien, die sich auf Anliegen von Liebe } \\
\text { und Beziehungen spezialisiert haben }\end{array}$ \\
\hline $\begin{array}{l}\text { hov braling } \\
\text { (hau prolin) }\end{array}$ & เบ่ไโตญิน & $\begin{array}{l}\text { - Rufen der Lebenskräfte‘; Heilungs- } \\
\text { ritual zum Herbeirufen von fehlen- } \\
\text { den } \Rightarrow \text { braling in den Körper einer } \\
\text { kranken Person; } \\
\text { - } \text {,Rufen der (verstorbenen) Seelen‘, } \\
\text { Ritual zum Befrieden von, schlecht } \\
\text { Gestorbenen“ }\end{array}$ \\
\hline Karma & กียู & $\begin{array}{l}\text { „Handlung', ,Tat'; Karma stellt einen kausa- } \\
\text { len Zusammenhang zwischen den Hand- } \\
\text { lungen von Menschen und dem Schicksal } \\
\text { ihrer (zukünftigen) Leben her }\end{array}$ \\
\hline kathen & กิบิฐ & $\begin{array}{l}\text { Zeremonie zur Erneuerung der Mönchsro- } \\
\text { ben, gefeiert im elften Monat des lunaren } \\
\text { Kalenders nach einer Zeit der Einkehr (cul } \\
\text { vassa), in der Mönche strengeren Regeln } \\
\text { unterworfen sind }\end{array}$ \\
\hline khdoey & โ己્డిய & $\begin{array}{l}\text { (männliche) Homosexuelle oder Transfrau- } \\
\text { en. }\end{array}$ \\
\hline $\begin{array}{l}\text { khmoc } \\
\text { (khmaodj) }\end{array}$ & โ己ูง & $\begin{array}{l}\text { - } \text {, leerer Körper }{ }^{\varsigma} \text { oder,Geist‘; } \\
\text { - allgemeine Bezeichnung für Geister } \\
\text { - } \text { spezifischer Ausdruck für ,Toten- }^{\varsigma} \text { geist }^{\varsigma}\end{array}$ \\
\hline $\begin{array}{l}\text { khsae } \\
(k s a \ddot{a})\end{array}$ & โૅฮ & $\begin{array}{l}\text { „Faden', ,Folge', ,Verbindung', bezeichnet } \\
\text { sowohl die rituell benutzten Baumwollfä- } \\
\text { den als auch die Zugehörigkeit/Loyalität zu } \\
\text { anderen Personen }\end{array}$ \\
\hline Krung Bali & โก,ฟัตกญ & Name von Geist/Gottheit der Erde \\
\hline $\begin{array}{l}\text { krung pali } \\
\text { (krong balie) }\end{array}$ & 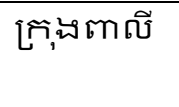 & $\begin{array}{l}\text { Zeremonie zum Bitten um Segen von } \\
\text { Geistern }\end{array}$ \\
\hline KVP & & $\begin{array}{l}\text { Akronym der ,Kambodschansichen Volks- } \\
\text { partei'; englisch: ,Cambodian People's } \\
\text { Party“ (CPP) }\end{array}$ \\
\hline
\end{tabular}




\begin{tabular}{|c|c|c|}
\hline $\begin{array}{l}\text { loeng anak tā } \\
\text { (larn neak tā) }\end{array}$ & 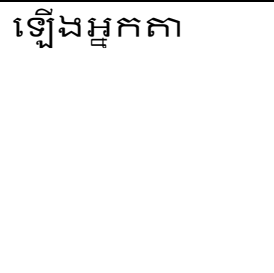 & $\begin{array}{l}\text { 'Hochpreisen der anak tä'; jährliche Zere- } \\
\text { monie für die } \Rightarrow \text { anak tā, die zwischen Ern- } \\
\text { te und Pflanzzeit durchgeführt wird. Ich } \\
\text { beschreibe in Kapitel 8.2. eine weitere } \\
\text { Form, bei der die Beziehung zu Sponsoren } \\
\text { der Veranstaltungen im Mittelpunkt steht }\end{array}$ \\
\hline $\begin{array}{l}\text { lok tā } \\
\text { (lock taa) }\end{array}$ & โบยกีส & $\begin{array}{l}\text {,Verehrter Großvater'; höfliche Anrede } \\
\text { von älteren Männern; wird im spirituellen } \\
\text { Kontext als Anrede von } \Rightarrow \text { anak tā benutzt }\end{array}$ \\
\hline $\begin{array}{l}\text { lok tā Eysey } \\
\text { (lock taa eisei) }\end{array}$ & & $\begin{array}{l}\text {,Verehrter Großvater Eysey'; populärer } \\
\Rightarrow \text { anak tă. Sein Name leitet sich vom } \\
\text { Khmer-Namen für Shiva ab } \Leftrightarrow \text { brah } \\
\text { Eysor). Er wird meist als Asket mit weißem } \\
\text { Bart dargestellt, dabei ist er oft mit }- \text { dem } \\
\text { für Shiva typischen Tigerfell - bekleidet }\end{array}$ \\
\hline $\begin{array}{l}\text { lok tā Kleang } \\
\text { Moeung }\end{array}$ & 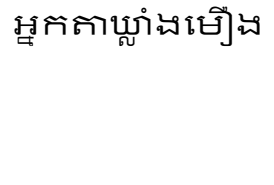 & $\begin{array}{l}\text { „Bewacher' (glāmn), ,Region“ oder ,Gebiet‘ } \\
\text { (mīoèn); prominenter anak tāa, der in ganz } \\
\text { Kambodscha verehrt wird. Die Herkunft } \\
\text { des Namens ist thailändischen Ursprungs }\end{array}$ \\
\hline $\begin{array}{l}\text { lok yāy } \\
\text { (lock yeay) }\end{array}$ & โญกรผบษ & $\begin{array}{l}\text {,verehrte Großmutter (lok yāy); höfliche } \\
\text { Anrede für ältere Frauen und weibliche } \\
\text { Geister }\end{array}$ \\
\hline $\begin{array}{l}\text { lok yāy Mao } \\
\text { (lock yeay mao) }\end{array}$ & 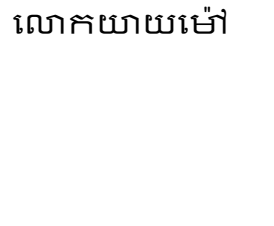 & $\begin{array}{l}\text {,verehrte Großmutter (lok yāy), ,schwarz' } \\
\text { (khmao, kurz: mao); weiblicher } \Rightarrow \text { anak tā; } \\
\text { mit Ähnlichkeiten zur indischen Göttin } \\
\text { Kālī. Zum dynamischen Bedeutungswandel } \\
\text { dieses Geistes, siehe Kapitel 5.2. }\end{array}$ \\
\hline magic monk & 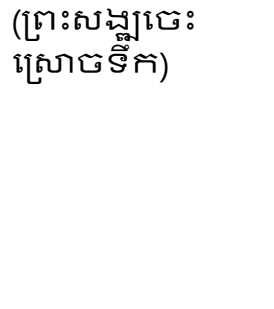 & $\begin{array}{l}\text {,Mönche“ }(\Rightarrow \text { brah sangdh), die ,wissen` (ceh), } \\
\text { wie man } \Rightarrow \text { sro dyk praktiziert; eine der } \\
\text { möglichen Umschreibungen für Mönche, } \\
\text { die mit Geistern kommunizieren oder von } \\
\text { ihnen besessen werden; einen einheitlichen } \\
\text { Begriff gibt es im gesprochenen Khmer } \\
\text { nicht }\end{array}$ \\
\hline Medialität & & $\begin{array}{l}\text { Übergeordnetes Konzept, abgeleitet vom } \\
\text { englischen Begriff mediumship }\end{array}$ \\
\hline
\end{tabular}




\begin{tabular}{|c|c|c|}
\hline $\begin{array}{l}\text { mnāin pdah } \\
\text { (meang p.teah) }\end{array}$ & 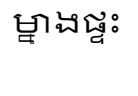 & Hausschrein, meist den $\Rightarrow$ Ahnen gewidmet \\
\hline $\begin{array}{l}\text { Nāga } \\
\text { (neak) }\end{array}$ & Sากั & $\begin{array}{l}\text { Mythische Schlange, die als Beschützerin } \\
\text { des Wassers und seiner Lebewesen gilt }\end{array}$ \\
\hline $\begin{array}{l}\text { namasakāra (neak- } \\
\text { massaka) }\end{array}$ & รษญก่ & $\begin{array}{l}\text { Buddhistisches Ritual der Ehrbietung der } \\
\text { buddhistischen Lehre }\end{array}$ \\
\hline $\mathrm{NGO}$ & & $\begin{array}{l}\text {,Non-Governmental Organisation' ist der } \\
\text { internationale (und auch im Deutschen } \\
\text { gebräuchliche) Begriff für Nichtregie- } \\
\text { rungsorganisationen }\end{array}$ \\
\hline $\begin{array}{l}\text { pāragū } \\
(\text { baku) }\end{array}$ & ตารณู & $\begin{array}{l}\text { Am kambodschanischen Königshof ange- } \\
\text { stellte, brahmanistische Ritualexperten }\end{array}$ \\
\hline $\begin{array}{l}\text { pāramī } \\
\text { (boramey) }\end{array}$ & ตาริิ & $\begin{array}{l}\text {,Charisma', bzw. ,(spirituelle) Macht'; un- } \\
\text { klare Herkunft des Wortes; kann in abs- } \\
\text { traktem Sinn auf eine Macht eines Ortes } \\
\text { oder eines Gegenstands oder auf eine spe- } \\
\text { zifische Macht bezogen sein, die synonym } \\
\text { zu } \Rightarrow \text { anak } t \bar{a} \text { oder } \Rightarrow \text { lok } t \bar{a} \text { verwendet wird }\end{array}$ \\
\hline $\begin{array}{l}\text { pārāng } \\
\text { (barang) }\end{array}$ & ตภปั & $\begin{array}{l}\text { Pārāng ist von dem Wort ,francais' abgelei- } \\
\text { tet. Seit der französischen Kolonialzeit } \\
\text { werden alle westlich-aussehenden Men- } \\
\text { schen so bezeichnet }\end{array}$ \\
\hline $\begin{array}{l}\text { pāy sī } \\
\text { (beysey) }\end{array}$ & ตาษญี & $\begin{array}{l}\text { Schrein; wird sowohl für Schreine in bud- } \\
\text { dhistischen Tempeln als auch für Schreine } \\
\text { von Geistmedien benutzt }\end{array}$ \\
\hline phlāk' & 萝官 & $\begin{array}{l}\text { „Bewusstlosigkeit'; oft mit dem Zusatz choh } \\
\text { (,nach unten') verwendet }\end{array}$ \\
\hline $\begin{array}{l}\text { pisāca } \\
\text { (beisadj) }\end{array}$ & บิธีธ & $\begin{array}{l}\text { Ein bösartiger Geist, der im Wald lebt und } \\
\text { Menschen unfreiwillig besetzen und damit } \\
\text { krank machen kann }\end{array}$ \\
\hline $\begin{array}{l}\text { preta } \\
\text { (pret) }\end{array}$ & โโตร & $\begin{array}{l}\text {,hungriger ' Totengeist nach buddhistischer } \\
\text { Konzeption }\end{array}$ \\
\hline
\end{tabular}




\begin{tabular}{|c|c|c|}
\hline PRKN & 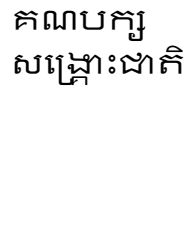 & $\begin{array}{l}\text { Akronym der ( } 2018 \text { aufgelösten) ,Partei zur } \\
\text { Rettung der kambodschanischen Nation“ } \\
\text { von Oppositionsführer Sam Rainsy; im } \\
\text { Englischen als ,Cambodia National Rescue } \\
\text { Party' (CNRP) bezeichnet }\end{array}$ \\
\hline $\begin{array}{l}\text { punya } \\
\text { (bonn) }\end{array}$ & บุณู & $\begin{array}{l}\text { - Verdienst, der durch Opfergaben an } \\
\text { Mönche entsteht } \\
\text { - buddhistisches Ritual } \\
\text { - verdienstreiche Handlung }\end{array}$ \\
\hline $\begin{array}{l}\text { purāna } \\
\text { (boran) }\end{array}$ & ตุรณก & ,altertümlich \\
\hline $\begin{array}{l}\text { samăya } \\
\text { (samai) }\end{array}$ & ถิษัษ & ,modern' oder ,neu' \\
\hline sangha & ஸิ於 & $\begin{array}{l}\text { Gemeinschaft der Mönche, neben der } \\
\text { Lehre (Dharma) und dem Buddha einer } \\
\text { der sogenannten ,drei Juwelen' des Bud- } \\
\text { dhismus }\end{array}$ \\
\hline sangharāja & 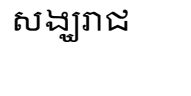 & $\begin{array}{l}\text { „König‘ (rāja) des } \Rightarrow \text { sangha; höchstgestellter } \\
\text { Mönch eines Ordens }\end{array}$ \\
\hline $\begin{array}{l}\text { sāsanā } \\
(\text { sasna) }\end{array}$ & ธ่ஸ் & $\begin{array}{l}\text { 'Lehre', ,Doktrin', ,Gewohnheit'; kambod- } \\
\text { schanisches Äquivalent des westlichen } \\
\text { Religionsbegriffes }\end{array}$ \\
\hline $\begin{array}{l}\text { sila } \\
\text { (sil) }\end{array}$ & ธิธี & $\begin{array}{l}\text {,tugendhafte Geisteshaltung'; wird durch } \\
\text { Praktiken wie Meditation erlangt } \\
\text {,richtiges Verhalten', ,Regel' oder ,Moral'; } \\
\text { bezeichnet buddhistische Regeln für Mön- } \\
\text { che (10) oder Laien (5 oder 8) } \\
\text { als Adjektiv: anak sīla (,tugendhafter } \\
\text { Mensch) oder thgnai sīla (,günstiger Tag) }\end{array}$ \\
\hline $\begin{array}{l}\text { sneh }^{\circ} \\
(\text { snäh) }\end{array}$ & โஸ્๊บ์ & $\begin{array}{l}\text {,(Liebes-)Zauber' wird auch als ,Ausstrah- } \\
\text { lung', oder, Wirkung' eines Menschen auf } \\
\text { andere Personen bezeichnet; kann in ent- } \\
\text { sprechenden Ritualen erhöht werden }\end{array}$ \\
\hline
\end{tabular}




\begin{tabular}{|c|c|c|}
\hline $\begin{array}{l}\text { sro dyk } \\
\text { (srao toek) }\end{array}$ & โโธ่ธึึก & $\begin{array}{l}\text {,Werfen (sro), Wasser }{ }^{`}(d \dot{y} k) \text {; Ritual von } \\
\text { religiösen Würdenträger_innen (Mönchen, } \\
\text { Geistmedien), in dessen Verlauf die Körper } \\
\text { der Gläubigen zum Segen mit Wasser } \\
\text { überschüttet werden }\end{array}$ \\
\hline$t \bar{a}$ & ถา & $\begin{array}{l}\text {,Großvater'; respektvolle Anrede für ältere } \\
\text { Menschen und Geister }\end{array}$ \\
\hline thān & บาs & ,Ort' ,Platz' ,Region` (Pāli: țhāna) \\
\hline $\begin{array}{l}\text { thān manuss } \\
\text { (tan menu) }\end{array}$ & 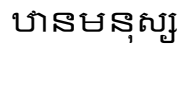 & ,Ort ${ }^{`}$ (der) ,Menschen'; Menschenwelt \\
\hline $\begin{array}{l}\text { thān suok } \\
\text { (tan sua) }\end{array}$ & บาనஸูก์ & $\begin{array}{l}\text {,Ort' (des) ,Himmels' (Skr.: svarga); Reich } \\
\text { der wohlwollenden Geister wie } \Rightarrow \text { anak tā } \\
\text { oder } \Rightarrow \text { devata }\end{array}$ \\
\hline $\begin{array}{l}\text { thān norok } \\
\text { (tan norok) }\end{array}$ & 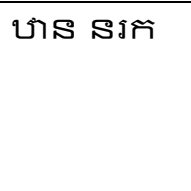 & $\begin{array}{l}\text {,Ort }{ }^{\varsigma} \text { (einer) ,Hölle‘; (Pāli: naraka); eine der } \\
\text { buddhistisch konzipierten Höllen, Reich } \\
\text { der ,hungrigen Toten` ( } \Rightarrow \text { preta), regiert von } \\
\Rightarrow \text { Yum Riek }\end{array}$ \\
\hline $\begin{array}{l}\operatorname{tu} \bar{n} \\
(\text { doan })\end{array}$ & 屹 $S$ & ,Großmutter', Synomyn für $\Rightarrow y \bar{a} y$ \\
\hline $\begin{array}{l}t+\bar{u} n j \bar{\imath} \\
\text { (doanchi) }\end{array}$ & แ్రీనิ & $\begin{array}{l}\text { Asketisch lebende Frauen, die sich nach } \\
\text { den } \Rightarrow \text { sila der Mönche richten, aber nicht } \\
\text { ordiniert werden dürfen }\end{array}$ \\
\hline $\begin{array}{l}\text { vedamant } \\
\text { (vetamun) }\end{array}$ & โรSG甭 & $\begin{array}{l}\text { 'Veden', ,Vorhersehung' (veda) Segen } \\
\text { (manț); gängiger Begriff für ,Magie }\end{array}$ \\
\hline $\begin{array}{l}\text { viññanna } \\
\text { (vitanea) }\end{array}$ & ริตฺ̣n & $\begin{array}{l}\text { „Bewusstsein‘; eins von fünf ,Aggregaten“ } \\
\text { (khanda) des menschlichen Körpers nach } \\
\text { buddhistischer Konzeption }\end{array}$ \\
\hline $\begin{array}{l}\text { yāy } \\
\text { (yiey) }\end{array}$ & צตש & $\begin{array}{l}\text {,Großmutter', respektvolle Anrede für } \\
\text { ältere Frauen }(\text { vgl. } \Rightarrow t \bar{n} n)\end{array}$ \\
\hline $\begin{array}{l}\text { Yum Riek } \\
\text { (jum riek) }\end{array}$ & ๒ษยภณ & $\begin{array}{l}\text { Wächter der Totengeister in der } \Rightarrow \text { thān } \\
\text { norok. Große konzeptionelle Ähnlichkeiten } \\
\text { mit dem Hindu-Gott der Unterwelt, Yama, } \\
\text { auch Yamarāja genannt. }\end{array}$ \\
\hline
\end{tabular}





\section{Literaturverzeichnis}

ADB (2014): Cambodia. Country Poverty Analysis 2014. Asian Development Bank. Unter Mitarbeit von Karin Schelzig. Oakland: O Books Sun \& Moon.

Agger, Inger; Igreja, Victor; Kiehle, Rachel; Polatin, Peter (2012): Testimony Ceremonies in Asia. Integrating Spirituality in Testimonial Therapy for Torture Survivors in India, Sri Lanka, Cambodia, and the Philippines. In: Transcultural Psychiatry 49 (3-4), S. 568-589.

Anderson, Benedict R. (1991): Imagined Communities. Reflections on the Origin and Spread of Nationalism. London, New York: Verso.

Ang, Chouléan (1986): Les Êtres Surnaturels dans la Religion Populaire Khmère. Paris: Cedoreck (Traveaux et Recherche, Bibliothèque Khmère).

- (1988): The Place of Animism within Popular Buddhism in Cambodia. The Example of the Monastery. In: Asian Folklore Studies 47 (1), S. 35-41.

- (1993): Recherches recentes sur le Culte des Megalithes et des Grottes au Cambodge. In: Journal Asiatique 281 (1-2), S. 185-210.

- (2004): The Human-Nature Relationship Seen through Animistic Belief and Ritual in Cambodia. In: Symposium Report Okinawa International Forum, S. 58-65. 
— (2016): Yāy Mau. In: Nasir Abdoul-Carime, Grégory Mikaelian und Joseph Thach (Hg.): Le Passé des Khmers. Langues, Textes, Rites. Bern: Peter Lang, S. 249-262.

Appadurai, Arjun (1996): Modernity at Large. Cultural Dimensions of Globalization. Minneapolis: University of Minnesota Press (Public worlds, 1).

Arensen, Lisa J. (2017): The Dead in the Land. Encounters with Bodies, Bones, and Ghosts in Northwestern Cambodia. In: The Journal of Asian Studies 76 (1), S. 69-86.

- (2012): Making the Srok. Resettling a Mined Landscape in Northwest Cambodia. Dissertation. University of Edinburgh. Online unter https://www.era.lib.ed.ac.uk/handle/1842/6424, letzter Abruf am 04.02.2020.

Århem, Kaj; Sprenger, Guido (Hg.) (2016): Animism in Southeast Asia. London, New York: Routledge (Routledge Contemporary Southeast Asia Series, 77).

Aspers, Patrick (2010): Relational Ontology. Being and Order out of Heidegger's Socioontology. In: Jan A. Fuhse (Hg.): Relationale Soziologie. Zur kulturellen Wende der Netzwerkforschung. 1. Aufl. Wiesbaden: VS Verlag für Sozialwissenschaften (Netzwerkforschung, 2), S. 257-272.

Aymonier, Étienne (1883): Notes sur les Coutumes et Croyances Superstitieuses des Cambodgiens. Unter Mitarbeit von Saveros Pou. Paris: Cedoreck (Bibliothèque Khmère. Série A, Textes et Documents, 3).

Bareau, André (1962): La Construction et le Culte des Stūpa d'après les Vinayapitaka. In: Bulletin de l'École française d'Extrême-Orient 50 (5), S. 229-274.

Baumann, Benjamin (2013): Tamnan Krasue. Constructing a Khmer Ghost for a Thai Film. In: Kyoto Review of Southeast Asia (14). Online unter http://kyotoreview.org/issue-14/tamnan-krasue-constructing-a-khmerghost-for-a-thai-film/, letzter Abruf am 04.02.2020.

- (2014): From Filth-Ghost to Khmer-Witch. Phi Krasue's Changing Cinematic Construction and its Symbolism. In: Horror Studies 5 (2), S. 183-196.

- (2015): The Khmer Witch Project. Demonizing the Khmer by Khmerizing a Demon. Working Paper No 19. Dynamics of Religion in Southeast Asia. Göttingen. Online unter http://www.dorisea.de/de/node/1839, letzter Abruf am 04.02.2020.

Baumgärtel, Tilman (2011): Cinema aus Kambodscha. Cinema - Unabhängige Schweizer Filmzeitschrift (56). Online unter https:/ /www.cinemabuch.ch/article/560019, letzter Abruf am 04.02.2020.

Beban, Alice; Work, Courtney (2014): The Spirits are Crying. Dispossessing Land and Possessing Bodies in Rural Cambodia. In: Antipode 46 (3), S. 593-610. 
Bell, Catherine M. (2002): “The Chinese believe in spirits”. Belief and Believing in the Study of Religion. In: Nancy Frankenberry (Hg.): Radical Interpretation in Religion. Cambridge, UK, New York: Cambridge University Press, S. $100-116$.

Belliger, Andréa; Krieger, David J. (2006): Einführung in die Akteur-NetzwerkTheorie. In: Andréa Belliger und David J. Krieger (Hg.): ANThology. Ein einführendes Handbuch zur Akteur-Netzwerk-Theorie. Bielefeld: transcript Verlag, S. 13-50.

Benjamin, Andrew E. (2015): Towards a Relational Ontology. Philosophy's Other Possibility. Albany, New York: SUNY Press (SUNY Series in Contemporary Continental Philosophy).

Benjamin, Walter (2017): Über den Begriff der Geschichte. Zweite Auflage. Hg. v. Gérard Raulet. Berlin: Suhrkamp (Werke und Nachlass, Bd. 19).

Bennett, Caroline (2015): To Live Amongst the Dead. An Ethnographic Exploration of Mass Graves in Cambodia. PhD. University of Kent, Kent. Online unter https://kar.kent.ac.uk/53561/, letzter Abruf am 04.02.2020.

- (2018): Living with the Dead in the Killing Fields of Cambodia. In: Journal of Southeast Asian Studies 49 (2), S. 184-203.

Bernard, H. Russell (2011): Research Methods in Anthropology. Qualitative and Quantitative Approaches. 5. Aufl. Lanham, Md.: Altamira Press.

Bertrand, Didier (2001): The Names and Identities of the "Boramey" Spirits Possessing Cambodian Mediums. In: Asian Folklore Studies 60 (1), S. 31-47.

- (2004): A Medium Possession Practice and Its Relationship with Cambodian Buddhism. The Grū Pāramī. In: John Marston und Elizabeth Guthrie (Hg.): History, Buddhism, and New Religious Movements in Cambodia. Honolulu: University of Hawai' 1 Press, S. 150-169.

- (2005): The Therapeutic Role of Khmer mediums (kru boramei) in Contemporary Cambodia. In: Mental Health, Religion \& Culture 8 (4), S. 309-327.

Bielo, James S. (2015): Anthropology of Religion. The Basics. New York, Abingdon, Oxon: Routledge (The Basics).

Bijker, Wiebe E.; Hughes, Thomas Parke; Pinch, Trevor (Hg.) (1987): The Social Construction of Technological Systems. New Directions in the Sociology and History of Technology. Cambridge, Mass.: MIT Press.

Bird-David, Nurit (1999): “Animism” Revisited. Personhood, Environment, and Relational Epistemology. In: Current Anthropology 40 (1), S. 67-91.

Bird-David, Nurit; Naveh, Danny (2008): Relational Epistemology, Immediacy, and Conservation. Or, What Do the Nayaka Try to Conserve? In: Journal for the Study of Religion, Nature and Culture 2 (1). 
Bizot, François (1994): La Consécration des Statues et le Culte des Morts. In: François Bizot (Hg.): Recherches Nouvelles sur le Cambodge. Paris (Publications de l'École Française d'Extrême-Orient, 1), S. 101-127.

Blanes, Ruy; Espirito Santo, Diana (2014): Introduction. On the Agency of Intangibles. In: Ruy Blanes und Diana Espirito Santo (Hg.): The Social Life of Spirits. Chicago, London: The University of Chicago Press, S. 1-32.

Bond, David; Bessire, Lucas (2014): The Ontological Spin. Fieldsights Commentary. Hg. v. Cultural Anthropology Online. Online unter http:/ / www.culanth.org/ fieldsights/494-the-ontological-spin, letzter Abruf am 04.02.2020.

Bourdieu, Pierre (1991): Language and symbolic power. Hg. v. John B. Thompson. Cambridge: Polity Press.

Bowie, Fiona (2013): Building Bridges, Dissolving Boundaries. Toward a Methodology for the Ethnographic Study of the Afterlife, Mediumship, and Spiritual Beings. In: Journal of the American Academy of Religion 81 (3), S. 698-733.

- (2014): Believing Impossible Things. Scepticism and Ethnographic Enquiry. In: Jack Hunter und David Luke (Hg.): Talking with the Spirits. Ethnographies from between the Worlds. Brisbane: Daily Grail Publishing, S. 19-55.

Brac de la Perrière, Bénédicte (2017): About Buddhist Burma. Thathana or Religion as Social Space. In: Michel Picard (Hg.): The Appropriation of Religion in Southeast Asia and Beyond. New York: Palgrave, S. 39-66.

Bradley, Mark Philip (2001): Contests of Memory: Remembering and Forgetting War in the Contemporary Vietnamese Cinema. In: Hue-Tam Ho Tai (Hg.): The Country of Memory. Remaking the Past in Late Socialist Vietnam. Berkeley: University of California Press, S. 196-227.

Brambilla, Chiara (2014): Exploring the Critical Potential of the Borderscapes Concept. In: Geopolitics 20 (1), S. 14-34.

Bräunlein, Peter J. (2010): Passion / Pasyon. Rituale des Schmerzes im Europäischen und Philippinischen Christentum. München: Fink.

- (2014): Spirits in and of Southeast Asia's Modernity. An Overview. In: Volker Gottowik (Hg.): Dynamics of Religion in Southeast Asia. Magic and Modernity. Amsterdam: Amsterdam University Press (AUP), S. 33-55.

Bräunlein, Peter J.; Lauser, Andrea (Hg.) (2016): Ghost Movies in Southeast Asia and Beyond. Narratives, Cultural Contexts, Audiences. Leiden, Boston: Brill (Southeast Asia Mediated, 3).

Breidenstein, Georg; Hirschauer, Stefan; Kalthoff, Herbert; Nieswand, Boris (2013): Ethnografie. Die Praxis der Feldforschung. Konstanz: UVK Verlagsgesellschaft. 
Bronkhorst, Johannes (2011): Buddhism in the Shadow of Brahmanism. Leiden: Brill (Handbook of Oriental Studies, 24).

Bubandt, Nils (2014): Democracy, Corruption and the Politics of Spirits in Contemporary Indonesia. Abingdon, Oxon, New York: Routledge (The Modern Anthropology of Southeast Asia).

Buß, Johanna (2006): Preta, Pitr und Pisaca. Rituelle und mythische Totenbilder im Pretakalpa des Garudapurana, dem Garudapuranasaroddhara und der Pretamanjari. Dissertation. Universität Heidelberg, Heidelberg. Online unter http://www.ub.uni-heidelberg.de/archiv/11546, letzter Abruf am 04.02.2020.

Carrithers, M.; Candea, M.; Sykes, K.; Holbraad, Martin; Venkatesan, S. (2010):

Ontology Is Just Another Word for Culture. Motion Tabled at the 2008

Meeting of the Group for Debates in Anthropological Theory, University of Manchester. In: Critique of Anthropology 30 (2), S. 152-200.

Carsten, Janet (2007): Ghosts of Memory: Essays on Remembrance and Relatedness. Oxford [u.a.]: Wiley-Blackwell.

Castro, Madeleine; Burrows, Roger; Wooffitt, Robin (2014): The Paranormal is (Still) Normal. The Sociological Implications of a Survey of Paranormal Experiences in Great Britain. In: Sociological Research Online 19 (3), S. 1-15.

Chakrabarty, Dipesh (2000): Provincializing Europe. Postcolonial Thought and Historical Difference. Princeton: Princeton University Press.

Chandler, David (1972): Cambodia's Relations with Siam in Early Bangkok Period. The Politics of a Tributary State. In: Journal of Siam Society 60 (1), S. 153-169.

- (1974): Royally Sponsored Human Sacrifices in Nineteenth Century Cambodia. The Cult of Nak Ta Me Sa (Mahisasuramardini) at Ba Phnom. In: Journal of Siam Society 62 (2), S. 207-222.

- (1982): Songs at the Edge of the Forest. Perceptions of Order in Three Cambodian Texts. In: David K. Wyatt, Alexander Woodside und Michael Aung-Thwin (Hg.): Moral Order and the Question of Change. Essays on Southeast Asian Thought. New Haven, CT: Yale University Press (Monograph Series, 24), S. 53-77.

- (1992): Brother Number One. A Political Biography of Pol Pot. Boulder, Colo.: Westview Press.

- (1999): Voices from S-21. Terror and History in Pol Pot's Secret Prison. Berkeley: University of California Press. Online unter http://www.loc.gov/catdir/description/ucal042/99013924.html, letzter Abruf am 04.02.2020

- (2008): A History of Cambodia. 4. Aufl. Boulder, Colo.: Westview Press.

Christensen, Paul (2009): Jathilan. Ein Trancetanz in der Region Yogykarta, Indonesien. Unveröffentlichte Magisterarbeit. Bremen: Universität Bremen. 
- (2014): Modernity and Spirit Possession. Horse Dance and its Contested Magic. In: Volker Gottowik (Hg.): Dynamics of Religion in Southeast Asia. Magic and Modernity. Amsterdam: Amsterdam University Press (AUP), S. 91-113.

CIA (2018): The World Factbook. Cambodia. Online unter https://www.cia.gov/library/publications/the-world-factbook/geos/cb.html, letzter Abruf am 04.02.2020.

Ciorciari, John D. (Hg.) (2006): The Khmer Rouge Tribunal. Phnom Penh: Documentation Center of Cambodia (Documentation Center of Cambodia, 10).

Comaroff, Jean (1985): Body of Power, Spirit of Resistance: The Culture and History of a South African People. Chicago: University of Chicago Press.

Davis, Colin (2007): Haunted Subjects: Deconstruction, Psychoanalysis and the Return of the Dead. Annotated Edition. New York: Palgrave.

Davis, Erik W. (2008a): Between Forests and Families. A Remembered Past Life. In: Alexandra Kent und David Chandler (Hg.): People of Virtue. Reconfiguring Religion, Power and Morality in Cambodia Today. Copenhagen: NIAS Press (NIAS Studies in Asian Topics, 43), S. 128-144.

- (2008b): What is the Krung Palii Ceremony, and Why is Bun Rany performing it at Preah Vihear? Online unter https://erikwdavis.wordpress.com/2008/08/01/what-is-the-krung-paliiceremony-and-why-is-bun-rany-performing-it-at-preah-vihear/, letzter Abruf am 21.03.2016.

- (2009): Treasures of the Buddha: Imagining Death and Life in Contemporary Cambodia. PhD. Chicago: University of Chicago Press.

- (2015a): Deathpower. Buddhism's Ritual Imagination in Cambodia. New York: Columbia University Press.

- (2015b): Kinship Beyond Death. Ambiguous Relations and Autonomous Children in Cambodian Buddhism. In: Contemporary Buddhism 16 (1), S. 1-16.

Davis, Kyle Frankel; Yu, Kailiang; Rulli, Maria Cristina; Pichdara, Lonn; D’Odorico, Paolo (2015): Accelerated Deforestation Driven by Large-Scale Land Acquisitions in Cambodia. In: Nature Geoscience 8 (10), S. 772-775.

Deleuze, Gilles; Guattari, Félix (2004): A Thousand Plateaus. Capitalism and Schizophrenia. London, New York: Continuum.

Descola, Philippe (1996): The Spears of Twilight. Life and Death in the Amazon Jungle. New York: New Press.

DeWalt, Kathleen Musante; DeWalt, Billie R. (2011): Participant Observation. A Guide for Fieldworkers. 2. Aufl. Lanham, Md.: Altamira Press. 
Diepart, Jean-Christophe; Schoenberger, Laura (2017): Concessions in Cambodia. Governing Profits, Extending State Power and Enclosing Resources from the Colonial Era to the Present. In: Katherine Brickell und Simon Springer (Hg.): The Handbook of Contemporary Cambodia. New York: Routledge, S. 157-168.

Dror, Olga (2016): Establishing Hồ Chí Minh's Cult. Vietnamese Traditions and Their Transformations. In: The Journal of Asian Studies 75 (02), S. 433-466.

Dy, Khamboly; Dearing, Christopher (2014): A History of the Anlong Veng Community. The Final Stronghold of the Khmer Rouge Movement. Phnom Penh: Documentation Center of Cambodia (Documentation Center of Cambodia, 20).

Ebihara, May (1968): Svay, a Khmer Village in Cambodia. PhD Thesis. Columbia University.

Edwards, Penny (2007): Cambodge. The Cultivation of a Nation, 1860-1945. Honolulu: University of Hawai'i Press (Southeast Asia - Politics, Meaning, and Memory).

- (2008a): Between a Song and a Prei. Tracking Cambodian History and Cosmology through the Forest. In: Anne Ruth Hansen und Judy Ledgerwood (Hg.): At the Edge of the Forest. Essays on Cambodia, History, and Narrative in Honor of David Chandler. Ithaca, NY: Southeast Asia Program Publications, S. 137-162.

- (2008b): The Moral Geology of the Present: Structuring Morality, Menace and Merit. In: Alexandra Kent und David Chandler (Hg.): People of Virtue.

Reconfiguring Religion, Power and Morality in Cambodia Today. Copenhagen: NIAS Press (NIAS Studies in Asian Topics, 43), S. 213-237.

Eisenbruch, Maurice (1990): Classification of Natural and Supernatural Causes of Mental Distress. Development of a Mental Distress Explanatory Model Questionnaire. In: Journal of Nervous and Mental Disease 178, S. 712-719.

- (1992): The Ritual Space of Patients and Traditional Healers in Cambodia. In: Bulletin de l'Ecole française d'Extrême-Orient 79 (2), S. 283-316.

Eisenlohr, Patrick (2004): Temporalities of Community. Ancestral Language, Pilgrimage, and Diasporic Belonging in Mauritius. In: Journal of Linguistic Anthropology 14 (1), S. 81-98.

- (2015): Mediating Disjunctures of Time. Ancestral Chronotopes in Ritual and Media Practices. In: Anthropological Quarterly 88 (2), S. 281-304.

Elder-Vass, Dave (2014): Disassembling Actor-Network Theory. In: Philosophy of the Social Sciences 45 (1), S. 100-121.

Endres, Kirsten (2011): Performing the Divine. Mediums, Markets and Modernity in Urban Vietnam. Copenhagen: NIAS Press (NIAS Monographs, 118).

Endres, Kirsten; Lauser, Andrea (Hg.) (2011): Engaging the Spirit World. Popular Beliefs and Practices in Modern Southeast Asia. New York: Berghahn Books. 
Etcheson, Craig (2004): Reconciliation in Cambodia. Theory and Practice. Washington, D.C.: Etcheson.

Evans, Grant (2002): Revolution and Royal Style. Problems of Post-Socialist Legitimacy in Laos. In: Cris Shore und Stephen Nugent (Hg.): Elite Cultures. Anthropological Perspectives. New York: Routledge (ASA Monographs, 38), S. 189-208.

Evans-Pritchard, Edward Evan (1976): Witchcraft, Oracles, and Magic among the Azande. Unter Mitarbeit von Eva Gillies. Abridged ed. Oxford: Clarendon Press.

Fabian, Johannes (1983): Time and the Other. How Anthropology makes its Object. New York: Columbia University Press.

Falzon, Mark-Anthony (Hg.) (2009): Multi-Sited Ethnography. Theory, Praxis and Locality in Contemporary Research. Oxford: Routledge.

Feuchtwang, Stephan (2011): After the Event. The Transmission of Grievous Loss in Germany, China and Taiwan. New York: Berghahn Books.

Fjelstad, Karen; Nguyễn, Thị Hiên (Hg.) (2006): Possessed by the Spirits.

Mediumship in Contemporary Vietnamese Communities. Ithaca, NY: Cornell Southeast Asia Program Publications.

Forest, Alain (1992): Le Culte des Genies Protecteurs au Cambodge. Analyse et Traduction d'un Corpus de Textes sur les Neak Ta. Paris: L'Harmattan (Collection Recherches Asiatiques).

- (2008): Buddhism and Reform : Imposed Reforms and Popular Aspirations. Some Historical Notes to Aid Reflection. In: Alexandra Kent und David Chandler (Hg.): People of Virtue. Reconfiguring Religion, Power and Morality in Cambodia Today. Copenhagen: NIAS Press (NIAS Studies in Asian Topics, 43), S. 16-34.

- (2012): Histoire Religieuse du Cambodge. Un Royaume d'Enchantement. Paris: Les Indes Savantes.

Foucault, Michel (1998): Die Ordnung des Diskurses. [Inauguralvorlesung am Collège de France, 2. Dezember 1970]. Unter Mitarbeit von Ralf Konersmann. Frankfurt am Main: Fischer (Fischer Taschenbücher, 50126).

Fox, James J. (1973): On Bad Death and the Left Hand: A Study of Rotinese Symbolic Inversions. In: Rodney Needham (Hg.): Right \& Left. Essays on Dual Symbolic Classification. Chicago: University of Chicago Press, S. 342-369.

Foxeus, Niklas (2017): Possessed for Success. Prosperity Buddhism and the Cult of the Guardians of the Treasure Trove in Upper Burma. In: Contemporary Buddhism 18 (1), S. 108-139.

Freilich, Morris (1970): Marginal Natives. Anthropologists at Work. New York: Harper \& Row. 
Gaudes, Rüdiger (1993): Kaundinya, Preah Thaong, and the 'Nagi Soma'. Some Aspects of a Cambodian Legend. In: Asian Folklore Studies 52 (2), S. 333-358.

Gombrich, Richard F. (2006): Theravāda Buddhism. A Social History from Ancient Benares to Modern Colombo. Second Edition. New York: Routledge (The Library of Religious Beliefs and Practices).

Gordon, Avery F. (2008): Ghostly Matters: Haunting and the Sociological Imagination. Minnesota: University of Minnesota Press.

Gottlieb, Alma (1995): Beyond the Lonely Anthropologist. Collaboration in Research and Writing. In: American Anthropologist 97 (1), S. 21-26.

Gottowik, Volker (Hg.) (2014): Dynamics of Religion in Southeast Asia. Magic and Modernity. Amsterdam: Amsterdam University Press (AUP).

Grabowski, Volker (2011): Heritage and Nationalism in the Preah Vihear Dispute. SEATIDE Online Paper No. 3. SEATIDE. Paris. Online unter https:// hal.archives-ouvertes.fr/hal-01963845, letzter Abruf am 04.02.2020.

Graham, Colum (2013): Cambodia's Inverted Mandala. New Mandala. Australian National University. Canberra. Online unter http://www.newmandala.org/cambodias-inverted-mandala/, letzter Abruf am 04.02.2020.

Gray, Tallyn (2014): Justice and Transition in Cambodia 1979-2014. Process, Meaning and Narrative. Westminster: Westminster Law School.

Guggenheim, Michael; Potthast, Jörg (2012): Symmetrical twins. On the relationship between Actor-Network theory and the sociology of critical capacities. In: European Journal of Social Theory 15 (2), S. 157-178.

Guillou, Anne Yvonne (2012): An Alternative Memory of the Khmer Rouge Genocide. The Dead of the Mass Graves and the Land Guardian Spirits [Neak Ta]. In: South East Asia Research 20 (2), S. 207-226.

- (2013): The Living Archeology of a Painful Heritage. The First and Second Life of the Khmer Rouge Mass Graves. In: Michael S. Falser und Monica Juneja (Hg.): "Archaeologizing" Heritage? Transcultural Entanglements Between Local Social Practices and Global Virtual Realities. Berlin, New York: Springer (Transcultural Research), S. 263-274.

- (2016): Traces of Destruction and Thread of Continuity in Post-Genocide Cambodia. In: Veena Das und Clara Han (Hg.): Living and Dying in the Contemporary World. A Compendium. Berkeley: University of California Press, S. 729-742.

- (2017a): The (Re)configuration of the Buddhist Field in Post-Communist Cambodia. In: Michel Picard (Hg.): The Appropriation of Religion in Southeast Asia and Beyond. New York: Palgrave, S. 67-93.

- (2017b): The Integration of a Former Khmer Rouge Stronghold into the Cambodian National Territory. Land Management, Tourist Development and Ritual Activities. Vortrag (ICAS10). Chiang Mai, 23.07.2017. 
- (2017c): Khmer Potent Places. Pāramī and the Localisation of Buddhism and Monarchy in Cambodia. In: The Asia Pacific Journal of Anthropology 62 (2),

S. $1-23$.

- (2018): The "Master of the Land". Cult Activities Around Pol Pot's Tomb. In: Journal of Genocide Research 20 (2), S. 275-289.

Günther, Jelka (2018): (Thai-)Land in Bewegung. Nostalgien und inländische Tourismusmobilitäten. Dissertation. Online unter http://hdl.handle.net/11858/00-1735-0000-002E-E50A-7, letzter Abruf am 04.02.2020.

Guthrie, Elizabeth (2004a): A Study of the History and Cult of the Buddhist Earth Deity in Mainland Southeast Asia. Dissertation. University of Canterbury, Christchurch. Online unter https://ir.canterbury.ac.nz/handle/10092/4350, letzter Abruf am 04.02.2020.

- (2004b): Khmer Buddhism, Female Asceticism, and Salvation. In: John Marston und Elizabeth Guthrie (Hg.): History, Buddhism, and New Religious Movements in Cambodia. Honolulu: University of Hawai' ${ }^{\circ}$ Press, S. 133-149.

Gyallay-Pap, Peter (2002): Khmer Buddhism Resurfaces. In: John L. Vijghen (Hg.): People and the 1998 National Elections in Cambodia. Their Voices, Roles and Impact on Democracy. Phnom Penh: Experts for Community Research (ECR) (ECR Publications, 44), S. 109-116.

Hallowell, Alfred Irving (1960): Ojibwa Ontology Behavior and World View. Indianapolis: Bobbs-Merrill.

Hammersley, Martyn; Atkinson, Paul (2007): Ethnography. Principles in practice. 3. Aufl. London: Routledge.

Hang, Chan Sophea (2004): Stec Gamlan and Yay Deb. Worshiping Kings and Queens in Cambodia Today. In: John Marston und Elizabeth Guthrie (Hg.): History, Buddhism, and New Religious Movements in Cambodia. Honolulu: University of Hawai'i Press, S. 113-131.

Hansen, Anne Ruth (2004a): Cambodia. In: Robert E. Buswell (Hg.):

Encyclopedia of Buddhism. New York, N.Y.: Macmillan Reference USA, S. 105-110.

- (2004b): Khmer Identity and Theravāda Buddhism. In: John Marston und Elizabeth Guthrie (Hg.): History, Buddhism, and New Religious Movements in Cambodia. Honolulu: University of Hawai'i Press, S. 40-62.

- (2008): How to Behave. Buddhism and Modernity in Colonial Cambodia, 1860-1930. Chiang Mai: Silkworm Books.

Hansen, Anne Ruth; Ledgerwood, Judy (2008): At the Edge of the Forest. Narrative, Order, and Questions of Meaning in Khmer History and Society. In: Anne Ruth Hansen und Judy Ledgerwood (Hg.): At the Edge of the Forest. Essays on Cambodia, History, and Narrative in Honor of David Chandler. Ithaca, NY: Southeast Asia Program Publications, S. 1-17. 
Hardy, Cynthia; Phillips, Nelson; Clegg, Stewart (2001): Reflexivity in Organization and Management Theory. A Study of the Production of the Research 'Subject'. In: Human Relations 54 (5), S. 531-560.

Harman, Graham (2009): Prince of Networks. Bruno Latour and Metaphysics. Melbourne: Re.press.

Harris, Ian (2001): Buddhist Sangha Groupings in Cambodia. In: Buddhist Studies Review 18 (1), S. 73-105.

- (2005): Cambodian Buddhism: History and Practice. Honolulu: University of Hawai'i Press.

- (2012): Buddhism in a Dark Age: Cambodian Monks under Pol Pot. Honolulu: University of Hawai'i Press.

Hastrup, Kirsten (1990): The Ethnographic Present. A Reinvention. In: Cultural Anthropology 5 (1), S. 45-61.

Hauschild, Thomas (2012): Weihnachtsmann. Die wahre Geschichte. 1. Aufl. Frankfurt am Main: Fischer.

Hauser-Schäublin, Brigitta (2011): Preah Vihear. From Object of Colonial Desire to a Contested World Heritage Site. In: Brigitta Hauser-Schäublin (Hg.): World Heritage Angkor and Beyond. Circumstances and Implications of UNESCO Listings in Cambodia. Göttingen: Universitätsverlag Göttingen (Göttingen Studies in Cultural Property, 2), S. 33-56.

Hinton, Alexander Laban (2005): Why Did They Kill? Cambodia in the Shadow of Genocide. Berkeley [u.a.]: University of California Press.

Hinton, Devon; Hinton, Susan; Pham, Thang; Chau, Ha; Tran, Minh (2003): 'Hit by the Wind' and Temperature-Shift Panic among Vietnamese Refugees. In: Transcultural Psychiatry 40 (3), S. 342-376.

Hinton, Devon; Pich, Vuth; Chhean, Dara; Pollack, Mark H. (2005): ${ }^{\circ}$ The ghost pushes you down'. Sleep Paralysis-type Panic Attacks in a Khmer Refugee Population. In: Transcultural Psychiatry 42 (1), S. 46-77.

Hinton, Devon; Pich, Vuth; Marques, Luana; Nickerson, Angela; Pollack, Mark H. (2010): Khyâl Attacks: A Key Idiom of Distress among Traumatized Cambodia Refugees. In: Culture, Medicine and Psychiatry 34 (2), S. 244-278.

Hofmann, Stefan G.; Hinton, Devon (2014): Cross-Cultural Aspects of Anxiety Disorders. In: Current Psychiatry Reports 16 (6), S. 450.

Holt, John Clifford (2009): Spirits of the Place. Buddhism and Lao Religious Culture. Honolulu: University of Hawai' $i$ Press.

- (2012): Caring for the Dead Ritually in Cambodia. In: Southeast Asian Studies 1 (1), S. 3-75.

Huffman, Franklin E. (1983): English for Speakers of Khmer. Unter Mitarbeit von Proun Im. New Haven: Yale University Press (Yale Linguistic Series). 
Hughes, Rachel (2006): Memory and Sovereignty in Post-1979 Cambodia:

Choeung Ek and Local Genocide Memorials. In: Susan E. Cook (Hg.):

Genocide in Cambodia and Rwanda: New Perspectives. New Brunswick, NJ:

Transaction Publishers, S. 269-292.

Hunter, Jack (2015): 'Spirits are the Problem'. Anthropology and Conceptualising Spiritual Beings. In: Journal for the Study of Religious Experience 1 (1), S. 76-86.

Hunter, Jack; Luke, David (Hg.) (2014): Talking with the Spirits. Ethnographies from between the Worlds. Brisbane: Daily Grail Publishing.

Jackson, Peter A. (1999a): Royal Spirits, Chinese Gods, and Magic Monks.

Thailand's Boom-Time Religions of Prosperity. In: South East Asia Research 7

(3), S. 245-320.

- (1999b): The Enchanting Spirit of Thai Capitalism. The Cult of Luang Phor

Khoon and the Post-Modernization of Thai Buddhism. In: South East Asia

Research 7 (1), S. 5-60.

- (2009): Markets, Media, and Magic. Thailand's Monarch as a 'Virtual Deity'.

In: Inter-Asia Cultural Studies 10 (3), S. 361-380.

- (2016): The Supernaturalization of Thai Political Culture. Thailand's Magical Stamps of Approval at the Nexus of Media, Market and State. In: SOJOURN Journal of Social Issues in Southeast Asia 31 (3), S. 826-879. Online unter https://muse.jhu.edu/article/647410/pdf, letzter Abruf am 04.02.2020.

Jackson, Peter A.; Brac de la Perrière, Bénédicte (Hg.) (i.E.): A World Ever More Enchanted. Efflorescing Spirit Cults in Buddhist Southeast Asia.

Copenhagen: NIAS Press.

Jacobsen, Trude (2008): Lost Goddesses. The Denial of Female Power in Cambodian History. Copenhagen: NIAS Press (Gendering Asia).

Jacobsen, Trude; Stuart-Fox, Martin (2013): Power and Political Culture in Cambodia. National University of Singapur (Asia Research Institute Working Paper Series, 200). Online unter https:/ / ari.nus.edu.sg/wpcontent/uploads/2013/05/201305-WPS-200.pdf, letzter Abruf am 04.02.2020.

James, Alan (1990): Vietnam's Withdrawal from Cambodia (1989- ). In: Alan James (Hg.): Peacekeeping in International Politics. Houndmills [u.a.]: Palgrave (Studies in International Security, 29), S. 269-271.

Jensen, C. B.; Blok, A. (2013): Techno-animism in Japan. Shinto Cosmograms, Actor-network Theory, and the Enabling Powers of Non-human Agencies. In: Theory, Culture \& Society 30 (2), S. 84-115.

Karbaum, Markus (2008): Kambodscha unter Hun Sen. Informelle Institutionen, Politische Kultur und Herrschaftslegitimität. Münster: LIT.

- (2014a): Die Neuerfindung des Buddhismus in Kambodscha. In: südostasien (3), S. 10-12. 
- (2014b): Hun Sen sammelt seine Truppen. Blogeintrag. Online unter https:/ / cambodia-news.net/2014/02/23/hun-sen-sammelt-seine-truppen/, zuletzt aktualisiert am 04.02.2020.

Kaviraj, Sudipta (2005): An Outline of a Revisionist Theory of Modernity. In: European Journal of Sociology 46 (3), S. 497-526.

Kendall, Laurel (2001): The Cultural Politics of "Superstition" in the Korean Shaman World. Modernity Constructs its Other. In: Linda H. Connor und Geoffrey Samuel (Hg.): Healing Powers and Modernity. Traditional Medicine, Shamanism, and Science in Asian Societies. Westport, CT, London: Bergin \& Garvey, S. 25-41.

Kent, Alexandra (2003): Recovery of the Collective Spirit. The Role of Revival of Buddhism in Cambodia. Working Paper No 8. Department of Social Anthropology. Göteburg University. Online unter https://www.gu.se/english/research/publication?publicationId=71410, letzter Abruf am 04.02.2020.

- (2006): Reconfiguring Security. Buddhism and Moral Legitimacy in Cambodia. In: Security Dialogue 37 (3), S. 343-361.

- (2007): Purchasing Power and Pagodas. The Sīma Monastic Boundary and Consumer Politics in Cambodia. In: Journal of Southeast Asian Studies 38 (2), S. 335-354 .

- (2008): Peace, Power and Pagodas in Present-Day Cambodia. In: Contemporary Buddhism 9 (1), S. 77-97.

- (2011): Sheltered by Dhamma. Reflecting on Gender, Security and Religion in Cambodia. In: Journal of Southeast Asian Studies 42 (02), S. 193-209.

Kent, Alexandra; Chandler, David (Hg.) (2008): People of Virtue. Reconfiguring Religion, Power and Morality in Cambodia Today. Copenhagen: NIAS Press (NIAS Studies in Asian Topics, 43).

Keyes, Charles F. (1973): The Power of Merit [revised]. Bangkok: The Buddhist Association of Thailand, Annual Publication. In: Visakha Puja B.E. 2516, S. 95-102.

- (1977): Millennialism, Theravada Buddhism, and Thai Society. In: The Journal of Asian Studies 36 (2), S. 283-302.

- (1983): Merit-transference in the Kammic Theory of Popular Theravāda Buddhism. In: Charles F. Keyes und E. Valentine Daniel (Hg.): Karma. An Anthropological Inquiry. Berkeley, London: University of California Press, S. 261-286.

- (1989): Buddhist Politics and Their Revolutionary Origins in Thailand. In: International Political Science Review 10 (2), S. 121-142.

- (1990): Cambodia and the Legacy of Angkor. In: Cultural Survival Quarterly 14 (3), S. 60-63. 
- (1994): Communist Revolution and the Buddhist Past in Cambodia. In: Charles F. Keyes, Laurel Kendall und Helen Hardacre (Hg.): Asian Visions of Authority. Religion and the Modern States of East and Southeast Asia. Honolulu: University of Hawai'i Press, S. 43-73.

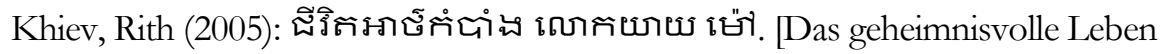
von lok yāy Mao]. Phnom Penh: Indradevi.

Khing, Hoc Dy (2008): Neak Mean Boun "être-de-mérites" dans la Culture et la Littérature du Cambodge. In: Péninsule (Paris) 56, S. 71-106.

Khy, Sovanratana (2008): Buddhist Education Today. Progress and Challenges.

In: Alexandra Kent und David Chandler (Hg.): People of Virtue.

Reconfiguring Religion, Power and Morality in Cambodia Today.

Copenhagen: NIAS Press (NIAS Studies in Asian Topics, 43), S. 257-271.

Kidron, Carol A. (2014): Glocal Spaces Lost in Translation. An Ethnographic

Reading of Deserted Genocide Monuments in Cambodia. Southeast Asia

Research Colloquium. Humboldt Universität Berlin. Berlin, 09.12.2014.

Kiernan, Ben (1989): The American Bombardment of Kampuchea. In: Vietnam Generation 1 (1), S. $4-41$.

Kiernan, Ben (2003): The Demography of Genocide in Southeast Asia. The Death Tolls in Cambodia, 1975-79, and East Timor, 1975-80. In: Critical Asian Studies 35 (4), S. 585-597.

Kiernan, Ben; Owen, Taylor (2006): Bombs over Cambodia. In: The Walrus, S. 62-69.

Klima, Alan (2004): Thai Love Thai. Financing Emotion in Post-Crash Thailand. In: Ethnos 69 (4), S. 445-464.

Kulke, Hermann (1974): Der Devarāja-Kult. Legitimation und

Herrscherapotheose im Angkor-Reich. In: Saeculum 25 (1), S. 24-55.

Kwon, Heonik (2006): After the Massacre: Commemoration and Consolation in Ha My and My Lai. Berkeley: University of California Press.

- (2007): The Dollarization of Vietnamese Ghost Money. In: Journal of the Royal Anthropological Institute 13 (1), S. 73-90.

- (2008): Ghosts of War in Vietnam. Cambridge: Cambridge University Press.

Ladwig, Patrice (2011): Can Things Reach the Dead? The Ontological Status of

Objects and the Study of Lao Buddhist Rituals for the Spirits of the

Deceased. In: Kirsten Endres und Andrea Lauser (Hg.): Engaging the Spirit

World. Popular Beliefs and Practices in Modern Southeast Asia. New York:

Berghahn Books, S. 19-41.

- (2013): Haunting the State. Rumours, Spectral Apparitions and the Longing for Buddhist Charisma in Laos. In: Asian Studies Review 37 (4), S. 509-526.

Langford, Jean M. (2013): Consoling Ghosts. Stories of Medicine and Mourning from Southeast Asians in Exile. Minnesota: University of Minnesota Press. 
Latour, Bruno (1987): Science in Action. How to Follow Scientists and Engineers through Society. Cambridge, Mass.: Harvard University Press.

- (1990): Drawing Things together. In: Michael Lynch und Steve Woolgar (Hg.): Representation in Scientific Practice. Cambridge Mass, London: MIT Press, S. 19-68.

- (1991): Technology is Society made Durable. In: John Law (Hg.): A Sociology of Monsters. Essays on Power, Technology, and Domination. London, New York: Routledge (Sociological Review Monograph, 38), S. 103-131.

- (1993): We Have Never Been Modern. Cambridge, Mass.: Harvard University Press.

- (1996): Der Berliner Schlüssel. Berlin: Akademie Verlag.

- (1999a): On Recalling ANT. In: The Sociological Review 47 (S1), S. 15-25.

- (1999b): Pandora's Hope. Essays on the Reality of Science Studies. Cambridge, Mass.: Harvard University Press.

- (2002): Die Hoffnung der Pandora. Untersuchungen zur Wirklichkeit der Wissenschaft. 1. Aufl. Frankfurt am Main: Suhrkamp (Suhrkamp Taschenbuch Wissenschaft, 1595).

- (2005): Reassembling the Social: An Introduction to Actor-Network-Theory. Oxford [u.a.]: Oxford University Press.

- (2006): Technik ist die stabilisierte Gesellschaft. In: Andréa Belliger und David J. Krieger (Hg.): ANThology. Ein einführendes Handbuch zur AkteurNetzwerk-Theorie. Bielefeld: transcript Verlag, S. 369-397.

- (2009): Perspectivism: 'Type' or 'Bomb’? In: Anthropology Today 25 (2), S. 1-2.

- (2010): On the Modern Cult of the Factish Gods. Durham, London: Duke University Press (Science and Cultural Theory).

- (2013a): An Inquiry into Modes of Existence. An Anthropology of the Moderns. Cambridge, London: Harvard University Press.

— (2013b): Rejoicing. Or the Torments of Religious Speech. Oxford: Polity Press.

- (2014): Existenzweisen. Eine Anthropologie der Modernen. Unter Mitarbeit von Gustav Roßler. 1. Aufl., neue Ausg. Berlin: Suhrkamp.

Latour, Bruno; Woolgar, Steve (1986): Laboratory Life. The Construction of Scientific Facts. Princeton Paperback ed. [Nachdr.]. Princeton, NJ: Princeton University Press (Princeton Paperbacks).

Lauser, Andrea (2008): Zwischen Heldenverehrung und Geisterkult. Politik und Religion im gegenwärtigen Vietnam. In: Zeitschrift für Ethnologie (133), S. 121-144. 
- (2015): Andrea Lauser in Conversation with the Filmmakers Katarzyna Ancuta and Solarsin Ngoenwichit From Thailand and Mattie Do From Laos. Ghost Movies, their Makers and their Audiences. Working Paper No 17. Dynamics of Religion in Southeast Asia. Göttingen. Online unter http://www.dorisea.de/de/node/1896, letzter Abruf am 04.02.2020.

- (2018): Lên đồng - Kult, Kulturerbe, Spektakel. Ein vietnamesisches Ritual: Von der kontrollierten Besessenheit zur Bühnenperformance. In: Michael Kraus, Bieker Ulrike, Lioba Rossbach de Olmos, Ingo W. Schröder, Dagmar Schweitzer de Palacios und Stéphane Voell (Hg.): Ich durfte den Jaguar am Waldrand sprechen. Festschrift für Mark Münzel zum 75. Geburtstag. Marburg: Curupira, S. 179-207.

Lauser, Andrea; Endres, Kirsten (2011): Introduction: Articulatory Spaces of Modern Enchantment in Southeast Asia. In: Kirsten Endres und Andrea Lauser (Hg.): Engaging the Spirit World. Popular Beliefs and Practices in Modern Southeast Asia. New York: Berghahn Books.

Law, John (2007): Actor Network Theory and Material Semiotics. Online unter http://www.heterogeneities.net/publications/Law2007ANTandMaterialSemi otics.pdf, letzter Abruf am 04.02.2020.

Leclère, Adhémard (1894): La Médecine chez les Cambodgiens. In: Revue Scientifique 2 (23), S. 715-721.

- (1895): La Sorcellerie chez les Cambodgiens. In: Revue Scientifique 3 (5), S. 129-136.

- (1898): La Divination chez les Cambodgiens. Partie 2. In: La Revue Scientifique 19 (10), S. 585-588. Online unter http://aefek.free.fr/iso_album/divination2.pdf, letzter Abruf am 04.02.2020.

- (1899): Le Buddhisme au Cambodge. Paris: E. Leroux.

- (1907): Histoire de Kampot et de la Rebellion de cette Province. In: Revue Indochinoise 60-61, S. 828.

- (1911): Le Sdach Kan. Saigon: Imprimerie Coloniale.

- (1914): Histoire du Cambodge. Depuis Le 1er Siecle de Notre Ere. Paris: Librairie Paul Guethner.

Ledgerwood, Judy (2008a): Buddhist Practice in Rural Kandal Province, 1960 and 2003. An Essay in Honor of May M. Ebihara. In: Alexandra Kent und David Chandler (Hg.): People of Virtue. Reconfiguring Religion, Power and Morality in Cambodia Today. Copenhagen: NIAS Press (NIAS Studies in Asian Topics, 43), S. 147-168.

- (2008b): Ritual in 1990 Cambodian Political Theater. New Songs at the Edge of the Forest. In: Anne Ruth Hansen und Judy Ledgerwood (Hg.): At the Edge of the Forest. Essays on Cambodia, History, and Narrative in Honor of David Chandler. Ithaca, NY: Southeast Asia Program Publications,

S. 195-220. 
- (2012): Buddhist Ritual and the Reordering of Social Relations in Cambodia. In: South East Asia Research 20 (2), S. 191-206.

LeVine, Peg (2010): Love and Dread in Cambodia. Weddings, Births, and Ritual Harm under the Khmer Rouge. Singapore: NUS Press.

Lezaun, Javier (2014): A Reader's Guide to the 'Ontological Turn'. Part 2.

Somatmosphere. Online unter http:/ / somatosphere.net/2014/01/a-readersguide-to-the-ontological-turn-part-2.html, letzter Abruf am 04.02.2020.

LICADHO (2009): Land Grabbing \& Poverty in Cambodia. The Myth of Development. Online unter http://www.licadhocambodia.org/reports.php?perm=134, letzter Abruf am 04.02.2020.

Lincoln, Martha; Lincoln, Bruce (2015): Toward a Critical Hauntology. Bare Afterlife and the Ghosts of Ba Chúc. In: Comparative Studies in Society and History 57 (01), S. 191-220.

Linton, Suzannah (2004): Reconciliation in Cambodia. Phnom Penh, Cambodia: Documentation Center of Cambodia.

Locard, Henri; Chandler, David (2004): Pol Pot's little red book. The sayings of Angkar. Bangkok: Silkworm Books.

Lopez, Donald S. (1988): The Heart Sūtra Explained. Indian and Tibetan Commentaries. Albany, N.Y.: State University of New York Press (SUNY Series in Buddhist Studies).

Löschmann, Heike (1989): Die Rolle des Buddhismus in der gesellschaftlichen Entwicklung der Volksrepublik Kampuchea nach der Befreiung vom PolPot-Regime 1979 bis Mitte der achtziger Jahre. Dissertation. Humboldt Universität Berlin, Berlin.

Luchesi, Brigitte (2015): Götter zu Gast im Bazar. Nordindische Jhanki-Bilder als Stimuli der Einbildungskraft. In: Lucia Traut und Annette Wilke (Hg.): Religion - Imagination - Ästhetik. Vorstellungs- und Sinneswelten in Religion und Kultur. Göttingen, Germany: Vandenhoeck \& Ruprecht (Critical Studies in Religion/Religionswissenschaft, 7), S. 81-106.

Luke, David (2013): Anthropology and Parapsychology. Still Hostile Sisters in Science? In: Time and Mind 3 (3), S. 245-265.

Malarney, Shaun Kingsley (2001): 'The Fatherland Remembers Your Sacrifice'. Commemorating War Dead in North Vietnam. In: Hue-Tam Ho Tai (Hg.): The Country of Memory. Remaking the Past in Late Socialist Vietnam. Berkeley: University of California Press, S. 46-76.

Malinowski, Bronislaw (1922): Argonauts of the Western Pacific. An Account of Native Enterprise and Adventure in the Archipelagoes of Melanesian New Guinea. London: Routledge \& Kegan.

Marcus, George E. (1995): Ethnography in/of the World System. The Emergence of Multi-Sited Ethnography. In: Annual Review of Anthropology (24), S. 95-117. 
Marston, John (2004): Clay into Stone. A Modern-Day Tāpas'. In: John Marston und Elizabeth Guthrie (Hg.): History, Buddhism, and New Religious Movements in Cambodia. Honolulu: University of Hawai'i Press, S. 170-192.

- (2006): Death, Memory and Building: The Non-Cremation of a Cambodian Monk. In: Journal of Southeast Asian Studies 37 (03), S. 491-505.

- (2008a): Constructing Narratives of Order: Religious-Building Projects and Moral Chaos. In: Anne Ruth Hansen und Judy Ledgerwood (Hg.): At the Edge of the Forest. Essays on Cambodia, History, and Narrative in Honor of David Chandler. Ithaca, NY: Southeast Asia Program Publications, S. 163-194.

- (2008b): Reconstructing 'Ancient' Cambodian Buddhism. In: Contemporary Buddhism 9 (1), S. 99-121.

- (2008c): Wat Preah Thammalanka and the Legend of Lok Ta Nen. In: Alexandra Kent und David Chandler (Hg.): People of Virtue. Reconfiguring Religion, Power and Morality in Cambodia Today. Copenhagen: NIAS Press (NIAS Studies in Asian Topics, 43), S. 85-108.

Marston, John; Guthrie, Elizabeth (Hg.) (2004): History, Buddhism, and New Religious Movements in Cambodia. Honolulu: University of Hawai'i Press.

Masuzawa, Tomoko (2005): The Invention of World Religions. Or, how European Universalism was Preserved in the Language of Pluralism. Chicago [u.a.]: University of Chicago Press.

Maurer, Ernstpeter (2007): Zwei Reiche. Apokalyptik in biblisch-theologischer Perspektive. In: Bernd Ulrich Schipper und Georg Plasger (Hg.): Apokalyptik und kein Ende? Göttingen: Vandenhoeck \& Ruprecht (Biblisch-Theologische Schwerpunkte, Bd. 29), S. 131-150.

McDaniel, Justin (2011): The Lovelorn Ghost and the Magical Monk. Practicing Buddhism in Modern Thailand. New York: Columbia University Press.

Michaels, Axel (1998): Der Hinduismus. Geschichte und Gegenwart. München: Beck. Online unter http://www.gbv.de/dms/fazrez/FR11999102863764.pdf, letzter Abruf am 04.02.2020

- (2004): Hinduism. Past and present. Princeton, Oxford: Princeton University Press (Princeton Paperbacks).

Milladino, Pedro (2014): The Legend of the Aap. Online unter http://www.khmer440.com/k/2014/02/9312/, letzter Abruf am 04.02.2020.

Min, Zin (2001): The Power of Hpoun. In: The Irrawaddy 9 (9). Online unter http://www2.irrawaddy.com/article.php?art_id=2471\&page=1, letzter Abruf am 04.02.20. 
Münzel, Mark (2017): Jaguar und Wildschwein, eine Fabel für Menschen. Oder:

Der Aufstieg des Jaguar zum Himmel, ein Karriereleitfaden für

Wissenschaftler. Institut für Ethnologie. Göttingen (GISCA Occasional Paper

Series, 9). Online unter http://resolver.sub.uni-goettingen.de/purl?gs-

1/14228, letzter Abruf am 04.02.2020.

Mus, Paul (2011 [1933]): India seen from the East. Indian and Indigenous Cults in Champa. Unter Mitarbeit von Ian William Mabbett und David Chandler.

Revised edition. Caulfield: Monash University Press (Monash Papers on Southeast Asia, 72).

Needham, Susan; Quintiliani, Karen (2008): Cambodians in Long Beach. Charleston, SC: Arcadia Publishing (Images of America).

Ngo, Duc Thinh (2009): Len Dong. Spirit Journeys in Contemporary Urban Vietnam. In: International Journal of Intangible Heritage 4, S. 80-91.

Nissen, Christine J. (2008): Buddhism and Corruption. In: Alexandra Kent und David Chandler (Hg.): People of Virtue. Reconfiguring Religion, Power and Morality in Cambodia Today. Copenhagen: NIAS Press (NIAS Studies in Asian Topics, 43), S. 272-292.

Norén-Nilsson, Astrid (2013): Performance as (Re)Incarnation: The Sdech Kân Narrative. In: Journal of Southeast Asian Studies 44 (01), S. 4-23.

- (2016): Cambodia's Second Kingdom. Nation, Imagination, and Democracy. Ithaca, New York: Southeast Asia Program Publications (Studies on Southeast Asia, 68).

O'Lemmon, Matthew (2014): Spirit Cults and Buddhist Practice in Kep Province, Cambodia. In: Journal of Southeast Asian Studies 45 (01), S. 25-49.

Ochoa, Todd Ramón (2010): Prendas - Ngangas - Enquiso. Turbulence and the Influence of the Dead in Cuban-Kongo Material Culture. In: Cultural Anthropology 25 (3), S. 387-420.

Ong, Aihwa (1987): Spirits of Resistance and Capitalist Discipline: Factory Women in Malaysia. New York: SUNY Press.

Ovesen, Jan; Trankell, Ing-Britt (2010): Cambodians and their Doctors. A Medical Anthropology of Colonial and post-Colonial Cambodia. Copenhagen: NIAS Press (NIAS Monographs, 117).

Pasuk, Phongpaichit; Baker, Chris (2008): The Spirits, the Stars, and Thai Politics. Vortrag. Siam Society. Bangkok, 02.12.2008. Online unter http:/ /pioneer.netserv.chula.ac.th/ ppasuk/spiritsstarspolitics.pdf, letzter Abruf am 04.02.2020.

Pattana, Kitiarsa (2002): "You May Not Believe, But Never Offend the Spirits". Spirit-Medium Cults and Popular Media in Modern Thailand. In: Richard King und Timothy J. Craig (Hg.): Global goes Local. Popular Culture in Asia. Vancouver, B.C.: UBC Press, S. 160-176. 
- (2005a): Beyond Syncretism. Hybridization of Popular Religion in Contemporary Thailand. In: Journal of Southeast Asian Studies 36 (3), S. 461-487.

- (2005b): Magic Monks and Spirit Mediums in the Politics of Thai Popular Religion. In: Inter-Asia Cultural Studies 6 (2), S. 209-226.

- (Hg.) (2008): Religious Commodifications in Asia. Marketing Gods. London: Routledge.

- (2012): Mediums, Monks, and Amulets. Thai Popular Buddhism Today. Chiang Mai: Silkworm Books.

Pedersen, Morten Axel (2012): Common Nonsense. A Review of Certain Recent Reviews of the "Ontological Turn". Hg. v. Anthropology of this Century. London (5). Online unter http:/ /aotcpress.com/articles/common_nonsense/, letzter Abruf am 04.02.2020.

Phạm, Quỳnh Phương (2009): Hero and Deity. Tran Hung Dao and the Resurgence of Popular Religion in Vietnam. Chiang Mai: Mekong Press.

Pina-Cabral, João D. E. (2000): The Ethnographic Present Revisited. In: Social Anthropology 8 (3), S. 341-348.

Platenkamp, Jos (2007): Spirit Representations in Southeast Asia. A Comparative View. In: Frédéric Laugrand und Jarich G. Oosten (Hg.): La Nature des Esprits dans les Cosmologies Autochtones. Nature of Spirits in Aboriginal Cosmologies. Québec: Presses de l'Université Laval (Collection Mondes Autochtones), S. 99-129.

- (2010): Political Change and Ritual Tenacity. The New Year's Ritual of Luang Prabang, Laos. In: André Iteanu (Hg.): La Cohérence des Sociétés. Mélanges en Hommage à Daniel de Coppet. Paris: Éditions de la Maison des sciences de l'homme, S. 193-234.

Poonnatree, Jiaviriyaboonya (i.E.): Looking for Fortune in the City. The Enchantment of Divination, Magic and Spiritual Rites in Cambodian Urban Culture. In: Peter A. Jackson und Bénédicte Brac de la Perrière (Hg.): A World Ever More Enchanted. Efflorescing Spirit Cults in Buddhist Southeast Asia. Copenhagen: NIAS Press.

Porée, Guy; Maspéro, Éveline (1938): Mœurs et Coutumes des Khmérs. Collection de Documents et de Témoignages pour servir a l'Histoire de notre Temps. Preface de M. Georges Coedès. Paris: Payot.

Porée-Maspéro, Éveline (1961a): Krŏn Pãli et Rites de la Maison. In: Anthropos 56 (1-2, 3-4, 5-6), 179-251, 548-628, 883-929.

- (1961b): Traditions Orales de Pursat et de Kampot. In: Artibus Asiae 24 (3/4), S. 394-398.

- (1962): Étude sur les Rites Agraires chez les Cambodgiens. Tome I. Paris, La Haye: Mouton \& Co (Monde d'Outre-Mer Passé et Présent: Études, 14). 
- (1969): Étude sur les Rites Agraires chez les Cambodgiens. Tome III. Paris, La Haye: Mouton \& Co (Monde d'Outre-Mer Passé et Présent: Études, 14).

Pou, Saveros (1987-1988): Notes on Brahmanic Gods in Theravadin Cambodia. Colette Caillat Felicitation Volume. In: Indologica Taurinensia (XVI), S. 339-351.

Pou, Saveros; Ang, Chouléan (1987-1990): Le Vocabulaire Khmer Relatif au Surnaturel. Paris: Cedoreck (Seksa Khmer, 10-13).

Restivo, Sal (2011): Bruno Latour. The Once and Future Philosopher. In: George Ritzer und Jeffrey Stepnisky (Hg.): The Wiley-Blackwell Companion to Major Social Theorists, Bd. 2. Malden, MA: Wiley-Blackwell (Blackwell Companions to Sociology, 27), S. 520-540.

Ros, Chantrabot (2007): Preah Sdach Kân. Phnom Penh: Angkor Bookstore Press.

Salemink, Oscar (2008): Spirits Of Consumption And The Capitalist Ethic In Vietnam. In: Kitiarsa Pattana (Hg.): Religious Commodifications in Asia. Marketing Gods. London: Routledge, S. 147-168.

Sanjek, Roger (1991): The Ethnographic Present. In: Man 26 (4), S. 609-628.

Schechner, Richard (1977): Essays on Performance Theory. 1970-1976. New York: Drama Book Specialists.

Schmidt, Bettina; Huskinson, Lucy (2010): Introduction. In: Bettina Schmidt und Lucy Huskinson (Hg.): Spirit Possession and Trance. New Interdisciplinary Perspectives. New York: Continuum (Continuum Advances in Religious Studies), S. 1-15.

Schober, Juliane (2005): Buddhist Visions of Moral Authority and Modernity in Burma. In: Monique Skidmore (Hg.): Burma at the Turn of the 21st Century. Honolulu: University of Hawai'i Press, S. 113-132.

Schüttpelz, Erhard (2013): Elemente einer Akteur-Medien-Theorie. In: Tristan Thielmann, Erhard Schüttpelz und Peter Gendolla (Hg.): Akteur-MedienTheorie. Bielefeld: transcript Verlag, S. 9-70.

Scopis, Sheila (2011): Cambodia's String Economy. PhD Thesis. The University of Melbourne, Melbourne School of Land and Environment - Resource Management and Geography.

Scott, Rachelle M. (2017): Religion, Prosperity, and Lottery Lore. The Linkage of New Religious Networks to Gambling Practices in Thailand. In: Juliette Koning und Gwenaël Njoto-Feillard (Hg.): New Religiosities, Modern Capitalism, and Moral Complexities in Southeast Asia. Singapore: Palgrave (Religion and Society in Asia Pacific, 1), S. 223-245.

Sharp, Bruce (2008): Counting Hell. The Death Toll of the Khmer Rouge Regime in Cambodia. Online unter http://www.mekong.net/cambodia/deaths.htm, letzter Abruf am 04.02.2020. 
Sorrentino, Paul (2013): Áp Vong: Appliquer l'Âme. Rituels Non-Médiumniques de Possession par les Morts dans le Nord du Vietnam. Thèse de Doctorat en Ethnologie. Paris.

- (2018): A l'Épreuve de la Possession. Chronique d'une Innovation Rituelle dans le Vietnam Contemporain. Nanterre: Société d'Ethnologie (Recherches sur la Haute Asie, 23).

Sprenger, Guido (2014): Where the Dead Go to the Market. Market and Ritual as Social Systems in Upland Southeast Asia. In: Volker Gottowik (Hg.):

Dynamics of Religion in Southeast Asia. Magic and Modernity. Amsterdam: Amsterdam University Press (AUP), S. 75-90.

- (2016): Graded Personhood. Human and Non-Human Actors in the Southeast Asian Uplands. In: Kaj Århem und Guido Sprenger (Hg.): Animism in Southeast Asia. London, New York: Routledge (Routledge Contemporary Southeast Asia Series, 77), S. 73-90.

- (2017): Communicated into Being. Systems Theory and the Shifting of Ontological Status. In: Anthropological Theory 17 (1), S. 108-132.

Strangio, Sebastian (2014): Hun Sen's Cambodia. New Haven, London: Yale University Press.

Swearer, Donald K. (2010): The Buddhist World of Southeast Asia. Albany: State University of New York Press.

Tabeau, Ewa (2010): Khmer Rouge Victims in Cambodia, April 1975 - January 1979. A Critical Assessment of Major Estimates. Unter Mitarbeit von Kheam They. Online unter https://www.eccc.gov.kh/sites/default/files/documents/courtdoc/D140_1 _1_Public_Redacted_EN.PDF, letzter Abruf am 04.02.20.

Tai, Hue-Tam Ho (Hg.) (2001): The Country of Memory. Remaking the Past in Late Socialist Vietnam. Berkeley: University of California Press.

Tambiah, Stanley Jeyaraja (1976): World Conqueror and World Renouncer. A Study of Buddhism and Polity in Thailand against a Historical Background. Cambridge, New York: Cambridge University Press (Cambridge Studies in Social Anthropology, 15).

Tappe, Oliver (2013): Faces and Facets of the Kantosou Kou Xat. The Lao "National Liberation Struggle" in State Commemoration and Historiography. In: Asian Studies Review 37 (4), S. 433-450.

Theara, Thun (2016): Review: Ros Chantrabot, Preah Sdach Kân [God-King Kân]. Phnom Penh: Angkor Bookstore Press, 2007. Havard-Yenching Institute. Online unter https://www.harvard-yenching.org/features/preahsdach-k-n-god-king-k-n, letzter Abruf am 04.02.20. 
Thompson, Ashley (2004a): The Future of Cambodia's Past. A Messianic MiddlePeriod Cambodian Royal Cult. In: John Marston und Elizabeth Guthrie (Hg.): History, Buddhism, and New Religious Movements in Cambodia. Honolulu: University of Hawai'i Press, S. 13-39.

- (2004b): The Suffering of the Kings. Substitute Bodies, Healing, and Justice in Cambodia. In: John Marston und Elizabeth Guthrie (Hg.): History, Buddhism, and New Religious Movements in Cambodia. Honolulu: University of Hawai'i Press, S. 91-112.

- (2005): Calling the Souls: A Cambodian Ritual Text. Le Rappel des Âmes: Texte Rituel Khmer. Phnom Penh: Reyum.

- (2008): Performative Realities: Nobody's Possession. In: Anne Ruth Hansen und Judy Ledgerwood (Hg.): At the Edge of the Forest. Essays on Cambodia, History, and Narrative in Honor of David Chandler. Ithaca, NY: Southeast Asia Program Publications, S. 93-120.

Tranet, Michel (1981): L'Origine de la Civilisation et de la Religiosité Khmères. Diss. Institut de Sociologie de l'Université de Caen: Editions à compte d'auteur.

Tresch, John (2013): Another turn after ANT. An interview with Bruno Latour. In: Social Studies of Science 43 (2), S. 302-313.

Turner, Edith B. (1993): The Reality of Spirits. A Tabooed or Permitted Field of Study? In: Anthropology of Consciousness 4 (1), S. 9-12.

Turner, Victor W. (1967): The Forest of Symbols. Aspects of Ndembu Ritual. Ithaca, N.Y.: Cornell University Press.

Turner, Victor W. (1969): The Ritual Process. Structure and Anti-Structure. New York: Aldine Publishing Company.

United Nations High Commissioner for Human Rights (OHCHR) (2007):

Economic Land Concessions in Cambodia. A Human Rights Perspective. Online unter http://cambodia.ohchr.org/en/economic-socialrights/economic-and-other-land-concessions, letzter Abruf am 04.02.2020.

van Gennep, Arnold (1909): Les Rites de Passage. Étude Systématique des Rites de la Porte et du Seuil, de l'Hospitalité, de l'Adoption, de la Grossesse et de l'Accouchement, de la Naissance, de l'Enfance, de la Puberté, de l'Initiation, de l'Ordination, du Couronnement, des Fiançailles et du Mariage, des Funérailles, des Saisons, etc. Paris: Nourry.

Viveiros de Castro, Eduardo (1992): From the Enemy's Point of View. Humanity and divinity in an Amazonian society. Chicago: University of Chicago Press.

- (1998): Cosmological Deixis and Amerindian Perspectivism. In: The Journal of the Royal Anthropological Institute 4 (3), S. 469-488.

- (2004): Exchanging Perspectives. The Transformation of Objects into Subjects in Amerindian Ontologies. In: Common Knowledge 10 (3), S. 463-484. 
— (2015): Perspektiventausch. Die Verwandlung von Objekten zu Subjekten in indianischen Ontologien. Übersetzt von Wilfried Prantner. In: Irene Albers und Anselm Franke (Hg.): Animismus. Revisionen der Moderne. Zürich: Diaphanes, S. 72-93.

Weber, Max (1973): Soziologie. Universalgeschichtliche Analysen. Politik. 5., überarb. Aufl. Stuttgart: Kröner (Kröners Taschenausgabe, 229).

White, Erick (2005): Fraudulent and Dangerous Popular Religiosity in the Public Sphere. Moral Campaigns to Prohibit, Reform, and Demystify Thai Spirit Mediums. In: Andrew C. Willford und Kenneth M. George (Hg.): Spirited Politics. Religion and Public Life in Contemporary Southeast Asia. Ithaca, N.Y.: Southeast Asia Program Publications (Studies on Southeast Asia, 38), S. 69-91.

— (2016): Contemporary Buddhism and Magic. In: Michael K. Jerryson (Hg.): The Oxford Handbook of Contemporary Buddhism. New York: Oxford University Press (Oxford Handbooks), S. 591-606.

Willerslev, Rane (2013): Taking Animism Seriously, but Perhaps Not Too Seriously? In: Religion and Society 4 (1), S. 41-57.

Willford, Andrew C.; George, Kenneth M. (Hg.) (2005): Spirited Politics. Religion and Public Life in Contemporary Southeast Asia. Cornell University. Ithaca, N.Y.: Southeast Asia Program Publications (Studies on Southeast Asia, 38).

Wolcott, Harry F. (2005): The Art of Fieldwork. 2. Aufl. Walnut Creek, CA: Altamira Press.

Wood, Timothy Dylan (2009): Tracing the Last Breath. Movements in Anlong Veng. Diss. Rice University, Houston. Online unter http://hdl.handle.net/1911/61829, letzter Abruf am 04.02.2020.

Work, Courtney (2012): Neak Ta Spirits of a Cambodian Village. New Research into Current Practice. Unveröffentlichtes Manuskript. Cornell University.

- (2014): Tides of Empire. Merit, Morality, and Development in Rural Cambodia. Dissertation. Cornell University, Ithaca, New York.

- (2018): Chthonic Sovereigns? 'Neak Ta' in a Cambodian Village. In: The Asia Pacific Journal of Anthropology 20 (1), S. 74-95.

Yamada, Teri Shaffer (2004): The Spirit Cult of Kleang Moeung in Long Beach, California. In: John Marston und Elizabeth Guthrie (Hg.): History, Buddhism, and New Religious Movements in Cambodia. Honolulu: University of Hawai'i Press, S. 213-225.

Zeiler, Xenia (2008): Die Göttin Dhumavati. Vom Tantrischen Ursprung zur Gottheit eines Stadtviertels in Benares. Dissertation. Universität Heidelberg, Heidelberg.

Zhou, Daguan (1992 [1296]): The Customs of Cambodia. Pelliot's Translation from Chinese (1902). Bangkok: The Siam Society. 
Zieger, Johann Reinhart (2006): Angkor und die Tempel der Khmer in Kambodscha. Chiang Mai: Silkworm Books.

Zucker, Eve Monique (2013): Forest of Struggle. Moralities of Remembrance in Upland Cambodia. Honolulu: University of Hawai'i Press (Southeast Asia Politics, Meaning, and Memory).

- (2017): From Soldier to Guardian Spirit. Cultural Resilience through Reenchantment. Asia Dialogue. University of Nottingham, Asia Research Institute. Online unter http:/ theasiadialogue.com/2017/08/10/fromsoldier-to-guardian-spirit-cultural-resilience-through-re-enchantment, letzter Abruf am 04.02.2020.

\section{Zeitungsartikel}

Al Jazeera (2008): Thai-Cambodia standoff persists. Troops remain near disputed temple area despite pledges to pull back. In: Al Jazeera, 01.08.2008. Online unter http://www.aljazeera.com/news/asiapacific/2008/08/200881449713953.html, letzter Abruf am 04.02.2020.

Aun, Pheap (2016): Facebook Death Threat Earns Man 6 Months in Jail. In: The Cambodia Daily, 25.02.2016. Online unter https://www.cambodiadaily.com/news/facebook-death-threat-earns-man18-months-in-jail-108936/, letzter Abruf am 04.02.2020.

Chrann, Chamroen (2009): Villagers Curse Stolen Land. In: The Phnom Penh Post, 10.02.2009. Online unter http:/ /www.phnompenhpost.com/national/villagers-curse-stolen-land, letzter Abruf am 04.02.2020.

Hay Pisey (2014a): 600-Strong Mob Kills Accused Sorcerer in Takeo. In: The Cambodia Daily, 29.04.2014. Online unter https://www.cambodiadaily.com/archives/600-strong-mob-kills-accusedsorcerer-in-takeo-57595/, letzter Abruf am 04.02.2020.

- (2014b): Alleged Sorcerer Beaten to Death Is Cremated. In: The Cambodia Daily, 30.04.2014. Online unter

https://www.cambodiadaily.com/archives/alleged-sorcerer-beaten-to-deathis-cremated-57747/, letzter Abruf am 04.02.2020.

Hruby, Denise (2013): Neutrality of Red Cross in Question After Bun Rany's Speech. In: The Cambodia Daily, 02.11.2013. Online unter https://www.cambodiadaily.com/archives/neutrality-of-red-cross-inquestion-after-bun-ranys-speech-46497/, letzter Abruf am 04.02.2020.

- (2014): Cambodians are increasingly being executed for Sorcery. Poverty and Inflation are on the Blame, Economists say. In: Global Post, 29.07.2014. Online unter www.globalpost.com/dispatch/news/regions/asiapacific/cambodia/140702/cambodians-executed-sorcery, letzter Abruf am 04.02.2020. 
Jackson, Will; Mao, Monkolransey (2015): How Serious are Cambodia's Land Rights Protesters about their Curses. In: The Phnom Penh Post, 08.08.2015 (Post Weekend). Online unter http://www.phnompenhpost.com/postweekend/how-serious-are-cambodias-land-rights-protesters-about-theircurses, letzter Abruf am 04.02.2020.

Kaing, Menghun; Colin, Meyn (2012): Spirit of Giving During Kathin Festival Brings Mutual Benefits. In: The Cambodia Daily, 16.11.2012, S. 19.

Khy, Sovuthy (2015): Court Denies Bail to Defrocked Khmer Krom Monks. In: The Cambodia Daily, 10.01.2015. Online unter https://www.cambodiadaily.com/archives/court-denies-bail-to-threedefrocked-khmer-krom-monks-75790, letzter Abruf am 04.02.2020.

Kuch, Naren; Woods, Ben (2012): In Future Life, Hun Sen Vows to Defend Koh Kong's Forest. In: The Cambodia Daily, 18.12.2012, S. 18.

Levy, Adrian; Scott-Clark, Cathy (2008): Country for Sale. In: The Guardian, 26.08.2008. Online unter http://www.theguardian.com/world/2008/apr/26/cambodia, letzter Abruf am 04.02.2020.

May, Titthara (2014): Monks 'face defrocking' after Protestors pour in. In: The Phnom Penh Post, 01.09.2014. Online unter http://www.phnompenhpost.com/national/two-monks-hauled-blessingstriking-workers, letzter Abruf am 04.02.2020.

Mech, Dara (2013): Villagers Ask Warrior's Spirit to Curse Officials. In: The Cambodia Daily, 15.01.2013, S. 4.

Moeun, Chhean Nariddh (1998): 500-year-old Spirit consulted by Front-Runners. In: The Phnom Penh Post, 24.07.1998. Online unter http://www.phnompenhpost.com/national/500-year-old-spirit-consultedfront-runners, letzter Abruf am 04.02.2020.

Mom Kunthear (2012): Villagers Pray to Coconut Tree. In: The Phnom Penh Post, 21.08.2012. Online unter http://www.phnompenhpost.com/national/villagers-pray-coconut-tree, letzter Abruf am 04.02.2020.

- (2013): 'Face' seen in Tamarind Sprout. In: The Phnom Penh Post, 01.11.2013. Online unter http://www.phnompenhpost.com/national/'face'-seentamarind-sprout, letzter Abruf am 04.02.2020.

Neou, Vannarin (2013): Hun Sen Tells of Eldest Son's Supernatural Arrival. In: The Cambodia Daily, 03.05.2013. Online unter https://www.cambodiadaily.com/archives/hun-sen-tells-of-eldest-sonssupernatural-arrival-21752, letzter Abruf am 04.02.2020.

Pichayada, Promchertchoo (2016): Cambodia's Health Care System Struggles to Cope with Mentally Ill Patients. In: Channel NewsAsia, 25.05.2016. 
Saing, Soenthrith; Kihara, David (2003): Inaction Over Monk's Killing Worries Observers. In: The Cambodia Daily, 28.02.2003. Online unter https://www.cambodiadaily.com/archives/inaction-over-monks-killingworries-observers-23771, letzter Abruf am 04.02.2020.

Sen, David (2014): Python 'Behind Lottery Win'. In: The Phnom Penh Post, 15.05.2014. Online unter http://www.phnompenhpost.com/national/python-'behind-lottery-win', letzter Abruf am 04.02.2020.

Sokal, Alan (1997): Pourquoi j'ai écrit ma parodie. In: Le Monde, 31.01.1997, S. 15.

Stewart, Ian (2008): During Pol Pot's reign of terror $1.7 \mathrm{~m}$ died. Now locals pray at his grave. In: The Scotsman, 14.04.2008. Online unter http://www.scotsman.com/news/world/during-pol-pot-s-reign-of-terror-17m-died-now-locals-pray-at-his-grave-1-1163942, letzter Abruf am 04.02.2020.

Supalak, Ganjanakhundee (2008): Si Sa Ket fends off Wizards' Black Magic. In: The Nation, Bangkok, 02.08.2008.

Wency, Leung (2003): F'pec Blasts Red Cross Claim Against Princess. In: The Cambodia Daily, 23.07.2003. Online unter https://www.cambodiadaily.com/archives/fpec-blasts-red-cross-claimagainst-princess-39215/, letzter Abruf am 04.02.2020. 



\section{Index der Personen, Orte und Begriffe}

Fettgedruckte Nummern zeigen eine Definition oder Diskussion des jeweiligen Begriffes an. Kursiv geschriebene Ziffern verweisen auf eine Bildunterschrift.

ācaryā Siehe Buddhismus/ācaryā

amboe Siebe Rituale/amboe

anak tā Siehe Geister/anak tā

Ahnen 58, 61, 120, 159n130, 160-161, 165, 167-170, 181n144, 225, 241, 247

Akteur-Netzwerk-Theorie (ANT)

20-21, 21n7, 36, 71, 74, 75, 77-83, 96-97, 234, 237

Siebe auch: Latour, Bruno; blackbox anak dham 166, 192-196, 196n154, $197-$ 199, 201-204, 206n168, 207, 209, 210, 215, 217, 219, 225-226, 242

anak mān punya 192-195, 242

Ang Chouléan 24-25, 42, 49, 59, 61, 65-66, 103, 111, 117-123, 135-136, 159n131, 174, 178, 181

Angkor-Zeit 21, 32, 41-42, 61, 122, 148, 203-204, 215

Anlung Veng (Stadt) 47, 86, 86n72, 88$89,88 \mathrm{n} 75,139,205 \mathrm{n} 167$

Appadurai, Arjun 21, 72-73, 232

Arensen, Lisa 104-105, 106n91, 117118 
Aufbruchsstimmung 46-49, 66-67, 171, 231

Aushandlungsprozesse 23, 29, 35-38, 69, 74, 81, 191-191, 231-232, 236

zwischen Moderne und Geistern 23 von Geister-Existenz 36, 74, 81, 8598, 129, 141

von Macht 53, 69, 71, 74, 238-239

Battambang (Stadt) 45, 48

Bennett, Caroline 9, 25, 46, 101, 102, 104-106, 106n91 115-116, 184, 185

Bertrand, Didier 10, 24, 64-66, 65n61 68, 122, 150n123, 152, 163, 169, $198 n 156$

Bizot, Francois 64

blackbox 82, 86-96, 97, 130, 134-135, 234

Siebe auch: Latour, Bruno; Akteur-

Netzwerk-Theorie

Brahmanismus 25, 35, 37, 43, 49-50, 52, 60-63, 67-68, 73, 84, 116-117, 122, 163, 201, 230-232, 243

braling 102, 107, 107n92, 111, 111n97, 115, 243, 245

Bräunlein, Peter J. 23, 74, 119, 176

Bubandt, Niels 23, 237

Buddhismus ācaryā 51, 59, 112, 177-178, 182, 188, 211-212, 211n172, 214, 222, 241
Buddhisierung 35, 66, 115-116, 118120, 122, 124, 126, 135-136, 139, 195, 234

Dhammayut-Orden 42, 47, 52, 218

Karma 20, 23, 35, 53, 55-58, 56, 63, 66-67, 69, 105, 107, 114, 128, 162-163, 165, 168, 188, 192-193, 195-196, 210-211, 225, 236-237, 245

magic monk 67, 159, 165, 167, 169, 246

Mahānikāy 42, 45, 50, 52

Mönch 18-19, 28, 42, 45-47, 50-55, 54n45, 57-59, 58n51, 61, 63, 91, 107, 109, 112, 119, 127n113, 129, 132, 147, 149, 154, 159-161, 159n129, 163, 169, 173, 179, 180182, 188, 195, 199, 209-210, 212, 214, 218, 222, 226, 243, 245-249

Ordination 45, 53, 53n44, 58n50 purāṇa 43, 45, 47, 47n30, 49-52, 59, 149-150, 189, 208, 212, 230, 248 samăya 42-43, 45, 47n30, 50, 52, 149, 188, 196, 203, 230, 248 Theravada 36, 42, 52, 55n47, 115, 193, 263

Verdienst 35, 51-53, 55-59, 58n50, 61-63, 69, 107-108, 114, 122, 128, 154, 160, 163, 165, 168n133, 177n140, 192-195, 193n152, 209_ 211, 225, 233, 236, 242, 248 
Bun Rany 59, 204, 210-215

Cakravartin 193, 193n149, 215, 236, 245

Chandler, David 24, 42, 44, 86n71, $111 \mathrm{n} 96,115,117,122,132,133$, 195n152, 202n161

chkuat $64 \mathrm{n} 57,147,158,188,201,243$

Chuon Nath 42, 86

Davis, Erik W. 10, 25, 49n36, 50, 51n40, 55, 61, 67, 104n87, 106-107, 109n95, 118n104, 123, 153, 167, 211, 211n172, 213n175, 220, 230-231

Demokratisches Kampuchea 86, 101, 213, 244

Siehe auch: Rote Khmer

devarāja 41-42, 41n20, 193, 236, 243

dhmáp 120, 153, 220, 244

Siehe auch: Rituale/amboe

Dharma 63, 126, 193n149, 244, 248

Edwards, Penny 42, 117, 128, 152n125, 216

Erleuchtung 53, 55, 64

Ethnografischer Präsens 34-35

Feldforschung 18, 22n8, 25, 33

Forest, Alain 24-25, 64, 66, 111n96, 118, 121-122, 132, 135, 148n118, 149n121, 178, 193

Forschungspartner_innen

Bun Ly 31-32, 32, 36-37, 92-96, 129, 148, 150-151, 164-166, 178181, 183, 185-189, 205-210, 218, 231
Chantrea 30-32, 181, 184-186, 188

Sothy 155, 157-170, 230

Srun 33, 112-114, 149, 166-168, 200-203, 200n159, 205

Frankreich 26, 42-44, 47n31, 93, 137, 168, 193, 204, 215, 216, 218, 247

FUNCINPEC 47, 47n32

Geistbesessenheit 29, 30-31, 31n17, 36$37,75,84-85,94,102,109,114-115$, 128, 141, 146, 150-151, 158, 163, 170, 183, 184, 185, 187, 199, 208, 210,

$222 \mathrm{n} 180$

Helfer_innen 31, 58, 87n73, 172, 181n146, 187, 205, 207

Geister

anak tā 30n15, 36, 46-47, 66, 85, 8698, 88n75, 105, 111, 118, 120, 121136, 121n109, 121n110, 139-141, 147-149, 164, 171, 177-178, 180182, 185-188, 193, 196, 201, 204 207, 209-212, 212n173, 218-224, 230-233, 235-236, 242, 246-250

app 119, 242

ārakkh 120, 242

brāy 65-66, 89, 118-120, 122, 141, 243

des Ortes Siehe anak tā des Waldes 117-118, 120 khmoc 64n58, 102-107, 103n85, 105n87, 108-111, 114-115, 117$118,120,141,230,242,245$ 
pisāca 11, 120, 141, 201, 220, 247

preta 107-111, 110n95, 114-115, $141,242,247,249$

Totengeister Siehe Geister/khmoc;

Geister/preta

Geisterlandschaft Siehe

spiritscapes

Geistmedien

grū cūl rūpa 146-147, 152, 168, 205, 244

grū dāy 146, 172, 244

grū khmer 146, 168, 244

grū pāramī 146-147, 152, 162, 164,

$168,172,244$

\section{Götter}

Erdgottheit Siehe Geister/Krung Bali

Muttergottheit (Vietnam)

Siehe Rituale/lên đông

Kāt̄̄ 135, 135n116, 246

Siehe auch: lok yāy Mao

Shiva 41, 122-123, 135n116, 199n158, 246

Yama 107, 107n94, 249

Gray, Tallyn 9, 46, 89, 90n78, 91, 92n 81,259

Guillou, Anne Yvonne 10, 23, 25, 43, 50, 60, 64, 66n62, 87n74, 90n78, 101, 105n88, 115-116, 121, 123, 130, 132 133, 135, 179, 219

Guthrie, Elisabeth 10, 24, 53, 211, 211n171
Hansen, Anne Ruth 24, 42, 43, 60

Harris, Ian 24, 42, 54, 121, 193, 218

Hastrup, Kirsten 34

Herrschaft 44-46, 46n29, 48, 135, 139, 196n154, 199n154, 215, 236-237, 242,244

Hinduismus 33n19, 35, 41-42, 122, 215,232

Holt, John Clifford 51, 51n40, 67, 107n94, 121

Hun Sen 21, 45n27, 46-47, 47n29, 48, 50, 59, 65, 88-89, 194n153, 196n154, 200, 200n161, 202n164, 204, 210211, 212n173, 213, 215-221, 225n181

Huot Tath 42

Indochina-Krieg 17, 45

Jackson, Peter A. 23, 37, 50n37, 67-69, $68 \mathrm{n} 63,171,176,196,231,237$

Jacobsen, Trude 23, 55, 65, 135, 192, 210, 237

Jayavarman VII. 42, 193, 225n181

Siebe auch: devarāja

Kambodschanischer Buddhismus 24, 35, 43, 49-52, 49n36, 61-63, 67-68, 135, 195, 219, 230-231, 239, 243 Kampong Cham (Provinz) 89, 110, 216 Karbaum, Markus 48, 193, 194n153

Karma

Karma-Wechselwirkung 52, 55, 55n47, 57-58, 63, 67, 69, 107, 114, 162-163, 192, 211, 225, 236 
Siehe auch: Buddhismus/Karma

Kent, Alexandra 9, 24, 26, 47n31, 50, 54-55, 54n45, 193, 195, 215

Keyes, Charles F. 42n22, 45, 55-56, 55n47, 58, 193-195

khdoey 151n124, 245

Khmer Rouge Siebe Rote Khmer

khsae 172n135, 178, 194, 196, 199, 201, 245

Kolonialzeit 24, 26n11, 68, 128, 247

Kommunismus 43-44, 44n24, 47, 139, 242

KVP (Kambodschanische Volkspartei) 54, 59, 199, 236, 245

Kwon, Heonik 17, 68, 102

Ladwig, Patrice 10, 23, 237

Landvertreibung 48, 54n46, 176, 192, 220-221, 222, 225-226

Latour, Bruno 29n12, 73, 76-83, 77n66, 80n67, 96-97, 134, 234-235, 243

Lauser, Andrea 9, 17, 20-23, 23n10, 27, 67-68, 72, 119, 176, 196, 198, 231232

Leclère, Adhémard 24, 42, 86, 123, 153n126, 216, 218

Ledgerwood, Judy L. 24, 47, 101, 194, 215

Liberalisierung 53, 67-68, 176, 231

Lok tā (Anrede) 30n15
Lok tā Eysey 31, 122, 129, 133-134, 148, 164-165, 179, 183-184, 205-207, 209, 212, 246

Lok tā Kleang Moeung 87, 123, 123n111, 132-133, 137, 141, 206, 208, 212n173, 218-219, 235-236, 246 Lok tā Kong Cha 33, 122, 149, 167, 200, 205, 209

lok yāy Mao 36, 87, 90, 92, 118, 121, 130, 135-141, 138, 140, 246

Macht

spirituell 20, 23, 31, 35-38, 41-42, 46, 52-53, 55, 57-59, 61, 64n59, 65, 66-69, 66n62, 72-75, 83-84, 88n75, 87-88, 90n78, 92, 97, 110, 120-121, $123,128,130-134,140,144,152-$ 155, 160, 162-163, 168, 169n134, 171, 173, 175, 177, 181, 188, 192-194, 196n154, 201, 203-204, 209-213, 215-217, 225n181, 225-227, 229_ 233, 235-236, 237, 241, 244, 246

Siebe auch: pāramì politisch 23, 38, 40-41, 52, 64n59, 191-192, 194, 196-197, 220, 231232, 235-236

buddhistisch 21, 55, 59, 191-196 Magie 61, 63n56, 119, 120, 131, 153, 158, 162, 188, 192, 196n154, 214, 220, 222, 224, 225n181, 241, 244, 249

Siehe auch: vetamon; Rituale/amboe 
Mantras 58, 61, 84, 84n69, 167, 172173,222

Markt (Ort) 146, 164, 167,

Markt (Wirtschaft) 48, 67, 171, 176, 178n141, 231

Marston, John A. 10, 24, 43, 45, 47n30, 57, 121n110, 123n111, 177n140, 195, 197

Massengräber 17, 45, 103-105, 115

Medialität 21n6, 23n14, 29, 29n12, 33, 36-37, 52, 67, 114, 141, 143, 145146, 149-151, 149n121, 154-155, 157, 161-162, 168, 170, 176-177, 196, 203, 220, 230, 244, 246

Siehe auch: Geistbessenheit

Militär 20, 25, 37, 44, 45n26, 46-47, 5151, 54-55, 58, 60-61, 63-64, 64n57, 68-69, 84, 87, 103, 106-107, 107n93, 109, 120, 129, 133-136, 138-139, 150, 152, 154-155, 159, 162, 166, 169-170, 174-175, 188-190, 193n149, 194n153, 196, 198-200, 203, 205, 210, 221, 232

Moral 20, 44, 45n26, 46, 51-52, 54-55, 58, 61, 63-64, 64n57, 68-69, 84, 87, 103, 106-107, 107n93, 120, 129, 138, 150, 152, 154-155, 159, 162, 169-170, 174-175, 177, 188-189, 193, 193n149, 195-200, 214, 216, 220, 222, 224-225, 230, 236, 239, 243,

Nachtodkonzeptionen 86, 101n83, 102 103, 104-111, 113-115, 234
Nāga 122, 183, 198, 211n171, 247

Nationale Identität 21, 37, 43, 141 , 191-192, 203-215, 219, 226

Nirvana 12, 19n3, 55

Norén-Nilsson, Astrid 10, 46n29, 192 , 194, 212n173, 216-217

Objekte $62,73,97,123,140,154,172$, 229-230, 234

Opfergaben 51, 53, 73, 78, 86, 88-92, 97, 104-105, 108-109, 109n95, 112, 126, 128-129, 132, 134, 137, 141, 145, 152, 154, 159, 160, 164-165, 177, 179, 181-182, 181n144, 199, 207, 210, 212-213, 222-223, 225, 233, 248

Ovesen, Jan 146, 168-170, 175, 220 Pagode 24, 30, 45, 47, 47n30, 50-51, 53-54, 58-59, 58n51, 63, 63n55, 84n69, 84, 107, 110, 112-113, 115, 148, 148n119, 159-160, 167, 173, 173n136, 181-182, 181n143, 195, 199, 209, 216, 222n180, 226

Pailin (Provinz) 47

Pāli 43n23, 45, 51, 51n38, 51n41, 53, 64-65, 84n69, 104n87, 107, 152, 167, 173, 193n149, 211, 241, 249 pāramì 23, 46, 60, 64-69, 65n61, 87-89, 91-92, 95-96, 110, 122-123, 126, 128-129, 131, 137, 146-147, 150, 152, 154, 162, 164, 167-168, 172, 177, 179, 181n146, 187, 195, 200, 
202, 204-205, 209, 211-212, 222, 225,

235-237, 242, 244, 247

pārāng 26, 26n11, 94-95, 247

patronage-System 59, 67, 192-196,

196n154, 226, 236

Pattana Kitiarsa 23, 50, 67, 176-177

pāys s̄ 63n55, 83, 85, 93-96, 111, 125-

126, 127, 159-160, 164-179, 181-

183, 181n143, 185-187, 187, 195-196,

201-202, 205-207, 209, 212, 222, 247

Siehe auch: Schrein

Phnom Penh (Stadt) 19, 29, 33, 44, 47-

48, 54n45, 59, 88, 91, 96, 103,

107n94, 108, 127, 135, 137, 152, 158-

160, 165-168, 198, 200-203,

200n161, 207, 217, 221, 223, 226

Pol Pot 36, 46-47, 47n33, 60, 65, 72,

86-92, 87n71, 90n78, 97, 123, 132,

134

Porée-Maspéro, Éveline 24, 86, 121 123, 128, 133, 135, 135n116, 211n171

Pou, Saveros 42, 61, 65, 102, 104n87, $110,117,120,147 \mathrm{n} 117$

Preah Vihear (Provinz) 202

Preah Vihear (Tempel) 133n115, 203-

205, 204n166, 205n167, 210-213, 226

PRKN (Partei zur Rettung der

Kambodschanischen Nation)

215n176, 218-219, 248

prosperity religion $37,60,66,68,171$,

231 punya Siehe Verdienst

Reinkarnation (Wiedergeburt) 25, 32, $35,53,55,57,73,105-110,116,128$, 128n114, 192, 202, 216-217, 219, 232

Religion 17, 20-21, 23-25, 35, 38, 4143, 49-53, 50n36, 55, 59-63, 66-67, 69-81, 80n67, 84, 86, 101, 111, 115, 126, 129, 135, 141, 146, 152, 168, 176-177, 188, 191, 193-197, 198n156, 202, 210-211, 213-214, 220, 224, 229-232, 235-237, 239, 242, 247, 249-252, 254-257

Siehe auch: Brahmanismus,

Buddhismus

Rituale

amboe 63, 63n56, 119, 153, 162, 188, 220, 222-226, 241, 244

bhjum pinda 51-52, 51n40, 91, 108, 116,242

dāna 57-59, 58n49, 181, 188, 209, 243

der Heilung 25, 30, 37, 62, 123, 128, 145, 147, 149, 153, 158-159, 168-

170, 186, 201, 222, 230, 233, 245

hov braling 102, 111, 115, 234, 245

kathen 58-59, 245

krung pal̄ 182, 204, 210-215, 245

lên đông (Viet.) 67

loeng anak tā 92-94, 171, 177-188,

178n141, 179, 180, 181n144, 189- 
196, 205-206, 209-210, 222, 231, 236, 246

namasakāra 57, 84n69, 182, 188, 247 sīma 215

sneh $^{\circ}$ 166, 172, 174-175, 245, 248 sro dijk 166-167, 172-173, 174, 201, 246, 249

Rote Khmer 17-18, 24-25, 30, 36, 43, 44-45, 44n24, 46-47, 53, 86-89, 102106, 109, 115, 116n102, 119, 135, 137-139, 146, 181n146, 199, 200, 202, 204, 221, 232, 242-243 angkār 44-45, 242

Sam Rainsy 215, 215n176, 218-219, 248

sangha 47, 51-55, 57-58, 106, 188, 193 , $195,236,248$

sāsanā 43, 43n23, 52, 61-62, 62n54, 248

Schrein 24, 32, 63, 63n55, 78, 83, 93, 111-112, 121, 125, 126, 126n112, 127n113, 130, 135, 137, 148, 154, 159n130, 164-165, 169, 181n143, 204-207, 204n166, 209, 218-219, 235, 247

Siehe auch: pāy sī

Sdech Khan 216-219, 219, 236

Sicherheit 169, 194 im Verkehr 136-137, 139 politisch 176, 196, 210

Siem Reap (Provinz) 131, 131 Siem Reap (Stadt) 48, 59n32, 205
Sihanouk, Norodom 43-44, 44n24, 46-

47, 46n29, 65, 90n78, 216

Sorrentino, Paul 10, 23n10, 31n17

spiritscapes 20-21, 35-36, 71-75, 75, 116-117, 130, 145, 148, 154, 177, 226, 231-233, 235, 237

Sprenger, Guido 23, 66, 77n66, 97, 231, 233-234

Statue 63, 65-66, 83, 87, 90, 107, 122-

124, 126-128, 130, 134, 137-139,

164, 166, 201, 207, 212, 217

Geister 66, 83, 87, 90, 122-124, 128, 130, 134, 137-140, 137n113, 164, 201, 205n94, 207, 212n173

Buddha 63n55, 126-127, 166, 212

Strangio, Sebastian 48, 50, 217, 219

tā Mok 88, 200

tā Noël 36, 72, 92-97, 93n82, 134, 233,

$148 \mathrm{n} 120$

Takeo (Provinz) 29, 32, 44, 126, 180, 205

Thailand 23n10, 26n11, 37, 42, 42n21, 42n22, 45, 47, 50, 50n37, 55n47, 61, 67, 88-89, 89n76, 93, 119n107, 133, 133n115, 137, 139, 176-177, 194, 199, 203n165, 204-205, 207, 209, 212-214, 221, 235, 237 thān thān manuss 51, 72-73, 107n93, 193n150, 233, 249 
thān norok 72, 107n93, 112, 114, 116, 233,249

thān suok 72, 96, 107n93, 112, 148149, 165, 179, 183, 200, 233, 239, 249

Thompson, Ashley 106, 111, 150n123, 193, 197, 216, 253

Tod 17, 19n3, 36, 46, 46n28, 51, 55-56, 56n48, 59, 62, 67-68, 73-74, 85-86, 88, 101-102, 101n83, 103n85, 104 116, 111n97, 123, 128, 128n114, 132133, 136, 147, 149, 153-154, 181, 202, 212n173, 223, 233

Trankell, Ing-Britt 146, 168-170, 175, 222

Trauma 18

țūnjì 53n44, 57, 249

Verdienst

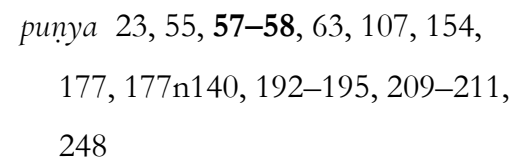

sīla 57-58, 84, 89, 91, 127n113, 152, 152n125, 165, 248
Verehrung der Geister 24, 42, 68, 73-74, 128 der Toten 91 -Praxis 135-136, 212 -sstätte 88,126

vetamon $\mathbf{6 1 - 6 2}$

Vietnam 17, 23n10, 36, 42-43, 45-48, 45n27, 53, 61, 67, 102-103, 112, 115116, 119n107, 133, 176, 181n146, 200, 219, 221

Viveiros de Castro, Eduardo 76-77, 169

Vor-buddhistische Ära 35, 60, 73, 106107, 114, 122, 181n146, 188

Siehe auch: Brahmanismus

White, Erick 23, 61

Wiedergeburt Siehe auch: Reinkarnation Work, Courtney 64, 87, 118, 121, 124 , 178, 221, 222n180, 235

Yamada, Teri Shaffer 121n110, 123n111, 133, 219

Yum Riek 107-108, 110, 112-114, 249 Zucker, Eve Monique 111n96, 135, 139 
A usgehend von der Frage nach der Relevanz von Geisterpraktiken untersucht Paul Christensen die bedeutsamen Rollen von Geistern in der kambodschanischen Gesellschaft. Die wichtigen thematischen Schwerpunkte legt er auf die Verarbeitung der traumatischen Vergangenheit, die religiöse Identifikation der Kambodschaner_innen, die politische Ermächtigung der Eliten durch spirituelle Legitimationsstrategien und die lebendige Ritualpraxis der Geistmedien in Kambodscha. Durch den ethnologischen Zugang einer 13-monatigen Feldforschung und eine innovative, an die Akteur-NetzwerkTheorie angelehnte Methodik kann im Sinne einer (wieder-),verzauberten Moderne' ein emisches Verständnis dieser religiösen Phänomene gewonnen werden, die in ähnlicher Weise in ganz Südostasien auftreten.

Die Arbeit liefert einen wegweisenden Beitrag zum wissenschaftlichen Verständnis von Geistern. Dabei überzeugt sie nicht nur mit der Anschlussfähigkeit der Methodik; die Ethnografie liefert Beschreibungen zu gesellschaftlichen Themen wie Macht, Existenz, Religion, Heilung, Liebe oder Trauer, die nicht nur das ,Andere' plausibel machen, sondern auch das ,Eigene‘ in Frage stellen.

Paul Christensen ist Religionsethnologe mit einem regionalen Schwerpunkt auf Südostasien. Vor seiner Arbeit am Institut für Ethnologie in Göttingen studierte er Kulturund Religionswissenschaft in Bremen und Yogyakarta. Neben seinem Schwerpunkt der Religionsethnologie beschäftigt sich Paul mit Wissenschafts- und Technikforschung (insbesondere der Akteur-Netzwerk-Theorie), Identitätskonzepten und alternativen Lebensmodellen in Südostasien. Die vorliegende Promotionsschrift wurde von der Studienstiftung des deutschen Volkes e. V. gefördert und von Prof. Andrea Lauser betreut. 